\title{
TIE BIRDS \\ OF THE BRITISH ISLES AND THEIR EGGS
}

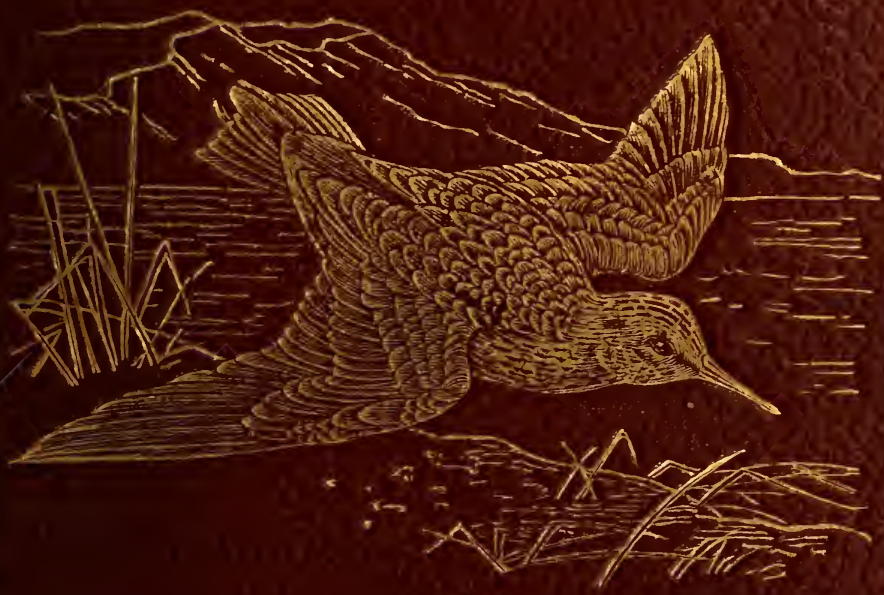




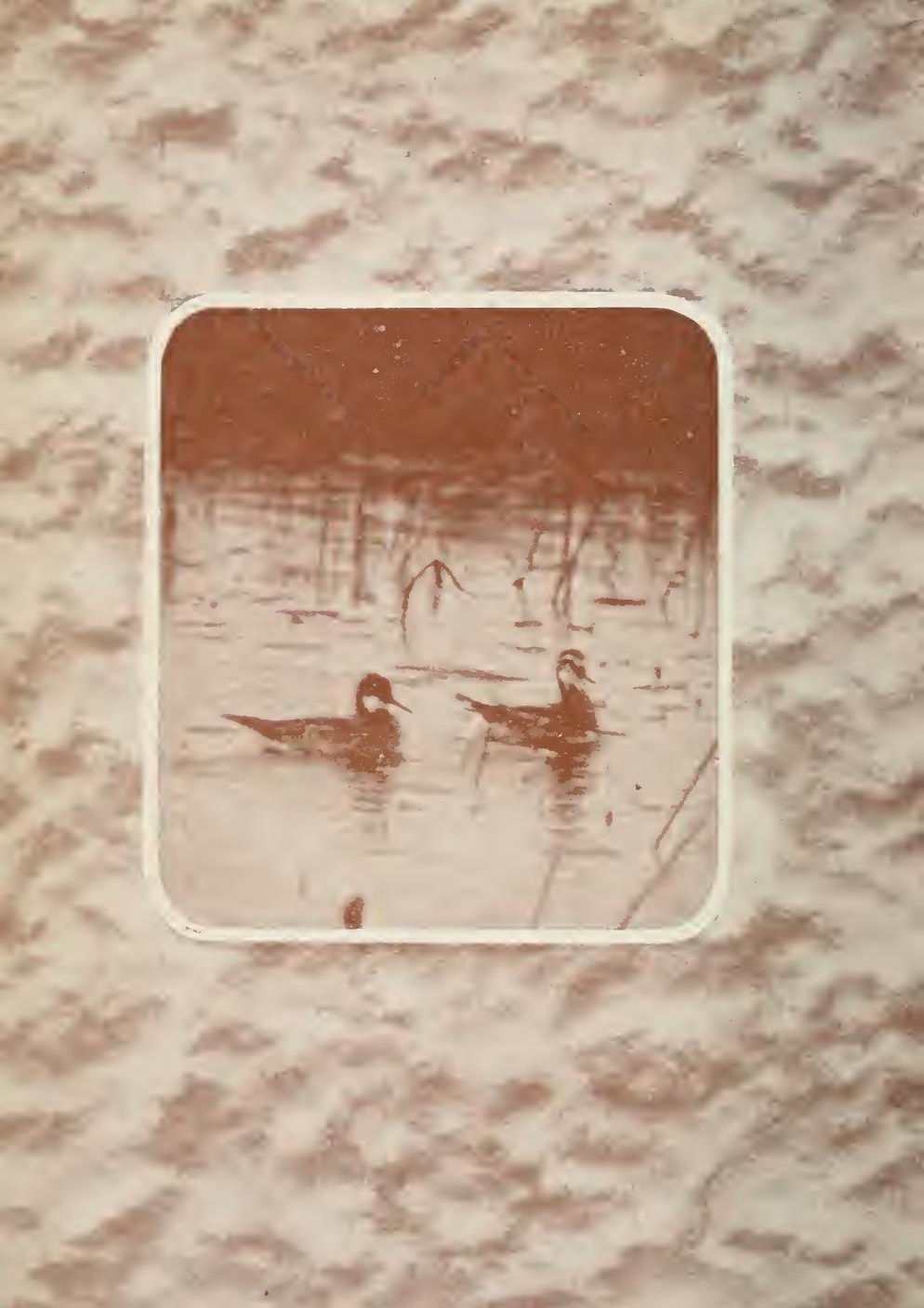




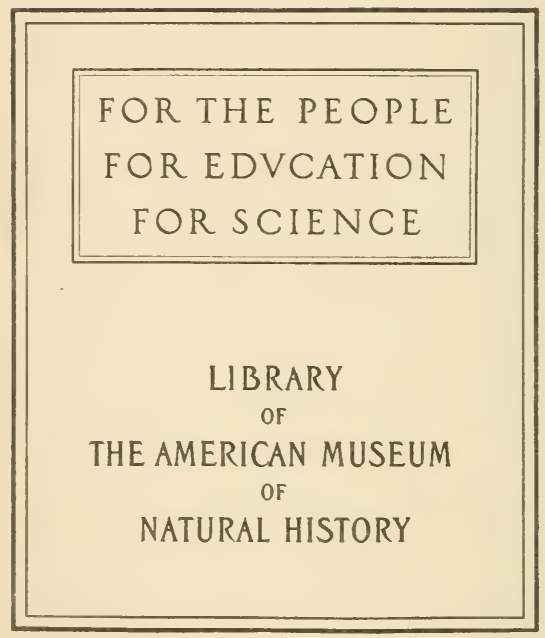


THE WAYSIDE

AND WOODLAND

* SERIES

\section{THE BIRDS \\ OF}

\section{THE BRITISH ISLES \\ AND THEIR EGGS}





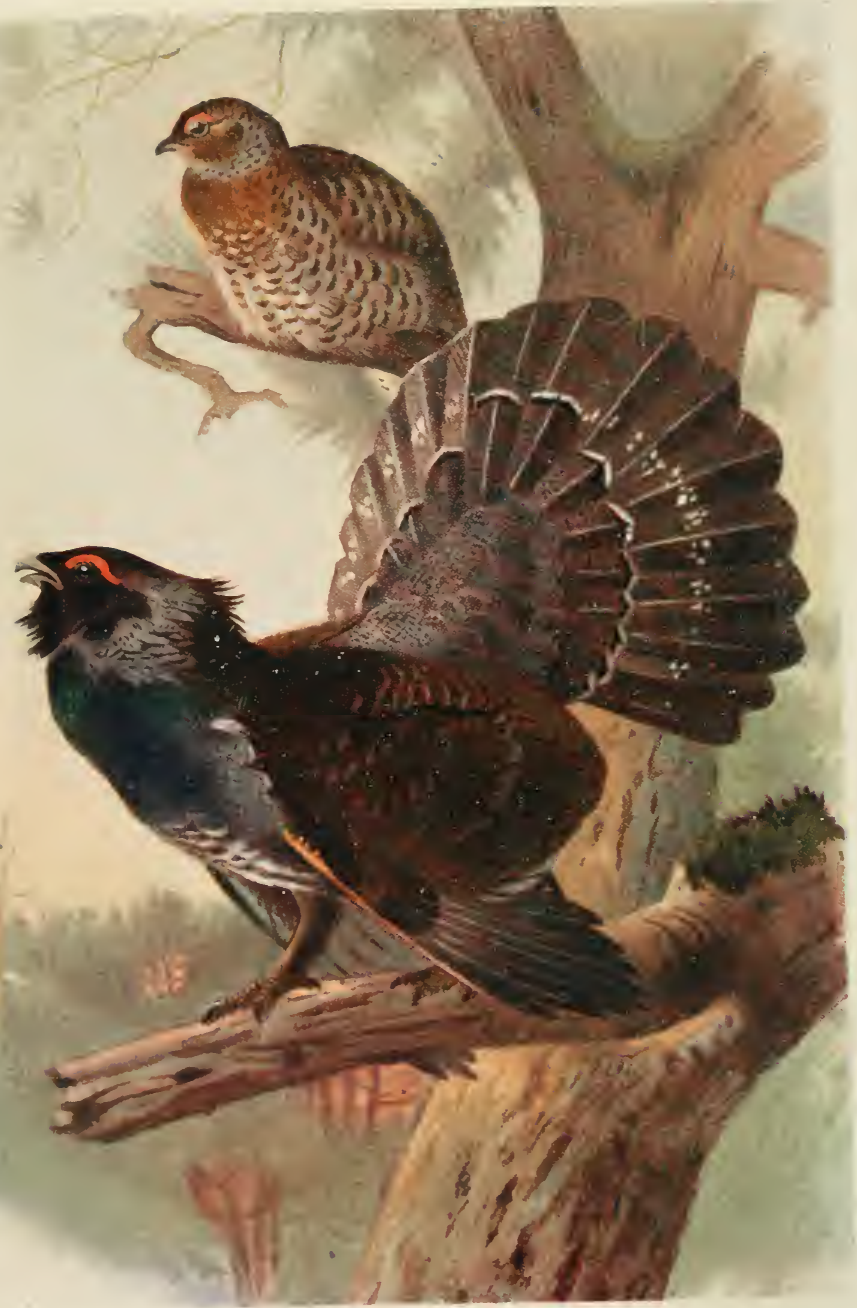

Firontespiece. 


\section{THE B I R D S}

\section{OF THE BRITISH ISLES}

\section{AND THEIR EGGS}

BY

T. A. COWARD, M.B.O.U. F.Z.S., F.E.S.

"MIRDS OF CHESHIRP," "AUTHOR OF
"MIGRATION OF BIRDS"

\section{SECOND SERIES}

COMPRISING

FAMILIES ANATIDE TO TETRAONIDAE

WITH

213 ACCURATELY COLOURED ILLUSTRATIONS

BY ARCHIBALD THORBURN AND OTHERS

REPRODUCED FROM LORD LILFORD'S WORK

"COLOURED FIGURES OF THE BIRDS OF THE BRITISH ISLANDS"

AND 69 PHOTOGRAPHIC ILLUSTRATIONS

BI E. L. TURNER, R. KEARTUN

AND OTHERS

\section{LONDON}

FREDERICK WARNE \& CO. LTD.

AND NEW YORK

I920 


$$
\begin{aligned}
& \begin{array}{l}
21-0 j 765-\text { M. } 11 \\
\text { COPYRIGHT } \\
\text { I920 }
\end{array} \\
& \text { (All rights reserved) }
\end{aligned}
$$




\section{P R E F A C E.}

THE reception of the previous series justifies the continuation of a work which provides accurate coloured figures of all but the very rare birds; the ornithological draughtsmanship of Archibald Thorburn, by whom most of the pictures were drawn, speaks for itself. In a book of this size it is not possible to figure a sufficient number of eggs to represent the great range of variation, but a type of egg of most birds which nest in Britain has been included, drawn to average size; in the present series white or very light self coloured eggs have been omitted, size being stated in the text. To figure all variations of eggs of certain species would fill every plate and still the range would be incomplete; the book is not intended solely for the egg collector.

All birds on the British list are dealt with in this and the previous series, but more space has intentionally been devoted to those which are likely to be met with than to rare stragglers and lost wanderers whose accidental occurrence on our shores entitles them to a place as birds which have occurred in Britain rather than as British birds. The list of reputed species might be swelled by the inclusion of many erroneous records; it is far too long as it is.

Classification and nomenclature are, in the main, as in the B.O.U. List of 1915 , but after consideration the Committee 
engaged upon revision has decided to adhere to the International rules, and a few alterations appear in the present volume. I have, moreover, slightly deviated from the list, including some species and excluding others, stating my reason for this change. In order that nomenclature in the First Series may also agree with the recent and it is hoped final decision of systematic ornithologists throughout the world, the following names should be altered:-

Sylvia orphea, page $16_{5}$, should be $S$. hortensis (Gmelin). Turdus musicus, page 196, should be $T$. philomelus Brehm. $T$. iliacus, page 199, should be $T$. musicus Linn.

Phanicurus titys, page 212 , should be $P$. gibraltariensis (Gmel.).

Accentor, pages 232, 235, should be Prunella.

Flammea flammea, page 28), should be $F$. alba (Scop.).

Asio accipitrinus, page 294, should be $A$. flammeus (Pontopp.). Vyctala, page 300 , should be Cryptoglaux.

Astur palumbarius, page 322 , should be A. gentilis (Linn.).

In the forthcoming British List and in the suggested List of Birds of the World, to be compiled by British and American ornithologists, other aiterations may be found necessary, but the above are the most important.

My object throughout has been to give more space to the life history and appearance in the field of the species described than to distribution or detail of plumage ; the salient colour and form as seen through a field-glass is of more value to the outdoor naturalist than minute particulars detected in examination of museum skins. Nevertheless the museum collection has not been neglected, and all descriptions have been checked.

Where my experiences differ from those of others, as recorded in text-books, I have adhered to my own observations, risking criticism ; many a statement, quoted as a rule, is really founded on an exception, and slavishly copied again and again because 
the original observer had a well-earned reputation. I would rather state what I believe to be true and be corrected if in error, than copy an orthodox view which may, some day, be shown to be misleading.

To all who have provided photographs for the black and white plates I am grateful, and for the assistance in field observation given by many personal friends. Miss E. L. Turner supplied the photographs for Plates 3, 22, 25, 30, 34, 37, $47,49,52,58,60,88,90,99$, 109, I $21,122,125,127,128,139$, I44, I46, and end papers I and 2 ; Mr. T. Taylor for Plates 8 , I I , 40,67,76,79,83,86, 92, 97, I01, 102, 104, 106, I I 8 , I48, I 5 I, 153, I55, and end paper 3 ; Mr. R. Chislett for Plates I6, 43, 50, $63,65,70,72,84,134$, and 142 ; Mr. R. Kearton for Plates 33 , 69, 75, 8I, I I3, I4 I, and end paper 4; Mr. O. J. Wilkinson for Plates 95 and 132 ; and Mr. A. T. Mole for Plate 5. Plate 6 is from a photograph by the late Canon Bower, and is reproduced by the kind permission of Mrs. Bower; Plate I IO is from my own photograph.

T. A. COWARD. 



\section{THE BIRDS \\ OF THE BRITISH ISLES AND THEIR EGGS.}

\section{Order ANSERIFORMES.}

Family ANATIDÆ. Geese, Swans, and Ducks.

The Anatida, all swimming birds, have the three toes in front connected by membrane; they are web-footed.

\section{Grey Lag-Goose. Anser anser (Linn.).}

The geese which occur in Britain fall into three natural divisions or groups, the first consisting of five species, known as the "grey geese." Of these the Grey Lag (Plate 2) is the only one that nests with us; the others are winter visitors. A century and more ago the Grey Lag bred on moors and marshes in various parts of England; now it nests only in the north of Scotland and some Hebridean islands. It breeds in northern Europe and Asia, and winters in the Mediterranean and southern Asia.

Grey geese are exceedingly variable in size and plumage; the assertion that any species may infallibly be identified by certain 
characters is apt to mislead. Passing "skeins" of grey geese usually fly too high and fast for identification, and "gaggles" feeding or resting are too alert to permit close scrutiny. Even in the hand a bird, especially if immature, may puzzle an expert by its variation from type; disputes over species, sub-species, and races are never ending.

The typical characters of the Grey Lag are lavender-grey shoulders, lower back and rump, and flesh-coloured whitenailed bill and legs. The Bean-Goose, which approaches it in size, has a brown rump, its legs are pink, and its bill black and orange. From the White-fronted Goose, with orange, whitenailed bill and orange legs, it may be told by its pale shoulders and rump; the Pink-footed has a dark rump, though its shoulders are blue and its legs pale and fleshy, but its bill is black and yellow and the terminal nail black. These characters look simple, but immaturity and individual variation have led to errors.

The origin of the name is obscure. The New Oxford Dictionary supports the view of Prof. Skeat that it was the goose that lagged behind when others migrated, but Mr. Harting sugrgests that it is derived from the Old English lear, a field, and others have cited the Middle English lac, a lake. An old sporting term for a flock of geese was a lag.

The general habits of all grey geese are similar; they are normally cliurnal feeders, cropping grass and gleaning grain. When, however, the fields are disturbed by farmers or others, or on moonlight nights, they adapt themselves to circumstances, and after spending the day on the banks or tide-line, flight inland at dusk. On the coast the uncovered banks are their usual nocturnal haunts, and inland the gaggles sleep in some open country or quiet water; at daybreak they go off to feed, flying in ordered lines or in chevron formation. If forced to remain in the estuary or on the shore during the day they are unsettled and restless, skeins repeatedly taking short flights to 


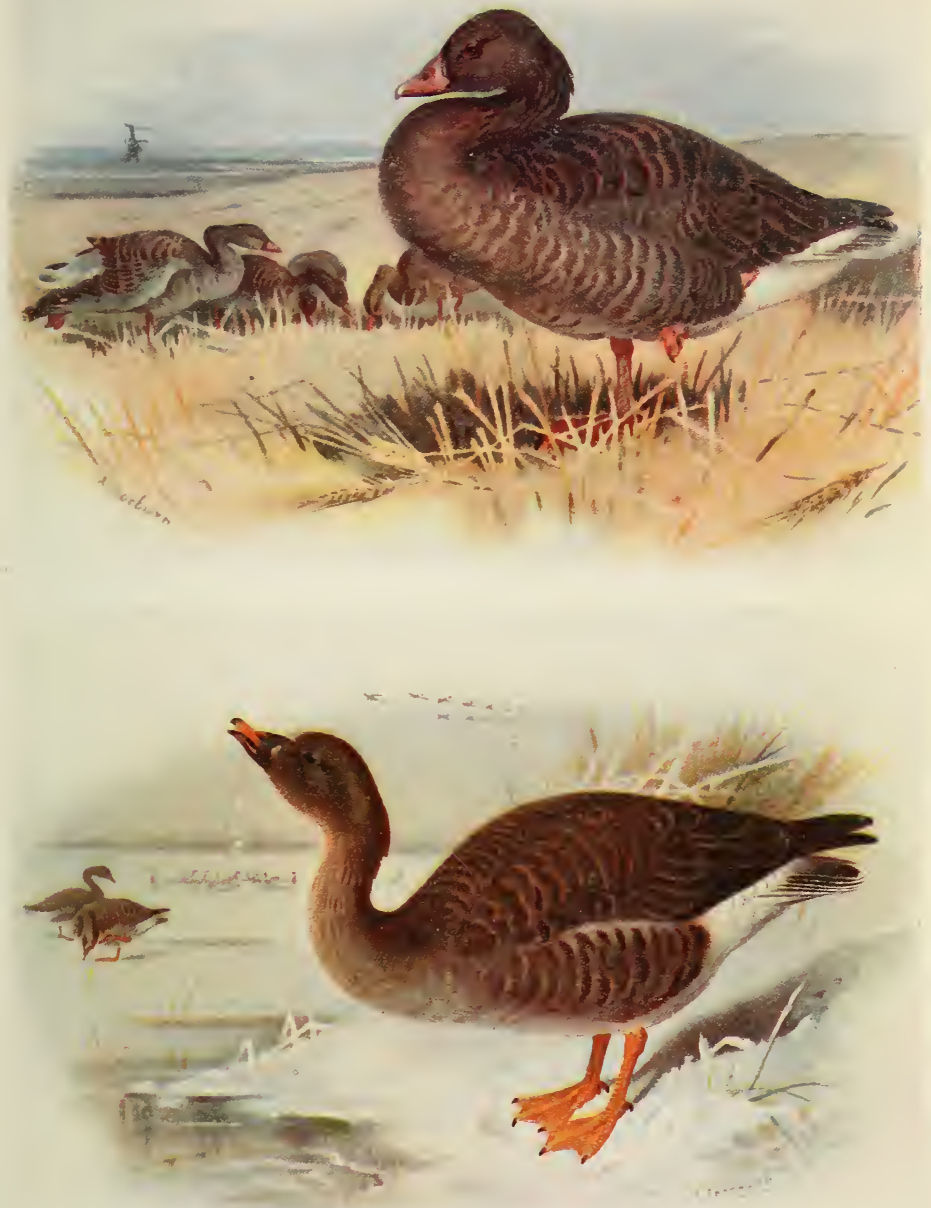

2 Pl. 2.

Grey Lag-Goose.

$B 2$.

Bean-Goose. 


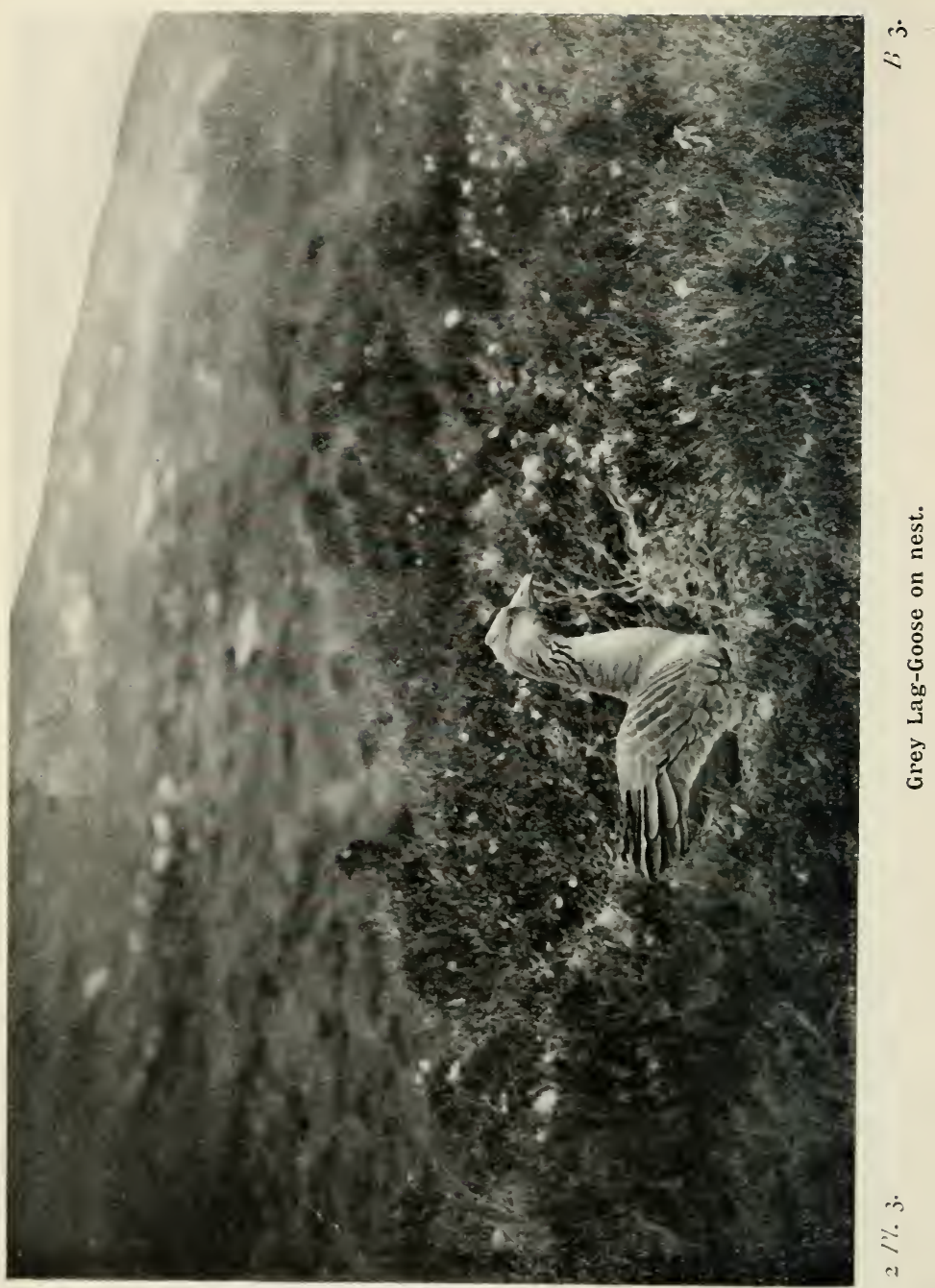


reconnoitre. Grain, grass, clover, and other vegetable substances are their regular food ; in many places they can find sufficient grass on the saltings without risking trips to the cultivated land.

Migratory Grey Lags reach us from mid-September onwards, and remain until April or May. Certain localities attract the bird, which is more plentiful on the west than east coast ; even in the west and in Ireland it is local. The call in flight is loud and sharp, a deep sonorous $a c k h, a c k h$, almost exactly the note of the domestic goose, of which it is probably the most direct ancestor; when the birds settle, the clonking clamour resembles that of other greys. During the breeding season the pair converse in familiar language, the contented undertones of the farm. yard. On land it walks with ease and dignity, without the waddle of the overfed domestic bird ; it swims lightly, and if threatened during the moult, when through the simultaneous loss of the flight feathers the bird is helpless, it dives with skill. In flight the slow, measured beats betoken strength, and the speed attained has astonished many an inexperienced sportsman.

The nest is large, placed in thick heather, rushes, or other vegetation. Little or no lining is provided when, in mid-April, the four to six yellowish-white eggs are liid, but the goose constantly adds down until the eggs are concealed. The average size, according to the Rev. F. C. R. Jourdain, is 3.4 ins. by $\mathbf{2}^{\circ} \mathbf{3}$ ins. The sitting goose (Plate 3 ) is shy and nervous, turning her head from side to side, her neck feathers dividing in sinuous creases; she is on the alert to sight or scent danger, as Miss E. L. Turner found when photographing the bird figured. The down-clad yellowish-brown and yellow goslings are usually hatched in May; their under surface is at first a wonderiul golden yellow.

The head and neck of the adult bird is light brown, the upper parts, greyish brown, darkest on the wings and scapulars ; the shoulders, lower back, and rump are blue-grey. The ashygrey tail is tipped and bordered with white, and the upper and 
lower tail-coverts are pure white. The breast is suffused with brown, and the belly is dull white with a few dark blotches and bars. There are often some white feathers at the base of the bill. The sexes are alike and there is no marked seasonal change. The white-nailed bill and the legs are flesh-coloured, the irides dark brown. The immature bird is darker and lacks the spots and bars on the under parts and the white above the bill, whilst the bill is yellow or orange and the legs are puler. Mr. Abel Chapman found great variation in the colour of legs and bill in both old and young; it ranged from almost white to yellow and, exceptionally, orange. The gander is the bigger bird, but the size varies greatly, and all measurements of this and other species must be treated as averages. Length, $30-34$ ins. WVing, 18 ins. Tarsus, 3.3 ins.

\section{Bean-Goose. Anser fabalis Latham.}

The Bean-Goose (Plate 2) is a rather uncommon winter visitor to most parts of Great Britain and Ireland, though locally it is numerous. It breeds far north in Europe and Siberia, and occurs in winter throughout Europe and in many parts of Asia. Bean-yeese with much yellow in the bill have been separated as $A$. arvensis, but there is great variety in the soft parts of all grey geese.

The back bill crossed by an orange band, and the orange legs serve to identify the typical Bean; the legs of the Pinkfoot, which has a somewhat similar bill, are flesh-coloured. The general colour, especially on the shoulders and rump, is darker than that of the Grey Lag; on the wing its head and neck look very dark, darker even than the Pink-foot, and the white upper tail-coverts show up against the brown rump. To my ears the call, honk, honk, is softer and more bell-like than the note of the Pink-foot. The flight is strong and direct, the wing.beats slow; on the water the bird looks large but rather 
slender, and its weak bill long; as in other greys, the feathers on the nape and back of the neck stand out in a mane. When the bird is feeding the neck is not curved as in the swans, but has a sharp kink or angle ; this is noticeable in any greys, when with neck stretched and beak open one bird attacks another in play or anger.

Immigrant Beans arrive in September and October, and some linger until April or later. They share the field-feeding habit with the Grey Lag, and both near the coast and inland the bird is a hanger-on at the harvest.

The upper parts of the mature bird are greyish brown, darker than in the Grey Lag, but the shoulders are sometimes grey, though never so blue. The pattern or barring on the wings and scapulars, due to the pale and often white edyings of the feathers contrasting with the brown, is more distinct than in the previous species. One March-killed male examined was almost as grey as a Grey Lag, but the rump was distinctly brown. The under parts are pale brown on the breast, passing to dirty white, often showing obscure bars. The bill is black at base and tip, including the nail, crossed by an orange or deep yellow band, the size and shape of which varies individually. The legs are orange or pinkish yellow, the irides dark brown. There are sometimes white feathers at the base of the bill. The goose is smaller than the gander; the young bird is darker except on the rufous-tinged neck. Length, 3I-34 ins. IVing, $17^{\circ} 5^{-19}$ ins. Tarsus, 3 ins.

\section{White-fronted Goose. Anser albifrons (Scop.).}

The White-fronted Goose (Plate 4) is a winter visitor, often numerous, especially on the west coast and in Ireland. Its northern breeding area extends from Greenland and Iceland to northern Siberia, including most Arctic islands; in winter it reaches southern Europe, northern India, and north Africa. 
The North American bird, often described as a sub-species, winters so far south as the Gulf of Mexico.

The White-fronted Goose, at any rate when mature. is easy to identify ; it is smaller than the Grey Lag and the white at the base of the bill is a broad and conspicuous band. The beak is orange with a white nail, distinguishing it from the Bean and Pink-foot, and the legs are darker than those of the Grey Lag ; the only species with which it can be confused is the smaller and darker Lesser White-fronted Goose. There are broad dark bars on the breast and belly, and the note, from which it gets its name of "Laughing Goose," is distinct, louder and harsher than the metallic cry of the Pink-foot. When the two are flying together the White-fronted is easily picked out by its frontlet and dark flanks. Immature birds, however, have less white on the forehead, and in some, young females probably, there are no bars; the nail may be not white but brown, though never black.

The habits are similar to those of other greys; it feeds on grass and clover, but is perhaps more of a marsh than cornfield species, and may be seen in estuaries moving with the tide, flighting to the marshes and fields at high tide and returning with the ebb. It arrives and departs at the same seasons as other greys, and is not infrequent in inland marshes and river valleys; the bird is most abundant in December and January.

The plumage is ashy brown with pale edges to the feathers of the back, and the under parts are crossed by dark brown or black bars and blotches; the flanks are dark brown, the under tail-coverts white. The legs and bill are orange, the nail white, the irides dark brown. Length, 27-28 ins. Wing, 16-17 ins. Tarsus, 2.6 ins.

\section{Lesser White-fronted Goose. Anser erythropus (Linn.).}

This small goose was added to the British list by Alfred Chapman, who shot one in September, 1886 , near Holy Island. 


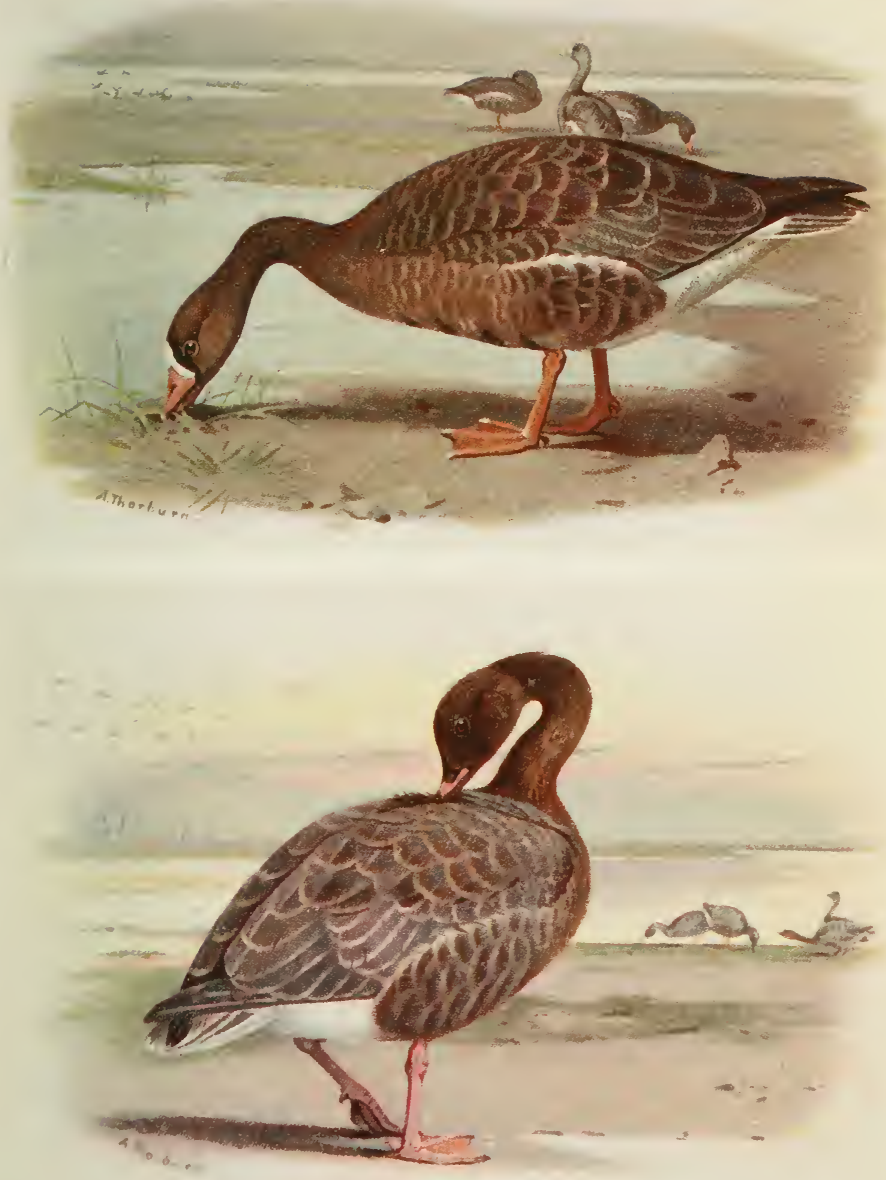

2 P. 4.

White-fronted Goose.

B 6 .

Pink-footed Goose. 
Others have since been reported, but the exact status of the species is uncertain. The range of the bird is restricted; it is known to breed in Lapland and Novaia Zemlia and in eastern Siberia, and winters rather further north than the last species. It is smaller, darker, and has a shorter bill than the other, and sometimes has a greater extent of frontal white; the validity of the species has, however, been questioned, and it might, with some reason, be treated as a small race of $A$. albifrons. Chapman's bird was immature; the breast was "warm reddish brown" and the belly grey dappled with black. The bill was pink, the legs yellow-ochre. Length, 20-2t ins. Wing, 15.5 ins. Tarsus, $2 \cdot 5$ ins.

\section{Pink-footed Goose. Anser brachyrhynchus Baillon.}

The Pink-footed Goose (Plate 4), a winter visitor, is in many parts the best known of our grey geese; though most numerous on the east coast it is locally abundant in the west, but only a straggler to Ireland. It breeds in Iceland and Spitzbergen and perhaps in other islands, and winters in western Europe.

As the specific name implies, the bird may be recognised by its short bill, black at base and tip and with an intermediate pink rather than orange band, usually smaller than that on the bill of the Bean. The legs are flesh-coloured or pink. Although a brownish bird it looks very light in sunlight, this being partly due to the blue-grey shoulders and greyish back, darker than those of the Grey Lag.

The Pink-foot is gregarious; the gaggles are frequently huge. The skeins fly in lines, V's, or double chevron formation; the birds call constantly as they fly ; their metallic voices carry for great distances. The quality varies, some are harsh, others shrill and musical. When following the tide the birds alight on the uncovered banks and stand alert with necks uplifted. 
When satisfied that they are secure, they rest or preen their plumage, but when driven off by the tide immediately begin to call and rise with a mighty rush of wings and babel of voices.

Many birds reach the west coast about the third week in September, but the skeins come in gradually and it is usually the end of October before the winter flocks are complete. Emigration begins in March, and most have left before the end of April. As soon as they arrive the birds visit the fields, gleaning in the stubbles in the early morning and at dusk, but when forced by circumstances to avoid the cultivated land they crop the grass on the saltings; they are always shy and nervous, and the approach of a man sends them off "honking" to the banks.

The Pink-footed Goose was long confused with the much larger Bean, but in the majority of examples the colour of the bill is noticeably darker than the legs. Ridgway's "vinaceous pink" was the shade of the bill of most birds that I have examined. In one bird the pale pink legs were distinctly tinged with vermilion. The head and neck are seal brown, the upper parts greyish brown, darkest on the wings and scapulars, and with bars formed by the pale feather tips; the rump is brown. The breast is brown, the belly suffused with grey shading to pure white. The irides are dark brown. The young bird is darker. Length, 27-28 ins. Wing, $16 \cdot 5-17^{\circ} 5$ ins. Tarsus, $2 \cdot 8$ ins.

\section{Snow-Goose. Chen hyperboreus (Pallas).}

As a winter visitor from the Arctic of eastern Asia and western America the Snow-Goose (Plate ro) has been reported so frequently as to claim a place in our avifauna, though it is always rare and uncertain. Two forms occur in America, the Lesser $C$. h. hyporboreus being the western race, and the Greater Snow-Guose, C. h. nivalis (Forster), breeding in Green- 
land, yet it is curious that the latter, which migrates south along the Atlantic seaboard so far as Florida, has only once been known to visit us-an example obtained in Ireland in 1886. The smaller bird ranges south in winter to the western States and Mexico, and has been met with in various parts of Europe ; it is therefore probable, especially as Gätke knew the bird in Heligoland, that the autumnal movements of the species are westward and that our visitors do not reach us via Greenland.

The Snow-Goose, white with black wings, is conspicuous and unlike any other wild goose; its black flight feathers prevent confusion with the swans, and the only other large white bird that in any way resembles it is the Gannet, whose short neck, cigar-shaped body, and easy sailing flight are distinctive. No wildfowler would be misled, and though there are more reports of birds seen than obtained, records by such observers as Sir R. Payne-Gallwey, H. A. Macpherson, and Mr. G. Bolam leave no doubt in the mind. Furthermore, in severe winters, flocks have been observed in different parts practically at the same time. The bird has been seen or shot on both the east and west coasts of England and in Ireland.

The flight is strong, and Macpherson noticed it as "leisurely"; the voice is described as harsh. The visits have usually been during exceptionally hard weather, but a bird was seen in the Solway on August 22nd, IS84.

The adult bird is white with black primaries. The legs and bill are red, the latter with a whitish nail ; the irides are dark brown. The young bird is brownish grey, darkest on the upper surface ; its bill is almost black, and its legs plumbeous tinged with reddish yellow (Dresser). Length, 25-28 ins. Wing, 15-17 ins. Tarsus, 3 ins. Greater Snow-Goose: Length, 30 ins. Wing, 17.4 ins. Tarsus, 3.25 ins. 


\section{Brent Goose Branta bernicla (Linn.).}

The Brents and Barnacles are collectively known as "black geese" to distinguish them from the "grey" group. They are more maritime in their habits than the grain-eating greys and feed largely on Zostera and other marine plants. Two. if not three geographical races of Brent have been recorded as winter visitors to our islands, and the B.O.U. Committee, though rejecting the Black-bellied Pacific $B$. nigricans (Lawrence), with a complete or almost complete white collar, as having been recorded on insufficient evidence, retain the dark B.b. bernicla and the Pale-breasted American B. b. glaucogaster (Brehm), which the editors of the "Hand-List" now consider as varieties, since, as shown by M. Alphéraky, they nest in the same area.

The Brent (Plate 7) is, on the wing, a small dark goose, stumpy and almost duck-like. The small white patches on its neck, and the white tail-coverts and abdomen show conspicucusly in contrast with the black head and neck and general dusky plumage; the white stern is specially noticeable, for the coverts above and below almost screen the dark tail. The bird is very gregarious; huge packs visit the east coast and Ireland, and it is met with in smaller numbers all round our shores.

October is the usual time of arrival, though a few come in September; Mr. Abel Chapman considers the 17 th of the latter month exceptionally early for Northumberland, and says that the numbers are seldom large until after Christmas. In two consecutive years the first reached the Yorkshire coast on October 6th and September IIth, but in the former case one bird only, some days before I saw others. Most leave in March or April, but stragglers may remain until May or even later. The Brent feeds by day, but it rarely leaves the shore, finding its vegetable, and occasionally 


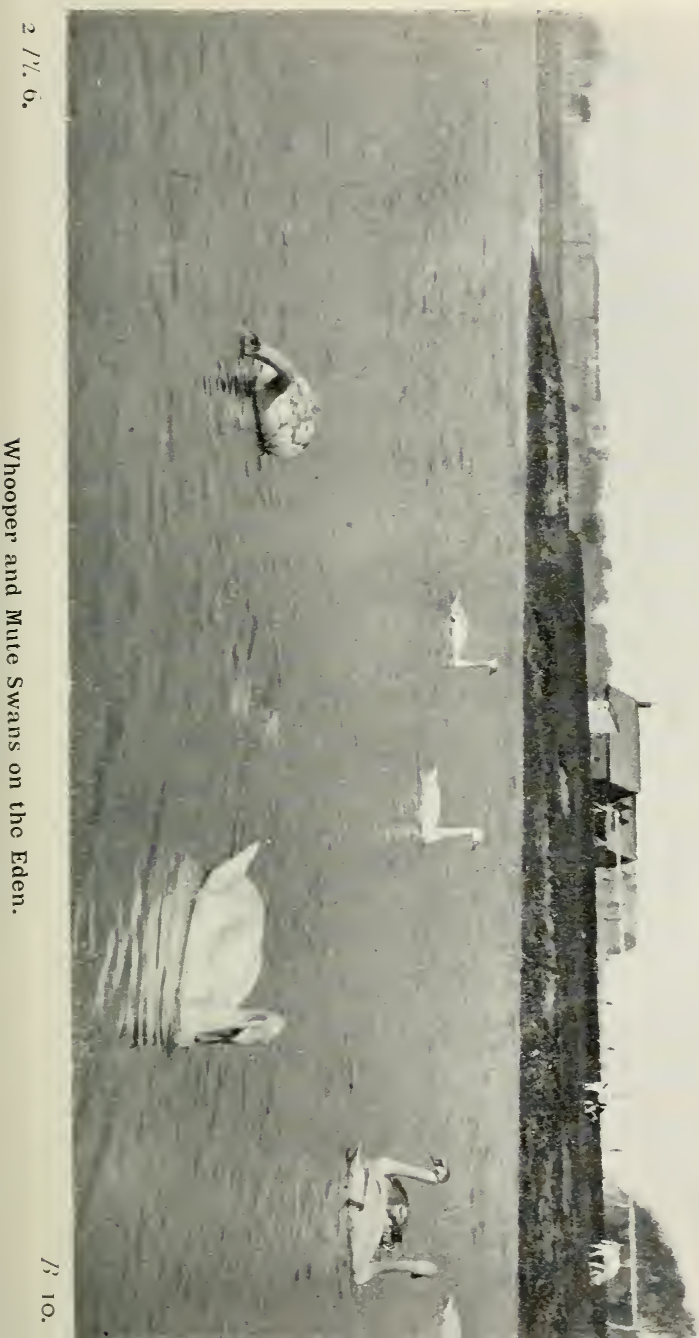



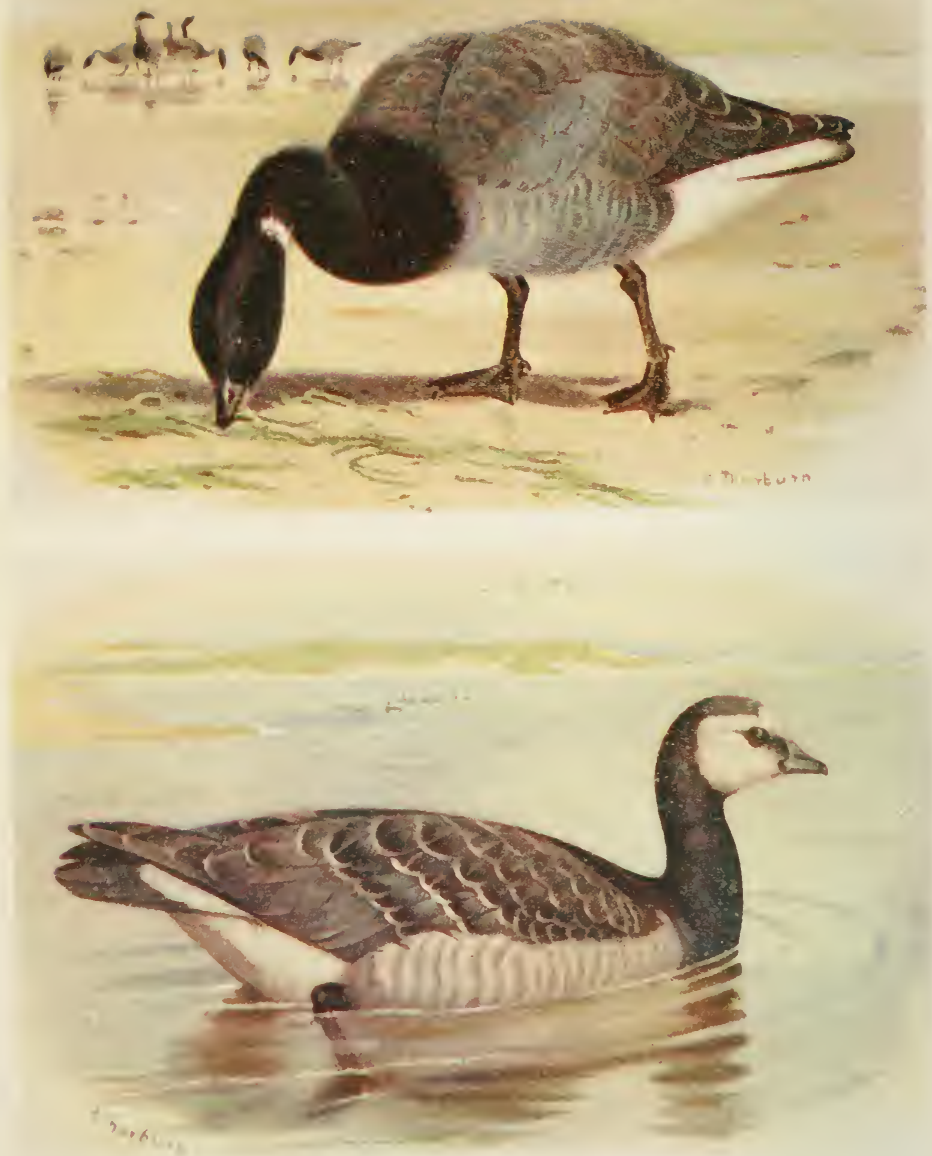

$21 \% 7$.

Brent Goose.

Barnacle-Goose. 
animal food-molluscs and worms-on or in the ooze of tidal estuaries. Naturally its movements are largely regulated by the tide, and it occasionally feeds in the dusk. The birds, in long lines, follow the receding water, their angled necks bent as they gobble the sea-grass, or are slowly driven back by the flood, still feeding; in shallow water they swim and dip their heads to drag up the weed, or upend like ducks, their white sterns alone visible. The Brent walks gracefully, can run fast, and flies with considerable speed. A disturbed pack flies hither and thither, taking ordered formation only when travelling for a distance. The flight call is loud and metallic, a double note frequently repeated. At high tide the birds swim in the open, avoiding the shore, but return as soon as the banks are exposed.

Adult Brents have the head, neck, upper breast, and back slate-black, a small white patch, in which black is often mingled, on either side of the neck. This patch varies in size, and occasionally meets in front, forming a more or less complete ring. The lower neck is slate-grey, the sides of the rump and upper tail-coverts white. In the dark-breasted form the under parts below the breast are slate-brown, showing distinct whitish bars on the flanks; in the paler form the lower breast is brown and the rest white or suffused with grey. The bill and legs are almost black, the irides dark brown. Immature birds are browner, and the neck spot is hardly visible. Length, 22 ins. IVing, $13 \%$ ins. Tarsus, 2 ins.

\section{Barnacle-Goose. Branta leucopsis (Bechst.).}

The Barnacle-Goose (Plate 7) nests in Greenland, Spitzbergen, and probably elsewhere in the Arctic, and in winter is common in northern European seas, and occasionally reaches the Mediterranean and Azores. It is more frequent in the Hebrides than the Brent, and is plentiful on the west coast of 
Scotland and the north of Ireland; in the Solway it is less numerous than formerly, and though it used to visit the Cheshire Dee in some numbers it is now only a rare straggler. Its winter quarters are more northerly than those of the Brent.

The Barnacle, though a marine feeder, is less strictly addicted to salt water than the Brent, for it will feed on marshes and cultivated land bordering bays and inlets. Larger and paler than the last species, its black crown and neck and white face are its noticeable features; its under surface is greyish white. The first Barnacles arrive towards the end of September, but the bird is seldom numerous until late October; they leave in March and April, but emigration is often delayed in the north. It is a nocturnal feeder, at any rate on the pastures; during the day it rests on flats or marshes, but I have disturbed birds which were apparently feeding by day, and the flocks will visit the edge of the saltings to graze. Dr. Patten describes the voice as low and "pleasing to the ear," though it has been likened to a "coughing grunt," and a gaggle can raise a clanging clamour of sharp yelping cries. Not only is the bird easy on its feet, but it can run swiftly, scampering across the flats with outstretched neck after a companion in anger or play. The flight is powerful and often at a height; indeed, it is likely that it is at times above the range of vision. When in April, 1913, eighteen birds were killed by lightning in the Solway, Mr. Portal records that none was seen or heard until their bodies crashed to the ground. The name is not derived from its food, though, like the Brent, it will eat molluscs and crustaceans, but from the ancient myth that the shipbarnacles gave birth to gee:e.

The white face and forehead of the Barnacle is set off by its black cap and neck, and there is a black mark from the bill through the eye. The upper back and breast are black, the lower back and rump brown, but the upper parts generally are lavender-grey barred with black and white. The under parts 
are white, as are the sides of the rump and upper tail-coverts; on the flanks are faint grey bars. The bill and legs are black, the irides dark brown. The blacks in the old bird are replaced by brown in the young, and the whites are suffused with buff and spotted; the barring on the flanks is often more distinct. Length, 25 ins. Wing, 16 ins. Tarsus, $2 \cdot 2$ ins.

\section{Canada Goose. Branta canadensis (Linn.).}

The Canada Goose (Plate 5 ) is usually denied a place in the British avifauna on the ground that when it has been recorded it must have "escaped from captivity or from ornamental waters." The bird, which has several well-marked forms, is a native of North America, migrating so far south as the Gulf of Mexico. Our bird is referable to the large eastern race.

Though there is no actual proof that the Canada Goose ever reaches us as a migrant, birds which have appeared in the Hebrides may have been truly wild. Yarrell included it as British because it has been known as an introduced species for more than two centuries. Indeed it is, at any rate in certain areas, so firmly established as a free-living and not domestic bird, that its claim seems to be as sound as that of the Mute Swan, the reintroduced Capercaillie, the Little Owl, and the Pheasant.

The Canada differs from the smaller Barnacle in the pattern and extent of the white on the face and the smaller amount of black on breast and neck. The upper parts are brown, not grey. In many parts of our islands the bird is merely a straggler, always treated with suspicion, but in East Anglia, Lancashire, and Cheshire, and a few other areas, it lives a wild life, nesting on the borders of broads, meres, or pools, and living gregariously during the greater part of the year. In Cheshire no one claims them, no one attempts to capture and mark them; flocks of a score to two hundred birds wander from mere to mere. 
The nest, usually close to water, is a large structure of reeds or other waterside plants, thickly lined with down. I have found from four to seven eggs. The gander swims on guard, though often at a distance, but the clanging alarm of the goose will bring him at once; then both will swim near the nest honking and extending their necks in sinuous curres, endeavouring to terrify the intruder. The whitish eggs are usually laid early in April.

The normal migratory instinct appears to have been lost, but the birds are wanderers during the winter, and the numbers to be met with in any particular haunt vary greatly. When the young are on the wing in July, the Cheshire birds, in flocks, flight nightly towards the hills, returning to the meres in the early morning, but whether the object is to roost on the reservoirs or to feed at night on the moors I have failed to discover. Normally the birds feed by day on the borders of the meres, cropping the grass, and they also visit cultivated fields. These passing flocks of "wild geese" are frequently noticed in the first half of July, but seldom later, though the birds move freely during autumn and winter. The note is a resounding honk, honk, sounded if the feeding birds are approached, and as they walk towards the safety of the water; they take wing if followed.

The face to behind the ear-coverts, and the chin and throat, are black, and the sides of the face are white, a marked cravat in contrast to the black neck. The upper parts are brown, pale feather-edgings forming bars; the light brown flanks and belly are faintly barred. The legs and bill are black, the irides brown. Length, 42 ins. Wing, 195 ins. Tarsus, 3 ins.

\section{Red-breasted Goose. Branta ruficollis (Pallas).}

The Red-breasted Goose is a western Siberian bird which visits and winters on the Caspian and other waters and 


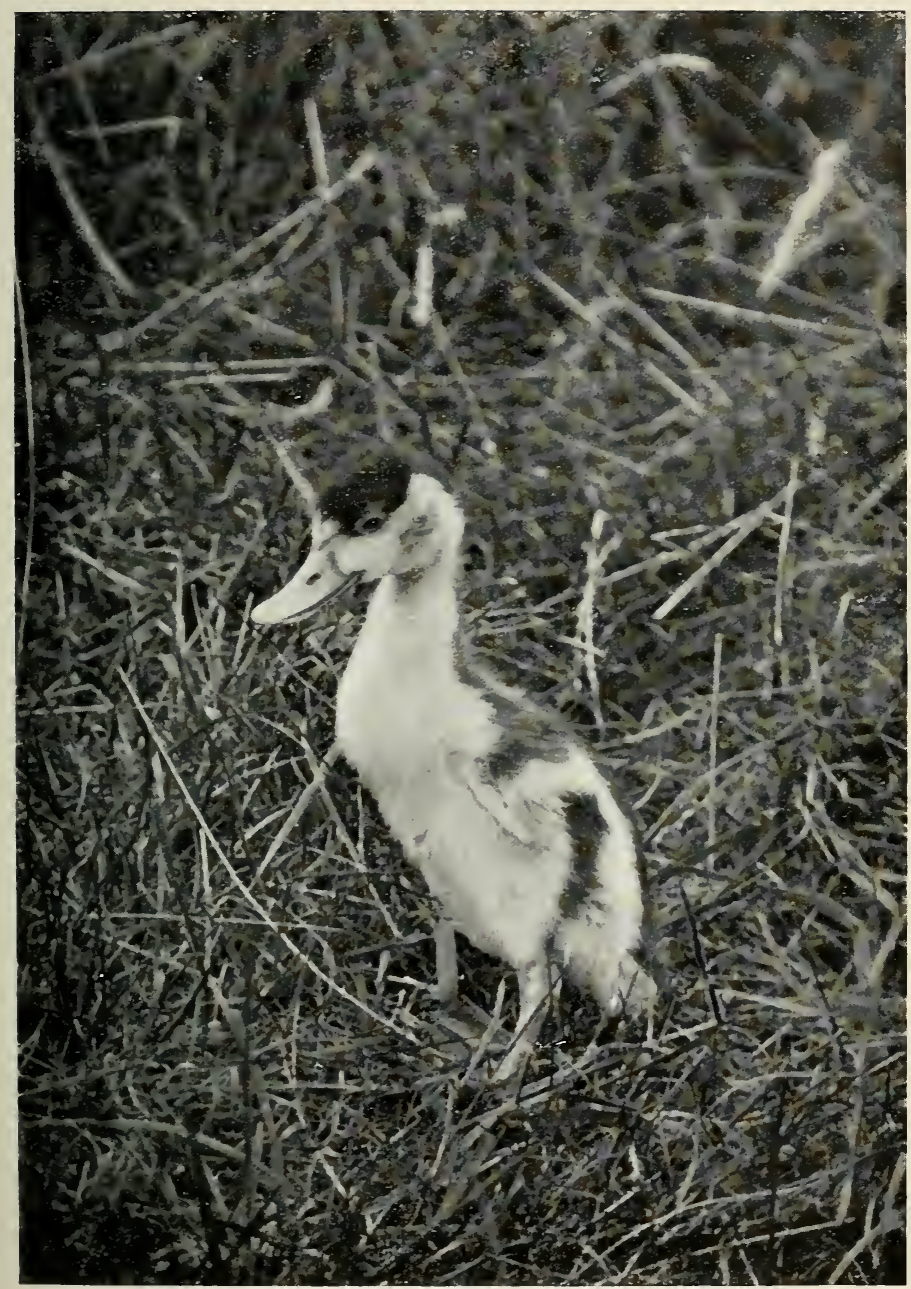



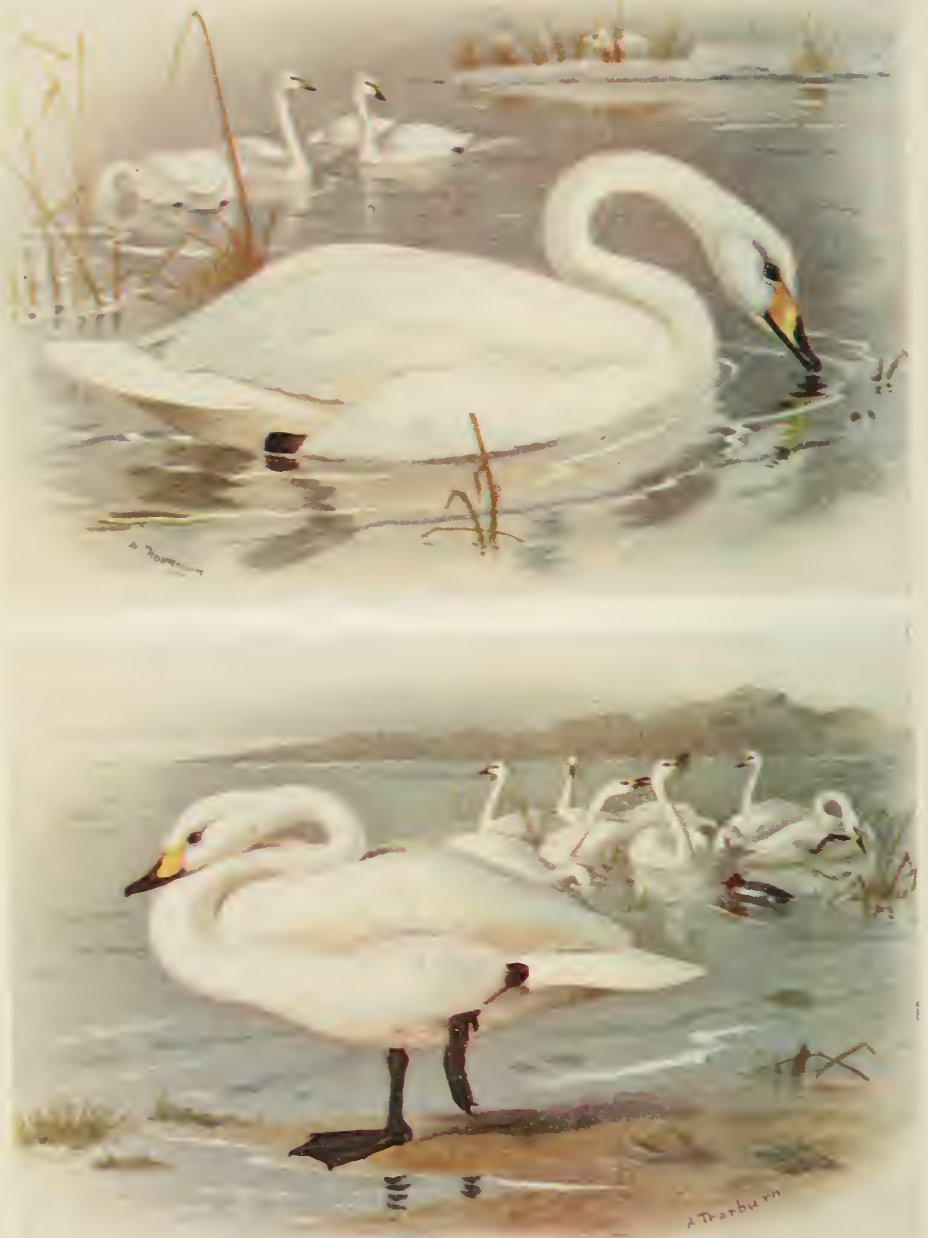

2 Fl. 9.

Whooper Swan.

Bewick's Swan. 
occasionally wanders westward. Half a dozen or so of the reported occurrences of the bird in England are supposed to be due to genuine migration, but others are either errors or may be due to wandering from private waters. The showy bird appears on mural paintings in Egypt. This goose is sociable and a vegetarian; it has been shot when consorting with both Brents and Barnacles. The upper parts are black, and the sides of the face and neck and the breast are rich chestnut bordered with white. There is a large white patch at the base of the bill, separated from the cheeks by a black line which passes through the eye from the crown to the chin. The belly is black, the flanks and tail-coverts are white. The short bill, legs, and irides are dark brown. The immature bird has less rufous on the face. Length, $2 \mathrm{I}$ ins. Wing, $I+5$ ins. Tarsus, 2 ins.

\section{Whooper Swan. Cygmus cygmus (Linn.).}

Three swans are on the British list, but two only, both winter visitors, can be counted as really wild. The Whooper, or Hooper (Plate 9), breeds in northern Europe and Asia and in Iceland, and winters in Europe, central Asia, and occasionally north Africa. It is frequent in Scotland and occurs round our coasts, though much rarer in Ireland than the smaller Bewick's Swan.

Size, when there is no chance for comparison, is insufficient as a means of identification in the field, and there is little difference between the Whooper and Mute. The best character is the beak. In the Mute this is black at the base, where there is also a prominent knob or tubercle; the rest, except for a black line along the cutting edge, is orange; the black reaches to the eye. In both Whooper and Bewick's the pattern is reversed and the lemon-yellow extends from the eye to the nostril ; in the former, however, the patch is larger and 
more angular, a wedge passing forward into the black tip beyond and below the nostril. A curious optical illusion is causcd by the pattern of the Whooper's bill; when the bird is some distance away the black tip appears to overhang.

The Whooper seldom arrives before November, for it is, as a rule, a severe weather visitor, the conditions in its northern haunts rather than those prevailing here regulating its appearance. Its stay depends largely upon its reception ; undisturbed birds sometimes linger until June. It is perhaps a more frequent visitor to inland waters than its smaller congener. I have watched it on meres when Mute Sivans were present, but have not seen it consort with them, but on the Eden at Carlisle a single bird came for several years in succession, and finally brought a family or companions to swim and feed with the Corporation herd of Mutes. Mr. L. E. Hope records that the visitors arrived at varying dates from November to February, and the latest stay of the original bird was until May Sth; when the numbers had risen to seven and eight the birds left in March and April. I saw these birds with the Mutes actually in the town at the end of December (Plate 6).

On the water the shy bird carries its neck stiffy erect, its bill at right angles as it turns its head sharply from side to side; its wings rest flat upon its back and are not arched as in the Mute. From behind the wings show like two smooth cushions ; the short pointed tail is carried horizontally. When the head is lowered to feed, the neck has a goose-like angle and not the graceful curve of the Mute. Like other swans the bird upends, submerging the head and fore parts, paddling slowly to hold itself in position; its wing tips are slightly raised. The food, aquatic weeds, molluscs and other animals, is mostly obtained from the bottom. When the bird rises, head to wind, it flogs the water for some distance. Once under way it flies with great speed and power, its neck extended, the swish of its long wings producing a whistling sound quite distinct 
from the throb of the flying Mute. It is, I believe, from this and not its call that the bird gets its name, "IVhistling Swan." The ordinary name is derived from the note, a distinctive character. The call is variously described as a " deep-toned whistle," a trumpet, bugle, or bass trombone sound; surely it must vary. My own notes say- " a clanging wu-uck or woo-uck, the ending sharply rising." On its breeding ground in Iceland Mr. Jourdain heard a nasal, goose-like cry of alarm, and "a low but musical song of about seven distinct notes."

All the swans are white when mature; their bills vary as described above. The legs are blackish, the irides brown. The male is the larger bird. The young is pale brown, palest beneath; the bill is flesh-coloured; the legs at first are fleshy, but gradually darken. Length, 60 ins. Wing, 25 ins. Tarsus, $4 \cdot 3$ ins.

\section{Bewick's Swan. Cygnus bequicki Yarrell.}

Bewick's Swan (Plate 9) breeds further north in Arctic Europe and Asia than the Whooper, and in winter, though it is found in various parts of the two continents, its range is more northerly. It is a winter visitor to our islands, most numerous in Scotland and the north and west of Ireland.

Although much smaller than the Whooper, the shape and size of the yellow patch on the basal portion of the short bill of Bewick's Swan is the best mark for identification. This patch is somewhat rounded in front and does not extend so far as the nostril. The colour of the patch is variously described as yellow, deep yellow, lemon-yellow, and orange in both this species and the IVhooper, but in living examples that I have seen, usually, at any rate, has been lemon-yellow. Possibly these birds were young, for the shade certainly deepens with age, but I suspect that in some cases the writers have been misled by the dark colour of a dry skin. One distinction between the two wild swans, not always clearly shown in 
figures and seldom mentioned, is that there is one patch in the Whooper and two in Bewick's; that is to say, the black on the bill of the Whooper only reaches part way up the culmen, whereas in this bird it extends to the forehead. This black line bordered on either side by yellow is very noticeable when the bird faces the observer. In the Whooper a band of colour crosses the base of the bill.

In general habits, food, flight, and appearance Bewick's resembles the larger bird, with which it was long confused, but on the average its visits are shorter. There are records of its arrival in October, and Dr. Eagle Clarke gives November as its usual month for Scotland, but as a rule it is in December, January, and February that we see it ; it seldom remains until March. It is more gregarious than the Whooper; herds of two or three hundred are not unusual, and in Ireland it is said to be often present in thousands. It frequents salt-water lochs and inlets, and though it occasionally wanders inland is on the whole more maritime than the Whooper. Its flight call is quite distinct, a sharp, repeated, barking note, loud and metallic; a puntsman I knew described a herd as yelping "just like a lot of poodle puppies." Mr. H. W. Robinson records that at night, on one of the Inner Hebrides, he repeatedly heard the "song," which "consists of the full octave, and both ascends and descends"; once he heard it in the daytime.

Many writers state that wild swans sometimes show a reddish or ochrcous tinge on the head and neck, and Mr. W. P. Pycraft has seen a dark copper hue. Years ago, however, Stevenson pointed out that this is due to peroxide of iron staining the plumage when the bird is feeding in certain waters. Mr. Jourdain saw a Whooper deeply stained after feeding in a peat bog, and 1 have seen Mutes deep red on the head and neck on a pool where the weed and mud is thickly covered with iron deposit. 

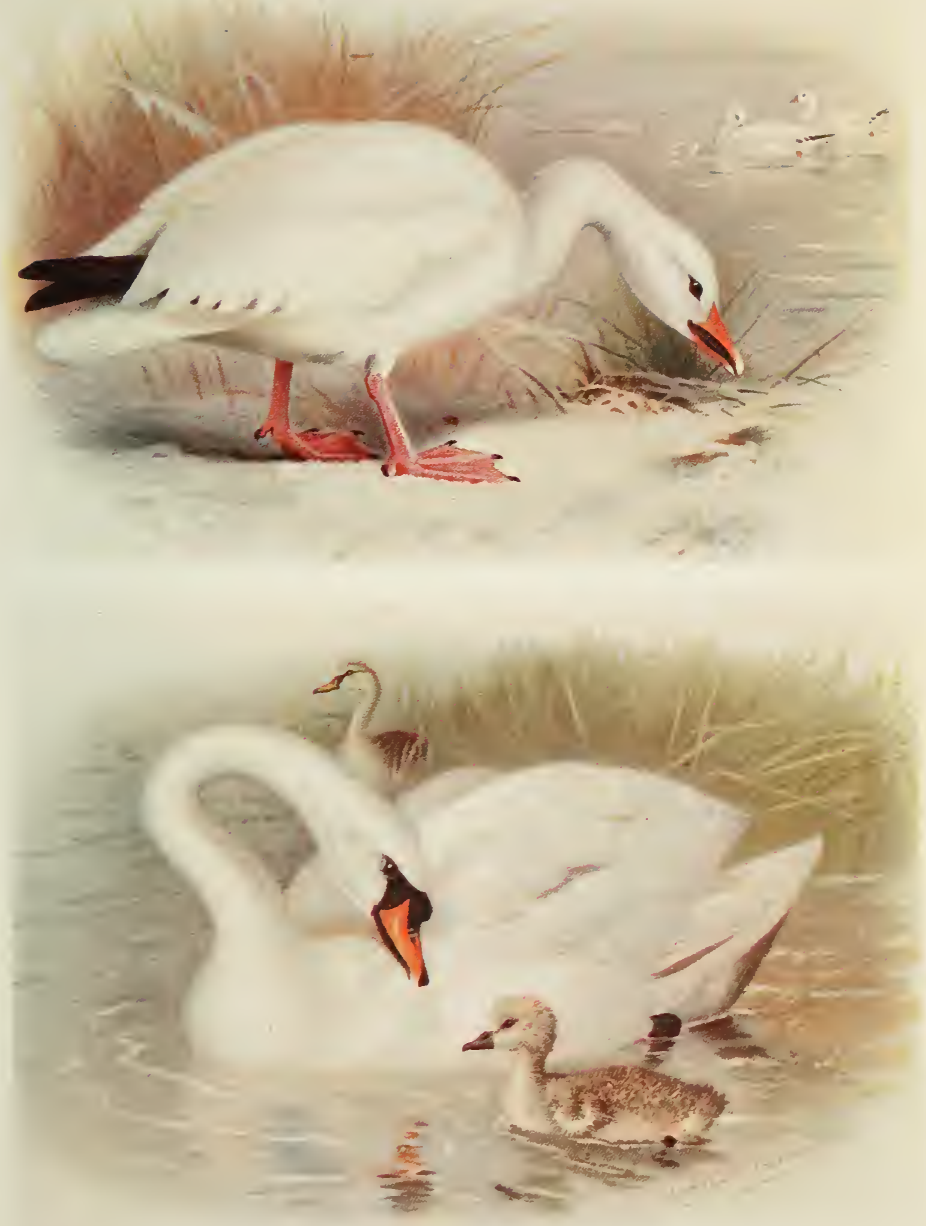

2 Pl. 10. 
The legs of the adult bird are black and its irides brown, but in the young they are reddish, even after the greyish-brown dress is lost. The patch on the bill is at first fleshy, and is paler in the second year than when fully mature. Length, about 50 ins. Wing, $2 \mathrm{I}$ ins. Tarsus, $3^{\circ} 8$ ins.

\section{Mute Swan. Cy'snus olor (Gmelin).}

The wild Mute Swan (Plate 10) nests in northern Europe so far snuth as Denmark and north Germany, and migrates in winter to the Mediterranean and northern Africa; it also breeds in central Asia, and occasionally reaches north-west India. Probably some of the birds which visit our shores in winter are wild migrants, but the $\mathrm{Swan}$ has been so long domesticated or semi-domesticated, and so many live a free and independent life, that the origin of any particular bird is obscure. Home-bred birds may become feral, may even enigrate and return as winter visitors, or our resident stock may be recruited from the Continent.

The Mute Swan may at once be known by the black knob or "berry" at the base of its orange bill ; this tubercle is smaller in the female. It may also be recognised by the graceful $\mathrm{S}$ curve of its head and neck, and its frequent habit of swimming with the wings half raised and the tail pointed slightly upwards. Young birds as a rule carry the neck straighter, and the alert, perhaps migrant birds that I have seen on the shore stiffened their necks when approached and readily took wing. In flight the wing strokes are deliberate but very powerful, and throb rather than whistle; the noise reminds me of horses galloping on hard ground. The name Mute is misleading, for the bird, especially the male or "cob" when guarding the nest, has a defiant trumpet note-an explosive grunt. The sitting bird will hiss defiance. The song-Yarrell's "soft low voice"is only heard in the breeding season. The food consists 
largely of aquatic plants; on private waters the bird is a useful check to the troublesome American weed, Anacharis. Insects are eaten, and, it is said, frogs, but these and toads it will worry and discard, and it will kill the young of other water fowl.

The nest is a large structure of rank vegetation lined with down, and is usually placed near water, on an islet if one is available. The five to twelve greenish-white eggs, laid as a rule in April, average in size 4.3 by 2.9 inches. The bird pairs for life, and the cob shares in incubation, but usually guards the nest, "buskiug," as it is called, when approached. In this terrifying performance the wings and scapulars are further raised, and the neck is drawn back until almost hidden by the wings; the bird forces itself forward in rushes with simultaneous strokes of its feet, ploughing up the water. The ash-grey downy young are at first carried on the parent's back. The male will at times monopolise domestic duties, refusing to allow his mate to relieve him during the long incubation.

The bill, already described, is black at the tip and along the cutting edge as well as at the base and on the lores. The legs are black, the irides dark brown. The young in first plumage are sooty grey, the legs are lead-coloured, and the bill, without any berry, is greyish black. When over a year old and nearly white, the bill is still fleshy rather than orange. White cygnets, by no means uncommon, gave rise to the so-called Polish Swan, which is now known to be a variety. Length, 60 ins. Wing, 27 ins. Tarsus, 45 ins.

\section{Common Sheld-Duck. Tadorna tadorna (Linn.).}

The Common Sheld-Duck (Plate I2) breeds near salt water in northern Europe and Asia. It reaches north Africa, India, and south China in winter. Its distribution in the British Isles is general but uneven; it is a sand and dune haunting 
species, locally abundant on the east coast and in Somerset, and exceedingly plentiful in some parts of Wales and Scotland. In Lancashire and Cheshire, where writer after writer has stated that its numbers are greatly reduced, it is steadily on the increase.

This large and handsome duck has certain goose- and swanlike characters, and is not easily confused with other species. When flying over the distant banks it looks black and white, but if nearer, the broad chestnut band across the white chest is conspicuous, and the scarlet bill with its prominent knob is characteristic. The drake Shoveler when sleeping shows the same stout white breast and chestnut band, but is a squatter, short-necked bird with a lower pose on the water. The name means pied, and has no connection with shield; the bird is often called the "Sheldrake," irrespective of sex, or "Shell-duck" or "Mussel-duck," from its food.

Tidal flats, whether of sand or mud, are favoured feeding grounds; it is said to feed by night, but certainly also feeds in the daytime; doubtless its times are regulated by the tides. It is gregarious, but the "droppings," the sporting term for the flocks, are seldom large; though at times of migration, for many immigrants come in autumn, it congregates in thousands. The birds scatter over the banks hunting for molluscs, worms, or crustaceans, even racing after sand-hoppers. Mussel-beds are frequented, and some marine weeds are eaten. Like gulls, the Sheld-Duck will mark time or paddle in shallow water to bring worms or other animals to the surface, but much of its food is obtained when swimming by dipping the head and neck, and upending like other surface feeders. On dunes and marshes, frequented at high tide and during the breeding season, land molluscs and other animals are eaten. The bird walks easily, and its flight is slow and regular, suggestive of a goose rather than a duck. The drake has a low whistling call, and the duck a subdued barking quack; which 
when rapidly repeated has a laughing ring. I have heard the drake utter a laughing croak, and a deep angry $u$ wrk, as well as the whistle when alarmed for the welfare of the young. The drake may be distinguished by his superior size and the large knob on the bill. The bird swims lightly, sitting high on the water; it seldom dives unless wounded or when threatened by an enemy.

Though exceptionally the nest is in a crevice in rocks or in dense undergrowth the normal site is in a burrow, generally that of a rabbit, whence its name, "Burrow-Duck" and the corruption, "Bar-duck." A small collection of grass, moss, and often bracken, with a plentiful lining of pearl-grey down, is placed in a hollow at a variable distance, two to twelve feet, from the entrance. Occupied burrows may be told by the footprints left by the birds. Mr. IV. H. Hudson says "the strange and beautiful Sheldrake" leads his mate to the burrow and courteously but firmly persuades her to enter. There is an element of romance in his account of the April gatherings, but these communal meetings on the dunes are continued until June or July. In early spring the birds collect for pair. ing display; the drakes stretch up their necks and dip them suddenly, and walk round the ducks, their necks depressed and bent, their shoulders hunched up. When rivals meet there is a short tussle, the combatants springing clear from the ground, but one soon gives in and is chased away on foot or wing by the victor. Later, according to Mr. Hudson, the drake drives or leads his mate to the nest after her daily meal, but these parliaments meet long after incubation has begun, the members resting, preening themselves and chattering softly on the grassy levels amongst the dunes. I have counted thirty-five birds at the meetings; Mr. F. IV. Holder has seen more than seventy.

The eggs, usually laid early in May, are creamy white, and measure about 2.6 by $I^{\circ} 9$ inches. The usual clutch is seven to 

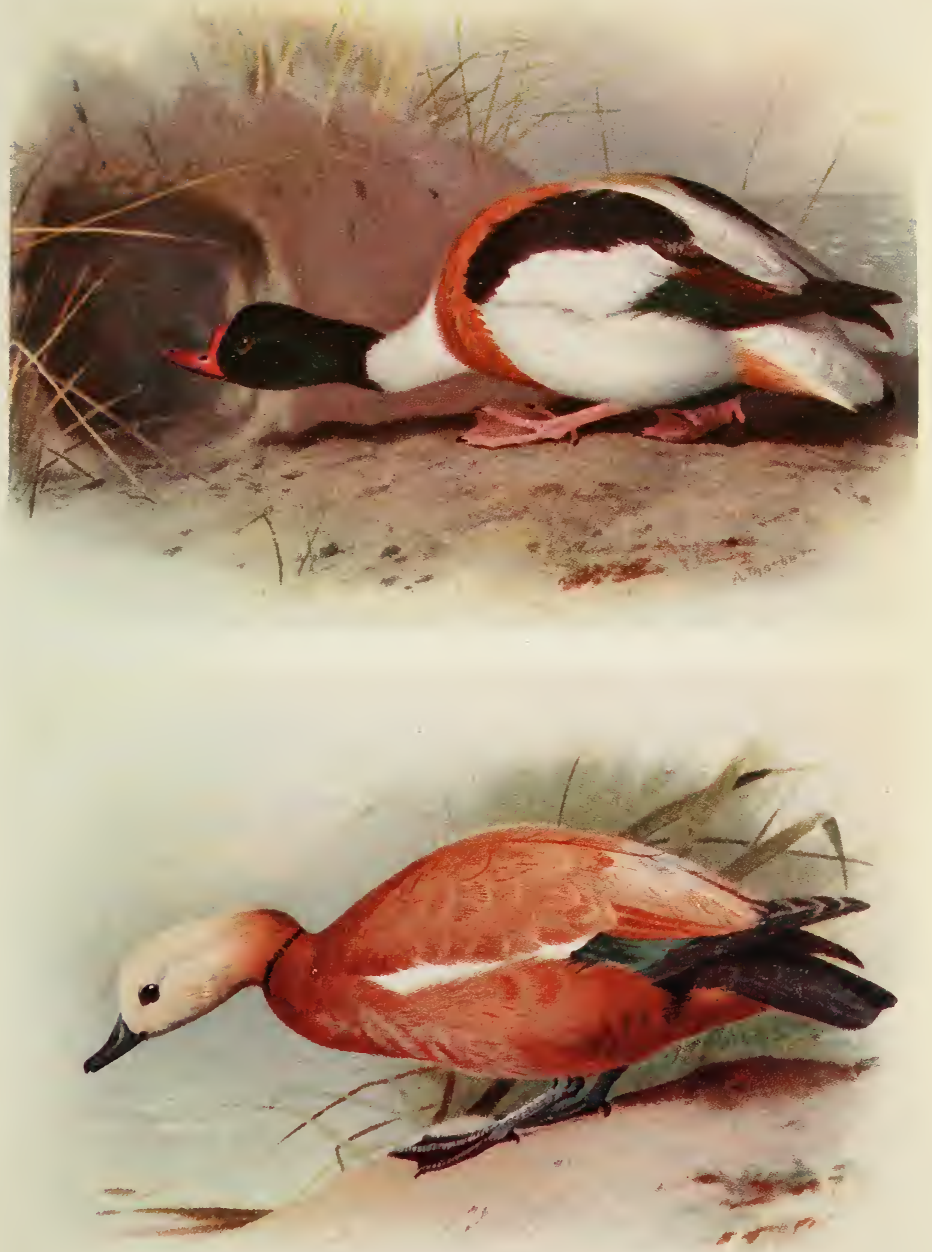

2 Pl. I2.

Sheld-duck.

C 22.

Ruddy Sheld-duck. 
iे

离
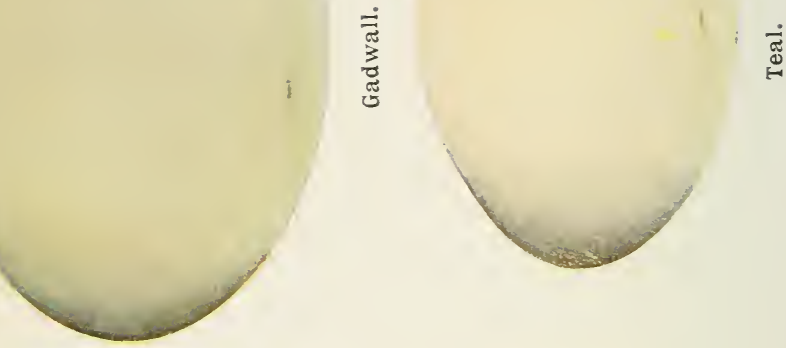

ב.

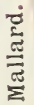

$\stackrel{4}{i}$ 
twelve ; the large numbers occasionally reported are doublless produced by two ducks. The nests are often in colonies. On Brean Down and in some Welsh localities the bird nests on high ground-on Puffin Island on the cliff roo feet or more above the sea-but as a rule sandhills and links are favoured. Inland nesting, especially since the marked increase of the species, is not uncommon; the statement that those that nest at a distance from the coast have escaped from ornamental waters has no foundation. The young bird figured (Plate 8) was hatched in a burrow at the edge of a Cheshire mere nine miles from salt water; for many years a brood has been hatched at this spot. Within a day or two of leaving the egg the ducklings are taken to the sea by their parents, and an annual attempt is made to conduct these inexperienced pedestrians from their fresh-water home. Naumann and others affirm that the ducklings are conveyed in the beak or on the back of the old birds, and though such aid may have to be given to birds hatched on high ground, walking is the usual method. The little procession is watched for and intercepted by fishermen, who can sell the young into captivity. On one occasion I met the ducklings with their parents just after they had left the burrow, and the inexperienced infants came cheeping to meet me, heedless of the agonised cries and extravagant behaviour of their parents, and allowed me to take them in my hand. Later they learn wisdom, and on the shore run with wonderful speed; on the water they dive with skill, and I have seen a brood tire out an energetic retriever and never be in danger.

Both parents attend the brood, and either there is some nursery-school arrangement or frequent adoption of orphans, for it is not unusual to see a single pair escorting two or more combined families; I have seen twenty-one, by no means all of one age, and heaid of over forty and even sixty-two. In each case only a pair of old birds tended the young, though 
many others were about. When families meet on the banks the attending old birds usually fight, so that it is possible that kidnapping may explain the phenomena. So far as is known, only single broods are reared.

The adult bird has a metallic green-black head, but the plumage generally is white and black; a white neck collar is followed by a broad, rich chestnut band; the back, coverts, and flanks are white, the primaries and scapulars black. On the wing is a chestnut and bronze-green speculum, and a black band passes down the centre of the belly. The bill is scarlet, the legs pink, the irides brown. Immature birds are browner, have a grood deal of white about the face, and their under parts are mottled; for over a year their bills are flesh-coloured. The duckling is clad in white down with a sepia band from the crown to the tail, crossed by a band at the shoulders and another, less complete, to the thighs. The bill is lavender-grey, the legs olive-grey, and the irides chestnut. Length, 25-26 ins. Wing, 13 ins. Tarsus, $2 \cdot 3$ ins.

\section{Ruddy Sheld-Duck. Tadorna casara (Linn.).}

There is always a suspicion that any Ruddy Sheld-Duck that is seen in Britain in an apparently wild state may have wandered from private waters, for the bird is a favourite ornamental fowl much addicted to wandering. On more than one occasion, notably in the spring and summer of $1 \$ 92$, the bird has spread northward and westward throughout Europe, and numbers have invaded our islands. It is an occasional but irregular visitor. From south Spain and north Africa, through south-eastern Europe to west and central Asia the bird breeds, and is common as a winter visitor to India and Burma. During the irruption of 1892 it was met with in many parts of Great Britain and Ireland in small flocks, and wanderers even reached Iceland and Greenland. In June, 1909, one was killed at Suliskerry, Orkney. 
Even those who do not know the Ruddy Sheldrake (Plate 12) in captivity cannot fail to identify the bird; its orange-brown and buff plumage, and the square white patch which shows plainly on its open wing, are distinctive. On the water it swims with the breast and fore parts low and the stern high, showing a raised and rounded lower back above the deep counter of its black tail and coverts; the neck is carried well erect. On the wing it is heavy and slow. It has a loud double call and a barking cry. In India, where it is common in the cooler months and is known as the Brahminy Duck, it is rather troublesome in growing crops, and in our parks and public gardens it walks easily, cropping the grass like a goose ; insects, worms, and frogs are also eaten.

I have watched the bird on a Cheshire mere early in July, and from its behaviour and the time of its appearance it may have been a wild visitor; but Lord Newton, who has a number of unpinioned birds in his park at Lyme, tells me that they get restless in summer and often wander off in August and return, if allowed, in October. Though a month earlier than the usual time of this seni-migratory movement, it is possible that it had wandered from Lyme, for in the same summer three were shot in the neighbourhood, and some of Lord Newton's birds never returned.

The general colour of the adult male is orange-brown, paler below; the head is buff, there is a black neck collar, and the wing-coverts are white. When swimming the white is hidden by the scapulars, but in flight shows plainly a large square patch. The speculum is bronze-green. The legs are blackish, the bill lead-grey, the irides yellowish brown. The female and young male have no black collar, and it is asserted that the male loses this distinctive mark in winter. Length, 25 ins. Wing, $1+5$ ins. Tarsus, $2 \cdot 25$ ins. 


\section{Mallard or Wild Duck. Anas platyrhynchos Linn.}

The Mallard (Plate 15 ) is our most abundant and best-known duck ; it occurs throughout the Holarctic region, and in winter is found in northern Africa, India, Burma, and the Gulf of Mexico. Resident throughout our islands, it is also an abundant migrant, winter visitors arriving in autumn, when some of our home-bred stock leave for the south.

The really masculine name Mallard is more distinctive than the older comprehensive Wild Duck, and is now applied to both sexes. The drake is not difficult to identify when in full dress, with glossy bottle-green head, white collar, grey scapulars and flanks, and the perky upcurled feathers on the tail. His breast is warm brown, whilst that of the dark-headed Shoveler drake is white above a chestnut band. The duck, in mottled browns and buff, is less distinctive, and may be confused with the Gadwall, Shoveler, or even Pintail ; in summer, when the drake has donned his extra or "eclipse" dress, a protection during the moult, he is more sombre and feminine. But the Gadwall has a greyer, more vermiculated mantle and a white patch on the wing, the Shoveler a broad and heavy bill, a short neck and a marked tip forward when swimming, whilst the Pintail duck is long-necked and slender, and her pointed tail is generally visible. In flight drake or duck may be told by the wing pattern, a purple green-shot speculum, bordered above and below with black and white-two distinct white bands, one the outer edge of the wing. The white borders of the wedge-shaped tail are also plain.

The haunts of this duck are varied; in winter it abounds along our shores and on marshes, on large or small sheets of water in the lowlands, and on reservoirs and moors on the hills. Its usual feeding-time is from dusk to dawn, and during the day it rests in packs or scattered flocks on open water, swimming idly with head drawn back or snoozing with its bill tucked 


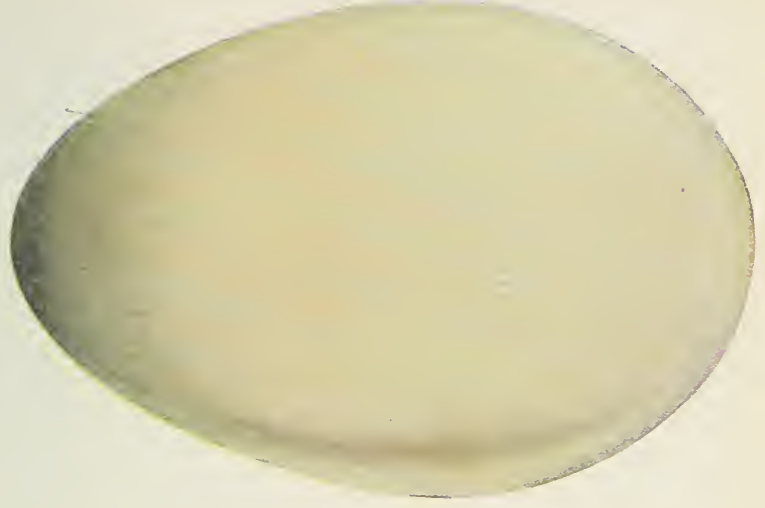

Eider.

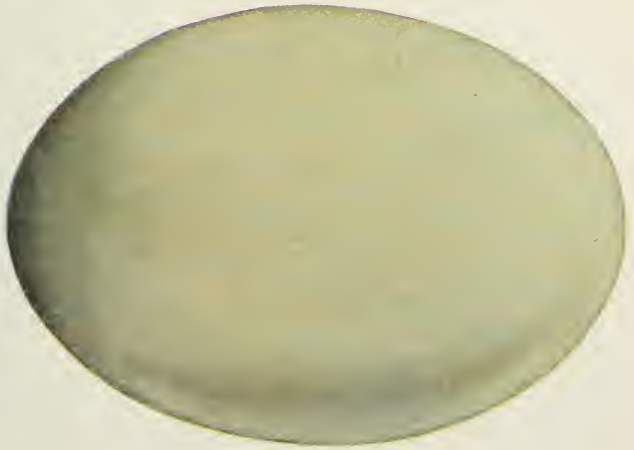

Pochard. 
amidst the feathers of its back. It will sleep on the bank or dawdle about, picking a scrap here and there, and at times a few birds will feed at the water's edge; but it is not until the evening that "flighting" takes place. Then in couples, for the Mallard pairs for life, the birds go off to the ponds, ditches, or fields to seek food, returning at dawn. Food, animal or vegetable, for it is omnivorous, is sifted from the mud which passes through its laminated bill. In the fields it picks up grain, in the woods acorns, and worms, snails, slugs, and insects are all accepted; it plucks ripe berries from the brambles or the seablite seeds on the marsh, and on the sandbanks devours cockles and other shellfish. In frost the majority retire to salt water, but some will linger, roosting on the ice; should snow fall the oblong, half-thawed patches mark their chilly beds. At all times gregarious, the winter flocks of Mallards, especially on the coast, are sometimes immense, and even when the ducks are sitting the drakes form little bachelor groups on the water. During the diurnal rest the birds are alert, and, if disturbed, all rise in a body with a rush of wings, and, splitting into twos and threes, fly to and fro high above gunshot.

The flight is swift, the wing-beats, rapid and strong, produce a swishing whistle. The bird springs c.ear of the water when disturbed, shooting upwards, and when about to alight comes down with head well forward, but with the body upright, striking the surface with the feet and tail, ploughing up the water as it checks its pace with open wing. It seldom if ever dives for food, but when at play a number will splash together and take short superficial under-water excursions, and a wounded bird will try to escape by diving. In June I disturbed a drake in eclipse ; it tried to fly but failed, and was promptly chased by an irate Moorhen, when it dived, followed by its pursuer.

Immigrants arrive from August onward, but the largest numbers collect on inland waters in December and January; 
many remain until April and May; parties of migrants are about long after our resident birds have begun nesting. All sportsmen agree that "foreign" Mallards are smaller and lighter than our birds, but no racial difference has so far been discovered. Marking birds has demonstrated that some of our immigrants come from Scandinavia, Lapland, and Holland, and British birds have been found in Germany and Fiance. The voice of the drake is a low, conversational chuckle during the breeding season, with an occasional sonorous quack. But when the birds are startled it is the duck which quacks in alarm, but in a different tone. Seebohm spells the male note quork, and the female quark, a good distinction. When pairing the drake also whistles. Pairing begins early; I have often watched display in October. A number of drakes swim round a duck, posturing in various ways, but the sequence of actions is not always the same. The bird sits up in the water, as if making its seat more comfortable, and dipping the head, strokes its breast with its bill. It raises and fans its tail, showing off the white, and stretches its neck along the water as a final compliment to its selected mate.

Incubation often begins in March. The nest is usually at a short distance from the water, in thick vegetation, in woods, dry reed or willow beds, hedgegrows, or in heather on the moors. Sometimes it is in the fork of a tree or the deserted nest of some large bird. Grass and dead leaves are the usual materials used, and a lining of clark brown clown is added as incubation proceeds, with which the eggs are covered when the duck leaves them; when she is sitting (P'late II) her sombre dress is sufficient protection. The eggrs (Plate 13), eight to fourteen in number, are variable-greenish blue, olive-brown, cream, or white. The normal moult begins in August, and by the end of September most drakes are in full dress. The spring moult of drakes is incomplete, but in ducks it even includes the down. In May the drakes assume the so-called 
eclipse plumage and moult the flight feathers; this dress is a mixture of that of the female and young male.

The downy juveniles are brown and buff, with a few white patches and a noticeable dark streak through the eye beneath a stripe of buff, also a dark mark on the ear. They are carefully guarded by the duck alone, and if threatened she strives to lure away the intruder by extravagant performances, flogging the water with her wings, taking short rushing flights, quacking vigorously, indeed any action that will call attention to herself. The ducklings scatter, some dive in the rushes or grass and hide, others run out over the water, their light bodies unsubinerger, and dive when well clear of the bank; when they reappear they show only head and neck and again go under.

The drake in winter dress, already described, has the upper and under tail-coverts black. The bill is yellowish olive, occasionally orange in old birds, the legs reddish orange, the irides brown. Young males closely resemble the mottled, olive-billed females, but their heads and backs are noticeably darker. Wild hybrids with Gadwall, Pintail, and Eider have been described. Length, 23 ins. Wing, I ins. Tarsus, 175 ins.

\section{Gadwall. Anas strepera Linn.}

The breeding range of the Gadwall (Plate 17) is almost as wide as that of the Mallard, practically the northern temperate regions south of the Arctic circle; in winter it is found in Africa as far south as the Sudan, is well known in India and China and throughout North America. In the British Isles it has been successfully established as a breeding species in East Anglia, the first attempt made some sixty years ago by pinioning birds that had been captured in decoys ; not only did these birds rear young, but wild immigrants were attracted and remained to nest. Within recent years a few pairs have been found nesting in Scotland, even in the extreme north; indeed 
there, as in Norfolk and Suffolk, the bird seems to be increasing. For the most part, however, the Gadwall is a rare and irregular but widespread winter visitor to all parts of Great Britain and Ireland.

Superficially the Gadwall resembles a rather dark female Mallard, but may always be told by the black and white speculum ; the overhanging scapulars or the fluffed-out flanks often almost conceal the white. Ducks, if watched long enough, usually rise in the water to flap their wings, and then the white flashes into view. As it frequently swims with Mallards, opportunity is given of comparing size; it is distinctly smaller and greyer than the ducks, and in flight its wings look more pointed. Crescent-shaped marks, grey in the drake and brown in the duck, show on the head and neck. It swims buoyantly and flies swiftly, its wings whistling, but its feeding and other habits differ little from those of other surface-feeding ducks. Normally nocturnal, it may, however, be seen feeding in the day, paddling gently as it holds itself vertically in the water with its fore parts immersed. Migrants, which reach our shores from the end of August onwards, may be noticed at sea, but the favourite haunts are fiesh-water lakes and pools, where, shy and retiring, it seeks the shelter of the aquatic vegetation. The note is described as a cackling quack, and by Lilford as "a sharp rattling note continually repeated "; an amorous drake, which with its neck affectionately stroked its mate's back, constantly uttered a clear and deliberate, though not loud, $c p, e p$, pair. The duck has a Mallard-like quack.

The nest (Plate 16), seldom far from water, is as a rule well concealed by its surroundings; it is built of grass or other try plants, and is lined with dark greyish-white down, lighter than the nest-down of the Mallard. The eight to thirteen eggs are buffish white (Plate 13), and are usually laid in May. The down of the juveniles is similar to, but a little darker than that of the Mallard. 


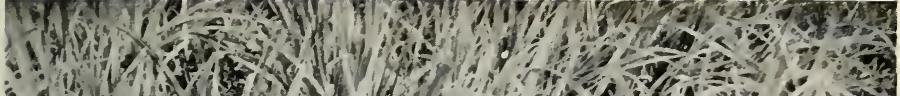

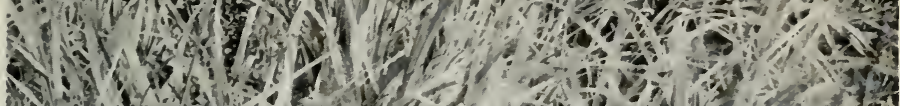

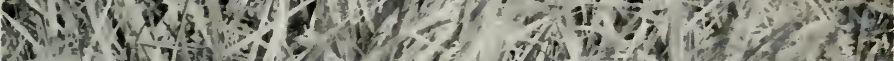

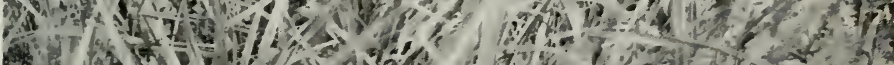

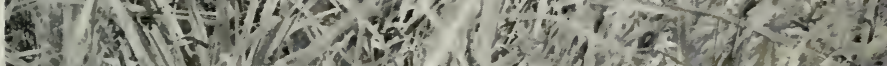

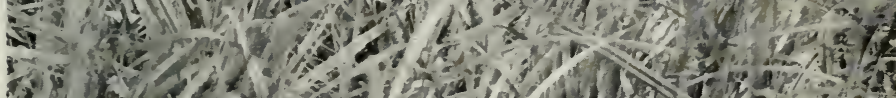

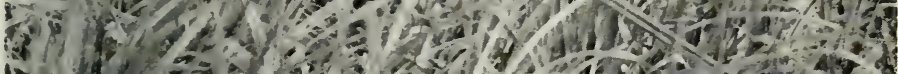
T. W.

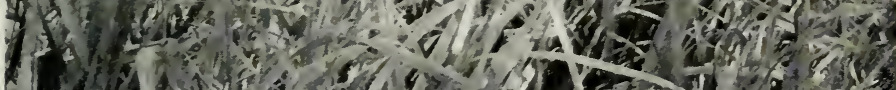

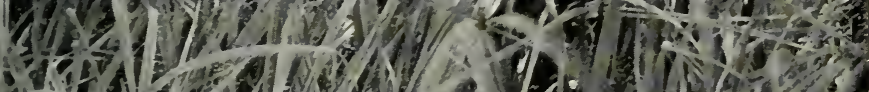
i. 1501010

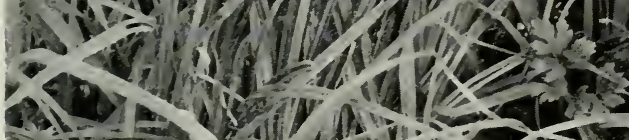

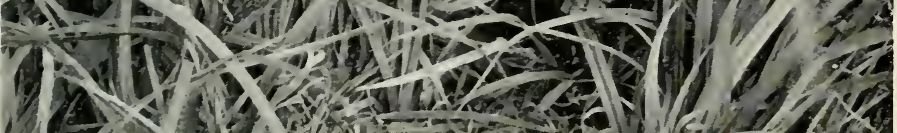
Cof -

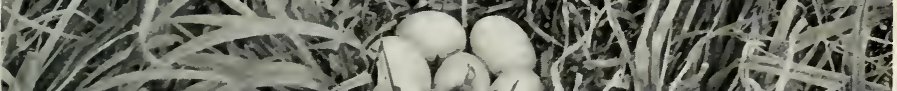

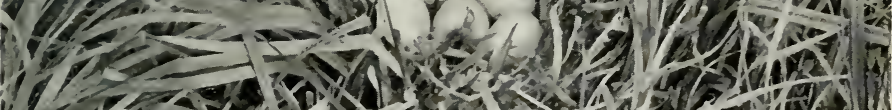

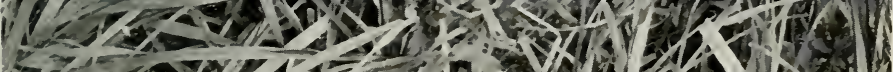

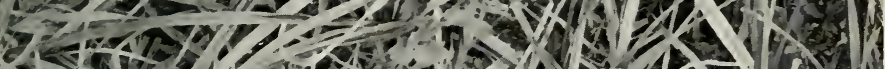

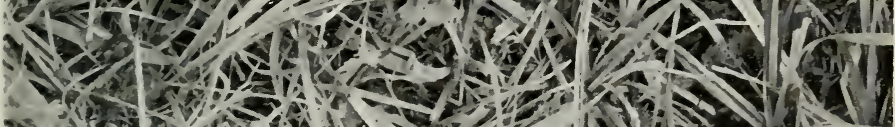

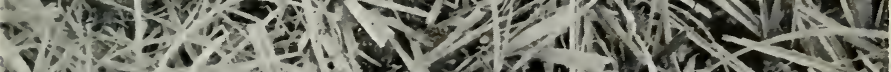
F. 

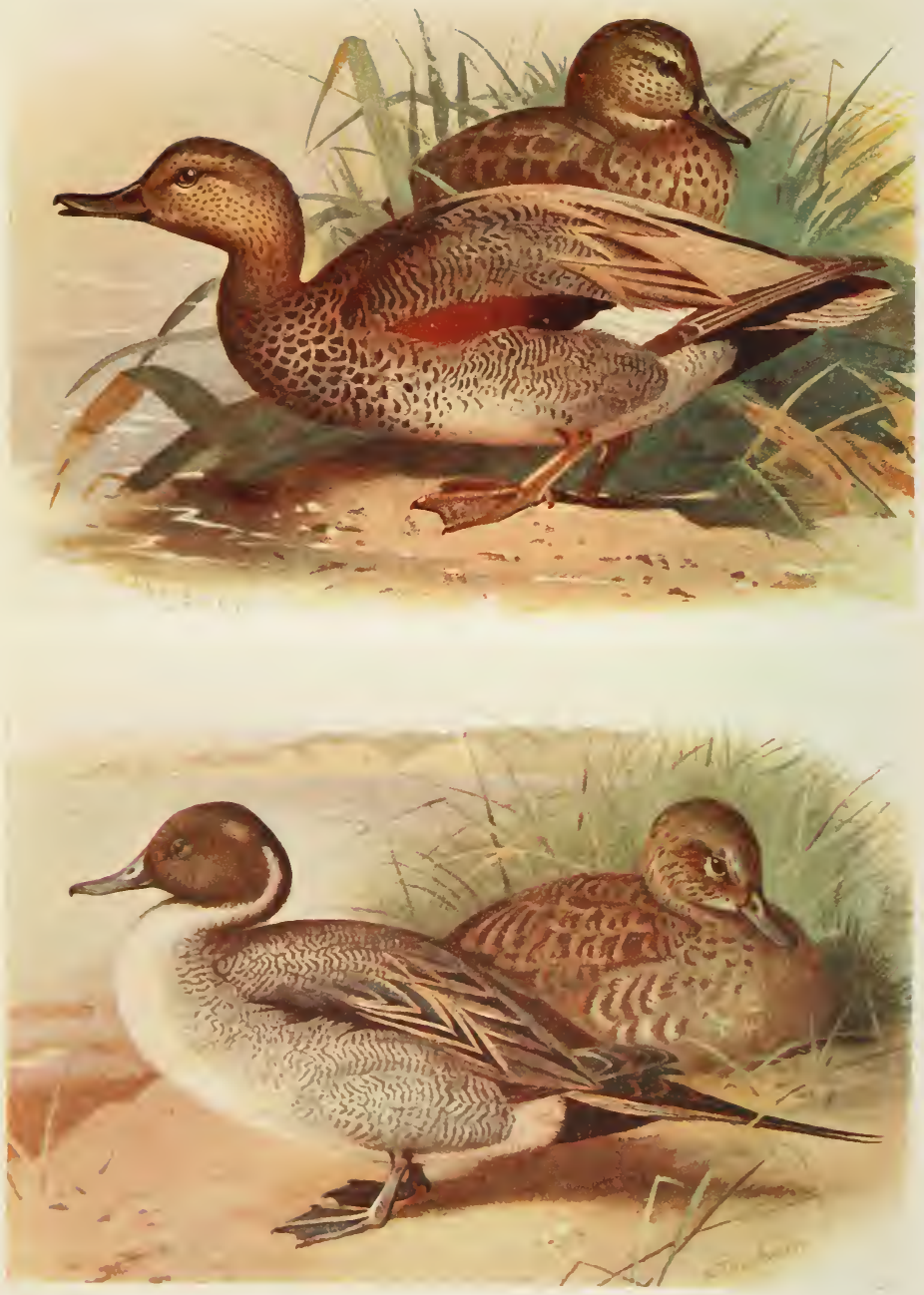

Gadwall. 
The adult drake, in winter, has the head and neck greyish brown with darker speckles and most of the upper parts dark brown with crescentic grey markings; the wing-coverts are dark chestnut shading to black, the speculum black and white ; the inner secondaries are noticeably pointed, and the upper and under tail-coverts conspicuously velvet-black. The breast is dark brown with pale markings shading to the whitish abdomen, and the grey pencilling of the flanks commands attention. In May an eclipse dress is assumed, approaching that of the duck, but the chestnut coverts are retained. The bill is lead-blue, the nail black, the legs dark orange, and the irides brown. The duck is a browner bird, and the feather centres and markings are more pronounced; she lacks the chestnut on the wing and her under tail-coverts are speckled with grey and brown. Her bill is darker and banded laterally with dull orange. Immature birds have reddish-brown marks on the head and neck, and though young drakes are said to resemble the duck, one, shot in August, that I examined in the flesh, showed chestnut on the wing-coverts, and its under tailcoverts were thickly mottled with black. The bill was dull orange, black in the centre, the legs yellowish, and the webs dusky. Length, 20 ins. Wing, $10^{\circ} 5$ ins. Tarsus, 1.8 ins.

\section{Garganey. Querquedula querquedula (Linn.).}

South of the Arctic circle the Garganey breeds throughout the Palæarctic region, and in winter visits tropical Africa and southern Asia. Its range is rather more southerly than that of the other surface-feeding ducks. To England it is a summer visitor, for it breeds regularly in Norfolk, Suffolk, and Kent, and has, within recent years, nested in other counties, even so far north as Durham and west as Somerset. Elsewhere in England and Wales, and in Scotland and Ireland, it is a rare and irregular visitor on spring migration; few are noticed on the return passage, and in winter it is most unusual. 
The strikingly beautiful plumage of the drake Garganey (Plate IS) cannot be confused with that of the Teal, a bird of about the same size. The noticeable features of the drake are the broad white stripe, shown up by a dark crown, which passes from above the eye in a graceful curve to the nape, and the blue shoulders, blue as in the Shoveler. Indeed, from a distance the whole wing appears to be blue-grey ; I have noticed this on birds on the wing as well as on the ground. Long pointed black and white feathers droop over the wing, and one commanding character is that the warm brown of the breast ends abruptly and does not shade into the white of the abdomen. A metallic green speculum, often concealed by the grey flanks, is bounded by white bars, also present in the duck, though the speculum itself lacks lustre. The brown duck has less character, but as she usually travels with her mate he does the advertising. Pale edgings to her feathers, however, give her a much lighter appearance than the duck Teal.

The migratory Garganey is often called the "Surnmer Teal" ; it usually reaches the Kentish coast in March, and, according to Dr. N. F. Ticehurst, departs about August. In habits it differs little from other surface-feeders, but is certainly not exclusively nocturnal. On the wing it is even swifter than the Teal; I noticed this particularly in breeding birds in Norfolk. In flight the wings look lightish, but do not show clean patches or bars as do those of the Goldeneye and Tufted Duck. When scared it springs clear from the water with the agility and velocity of the Teal. Several observers assert that the bird sits high in the water, swimming buoyantly, but this has not impressed me; not infrequently it swims low, and with neck extended "bibbles" along the surface like the feeding Shoveler, a bird with which it has much in common. More animal than vegetable matter is consumed, and in addition to crustaceans and aquatic insects it has been known to catch small fish. Although both sexes have a sharp quack, it is 
the distinctive male breeding note that has earned it the name of "Cricket-Teal"; Merrett calls it "a kind of teale which some fowlers call crackling teale from the noyse it maketh." This is a rattling or clicking note, likened by Saunders to the whirr of a child's rattle, but to my ears it more closely resembles the popular imitation of a pig's grunt, or a feeble, vibrating version of the note of the male Mute Swan. Captain A. W. Boyd, however, who listened to the same birds that I heard, inclines to the rattle simile.

When making their toilet the drakes of a little party paid special attention to their sickle-shaped scapulars, but they did not indulge in any elaborate postures to exhibit these to the ducks. They occasionally swam round the ducks, rattling and grunting, and now and then sparring, but were little excited. Immature drakes are slow in attaining full dress, and old ones remain late in the eclipse plumage. In England the nest (Plate 22) is usually in a marsh, a depression amongst thick herbage thinly bordered with grass; the down, added as incubation proceeds, is blackish tipped with light buff. The creamy eggs (Plate $2 \mathrm{I}$ ), six to thirteen in number, are laid in the latter half of April or in May. The duck attends to domestic duties.

The crown of the drake is dark brown, emphasising the tapering white superciliary streak; the lower part of the face is chestnut flecked with white. The brown neck and breast are beautifully pencilled with black, and this breast, variously described as light, dark, or yellowish brown, sandy buff or pale chestnut, struck Mr. T. Hadfield and me as being distinctly vinaceous; Montagu speaks of the neck as "purplish." Below the sharp line of demarcation the abdomen is white, and the greyish flanks are fincly vermiculated. The wing is described above. The bill is black, the legs leaden tinged with brown or green, the irides brown. The duck is brown and buff; her markings are bolder than in the drake. The eye-stripe is buff, and the chin and under parts are white faintly suffused with 
buff; the face is speckled with brown. "The wing-coverts are greyish, and the absence of a distinct speculum distinguishes her from the duck Teal. The brown drake in eclipse retains the blue shoulders and speculum; young birds are at first like the duck. The down of the ducklings is rich brown and buff, shading to dirty white. A dark stripe passes through the eye, and another across the cheek. Length, 15-16 ins. Wing, $7^{\circ} 8$ ins. Tarsus, $1 \cdot 3$ ins.

\section{Blue-winged Teal. Querquedula discors (Linn.).}

This American Teal breeds in Canada and the northern States, and winters so far south as Colombia and Peru. Four examples have been obtained in the British Isles, and the bird has once occurred in Denmark; all are considered to have been genuine wild birds. In the spring of 1858 a female was killed in Dumfries, and about the same date one was shot on the Cheshire Dee; in September, I910, a third female, a young bird, was obtained near Cork, and in the spring of 1919 Mr. L. R. A. Gatehouse shot a male on a fresh-water pool in Anglesey, and kindly permitted me to examine the skin.

The distinctive mark of the drake is a prominent white crescentic patch in front of the eye on its black and slate-grey head, and in both sexes the China-blue shoulder, differing from the blue-grey of the Garganey. The clove-brown back of the Anglesey drake had $U$-shaped buff marks, and the sepia rump was bordered with white. The under parts were buffish white, warmest on the breast, which was crossed by a cinnamon black-barred band; the flanks were spotted. The buff and black streaked scapulars were glossed with green, and the metallic green speculum bordered with white; in various lights the speculum showed black, metallic bronze, or brilliant green. The bill was black and glossy, the legs reddish, inclining to yellow on the feet. The irides are described as brown. The female is a brown and umber bird, pale on the speckled head 
and neck, and white on the chin. Length, 16 ins. Wing, $7 \cdot 3$ ins. Tarsus, $I \cdot I 5$ ins.

\section{Teal. Querquedula crecca (Linn.).}

The Teal (Plate-18), our smallest duck, is resident in varying numbers throughout England, Wales, and Ireland, commonest in the north, and in Scotland it breeds freely. As a winter visitor it is abundant, large numbers reaching our shores in August and September. Abroad it nests throughout northern Europe and Asia, and ranges south in winter into Africa, India, and China.

The most noticeable mark on the drake is the long white line on the wing, emphasised by the black line below it, showing as a longitudinal streak on the swimming bird, and as two lines down the back when in flight. At closer quarters a conspicuous buff-framed metallic green patch, from the eye to the neck, is visible on the rich brown head, the finely vermiculated back and flanks are seen, and a prominent black-bordered warm buffish triangle below the tail. The open wing exhibits a broad band of white above the velvety black and metallic green speculum, and a narrower rim of white at the edge of the flight feathers. The brown and buff duck has less distinctive colouring, but her white-bordered green speculum distinguishes her from the Garganey, and her small size from the Mallard.

Though in winter found in considerable numbers in tidal estuaries the general haunt of the Teal is fresh water; it frequents lakes and quiet pools, especially where there is abundance of cover. In autumn and winter the numbers increase as the coast birds move inland, and though there is some emigration of our home-bred stock in autumn, the idea that the whole body of Teal moves southward is mere guesswork; some of our birds, but not all, are replaced by more northern visitors. The system of marking birds has shattered 
some of the older dogmatic theories; individual variation is evident amongst Teal as in other species. Some Teal, reared in Cumberland, after having been temporarily pinioned were released in February in Essex; one was reported in August in Schleswig, but another was recaptured in Cumberland at the place where it first chipped the shell. The return passage in spring begins in March.

In its feeding habits the Teal is by no means always nocturnal, though where it is much persecuted it feeds at dawn and dusk. On inland waters it spends some time dozing on the bank or open water, but it also upends in the shallows, and sifts the plankton from the water with its laminated bill. Rotifers and minute crustacea form a considerable part of its varied diet, and vegetable substances are not neglected; indeed, decoy-men find corn a tempting bait. In flight the Teal is distinctly swifter than the Mallard; when put up, Teal keep together, flying to and fro in a compact flock, turning and twisting with the precision of waders. No birds leave the water with greater skill and velocity, shooting dircctly upward; a flock may well be called a "spring" of Teal. At full speed, which has been estimated as over I 40 miles an hour, though this is not proved absolutely, a flock will suddenly and with unanimity take a short corkscrew dive of a few feet and instantly resume horizontal flight. As the birds turn with one accord their light under parts flash like those of waders. These dives do not necessarily mean a change of direction; indeed, a swiftly flying Teal will turn its head, and even look behind it without losing speed or altering the line of flight. When the flucks intend to alight they will often shoot downwards with great speed, almost falling oblıquely, but when near the water they throw the feet and tail forward and check their pace with widespread fluttering wings.

There are few more talkative ducks than the Teal; birds in the winter flocks chuckle conversationally, and on the meres the loud clear call, a short sweet whistle, rings out incessantly. 

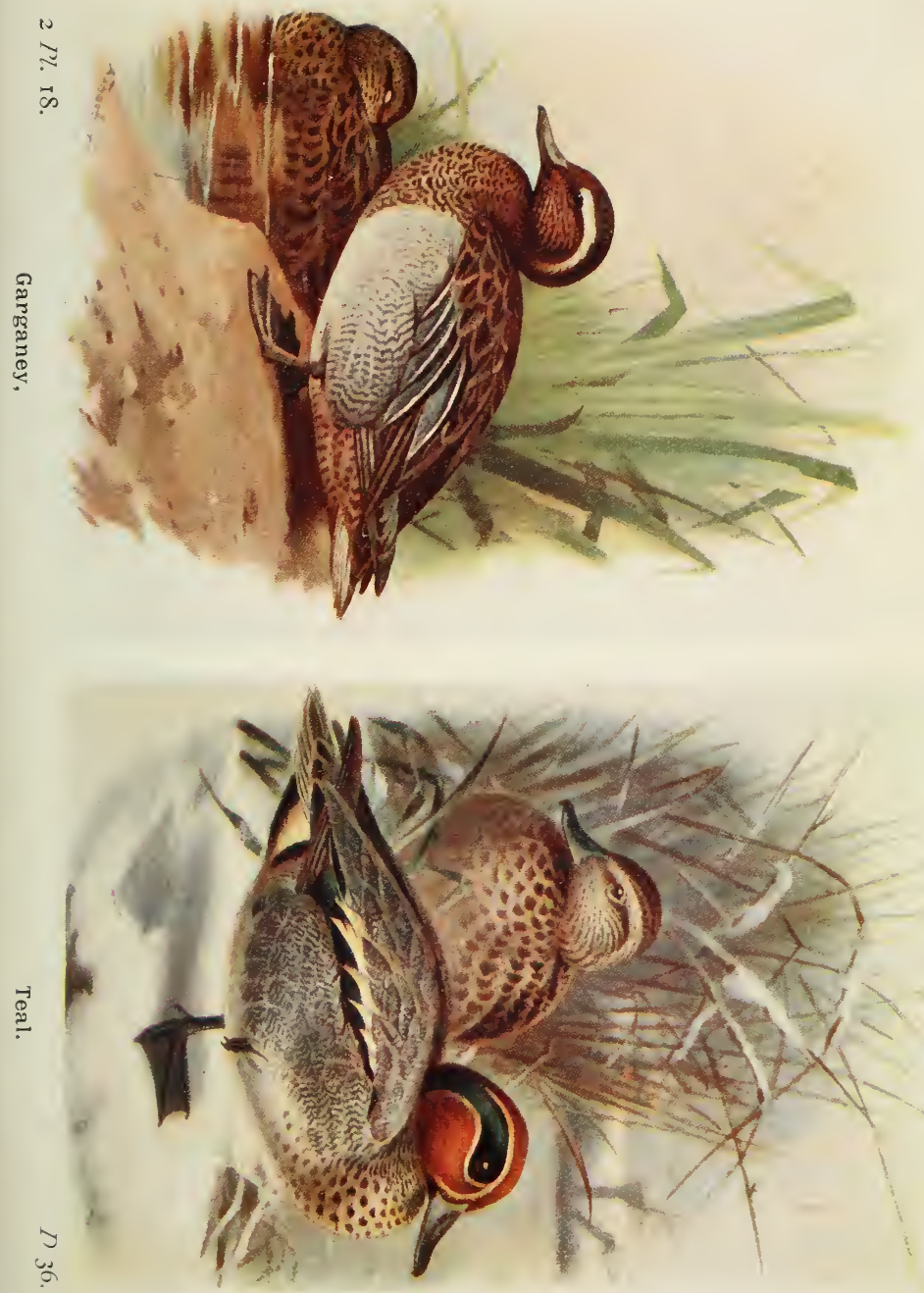

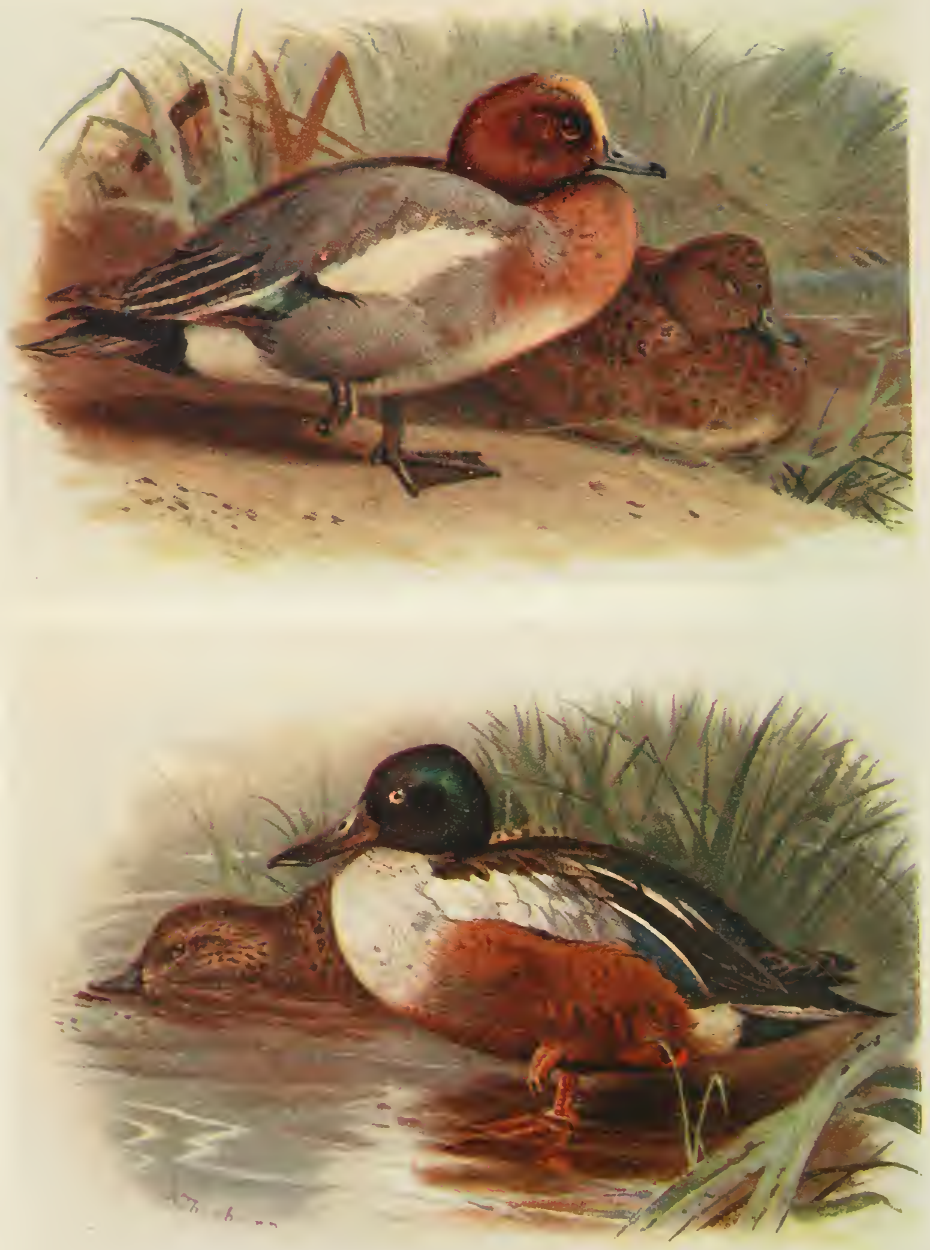
When the drakes are courting the low double whistles run into a musical jumble, a delightful chorus. The duck, especially when alarmed, has a short harsh quack. In nuptial display a favoured duck, ready for admirers, is surrounded by several drakes, who constantly raise themselves in the water, shooting up the head and neck and lowering it at once, with an action that suggests a hiccough; for a second the facial glories are displayed, and as the bird resumes its normal pose it exposes the long white side streak. During this competitive exhibition the whole flock will rise for a flight round the lake, and after wheeling, turning, and twisting, return to the display; both rival drakes and ducks from time to time chase one another with open bill, but there is no serious fighting. These displays may be witnessed in autumn, but from January to April the birds are really busy.

The nest, of the ordinary duck type, may be in a marsh, a dry wood, or amongst heather on a moor ; it is lined with very dark down with hardly noticeable pale tips. The creamy eggs (Plate I3) are often tinged with green; they are usually eight to ten, but sometimes more in number, and are laid between April and June. The young have light chocolate down, yellowish buff beneath, and a dark line passes from the eye to the ear and thence down the side of the neck, and a second borders the cheek. When the duck is alarmed for the safety of her brood her behaviour is often extravagant. On one occasion I scattered a brood of ducklings which at once vanished in the rushes, but the anxious mother flew and swam opposite so long as I watched, constantly calling whelp, whelp. In her short flights with head curiously held back, her almost upright body hung heavily, and she repeatedly dropped on the water, flogging it with her wings. The white bars on her wings showed more conspicuously than usual, as if intentionally exhibited to catch the eye.

The main points of the drake plumage are described above. 
The white breast is spotted with black, the abdomen is white. The bill is blackish brown, the legs dusky, and the irides brown. In eclipse a plumage not unlike that of the duck is assumed, but the back is darker and the under parts more spotted. In the brown duck, mottled and barred with buff, the white breast and under parts are spotted after her spring moult. Immature birds are darker on the upper parts and their markings are less defined than those of the adult duck. Length, $14-15$ ins. Wing, $7 \cdot 25$ ins. Tarsus, $I$ in.

The American Green-winged Teal, Q. co carolinensis (Gmelin), the transatlantic representative of our species, has been reported at least three times in our islands, and is not unlikely to occur occasionally. The drake lacks the distinctive white side streak, but has a whitish crescentic band between the breast and flanks, and the buff frame of the facial ornament is incomplete. In size and habits it agrees with our bird; the female cannot be distinguished with certainty.

\section{Wigeon. Mareca penelope (I,inn.).}

As a regular nesting species the Wigeon occurs in northern Scotland, but, though odd pairs have nested in England and Wales, it is in most parts of the British Isles a common winter visitor. Abroad it nests in northern Europe and Asia, and in winter visits Africa, southern Asia, and occasionally North America.

On the water an old drake Wigeon (Plate 19) is a conspicuous bird, his large white wing-patch never concealed; a yellowish-buff or creamy crest forms a wide parting on his warm burnt-sienna head, and his back and flanks, divided by the white line, are finely pencilled with black on grey. His pinkish breast shades somewhat abruptly into white, and as he swims with pointed tail a little elevated, the white contrasts noticeably with the velvet-black of the under coverts. The more sombre duck shows but little white on the wing when 
swimming, but her rufous head, well-marked back, and white under parts separate her from the much larger Mallards and the smaller Teal, her frequent companions on inland waters. When the birds rise, white shows distinctly on the wing of either sex; on the drake it is a great oblong patch, $3 \frac{1}{2}$ by 2 inches, formed by the black-tipped greater wing-coverts, on the duck a conspicuous double bar.

A few Wigeon reach our shores and inland waters in August, but they are seldom numerous until mid-October. Though often abundant on meres and lakes at some distance from the coast, the Wigeon is a salt-water duck; in muddy and sandy bays and inlets it feeds in thousands, and floats off-shore in great packs and lines, looking from the land like undulating collections of floating wrack as the birds rise and fall on the waves. Even in a rough sea they sleep peacefully, and where their feeding grounds are liable to be disturbed they spend the day at sea, flighting inward at dusk. Although on the banks the bird picks up molluscs, crustaceans and marine worms, its main food is the sea-grass, Zostera, which grows in profusion on tidal flats. Whether the Wigeon is normally a diurnal or nocturnal feeder is a disputed point, but certainly when unmolested it will feed by day, and its times are to some extent regulated by the tides. The weed is dragged up by the roots, the bird swimming or wading in shallow water and only dipping the head and neck; it seldom feeds in the vertical reversed position common to most surface-feeders. Some observers state that it never dives for food, others have seen it do so; it will, however, like most ducks, dive and splash in play, and a wounded "cripple" dives with great activity. Grain it will eat; I have found a considerable quantity in birds that had been shot at sea, proving that they make occasional excursions to the fields, and Mr. Dockray has found them in autumn crammed with blackberries which they had doubtless gathered on the edge of ponds and ditches. 
The Wigeon is perfectly at home on land, walking with ease and running swiftly; the drakes race after one another, openmouthed, on the grass or sand. On the wing it is quicker than the Mallard, though hardly so swift as the Teal. A flock will turn and twist in flight, but the evolutions are less erratic than those of the last-named bird. The call of the drake, from which the bird gets its name, and the fowler's names- "Whewduck" and "Whistler," is a long musical whistle, whec-oo. Throughout the winter this call is constantly uttered; the bill is opened wide when the bird calls. The contented purring note of the duck is very different from her quack of alarm, a harsh growling kraak, kraak, for Saunders was in error when he said that "the birds rise in silence." During courtship, when the drake is most musical, his neck is carried stiffly erect, and he frequently sits up in the water to flap his wings, advertising the glory of his white patch.

The majority depart north at the end of February or early in March, but passage flocks are met with in April and May, and I have seen them on Cheshire waters in early June. Some, at any rate, of our home-bred birds emigrate; out of a brood marked in June in Sutherland one bird was recovered in September in Holland, though another was taken in Lincolnshire in the following January.

The nest, built in grass, heather, or other herbage, is seldom far from water ; the down is dark with pale centres. The eggs, six to ten, are creamy white, similar to but lighter and a little larger than those of the Shoveler; they are laid from April to June. The duckling in down is almost uniform brown above with rufous cheeks and neck, and lacks the distinctive eye streak of the infant Mallard and Teal.

On the brown face of the adult drake in winter are flecks of metallic green and a mark of the same colour crosses above the eye; the chin is black. The speculum on the wing is velvety black and bottle-green, bordered by black. The bill is 
lavender-grey, the legs olive-grey with darker webs, and the irides brown. The head of the duck is pale rufous spotted with black, and her chin is pale; her upper parts generally are brown barred with buff; her wings, smoke-grey on the shoulder, have the greater coverts drab, edged with buff and white, and a white border to the green speculum. The flanks are rufous, the belly white. The slate-grey bill is darker than that of the drake. Other characters of the plumage are already described. In eclipse in summer the drake is more rufous than the duck, but he loses most of his masculine characters. Immature males are at first very like the duck in winter, but by November and December they are in very intermediate dress, brown and vermiculated grey feathers mingled on back and flanks, and the black chin almost concealed by umber tips; the bill was lighter in some birds I examined than in the adult, though that of the duck is darker. Length, 18.5 ins. Wing, Io ins. Tarsus, $1 \cdot 75$ ins.

\section{American Wigeon. Mareca americana (Gmel.).}

The American Wigeon, which nests in Canada and the northern States, and winters so far south as the West Indies, has wandered three or four times to Great Britain and France ; it has been recorded from the Azores. Some records of its occurrence are questioned, and now that the bird is kept on private waters and breeds, the young being allowed freedom, any occurrence may be due to introduction.

The most marked differences between this bird and the Wigeon are on the head of the drake. The central crest is yellowish white, and below it is a dull green stripe from the eye to the nape; under this again the whitish face and throat are speckled with black. The rest of the plumage corresponds in pattern, but is browner and more vinaceous. The head of the duck is yellowish white speckled with black. The bill is 
greyish blue, the legs and irides brown. Length, $18 \cdot 5$ ins. IVing, 10.5 ins. Tarsus, $1 \cdot 5$ ins.

\section{Shoveler. Spatula clypeata (Linn.).}

The handsome Shoveler (Plate 19) is increasing as a resident in all parts of our islands, though still rare in English and Welsh counties; recently it has begun to nest regularly in fresh localities, and in certain Welsh bogs is now plentiful. As a passage migrant and winter visitor it is common on many inland waters. Its range is wide, practically Holarctic, and in winter it reaches tropical Africa, southern Asia, and South America.

The long, broad, spatulate bill of the Shoveler, from which it gets a local name, "Spoonbill," is its most noticeable feature ; but the bluff white breast of the drake, followed by rich chestnut on the lower breast and belly, make it a conspicuous bird, even on a pool crowded with other fowl. A nearer view reveals a glossy green head and neck, light blue shoulders, and, a rare character of surface-feeders, a yellow eye. Except for her blue shoulders, duller than those of her mate, the mottled brown duck differs little from the female Mallard, but the slimmer, long-necked Mallard should never be confused with the stocky, short-necked, big-billed Shoveler, which, even when at rest, floats down in the bows, and with its heavy bill resting on its breast. From March to May, when the passage birds are bound north, and again from August to November, the numbers are greatest; far more pass through our islands than remain to nest or winter. Britain is its half-way house, a food-providing hostelry; April and September are the busiest months. Though its wings move with great rapidity the flight of the Shoveler is neither so swift nor strong as that of the Mallard; the flying bird looks what it is, heavy and unwieldy. Yet the flight is not always straight; the Shoveler will swoop 
and change direction like the Teal, though with much less skill, and Lilford noticed what has often struck me, how frequently it turns its head from side to side; possibly the broad bill, silhouetted against the sky, catches the eye more than in smaller-billed ducks. On the ground it is less agile than many species, for, in proportion, its feet are small and weak. The flight call is a repeated $t u k, t u k$, but both drake and duck have a deep quack, lower than the resounding note of the Mallard.

On the water the bird is often remarkably active, swimming in short rushes this way and that as it scoops the water with its spoon, "bibbling" as the fowlers call it. WVater, especially when full of weed or mud, is passed rapidly through the bill, and visible and invisible contents are sifted and retained by the well-developed lamellæ; the bill of the Shoveler is an effective sieve. It by no means confines itself to planktonic feeding, well equipped though it is for this form of diet. The bird is most excited when catching insects, either on or just above the water, cleverly intercepting those that fly near; $\mathrm{Mr}$. J. G. Miliais noticed it watching for and snapping up the water beetles and other aquatic insects when they came up for air. The assumption of the vertical pose, head down and tail up, is not popular with the Shoveler, nor does it dive often. It feeds at night and by day, though it often spends hours asleep on the water, its head tucked in its scapulars, its white upper breast puffed out, as it swings slowly round and round. Frost drives it to salt water, but small pools, bogs, and marshes, be they ever so dark and muddy, fresh or brackish, are its favoured haunts.

The nest is often in a marsh, and where the ground is wet is a large structure of grass and rushes, but in a dry site, which it prefers, is not above the level of the ground, though well concealed by surrounding vegetation. In Norfolk it is seldom if ever in the reeds. Mr. F. W. Holder saw cne in Iancashire, 
where the bird is increasing, built on the top of a haystack. In the Cheviots it is often in heather or dwarf willow. The nest down is blackish brown with faint white tips. The eight to twelve eggs (Plate 2I), usually greenish, are laid in April or May. The nestling is clad in yellow and brown down like that of the Mallard, but without the buff on the wings. At first the small bills show little lateral expansion. When the young have passed the flapper stage, they and the old birds leave many of the nesting haunts, though on some bogs and pools Shovelers may be met with all the year round.

The main features of the nuptial dress are already described. In the drake the bill is slate-grey, the legs are orange-red, and the irides yellow, but in the duck these are respectively olivebrown with orange at the base, dull orange, and dark brown. In eclipse the drake closely resembles the duck, but Mr. F. W. Smalley points out that the pattern of the flank differs, and the belly is tinged with rufous. The shoulder blue,-which is retained, is brighter than in the duck. At first the plumage of all young is feminine, but drakes in all stages of intermediate mottled dress are often on the water in winter. Length, $20 \%$ ins. Wing, Io ins. Tarsus, 1.4 ins.

\section{Pintail. Dafila acuta (Linn.).}

As a breeding species the Pintail (Plate 17) is extending its range in Scotland and the northern isles; it has been reported as nesting in Ireland. In England and Wales it is a regular but not abundant winter visitor, more frequent on the sea than inland. It is found nesting throughout Europe, northern Asia, and North America, and in winter reaches Africa, southern Asia, and the West Indits.

The Pintail is just as slender and elegant as the Shoveler is bluff and heavy. Naturally the two elongated central tail feathers of the drake, whence one local name, "Sea-Pheasant," 

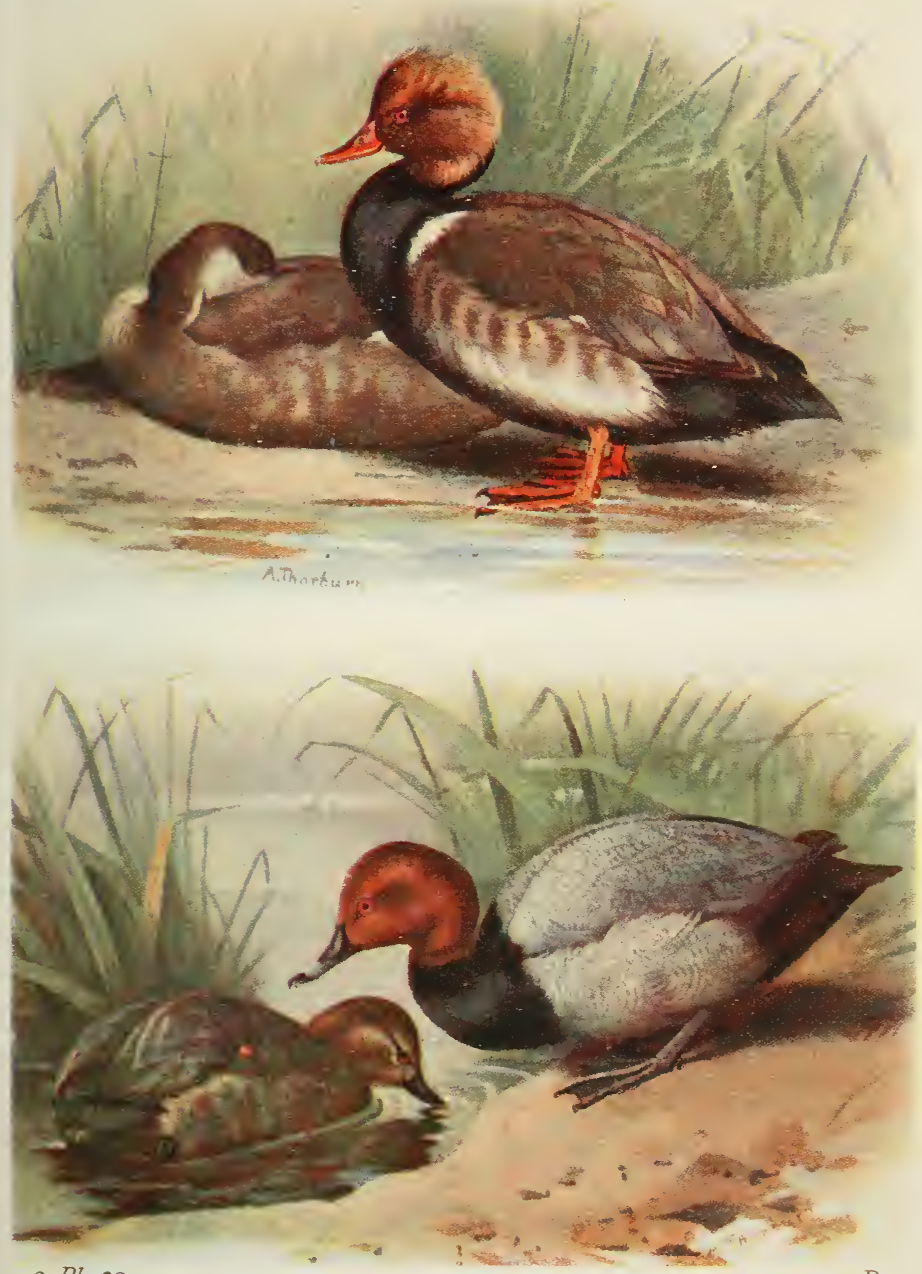

2 Pl. 20.

Red-crested Pochard. 
$\stackrel{\dot{q}}{9}$

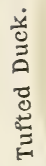

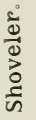
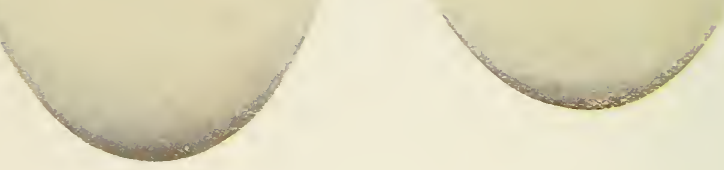

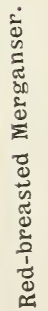

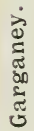

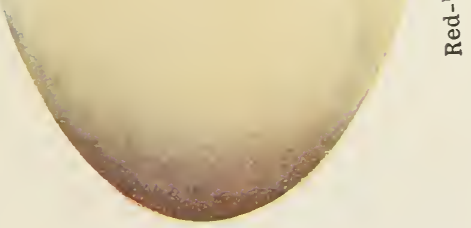


are his most distinctive character, but his long neck and high forehead give him a somewhat misleading short-billed appearance. A narrow white stripe passes down each side of his long neck, starting at the back of the face and extending to and joining the pure white breast and under parts; the rich brown of the head and upper neck throw this streak into prominence, and it catches the eye, even when the bird is at a distance. The pointed tail of the duck is shorter, but her speckled head and slender neck, and long narrow wings give her character in flight. Immigration begins in September, but it is seldom until October that any appear in the Dee and Mersey; to both these estuaries the bird is a regular and sometimes common visitor. Most appear to leave the west coast in March, but on the east coast they have been recorded so late as May. November to January are the montlis of greatest abundance. Though uncommon far inland, the Pintail is partial to fresh water near the shore, and is frequently lured into decoy pipes; in one west coast decoy it is, in some years, captured in greater numbers than the Mallard. It is, however, a shy and cautious fowl, spoiling the sport of the fowler, straining its long neck over the low banks and sichting his approach.

The Pintail is quick on the wing, pulling ahead of its companions, Mallards and Wigeon, and its pinions move with unusual rapidity. On the water it is buoyant and graceful, carrying its tail slightly elevated. It certainly often feeds by day, though it has been described as nocturnal, and when it tips its body and immerses head and neck to secure food from the bottom, the long tail is depressed as if to preserve the balance. Crustaceans and molluscs are eaten, but its main food is vegetable; it will visit the stubbles for grain. As a rule it is a quiet bird, though it has a quack of alarm, and a low chuckle when undisturbed, but during courtship it utters a musical double quuck, quuck, which Mr. J. A. Dockray aptly describes as "violin-like notes." The courtship of the Pintail 
noticeable in January and February, is an interesting performance; several drakes will swim round the duck, their necks stiff, bills depressed, and tails elevated skyward. With that quick rise and fall, as if settling themselves more comfortably in their aquatic seat, they posture before the apparently bored female, repeating the mellow, deep pairing call. Sometimes, with open bill, the duck drives away a too importunate admirer. If this performance is disturbed every tail goes down at once, for when alarmed the bird carries it horizontal.

The nest in Scotland is usually on dry ground, and is not always carefully concealed; it is lined with sooty-brown down as incubation proceeds. The eggs (Plate 13 ), seven to ten in number, are yellowish green as a rule, and are smaller than those of the Mallard; they are laid in April or early May. The duckling in down is whiter beneath than the juvenile Mallard.

The drake in winter has the back and flanks vermiculated with grey on white, and long-pointed, black-centred, buff-edged secondaries; the sides of the abdomen are buff, showing distinctly against the velvet-black of the under tail-coverts. The speculum is glossy bronze-green, bordered above with buff, and below with black and white bands. The mottled duck is light on the under parts, but her breast and abdomen are speckled and her flanks boldly marked with dark brown. Two white bars cross the wing, but the space between is dull. Her tail feathers are obliquely barred with buff and brown. The bill of the drake is blue grey with a black central stripe, but in the duck the marginal streaks are light yellow, fading to grey at the tip. In both sexes the legs are slate-grey and the irides brown. In eclipse, from July to October, the drake is brown, though duskier than the duck; a few vermiculated feathers may remain, and the speculum does not lose its brightness; I noticed this particularly in one drake which I watched through his post-nuptial dress; he was not in full breeding plumage 
until the middle of October. The brown immature drake is duck-like at first, though he shows a tendency to slate about the head and neck, and, later, vermiculations and other masculine characters. Length, $2 S$ ins. WVing, I I ins. Tarsus, 175 ins.

\section{Red-crested Pochard. Netta rufina (Pallas).}

Those ducks which habitually obtain their food by diving are collectively known as the Diving Ducks, as opposed to the Surface-feeders. The Red-crested Pochard (Plate 20), an uncommon visitor to Britain, is one of this group. The majority of its occurrences have been in the eastern and southern counties, though it has been met with on single occasions in Scotland and Ireland. Its home is the Mediterranean area, eastward into western Asia. At times flocks wander northward into Europe.

Compared with the familiar Pochard this bird is large, but apart from that it has several distinctive characters. The adult drake has a crimson, yellow-tipped bill, and a conspicuous golden bay crest on his otherwise rich chestnut head; the crest shows distinctly in flight as well as on the water. At the base of the wings, on the shoulders, and on the flight feathers, are three distinct white patches, the last, often slightly tinged with pink, represents the speculum or wing spot of the surfacefeeding ducks. The neck, breast, and abdomen are so dark a brown as to look black from even a short distance; the rest of the upper parts are yellowish brown and the flanks greyish white. The duck has no crest, but her very dark crown contrasts with her grey cheeks, whilst her upper parts are almost uniform pale brown, her under parts grey; her wing spot is dull white, and her bill reddish brown.

Its habits roughly correspond with those of its congeners; it is a diurnal feeder, diving for its animal and vergetable food 
in fresh water. It rises from the water with apparent labour, and flies with rapidly whirred wings; on the ground it is not as good a walker as most of the surface-feeders, for the feet of all diving ducks are better fitted for under-water progression than for exercise on land. Its rote is harsh and grating, another common character, though the drake is said to whistle.

The legs of the drake are red, the webs blackish; those of the duck, and her bill, are reddish brown. The male irides are red, the female brown. In eclipse the drake resembles his mate, though he retains indications of the crest ; young males at first closely resemble females. Length, 22 ins. Wing, $10^{\circ} 5$ ins. Tarsus, $1{ }^{\prime} 5$ ins.

\section{White-eyed Pochard. Nyroca nyroca (Güld.).}

The White-eyed Pochard or Ferruginous Duck (Plate 15) is another southern European and western Asiatic bird which occasionally varies its normal south or eastward migration by a northward wandering, and from time to time appears in our eastern and southern counties, and more rarely still in the west, or in Scotland and Ireland. In Egypt and India it is a familiar winter duck.

There is some excuse for confusing this species with the duck Pochard, for its general colour pattern is similar, but birds of either sex or at any age may be told by the presence of a white wing bar. In addition, the drake has a much browner chestnut head and neck than that of the drake Pochard, and his back is umber, not grey with vermiculations, like that of the common bird. On his chin is a small but distinct white spot, whilst the white iris, from which he gets his name, is very noticeable; in the duck it is tinged with brown and her plumage is duller, whilst young birds are even more dingy. The flanks of the drake are more chestnut than the back, and the rest of the under parts are white crossed by a greyish-brown band at 
the vent, very conspicuous in flight. The under parts of the duck and young bird are greyer. The bill and feet are slateblue to leaden.

The Fcrruginous Duck is an expert diver, seeking its foodweeds, aquatic insects, molluscs, and crustaceans-in freshwater pools in marshes and other quiet spots, for it is shy and retiring, and even when kept on private waters lurks in those parts where vegetation is thickest. Its call on the wing is similar to that of the Pochard, a harsh, growling kurr. It is not specially quick on the wing, leaving the water with much splashing, and on land is decidedly awkward, but when swimming or diving is perfectly at home. Length, I6 ins. IVing, 7.75 ins. Tarsus, $1 \cdot 2$ ins.

\section{Pochard. Nyroca ferina (Linn.).}

Within recent years there has been a remarkable increase of the Pochard (Plate 20) as a resident species in England, Wales, and Scotland, though it has not yet begun to nest, regularly at any rate, in Ireland. The range of the bird is Palæarctic, though it does not nest far north ; it winters in northern Africa, and eastward to India and China. Great numbers visit our islands in winter, congregating in flocks on the larger waters inland, and, unless frozen out, seldom appear on salt water.

The "Red-headed Pochard " or "Poker," as it is often called, is also known as the "Curre," from its note, or the "Dunbird." The pronunciation of Pochard is an unsettled point; the $c h$ is often hard, but at times the first syllable is sounded as if spelt poach. It is not a difficult bird to identify, for the head and neck of the drake are rich chestnut-red, and most of the upper parts lavender.grey, finely pencilled with undulating black lines. It has no central paler crest as in the Wigeon, nor any distinct wing patch; yet there are many gamekeepers and others who fail to realise the difference. The back of the Scaup is vermicu

Series $I I$. 
lated like that of the Pochard, but it has a black head, and the absence of wing bar prevents confusion with the rare Whiteeyed Duck. Probably it is the carriage of the head and neck of the Pochard which causes the impression that the bill has a slight but distinct upward tilt, for in the hand this is no more noticeable than in several other species.

September or October are usually stated to be the months in which the immigrant Pochards reach most districts, but of late years some have been on Cheshire waters, which are much frequented, early in August. Indeed, though so far the bird has not been proved to nest in the county. a few at times remain all summer. From year to year the numbers of winter visitors varies, and during the season there is much fluctuation on any particular water, at one time only a few small parties being present, but at others hundreds or even thousands of birds. The Pochard is sociable, and flocks move from water to water. The flight is fairly quick and direct, but the rapid movements of the short wings give the impression of greater speed than is actually attained. When about to alight the whole flock will suddenly slide down diagonally at great speed, the wings producing a startling rushing sound, skim above the surface, and enter with a splash. Diving ducks do not spring clear like surface-feeders when rising, but beat along the water for some distance like Coots, striking with wings and running feet. The bird is, as a rule, in no hurry to rise, and when approached draws off into open water, sinking its body until the wavelets wash across its neck, and glancing back over its shoulders as it swims swiftly away. With a little care it is possible to get close to a party feeding inshore. The manner of diving varies individually, probably according to the depth the bird desires to work; at times the bird springs up and with a graceful curve takes a header, but frequently it slips below the surface, often kicking up a little shower of spray, and swims so superficially that its under-water progress can be 
followed by a ripple on the surface. It is difficult to estimate the size of a feeding flock, for the birds bob up and go under again at once; two or three, a dozen, or none may be visible at any moment. Weeds are dragged from the bottom, vegetable food being preferred, but molluscs and water insects are also taken. The alarm note is a guttural $q u-a-a-a-a k$, but the flight call is a harsh currah. When courting, the drake extends his head along the water and whistles softly to the duck. On land the Pochard is ungainly, its large feet, set far back, are adapted for subaqueous progression. The hind toe in the diving ducks is lobed.

The nest is usually in a very wet or boggy situation, never far from and often actually over water; in consequence it is a bulky structure of rushes, reeds, or flags, raised well above the surface like the nest of the Coot. The quantity of blackish down, acquired in the spring moult, varies considerably, and in some nests, even when the young are hatched, is scanty. The eggs are remarkably large (Plate 14), especially when compared with those of Mallard and other large-sized surface-feeders. They are greenish, six to ten in number, and are laid from April to June. The nestling is olive-grey above and buff beneath, and has a buff eye-stripe and small patches on the wing.

Below the chestnut on the drake in nuptial dress is a band of black, narrow above and broad on the breast; the lower back, beyond the grey, and the under tail-coverts are also black. In the duck the head and neck are a darker brown and the cheeks and chin greyish white; the breast and upper parts are reddish brown, the latter shading into greyish brown, crossed by undulating grey lines. The browner male in eclipse is indistinctly barred with grey, but is not strikingly different in this plumage. Young males resemble the ducks, but soon show grey feathers on back and wings; the black breast is not gained during the first year. The bill is black, crossed by a 
band of slate-blue, much broader in the drake than the duck; the legs are slate-grey. In the young drake the irides are yellow, but become redder as the bird matures; in the duck they are brown. Lyddeker states that the iris is reddest when the bird is excited, and Mr. Millais noticed that the pupils were contracted till the eyes "blazed" red when the male was sexually excited. In the previous series (page 302) I referred to the effect of excitement upon the iris of the Eagle-Owl. Length, 19 ins. Wing, $8 \cdot 25$ ins. Tarsus, $1 \cdot 5$ ins.

\section{Scaup. Nyroca marila (Linn.).}

Although the Scaup (Plate 23) has, within recent years, been discovered nesting in Scotland and the Outer Hebrides, it is mainly a winter visitor, often abundant, to our coasts. It seldom appears on inland waters, but when it does so consorts with other diving ducks. It breeds in both the Palæarctic and Nearctic regions, but has been "split" into geographical subspecies by some systematists; it only breeds in the mole northerly and often Arctic portions of its range.

The Scaup is as partial to salt water as the Pocliard to fresh. Its black head and breast, grey mantle, and white flanks show up well on quiet water, but when at a distance, tossed on a rough sea, it is not so easy to distinguish from the much larger Scoter or even other marine ducks. It is a typical diving duck, short and squat, and, as in the Pochard, its bill slightly uptilts. From this bird the drake Scaup can be distinguished by its black, green-shot head and the distinct white bar on its wing, very noticeable in flight, and the female by a broad white mask surrounding her lead-blue bill. From the black-backed drake Tufted it can be told by its larger size, grey back, and absence of crest, but with females more care is needed. The immature Tufted Duck, in brown uncharacteristic dress often has a patch of white at the base of the bill. The wing bar is 
$121=0$

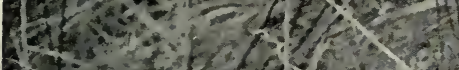

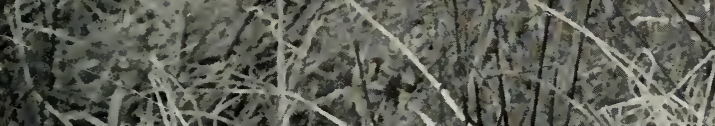

(5)

the

a)

N.1.

5.

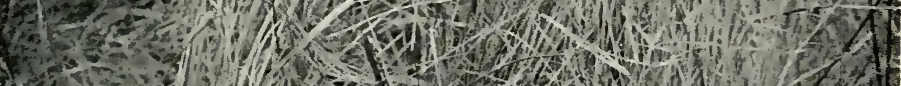

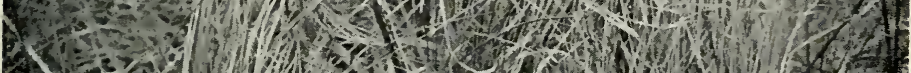

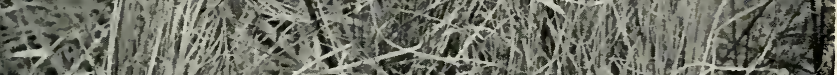

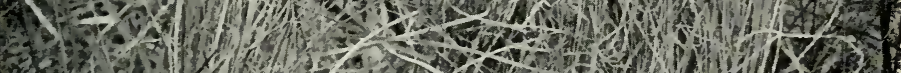

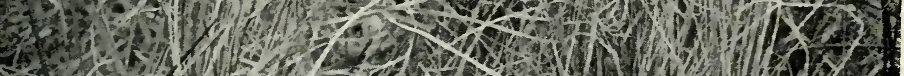

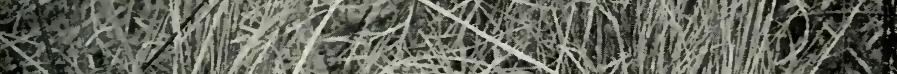
2.

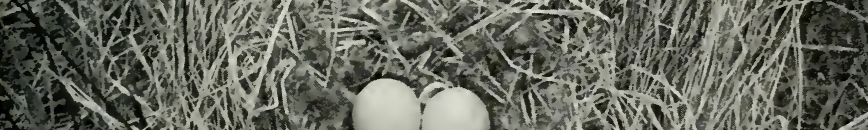
Ex-303.

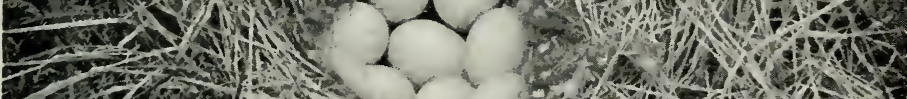

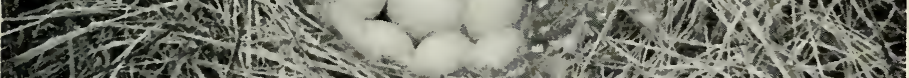

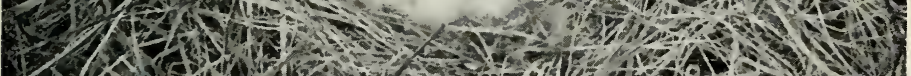

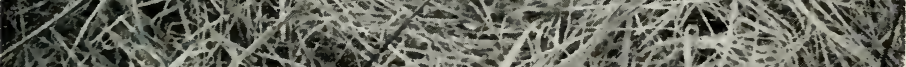

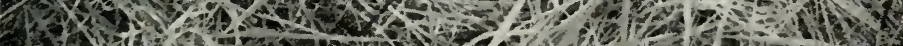

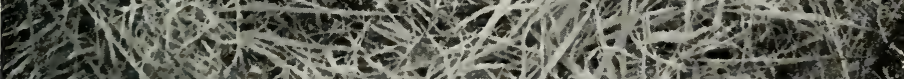

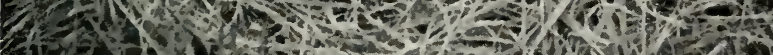

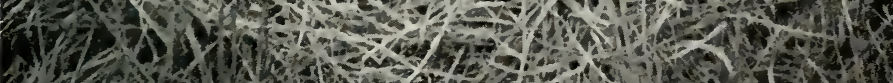

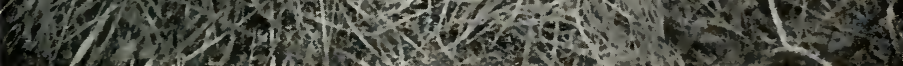



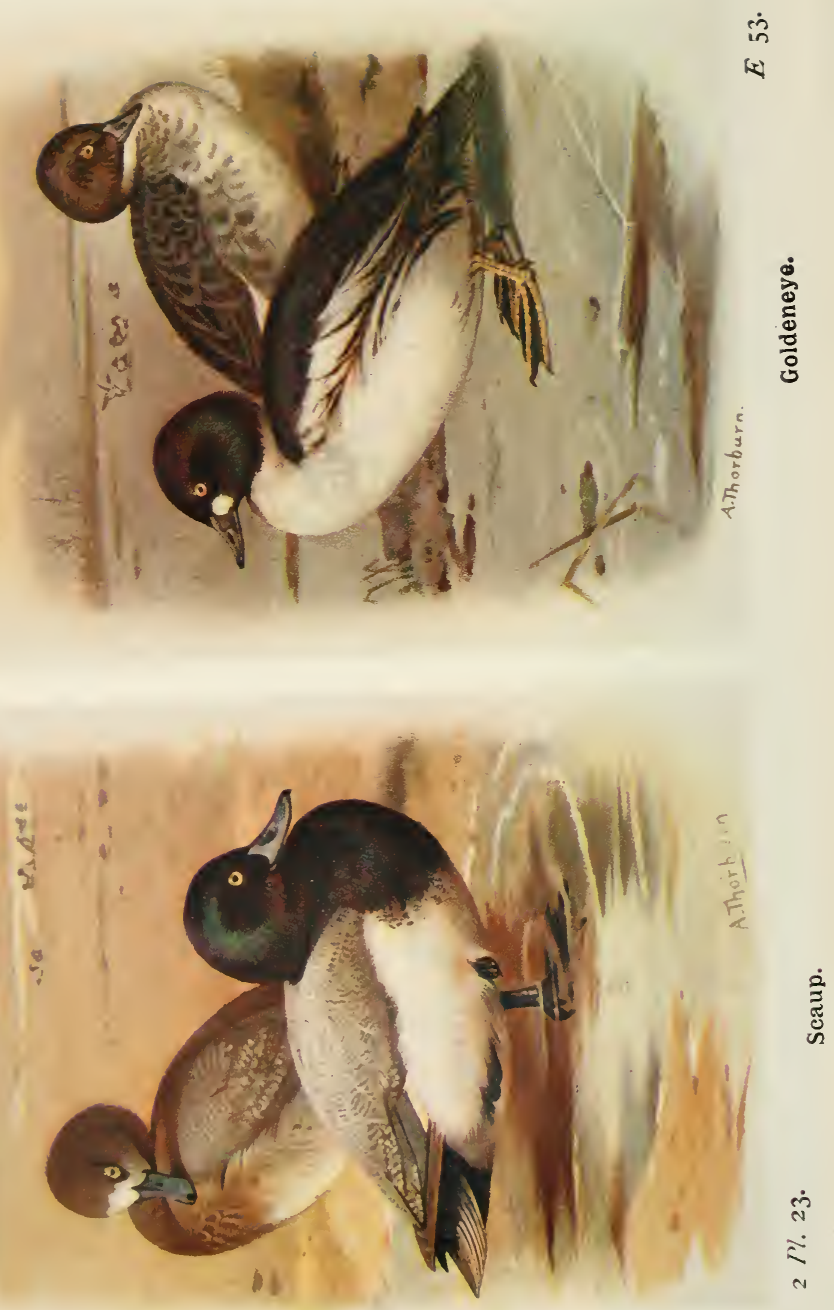
present in both; indeed, the main difference is in the size of this frontal patch, which in the Scaup reaches to the level of the eyes. On rising from calm water the bird splashes along the surface, paddling with its feet, but from the crest of a wave it has less difficulty in getting on the wing. It is sociable, but usually swims in small parties, a dozen or so together, though at times these little gatherings are scattered everywhere, thousands of birds in sight at once. Except when resting on the banks it seldom packs closely like the Wigeon. Being a deepwater feeder it can obtain food in rough weather and is not forced ashore by storm; it feeds where the depth is not too great for it to reach bottom to hunt for molluscs, worms, and crustaceans, or to pull up the sea-grass. The name is supposed to be derived from the habit of frequenting the "musselscaups" or "scalps," the rocks or estuarine mud-banks where these bivalves live. Cockles and other "shell-fish" are eaten.

If Seebohm's interpretation of sound is to be relied on, the name may be derived from one of its notes, which he describes as loud and discordant, like a man "with an exceptionally harsh, hoarse voice screaming out the word scaup at the top of his voice." But his description is rather discounted by his further remarks about "a peculiar toss of the head," borrowed from Montagu, who states that the bird when it so tosses its head in spring utters a "grunting noise." Mr. Millais, who describes the display in detail, says that when the male throws up its head it utters a gentle note. Indeed, there is much diversity in the description of the sounds uttered by the Scaup, and as I have never heard any except the grating call of alarm, very similar to that of the Tufted Duck, I offer no opinion.

Scaup congregate to rest on exposed banks in estuaries and bays, and are then difficult to approach, but the small parties met with near the shore are not so shy. I have watched the bird feeding in the marine lake at West Kirby, close to the promenade, and Mr. F. W. Holder tells me that sixty-five 
frequented the lake at Southport for some days in April. The usual time for arrival of migrants is from the middle of September onwards, but birds are often noticed in August, and I have seen it in mid-July. Passage birds are most numerous in October. Many return north in March, but some linger until May or even June.

Very few birds have been found nesting in our islands, though in Iceland it breeds freely. The immediate neighbourhood of water is usually selected; the eight to eleven eggs, greenish but darker than those of the Pochard, average $2^{\circ} 43$ by 1.71 inches in size (Jourdain). Eggs in Scotland have been found in June.

The adult drake has the head, neck, and breast black with a green sheen, the upper parts white with fine vermiculations of black and grey, and the flanks and under parts white. On the wing is a white bar. The parts black in the drake are chocolate in the duck, except the facial patch, which is white. The upper parts are dark brown with grey pencilling, the sides dull brown and also lined, and the under parts tinged with brown. In both sexes the bill is greyish blue, darker in the female, and the legs lead-blue; the irides at all ages are yellow. The drake in eclipse is said to resemble the duck, but an old drake in July, swimming with a Tufted drake, had no trace of a mask. Its greyish back was browner towards the rump, and its wings brown. The broad mask of the young birds is suffused with brown, but still indistinct, and in immature drakes the head is sooty. Length, 19 ins. Wing, $8 \cdot 5$ ins. Tarsus, $I^{\cdot} 5$ ins.

\section{Tufted Duck. Nyroca fuligula (Linn.).}

The increase of the Tufted Duck (Plate 24) within the last fifty years is more striking than that of the Pochard; in all parts of the british Isles, including Ireland, where the Pochard is yet feeling its way, the Tufted Duck is establishing itself as a permanent resident. It is a fresh-water species with a 
breeding range extending across northern Europe and Asia, and a wintering area in southern Europe and Asia and northern Africa.

The black and white "Magpie-Diver," as some sportsmen call it, black above and white below in the drake, is not a difficult bird to tell; the long, graceful crest in winter sets it apart from other ducks. The female and young birds are less distinctive; they are dark brown above, and have dull white under parts, whilst the crest is but slightly developed. It is not, at first sight, always easy to separate them from Pochards, especially when their lavender-tinted flanks obscure the white wing bar. On the wing, however, this white bar is very plain, though less noticeable than that of the Goldeneye. On account of the Tufted's golden-yellow irides, it is often called the "Goldeneye," leading to confusion with the next species. The residents receive large additions from oversea in autumn, October being the month when most arrive or visit our waters on passage ; but the numbers, at any rate in Lancashire and Cheshire, begin steadily to increase in August. From then onwards there are flocks of varying size on all the larger waters, but these diminish from March to May, and in June and July the only birds in evidence are the breeding stock and a few which for some reason show neither inclination to nest nor migrate. The summering of non-breeders has, during the last ten to twenty years, become an almost regular habit, preceding the settlement of a few nesting pairs.

Undoubtedly the Tufted is our best-known diving duck, and it is expert at the art. Some consider that it is a cleaner diver than the heavier Pochard, which they say has to spring out of the water before going under; but the spring is a habit of both species, and is merely used when the bird wishes to dive deep. The Tufted may take a header or merly slip out of sight, but like the Pochard it usually kicks up a parting jet of water. Ussher states that the bird has been caught in Lough Neagh in 
nets sunk to fifteen fathoms, but confirmation is desirable; in clear water the bird may be watched swimming easily at a depth of ten feet or more, but it is difficult to believe that it would, if it could, dive so deep as ninety. Normally the dives do not exceed fifteen seconds in duration. The Tufted's habits are fairly regular; as a rule most of the day is spent idly on the water, the birds slumbering with the blue bill tucked into the black back, floating lightly, small black and white buoys swinging in the wind. Others attend to the toilet, rolling on one side and showing the white under parts to perfection, as they scratch neck or flank with a foot. Small wonder that they are called "White-sided Ducks." Grebes careen to preen and flash white in the same way, but even at a distance there is a difference in the silky gloss of the Grebe and the dead Chinese white of the Tufted drake. The social habit is well developed, and flocks of considerable size consort with Pochards ; the bird is seldom met with in any numbers on the sea. Towards evening the flocks fly or swim to the feeding ground, which may be on another lake or the shallower parts of that on which they have spent the day, and again in the early morning the birds usually feed. Tufted Ducks, however, may be seen diving for food at all hours, often in little groups close inshore, vanishing one after the other until the water swirls and eddies. Aquatic weeds are their main food, but molluscs and insects are taken. If alarmed the birds sink the body, stiffen the neck, and make for open water, but are slow to take wing; when they do they splash with wings and feet. Flocks on the wing flash as they turn, but aerial gymnastics are not frequent; at times a flock will suddenly drop diagonally to a lower level and at once resume horizontal flight, and the descent to the water is swift and accompanied by a loud rushing sound. The flight and alarm note are, to my ears, similar-a growling currah or kurr, but the breeding call is a soft, liquid puk, with a little of the Pintail twang. I have heard this from drakes as 
they circled round the selected female in February and March. As the drake calls he rises vertically in the water and jerks his head upwards. A duck, if uneasy when conducting her brood, utters a frequent short grunt.

The nest is placed in various situations, usually dry spots near water, and is well concealed by rushes, reeds, heather, or other herbage; it may be in a hollow or beneath a bush, but is occasionally exposed; I have seen it on a fallen log. It is formed of dry grass, sedges, and leaves, and the dark down varies in quantity. The eight to ten eggs (Plate $2 \mathrm{I}$ ) are large, greenish or olive-brown. They are laid late in May or in June, and it is often well into July on Cheshire waters before the sooty-brown little balls of down venture out into the open. The duck in charge shows her anxiety by her stiffly upright neck, and though prior to sitting she was constantly attended by her mate, she is usually left to take all family responsibilities. Drakes in eclipse swim together well away from the brood, though I have seen one join the duck when the young had nearly reached flapper stage. The juveniles crowd after their mother, often pressing against her flanks, and if alarmed she by no means always lures them to deeper water, as has been stated to be her habit, but will lead them into the shelter of the aquatic fringe. As the young grow the down becomes browner -less sooty - and the eyts, at first brown, change to dull white, and much later to yellow. Many birds in first plumage have a marked white patch at the base of the bill, and adult females at times retain a few white feathers; the amount of white varies in birds of the same brood. An interesting sidelight on the spread of the species is suggested by the record of a nestling, ringed in Northumberland, which was caught in Finland in June two years later, where presumably it had gone to nest.

The bill of the drake is slate-grey, almost blue, that of the duck a little darker; the legs are slate, the irides golden. The male in eclipse is brown, but not so brown as the duck, and he 
shows white when he rolls, but his flanks are suffused with lavender; his crest is short. Young males resemble females, but even before they can fly are whiter on the flanks than the young ducks. Length, $17 \cdot 25$ ins. Wing, 8 ins. Tarsus, $I$ in.

\section{Goldeneye. Glaucion clangula (Linn.).}

The smart Goldeneye (Plate 23) is a well-distributed, though not very abundant winter visitor to salt and fresh water; it has not been proved to have nested in a wild state in Britain. It nests, however, in Scandinavia and across Arctic and sub-Arctic Europe and Asia, and a closely allied form occurs in America. Its winter wanderings do not, as a rule, extend so far south as those of other diving ducks. In our islands immature birds are much more abundant than fully mature drakes, and fowlers often insist that "Morillons," as they name the grey birds, are not the same species as "Magpie-Divers." These local names are apt to confuse, for Morillon has been applied to other species, and the Tufted Duck is called in some parts the Goldeneye and Magpie-Diver.

The adult drake Goldeneye is a very black and white bird, with a large white spot at the base of the bill, below and in front of the eye, which shows clearly on his glossy green head. The round shape of this spot at once distinguishes him from Barrow's Goldeneye, a bird that is reputed to have occurred in Scotland, for in this species the spot is semi-lunar. The female and young are brown on the head, grey, mottled with darker brownish grey, on back, wings, and flanks, and have a white collar. They have no face spot but a broad white wing bar divided by a black line; the white on the back and wings of the adult drake is in three parts. There is, however, little difficulty in identifying the Goldeneye of either sex at any age, once we have become familiar with its short squat shape and "buffel head." It swims with head well up, the long mane-like 
feathers of the nape standing out, giving it a peculiarly bigheaded appearance; on the wing this is just as prominent, for the feathers stand out round the short, thin neck. The difference in size between the females and males is very remarkable, but the young drakes do not look so hig as the old pied birds. As a winter visitor the Goldeneye is frequent, but it is as a passage migrant that it is most abundant, at any rate in Cheshire, where little parties may constantly be seen throughout October and November, and again in March and April. The first birds usually reach the inland waters in August, and some linger until May or even June. The Goldeneye is nervous, and unsociable so far as other species are concerned; it swims and feeds by itself or with a few of its own kind, but seldom consorts with other ducks. When a man approaches the lake it is the first to rise, and is quicker in getting on the wing than other divers, though it often scutters across the water, splashing with its feet. Once on the wing it flies swiftly, often close to the surface, and does not drop until it reaches the farthest extent of the pool. "Rattlewing" and "Whistler" are two descriptive local names, for the noise it makes in flight-more of a whistle than a rattle-is far louder than that produced by other ducks; it reminds me of the ring of thin ice cracking under the bows of a boat. I have heard the whistle of an old drake's wings across water from fully half a mile away. Vocally the bird is not demonstrative, though I have startled it into uttering a harsh grunting expostulation, deeper than that of the Pochard, but with the same guttural suggestion of $k r$. It has also a nuptial note, emitted with the head thrown upward, but this I have not heard. Gould figures drakes, flat on the water, with wings half spread so as to show the white pattern to advantage, and with the head drawn back and bill pointed upward as they call.

The Goldeneye is thoroughly at home on the water; it seldom comes to land; ashore it stands in a more upright 
position than most ducks. Even where there are a number of lakes in one district the bird usually shows partiality for certain waters, probably because they provide some particular food. In Lakeland, Macpherson found it the commonest diving duck, and this is still the case. As an expert diver it is distinctly ahead of its relatives; my notes give an average of twenty-three seconds below the water, and of three or four seconds on the surface between each dive. Thus when the bird is busily. feeding it is much longer invisible than visible. Often if surprised it dives, swims out for a distance and takes wing when it comes to the surface, and does not sink its body and draw off from the shore like Tufted or Pochard. It is mainly an animal feeder, diving for molluscs and crustaceans, and, in fresh water, aquatic insects ; Prof. Newstead counted over I 50 water bectles of one species in the stomach of a bird. In its nesting habits it differs from other ducks, for choice selecting a hole in a tree; it can be induced to make use of nesting-boxes.

The bill of the drake is blue-black, that of the duck darker and tipped with dull yellow; the legs are yellow, often orange in old drakes, the irides golden. One summer I was able to watch the progress of the moult into eclipse dress, for a "pricked" drake in, I should say, its second spring, was unable to migrate. In April its head was green, though with less sheen than in an older bird, and the patch near the bill was small though distinct. The head was quite brown by the second week in July, and the cheek spot had entirely vanished, though some authorities insist that it is retained; white showed on the neck, though flecked with grey, but the wing patch was unaltered. At the end of August the bird reached its greatest obscurity, and early in September the head darkened, and the white patches showed more clearly on one side; probably the reason was that the damaged wing did not recover so quickly. The bird was shot before it had attained full dress, and when last seen in September the face spot had not developed. 

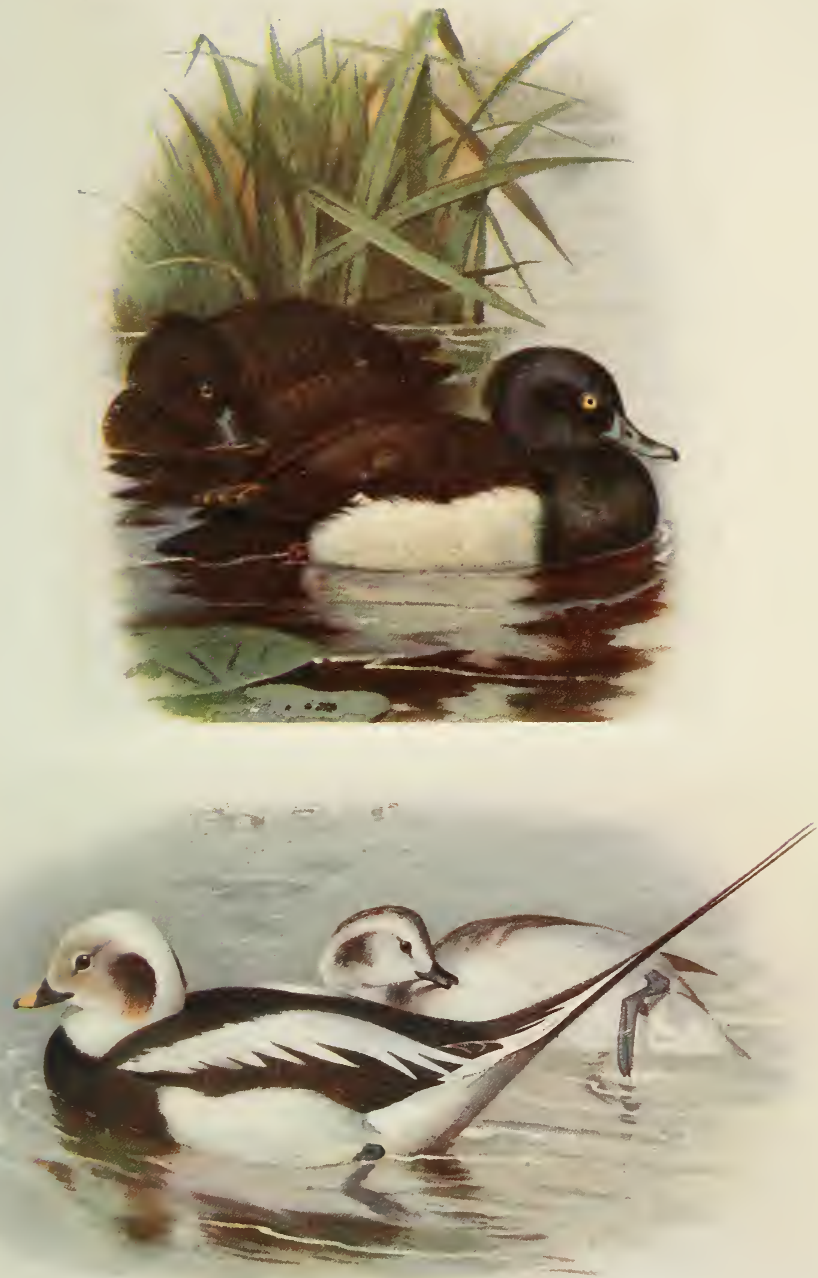

?. I. 24 .

Tufted Duck.

E 6 o.

Long-tailed Duck (male and female, winter). 


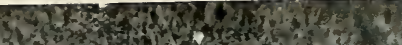

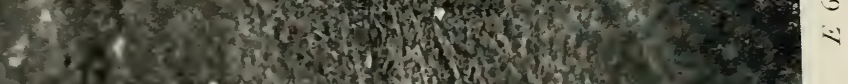

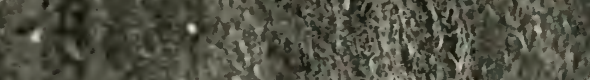

-1.5.

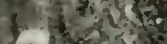

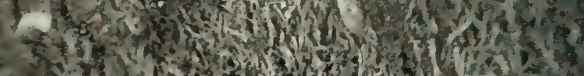

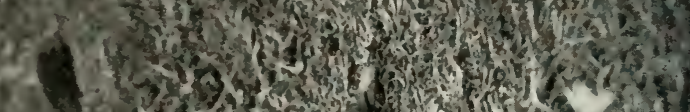

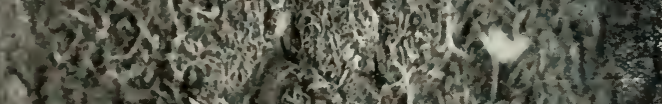

-

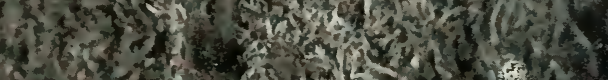

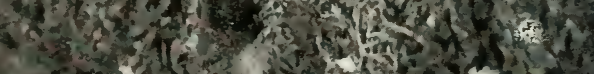

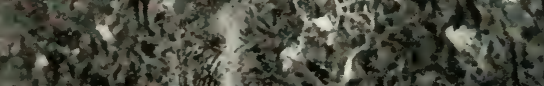

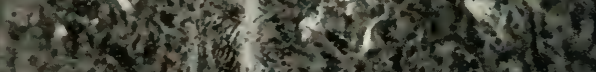
Bes

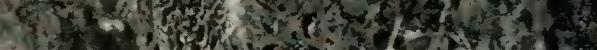

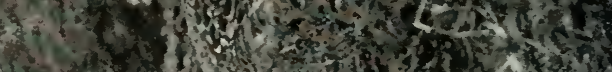

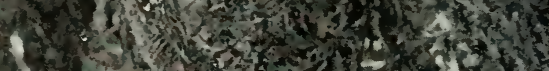
3. 3 की

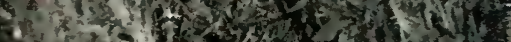
5. (1) A A A

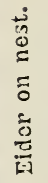


Immature drakes show more white than ducks. An immature duck in December had head and neck mummy brown and an incomplete white collar, mouse-grey shoulders and mottled-grey wings, and smoky-grey breast. The bill was brown tinged with yellow, the legs dull yellow, and the irides brown. Male: Length, 18 ins. IVing, $8 \cdot 25$ ins. Tarsus, I'5 ins. Female : Length, 16 ins. Wing, $7 \cdot 75$ ins. Tarsus, $1{ }^{\circ} 4$ ins.

\section{Buffel-headed Duck. Glaucion albeola (Linn.).}

Buffel-head, a contraction of buffalo-head, is descriptive; it conveys the idea of a heavy-maned head like that of the American bison, and this, with a slight stretch of imagination, is what is suggested by the elongated head feathers of the Goldeneyes and their near relatives. The Buffel-head breeds in the north of America and wanders so far south as the West Indies; on two or three, and probably more, occasions it has strayed to Britain. It is a smaller bird than our Goldeneye, and both drake and duck may be recognised by the white patch or band which runs upwards from behind the eye to the crest. In the drake this mark is larger and more distinct on his glossy green head than on the more soberly coloured duck. Females and immature birds, in addition to showing this mark, are browner than Goldeneyes in similar dress. The bill is bluish, tipped with yellow, the legs yellowish, and the irides brown. Length, $14-16$ ins. WVing, 6.5 ins. Tarsus, $I$ in.

\section{Harlequin Duck. Histrionicus histrionicus (Linn.).}

Mr. J. H. Gurney investigated the many reputed occurrences of this bird and relegated some twenty to the obscurity they deserved, leaving only two or three trustworthy records. The drake Harlequin, as the name suggests, is a gay, parti-coloured bird, utterly unlike any other, but the sombre duck is apt to be confused with the female Long-tailed Duck. Perhaps it is strange 
that the bird has not more frequently been met with, for it nests in some numbers in Iceland. It is not common in north-western Europe, but ranges eastivard through Asia into North America. In Iceland it appears to be resident, merely migrating in winter from the north to the south of the island.

The drake is a showy bird, blue-black in general colour of the upper parts, rich chestnut on the flanks and with a streak of the same colour on either side of the crown, bo!dly marked with white on the sides of the face in front of the eye, on the cheeks and sides of the nape, and with a white co!lar, incomplete breast band, and patches on the wings. The bill is blue-black, the legs brownish slate, and the irides orange. The female is almost uniform brown above, and on the throat and under parts brownish white with darker mottlings. In front and behind the eye are dull white patches; in the duck Long-tail the face is whitish, the cheek patch brown. Length, 17 ins. WWing, 8 ins. Tarsus, $I \cdot 3$ ins.

\section{Long-tailed Duck. Clangula hycmalis (Linn.).}

The Long-tailed Duck (Plate 24) is a winter visitor all round our shores, though more plentiful in Scotland and on the east coast than elsewhere. It is, almost certainly, an occasional nester in the Shetlands and Orkneys, where it is frequently met with in summer. Mr. O. V. Aplin's statement that the bird nested in Orkney in I9 I was questioned, as he refused to disclose his evidence, though the eggs and down-not taken by him-were examined and confirmed as those of this species; his reticence was justified, for attempts were made by collectors to discover the nesting site; he was silent for the sake of the birds. The breeding range of the Long-tail is circumpolar and mainly Arctic; it is abundant in Iceland. In winter it reaches southern Europe, and Florida in America.

There is always something characteristic about the Longtailed Duck whatever plumage it is in; it is small and squat 
and its bill is noticeably short. It swims buoyantly, and when the bill does not show clearly may be confused with the young Smew. In both winter and summer dress, which markedly differ, the drake has the two central tail feathers four or five inches longer than the others, and as a rule he carries his tail proudly erect. In winter his plumage is mainly black and white, but with a pronounced brown mark on the side of the neck. His head and neck are otherwise white. Much of the white is retained on the face in summer, but the crown and practically all the upper parts are rich brown. In winter the scapulars and inner secondaries are elongated and white, but in summer they have black centres and broad rufous edges. The brown females have no very salient characters, but a brown patch shows plainly on the greyish-white cheek. In old females the head is often very white. Long descriptions of the immature plumages are apt to confuse, for no two birds are exactly alike, and the drake is often in a curious mixture of winter and summer dress. The usual time of autumnal arrival off our shores is September, and of departure, March or April, but there are many records of early birds in August or even July, and of belated ones in May. One female arrived on a Cheshire mere at the end of July and remained for two months; an unusually long stay, for the bird is distinctly a sea and not fresh. water duck.

The Long-taiied Duck is perfectly at home on the sea, apparently rejoicing in a rough day. Facing the wind it rides buoyantly up the advancing wave, breasts the breaking crest, and glides into the hollow; from the shore we see the small bodies for a moment, then they vanish to appear inmediately on the next crest. Its feeding grounds are, as a rule, well off shore; it dives fearlessly in the troubled water above some sunken reef, seeking molluscs on the rocks and crustaceans in the tangle. Even rocks and seaweed are not necessary, for it subsists largely on the plankton-finding sufficient nourishment 
in pelagic eggs and larvæ of fish and crustaceans. "SeaPheasant " is a name that it shares with the Pintail, and indeed in some parts of Scotland this bird is the "Pintail," but a commoner and better Scottish name is "Calloo." The Longtail is a noisy bird, especially in winter and early spring, and it is from its oft-repeated musical cry that it has earned this name, though at times the Scots go further and affirm that it says"coal-an-can-le-licht." The lively conversational calls may be heard at any time, and often through the night; when it calls it throws the head upward and opens wide its bill.

The bird is a lively and neat diver, and swims under water with the feet alone, though the wings may be opened in turning, at least that is my experience when I have seen it in shallow water. One bird I watched swam so superficially that I could trace its course by the occasional splashes, and now and then a foot protruded. Nearer inshore, where the water was only a few inches deep, it swam with the back exposed and its head beneath the surface. If suddenly alarmed on reaching the surface the bird rises more cleanly than other diving ducks, and on dropping to the water it will sometimes go under at once. The duration of dives has been estimated at over forty seconds, but birds I have watched hardly remained so long, though when busily feeding they were much oftener below than on the surface. The courtship attitudes of the drakes have been described, and the disp'ay is frequently interrupted by squabbles, though these slight differences of opinion are not confined to the breeding season. In display the long tail is carried almost at right angles to the back, and, it is said, vibrated. The duck has a low note which is drowned by the clamour of the drakes. The eggs are elongated, greyish green to buff, and average $2 \cdot 1$ by $1 \cdot \xi$ inches.

The difficulty of describing the plumage is, as already stated, complicated by the varying phases due to season and progress towards maturity. The adult drake in winter has the head, 
neck, scapulars, inner secondaries, flanks, and under parts white, the rest of the plumage brownish black, the most noticeable mark being the large oval brown patch on the side of the neck. The elongated tail feathers are black, the others white. The short bill is rose-pink, black at the base and tip. I have not handled an adult drake and cannot express an opinion about the legs and irides, but the accounts vary so much that possibly the colours differ individually, and even in the same bird under different stimuli so far as the eyes are concerned. The legs are said to be pale lead coloured, dull yellow, red and reddish brown; the irides red, yellow, or brown, and Thorburn figures them as brown, Gould as whitish yellow. Probably Saunders is correct when he says "varying from yellow to hazel and red." In its summer dress the drake is reddish brown, as already mentioned, and the short-tailed brown female has an incomplete white collar. One female that I saw in December, evidently an old bird, had the head distinctly greyish white, except on the dark crown and oblong brown patch below the lead-blue bill. The legs were slate and the irides pale brown, certainly not yellow, in a female watched at close quarters. An immature bird in October had the head and neck delicately shaded with grey on white, and an immature drake, with a fairly long tail, was greyer on the back and browner on the nape than the duck with which he was swimming. The bill of immature birds is bluish grey, the legs look dark, and the irides are brown. Male: Length, 20-23 ins. Wing, 9 ins. Tarsus, $\mathrm{r}_{2} 2$ ins. Female: Length, 16 ins. Wing, 8 ins. Tarsus, $I \cdot I$ ins.

\section{Steller's Eider. Heniconetta stelleri (Pallas).}

This beautiful little duck has occurred twice on our east coast. It is a circumpolar species, which has not been proved to nest in Europe, but is found off the shores of Norway and in the Series II. 
Baltic in winter. The drake has the head and neck white, the chin black, and a glossy purple-shot black collar joins its black back; the wings are black and white, the lower breast and flanks rich chestnut, and the abdomen dark. It is much smaller than the other two eiders, but has the same art green on the head-in front of the eye and on the nape. The duck is dark brown mottled with buff, and has a brown-black speculum narrowly bordered with white. The bill is bluish grey, the legs dark grey, and the irides brown. Length, 17 ins. Wing, $8 \cdot 5$ ins. Tarsus, $1 \cdot 4$ ins.

\section{Eider-Duck. Somateria mollissima (Linn.).}

The Eider (Plate 26) nests abundantly in Iceland, Scandinavia, and the western Palæarctic region generally, and in winter wanders south along the Atlantic seaboard, occasionally to the Mediterranean. The eastern American sub-species is closely allied to ours, but the western, Pacific form, $S . m$. r'nigra Gray, has a distinct black chevron on the chin; the presence of indications of a similar mark on some examples was responsible for the erroneous idea that this bird occurred in British waters. On the Scottish coasts, in the Shetlands and Orkneys, and some of the Hebrides, the Eider is a resident, and on the north-east coast of England some numbers nest annually, most plentifully on Holy Island and the Farnes. Except for one nest recorded for Ireland, it is elsewhere a winter visitor, more frequent in the east than the west.

The Eider is a large, heavy duck, with a bill sloping from the forehead. Down the centre of the bill, about half-way to the nostrils, is a feathered peak, but even more noticeable than this is the angular tract of feathered skin that runs forward on each side of the bill, dividing the upper mandible, as far as the nostrils, into two portions. The handsome drake, white above, except on the crown and lower back, which, like most of the 
under parts, are black, can hardly be confused with any other species, for the King-Eider has an entirely different bill.

The brown duck, mottled and barred with black, has little beyond her size and shape that can be called distinctive when she is seen at a distance. The female King-Eider has a longer peak on the bill, but this is not easily seen on a bird tossing on the waves. The sea, and usually a restless sea, is the place where we are most likely to meet with the Eider, for no duck, not even a Scoter, is more maritime ; an Eider inland is exceptional. Off shore, especially at high tide, fleets of Eiders cruise in any weather; the birds lift on the waves, ride through the curling crests, and dip into the troughs without raising their sleepy heads from their breasts. Birds in these flocks are often in puzzling plumage, old white drakes and brown females, and in between young males in various stages of immaturity, mottled, streaked and banded with white, black, and brown. When white foam indicates sunken reefs the birds draw in to feed, diving fearlessly in the rough water for molluscs on the rocks or crustaceans in the weed. They swim close to the exposed rocks, without apparent effort floating back when a wave threatens to dash them on to the reef. As the tide sinks some mount to rest upon the reef, and others, with head and neck below, but not with the body uptilted, investigate the sand in shallow pools. Small molluscs are swallowed whole, but larger ones and crabs are crushed in the powerful bill ; starfish and small cuttles are also eaten.

On the wing the Eider looks heavy, but its speed is considerable; it often flies straight, just above the waves. In flight it has a harsh grating call, but this is less noticed than the low coo, which the drakes utter with head thrown up with a jerk, as if gulping. During courtship this note, frequently repeated, becomes a crooning love-song as, bobbing and jerking, the amorous drakes swim round the duck, unconcernedly sivimming, her tail a little elevated, as if bored by their overtures. 
In the performance, it is asserted, the drake constantly raises himself in the water to flap his wings so as to display his best "points," but after watching the birds for several consecutive days I came to the conclusion that the duck and immature drakes flapped as often as the suitors. At all and any time ducks raise themselves in the water and flap their wings, just as we and other animals stretch and yawn.

In many places the Eider gets more or less protection on account of the value of its well-known grey down; indeed, the misguided duck is shamelessly exploited, tempted to nest under protection and thus induced to pluck herself, and when the eggs most need the heat-retaining down, it is stolen, and the bird has to begin again. The nest, constructed of grass, heather, or seaweed, is placed in various situations, sometimes in heather or thrift in the open, but often under the shelter of a wall or rock. The large greenish eggs (Plate I 4) usually number four or five, but much larger clutches are recorded. Fresh eggs may be found from May to July, but late broods may be due to the earlier eggs having been taken for food. Where the bird is protected it is a close sitter and absurdly tame; it is possible to stroke the sitting "St. Cuthbert's Duck" on the Farnes. In the Hebrides, however, Miss Turner found it rather camera shy: The sitting or rather crouching position of the bird on the nest, shown on Plate 25, suggests a desire to gain concealment. It might well express nest weariness, for Mr. IV. H. St. Quintin found that his captive Eiders sat for twenty-eight day's without taking food or water, and apparently never left the nest. Long before the eggs hatched the old duck was "buried overhead, nest and all, in a mass of luxuriant chickweed." The young in down are brown with grey or yellowish eye-stripes and uncler parts, and their bills and feet are blue-grey. The duck leads them to the water at an early age, and sometimes joins forces with other old birds. Some observers state that the drake, like other ducks, deserts the female during incuba- 

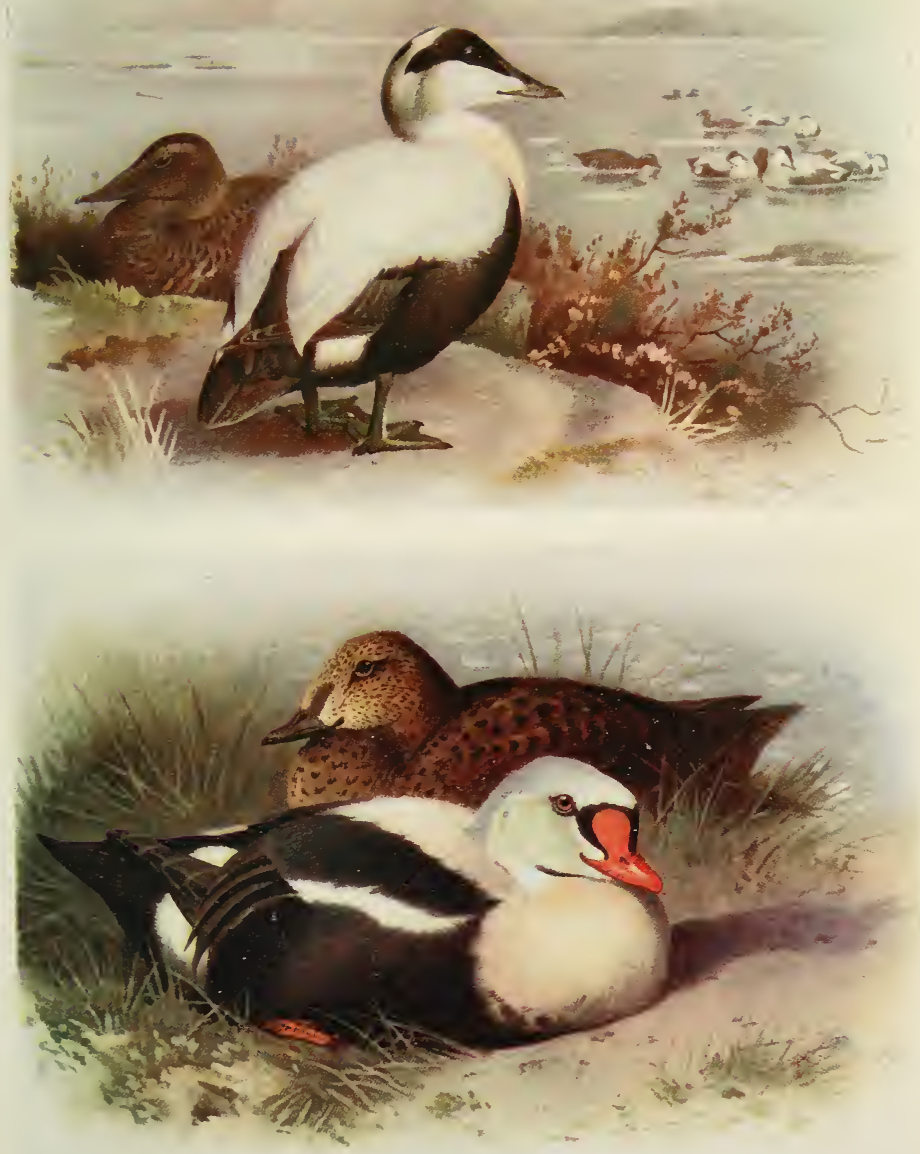

2 Pl. 26.

Eider.

King-Eider. 

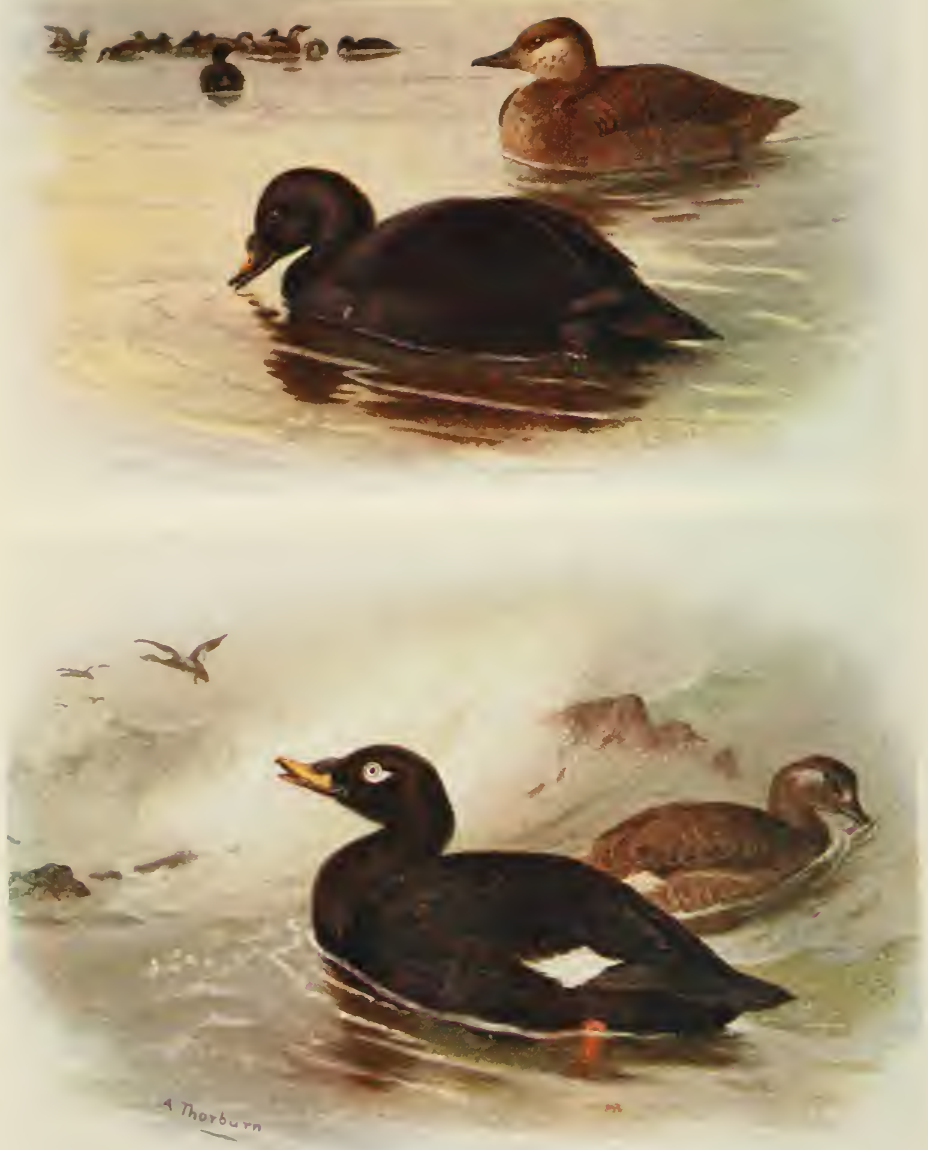
tion and leaves her to take charge of the young, whilst others have noted him anxiously keeping guard. Probably there is individual difference in the behaviour; I have, however, seen many ducks, unaided by any drake, convoying their little fleet of four or five young, and in mid-June forty-eight mature drakes together.

The forehead, crown, a stripe on either side of the bill, lower back, and under parts of the drake Eider are black; a white stripe divides the crown, and the neck, face, upper parts generally, and a patch on either side of the abdomen are white. The breast is a beautiful rose-buff, but the most delicate colour is the pale green on the nape and cheeks and the yellow of the elongated inner secondaries. The bill is olive-green, at any rate shortly after death; there is difference of opinion as to the actual shade during life. The tip is pale yellow. The legs are olive, the irides dark brown. In the brown duck the bill is bluish grey, the feet and eyes as in the drake. The drake in eclipse has irregular marking on the back and scapulars, and is much blacker than in his winter dress. Young drakes vary so much that only a specialist could tell the age of most individuals, for the bird is not mature until its third year; there would be a suspicion of guesswork in any case, for it is most unlikely that the various feminine characters are lost and the spots and mottles on the whitening portions gained at the same age in every bird. Length, 25 ins. Wing, 12 ins. Tarsus, $175 \mathrm{ins}$.

\section{King-Eider. Somateria spectabilis (Linn.).}

The Arctic and circumpolar King-Eider (Plate 26) travels south in winter and consorts with the commoner bird; in British seas it is uncommon, merely an occasional visitor. Some numbers have, however, been observed in the Orkneys and Shetlands, and a few on the east coast and in Ireland. 
Rather smaller than the Common Eider, the drake can, without difficulty, be recognised by the prominent orange boss or lobe on its flesh-coloured or orange bill; a fringe of black frames the knob, showing it up. The drake is also blacker on the wings and back than the Common Eider. The duck cannot be safely distinguished on the water, but in the hand the length of the wedge in the centre of the bill is a good character-it reaches to the nostrils. The habits and food, so far as they have been observed, differ little from those of the Eider; it is ungainly, especially on land, but flies quickly, close to the water. Seebohm and others thought that a few pairs may occasionally nest on outlying British islands, but the evidence, the presence of birds in summer, is inconclusive. Off the Farnes and in other places drake King-Eiders have remained with other birds until June or even July, and Slater noticed the same habit in Iceland, but points out that these drakes are not fully mature. The natives imagined that the presence of the rarer birds favourably affected the fertility of the other Eiders.

The head and neck of the adult drake are white, with black round the knob on the bill and a strong black chevron on the chin; the crown is lavender, the cheeks suffused with delicate green. The upper back, a patch on the wings, and another on the sides of the abdomen are white, the breast is buff, and the rest of the under and upper parts, including the elongated secondaries, are blackish brown. The duck is brown, palest on the head and neck, and redder than most female Eiders, but these last vary considerably. The legs of the drake are orange, of the duck greenish grey, and her bill is greenish tinged with yellow. The irides in both sexes are usually said to be yellow, though others, including Coues, affirm that they are brown; observation of the living birds should decide it. Length, 22-24 ins. Wing, $10 \%$ ins. Tarsus, $1 \cdot 8$ ins. 


\section{Common Scoter. Edemia nigra (Linn.).}

The Common Scoter or Black Duck (Plate 27) nests regularly in the north of Scotland, and has nested in at least one place in Ireland for some years. It is, however, best known as an abundant visitor to our shores, not merely in winter but at all seasons, for many immature or otherwise non-breeding birds remain during summer. The breeding range extends across northern Europe and Asia, and in winter it is abundant along the Atlantic coasts.

The black Scoter, blacker than any other duck, is a heavylooking bird, even when, like a cork, it rides buoyantly on the waves. It is seldom very near shore, therefore difficult to see clearly, but in a good light its one colour spot, an orange patch upon its bill, is conspicuous; it is the drake only who sports this label, and the base of his bill is much swollen; the duck is a grey-cheeked brown bird. Drake and duck alike, when swimming at ease, carry their pointed tails elevated like the Pintail; this pose catches the eye when the birds are with other diving ducks. When swimming fast the tail is lowered. The absence of white marks on the head prevents confusion with the Velvet-Scoter, the absence of the wing bar is less reliable, since that of the Velvet is often concealed by the flanks of the swimming bird. The majority of the winter birds reach our seas in September, but August arrivals are common; in September and April there are large passage movements. All winter the birds are common, and, at any rate off the Lancashire, Welsh, Northumberland, and Yorkshire coasts, numbers of immature or other non-breeding birds remain the whole summer. How long the Scoter takes to reach maturity does not seem to be known, but many of these summering birds are apparently in full adult dress.

The Scoter is certainly a salt-water duck; except when nesting, many writers affirm, it seldom if ever voluntarily goes 
inland. Either the bird has changed its habits or been overlooked, for it frequently visits the Cheshire meres, and Mr. C. Oldham has often seen it in Hertford and Buckingham. Not only are these visits in April, when there is an occasional and possibly regular overland migration, but little parties appear from time to time in July. Off the North Wales and Lancashire coasts the bird is frequently in immense numbers, the sea, so far as the eye can reach, dotted with ducks, or lined with little strings flying swiftly close to the waves. I have watched what Mr. Bolam describes, the birds feeding on a falling tide, those furthest out rising to fly shorewards over their companions and dropping where the waves are breaking. I have seen them flying in long lines far out, undulating like distant steamer smoke, their numbers countless; yet we are told that the bird is uncommon on the west coast ! At close quarters the buoyancy of the swimming bird is very noticeable; it constantly uplifts itself to flap its wings after its frequent dives and shakes a shower of drops from its bill. If disturbed it swims quickly, the head well forward, bobbing like that of the Moorhen, and utters a low $t u k, t u k$. In flight, when its wings whistle, it has a harsh, grating call, but the courtship note is more melodious.

The duration of timed dives varied from sixtcen to forty-nine seconds. Molluscs of various kinds are the chief food; one young bird that I examined had fed exclusively on Tellina balthica, but Mr. G. Bolam found one full of nothing but small marine crustaceans. Mr. R. W. Jones notices that the summering birds in North Wales regularly pass in flocks in the morning and afternoon between their feeding grounds near shore and some night haunt at sea, suggesting that they are normally diurnal feeders. Dr. Patten says that when diving the Scoter "disappears without warning or splash," and does not take a header; but surely the amount of effort depends upon the depth of the water. I have seen the bird dive with a graceful 
forward curve. Under water the leg strokes are lateral like those of a grebe.

Usually in wet surroundings, the nest is a slight grass-lined hollow, well concealed; the five to eight creamy-white eggs are laid in June, and surrounded with very dark down. They measure about $2 \cdot 5$ by 1.8 inches. The duckling is dark brown above and on the breast, and white beneath.

The drake is glossy black above, very dark brown beneath, and his bill is lead-blue, with an orange line on the prominent basal knob and a wider mark below; the legs are brownish black, the irides dark brown. The brown dress of the duck is relieved by the pale cheeks and whitish chin, and the young have the under parts white mottled with brown. A young male I examined in the flesh in March showed a small patch and line of lemon-yellow on his but slightly swollen black bill; his legs were olive-brown, with darker webs. A younger bird, in November, had the bill black and the legs dull yellow, the dusky webs very noticeable between the yellow toes. Sir R. Payne-Gallwey noticed that birds in their first winter often show white feathers on neck and breast; the young male above had white patches, small and irregular, on its face and odd white feathers on the nape. Length, 19 ins. Wing, 9 ins. Tarsus, 175 ins.

\section{Velyet-Scoter. Edemia fusca (Linn.).}

The Velvet-Scoter (Plate 27) breeds in northern Europe and north-western Asia, and in winter visits the Atlantic and Mediterranean. To our shores it is a winter visitor in small numbers, but is sometimes rather numerous off the east coast.

The broad white wing bar of the glossy black Velvet-Scoter shows well on the flying bird, or when, raising itself in the water, it flaps its wings, but, as in other wildfowl, it is commonly concealed by the secondaries or fluffed-out flank feathers when 
the bird is on the water. Distance-for scoters keep well off shore-adds to the difficulty of identifying species, but in a good light the Velvet may be told by its superior size, the broader band of orange on the bill, the white spot immediately below the eye of the drake, and the two almost white patches, one behind the eye and the other at the base of the bill, on the face of the brown duck. In habits, time of arrival and departure, and general behaviour, this bird differs little from the Common Scoter, its frequent companion at sea. Pairs are said to swim more together, but in the huge flocks of Common Scoters, as in packs of Mallards, this marital constancy is little evident until the birds rise, when the pairs often fly together; I have, however, seen Velvets fly in little parties. The flight is quick and near the water, the grunting note very similar to that of the other bird. Though very much a sea duck, I doubt if there is much in the assertions, both of which are made, that it is more, and less frequent on inland waters than the Common Scoter; it is occasionally seen inland, and the fact that it has been more often recorded may have given the idea of more frequent occurrence, whilst its smaller numbers and consequently rarer appearance have conveyed an erroneous impression to others. Young and non-breeding birds, probably immature, though the less glossy summer dress of old drakes is hard to distinguish from that of nearly mature males, sometimes linger through the summer off our northern shores. One point in which it differs from the Common Scoter is that the plumage of the young bird is not strikingly different from that of the duck.

The amount of yellow on the bill of the drake Common Scoter varies considerably, but in the Velvet-Scoter the pattern is different. Practically the bill is orange and red with the basal knob black, and a black line running through the nostril towards the light nail, where it meets the black line along the edge of the upper mandible ; or we may say that the bill is black with a central and two lateral patches. The bill of the duck 
is leaden, and the basal knob but slightly developed. In both sexes the legs are orange-red, but much brighter in the male. The irides of the drake are greyish white, but in the duck and immature bird they are brown. Length, $2 \mathrm{I}$ ins. Wing, $I \mathrm{I}$ ins. Tarsus, 2 ins.

\section{Surf-Scoter. Cidemia perspicillata (Linn.).}

The Surf-Scoter (Plate 28) is a North American bird, breeding far north, and in winter migrating south by both overland and coastwise routes. From time to time wanderers reach our shores and consort with other scoters, from which, so far as has been observed, they differ little in habits. The bird is always a casual, but it has been more frequently detected in the Orkneys and off the west coast than elsewhere.

As in the eiders, a triangular feathered tract runs down the centre of the swollen and rather massive bill towards the nostrils. The basal protuberance is long and sloping and not a knob. In the drake the bill is showy, shading from deep red to orange and pale yellow; on the sides are white spaces and large squarish black patches. Even more distinctive and conspicuous are a rectangular white mark between the eyes and triangular white patch on the back of the neck; the rest of the plumage is glossy black. The duck is a brown but variable bird, sometimes showing the neck mark more or less clearly and occasionally two whitish spots on her pale brown cheeks. Young males and old females have much in common, but the distinctive male marks appear before the birds attain glossy dress; young birds of either sex have white under parts mottled with brown. From the duck Velvet the female may be told by the absence of the white wing bar, and from the Common Scoter by the neck marks and facial spots. The bill of the duck is dark olive; the legs of the drake are reddish orange, and the webs are dusky, but those of the female are dull 
orange, and in some birds are said to be yellowish green. There is also difference of opinion about the irides, which Gould figures as yellowish white in both sexes; descriptions vary from "bright yellow" to white, but in some females and young birds they are said to be brown. Length, $2 \mathrm{I}$ ins. Wing, 9.5 ins. Tarsus, $I_{5} 5$ ins.

\section{Goosander. Mergus merganser Linn.}

Although several ducks will occasionally eat fish, the "sawbilled ducks" are the only ones that habitually fish for a living; their long, narrow, serrated bills are well fitted for catching and holding slippery prey. The Goosander(Plate 29), the largest of the group, inhabits northern Europe and Asia, migrating south in winter, and regularly visits estuaries and inland waters in Scotland and northern England. Elsewhere in Britain and Ireland it is more casual. In the north of Scotland a number nest annually.

The Goosander shares with the Red-breasted Merganser the popular name of "Sawbill." The handsome drake, with glossy green-black head, black and white wings, grey lower back, and salmon-pink under parts, cannot be confused with the longcrested and ruddy-breasted Merganser drake, but the brownheaded, grey-backed females are very much alike. The Goosander is the larger bird, but size is of no value when the two are not together; the wing patch is not, as has been stated, single in one and double in the other, but in both a black line crosses the white. Perhaps the best distinction is in the manelike crest, which in the Goosander is graduated from the nape to the lower neck, whereas in the Merganser it is long at its highest and lowest point and short between; when it stands out it looks more ragged. On the west coast and on western inland waters the Goosander is far more of a fresh-water duck than the other; it seldom appears on the shores and estuaries, 

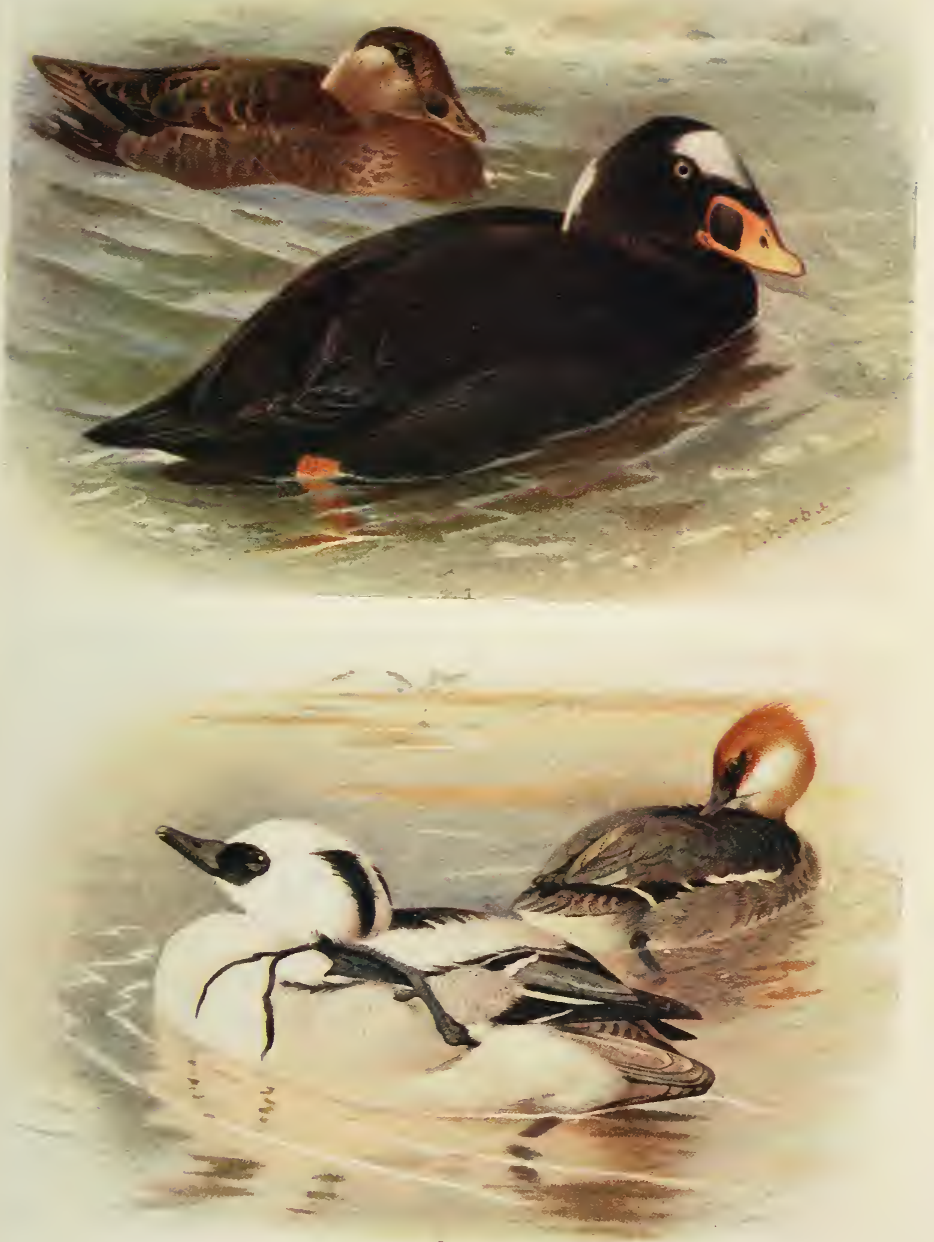

2 Pl. 28.

Surf-Scoter.

$F 76$. Smew. 

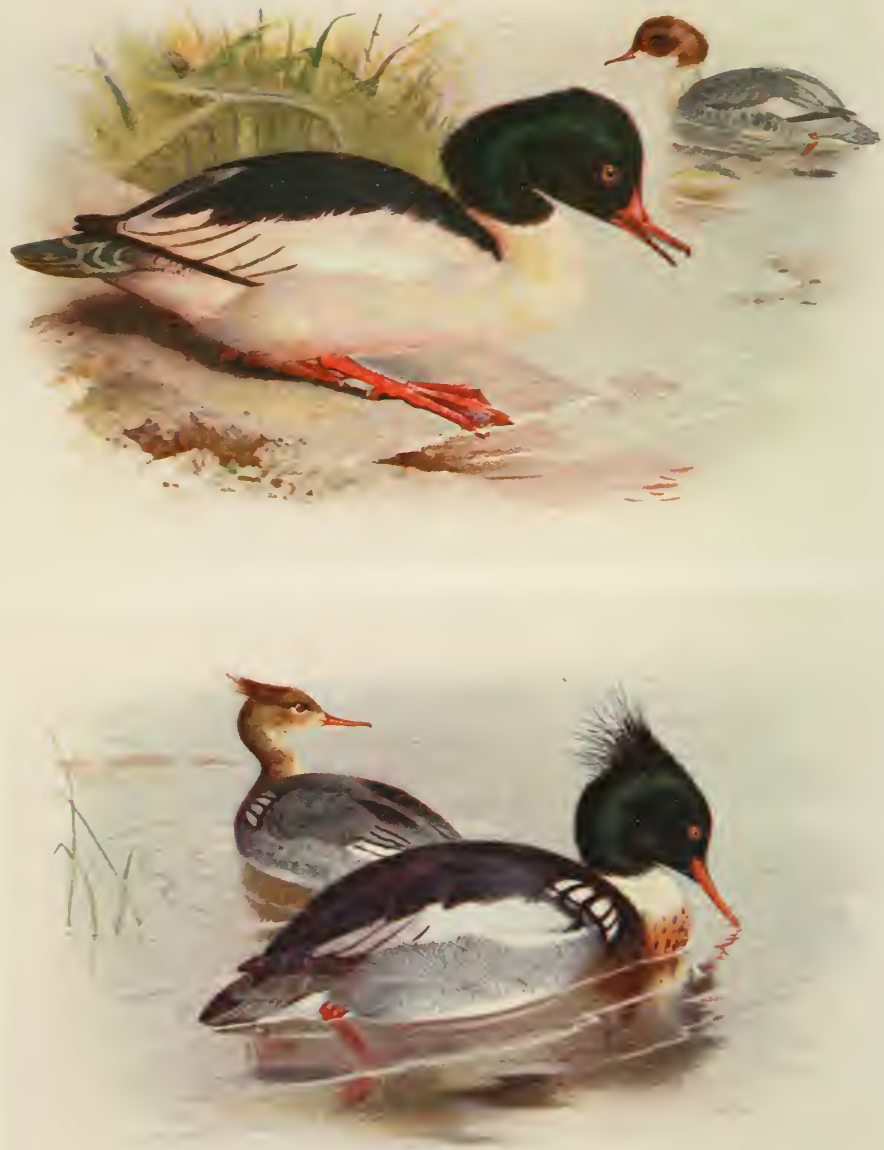

2 Pl. 20. 
where the Merganser is common. Goosanders reach Britain in October, but few appear in Cheshire before December; even then their visits are irregular. April is the month of emigration, but birds on passage will linger for a few days, even in mid-May.

The elongated, cigar-shaped body is well adapted for rapid progress in the air, on or under the water; the bird swims with great speed, easily forging ahead of Mallards, even when not hurried. With neck awash and head well forward it slides through the water, its rounded back just showing like a small submarine travelling on the surface, but if suspicious it sinks its deck and leaves only its periscope visible. When resting on the water its attitude is similar to that of the sleeping Great Crested Grebe, the head and neck laid back between the wings; the white coverts and flanks then hide the clark portions of the wing, and the back merely shows as a crescentic line above the white side. The rosy tinged under parts show when the bird raises itself and flaps its wings, and when it rolls to scratch its blood-red bill an orange leg appears. The ducks, both when swimming and flying, look much darker than the drakes, although their backs are ashy grey, for the white under parts on breast and flanks are tinged with grey. Goosanders rise heavily, splashing like diving ducks, but when clear of the water fly straight at great speed; they will fly high above an inland water. The only note that I have heard is a harsh karrr, but in spring the drake is said to utter a "soft, low croak." When a party is fishing, the water swirls as the birds pop up and dive again one after the other; so far as I have sten, the wings are not used for under-water swimming, though they may be slightly opened, like those of the Cormorant, as the bird rises. Fish are, frequently at any rate, swallowed under water. The duration of the dives varies; the shortest that I have timed lasted only 1o seconds, the longest 110. A minute below is common, and the bird will often travel fifty yards or more before 
reappearing. Seebohm affirms that on land it stands like a Cormorant and walks clumsily. It is neither so upright nor awkward, but is easy on its feet and, considering the far back position of the legs, remarkably horizontal in pose. The courtship performances differ little from those of other ducks; there is the same head throw and gulp as the competing drakes swim round the duck, the same occasional squabbles, and now and then the bird forces itself forward with a strong stroke, after the manner of the cob Swan.

The Goosander nests in holes, often in hollow trees, under rocks or in peat banks, and but little nesting material is collected. Eight to twelve creamy eggs, not unlike those of the Sheld-Duck, are surrounded with light down, and the clutches are often complete early in May. The average size is 2.7 by 1.8 inches. When the ducklings, brown above, white on wings, sides, and under parts, and with chestnut heads, hatch out, they are led to the water; if the nest is in an elevated position, the young require help in descending. Mr. O. A. J. Lee witnessed this performance, and saw that the duck brought down some in her bill, others pressed against her breast-a lesson for those who insist with regard to other species that only one method is followed.

The irides are red. An eclipse dress is assumed; the wings are whiter than those of the duck, and a dark collar shows. Young drakes have shorter crests than ducks; in the adult drake there is no noticeable crest, though the head looks large, but that of the female is long. Immature drakes can often be recognised when swimming with ducks by their superior size. Male: Length, 26 ins. Wing, I I ins. Tarsus, $1 \cdot 9$ ins. Female : Length, 24 ins. Wing, $9^{\circ}+$ ins. Tarsus, 17 ins. 


\section{Red-breasted Merganser. Mergus serrator Linn.}

'The Red-breasted Merganser (Plate 29) breeds in northern Europe, Asia, and America, and reaches north Africa and India in winter. In many parts of Scotland, the Scottish islands, and Ireland it is a common resident, but in England and Wales is only a winter visitor and regular bird of passage, more abundant on the west than the east coast.

The drake is smaller than the Goosander, from which it may at once be told by its chest band, reddish brown streaked with black, by the noticeably longer crest, and the conspicuous white and black patch on the shoulder. When swimming it shows a creamy streak on the wing. The female closely resembles the duck Goosander, but when with Mallards looks smaller, whereas the Goosander is larger; her neck is browner and she shows a much darker and more distinct bar across the wing patch than the female Goosander, but as she swims low in the water the bar is often hidden and only visible when she flaps or takes wing. When swimming she moves her head forward and backward, after the manner of the Moorhen, a trick I have not noticed in the other bird. The Merganser is far more a sea duck than the Goosander; indeed, in Cheshire I have only occasionally seen it inland, though it is often plentiful in the Dee and along the coast of North Wales. Its food, fish of various kinds, is hunted below the surface, but in shallow gutters it will swim with the head alone below, picking up small flat fish and crustaceans. It is said that captured fish are brought to the surface to be eaten, but probably this is only when the captive is too large to be at once swallowed, and is so lively that it has to be subdued. When the fish has been swallowed a sip of water is taken, a common habit of fish-eaters. Sand. eels are favourite food; for these the birds dive excitedly near the shore. 
If disturbed the Merganser sinks its body or dives, but when it rises scutters along the surface for some yards. On the wing it is quick, flying straight and usually low. It has a grating flight call, not unlike that of the Goosander, but as a rule it is not noisy except when pairing, when it constantly coos as it stretches its head upwards, after the fashion of the Eider. Some of the winter visitors arrive in September, and the largest numbers are passing in October and throughout May. In spring the drakes go through display long before they leave the coast; I have seen them very fussy in January, as many as half a dozen showing off before one duck, who frequently dashed at one of her too attentive admirers. There is a family likeness in all duck displays, but they differ according to the colour or pattern adornment of the drake; he strives to exhibit his best points. Thus the Merganser slightly raises his wings so as to extend the black-barred white secondaries, and stretches up his neck to show his collar; when he raises himself in the water, as if seating himself more comfortably, the breast band is exhibited. I have seen the drakes force themselves suddenly through the water when striving to frighten away a rival. The habit of rising in the water, with or without wing flapping, is by no means confined to the pairing season.

The nest in most cases is well concealed by brambles or other bushes, or by rank herbage; the bird sits closely. It is a slight structure, well lined with grey down when the clutch of eight to twelve drab or slightly greenish eggs (Plate $2 \mathrm{I}$ ) is complete at the end of May or in early June. Sometimes many nests are in a small area. The ducklings, brown with white spots on wings and sides and with rich chestnut cheeks, are led to the nearest water, and a few days later conveyed along the outflow stream to the sea. If falls or rapids bar the way the duck walks them down to quieter water. In the estuary or on the shore the ducklings share the strange habit of the Sheld-Duck and Eider; some of them leave or are left by the 
parents, and join forces with other broods; thus a single old bird may be seen tending two or more families.

The drake Merganser is an exceedingly handsome bird. His head and neck are glossy green-black, his crest long and tufted; a line down the back of the neck passes through the white collar to the black upper back, and the lower back and flanks are finely pencilled with grey. The wings are black and white, the white crossed by two black bars, and on the shoulder is a patch of black and white feathers. Beneath the breast the under parts are white. The bill and irides are red, the legs orange. The duck has a brown head and neck, grey back, and a bill duller than the drake, but red at its base. In eclipse dress the drake shows more grey on breast and flanks than the duck. Length, 24 ins. Wing, $9{ }^{\circ} 5$ ins. Tarsus, $I^{\circ} 5$ ins. The female is rather smaller.

\section{Hooded Merganser. Lophodytes cucullutus (Linn.).}

The Hooded Merganser is a North American bird which in winter has been met with so far south as Cuba. There are more than a dozen records of its occurrence in Great Britain and Ireland, but only four are generally accepted. The drake, however, is so distinctive with his upstanding and outstanding crest, white with a black margin behind the face, and with two curved black marks on the side of his white breast, that birds seen by reliable and experienced observers, even though not shot, may be accepted. For instance, at the end of March, I9II, Prof. K. J. P. Orton saw a drake drifting on the tide in the Menai Straits, and tells me that the hood and markings were very distinct. It was in these Straits that E) ton, in the winter of $1830-31$, obtained his historical specimen. The drake swims with the crest fanned out, but Sir R. PayneGallwey, who shot three in Ireland, says that a crippled bird swam low "with the crest laid flat and smooth."

Series 11 . 
The head and neck of the drake are black glossed with green and purple, and with the fan-shaped white patch from the eye to the nape. The head is a little like that of the Buffel. headed Duck, but the white patch in this bird is not edged with black, nor has it the breast marks or merganser bill. Otherwise the Hooded Merganser is mainly black and white, with grey vermiculations on the brown flanks. The female is brown above and on the breast, and the crest-without any white-is smaller and more of the merganser shape. The under parts are white. The bill is black, the legs dark red, the irides yellow. Length, 19 ins. Wing, 7775 ins. Tarsus, I'5 ins.

\section{Smew. Mergellus albellus (Linn.).}

The Smew (Plate 28), the smallest of the mergansers, is a native of north Europe and Asia, and in winter visits the Atlantic and Mediterranean coasts as well as the larger European lakes. Although more abundant as a winter visitor to our east coast, it occurs from time to time in all parts of Britain, visiting bays, estuaries, and inland waters. Immature brown-headed birds are commoner than old drakes.

The adult drake, about an inch and a half longer than the duck, is without being really white one of the whitest looking of our birds, for the velvet-black markings enchance the snowy appearance. The "White Nun," as it is called to distinguish it from the female and immature "Red-headed Smews," has a drooping white crest with two converging green-black lines; round the eye, from the short and slightly uptilted blue-grey bill, is a circular patch of black, and as the bird swims with all its feathers in place and with the finely grey lined flanks concealing most of the black on the wings, the general effect is of a white bird with fine and regular black lines. The back shows as a black line above the scapulars, another narrow line marks the edge of the wing, and two inward curving lines cross 
the side of the white breast. Pictures drawn from skins suggest irregularity and interruption in these lines, but in the living bird they are wonderfully regular. When, however, the drake raises itself and flaps its wings the black on back and wings shows plainly; the effect is black and white instead of white and black. The female is, at first sight, a little like the Longtailed Duck, but her head and neck are bright chestnut and she has a decided crest. The back is grey, the under parts white, greyer on the upper breast, and, except when hidden by her low pose on the water, there is a noticeable double wing bar. The points which attract the eye are the very white cheeks and chin.

On Cheshire meres I have seen a drake consorting with Goosanders, and brown-headed birds swimming and diving with Goldeneyes. When the former flew with its companions it actually outstripped them, its wings moving with great rapidity. When swimming, if unsuspicious, the Smew is buoyant and carries the neck gracefully arched, but if alarmed, at once straightens the neck and sinks the body; it swims rapidly away or rises, splashing with its feet for a few yards; the flight note and call of alarm have the family grating character. Although the legs are set far back, the bird takes the water feet first like other ducks. I have seen the Smew diving in very shallow water, so superficially indeed that its back was often exposed. Probably it was hunting for small crustaceans or insects, for these as well as fish are eaten.

The bill and feet in both sexes are slate or blue-grey, the irides red in old birds, but browner in the young. The back and wings are more or less mottled in immature birds, and the dark mark round the eye less distinct. Length, 16-17.5 ins. Wing, 7.6 ins. Tarsus, $I \cdot 25$ ins. 


\section{Order PHCENICOPTERIFORMES.}

Family PHOENICOPTERID E. Flamingoes.

Long-legged Stork-like birds with many Duck-like characters. Serrated bill much bent.

\section{Flamingo. Phenicopterus antiquorum Temm.}

The claim of the Flamingo, an African, Asiatic, and south European species, to rank as British is founded upon a few records of apparently wild birds killed or seen in England. The Flamingo is often kept in captivity, and numbers are known to have escaped or have been given freedom; it is practically impossible to say which of the records should be trusted. There is no reason to doubt the occasional wandering of a bird that nests in Spain and southern France, especially as it has many times been met with in western Europe, but to trace the history of any particular bird is most difficult.

The Flamingo is a tall pinkish-white bird with black flight feathers and scarlet coverts; its neck is long and its heavy pink and black bill, lamellated like that of a duck, is curiously bent downwards. Its very long legs are pink and its feet are webbed; the eyes and the surrounding skin are yellow. Young birds are barred on the wings, show much less pink, and have leaden bills and legs. The size is variable. Length, about 55 ins. Wing, 16 ins. Tarsus, 13 ins.

\section{Order ARDEIFORMES.}

Family ARDEIDÆ. Herons.

Wading birds with long legs and strong, straight bills; toes on same level; claw of middle toe with a comb. 


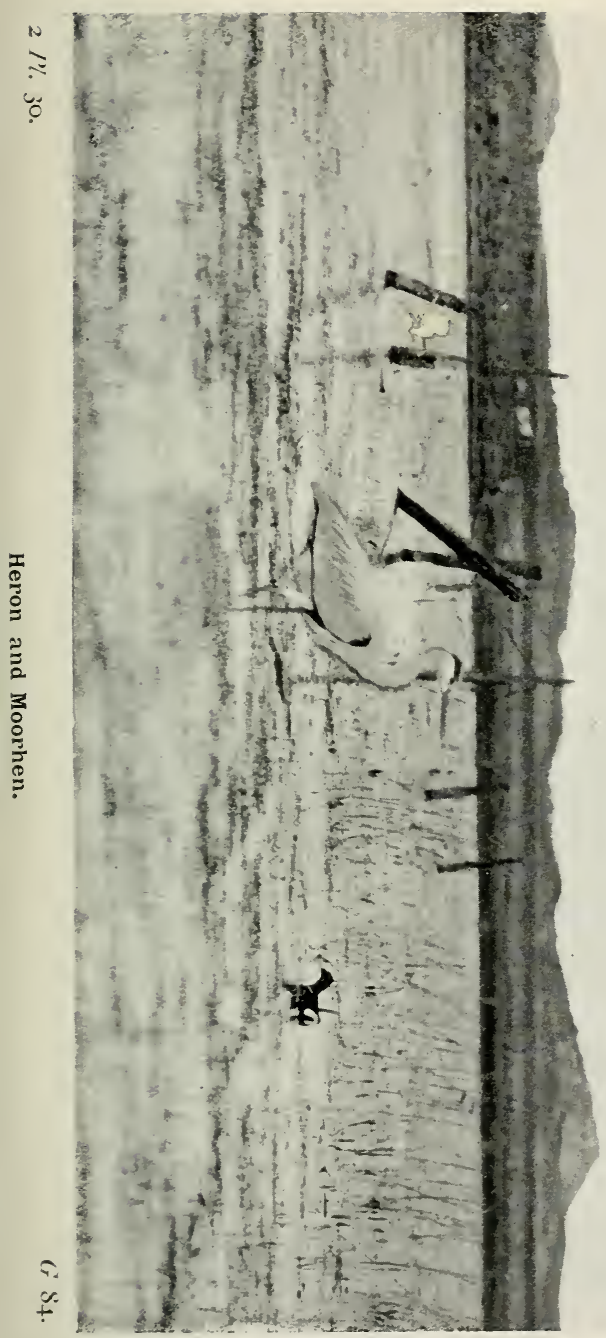




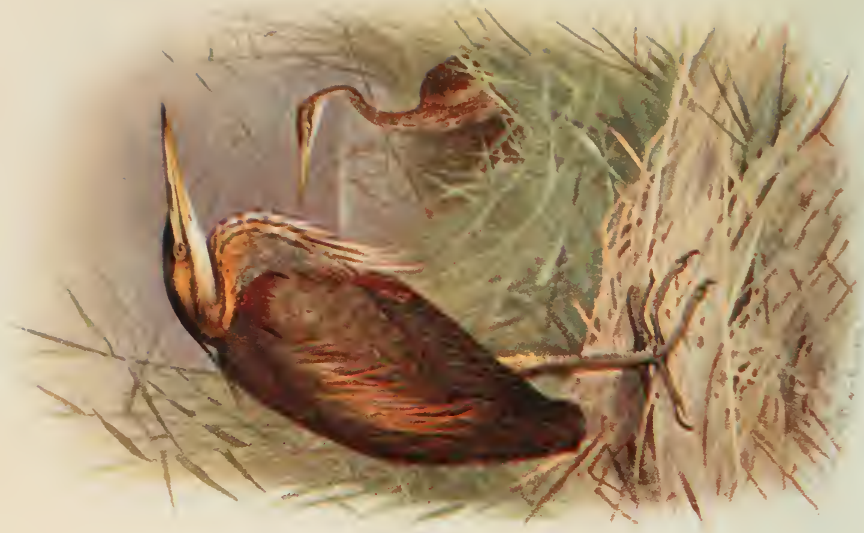

2
0
0
0
$\frac{1}{2}$
$\frac{1}{2}$
3
0

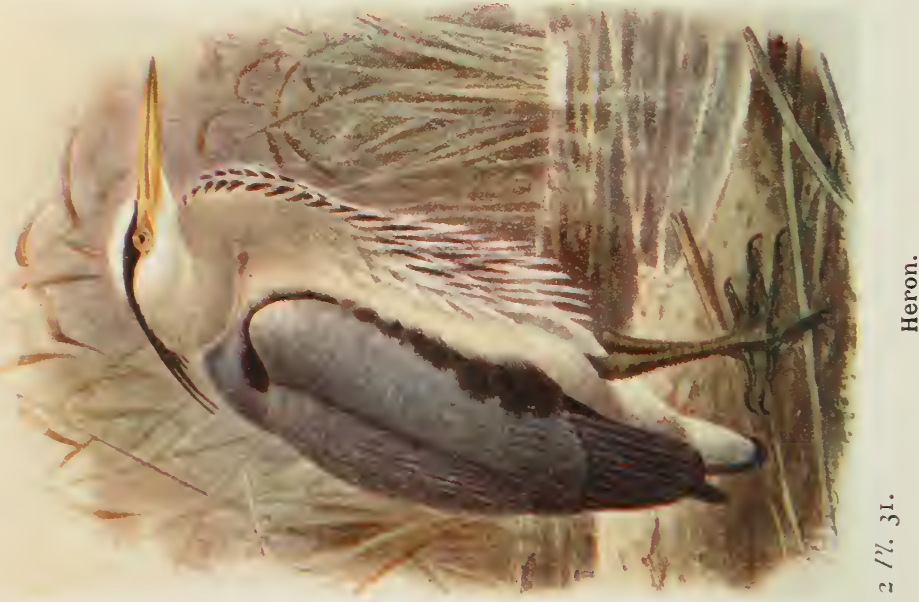




\section{Heron. Ardea cinerea Linn.}

The Common Heron (Plate 31) has a wide Old World range and is migratory in the northern portion. In our islands it is a resident, though numbers of immigrants reach us in autumn.

The specific name of the Heron is descriptive; when it stands patiently in the shallows it looks a grey bird, and greyer still when it perches, as it often does, on the dark branch of some fir. Its French-grey mantle, dark slate, almost black flight feathers, white forehead, head and neck with black markings and trailing black crest, its filamental bushy breastplate, and stout yellow bill, are unlike those of any o:her British bird. In many parts it is called the "Crane." The Heron is a water bird, but whether fresh or salt, clear or muddy, does not matter so long as it will yield something worth waiting for. It does not, however, alivays wait for its quarry, but stalks through the water with long, deliberate strides (Plate 30), ready to dash its pick-axe bill upon any unsuspecting fish, frog, beetle, or other animal. Young wildfowl are killed, and indeed in hard weather full-grown birds; a Water-Rail has been found whole in its stomach. Mice and rats are eaten, and, judging by the fur in cast-up pellets, large numbers of water-voles. In its nesting habits the Heron is gregarious, and though a solitary Heron is a common sight, it is often sociable ; three or four will feed close together or stand in a group on the bank as they preen their feathers.

In its characteristic resting position the bird stands very upright, often on a mooring post, stump, or dead branch, with its neck drawn in and its head sunk between its hunched-up shoulders; when feeding the carriage is less upright, the head and neck and even the body tilted forward. If prey is sighted the dart downward, swinging as if hinged on the legs, is very rapid. The bird stabs its prey, sometimes several times, to "knock it out," and large fish are carried to the bank and the 
flesh picked from the bones. The Heron will wade until the body is afloat and even swim for a short distance; I have several times seen a bird alight on the water and swim, once to rob a Grebe of its meal. The head and neck of the bird shoots up at once on the least suspicion of alarm, and the great wings are unfolded, but the actual launch is slow; the flight is deliberate, but the strokes are so powerful that the speed attained is considerable ; in a few seconds, croaking in alarm, the bird is far away. Almost immediately the head is drawn back and the long legs trailed, the normal position in flight. The call, a resounding frank, differs only slightly from the cry of alarm; it is frequently uttered on the wing.

The nuptial dances of cranes are well known, and possibly the Heron may join with others in display at times. I have, at the end of January, seen a bird perform a pas seul before five companions. It skipped lightly along the bank, beating the air with its wings, first in one direction and then back, but the performance created no visible enthusiasm. At the heronry, where the birds gather in January, groups stand together on the grass, attending to their toilet. On the sides of the breast and in other places the Heron has patches of what are called "powder down," the use of which has caused discussion; they are powdery brittle feathers of a waxy nature. Mr. J. M. Dewar, who has watched the birds carefully, believes that the powder is transferred on the bill to the plumage, used as a cosmetic, and probably acts as "proofing" against wet.

The nests are usually in a colony, huge platforms with shallow cups, in the branches of tall trees; occasionally they are built on the ground, on rocky cliffs, or in marshes. Large sticks are used, with smaller but seldom soft material for lining; Prof. Newstead found dead stems of purple loosestrife, and I have seen large twigs and bracken. By the middle of February or early in March the four to five pale greenish blue eggs (Plate 44) 

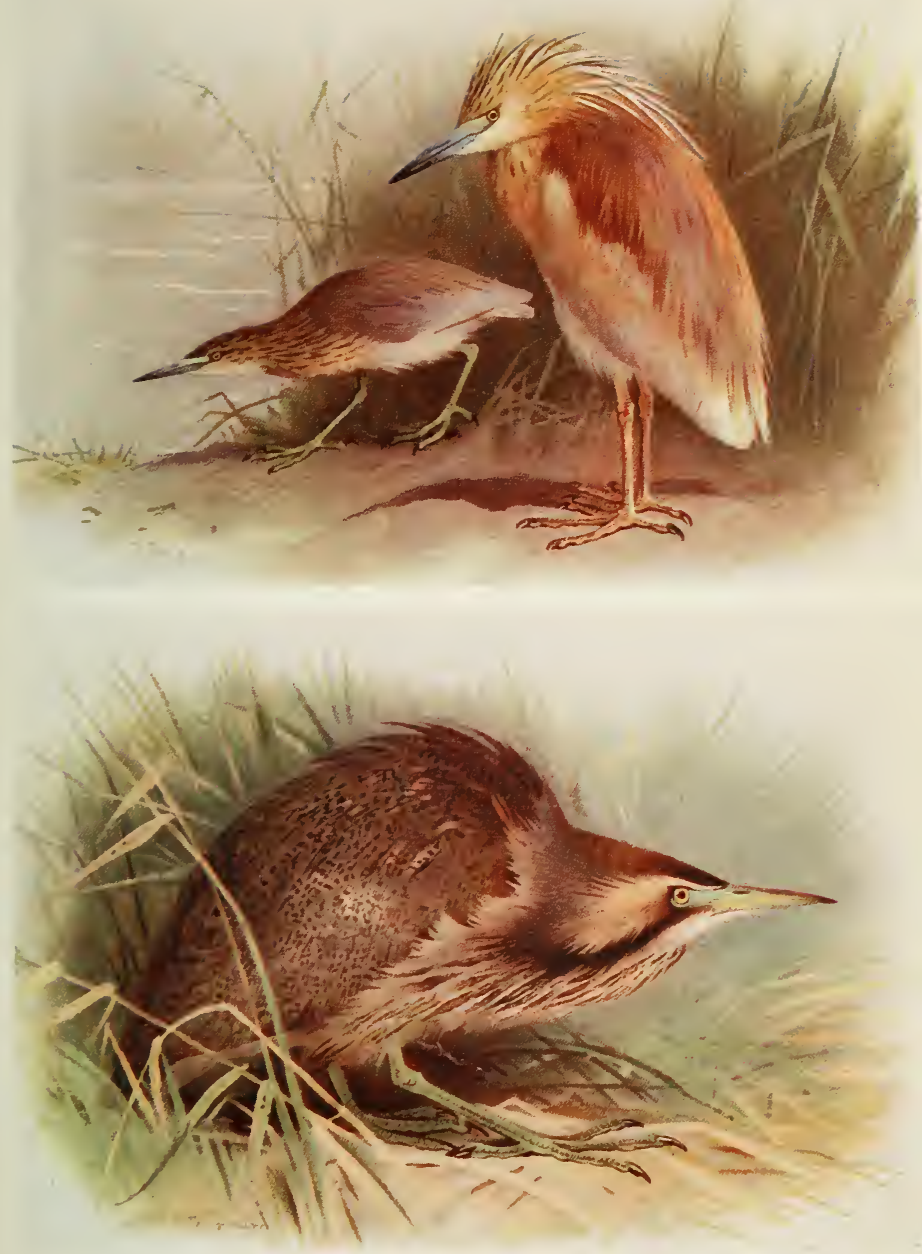

2 I\% 32.

Squacco Heron.

G 86 

are laid, and a few weeks later the heronry is lively. So large are the nests that the old birds look small when they alight upon them, uttering a deep growling gwrronk, answered by a feeble pipe from newly hatched young. The hunger call of older nestlings is an incessant chittering tac, tac, tac, very like the roosting note of the Blackbird. The nestlings are quaint, half-naked little objects, with short, thick, blunt bills, showing a trace of yellow, and stout lead-coloured legs. Prof. Newstead found them "handy" with their bills when climbing amongst the branches, hooking them over twigs when foothold was insufficient.

The bill of the adult bird and the irides are yellow, the legs greenish brown. Length, 37 ins. Wing, $17^{\cdot 25}$ ins. Tarsus, 6.75 ins.

\section{Purple Heron. Ardea purpurea Linn.}

The Purple Heron (Plate $3 \mathrm{I}$ ) nests in many parts of Europe, even so near England as Holland and France, in western Asia, and Africa, but in our islands is only known as an uncommon visitor on migration.

In general build it resembles our Heron, but is smaller and more richly coloured. Its crown and crest are purplish black, whereas in our bird the forehead is white; its back and wings are dark slate-grey, but the elongated plumes on the back are chestnut, and those overhanging the purplered breast are black, white, grey, and chestnut. The bill and irides are yellow, the legs greenish yellow. Our Heron is shy, but the Purple Heron is skulking ; indeed, in its love of dense cover it resembles the Bittern more than the Heron. It has a very long, thin neck, lined with black, and as it stands amongst, reeds is difficult to detect ; its feet are large in proportion, well fitted for marsh walking. Its position in flight, its note and food, are similar to those of our bird; it feeds after dark when its prey is most active. One bird, killed in Cheshire in April, 
had in its stomach a number of small fish, half a dozen mice and shrews, and a quantity of frog-spawn. The nest (Plate 33), often in a dense reed-bed, is a large platform raised well above the water; the nestlings have yellowish-green bare skin and white down. Most of the birds seen in England are in immature dress, when the long plumes are absent, and the general colour is more rusty above and a whiter brown beneath. Length, 33 ins. Wing, 14 ins. Tarsus, $5^{\circ} 2$ ins.

\section{Great White Heron. Egretta alba (Linn.).}

The Great White Heron, which has on a few occasions wandered to Britain, breeds in south-eastern Europe and Asia, and migrates to Africa. Closely allied forms and species occur in Asia, Africa, and America, and all are in danger of extermination, for these birds and the egrets provide, at the expense of their lives, the "osprey" plumes and "aigrettes" of commerce. Many large colonies have been destroyed by the rapacity of dealers, who are no more to blame than the women who, thoughtlessly no doubt, persist in wearing these decorations.

Mr. J. H. Gurney, by careful investigation, proved that this bird is much rarcr as a visitor than reports suggested; he disposed of a large number of erroneous records, retaining only five as reliable, though one or two others have been added since. Inexperienced people, seeing our grey Heron against a dark background, often describe it as white. This bird, about the size of our Hcron, is snowy white; long, graceful plumes hang over the back in the breeding season, and there is a smaller tuft at the base of the neck. The bill is black in summer, yellow at other times; the legs are reddish black, the irides yellow. The young bird has no plumes, and those of the female are shorter. Length, 35 ins. Wing, 17 ins. Tarsus, $7 \cdot 75$ ins. 


\section{Little Egret. Egretta garzetta (Linn.).}

This small white heron breeds in southern Europe, Asia, and Africa, and a few stragglers have apparently lost their way and wandered to England; only two or three of the records are reliable.

Two slender plumes project beyond the nape of the Little Egret, and on its back and breast are soft filiform plumes, which are even more sought for than those of the larger white herons. These are the commercial "ospreys," worn by the unfortunate bird during its courtship, and, after its untimely death, by a less rightful owner. The young bird is greyer and sports no plumes. The beak is black, the legs black, and the toes marked with yellow, which is also the colour of the irides. Length, $2 \mathrm{I}$ ins. IVing, $I^{\circ} \cdot 25$ ins. Tarsus, $4 \% 5$ ins.

\section{Buff-backed Heron. Ardeola ibis (Linn.).}

From 1805 , when a young female Buff-backed Heron was shot in Devon, as recorded by Montagu, there was no satisfactory record of the species as a British visitor until October, 1917, when Mr. F. W. Smalley saw a male that had just been killed on Breydon Marshes, Yarmouth. It was shot when feeding amongst cattle, a common habit of the bird in the Spanish marshes, its only breeding-place in Europe; like the Starling, it settles on the backs of the cattle to obtain ticks and other parasites. In summer the plumage is white, but the crown, crest, and elongated plumes on back and neck are buff. In winter, when the plumes are absent, it is almost white; the Norfolk bird had only a tinge of buff on the crown. Its bill was chrome yellow, its irides golden yellow, and its legs "brownblack." Saunders says that the legs of young birds are olive, and Mr. Smalley believes this bird to be mature. The measurements as taken by Mr. Smalley were-length, $20^{\circ} 5$ ins.; wing, 10.25 ins.; and tarsus, 3.25 ins. 


\section{Squacco Heron. Ardeola ralloides (Scop.).}

The Squacco Heron (Plate 32) is a summer visitor to southern Europe, and it breeds as well as winters in Africa. It is a frequent visitor to central Europe, and over sixty, mostly immature, are known to have occurred in different parts of our islands, the majority, naturally, in the south.

The Squacco is a small skulking heron, hiding in thick aquatic herbage during the day and feeding at night; it is a silent bird when away from its breeding haunts. It has the usual varied diet, but takes more insects and crustaceans than the larger herons. The general plumage in summer is buff and white; on the head and hind neck are dark streaks, and it has a drooping crest of long, black-edged, white feathers. The buff is richest on the neck and elongated breast feathers, browner on the back and long, narrow plumes, and very pale on the coverts. The bill is cobalt-blue with a black tip, the legs are yellowish pink, the skin surrounding the eyes green, and the irides yellow. In winter the plumes are lost and the back is browner, and it is still darker brown in young birds, whose neck streaks are more pronounced. Length, 20 ins. Wing, 9 ins. Tarsus, 2.6 ins.

\section{Little Bittern. Ixobrychus minutus (Linn.).}

The Little Bittern (Plate 35) brecds in central and southern Europe and Asia and winters in Africa. To the British Isles, where it has occurred in all parts, even in the Shetlands, it is an irregular visitor on migration, and, though actual proof is lacking, probably nested within recent years in Norfolk and perhaps elsewhere. As birds have been killed, regardless of the close season, in spring and summer, there can be little doubt that if unmolested the bird would nest.

The small size-a heron about as big as a Lapiving-should 


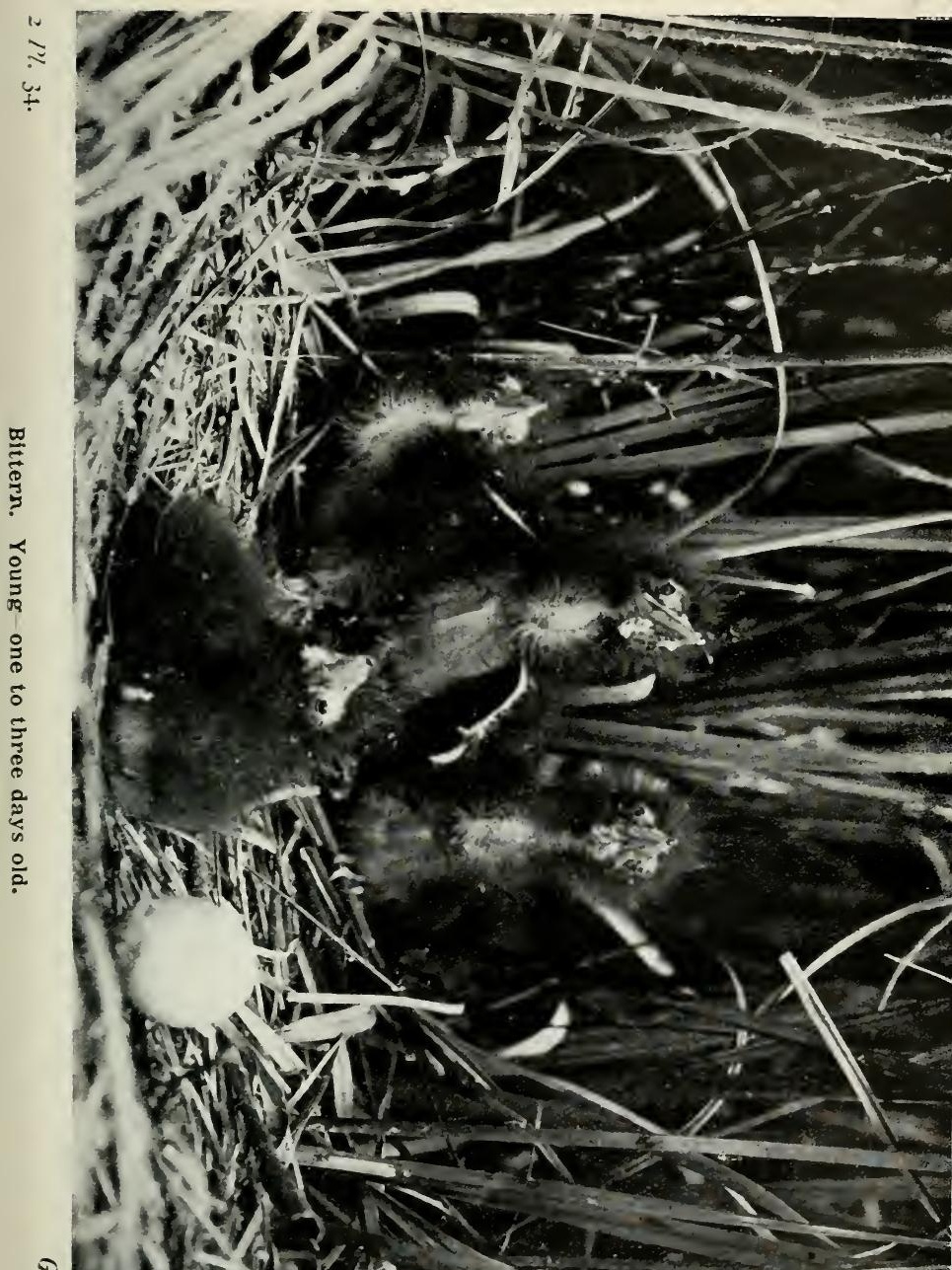

$: 1205$ 


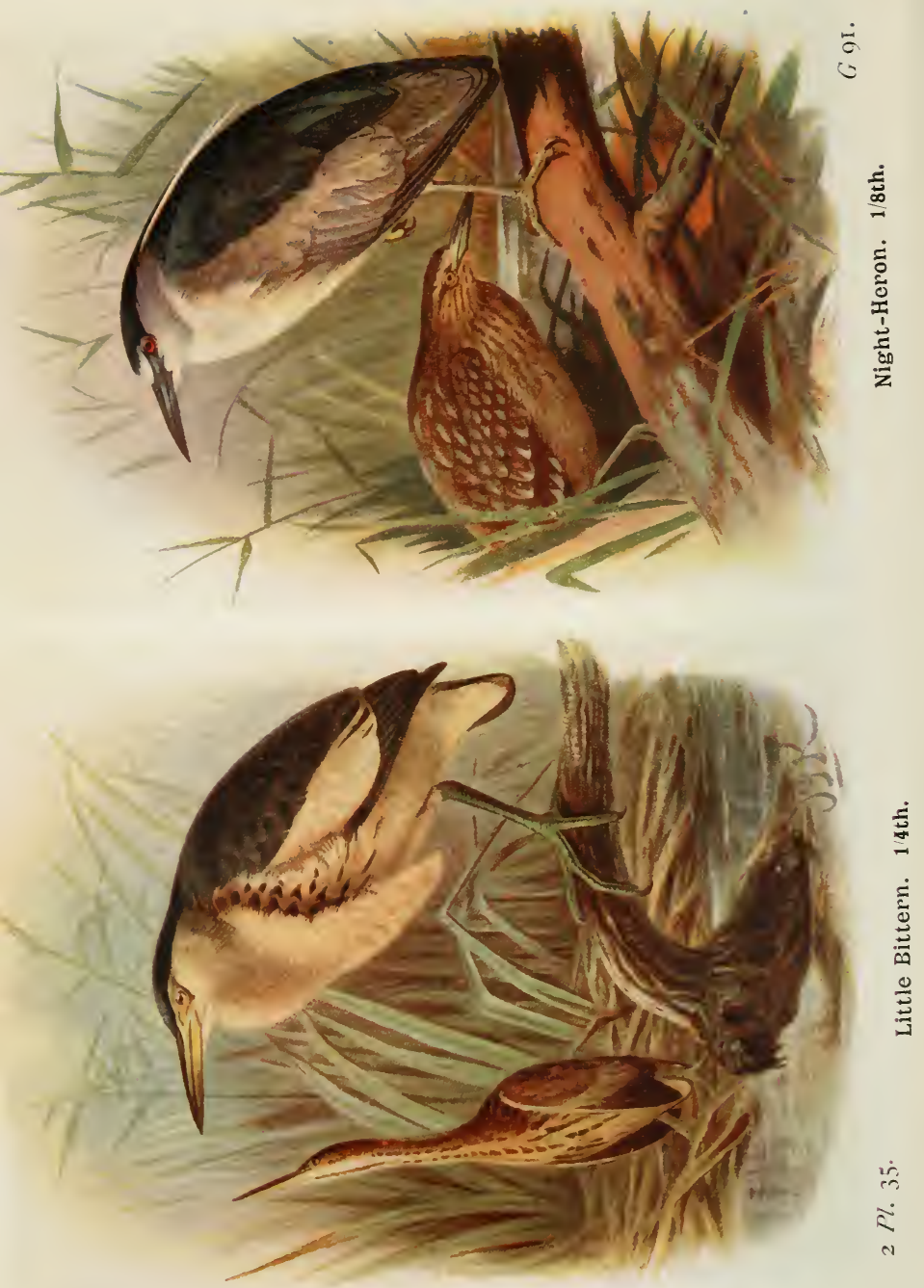


prevent confusion with any other bird, but it is not an easy bird to see, for it skulks all day in the herbage and feeds at night. Apart from nocturnal habits, it is an expert at camouflage, clever enough to deceive the expert bird watcher. Heron-like, it stands motionless with its head sunk in its shoulders, but if approached turns its buff breast towards the intruder, and pointing its bill skywards, slowly stiffens itself upward. As it stretches it becomes attenuated, gaining several inches in height, until it is hardly distinguishable from a dead reed blade. When feeding or protecting itself it can dart its head and bill forward with dangerous speed, but this lengthening trick is slow, so also is the rotation of its body as it keeps its breast towards and its eyes upon the moving observer. Mr. R. B. Lodge found a bird lying stretched out upon the water as if dead, but when he picked it up it was uninjured; indeed, the bird will allow itself to be caught by man or dog, trusting to being missed so long as it remains still. It can, however, run swiftly through dense herbage. In flight its wing-beats are more rapid than in the larger herons.

The nest, which may yet be discovered in England, is not unlike that of the Moorhen, and, though occasionally in a low bush, is usually in a reed-bed. The eggs are muddy white. The male has a call which corresponds to the boom of the Bittern; it has been heard in England. It is sometimes described as a grunting croak, but Lilford calls it "a sort of deep guttural cough." Mr. J. H. Gurney was reminded of "a paviour ramming stones," and Mr. Jourdain of "the impact of a heavy mallet on a pile," repeated three times in succession and then a short pause.

The crown, hind neck, and back of the male are greenish black, the primaries and tail browner, the wing-coverts pale buff, and the face and under parts rich buff; on the breast and flanks are dark streaks, which aid in concealment. The bill and legs are greenish yellow, the irides and bare skin round 
the eyes yellow. The female and young bird are brownish black on the crown, brown on the back, and have the hind neck rufous and the under parts buff streaked with dark brown. Length, 13 ins. WVing, 6 ins. Tarsus, 175 ins.

\section{Night-Heron. Nycticorax nycticorax (Linn.).}

The Night-Heron (Plate 35 ) is a summer visitor to central and southern Europe, and at one time nested in colonies in Germany and Holland, where, however, most of its former breeding haunts have been destroyed. It ranges through southern Asia and Africa. Its visits on migration to the east and south coasts are almost regular, and it has occurred in all four kingdoms as frequently in spring and summer as in autumn. Whether it has ever nested in England or would do so if permitted is uncertain, though there is evidence that it has made the attempt, and the least we can do is to give it a chance. It is hardly to the credit of "the cloth" that a clergyman's name should be handed down to posterity as being responsible, on his own showing, for the slaughter of six out of eight birds-tour pairs-obtained in Devon in a single May and June.

The build of the Night-Heron is short and dumpy ; it looks about a third shorter than the Common Heron as it stands with its head deep in its shoulders. The long, white, narrow nuchal plumes are perhaps its most noteworthy character; these vary in number from two to five, and even ten is recorded. Mr. J. Moore, who watched a bird in Cheshire, tells me that the contrast of black on head and back with grey on the neck, wings, and tail, struck him when the bird flew. Its very broad wings flap deliberately, but it is buoyant in flight, and carries its head drawn back and its legs trailed. A swamp bird in habits, it feeds at night, spending the clay in silence in some secluded spot, but often standing on a branch, partly screened 


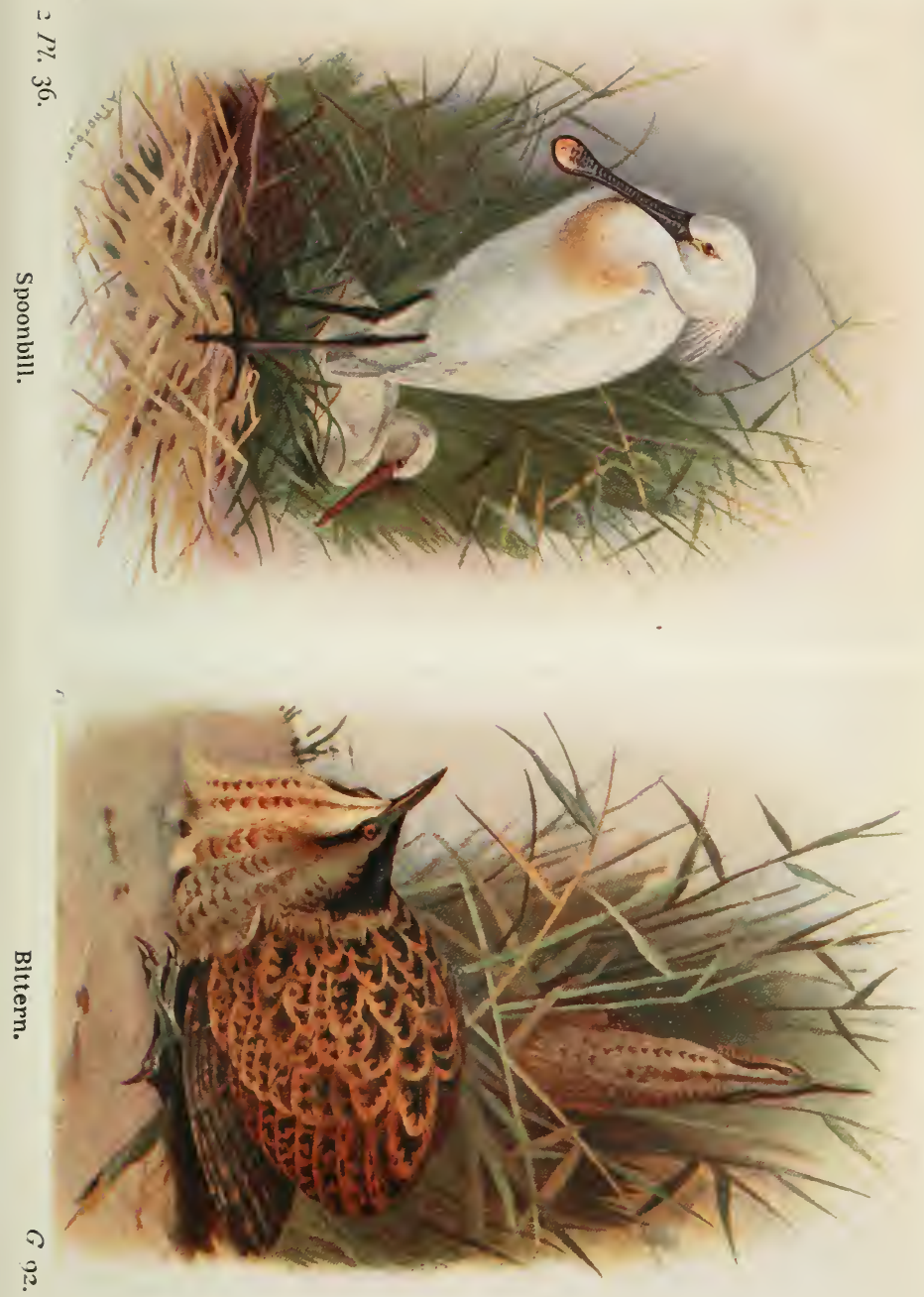




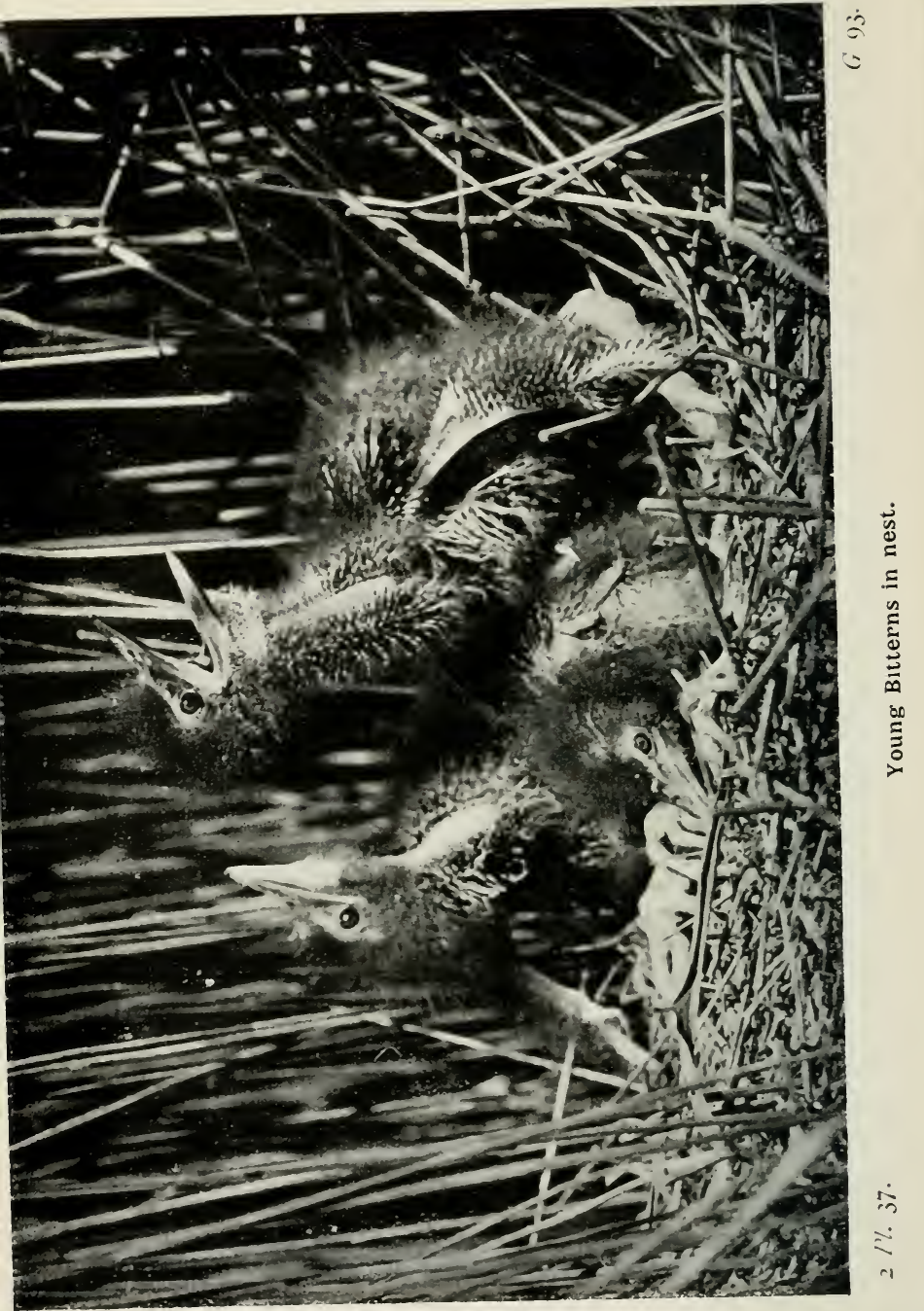


by the foliage. At dusk it becomes more lively, and the male, at any rate, is a noisy bird, constantly uttering a harsh croak, monotonous, and, to some ears, plaintive. A Cheshire man, whose father shot a Night-Heron, said that he remembered hearing it in the evening "at hay-making time, making a noise like a man vomiting." If disturbed during its diurnal rest it will not alway's take wing, but, raising its crest in anger, strike at an intruder with its bill.

Most descriptions of plumage differ more or less from the notes I made of the only one I have had opportunity of examining in the flesh-a mature bird killed in Anglesey at the end of May. The head, bxck of neck, and back were plumbeous to slate, with a distinct indigo, not green sheen, though many skins I have examined show green. The neck and breast were drab. grey, the wings and tail cinereous, the forehead, a marked superciliary stripe, and the under parts below the breast white, but the last distinctly washed with yellow. There were only two white plumes, one longer than the other. Along the ridge of the upper mandible and at the tip of the lower the bill was black, but the rest was reddish flesh, and the bare skin on the lores and round the eyes was dark green, not blue. Gould figures it blue, but in nestlings it is described as sea-green. The legs were ochre-yellow. The female is duller and her plumes are shorter than in the male, and the young bird has no plumes and is brown, streaked with buff and spotted with white on the upper parts, and with the white under parts broadly streaked with buff and brown. In the old bird the irides are ruby red, in the young brown. Length (of bird described above), 22 ins. Wing, $11 \cdot 25$ ins. Tarsus, 315 ins.

\section{Bittern. Botaurus stellaris (Linn.).}

The Bittern (Plate 36 ) is found throughout Europe and most of Asia, and is a partial migrant. In the first half of the last 
century it nested in many parts of the British Isles, and, in spite of persecution, survived in Norfolk until the end of the sixties. After $\mathbf{I} 868$, except for one young bird which had evidently been hatched in the neighbourhood, reported in I 886 , it was extinct as a breeding species until I9I I, when Miss E. L. Turner and James Vincent located a nest. How many pairs managed to rear young in the next few years is uncertain, but in I9I 8 and 1919 a number of broods were safely reared. Collectors and not drainage were responsible for the loss of the Bittern; when under protection it found a safe area it quickly increased. To Britain the bird is a spring and autumn migrant and a winter visitor, and undoubtedly the present breeding stock had origin in oversea immigration; yet, outside strictly preserved districts, ruthless shooting of Bitterns continues.

The only bird with which the mottled and barred Bittern can be confused is its American representative, described later. It is a large heron, rich buff, barred, mottled, and vermiculated with black and brown. Most local faunas contain mere obituaries, the shooter having no time to study habits. In the more recent journals we get some insight into the home life of a shy and elusive bird; to Miss Turner's vivid pen we owe most, and in my more recent experiences of the Bittern I have had the benefit of her guidance. In Cheshire, where it might recolonise if left alone, the birds appear, often in pairs, in December and January; once, in spring, I heard a bird booming at night. In Norfolk the birds begin to boom in January and continue until the young are hatched in June. During the day the Bittern hides in reeds or other vegetation, and unless disturbed is not seen on the wing until the young require attention. When approached it assumes protective attitudes, pointing the bill upward so as to expose to view the thin buff neck with its irregular brown streaks, which, in reeds, confuse the eye. The first young bird Miss Turner found assumed this 
pose and "was transformed into the semblance of a bunch of reeds." It will crouch amongst the dead and broken litter in winter, with its long neck outstretched, or flatten itself out with the head resting on the shoulders and the bill alone pointing ùp. In this position, with crest erect and breast frill spread, it is prepared to defend itself; it is unwise to handle it without caution, for a Bittern can shoot up to full height with great suddenness, and aims for the eyes. When I have walked the bird up in the reed-bed it has risen a yard or two beyond me in a heavy disjointed manner, its long grass-green legs dangling awkwardly, but soon drew back its neck and trailed its legs in orthodox heron flight. When feeding young the female is less cautious, flying to and fro all day between the nest and the feeding ground. On the wing the bird looks light brown, cinnamon in sunlight, compact, and short necked. The flight is slow and owl-like, though direct; the wings move faster than the measured beats of the Heron. Some individuals fly fairly high, calling a deep $a g h$, agh, but others hardly clear the reed tops and are difficult to see. One bird I put up rose with a short sharp cry of alarm, but another, suddenly sighting me amongst the reeds as it passed to the feeding ground, gave a disyllabic uawark, uawark, as it swerved, then, rising, wheeled high overhead. In the vegetation the Bittern walks or runs, if disturbed, with the shoulders high and the head lowered; it slips with ease out of sight. On alighting it will stand for a few moments, bill up and neck stretched, as it turns its head in all directions, before sinking out of sight.

The boom of the Bittern, familiar in literature and fable, is the call of the male-a deep, bovine, resonant note, certainly audible for over a mile. I have heard it all day and all night in May, and listened to three or more birds answering one another. The boom is repeated three or four times in succession, with a one or two second interval between each note, then a pause of variable duration. One bird boomed six or seven 
times before the pause, another eight or nine, and once I heard twelve booms in quick succession, but suspect that an answering male had taken up the challenge before the other had finished. At close quarters, two or three preliminary grunts or coughs are andible, followed by a sound like an inspiration; the boom bellowed only a few feet away, was not very loud; it is its carrying power that is so remarkable. When booming, the bird points the bill upward. The male booms in the vicinity of but not very near the nest, but whether his notes are intended for the edification of the female, are a challenge, or merely a social signal, is hard to determine. That male answers male is certain, and Miss Turner witnessed one high aerial skirmish between two birds, but could not tell the sex of the rivals. The Bittern feeds on the smaller animals of the marsh, and is a great eel-catcher. When the young are hatcked the female makes frequent journeys to some dyke, deep bog, or other selected feeding ground, perhaps a mile from the nest, where for half an hour or more she collects food, returning with her gullet visibly distended. Miss Turner saw one nestling disgorge an entire eel nine inches long, and seven inches of another.

Most of the nests are in reeds and built of reeds, but one I saw was in sedge of no great height. It was a very large platform, about thirty inches across, trodden down by the birds, supported in its wet bed by the bent outward stems; Miss Turner has seen nests wide at water-level, but only fourteen inches across at the top. The eggs (Plate 44), usually five in number, are olive-brown and match the dead reeds or sedge. In the nest I saw were five young and an addled egg. Eggs are laid from the end of March until June. The young when first hatched are quaint little "animated golliwogs"; those in the nest shown on Plate $3 t$ had been hatched from two to three days, but the smallest and weakest less than twenty-four hours. The three oldest sat well up, with their thick, ungainly slate-blue 
feet sprawling, often holding themselves in position by using their naked wings as hands, the "thumb "very noticeable as they pushed against the sedges. They rested on the whole leg, not merely on the tarsus. The long soft down, Mars brown to fawn, rose like a golden halo, filmy when stirred by the wind, above their diabolical bare faces. On back and shoulders it was thicker and warmer in tint, but through it the skin looked greenish. Their bills were livid blue-green, and from the chin, down the scraggy neck to the breast and belly was a naked tract, livid blue. The browns, blues, and greens were wonderfully in harmony with the surroundings. The irides were very pale brown, but they appear to vary, changing to greenish blue, and later to the yellow of maturity. The birds did not appear to be frightened ; indeed, they looked as if they wished to frighten, and they kept up an incessant quaint cackling, impossible to describe. Older birds (Plate 37 ) have a bubbling cry. The youngest bird had the bill rose-pink, and in adult birds it is greenish yellow. Two days later these young birds were more active, the bigger ones constantly leaving the nest to hide, and when they are some days old they wander and are difficult to find, though keeping near the nest so long as they need the help of the parent.

The sexes are alike in plumage. The head is blackest, the back streaked and barred with black, the lighter under parts boldly streaked with brown. Length, 28 ins. Wing, 13 ins. Tarsus, $3 \cdot 8$ ins.

\section{American Bittern. Botaurus lentiginosus (Mont.).}

About forty examples of the American Bittern (Plate 32) have wandered to Britain; at least fifteen of these are recorded for Ireland. The bird is found throughout North America, and in winter in the West Indies. Where the date of occurrence is known it has been, with very few exceptions, during the normal time of migration, between October and February. 
The American Bittern is a smaller bird than ours, and the main distinction is in the primaries, which are uniform greyish brown and not barred as in the Common Bittern. There is, ton, less black on the head and back, the markings, though profuse, being finer. The food, voice, and general habits are, in the main, similar to those of our bird. The colours of the soft parts differ little from those of the Common Bittern. Length, 24 ins. Wing, 12 ins. Tarsus, 3.5 ins.

\section{Family CICONIIDÆ. Storks.}

Long-legged, strong billed-birds ; slight membrane at base of front toes; no pectination on middle claw.

\section{White Stork. Ciconia ciconia (Linn.).}

The White Stork (Plate 38 ) is a well-known inhabitant of Holland, Germany, and southern Scandinavia, where it is protected and encouraged to nest on and amongst the houses, being a useful scavenger; meat, alive or dead, pleases the Stork. It occurs throughout most of Europe and western Asia, as well as north Africa, and in winter reaches South Africa. In spite of the fact that it nests freely in Holland, it is only known in England as an irregular visitor on passage migration; it has most frequently appeared in East Anglia, but has been noted in Scotland and Ireland, usually on spring passage.

Familiarity with pictures may cause error; Herons are often called Storks. The White Stork is a tall, stately bird, dignified in movements, white with black flight feathers, scapulars, and greater coverts, and with very red bill and legs. In western Europe the arrival in spring and departure at the end of August of the migratory Stork create as much interest as the movements of the Swallow and Cuckoo here. The bird moves by day, usually at a great height, flying 

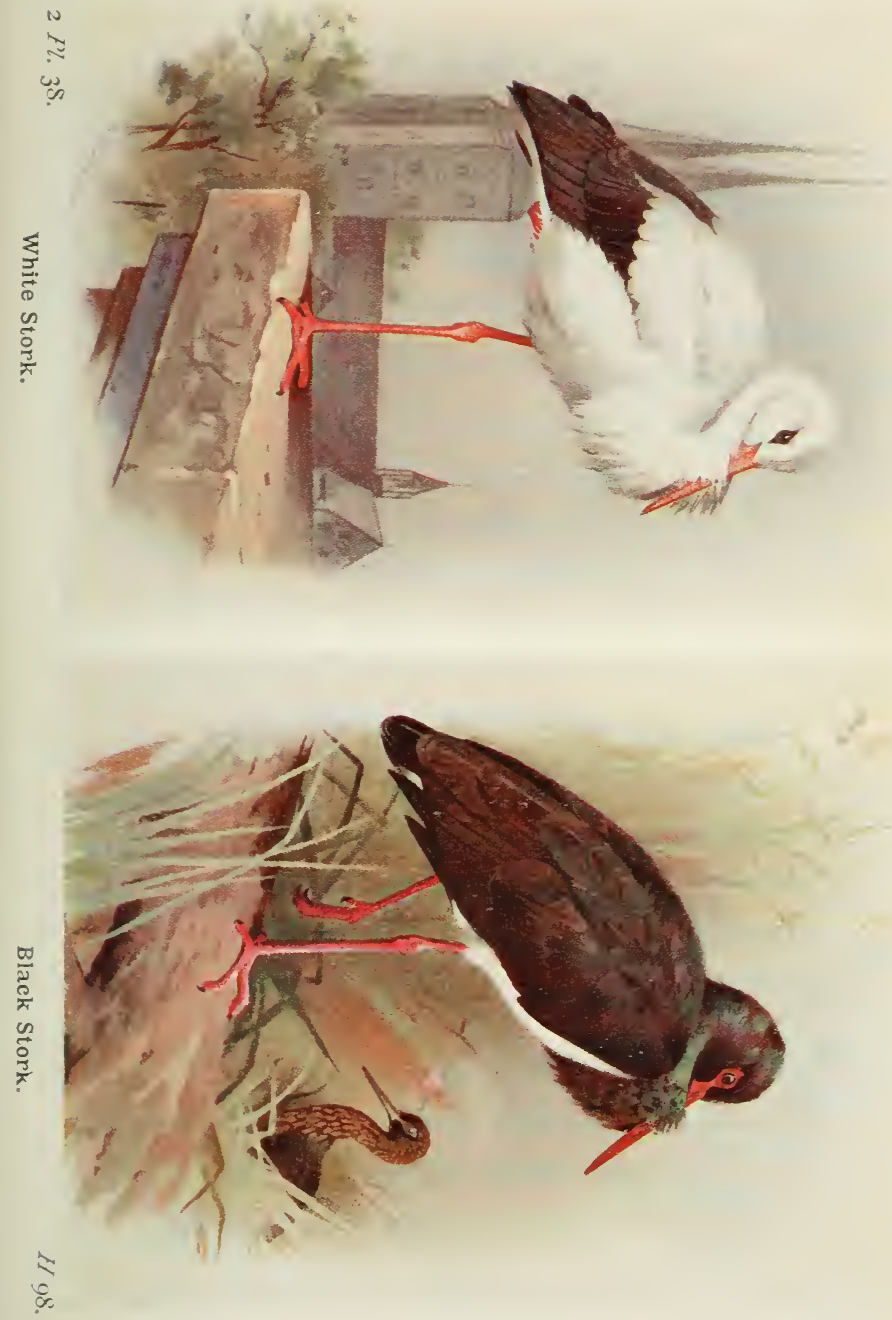


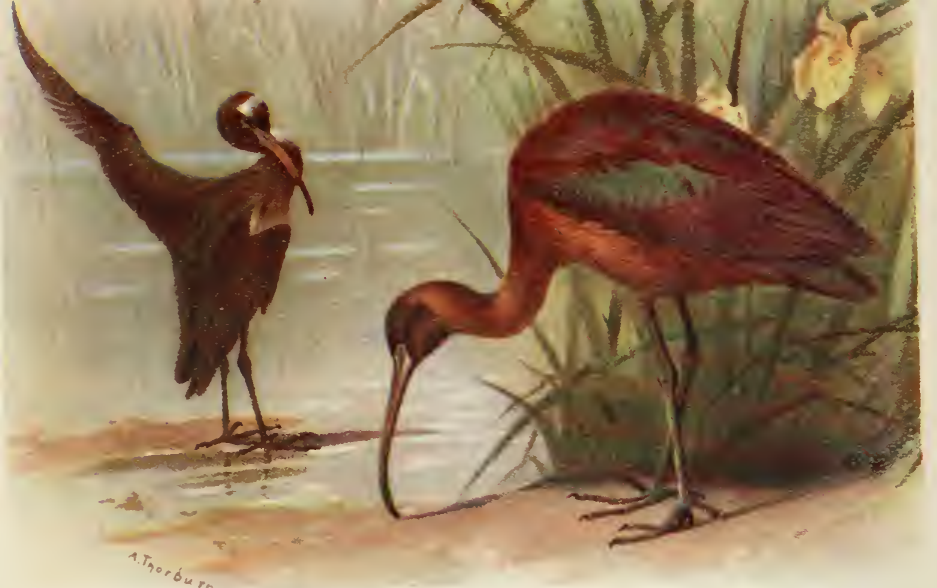


with slow and measured wing-beats, but on the wing can immediately be distinguished from the Heron, for it carries its neck outstretched, and though the red legs trail behind they sagr a little and are not in a straight line with the long axis of the body. The Stork is a silent bird; it has no flight call; but in the breeding season and under excitement it claps or clatters its bill, at times so rapidly as to produce a trill.

The sexes are alike and the young bird is browner on the wings, and its bill and legs are duller. The irides are brown. Length, 40 ins. Wing, 23 ins. Tarsus, 8.8 ins.

\section{Black Stork. Ciconia nigra (Linn.).}

Less frequent in its visits than the last species, the Black Stork (Plate 38 ), which has a wider but roughly similar range, has occurred, chiefly in southern counties, in England, but not in Scotland or Ireland. Its whole plumage, except for a white lower breast and abdomen, is black, with variable metallic sheen-purple, green, or coppery. Its bill and orbits, bare skin on the pouch, and legs, are bright red; its irides are brown. In general carriage, flight, and food it differs little from the White Stork, but is as shy as the other is trusting; it shuns houses and delights in the wilds. In England it has been met with on both spring and autumn migration. Length, 38 ins. Wing, 22 ins. 'Tarsus, $7 \cdot 5$ ins.

\section{Family PLATALEIDÆ. Spoonbills.}

Bill wide and flat at end; toes partly webbed.

\section{Spoonbill. Platalea lencorodia Linn.}

The summer range of the Spoonbill (Plate 36 ) extends over central and southern Europe, Asia, and northern Afica. It breeds in Spain and Holland, but many of its former haunts 
are deserted, amongst these Britain, where until the seventeenth century it nested in East Anglia, some southern counties, and South Wales. One of the earliest birds to receive legal protection, it was even unlawful to take its eggs, but these efforts failed to save it. To-day it is a more or less regular visitor to Norfolk and Suffolk, on spring and autumn migration, sometimes appearing in small flocks. To other parts of our islands it is a casual visitor.

Tall, white, crested, and with a long bill broadly spatulate at the tip, the Spoonbill is unlike any other bird, yet confusion has arisen through duplication of names. Its old name was "Shovelard" or "Shoveler," and the Shoveler Duck is still called the "Spoonbill" ; indeed, one old wildfowler distinguished it as the "White Spoonbill." Now that the Breydon tidal mud is under the eye of a watcher, passing Spoonbills wisely balt on this safe water when their migration route carries them over East Anglia ; if they wander further afield the protection laws seldom save them from the "sportsman." So conspicuous a bird is an casy mark. E. T. Booth rightly states that gulls will mob a Spoonbill, but I have seen a Spoonbill sleeping on a spit of sand surrounded by tired and equally peaceful gulls. Its bill was tucked away in its scapulars, but its long crest showed very distinctly; one tucked-up leg was invisible, the tarsus of the other perpendicular, its body horizontal, though, as a rule, the pose is upright (Plate 40). I was near enough to see a ruddy tinge on its white breast. Then it woke, yawned, and stretched a wing along its raised leg, and lazily flapped across the Broad, alighted in shallow water, and began to feed. Dipping its paddle bill, it scooped for molluscs or crustaccans, moving it round with a circular motion; in deeper water the bill was immersed to the base, but the same circular sweep from side to side was made. Snall fish and frogs, as well as worms and insects, are eaten. I found it again on the sand next morning, and watched it depart, its great 
wings flapping slowly, its neck outstretched, and its long legs trailing in a line with the body. Dr. Patten describes the flight as heavy, and says that the neck is slightly inclined upward. I have twice watched the bird on the wing, and the flight was easy and buoyant; and though the bill was carried straight, pointing in the direction of flight, the neck was slightly curved downwards, as if sagging a little. Both birds soared on motionless, widespread wings, sweeping grace. fully round, and when at a great height, mere specks in the sky, alternately showed as white spots and vanished, the sunlight reflected at certain angles. The Spoonbill is not a secretive bird, hiding in dense vegetation; it feeds in open marshes and shallow lagoons, especially near the sea; Breydon flats and its mud-frequenting crustaceans are just to its taste. Like the Stork, it is a silent bird, though it has been heard to call softly near the nest. Its feet are slightly webbed, and it occasionally swims.

There is a tinge of yellow on the drooping crest and upper breast of its otherwise white plumage. The bill is yellow, spotless on the spoon, but above mottled with irregular bars of black; at the base of the under mandible is a large orange patch. The legs are black, the irides red. The crest of the female is shorter than in the male; in the young bird it is absent, and the primaries are blackish at the tip. Length, 36 ins. Wing 145 ins. Tarsus $5 \%$ ins.

\section{Family IBIDID瓜.}

Bill long and decurved; legs long; toes united at base.

\section{Glossy Ibis. Plegadis falcinellus (Linn.).}

The Glossy Ibis (Plate 39) breeds in south Europe, Asia, Africa, and the United States; in winter it occurs far south in Africa and Asia, and is occasionally met with in Australia. 
With us it is a not uncommon visitor on passage in autumn, but less frequent in spring. The southern and eastern coasts are visited more regularly than other parts, but it has been met with in Scotland and Ireland on many occasions. It is still unexplained why a bird travelling, presumably, from southern Europe to still more southern winter quarters, should in autumn frequently pass through Britain; it has also wandered to Iceland and Scandinavia. Either many Ibises and other birds are unable to orientate, or they are wind-borne far from the route they desire to follow.

There is another possible explanation, suggested to me by the disgustingly long list of birds shot in Britain. In certain years so many were killed that we should call them Ibis years, and often the birds were noted in small flocks. The majority obtained were immature. Thus, when in the autumn of 1907 twenty visited Orkney, all the ten that were shot were young birds. Are not these autumnal wanderings of young birds in the nature of "irruptions," and an effort to extend the range? This seems more reasonable than the theory that they are visiting a long-deserted breeding area. That marshmen and fowlers used to call and still call it the "Black Curlew" need not imply that the Ibis was ever really common; occasional irruptions or invasions would be reason enough for keen fowlers to create a name.

The curved bill and general shape of the Glossy Ibis certainly suggest a dark-coloured Curlew or Whimbrel. The legs are trailed and the neck outstretched; the wings move rapidly, with intervals when it glides; the quick beats cause a whizzing sound. The bird is at all times sociable; flocks move in bunches, lines, and chevrons. On the ground it walks like a Heron, and it frequently perches in trees. Lilford kept a number in captivity; from these Plate 39 was drawn. The birds frequently basked in the sun, elevating one wing. Mr. Thorburn noticed that the long axillaries showed below the 


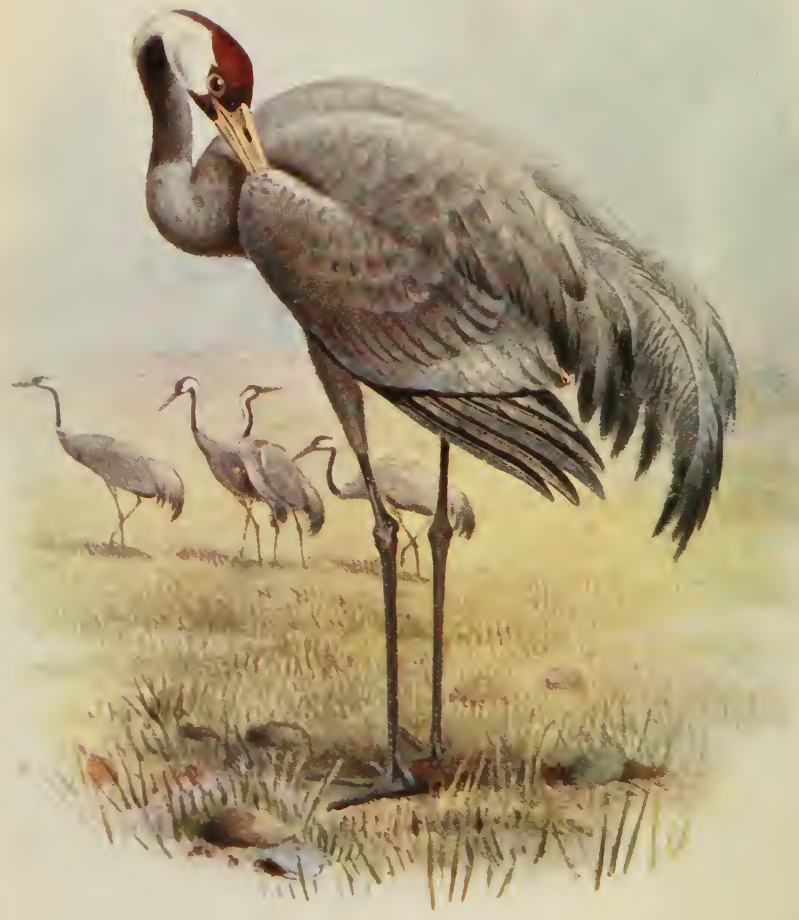

$21 \%$. 1. 
wing of the standing bird. The food consists of worms, crustaceans, and molluscs, picked up in the tip of the bill and swallowed with a single upward jerk, or probed for in the mud. The note, seldom heard, is a guttural croak.

The adult bird in summer is dark maroon on head, neck, back, and under parts; the head is burnished green, and the blackish wings are glossed with green and purple. The bill, five or six inches long, is brown, and on the lores and round the brown eye the skin is green; the legs are greenish grey. The female is smaller than the male, but there is much variation in size in both sexes. The winter dress is duller, and that of the young bird brown and barely glossed, whilst on the head and neck are greyish-white streaks and mottles. Length, 22 ins. Wing, $1 I^{\cdot} 75$ ins. Tarsus, 4 ins.

\section{Order GRUIFORMES. \\ Family GRUID瓜. Cranes.}

Tall birds with long, straight bills; hind toe elevated.

\section{Crane. Megalomis grus (Linn.).}

The tall and graceful Crane (Plate $4 \mathrm{I}$ ) is a lost British bird, but so long lost that we cannot tell why it deserted its ancient home. It nests in Europe and western Asia, and in winter travels as far south as Nyassaland; in Britain, where it bred in the sixteenth century, it is now a rare passage migrant, but so many birds are kept in private parks that all recent occurrences are suspicious. How regularly migrating parties pass we do not know, for the Crane is known to travel at a great height, far above the range of vision. Laws passed in the sixteenth century failed to preserve it, but as its visits appear to be growing less frequent, we may believe that some factor other than persecution is responsible for the decrease. 
The Crane is long-necked and heron-like in build, but has little $\epsilon$ lse in common with the group. Its general colour is slate-grey, relieved by a white streak on the side of the face and neck, but the most striking character is the large bunch of drooping blue-black plumes-the inner secondaries-which gracefully curves over the wings and tail. It walks sedately, as a rule, and flies with neck extended and legs trailing, but below the line of the body. Migrating flocks keep regular order, flying in $\mathrm{V}$ and $\mathrm{W}$ formation, or with a line leading from the apex of the chevron, an inverted Y. The loud trumpet blast of the bird is sounded as it flies, and also when on the ground. I have heard this strong note from captive birds, and watched the quaint dance, for the Crane is not always sedate. It will trip lightly with uplifted and slightly fanned wings, leap into the air, and stop, point the bill skyward, and sound its horn. Whether this is purely nuptial display or a normal pastime I cannot say, but Wolley saw a pair dance after the eggs were laid; I have heard visitors at Regent's Park pity the "poor birds" that were trying to fly. In this dancing habit, as well as in other ways, the Crane shows similarity if not relationship to the rails. The Crane eats anything from grass and grain to insects, small birds, and mammals.

On the crown of the adult bird is a warty red patch devoid of feathers; the bill is greenish, the legs dark green, the irides red. Immature birds at first have no red patch, but their heads are rusty, and the slate is mixed with brown. One of the more recent examples-a young female killed in Anglesey in May r 908 - had the red on the head well marked, but the feathers of the back margined with rufous. The size given is that of this bird. Length, 44 ins. Wing, 21 ins. Tarsus, 8.75 ins. 


\section{Order CHARADRIIFORMES.}

\section{Family OTIDID E. Bustards.}

Long-legged running birds with three toes, united at the base and fringed with membrane.

\section{Great Bustard. Otis tarda Linn.}

Up to the end of the eighteenth century the Great Bustard (Plate 42) nested in wild open spaces in England and south-east Scotland, and the "droves" which roamed over the Yorkshire wolds, Salisbury Plain, and similar uncultivated areas were often immense, but the bird was too big and edible to survive. Eariy in the nineteenth century it vanished from Salisbury, and though a few pairs lingered in East Anglia and Yorkshire until the late 'thirties, spread of cultivation, increase of population, and, perhaps more than either, improvement in sporting guns, swept them away. So to-day the Great Bustard is only an occasional winter visitor to our eastern counties, sometimes arriving in such numbers as to suggest invasion, or, possibly, repopulation. In central and southern Europe, notably in Spain, and in western Asia, it survives locally, but everywhere suffers where man can outwit it. It is not, apparently, a regular migrant, but an occasional wanderer.

The large size of the Great Bustard renders it an easy bird to see and identify, and a tempting mark for the gunner, for a male is as big and tasty as a Turkey, and may weigh over 30 lbs. Indeed, when in 1900 Lord Walsingham turned a number of birds down, they foolishly wandered and were soon accounted for. The Bustard walks with "stately and deliberate gait," carries the body horizontal and the head well erect; in Spain it frequents cornfields, and is thus often partially hidden. It feeds largely on grain and other vegetable substances, but 
also eats insects, especially grasshoppers, worms, and other small animals. It seldom runs, even when pursued, for its feet are small; if alarmed it takes a few quick steps and unfolds its ample wings, flying quickly, though with slow, strong beats, and seldom at much altitude. There is so much white in the bird's wings and on its under parts that, Col. W. Verner says, when flying at a distance it looks as white as a gull.

Naumann affirmed that the Bustard is monogamous, but Lord Lilford, Mr. Abel Chapman, and Col. Verner found it polygamous. The droves, including more females than males, have their favoured haunts - $a$ habit which proved fatal in Britain and is little to its advantage elsewhere-and there the birds feed day after day, or sit with the head sunk in the breast, Turkey-like, resting in the sun. In spring these gatherings are not always peaceful, for the male has a wonderful display, an exaggeration of the silly performance of the domestic Turkey-cock, and this swagger usually ends in a fight with a rival. Though there is little bloodshed, feathers fly and are broken, and at times, after a bout, a cock is incapable of flight and is an easy victim for the hunter. The display consists of many contortions; the tail is spread and brought forward, often meeting the head, which as the bird puffs out its breast and inflates to the full a curious gular pouch or air bladder, is drawn far back. At the same time the wings are drooped, inverted, and apparently dislocated, so that the white axillaries and under surface hide all the coloured feathers; a brownish bird is "converted into a mass of snowy white, double its natural size." The bird grunts or barks during this performance, but as a rule it is very quiet. Even after the hens have withdrawn to sit their two to four large eggs in a shallow scrape, the cocks, retiring in little groups, continue their foolish rivalry, threatening one another, but if a challenge is accepted the challenger frequently retires; indeed, as in the fights of the Ruff, much of the show is mere bluster. 


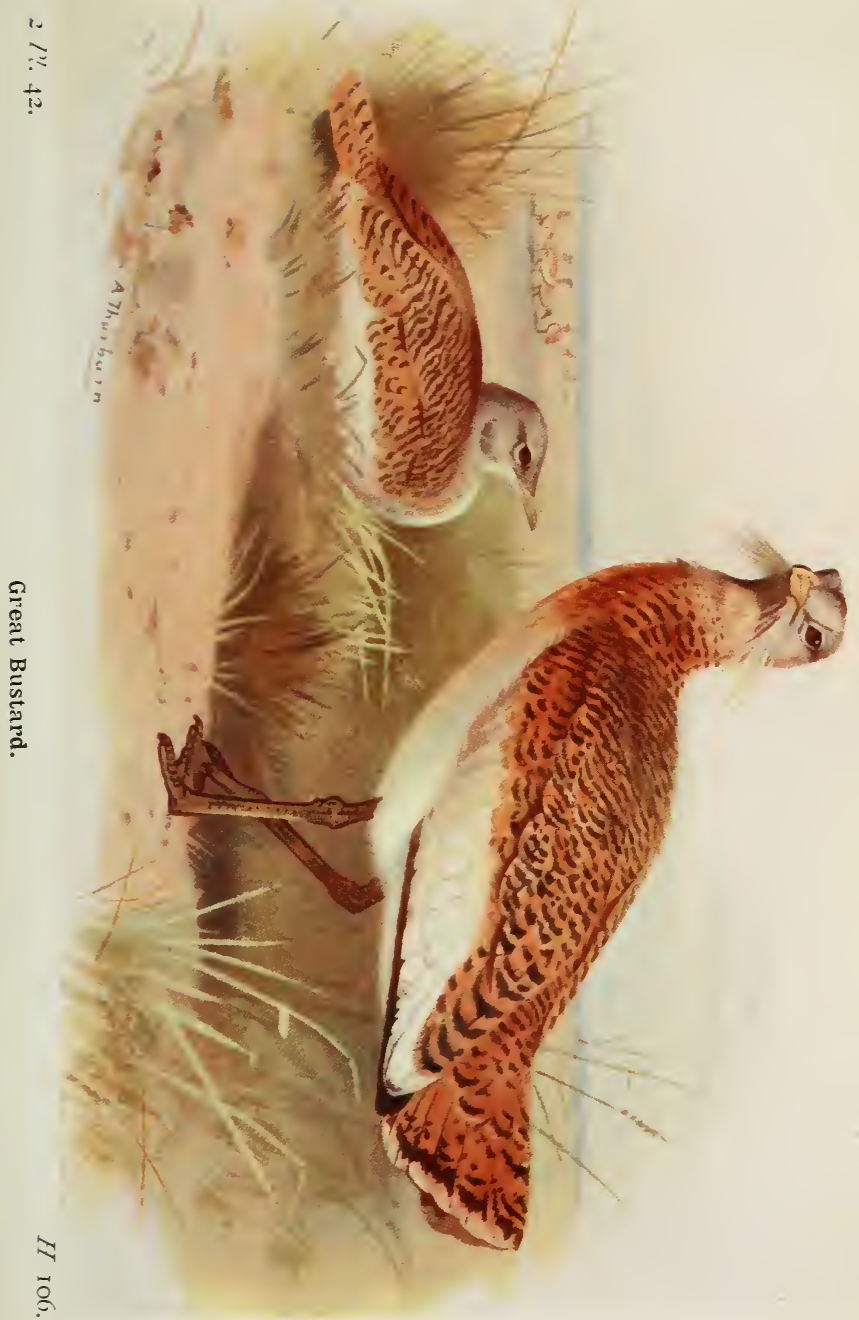




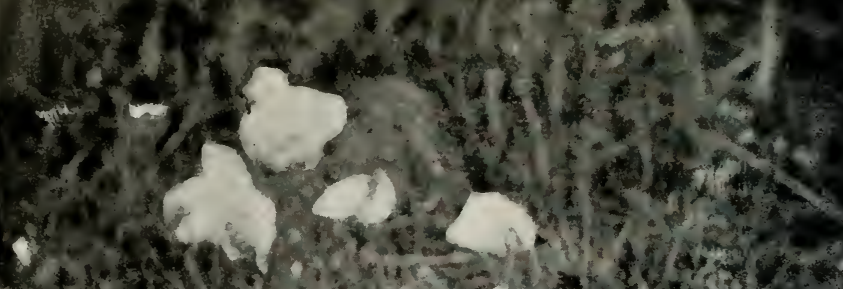

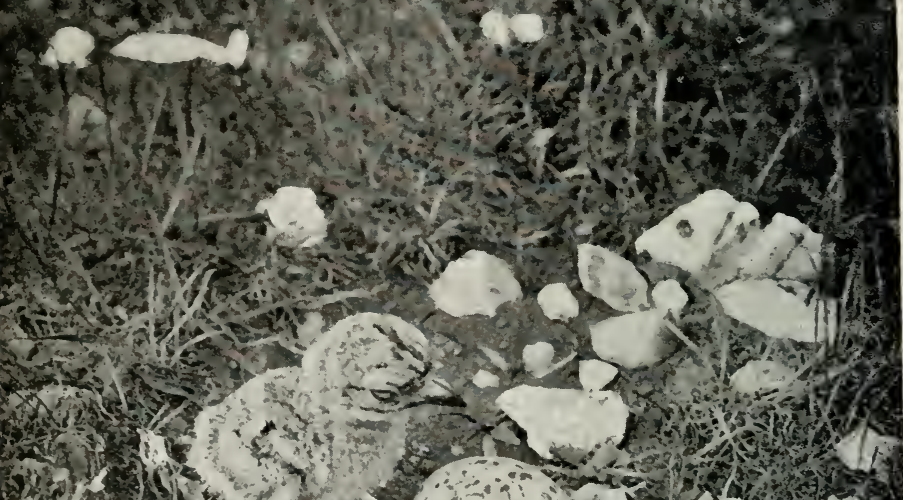

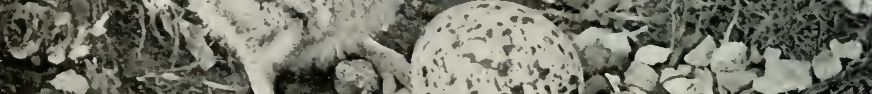

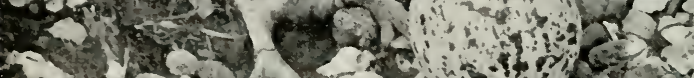

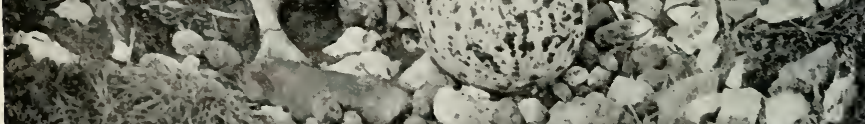

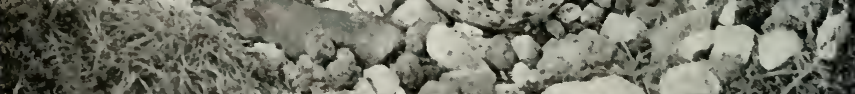

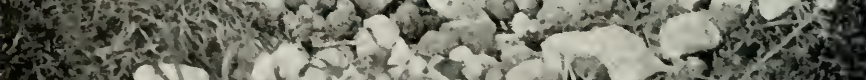

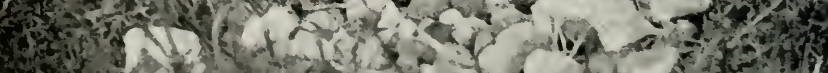

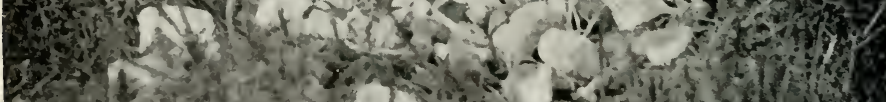

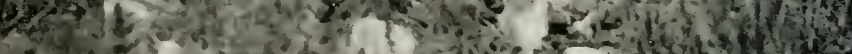

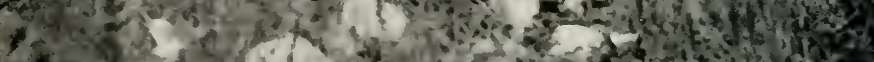

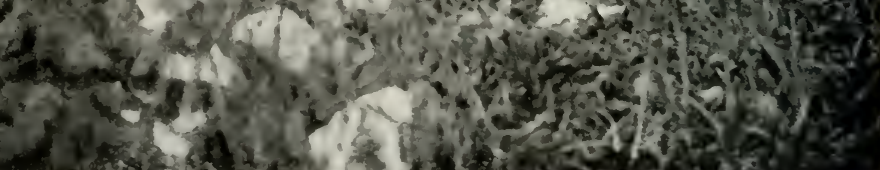

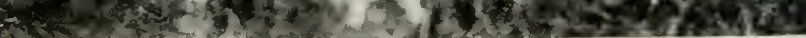


The male is much larger than the female; his head and neck are slate.grey, and on his chin are tufts of long whitish bristles; his upper parts are yellowish barred with black, but with the coverts mostly white. The breast is brown and barred, the rest of the under parts dead white. The female has no bristles and her breast is white. The young resemble her, but there are blick bars on the coverts. The bill is slate, dark at the tip; the legs are brown and the irides dark brown. Male: Length, 44 ins. Wing, 24 ins. Tarsus, 6 ins. Female: Length, 30 ins. Wing, 19 ins. Tarsus, 575 ins.

\section{Little Bustard. Otis tetrax Linn.}

A more southern species than the last, the Little Bustard (Plate 39) is a rare winter visitor to England, notably to the east coast, and is very occasional in Scotland and Ireland. Its range extends from central and southern Europe to western Asia and northern Africa, and it is a more regular migrant than its larger relative. On a few occasions birds, even males in breeding dress, have been noticed in spring, but it is not known to have nested in Britain.

In winter dress, in which it usually appears in England, the Little Bustard is a yellowish-brown bird, delicately vermiculated, barred and streaked with black, and with white under parts. It looks like a game-bird, and has many game-bird habits. It rises on whirring wings, and, to quote Mr. Chapman, "cackles like a cock-grouse." It runs like a Partridge, and when flushed rises high, eluding the sportsman; flocks will wheel at a great height with plover-like evolutions. Col. Verner says that on the wing it looks even whiter than the Great Bustard. The rapidly moving wings make a loud swishing sound, from which, Col. Verner suggests, the Spanish name Sison, pronounced "see-sone," is derived. In the breeding season the cock, as he struts with head drawn back against his uplifted and expanded 
tail, and with throat distended, utters a repeated call, which Lilford writes prrut. After calling, he frequently leaps from the ground. The females are competed for with pugnacity, but the fights are seldom serious. The food is largely grain and insects.

The distinctive summer dress of the male is attained in April. The chin and upper throat are then lavender, the lower throat and neck almost black, crossed obliquely by two white bands on either side; the upper bands meet in a peak in front. The sandy head is striated, the back and upper parts finely marked with wavy black and brown lines. The outer wing-coverts and under parts are white. In autumn the neck ornamentation is lost, and in distribution of colour the male agrees with the female, though her back is at all times more boldly blotched, and her neck and breast are barred and speckled. She has no dark throat ; neither is this present in the immature bird, which is like her, but has more barring on breast and upper tailcoverts. The bill is horn, dark at the tip, the legs are yellow, and the irides brown. There is little difference in the size of the sexes. Length, 17 ins. Wing, $9{ }^{\circ} 5$ ins. Tarsus, 2.5 ins.

\section{Macqueen's Bustard. Chlamydotis undulata macqueeni (Gray).}

Macqueen's, often called the Houbara Bustard, though this name is also given to the African form, C.u. undulata (Jacq.), in which the crest and breast frill are white, is a native of western Asia, and in winter is known in India. On many occasions it has wandered into Europe, and three examples are recorded from England and one from Scotland. The black and white crest and the drooping frill or ruff, partly black, partly grey, are sufficient to distinguish it from other bustards. It is about the size of the female Great Bustard, to which in general colour it is similar. Length, 28 ins. Wing, 155 ins. Tarsus, 4 '9 ins. 
Family EDICNEMID E. Thick-knees.

Bill short and straight; legs long, with three toes, united to second joint.

\section{Stone-Curlew. Edicnemus adicnemus (Linn.).}

The Stone-Curlew, Great Plover, Norfolk Plover, or Thickknee (Plate $4 j$ ), has many names, none of which is specially local. In many ways it resembles the plovers, but in othersits choice of habitat, for instance-is more of a bustard. It is found in suitable places in central and southern Europe, Asia, and northern Africa, and is a partial migrant. Even in England, where it is normally a summer visitor, some remain to winter, occasionally in Yorkshire and East Anglia, but more frequently in Cornwall and Devon. To Scotland and Ireland it is only a wanderer, and in eastern and southern England is decidedly local, haunting only wide, open spaces-wolds, chalk-downs, and the "brecks" of Norfolk and Suffolk.

The large, bright yellow eye of the Stone-Curlew is its most salient character; it attracts the eye when the surroundings obliterate the lines of the motionless bird. It is a long-legged, large plover, giving an impression of a round head framing a very round eye. Whether its colour hides it or gives it away depends entirely upon the nature of the ground, but in most of its usual haunts it is a very inconspicuous bird.

When in flight, the double wing bar, obscure when the wing is closed, strikes me as very noticeable. If disturbed in the daytime the flight is direct and low, but at night, and especially in autumn, it is often erratic. I have seen the bird run quickly, with head low, but neck drawn in, for a long distance before taking wing.

Birds occasionally arrive in March, but April is the usual month; most leave in October. Though not continuously 
gregarious, several pairs will nest in one restricted area, but in autumn, shortly before departure, the social habit becomes marked. Mr. W. Farren has seen about 200 together. At these autumn gatherings the birds are very lively, and go through a performance which, if in spring, would be called nuptial display; the birds run rapidly with uplifted wings or posture as if courting.

Normally the Thick-knee is crepuscular, and, certainly on moonlight nights, nocturnal; it is sometimes known as the "Night-Hawk," a name a'so given to the Nightjar. In the daytime it is a shy, silent, secretive bird, but at dusk it becomes lively, and its weird, wailing, but musical calls are responsible for its name Curlew. It feeds on nocturnal insects, but does not refuse a frog or mouse.

The nest is a scratched hollow and the lining seldom more than a collection of rabbit-droppings, the number of these varying considerably. The ground colour of the two-seldom more-eggs, usually laid late in April (Plate 54), varies from buff to stone-colour, and the markings may be only specks and blotches or a network of lines. On stony ground, a favourite site, the eggs are difficult to see ; indeed, from the egg onward the life of the Stone-Curlew is spent in hiding itself from view. The crouching habit-that of lying still and trusting to colour and form to produce invisibility-is assumed so soon as the chick is hatched, but at first is imperfect.

The newly hatched bird (Plate +3 ) is a naturally protected ball of sandy down, patterned with black, but when it lies still in the presence of an imagined enemy it crouches in the position adopted by many other young plovers, and not for some days, according to Mr. Farren, does it flatten itself with outstretched neck in the characteristic attitude of older juveniles (Plate 47) and adult birds. When lying prone these shammers will allow themselves to be touched or even lifted without moving. The parent birds slip away and wisely leave the motionless young, 


\section{Heron.}
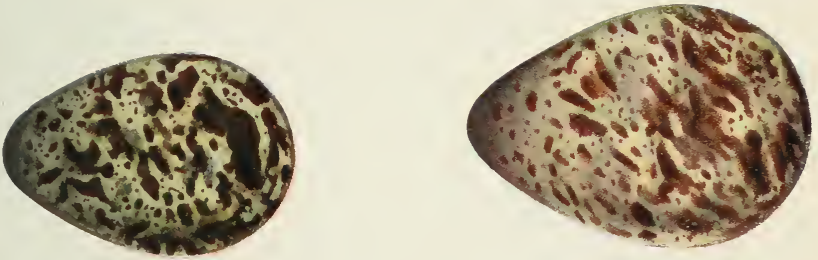

Red-necked Phalarope.

Dunlin。

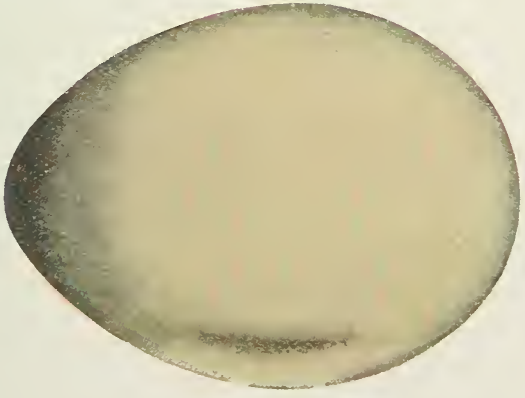

Bittern. 

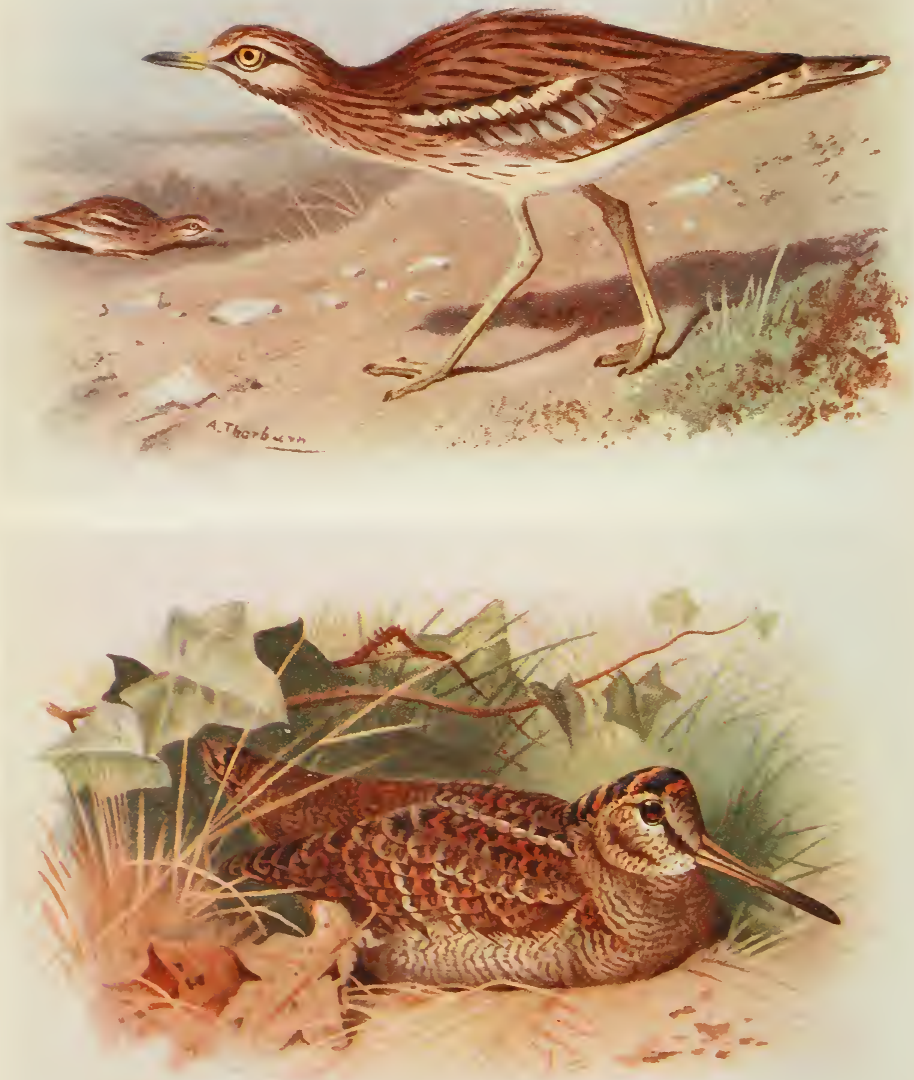

$H$ III. 
unlike many plovers, which by their noisy or fussy behaviour reveal the presence of eggs or young. From the young bird, with its large, apparently swollen heel (not knee)-the top of the tarsus-the name Thick-knee is derived, though a similar enlargement is present in many young plovers.

The adult Stone-Curlew of either sex is sandy brown, streaked with dark brown; the chin, throat, and a line below the eye are white. The neck, breast, and flanks are paler, and the abdomen almost white and unstreaked; the under tail-coverts are reddish buff. The bill is yellow, black at the tip, the legs greenish yellow, and the irides golden yellow. Young birds have the bars on the tail more distinct than when mature. Length, 16 ins. Wing, 95 ins. Tarsus, 3 ins.

\section{Family CURSORIID $Æ$. Coursers.}

Bill short and decurved; three toes, the middle elongated.

\section{Cream-coloured Courser. Cursorius gallicus (Gmel.).}

The Cream-coloured Courser (Plate 46), not a native of France though the type was obtained there, is an inhabitant of sandy deserts in Africa and southern Asia, but wanders in autumn into Europe, and quite a number-certainly over a score-have been noticed, and mostly shot, in England and Wales, and at least one in Scotland.

The English name of this bird is descriptive; it runs well, and is noticeably light coloured. It is easy to identify; there is no mistaking the isabelline colour, the long, almost white legs, curved bill, and white and black stripes on face and neck. Being a desert bird, it naturally remains on our sandy shores; it has seldom been noticed far from the coast, where it eats insects and small molluscs. On the wing it is strong and swift, and Mr. H. G. Alexander, who met with it on Dungeness beach, 
was struck by the contrast between the black wing feathers and the rich buff upper parts when it rose. The axillaries and under wing-coverts are black and show in flight. This bird, which reminded Mr. Alexander in some ways of the Golden Plover, allowed a near approach, running some distance in front of him, and only taking wing when he was about twenty yards away. All the information about the more recent records, with this one exception, refer to the appearance of the bird after death.

Most of the visits of the Courser have been in autumn and winter, between September and December, but there are two recent records, one for February, the other for May. In each case a pair in summer dress were obtained. If there is no error about the facts-that the birds were seen in the flesh is not absolute proof-what is the excuse for the slaughter? Why may a man shoot birds which, so far as any one can tell, might nest? Collectors could prevent this destruction if they would refuse to buy from shooters who are ever on the look-out for victims, and sometimes victimise the purchaser.

On the nape of the adult Cream-coloured Courser is a slateblue patch, and the back of the head has a line of black. Below this is a white streak passing from above the eye down the side of the neck, and from the eye to the nape a blackish line. The young bird has the eye streak buff, and the breast and back marked with wavy brown lines. The bill is dark brown, the legs creamy or dull white, and the iriues brown. Length, 9 ins. Wing, $6^{*} 3$ ins. Tarsus, $2 \cdot 25$ ins.

\section{Family GLAREOLIDÆ. Pratincoles.}

Bill short and curved; wings long; legs long; hind toe present, middle and outer toes connected. 

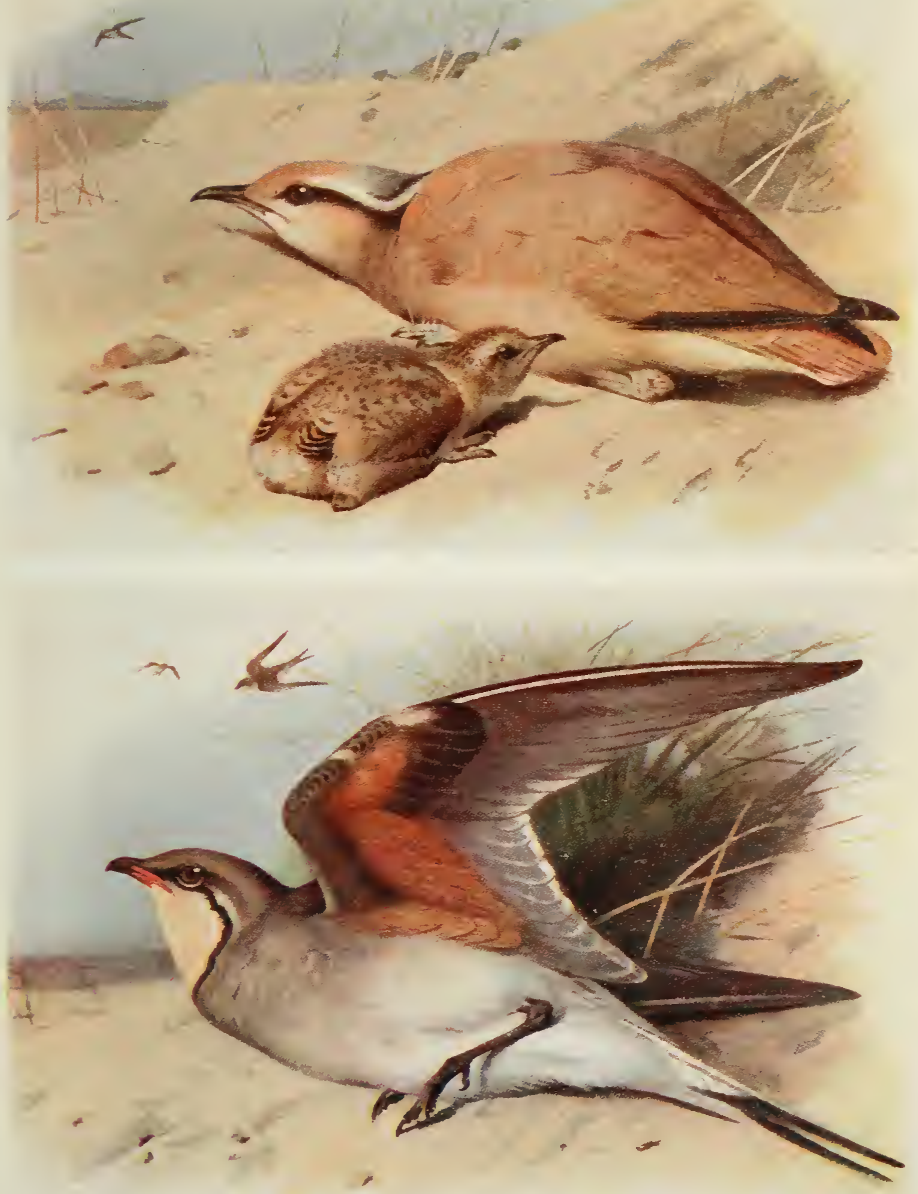

2 P. 46.

Cream-coloured Courser.

H I 2 .

Collared Pratincole. 


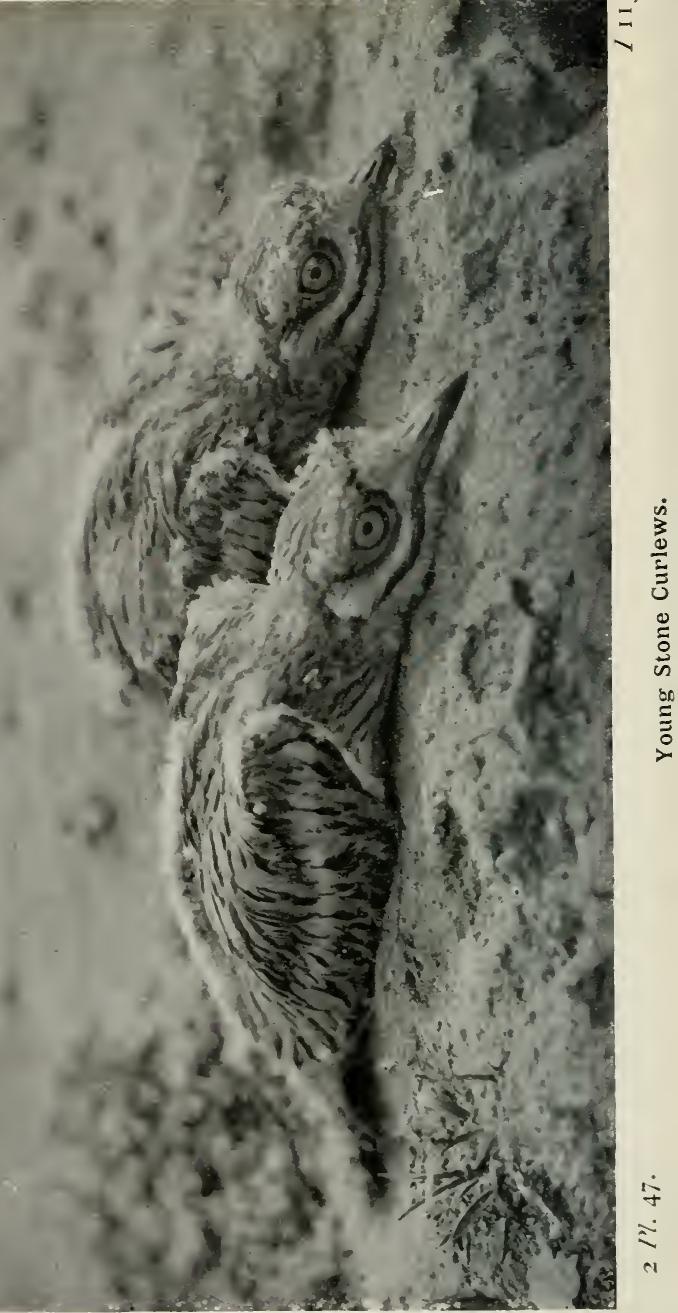




\section{Collared Pratincole. Glareola pratincola (Linn.).}

As an irregular wanderer from southern Europe or western Asia, the Collared Pratincole (Plate 46) has occurred nearly thirty times in England, Scotland, and the northern islands, for it has even reached the Shetlands and the Flannans. Most of the records are from southern and eastern counties, but the earliest were from Lancashire and Cumberland. Normally it winters in Africa.

The long, narrow wings and forked tail, together with the swift, sustained flight, suggested the Swallow to Linnæus; but in general appearance, and in its harsh angry voice if its breeding colony is invaded, it has much in common with the terns. The long legs and excellent running power of the Pratincole are those of a plover; it is a tern-like plover with a short, curved bill. The forked tail alone is enough to put it apart from other plovers, and, as if to emphasise this character, it jerks its tail up and down when at rest. The times of its appearance in Britain are varied; it cannot be looked upon as a regular spring and autumn migrant; it has also been noted in summer and winter. As our islands are far from its usual winter quarters, we must consider it a repeatedly lost rambler.

The collar, from which the bird gets its name, is a black line bordering its dull yellow chin and upper throat. The general colour of the mature bird is clove brown on the upper parts, yellower brown on the breast, and white on the abdomen; the tips of the secondaries and the base of the tail are also white. Under the wing the axillaries and coverts are reddish brown, and in flight this is sufficient to distinguish it from the only other pratincole on the British list. The bill is dark brown, red at the base, the legs are blackish, the irides brown. Young birds have bars of black and buff on the back and wings. Length, $10^{\circ} 5$ ins. Wing, $7 \cdot 5$ ins. Tarsus, $1 \cdot 25$ ins. 


\section{Black-winged Pratincole. Glareola nordmanni Fischer.}

The range of the Black-winged Pratincole is rather more easterly than that of the last species, though apparently both occur in south-eastern Europe and western Siberia. In May and June, 1903, and again in May, 1913, small parties were seen in Kent and Sussex, were ruthlessly shot down, and passed into the hands of the taxidermist and eventually into private collections. Only one other bird is recorded, a bird of the year killed in August, 1909, in Yorkshire. It was feeding with Lapwings when shot.

The main points of difference from the Collared Pratincole are that the axillaries and under wing-coverts of this bird are black, and that the secondaries have no white tips. Length, 10.5 ins. Wing, $7 \cdot 3$ ins. Tarsus, 1.7 ins.

\section{Family CHARADRIID $Æ$ Sub-family PHALAROPODIN E.}

Three anterior toes with membranous lobes.

\section{Grey Phalarope. Phalaropus fulicarius (Linn.).}

"Coot-footed Sandpiper" is a fowler's name for the Grey Phalarope (Plate 48), and a similar reference to the Coot is implied in both generic and specific names. The imperfect web, forming distinct lateral lobes on the distal joints of the toes, is a character that separates the phalaropes from the other sandpipers. The Grey Phalarope has an Arctic circumpolar range; the nearest breeding haunts to Britain are Greenland and Iceland. After the breeding season it is a long. distance traveller, for it has been noted in the Falkland Islands and New Zealand. Though it occurs in winter on inland waters in all parts of Europe, its migration travels are often 
oceanic; it can rest when it wishes and find sufficient food for its needs in the surface-swimming marine organisms. On autumn migration large numbers, probably of birds from Greenland, must frequently if not regularly pass our islands, for if contrary winds-usually gales from the south-west-are encountered, many are forced upon the southern and south-western shores of England and Ireland. So numerous are these unwilling visitors in some years that it has been suggested that the irruptions are similar to the occasional westward movements in mass of birds like the Crossbill and Sand-Grouse, but the direction of wind seems alone responsible. In some years hardly any Grey Phalaropes are recorded, but in others the numbers thoughtlessly slain with shot and stone are very great; Mr. J. H. Gurney estimated that over 500 were killed in the autumn of 1866 . Spring visits, though recorded occasionally, are rare, and the bird has been noted in winter; the majority are seen between August and December.

Naturally most of the Grey Phalaropes seen in Britain are in autumn and winter dress, and a large number evidently immature. On the water the bird swims very lightly, looking more like a tiny gull than a sandpiper - a pearly grey and white bird. So tame, or rather indifferent, it is, that inland, when it often settles to rest and feed on small ponds, it may be examined at close quarters, and is then often stoned to death by fools who cannot look at a bird without wanting to kill it. I have watched it more than once flitting over the water and swimming on'y a few yards away; it swims in a zigzag course and with a quaint bobbing action of the head and neck, darting this way and that as it snaps at gnats and flies, its favourite food inland, though it will pick small molluscs from the weeds. It rises frequently, flitting rather than flying, and in the air darts from side to side like a wagtail, often hovering for a second. In these short flights the small lobed feet hang limply, but are trailed when longer distances are undertaken. 
One I watched always jumped clear of the water when it took wing and did not run, paddling along the surface, as it is said to do when frightened; indeed, it is difficult to frighten. This bird, when swimming amongst the weeds, often mounted and tripped across a floating lily-pad, but was not long enough on its feet for me to notice "the quaint perky dignity of the Moor. hen," which struck Miss M. Haviland when she saw it on the land on the Yenesei. Its action when swimming, however, certainly suggested Moorhen. The notes of the bird are variously described, but no combination of letters conveys to my mind the short, low whistle that the bird repeatedly gave when on the wing. Miss Haviland, who saw the bird in its breeding haunts, speaks of a rapidly repeated $z h i t, z h i t$, as the bird flitted round "rather like a big red moth."

In winter dress the back is clear pearl grey, the wings more smoky and mottled; the forehead, crown, and under parts are white, and on the wing is a well-defined white bar. From the eye a dark streak runs back towards the slate nape. White edges show on the wing-coverts and dull streaks on the flanks. The bill is black, the legs dark grey, the irides brown. In summer the female, which, according to Herr Manniche, does all the courting and bullies the male into undertaking the more feminine domestic duties, is the more brightly coloured bird. The warm chestnut of the under parts is the most noticeable colour; it is a grey bird in winter, a red bird in summer, a not uncommon sequence in sandpipers. The upper parts are brownish black streaked with buff or chestnut ; Miss Haviland noticed the protective value of the longitudinal buff streaks on a male which she photographed on a nest. The dark colouring is relieved by white superciliary stripe, cheek, and wing bar. The bill is yellow, dark at the tip, the legs are greenish yellow, yellow or orange on the toes, and the irides brown. In autumn the chestnut is gradually lost; it is not always easy to say if a bird is mature in transition dress or young when 

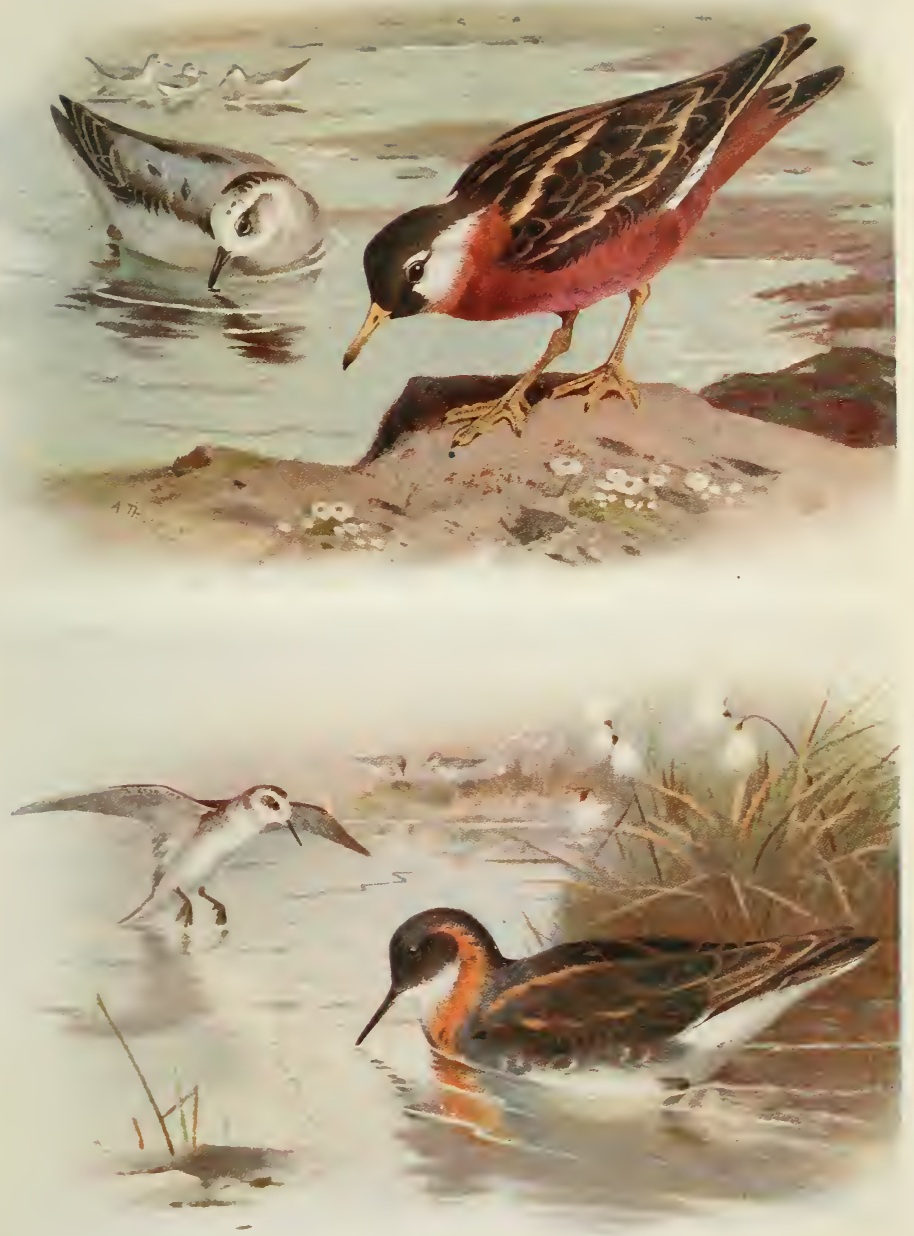

$21 \%{ }_{4} \mathrm{~S}$. 


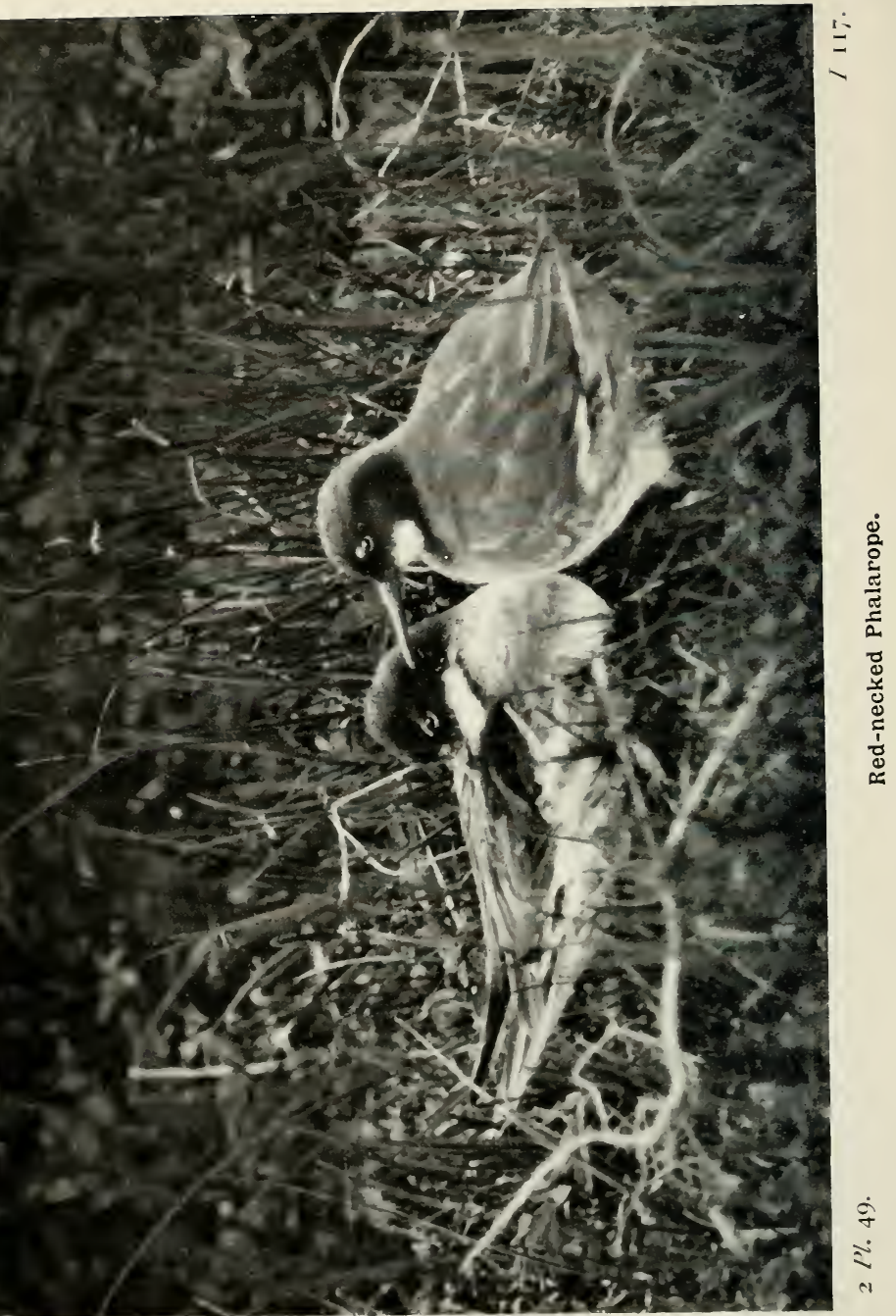


there are buff margins to the feathers of the upper parts, but as a rule the young are redder on breast and wings than a bird which is losing summer dress. Length, $8 \cdot 25$ ins. Wing, 5 ins. Tarsus, 0.9 in.

\section{Red-necked Phalarope. Phalaropus lobatus (Linn.).}

The circumpolar breeding range of the Red-necked Phalarope (Plate 48 ) is rather more southerly than that of the Grey, and in winter the bird has not been recorded so far south. To the Orkneys and Shetlands, the Outer and Inner Hebrides, and one district in western Ireland, it is a summer visitor, nesting in small and scattered colonies, but elsewhere only an uncommon passage migrant, more frequent in autumn than spring, and a rare winter visitor.

The diminutive size of the swimming Red-necked Phalarope is striking; it looks about half as big as a Dabchick. It swims as buoyantly as the Grey, with the same restless, jerky energy, darting from side to side after insects. Its slender sandpiper head and neck bob as it swims-wonderfully strongly for so small a bird. Characteristically tame or indifferent to the presence of man, it will alight on a wayside pond and feed with confidence. The colour scheme of the summer dress is very neat, a combination of slate grey, fox-red, and white. What struck me most in a female that I watched on two consecutive days was the contrast between the white chin and the rich chestnut throat, and the long, slender bill. The white of the under parts ran up to a peak on the breast, and above the eye was a small white spot. This spot is not always distinct, and in skins is lost by shrinkage; it is not shown in Gould's, Dresser's, or Lilford's plates, but Mr. Thorburn noticed it when drawing for his "British Birds," and it is clear in Miss Turner's photograph (Plate 49). With difficulty Mr. Oldham and I made this bird fly; at first it j'mped into the air and 
dropped again when startled by clods thrown into the water, and when at last we got it up, it flew swiftly, rather like a Ringed Plover, but soon returned to the water. As it flew, a long angled white stripe-the edges of the coverts-crossed the open wing. Sometimes it dipped head and neck when feeding, sometimes jumped to catch a flying insect, and it constantly uttered a short weak pipe-plecp, pleep-but this was the only note we heard. Other notes are described, including a trill like the Ringed Plover when courting. This bird did not swing round and round as if on a pivot, a habit noticed by some watchers, the object being to stir up the bottom or draw insects and crustaceans into the eddy formed by the movement. Probably a similar result follows the rotary motiun of the Spoonbill's bill, previously referred to. When bathing, the bird will swing the body to and fro, hinged on the legs, or quaintly roll from side to side, as it throws the water over the plumage.

The Red-necked Phalarope arrives at its British breeding haunts early in June, and seldom remains after the end of August. It is never numerous on passage, and either the nesting area is reached by a somewhat circuitous sea-route or by a high, uninterrupted, overland journey. The female usually courts and often bullies the male; however, on one pool Mr. P. H. Bahr saw two females worrying one rather reluctant male, and two males circling round another female. Miss Best and Miss Haviland watched four or five females forcing attentions on one apparently annoyed male. During these competitions the rival hens often fight. Even when the male has yielded to the wiles of a successful suitor, he is not in a hurry to take over his effeminate duties; Miss Turner watched one being conducted by his mate, and whenever he strove to have a short nap (Plate 49), she literally "henpecked" him into activity. The nest is as a rule well concealed, and after the four eggs (Plate 44) are laid, most if not all the incubation is performed by the male. The nestlings, clad at first in golden down which soon pales, 
have two white stripes on their darker backs. They are cared for by the cock bird, though the hen will mount guard and warn him to slip off the nest if danger threatens, when he will join her on the water and pretend to feed (End paper I). The nestlings, with large fleshy legs and flesh-tinted bills, can swim at once, though Mr. Bahr found some drowned. Mr. H. S. Gladstone, who visited the Irish colony and noticed its rapid growth from year to year so long as it was well protected and its position kept secret, has some strong things to say about the selfishness of collectors. Two well-known ornithologists (if they deserve the title) visited the place, illegally shot two birds, and took, so he heard, forty eggs. Nothing can justify such wholesale robbery, and it has, unfortunately, not ended with the one deed, for the natives have learnt that there is value in the eggs.

In summer the adult bird has the head, lower neck, and most of the upper parts slate-grey, darkest on the back where there are buff edges to some of the feathers. The chin, eyespot, and abdomen are white, and on the neck, extending to the lower part of the face, is a rich chestnut band. The bill is almost black, the legs greenish, yellower on the feet, and the irides brown. The male is duller than the female, and in both sexes there is considerable variation in the white on the chin and chestnut on the gorget. The autumn moult is gradual, and when the winter dress is complete the sexes are difficult to distinguish. The forehead, cheeks, throat, and breast are then white. The back of the head and eye-streak are dark brown, and the upper parts greyish marked with white and buff. The backs and wings of young birds are warmer-more buff and chestnut - than in old birds in winter dress. Length, $7^{\circ} 5$ ins. Wing, 4.4 ins. Tarsus, 0.8 in. 


\section{Sub-family SCOLOPACINE.}

Bill moderate or long, straight or slightly decurved; hind toe usually present, anterior toes free or slightly webbed.

\section{Woodcock. Scolopax musticola Linn.}

The literature of the Woodcock (Plate 45) is extensive; it is the bird of the sportsman. In the British Isles it is a resident, a winter visitor, and a passage migrant from northern Europe and Asia to winter quarters further south. Statements that all British-bred birds winter here or that all migrate do not cover the ground; the only conclusion that can be reached if we examine the reports of recovery of ringed birds is that there is no fixed rule, and that Woodcock, like many other species, show individuality. Some young birds remain near the place of birth, others wander in autumn, even travelling north, and others again go abroad. What proportion emigrate we do not know ; the fact that more are reported from near home than from the Continent is natural; the chances of marked birds being reported from abroad are small. Many birds marked in England and Scotland are found in Ireland.

The Woodcock has a noticeable character-a big eye set far back on a round head; this coupled with a long bill, a dark stripe from bill to eye, black bars on head and neck, and soft marbled and barred buff, brown, and black plumage, are a combination which even the rovice cannot mistake. As a matter of fact, however, our visions of the living Woodcock are as a rule fleeting. By day it shuns the open, crouching quietly in the woods, its colour and markings in such harmony with its surroundings that it is invisible unless disturbed. Then, rising with a swish of wings, it dodges through the trees, to drop at a safe distance. We may come upon it again, squatting in a ditch with long bill depressed and eye upon us, but the chances are that we shall not see it until it again takes wing. The 
sound, as the bird rises, resembles to my ears the sharp ripping of stiff paper; when on the ridge at Spurn on the night when the Woodcock arrived I heard every few yards this sound, and in the lighthouse beam caught sight of ghostly birds skimming into the darkness. The flight varies; it is swift and dodging when the bird is scared, or when, in spring, the males are "roding" as the nuptial sport is called. But it can be slow, uncertain, and owl-like as the birds return from their nocturnal feast to the shelter of the wood. The bill is carried pointed downwards. At times the speed is great, for on migration a bird, some years ago, crashed through the lantern at the Flamborough light.

A few immigrants reach the east coast in September, but the biggest flights are in October and November, and hard or rough weather abroad brings the laggards later. In winter westward movements to Ireland are common. At dusk the bird leaves the wood, usually by some well-used glade, to feed in the marshes or muddy ditches, and even in hard weather finds some soft spot in which to push its sensitive bill to feel for worms, its main food. It has been said that the Woodcock stamps to bring worms to the surface, and the statement has been freely copied; it is not easy to see how a nocturnal bird feeds. It does, however, turn its probe from side to side, and can evidently tell when it touches its victim, which is then gripped by the curiously prehensile portion of the upper mandible and dragged out. I do not believe that when its head is turned sideways it is listening for the sound of worm movement; the lateral position of the eyes of many birds causes them to turn the head when they concentrate upon one spot. Doubtless the Woodcock has good hearing; though exactly why the position of its ear, which is in front of and below the level of the eye, differs from the normal has never been discovered. In autumn the "Cock" is a silent bird, and often it rises without a sound; Seebohm says that it will, at times, utter a note like 
that of the rising Snipe, and I have heard a short pier, which reminded me of the winter flight note of the Skylark. In spring, when the males are "roding" in the early morning or at dusk, they have more to say. Mr. C. B. Moffat states that the bird gives "a deep, constantly repeated croak-croho, croho-varied at regular intervals by a shrill screech-chizzic." The birds roll and twist, dart and dash, during this courtship flight, and Mr. Moffat has seen rivals fly alongside, chirruping loudly, apparently in defiance. When displaying on the ground the cock struts with uplifted and spread tail, drooped wings, and puffed-out feathers.

In the winter wood the colour of the plumage hides the Woodcock; on the nest it is almost invisible. The nest in itself is little more than a depression in the fallen leaves, often of oak or beech, still plentiful in March when the four eggs (Plate 54) are laid, for the Woodcock is an early nester; our breeding birds are usually sitting before the emigrants have left. Though I knew that a bird was sitting under a particular honeysuckle spray a few feet from where I was standing, I only saw it when the warmer tints of a patch amongst the leaves led my gaze to the big brown eye and thus to the outline of the sitter. It never moved so long as I watched it. The nestlings are rich buff with dark longitudinal bands on head and back, and a dark band crosses from eye to eye ; the down is flecked with white. It is not certain that the old bird carries them to and from the wet feeding ground, but she will carry them away if the nesting site has been discovered. As to how this is accomplished is one of the ever-fruitful themes for ornithological squabbles; it does not seem to occur to most people that birds of one species or even an individual may employ different methods. I have not been lucky enough to sce the act myself, but I have the evidence of eye-witnesses in whoin I can rely. St. John's original statement that the young ate held in the feet, the legs hanging, is at times correct; Mr. 
C. B. Simpson saw this method from a hide only four yards away and sent me a sketch. St. John corrected (?) himself after later experience, and said they were held between the thighs, and others have added, kept in position by means of the depressed bill. Mr. Moffat saw the young thus held against the breast, but without any bill support, and Mr. Mackereth saw both bill and feet used. This last bird was attacked by a Sparrow-Hawk, and depositing its burden, led the hawk away for some distance and then threw itself into a terrifying attitude. It lowered its bill, hunched its wings forward, puffed out its feathers, and uttered a "harsh jabbering" note. The hawk retired, and then the Woodcock saw that a man was watching; it altered its tactics at once, and went tumbling along the ride as if wounded; then when the supposed human enemy had been lured away, returned to the young.

Variation in the plumage of Woodcocks is common, but I am unconvinced that British birds are darker and larger than migrants, as is frequently asserted by sportsmen and keepers. The colours are a wonderful combination of black, buff, chestnut, and grey in bars, mottles, and fine wavy lines. The bill is reddish horn, browner at the tip, the legs fleshy, the irides dark brown. There is no difference between the sexes, and young birds can only be distinguished by an expert, and then not always with certainty. Length, 14.5 ins. Wing, 7.5 ins. Tarsus, $1 \cdot 5$ ins.

\section{Common Snipe. Gallinago gallinago (Linn.).}

The breeding. range of the Common Snipe (Plate 51 ) extends over a great portion of Europe, Asia and north Africa, and in winter it visits Africa and southern Asia. From autumn until spring our resident stock is greatly increased by winter visitors, and there is also a passage migration. The bird is found in suitable localities throughout our islands, but is least abundant in the south. 
The Common, Full, or Whole Snipe, names by which the sportsman distinguishes it from the Jack and Great Snipe, is a bird of moor and marsh, perhaps most remarkable for its very long, sensitive bill. Its shot-battered corpse is a familiar object in the poulterer's shop, but few trouble to identify the species of a table bird. A bird in the hand, provided that it is neither mutilated nor moulting, can be told by its tail ; the Great Snipe has sixteen tail feathers, and the greater part of the outer ones is white towards the tip; the Common Snipe has the basal portion of its fourteen feathers black, and the tips red, only the outer pair having white ends, and all the feathers are marked with a subterminal black band. The twelve feathers of the Jack, especially the central pair, are pointed; they are dark brown with rufous margins. In the field such distinctions are seldom of value, but the behaviour of the Common Snipe differs from that of the Jack. When disturbed, it dashes into the air with a loud, harsh call-scaap-and immediately begins a rapid zigzag flight, which often saves its life ; its dodges are irregular and not always in the same plane; when just out of gunshot it straightens its route, but does not alight until some distance away. The Jack, on the other hand, often rises silently, and its call, if uttered, is not so loud; its turns and twists are more moderate, and it drops into cover within a few yards; it may be put up again and again.

The Snipe spends the day in some marsh or thick cover near water, and at dusk "flights" like a duck. One by one, or in "wisps," as the small parties are called, the birds shoot up from the marsh, calling, and vanish in the dusk, making for muddy ditches, the edges of ponds, oozy bogs, or other spots, where, probing the mud, it can feel for worms. The slightly swollen, pitted tip of the long bill is a wonderfully useful and flexible pair of forceps ; the last inch of the upper mandible can be raised or depressed at will. Worms are the main food, though insects and, in hard weather, some seeds are eaten. 


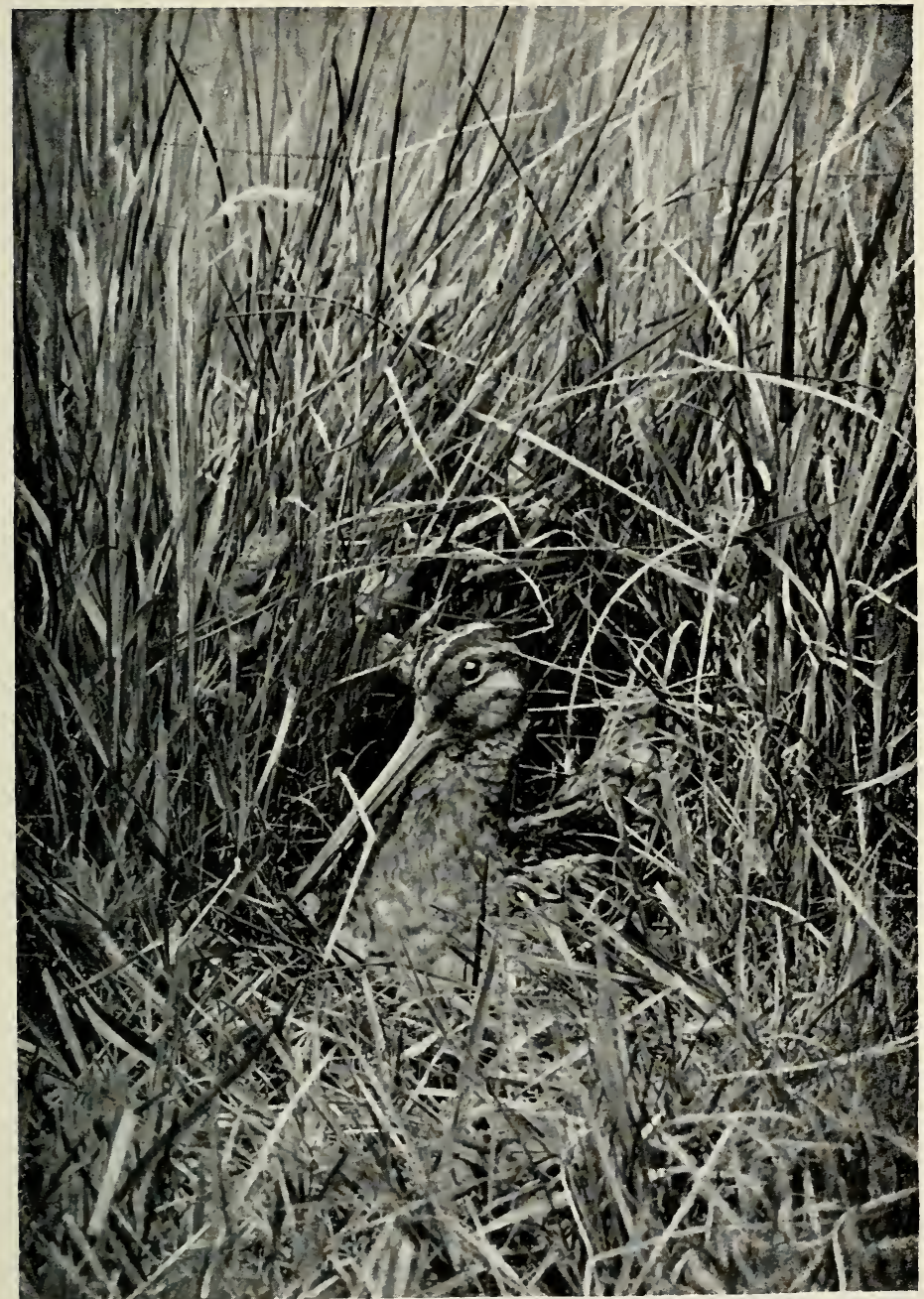


Large numbers of "foreign" Snipe arrive in October and November, and some of our home-bred birds go south; a hard frost or heavy snow causes westward movement, filling the Irish bogs with refugees. Return migration begins in March and lasts until after our birds have begun to nest. Display usually begins in March, but the strange "drumming," frequently heard during display, is by no means confined to the breeding season, nor, do I think, is it exclusively masculine. The displaying bird rises with strong, rapid wing-beats in towering circles, alternated with sharp descents, vol-planing steeply with wings half open and tail widespread. As it shoots down, the outer tail feathers stand out at an angle of about $45^{\circ}$, and the rush through the air causes these to vibrate with a booming note ; this noise reminds me more than anything of the bleat of a kid, and on northern moors the bird is known as the "Heather-bleater." It is probable that the vibration of the stiff primaries helps the sound, though the two tail feathers are mainly responsible. Mr. F. J. Stubbs saw one bird repeatedly descend back downward, and others have noticed the same strange action. Often in the air and commonly on the ground the Snipe has a vocal note, a deliberate chip-per, chip-per, chip-per; this is often uttered from a post, rail, or other elevated perch, when the rythmical movements of the head can be seen. I saw one bird calling when perched on the top sail of a motionless windmill.

The nest (Plate 50), a grass-lined cup, is well concealed in rushes, long grass, or, on the moors, cotton-grass and ling. The pyriform eggs, usually four, placed with their small ends inward, often have the dark smears and blotches more oblique than in the one figured (Plate 54); they have been found early in March, but clutches are usually complete about the middle of April. The nestling (Plate 52) is a ball of reddish-brown down, barred and streaked with darker brown and black, and plentifully frosted with specks of silvery white; the short, soft, greenish- 
black, or leaden bill has the under mandible wider towards the tip ; the thick legs are lead-blue, the irides dark brown, as in the adult bird. In the heather it looks like some brightly coloured, hairy caterpillar of a large bombycid moth. Trusting instinctively to its colouring for concealment, it crouches silent and motionless, even if threatened by a boot or taken in the hand. Though the young can run as soon as dry, the parents continue to feed them; it is said that at times they carry them to the feeding-place, but certainly they sometimes conduct them on foot, calling to them as they strut ahead with flirting tail and slightly drooped wings.

The adult has the head dark, with a median stripe and two lateral stripes of buff; there is a dark streak from the bill to the eye. The back is dark brown, with lighter streaks on the mantle; the wings are mottled and barred with black, buff, and brown, and the flanks barred with brown and white. The bill is horn, browner towards the tip, the legs greenish brown. Sabine's Snipe is a melanistic variety, still considered by some as worthy of specific rank. Length, $10 \%$ ins. Wing, $j$ ins. Tarsus, $1 \cdot 25$ ins.

\section{Great Snipe. Gallinago media (Latham),}

The Great Snipe (Plate 5I) nests in northern Europe and north-western Asia, and winters from the Mediterranean southward to the Cape. In the British Isles it is a passage migrant rather than winter visitor, for it has been most frequently observed in August, September, and October ; in spring it is infrequent. It has been found in all parts, even in St. Kilda and Fair Island, but in Scotland and Ireland it is decidedly rare.

There is often confusion between the Double Snipe, as this bird is called, and the Full or Common Snipe, for the markings and colour are similar on the whole, but as the tail is usually 
spread in flight the white terminal portion of the more outer feathers of the Great can generally be seen. These are not so white in immature as in mature birds, and most of those which visit us in autumn are birds of the year; but at any age the under parts, even the abdomen, of the Great are more barred and speckled than those of the Common, in which the centre of the abdomen is white. Solitary Snipe is one rather misleading name for this species, for though "wisps" are not noticed in Britain, couples may rise together. Its usual haunts are drier than those of either the Common or Jack Snipe; it may be found in fields, amongst bracken, or even in woods. From this choice of habitat, and from its manner of flight, without the sharp zigzags, it is at times called the "IVoodcock Snipe." It is slower on the wing, and flies heavily; indeed, it looks a bulkier bird than the resident species, though its actual length on the average is about the same, for the bill is proportionately short. So far as is known, it feeds rather more on what it can pick up than upon worms, for which it has to probe; insects and their larvæ have been found in its stomach. During the breeding season abroad it has several notes, but is not known to "drum"; in Britain it is a silent bird, rising without any call of alarm.

The plumage closely resembles that of the last species, except in the points already mentioned-the tail and under parts. The bill is brown, almost black at the tip, the legs are greenish brown, the irides very dark brown. Length, I I ins. Wing, $5 \cdot 5$ ins. Tarsus, $1 \cdot 3 j$ ins.

\section{Jack Snipe. Limnocryptes gallinula (Linn.).}

The Jack or Half Snipe (Plate 53) has a more northern and eastern breeding range in Europe and Asia than the last species; it winters in southern Europe and north Africa, in India and Burma. To Britain it is a common and regular winter visitor and passage migrant, usually arriving during 
September and leaving in March or April, but occasionally a few non-breeding birds remain all summer.

"Jack" is a diminutive, and thus well applied to this very small snipe ; indeed, its size alone is sufficient for identification. But when seen on the ground-no easy matter, for it loves thick cover-the absence of the central buff streak on its dark-brown head separates it from the other two snipe. Its twelve pointed, dark, pale-edged tail feathers are an even surer distinction, and its bill is short, nearly an inch and a half shorter than that of the Common Snipe. Though most sportsmen affirm that the bird rises silently and does not zigzag, neither statement is strictly correct. I put up a wisp of five and each bird uttered a low, weak, but perfectly distinct call as it rose ; another bird called the first time I flushed it, but though disturbed two or three times later made no further sound. Seebohm emphatically declares that it zigzags as much as the Common Snipe, but this is not my experience ; it is slower on the wing, and its uncertain dodges do not appear to have such sharp angles; it changes direction more deliberately. Mathew aptly speaks of its "butterfy flight." It seldom flies far, often not more than twenty yards, before it drops abruptly into cover, and, unless again forced to take wing, remains in hiding. Indeed, it will sometimes crouch so as to baffle the searcher, and even allow a dog to pick it up. When drumming, the Common Snipe certainly appears to carry its bill straight before it, but it is not easy to see the position when the flushed bird flies from the observer; I have, however, seen the slower Jack hold its bill inclined downward like that of the flying Woodcock. Not infrequently nests, said to be of the Jack Snipe, have been reported from our islands, but when. ever investigation has been possible they have been shown to be those of some other species, usually the Dunlin.

The most marked differences between the plumage of the Jack and Common Snipe have been mentioned, but in addition this bird has a broad buff stripe over the eye and two dark 
1.2.

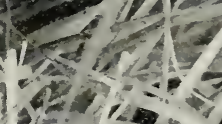

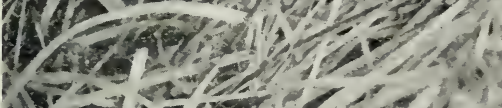

172

tal $x=1$

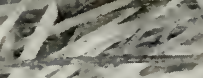

$x^{2}-\infty$

1. 101 .

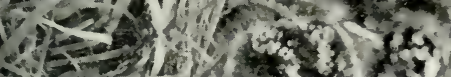

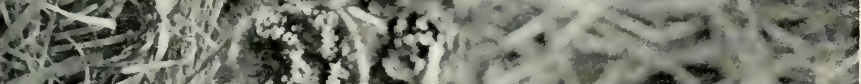

ֻ

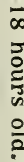

E.

E.

C.

- ngl w

Nar

N.

4 and

Tow

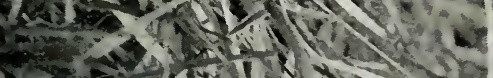

Giving

ans 30$\}$

hit 1 - 4 ?

- Noll
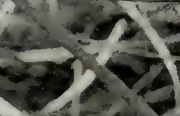

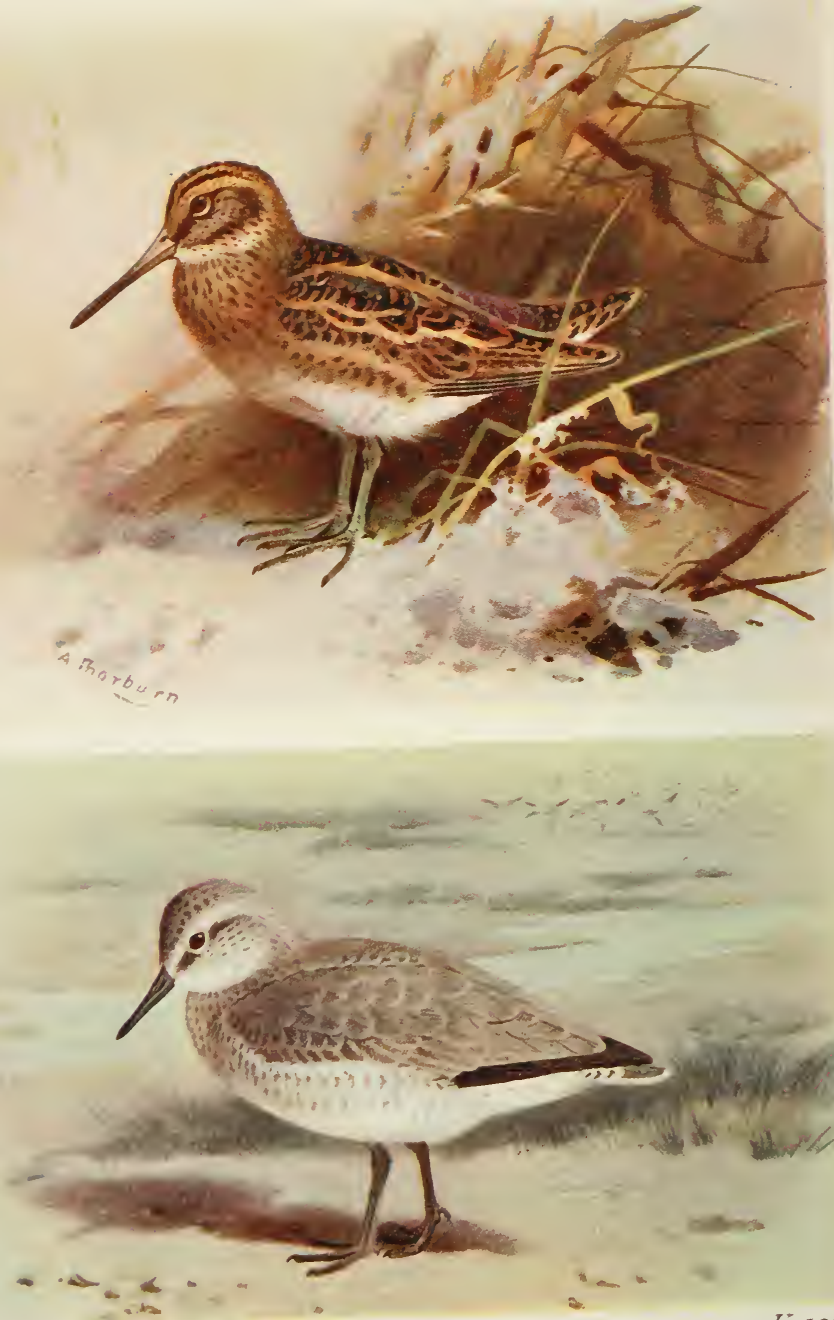
marks across its speckled face; the upper parts are glossed with green and purple. The buff and chestnut longitudinal streaks on back and wings are even more distinct then in the Common Snipe. The bill is brown, the legs yellowish brown, the irides blackish brown. Length, 755 ins. Wing, 4.25 ins. Tarsus, 0.8 in.

\section{Broad-billed Sandpiper. Limicola falcinellus (Pontopp.).}

Within recent years the records of the Broad-billed Sand. piper, a rare passage migrant, have been considerably increased ; probably the bird has been overlooked, taken for a small Dunlin or a large Little Stint. As it nests in Scandinavia, so near as the Dovrefjeld, as well as in northern Russia and probably in Siberia, and in winter is known as a visitor to the European coasts and inland waters, it is curious that it should so seldom be noted on our shores. Most of its few recorded visits have been in autumn, to the east and south coasts; but it has also occurred in spring.

The short, greenish-black bill is flat and broad, ard bert downward toward the tip. In summer the dark-brown head is streaked with buff, snipe-like in character, but the brown back and mantle have no long buff streaks, though the feathers are margined with chestnut and white. The flight and central tail feathers are almost black, the outer tail feathers pale brown. The throat and breast are buffish white streaked and speckled with black and brown; the abdomen is white. The legs are dark olive, the irides blackish brown. In winter the ashy grey upper parts, obscurely mottled, and the white under parts, are somewhat similar to the winter dress of the Little Stint. In both summer and winter a white bar shows in flight. Length, 6.5 ins. Wing, 4.25 ins. Tarsus, 0.75 in. 


\section{Terek Sandpiper. Tirekia cinerea (Gülden.).}

The Terek Sandpiper breeds in north-eastern Europe and Siberia, and in winter is known in Africa, Southern Asia, and Australia. The bird was added to the British list in I9I2, when four were recorded for Kent; in 1915 three were obtained in Sussex. All were killed in May, and apparently passed through the same hands. It is a grey-backed bird with dark markings on the back and streaks on the head; the under parts are white with dusky mottles on the flanks and breast. The long, greenish-black bill is recurved towards the tip ; the legs are yellowish green, the irides blackish grey (Dresser). Length, 9 ins. Wing, 5 ins. Tarsus, $I$ in.

\section{Knot. Canutus canutus (Linn.).}

Countless hordes of Knots visit the British Isles on passage, and very large numbers remain to winter, but it was not until I 876 that any breeding-place was discovered, and only within more recent years that we have gained light - still imperfectof the full range and nesting habits. The Knot (Plate 53) has apparently a circumpolar breeding range, but all the known haunts are far north of the Arctic circle in Greenland, Grinnell Land, Alaska, the Taimyr, and New Siberian Islands. Its winter wanderings take it to South Africa, Australia, New Zealand, and Patagonia.

In Britain the haunts of the gregarious Knot are the seashores where there are wide stretches of sand or tidal mud; in favoured localities its numbers are large in winter, immense during migration, and a fair number of non-breeding birds remain all summer. Amongst the crowds of waders which feed on the flats the Knot may be singled out by its intermediate size, considerably larger than the Dunlin and Sanderling, shorter in leg than the Redshank, and small beside the tall 
Godwits and heavy Curlew. It is a squat, short-billed, dumpy wader, always looking plump and in good condition-in winter grey and white, in spring and summer reddish chestnut. Immature birds with buffer under parts mix in the autumn and winter packs. The name is said to have origin in Canute's tidal experiences, but surely it is derived from the bird's note-a clear knut, knut, which is, strangely, described by some writers as a grunt! When a flock settles the chorus rises as a beautiful twitter. On the banks no waders pack so closely as the Knot; I have seen on the Yorkshire coast a strip of sand and shingle at high tide solid with Knots, not an inch of sand visible between their grey bodies. I have seen the Lancashire tide-line, for at least a mile, one continuous ribbon of birds, varying in width from two or three feet to six or more yards. Where the "Duns," as the fowlers call them, were thickest, and the birds moved, all in one direction with their heads down, the impression given was of a slowly advancing grey carpet. As they feed in these compact masses they must clear the shallowing water and wet sand of all the small marine worms, molluscs, and crustaceans, the winter food, but in the nesting haunts the bird is largely vegetarian-golden saxifrage and seeds of sedge and wood-rush are eaten. The bird feeds with the falling tide both by day and night.

Spring passage usually begins in April, and by May many of the birds have donned summer dress; partial summer plumage has been recorded in January. Mr. F. W. Holder, who for years has watched the Knots on the Lancashire coast, estimates that the winter flocks often contain two or three thousand birds, and when the passage migrants join them it is impossible to guess at numbers. Used though it is to exposure to weather, the Knot evidently prefers to be out of the wind; when the flocks are resting or feeding, birds on the windward side constantly rise, take two or three fluttering wing-beats, and drop into the thickest place so as to obtain the shelter of their 
comrades. At rest the bird stands on one leg, its head sunk in its shoulders or with its bill in the scapulars; if approached it will, without putting down the raised leg, hop slowly away. The rush of wings of one of the vast flocks when disturbed is a sound to remember, the sight most impressive ; the rising cohorts form a dense curtain. The aerial movements of the flock are as complicated and well ordered as those of the Dunlin; turning and twisting the compact body skims out over the water, rises or descends, or thins out into a long undulating line; often the whole body returns whence it rose. The Knot is strong and swift on the wing, capable of sustained flight. Many birds leave the west coast before the end of April, but passage continues throughout May; Mr. Holder saw over 500 on June 2oth in full chestnut dress. In the last week in July or early in August the young birds arrive from the north; Mr. Holder saw one flock 2000 strong on August rst, and notes how from a distance these mobs of buff-breasted birds look "as if suffused with rose." Within a few days some adult birds, already in grey dress, may be noticed, and the passage continues until October. All agree that the young come first, but most writers say that the old birds are much later, yet Herr Manniche saw no old birds in Greenland after August 8 th. The chestnut of the adult birds when gradually attaining winter grey is much deeper than the buff of the young, but it may be that some observers have thought that birds in partial winter dress were juvenile. Even in the second week in September I have seen birds showing much chestnut on the under parts amidst many hundreds in complete grey plumage, but $\mathrm{Mr}$. Holder rarely sees full summer dress even in early August.

The Knot occurs inland more frequently than is usually supposed, and occasionally in autumn there is overland migration. Single birds, probably weaklings that have fallen out of passing flocks, are met with on inland waters in winter as well as in autumn. 
The Knot in sumner dress is deep chestnut on the face, throat, breast, and abdomen; the streaked head is browner, and the mantle much darker, spotted with chestnut and with pale edgings to many of the feathers. The white-shafted primaries and secondaries are greyish black, the flanks and under tailcoverts are whitish, mottled with dark grey and black. The lower back and upper tail-coverts are white barred with black and chestnut. The bill is black, the legs deep olive, the irides dark brown. In winter the upper parts and breast are ashy grey, with dark streaks on head and breast, and with the coverts neatly patterned with dark grey. The tail-coverts are as in summer, but without any chestnut. There is a distinct white wing bar. The under parts are white with grey chevrons and bars on the flanks. The olive-green legs are much lighter than in summer. In the young the upper parts are ashy, but marked with bars of black and buff; the breast, abdomen, and flanks are suffused with buff, and the throat and breast are streaked with brown. The legs are dull olive. Length, Io ins. Wing, $6 \cdot 5$ ins. Tarsus, $1 \cdot 25$ ins.

\section{Little Stint. Erolia minuta (Leisler).}

Breeding in Arctic Europe and Asia, and travelling far south to winter, the Little Stint (Plate 55) pays short but regular visits to our shores in autumn and, less frequently, in spring. It is a passage migrant which reaches South Africa and India; the eastern Siberian form is met with in Australia.

In Yorkshire the Dunlin is commonly called the "Stint" by fowlers, but the true stints are much smaller waders; the Little Stint is the best known of the three which oscur in Britain. Mr. J. E. Harting was, I believe, the first to call attention to the similarity of this species to a small Dunlin; the rarer Temminck's Stint resembles a diminutive Common Sandpiper. The small size and shorter bill-roughly three-quarters the length 
of that of the Dunlin-is sufficient to attract attention when the bird is feeding with other shore waders; in the hand it is at all times a warmer-tinted bird than Temminck's, and the two outer pairs of tail feathers are brownish grey, whereas in the latter they are white. Passage Stints arrive in August, but early September is the time when most are noticed; they come in small parties and at first keep rather to themselves, but soon join the mixed congregations on the banks, feeding sociably with Dunlins, Sanderlings, and Curlew Sandpipers. By early October most have passed on, and a November Little Stint is uncommon. Its spring visits are from April to June. Although a typical shore bird, overland journeys are at times taken; the occurrence inland is not merely due to wandering or storm; at the beginning of September birds have been observed simultaneously on reservoirs in Yorkshire and Hertforshire, and at other times by the Cheshire meres and on Lancashire sewage farms; indeed, the repeated appearance on the sewage farms suggests intentional visits to places where food is abundant. In its behaviour when feeding the Stint is more of a Sanderling than a Dunlin, constantly active, running smartly to pick up insects, worms, and sinall molluscs, or to chase the sandhoppers and shrimps; it will swim when the water is too deep for its short legs. At times it will push its bill into the sand to capture a retreating worm, but does not probe for food like the Snipe. It flies swiftly, often outdistancing larger companions, and when small flocks are flying together the aerial performances are skilful-rapid turns, twists, and swerves, when the light under parts flash as every bird at the same instant smartly carcens. The triple call, tchik, tchik, tchik, is sharp and quickly repeated, and birds on the sand have a lower, more twittering note.

The upper parts of the bird in summer dress are reddish; the forehead is white, the crown streaked, and a dark line passes from the lores to the eye. The finely speckled breast is rufous, 


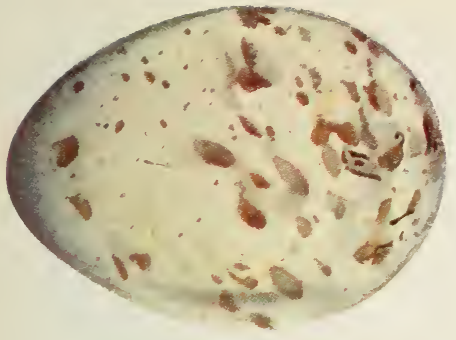

Woodcoek.

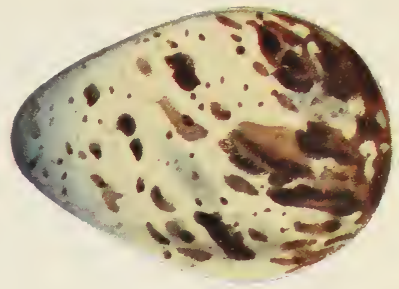

Snipe.

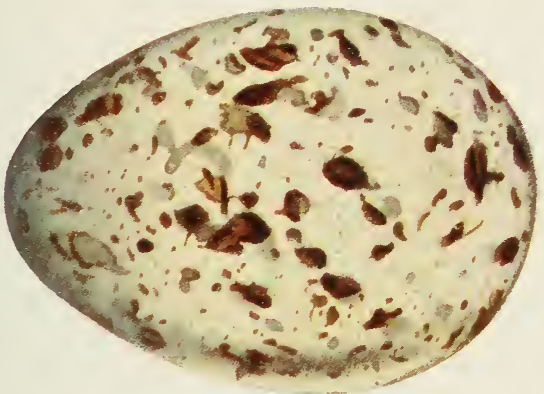

Stone-Curlew。

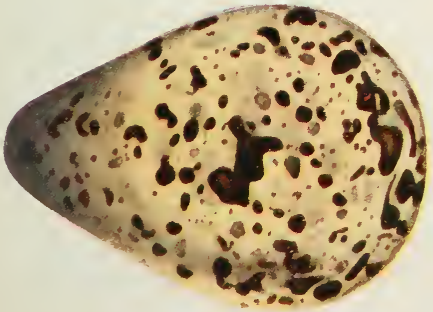

Redshank.

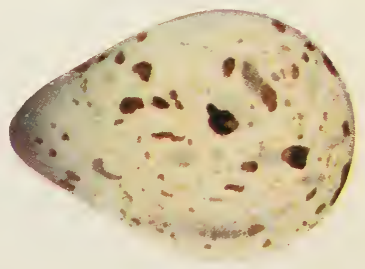



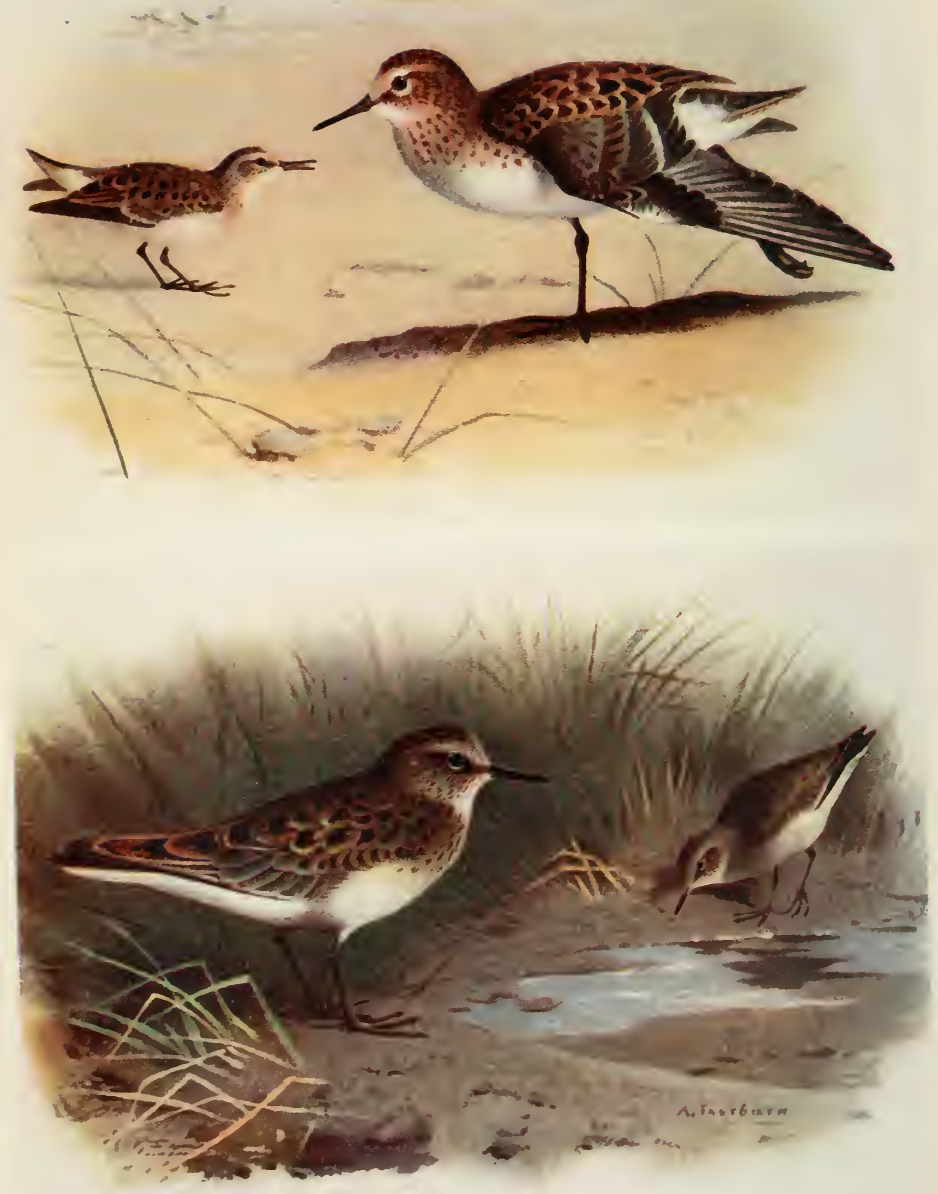
the rest of the under parts white. The quills are dusky, and a white bar crosses the open wing. The bill and legs are black, the irides very dark brown; in Temminck's Stint the legs are greener. In winter the general colour is ashy grey, the wings and coverts much greyer than in summer. The young, usually so tame in autumn as to allow close inspection, have darker backs and mantles, patterned with buff and chestnut, and with white on the wings and scapulars showing as irregular streaks. The white forehead and stripe above the eye show up the grey and reddish brown crown. The breast is tinged with buff, the under parts white. Length, 6 ins. Wing, $3 \cdot 5$ ins. Tarsus, 0.8 in.

\section{American Stint. Erolia minutilla (Vieillot).}

Only four examples of the American Stint have been obtained in England, all in Cornwall or Devon, on dates ranging from 1853 to 1892 , in the months of August, September, and October. The home of this species is Arctic America, and it normally travels in autumn to South America, but is known on migration in Greenland; it is evident that these wanderers, and doubtless others which escaped recognition, had taken a route more to the east than usual, probably wind-drifted.

The bird is a little smaller and much darker than the Little Stint, but otherwise very similar in appearance and habits, and its quick call-note recalls that of its congener. Its hind neck is greyer, the brown spots are larger and better defined, and the lower back and rump are black. The outer tail feathers are light grey, intermediate between those of the Little and Temminck's Stint. In the grey winter dress the rump is still very dark, and young birds with almost unspotted, buff-tinged breasts, have well-defined white edges to many of the feathers of the upper parts. The bill is blackish brown, the legs olive, the irides dark brown. Length, 5.25 ins. Wing, 3.5 ins. Tarsus, 0.75 in. 


\section{Temminck's Stint. Erolia tenmincki (Leisler).}

Temminck's Stint (Plate 55), even in autumn, is a rarer passage migrant than the Little Stint; it is more frequent on the south and south-east coast than elsewhere, though it has occurred in most parts of our islands, even in May on Fair Island. It nests in Arctic Europe and Asia, and winters in northern Africa and southern Asia.

Temminck's Stint is slightly smaller than the Little Stint, and at all seasons much greyer; its outer tail feathers are white. Its habits on the shore, its food-insects and their larve inland or in the tide wrack, or crustaceans, worms, and other marine animals on the sand or mud-and its quick, erratic flight, resemble those of the other species. Its note is described by Seebohm as "a spluttering but very distinct pt-r-r-r." Mr. A. H. Patterson points out that its call, and its habit of towering when flushed, are well known to east coast wildfowlers, rare though the bird is. In its summer haunts it has a trilling song, a modification of the distinctive call.

The summer dress is greyish brown with darker streaks and spots, but with a few chestnut bars and margins on the upper parts. Except at its dusky tip the outer primary is white; the others are brownish grey; a narrow bar crosses the wing. The buff breast is streaked, the rest of the under parts white. The bill is black, the legs olive, the irides dark brown. The winter dress is ashy with indistinct dark markings and pale margins; the breast is unstreaked. The feathers of the upper parts in young birds are tipped with white, and the under parts are suffused with buff. Length, 5.75 ins. Wing, 3.8 ins. Tarsus, 0.6 in. 


\section{American Pectoral Sandpiper. Erolia Maculata (Vieillot).}

The western form of the Pectoral Sandpiper (Plate 56) breeds in Arctic America and visits South America, even so far south as Patagonia, in winter. It has appeared so frequently in the British Isles as to be accepted as a genuine migratory wanderer, even by those who maintain that other trans-Atlantic birds must have had assisted passages. As it is known to visit southern Greenland on migration, it is possible that the few which have been noticed in Scotland and Scottish islands may have reached us by this island route, but most of the occurrences have been in the southern counties of England, suggesting an eastward and probably unconscious drift on westerly wind. The bird has occurred in spring, and certainly once in July, but the majority of the visits have been in autumn.

The Pectoral Sandpiper is a shore bird, not unlike a very large Little Stint with a pointed tail ; it feeds with Dunlins or other waders on the invertebrates left by the tide, but also, apparently, visits the tide-line or the maritime fields and marshes, since beetles and other insects have been found in its stomach. Saunders speaks of its breeding call, a muffled hoo, hoo, but Yarrell gives the note which the bird utters when rising as tweet, and this is the more likely sound to hear in Britain. Rickards, who recorded the bird for Devon, likened the note to that of the Curlew Sandpiper. Mr. M. J. Nicoll, who, with the Duchess of Bedford, watched one in Kent in July, says that its flight reminded him of that of the male Redshank when soaring.

The head and upper parts generally are blackish brown with rufous streaks and feather edgings; there is a slight wing bar. The central tail feathers are almost black, the outer ones dark brown; the breast is rather heavily streaked, and the abdomen 
white. A whitish superciliary stripe and a white chin set off the speckled cheek, and a dark streak runs from the bill through the eye. There is more white on the wing of the immature bird. The bill is greenish black, the legs yellowish brown, and the irides dark brown. Length, 8 ins. Wing, $5 \cdot 3$ ins. Tarsus, $\mathbf{I} \cdot 2$ ins.

\section{Siberian Pectoral Sandpiper. Erolia acuminati (Horsfield).}

The eastern Pectoral Sandpiper breeds in north-east Siberia, and winters so far south as Australia and New Zealand. It differs from the American bird in the shape of the tail, according to Mr. Mathews, as well as in its more rufous colour, and in the larger area with streaks or dark V-shaped markings on the under parts, which extends from the breast to the flanks. It has been at least once, and possibly twice, obtained in Norfolk in autumn. The distinction is less clear in the immature bird, which has unstreaked under parts. The bill and irides are much as in the other species, but the legs are greenish black. Length, 8 ins. Wing, 5.5 ins. Tarsus, $I \cdot I$ ins.

\section{Baird's Sandpiper. Erolia bairdi (Coues).}

Baird's Sandpiper, another Arctic American species, has, on four occasions, been recorded in the British Isles-twice from Sussex, once from Norfolk, and once from St. Kilda; all the occurrences have been in September or October. The bird is about the size of the Dunlin, and if feeding with these variable birds might easily be overlooked, mistaken for a dark Dunlin with a rather short bill. Its upper parts are, however, much blacker, though the feathers are margined with buff and chestnut; the crown is streaked, and the tail brown, with the pointed central feathers very dark. The under parts are white, suffused on the breast and flanks with buff and 

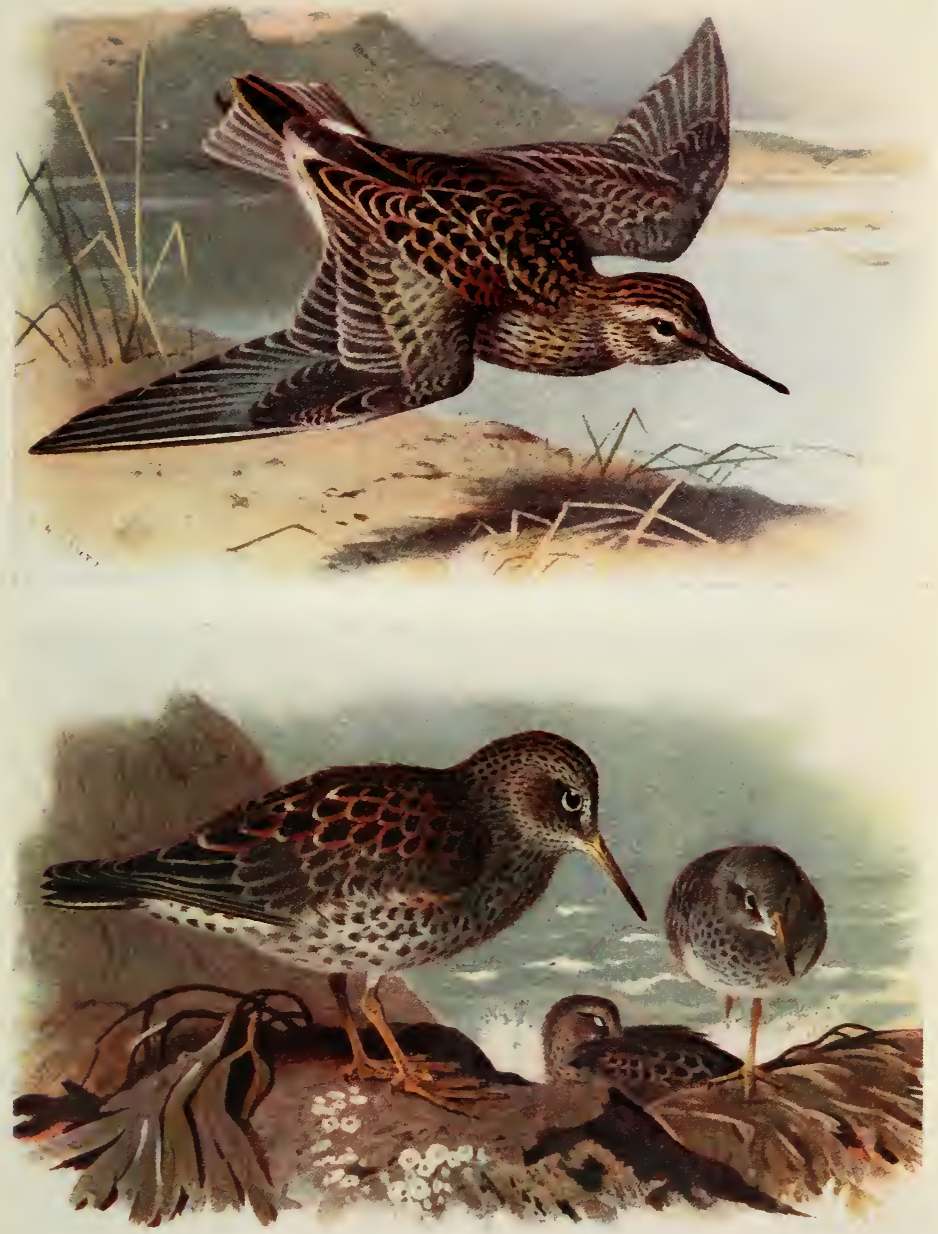

2 Pl. 56.

Pectoral Sandpiper. K 138. 


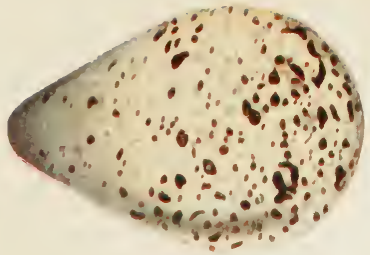

Ringed Plover.

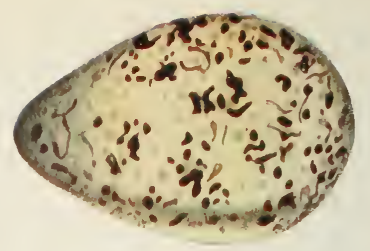

Kentish Plover.

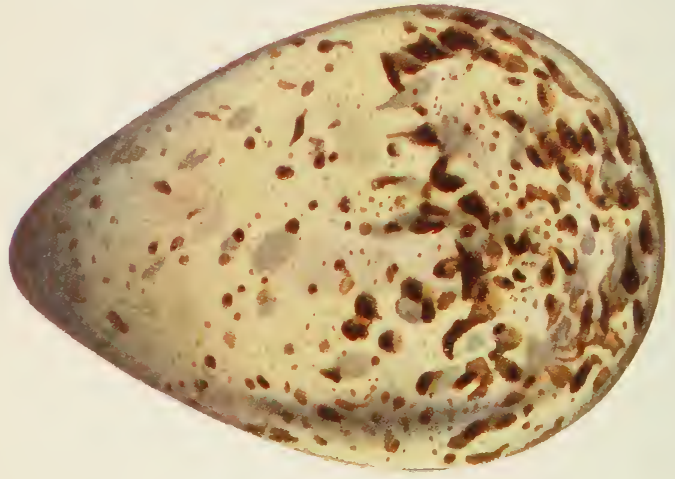

Curlow。

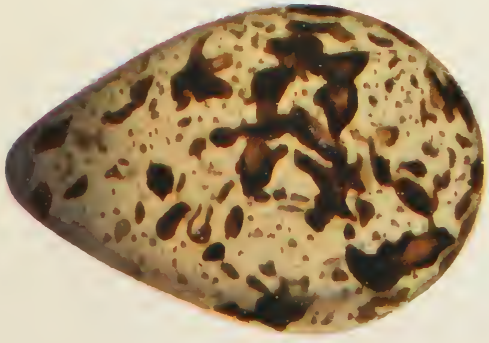

Lapwing

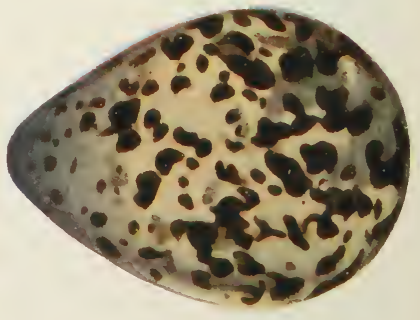

Dotterel. 
faintly striated in adult birds. The winter dress is much greyer. The bill and legs are blackish, the irides brown. Length, 7.5 ins. Wing, 4.7 ins. Tarsus, $0^{\circ} 9$ in.

\section{Bonaparte's Sandpiper. Erolia fuscicollis (Vieill.).}

The visits of Bonaparte's Sandpiper have been more frequent than those of the last species, but number under a score. Except for an unproved Irish record, and the first known example which was obtained in Shropshire, all have been to southern counties, and the majority in September and October, the time when the bird is travelling from its Arctic American home towards South America. It has been found in winter in Patagonia and the Falkland Isles, and occasionally touched Bermuda on passage.

This bird is not unlike a small, short-billed Dunlin in winter dress, but may always be distinguished by its white upper tailcoverts. In habits and food it differs little from other sandpipers ; its note, however, according to Dr. Coues, is distinctive, a low weet, and Rodd remarks that birds he saw in Cornwall had shorter, sharper calls than the Dunlin.

The head and upper parts, including the tail but excluding the upper tail-coverts, are brown; the head is streaked, and the feathers of the back have dark centres and rufous edges. The breast and flanks are grey, dotted with brown, the rest of the under parts white. In winter the bird is greyer, and the marks on the under parts fainter. The under parts of the young are tinged with buff, and white and rufous spots show on the back and mantle. The bill is black and short, the legs dark olive, the irides brown. Length, $7 \cdot 25$ ins. Wing, $4 \cdot 75$ ins. Tarsus, $0^{\circ} 9$ in.

\section{Purple Sandpiper. Erolia maritima (Brünnich).}

The breeding range of the Purple Sandpiper (Plate 56), though almost circumpolar and largely Arctic, extends further 
south than that of many of its relatives. It includes Scandinavia, Iceland, and the Froes; though nesting in the Shetlands is still unproved, reports that it has done so there and in other parts of Britain may have foundation. In the more southern portion of its range it is resident, and northern breeders do not travel far beyond the Mediterranean. In the British Isles it is a well-distributed visitor from August until June, and a few non-breeding birds remain all summer.

The Purple Sandpiper is local on our coasts simply because it is a rock-haunting species, and seldom visits sandy shores or mud flats. In small flocks it frequents tangle-covered reefs and rocky shores, feeding at low tide amidst the debris at the foot of the cliffs. It shares the tastes of the Turnstone, its constant companion. A very dark, squat bird, it may be recognised by its habits as much as by its appearance; if seen at close quarters, by no means difficult, for it is absurdly indifferent to the presence of man, its short yellow legs and the white patch on the inner secondaries when its flies are distinctive characters. The ebb is the favourite feeding time of this rock bird; it then catches the molluscs, worms, and crustaceans before they have hidden themselves under stones or in the thick weed; it wades in the shallowing rock pool, nipping up the retreating crab or prawn, and not refusing a small goby or other fish; Mr. G. Bolam has seen it devouring the ova of the lumpsucker. Surf on the rocks does not disconcert it; at the right moment it runs like a mouse to drier rock, or leaps into the air and hovers until the breaking wave retreats. It will alight in the backwash, and if swept from its foothold swims buoyantly. Stranded weed is thrown over and the astonished sandhoppers pounced upon.

Quick on the wing, its flight is more direct than that of most sandpipers; it hurries from reef to reef as each is uncovered. At high tide a little party will stand together on the rocks out of reach of the waves but not of the spray; there they will 
rest, preen the plumage, or sleep until the ebb. The bird is lethargic, deliberate, or very much in a hurry; it is a slow and systematic seeker for food, but immediately a fresh rock is exposed it hurries to reach it. In flight it has a low note, a whistle or pipe. As it flies a white patch is very distinct on its dark wing, and when it alights, and for a second holds its wings uplifted, the white under surface is very striking on so dusky a bird.

The upper parts are blackish in summer, but are relieved by buff and chestnut bars and spots, and white margins to the feathers. The lower back to the centre of the tail is very dark, almost black, the outer tail feathers are pale brown. The breast and flanks are greyish with dusky brown streaks and spots; the abdomen is white. In autumn and winter it is a still darker bird, glossed with purple sheen and with leaden feather edges ; the breast and flanks are mottled and streaked with blackish brown. The plumage of the young bird differs from the winter dress in the decided and neat pattern' caused by the white and buff fringes, whitest on the wing-coverts, buffest on head and lower back. The bill is orange at the base, dark towards the tip, the legs are yellow to orange, the irides blackish brown. The female is larger than the male, but I have not measured in the flesh any bird so large as 8.75 inches, the length given by Saunders and Dr. Patten. Length, 8 ins. WVing, $5 \cdot 3$ ins. Tarsus, 0.9 in.

\section{Dunlin. Erolia alpina (Linn.).}

Not only is the Dunlin (Plate 59) the commonest bird of the shore, but it is one of the most abundant British birds. It has a wide range in northern Europe and Asia, and migrates in winter to northern Africa and India, and in America is represented by a closely allied form. In the British Isles it is a resident, summer visitor, winter visitor, and passage migrant, 
for some of our home-bred birds leave in autumn, and certainly the majority of the vast hordes which may be seen in the spring and autumn on the west coast do not remain all winter. At all seasons there are Dunlins in our estuaries and on the shore, for numbers of non-breeding birds remain all summer. A few pairs nest in the south-western ccunties, but the true home of the Dunlin is from Wales and the Derbyshire Peak northward.

In any mixed party of small waders - "Little Birds," the Lancashire and Cheshire fowlers call them-the Dunlin predominates. It is a small, plump, fairly long-billed wader, ashy grey with white under parts in winter, reddish brown and black, with a large black patch on the lower breast, in summer. There is no more variable wader than the Dunlin in size as well as plumage. I have found birds vary in length from 6.9 inches to $7^{\circ} S$ inches, and in two cases both large and small birds were from the same party; it is now recognised that the so-called $T$. schinzii Brehm is merely a small Dunlin, and is not even entitled to sub-specific rank. The length of the bill is very variable; I have found it from an inch to an inch and a half long; the shorter bills were almost straight and the longer ones slightly curved downwards towards the tip.

Sandbanks and estuarine mud-flats are the favourite haunts of the Dunlin, but it is also common along any sandy shore, and in little sandy bays on a rocky coast; saltings and maritime marshes are also frequented; it delights in the tidal gutters. On the west coast, at any rate, the bird is most abundant at times of passage. Early in February, even in January, there is usually a northward movement, possibly of birds which have never left England, and in March the numbers are greatly increased, but in April and May the flocks are immense. Towards the end of July the second increase begins, which reaches its height in September. The winter flocks are often very great, but small compared with the countless hosts on migration. So familiar a bird has many lozal 
names; "Stint" is common in Yorkshire, where it is also the "Sand-runner" ; "Sand-lark," "Ox-bird," and "Purre" (from its note) are used in other parts. In many of its movements the Dunlin is deliberate and sedate, but it can run quickly, its short black legs twinkling, especially when chasing sandhoppers on the recently covered banks. At low water it wades in the shallow pools, its body low, its head forward, and shoulders hunched, as it probes the mud; it will swim a deep pool. It is never so energetic as the Sanderling or Ringed Plover, its constant companions. When feeding it does not pack so closely as the Knot, and often the birds scatter far and wide over the banks and saltings. It is less nervous than the Ringed Plover, often running rather than taking wing.

Flocks when feeding keep up a low twittering chorus, but the alarm note and flight call is a rather long purre; it is quick on the wing, swerving and rolling rather than zigzagging, and the pale outer feathers of the tail show clearly in contrast to the central pair as it flies from the watcher. Its greatest aerial skill, however, is shown by its ordered manœuvres in large flocks. The whole body will swing out over the water, skim the waves, rise until like a cloud they show against the sky, then suddenly rain down, flashing like silvery drops if the sun be shining. A rapidly moving flock at a distance flickers, now visible, now invisible, as white breast or dark back turn towards the observer, for every bird turns at the same moment. At times the flock thins out into a line stretching across the field of vision, and undulating in regular waves; then it will bunch, and without disorder every individual, moved by some strange social impulse, dives, swerves, or sharply changes direction at the required moment. The speed of the flying Dunlin is always great, and at night coastwise wires cause numerous fatalities. The rushing sound caused by the wings of a large party resembles escaping steam, and even two or three birds hurtling past produce a remarkable rustle. When the 
banks are flooded the birds will repair to the marshes or fields, and after a few evolutions settle to rest or hunt for insects. All will stand, head to wind, bobbing frequently, but if the wind is high, the nearest birds constantly rise, flutter over their companions and drop behind for shelter, so that the whole party slowly shifts down-wind.

The marine food is similar to that of all small waders, but when nesting, and halting inland on migration, insects are largely eaten. To the meres, reservoirs on the hills, and sewage farms the bird is a frequent visitor in winter as well as on passage ; it paddles in the settling tanks, finding an abundance of dipterous larve, and often remaining many days. On the coast it feeds with the rising and falling tide, by night as well as by day, sleeping at high water or at irregular intervals.

The Dunlin nests on the high moors, often at 2000 feet or more, but also on low marshes and saltings at sea-level, even in the vicinity of busy Lancashire towns. On the moors I have watched the bird soaring and swooping like a Snipe, and listened to its nuptial trill, mingled with the clatter of clogs and rattle of looms in the valley a few hundred feet below. The breeding call-dwee, dwee-is quite distinct from the purr of alarm when the bird is put off the nest. The nest (Plate 58) is a neat cup of grass, about three inches in diameter, often well hidden in ling or moorland grass, but at times barely screened. The four eggs (Plate 44) are variable in ground and markings, generally brown or yellow, sometimes green, with brown, sepia, and grey blotches, as a rule thickest at the larger end and often more or less oblique; they are laid in May or June. The nestling has rich buff or chestnut down, marbled with black and flecked with white; its under parts are almost white.

In summer the adult bird is reddish brown mottled with black on the upper parts; the wings and some of the coverts ashy grcy, and the upper breast greyish white and striated. The lower breast and part of the abdomen are black, the size 
of the area very variable; the rest of the under parts are white. The upper parts are ashy grey in winter, and the under parts, except for an indistinct band on the breast, are white. The black is lost gradually in autumn; in September I have seen bircls in almost unaltered summer dress, and Mr. G. Bolam records full winter plumage in June; indeed, he says no bird is "more casual in its change of dress." In the young the brown upper parts are mottled with rufous, buff, and black, and the dark head is streaked with rich brown; the breast is suffused with buff, and the white under parts are dotted and splashed with brown. The bill and legs are black, the irides very dark brown. Length, 7.5 ins. WVing, $4^{\circ} 6$ ins. Tarsus, 0.8 in.

\section{Curlew-Sandpiper. Erolia ferruginea (Brünn.).}

The Curlew-Sandpiper (Plate 59) breeds in Arctic Siberia, and in winter ranges as far south as the Cape, the Malays, and Australia. To the British Isles it is a passage migrant, irregular in numbers, but sometimes abundant; exceptionally, it is a winter visitor. Indeed, though it is never present in any numbers except when migration is at its height, there is no month in the year in which it has not been recorded. Autumn immigration begins in July, and often birds are about until November; spring migration lasts from March until June, and there are scattered records for the other three months. Though the largest numbers visit the east and south coasts it is by no means rare in the west, and its frequent occurrence inland, especially in September, indicates more or less regular overland migration.

In spite of the long, curved bill, from which it gets the rather trivial name of Pigmy Curlew, and the fact that its legs are longer, it is not always easy to distinguish from the Dunlin, when with this and other waders it is feeding on the shore. When, however, the flock takes wing, its white upper tail-coverts 
show at once if the bird flies away from the observer ; they are almost as striking as the lower back of the House-Martin. Immature bircls, and the majority that visit us in autumn are immature, have shorter and less curved bills than those which are adult. Even in mature birds the length of the bill varies; Mr. O. V. Aplin told me that he found bills varying from I' 35 to $x^{\circ} 6$; inches. In spring, when the summer dress is often partially attained, there is less difficulty, for it is even redder than the Knot; indeed, Seebohm calls it a miniature Knot with a long, curved bill. Its haunts are those of the Dunlin and Sanderling-the banks, mud-flats, and saltings. In some seasons very few birds are noticed; probably the force and direction of wind regulates its eastern or western route.

The flight of the Curlew-Sandpiper is rapid and strong, more undulating, but less erratic than that of the Dunlin; yet large flocks will indulge in complicated but well-ordered evolutions. Its call on rising sounds to me like twee, twee, twee, but it is sometimes written wiek-a-wiek; it has also a whistling twer-ret, which perhaps is the note said to resemble that of the Dunlin. When feeding, a flock keeps up a low, rather musical twitter. On the shore it often runs quickly, but at other times is as deliberate as the Dunlin, especially when working the pools at low tide. Marine invertebrates are its food on the shore, but inland it will eat fresh-water molluscs and insects. The tanks in sewage farms attract it more frequently than is generally supposed; on one farm near Manchester birds were present one autumn for five weeks. Captain A. IV. Boyd, who watched the varying numbers, counted nineteen one day, but I was not lucky enough to see so large a party. All those that I saw were buff-breasted birds of the year. On this same farm Captain Boyd saw a single bird in May.

In its breeding dress the Curlew-Sandpiper has the upper parts chestnut, variegated with black and grey; the wingcoverts show white margins, and the wings are ashy grey; the 


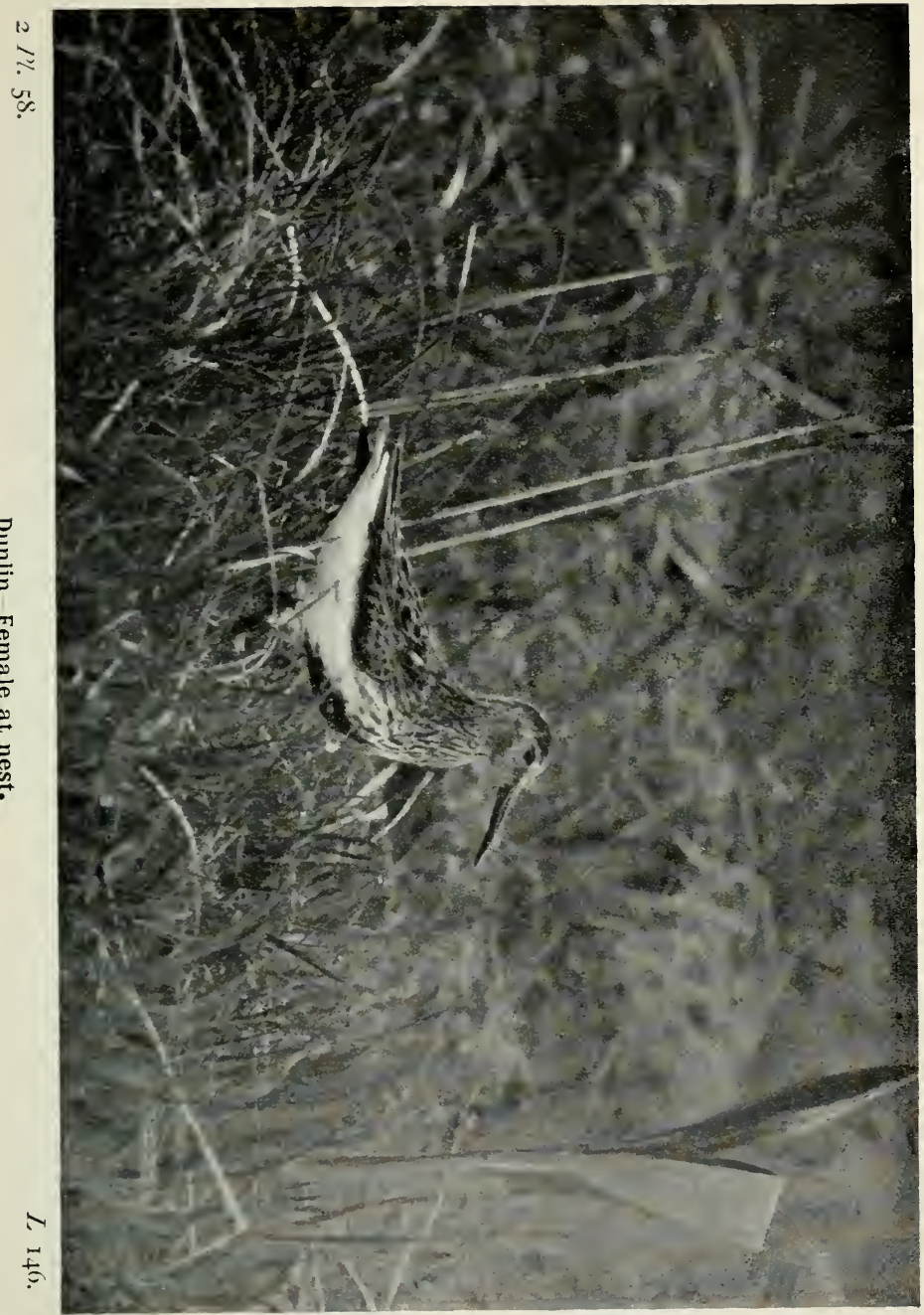




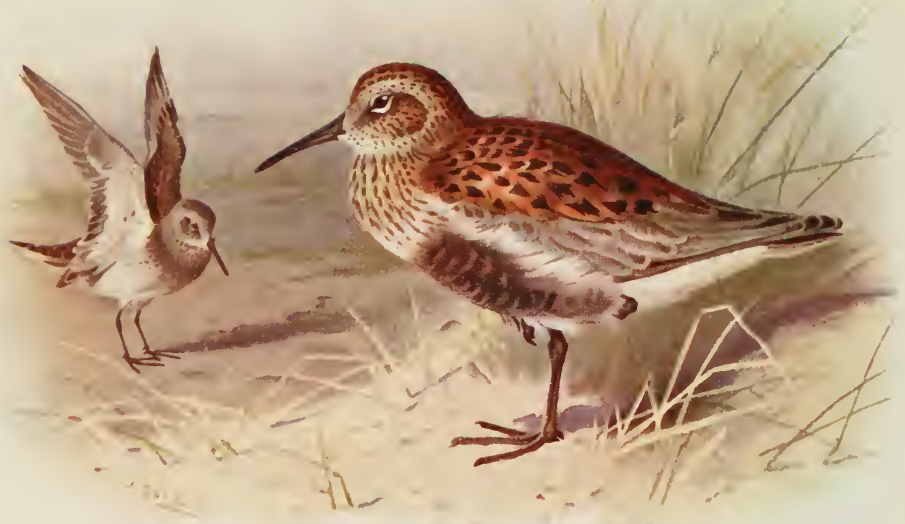

-

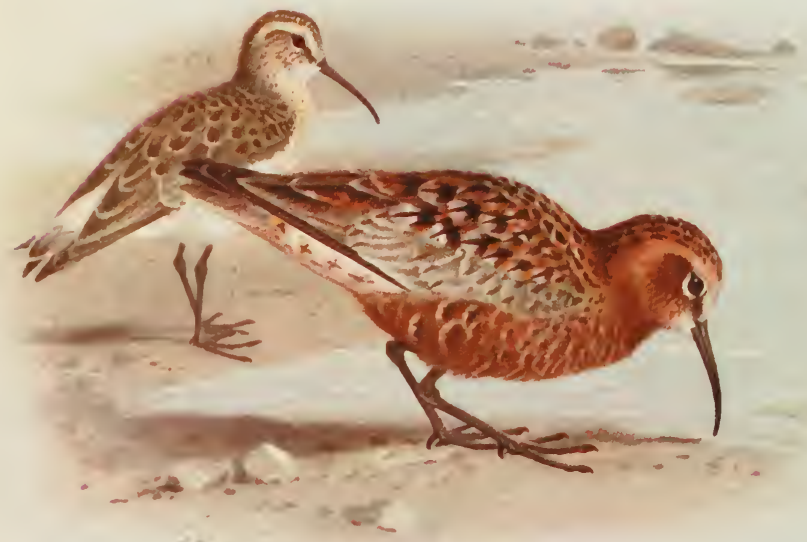

$2 / \% .59$.

Dunlin (Summer and Winter).

Curlew Sandpiper (Summer and Autumn). 
upper tail-coverts are white barred with black. The reddish chestnut under parts are but slightly marked with grey; the axillaries are white. The bill and legs are black, the irides brown. After the autumn moult the upper parts are ashy brown, but faintly edged with white and buff on the back; the head is streaked, and the pale-brown face darkest on the cheeks; the upper tail-coverts and under parts are white. The young have the breast and flanks washed with buff, and a considerable amount of buff shows on the greyish-brown back. Length, 8 ins. Wing, $5 \cdot \mathrm{I}$ ins. Tarsus, $\mathrm{r} \cdot 2$ ins.

\section{Buff-breasted Sandpiper. Tryngites subruficollis}

\section{(Vieill.).}

The Buff-breasted Sandpiper nests in Arctic America and, apparently, eastern Siberia, and winters in South America. It has occasionally wandered to central Europe, and has reachea England and Ireland, most having been seen in eastern and southern counties in September, though there are records for spring and summer. Possibly this, and some other species of American birds, may not have crossed the Atlantic, but have travelled by the easier though much longer westward route. It is not now possible to investigate the older records, including the Lancashire specimen, said to have been obtained in May, but some are not above suspicion.

Mr. G. Caton Haigh, who shot one on the Lincolnshire coast, confirms the remark of Saunders that the bird looks, both in flight and plumage, like a very small Reeve. In summer dress the upper as well as the under parts are buff, the former with black and brown spots and mottles; the outer tail feathers are barred. Most of the under surface of the wing and the axilliaries are white, but the secondaries and under wingcoverts are marbled with black, as are the inner webs of the quills. The winter dress closely resembles that of summer. 
On immature birds the marbling is obscure and greyer, and the upper parts show white edgings. The bill is greenish black, the legs are yellowish, and the irides brown. Length, 8 ins. Wing, 5.25 ins. Tarsus, $1 * 25 \mathrm{in}$.

\section{Sanderling. Calidris arenaria (Linn.).}

In winter the Sanderling (Plate 6r), which nests far north in Arctic Asia and America, reaches the southern limits of Africa, America, and Australia; the majority of the large numbers which visit our shores are halting on the long journey. September and May are the great Sanderling months, but there are some birds on the shore at all seasons; many winter here, and a few non-breeding birds linger through the summer.

This little wader, as its name suggests, prefers sand to mud, and is commoner on the beach than in the estuary. Inland waters are not infrequently visited on passage. Dunlins and Ringed Plovers are its companions, but it will mix with other waders, and when the big packs of Knots rest at high-water mark, there are generally a few "little birds" with them. The Knots line the ripples, the tall Godwits stand in the water, but the Dunlins and Sanderlings fringe the shore side, sheltered by their larger companions. When the feeding Dunlins sedately probe the mud, the more energetic Sanderlings, recognised by short black bills and restless activity, race to and fro, chasing the sandhoppers, and even hurrying to capture washed-up molluscs. The fact that the Sanderling may be distinguished from all other small waders by the absence of a hind toe is of small value unless the bird is in the hand; it is not easy to say, toe or no toe, on such quickly moving legs. But the grey, almost pearly, winter dress, is whiter than that of any other wader; in a good light, winter Sanderlings look white spots on the yellow sand. If summer plumage has been partially attained it is more like a Dunlin with a short bill, but it never has the 
black on the under parts. The quick flight, often with quivering wings, is rather like that of the Common Sandpiper, but the bird is not always in a hurry to fly. A number of Sanderlings will run along the beach more quickly than a man can walk, and finally skim out over the water to settle behind the disturber. As the bird runs it will often uplift its wings, holding them with the tips pointed skyward.

The first immigrants, usually in quite small parties, arrive about the middle of July, but in August the flocks are often large. They do not cling to the tide-line, but scatter over the beach at low water, working the shallow, slowly draining pools. Most of the earlier birds show warm chestnut in their dress, and the birds of the year, which have hurried from the short Arctic summer, have the necks and breasts tinged with buff. Later in August the chestnut markings are lost, and for a time adult birds have very black backs. In the same flock in September I have seen some in full winter grey, whilst others were very black and white. Even in October a few birds retain traces of warm colour, for like the Dunlin this bird is irregular in its changes, and often moults slowly. The returning birds arrive towards the end of March, and in April many are still grey, but by early June most are in nuptial garments. Perhaps more than other waders, the Sanderling varies its diet of marine invertebrates with vegetable fragments, picking up bits of seaweed or the buds and tender shoots of littoral plants. The note in flight is a sharp quik, quik, and on the beach a rapid wee, wee, whit.

The upper parts in summer are warm chestnut, streaked and speckled on the head and breast, and variegated with black, grey, and white on back and wings; the lateral tail-coverts and under parts below the breast are white. In winter the upper parts are delicate French grey with darker but not very distinct shaft streaks; the quills are greyish brown. A line above the eye and the under parts are white. Young in autumn are spotted with black, white, and buff on the back and wings, and 
have the upper breast tinged with buff. The bill and legs are black, and the irides dark brown. Length, 8 ins. Wing, +77 ins. Tarsus, 0.8 in.

\section{Sub-family TOTANINÆ. Sandpipers, Godwits, and}

\section{Curlews.}

Bill straight or curved; legs usually long; four toes, hind toe elevated; two or three anterior toes united at base.

\section{Ruff. Machetes pugnax (Linn.).}

The Ruff (Plate 62), formerly an abundant nesting species in Britain, was practically wiped out during the first half of the nineteenth century; it was good to eat, and easy to kill when obsessed with its spring madness; so soon as it was rare the collectors took care that no eggs were hatched. By I880 very few nesting pairs remained, and during the last forty years, though birds have occasionally attempted to nest, most of the eggs laid are in private collections. The breeding range includes much of northern Europe and north-western Asia, and in those parts of Holland where the bird is protected it is plentiful. It winters in Africa and southern Asia, and in Britain is now a regular though hardly abundant passage migrant in autumn and spring. As a spring visitor it is more frequent in the eastern counties than elsewhere, but it is by no means rare in autumn in the west. Occasionally birds are noticed in winter and summer months.

When, between April and the end of June, the male is in full dress, with frill and head tufts, he is unique, but no description of plumage can include all variations of colour that he sports; he is our most variable bird. The Reeve, the female, is more stable, and in winter the Ruff resembles her; she is a little like the Redshank, but can always be told by the dark secondaries and 


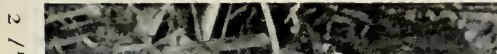

ant.

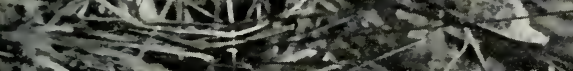

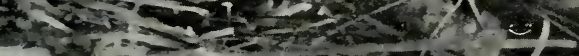

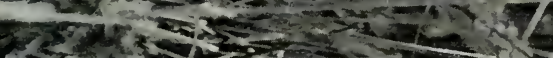

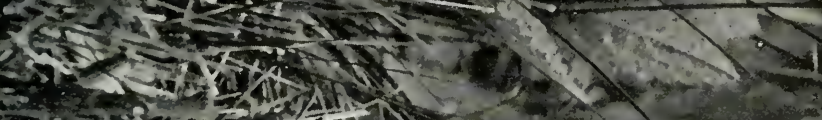

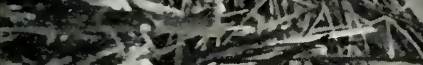

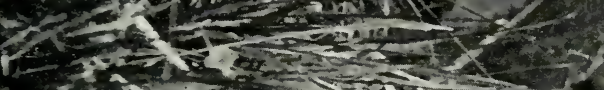

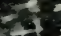

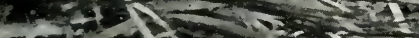

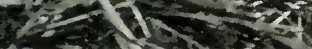

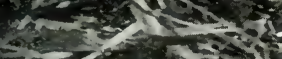

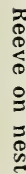

2

(1)

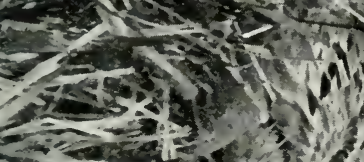

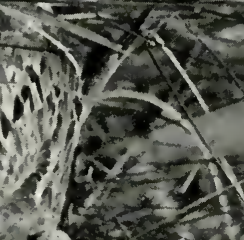

20

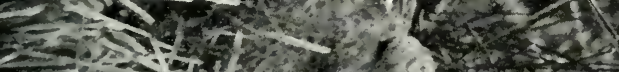

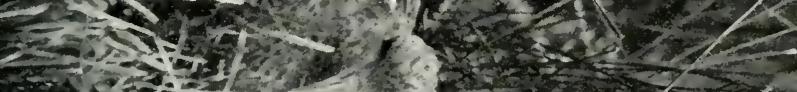

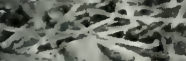

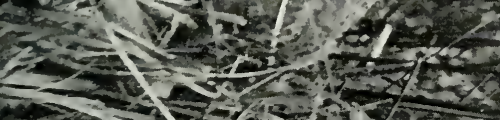

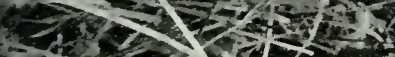

1
$p_{3}=3$

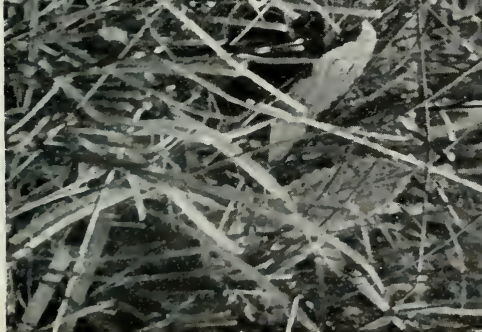

$$
\frac{13}{20}
$$

$\lim _{2}+\frac{2}{2}$

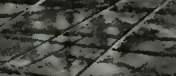

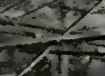
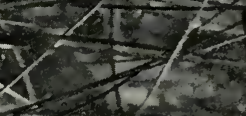

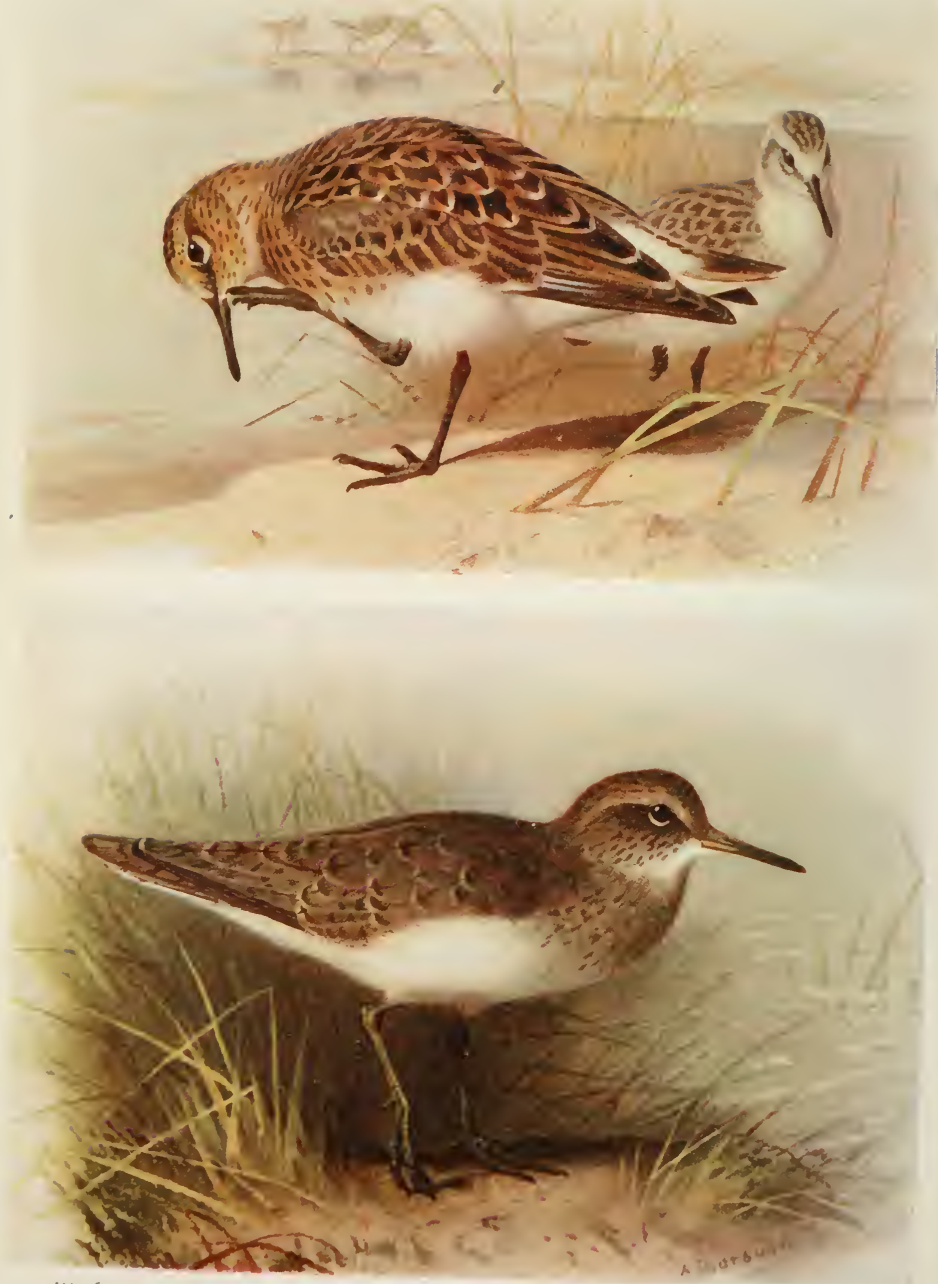

$2 / \% 6 \mathrm{I}$.

Sanderling.

L $15:$

Common Sandpiper. 
rump. The neatly patterned back and wings, due to the buff and grey feather margins, are, however, particularly striking. Though often seen on the shore, the bird is frequent by inland waters, visiting lakes, reservoirs, and sewage farms on migration, and lingering where food is plentiful if permitted; it feeds largely on insects and worms. It is quick on the wing, often rising high if flushed. In spring and autumn I have seen it with Redshanks ; it rose silently, they did not. Indeed, it is at all times a silent bird, and I have never heard its note, described as tu-whit, or by Macpherson as a "loud shrill whistle." It is said to croak when displaying, but when I have watched the display of aviary birds I have noticed no sound. Its carriage when feeding is erect, and if suspicious the neck is straightened, but it does not jerk like a nervous Redshank. It will probe the mud, though not so deeply as a Snipe. I find it described as a nocturnal feeder, but I have watched it feeding by day on a Norfolk marsh, on Lancashire sewage farms, and Cheshire meres.

Though it may be that females are more numerous than males, the bird is not exactly polygarnous ; promiscuous sexual intercourse seems usual; pairing does not necessarily imply permanent mating. The specific name, pugnax, refers to the habits during display, but though there is much "You hit me first!" in its behaviour, little actual fighting is indulged in ; the bird shows off its frill and "ear" tufts to full advantage, and tries to look fierce, but its aggressive rushes end in bluff if its rival refuses to move. The attitudes assumed during display are ludicrous, for the bird will crouch on the tarsus, with bill resting on the ground, ruff spread and tufts uplifted, and thus pose before either the Reeve or a rival Ruff. Often the wings are spread flat upon the ground. The Reeves appear to be rather bored, but doubtless do make selection, and their choice must be varied, for no two Ruffs are exactly alike. When the bird is not displaying, the frill lies back and is not conspicuous. 
The nest is well concealed in long herbage; the bird shown on Plate 60 was photographed by Miss Turner in 1907, and is perhaps the last authenticated case of nesting in England. It is true that the bird formerly nested in Lancashire, as Mr. R. J. Howard showed, but the statement that eggs were laid in the county in 1910 has not been confirmed; the evidence, so far as was made public, rests on the identification of eggs said to have been taken in Lancashire. The four pyriform eggs show considerable variation in ground and markings; they are laid in May or June. The nestlings have buff and chestnut down, streaked and barred with black, and frosted with white.

In spring the face of the Ruff is covered with rough warty and usually yellowish skin; on the head are two erectile bunches of long feathers, and a flowing frill hangs from the neck; the tufts and frill may or may not agree in colour, and may be purple, red, brown, black, or white, be plain or barred or streaked with some other colour. The variation also extends to the head, breast, and upper parts generally. There is, however, a conspicuous white patch on either side of the upper tail-coverts which appears to be constant in both male and female, and the central tail-coverts are almost invariably barred. The Reeve is greyish brown, spotted with black, the grey-edged spots forming regular streaks on the mantle. The neck, flanks, and breast are greyer and mottled with black; the rest of the under parts are white. In winter the sexes are alike, except in size, the male being much the larger ; the upper parts are ashy, with dark spots, and the under parts white, except on the neck and breast, which are streaked. The upper parts of the young are variegated with black, brown, and buff, and the breast is dull buff, but the same neatness of pattern shows on the back. The white tips of the secondaries form a narrow wing bar. The bill is not always straight; I have twice seen it almost as much curved as that of the Curlew Sandpiper; this was especially noticeable in a bird which 
Mr. T. Baddeley and I watched when it was feeding alongside some Curlew Sandpipers. The colour of the legs is generally described as yellow, brownish yellow, or orange, but though each is correct for certain males, the variation applies to soft parts as well as plumage. I have seen one Ruff in autumn with reddish-yellow legs, but the majority of adult birds and young that I have examined or seen at close-enough quarters to be sure about colour, had legs varying from greenish grey to olive brown or lead colour. Gould figures his immature bird with lead-blue legs, and the Reeve in summer dress with greenish grey. Most writers seem to have overlooked or ignored Montagu's pertinent remark that when identifying a Ruff at any age, "neither the colour of the bill, nor the legs, is to be depended upon." The irides also vary, usually brownish with a greenish or reddish cast. Male: Length, $12^{\circ} 5$ ins. Wing, $7 \cdot 25$ ins. Tarsus, 2 ins. Female: Length, 10 ins. Wing, 6 ins. Tarsus, 175 ins.

\section{Semipalmated Sandpiper. Ereunetes pusillus (Linn.).}

There is a single British record for the Semipalmated Sandpiper, a small wader, not unlike a Little Stint, but with the toes connected by slight webs at the base. An immature bird, recorded as shot in Kent in September 1907, was identified by Dr. N. F. Ticehurst. Length, 6 ins. Wing, 3.9 ins. Tarsus, 0.95 in.

\section{Bartram's Sandpiper. Bartramia longicauda (Bechst.).}

As a visitor to the British Isles, Bartram's Sandpiper, another American species, well known to wander on migration, is rare and irregular, but certainly deserves a place as a British bird. Ever since it was first recognised in 1851 , it has appeared at intervals and in widely scattered localities from Northumberland to Cornwall, and at least twice in Ireland. Most of the 
occurrences have been in autumn or early winter, but it has been reported in July. It is a large sandpiper, blackish brown on the head, where there is a median buff streak; the darkbrown upper parts are barred with black and most of the feathers have buff margins. The rump is blackish brown, the rather long tail buff, barred with black, and white tipped. Conspicuous arrow-head marks show on the buff breast and bars on the flanks; the chin and abdomen are white. Winter birds are yellower, and the young more rufous. The bill is yellowish, darker at the tip, the legs dull yellow, and the irides brown. Length, $\mathbf{2} 2$ ins. WVing, $6 \cdot 8$ ins. Tarsus, $\mathbf{I} \cdot 8$ ins.

\section{Redshank. Tringa totamus (Linn.).}

The noisy, restless Redshank (Plate 64 ) is a resident and abundant passage migrant and winter visitor to all parts of the coast; it has greatly increased in recent years. Abroad it breeds throughout Europe and Asia, wintering so far south as the Cape and the Malays. Not only does the bird nest freely on coastwise marshes and saltings, but during the last decade it has established itself in many far inland haunts, nesting in damp meadows as well as marshes. Most writers say that it is rare in Wales; in some localities it is plentiful.

The Redshank is easily recognised. It announces its presence by a triple call-tu, $t u, e e$-or a long, plaintive $t y u$, well suggested by one of its local names, "Teuke." It stands, bobbing in sandpiper fashion, dipping its head and breast as if hinged on its long red legs, and, when it takes wing, shows a white lower back and an even more distinctive broad white border to the wing, formed by the white secondaries and the white on the inner primaries. Although a greyish-brown, redlegged bird when feeding, it looks very black and white in flight. In March there is an increase of birds at the breeding stations, and in April and May a strong northward movement. 

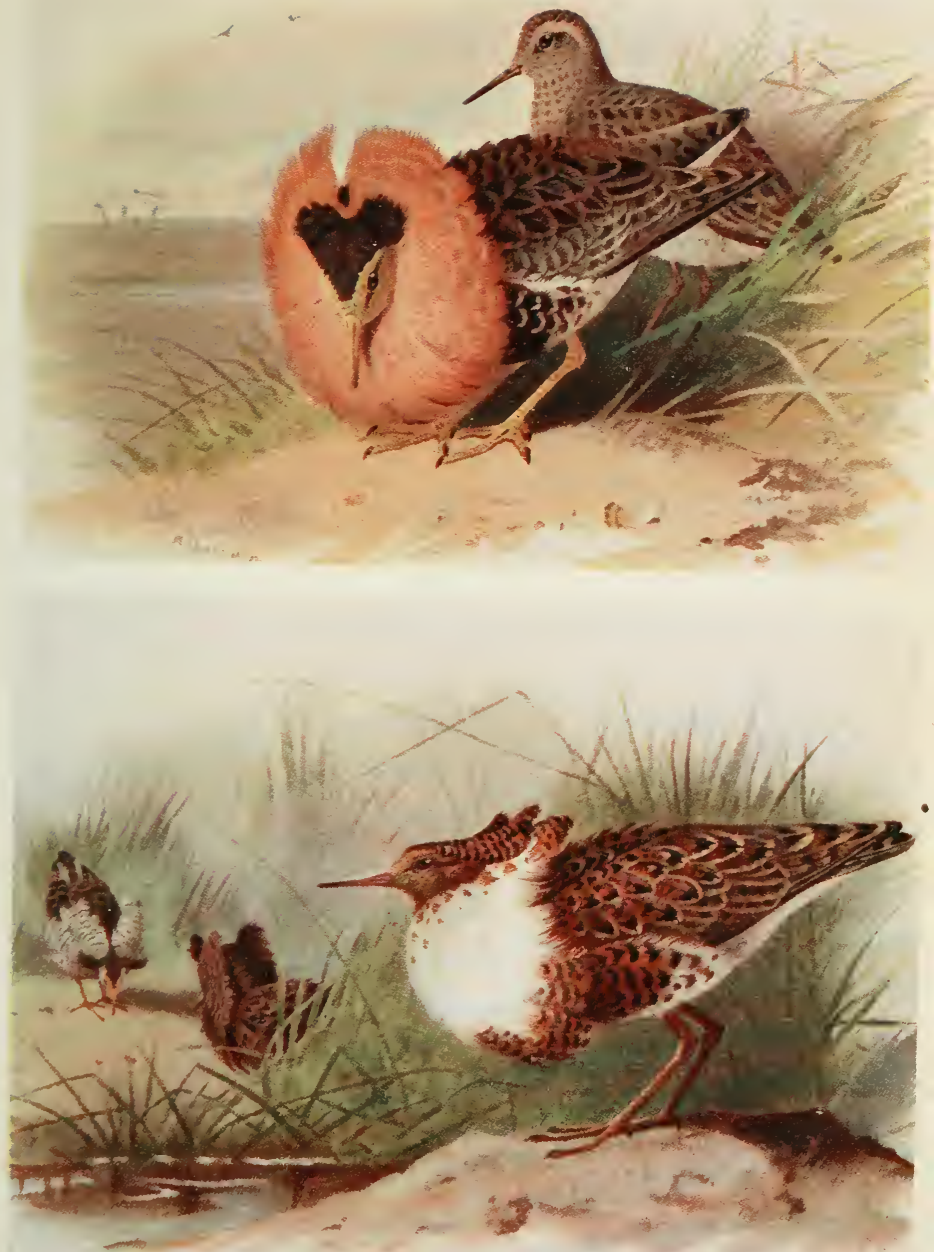

$21 \% .62$. 


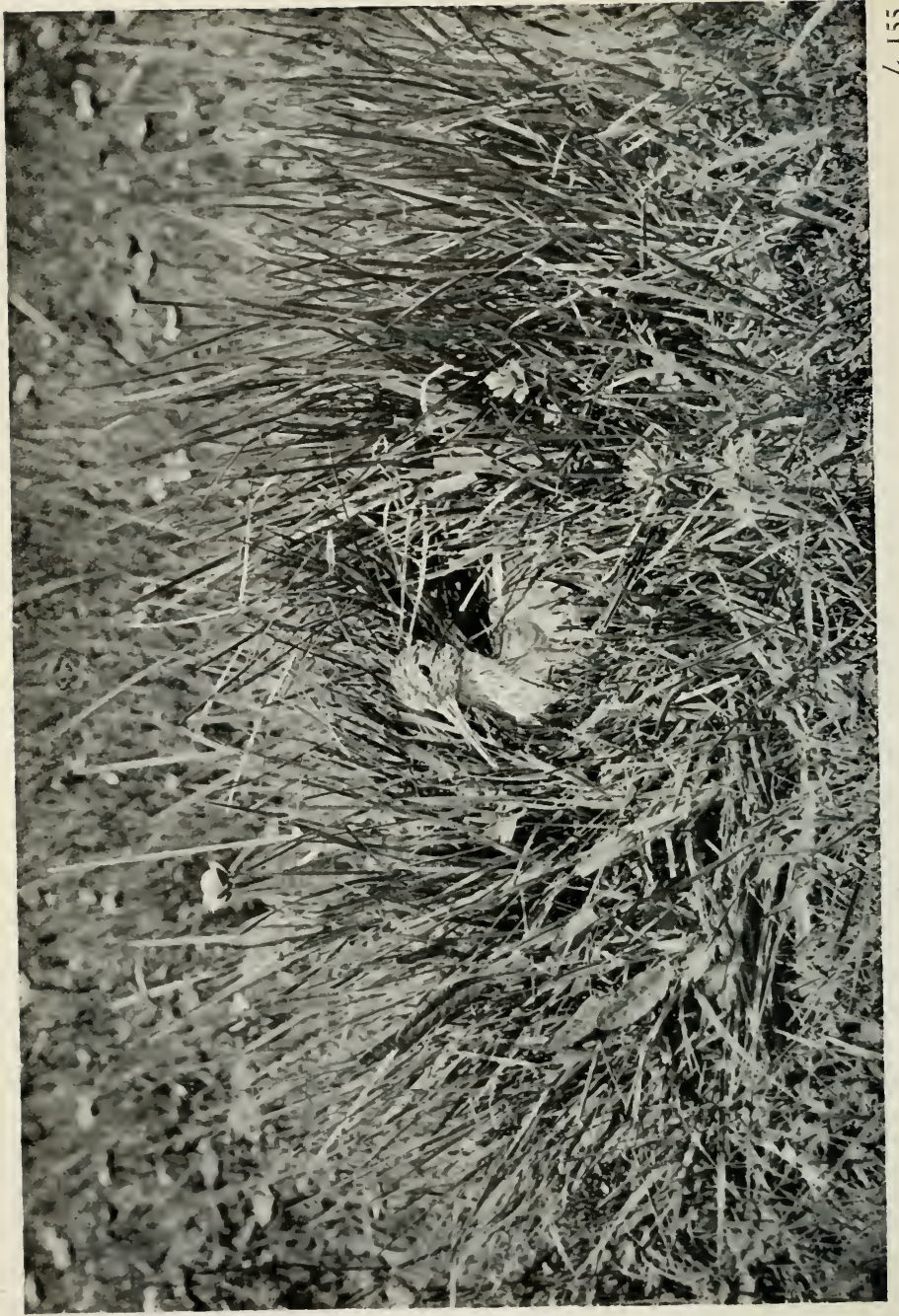


In August immature bircls appear on the shore, and in September southward migration is in full swing ; in favourable localities large flocks remain all winter. Grass-lands and saltings, mud-flats and sandy shores, even rocky coasts, are frequented, and no wader more frequently visits the sewage farms. Insects, inolluscs, and crustaceans are its food; I have seen it with Black-headed Gulls and Lapwings following the plough. In shore pools it wades belly deep, and swims easily, but at high tide it awaits the ebb on rocks, shingle, or sand, acting as a sentinel for its less wide awake companions, for it is ever on the alert, ready to take alarm. Its flight is swift and erratic, and it calls loudly as it flies.

In nuptial flight the Redshank dances in the air, rising on quivering wings, yodeling a long trilling tchu, tchu, tchu, with emphasis on the $t$. It drops a few feet and rises, again and again, dancing above one particular spot like a gnat in sunshine. As it descends, still trilling, gliding diagonally earthward, the wings are bowed, the tips held downward. If the nesting area is invaded the notes change to a yelping, scolding tuik, tuik, and it mobs the intruder long after he has passed the danger zone. I have seen half a dozen or more Redshanks fly yelling after a passing Harrier, a Kestrel, and even a harmless Cuckoo. The nest, which is usually in a dry spot, though sometimes in wet marsh, is often well concealed by the surrounding grass or rushes (Plate 63 ) ; the bird interweaves the ends of the grass so as to form a tent-like screen. Other nests are quite open; in one colony on sheep-cropped saltings all were exposed, and in another, two had thick tents, one a loose tunnel of rushes, and others had no cover. During display, when not in the air, the male will trip lightly towards the female, stiffly holding up the pointed wings, so as to exhibit the white under surface. Though so wary, the bird is often a close sitter; there are many recorded instances of females which would allow themselves to be taken in the hand rather 
than leave the eggs. The eggs (Plate 54), normally four, are laid in March or April ; they vary, but a not unusual type is like a small egg of the Lapwing with a very light ground. The nestlings, which crouch for concealment like other waders, are rich buff, with black lines or curves on the head and back. The legs are very pale yellow, and the bill blackish olive.

In summer dress the upper parts are brown, barred, speckled and streaked with darker brown; the streaked neck and breast are paler, and the flanks are barred. At all seasons and any age the lower back is white, the upper tail-coverts and tail are white barred with black, and the axillaries and under wingcoverts are white. The general colour is more ashy in winter, and the under parts are purer; the upper parts of the immature bird are buffer, and the streaks are more marked on the breast and flanks, but the most marked difference is in the colour of the legs, which are yellow. These in the adult bird are orange-red, as is the base of the bill, the tip being black. The irides are blackish brown. Length, 12 ins. Wing, 6.5 ins. Tarsus, $1 \cdot 9$ ins.

\section{Spotted Redshank. Tringa maculata (Tunst.).}

The Spotted or Dusky Redshank (Plate 64) is a rare visitor on passage from its Arctic European or Asiatic home to winter quarters in Africa; it also occurs on the northward migration, and has been recorded in the winter months. Though irregular, it has most frequently been noticed in south-eastern counties, but has occasionally occurred in the west, and in Scotland and Ireland. April, May, and June, and August and September, are the months when most have been seen.

The Spotted is a larger, taller bird than the Common Redshank ; its bill and legs are longer. It can always be told from the commoner bird, even in the field when its red legs might confuse, by the secondaries, which are barred with black and 
grey-brown, so that they do not show as a conspicuous white band. The central tail feathers also differ, being ashy grey or brown, but with obscure bars. Its habits and food are practically those of the Redshank, though it is said to haunt the shore less frequently, and many of the records are from inland localities, but nowadays the Common Redshank is very much an inland as well as shore species. Its call-note, however, is distinct to any one fainiliar with the Redshank's voice; Mr. C. Oldham writes it tchuet, and Dr. Pattentu-zuhee-te.

In summer the bird is indeed a Dusky Redshank, for the general colour of both upper and under parts is blackish. On the back and wings, which are tinged with brown, are the white flecks which give it the name Spotted. The rump and upper tail-coverts are barred with black and white; the centre of the tail is brownish grey, faintly barred. The base of the bill and the legs are dark red, much duller than in winter; the irides are dark brown. The winter bird more closely resembles the Common Redshank, especially as its legs are more orange-red, but the upper parts are flecked with triangular white marks; the distinction of the secondaries and tail holds good. The under parts and the under surface of the wing are white. The young bird in autumn has the upper parts as in the winter dress but browner, and the throat, breast, and flanks are grey with darker markings. A noticeable dark streak passes through the eye, showing up a white superciliary stripe. Length, I 3 ins. Wing, $6 \cdot 5$ ins. Tarsus, 2 ins.

\section{Greater Yellowshank. Tringa melanoleuca (Gmelin).}

The Greater Yellowshank, a North American bird, where it is sometimes called the "Winter Yellowlegs," has occurred once, in September, on the Scilly Isles, and has been reported from Warwick and Sussex. It is a larger bird than the Red- 
shank, and distinguished by its bright yellow legs, and from the Greenshank, which it approaches in size and plumage, by its greyish brown, not white, rump, and its barred upper tailcoverts and axillaries. Its dusky-brown rump differs from that of the Yellowshank or "Summer Yellowlegs," which is white, barred with brown. The bill is blackish, the irides brown. Length, 14 ins. Wing, $7 \cdot 75$ ins. Tarsus, $2 \cdot 5$ ins.

\section{Yellowshank. Tringa flazipes (Gmelin).}

The American "Summer Yellowlegs" is a much smaller bird, which Seebohm likens to a large Wood-Sandpiper. Immature Redshanks, with their yellow legs, have been reported as Yellowshanks, but the secondaries are dark, so that no broad white wing border shows in flight; a further distinction is that the axillaries are barred. The bird has occurred on migration two or three times in England and once on Fair Island. Length, $0^{\circ} 75$ ins. Wing, 6.4 ins. Tarsus, 2 ins.

\section{Marsh-Sandpiper. Tringa stagnatilis (Bechst.).}

The Marsh-Sandpiper inhabits southern Siberia and some parts of south-eastern Europe, but it has seldom wandered to Britain. One was obtained in autumn at Tring, and three have since been recorded from Sussex in spring and summer. Mr. M. J. Nicholl, who knows the bird in Egypt, says that it is not unlike a small. Greenshank with the call and flight of the Wood-Sandpiper, from which it may be distinguished by its paler colour and longer legs. It is a grey and greyish-brown bird with white under parts in winter, but in summer the breast is spotted and the upper parts show decided black marks; like the Greenshank, it has a slightly recurved bill, greenish brown in colour, and the legs are dark greenish, the irides brown. Length, $10^{\circ} 5$ ins. Wing, 5.3 ins. Tarsus, 2 ins. 

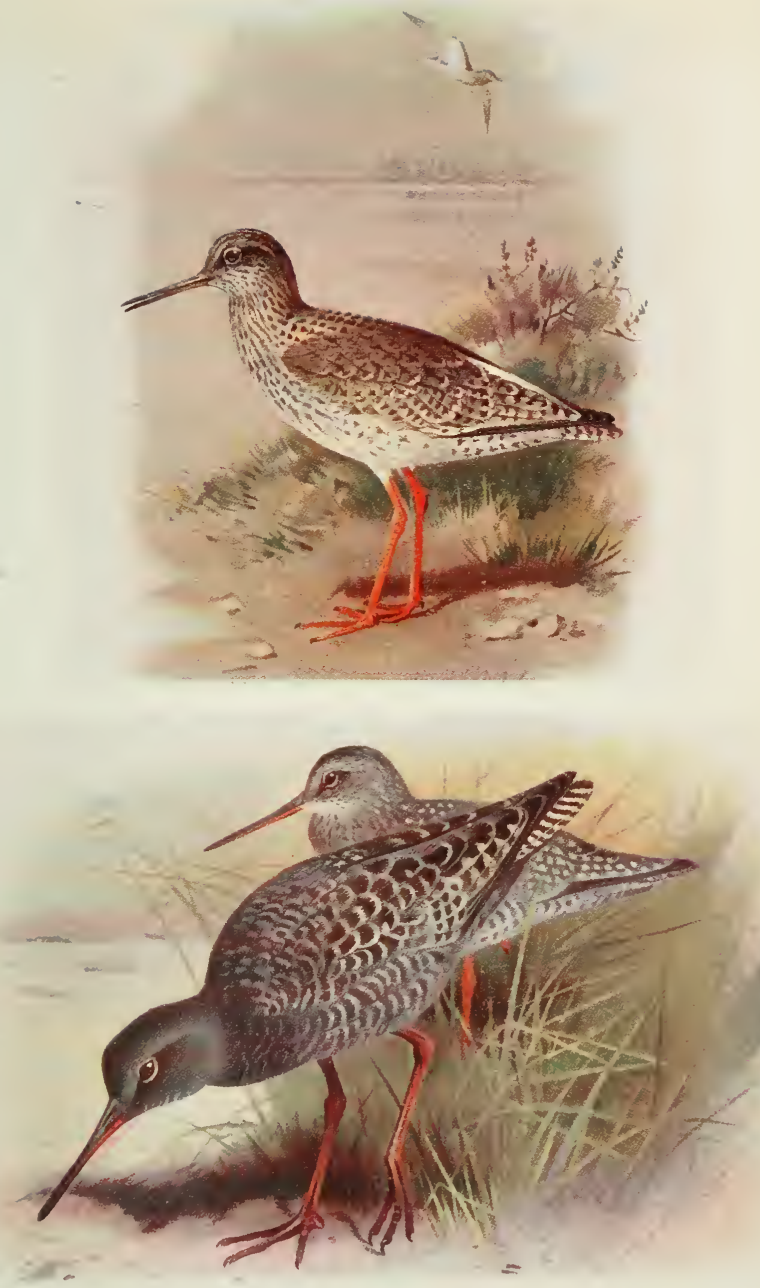

2 P. 64.

Redshank. 


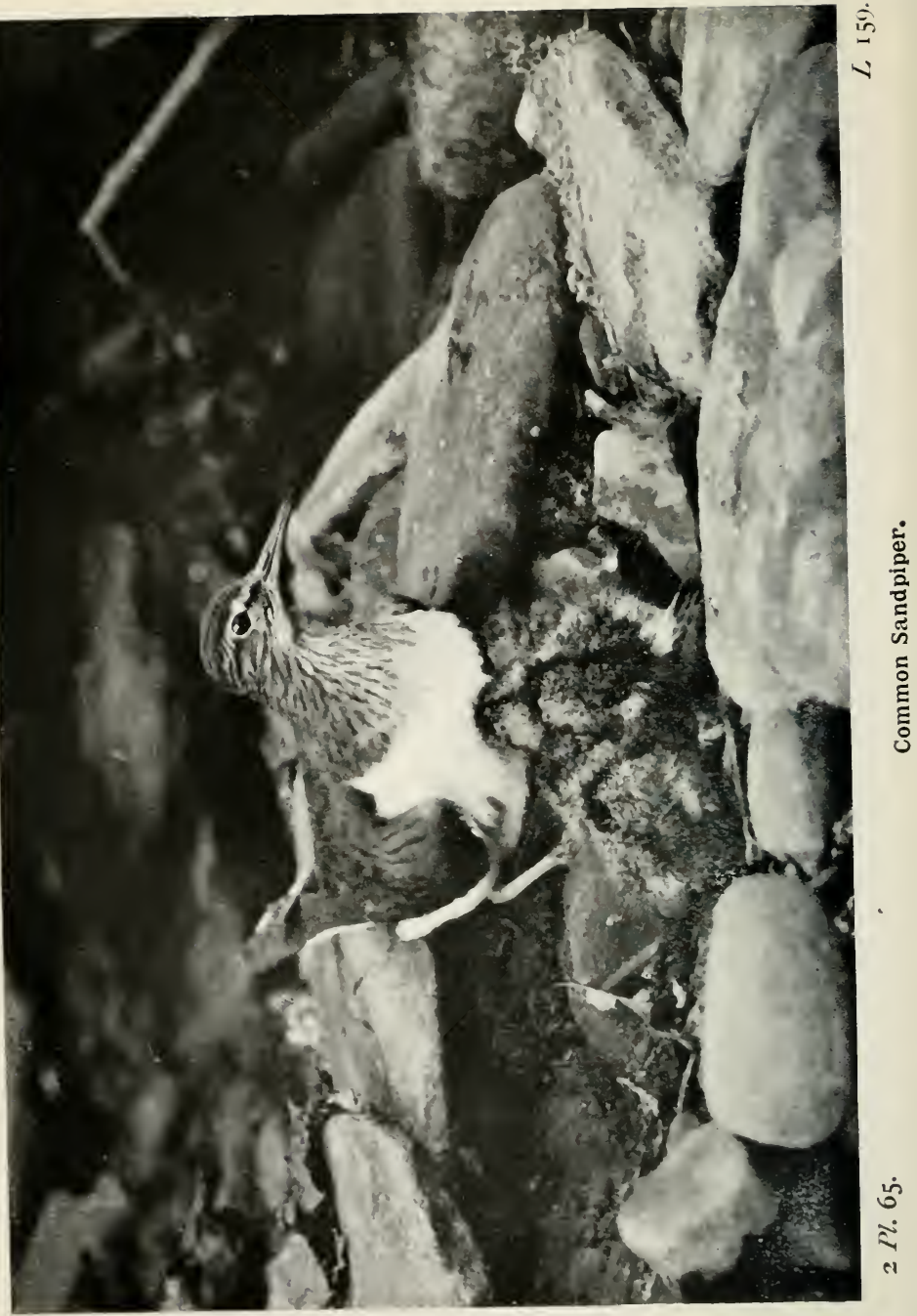




\section{Greenshank. Tringa nebularia (Gunner.).}

In northern Europe and Asia the Greenshank (Plate 66) nests south of the Arctic circle, and it visits southern Europe and Africa in winter ; in most parts of the British Isles it is a regular though seldom abundant passage migrant, joining other waders on the shore and frequently appearing on inland waters. In the north of Scotland, and on a number of Scottish islands, it nests in small numbers. A few birds winter in Ireland and, more rarely, in England.

The long, slightly uptilted bill of the Greenshank is usually a character by which we can separate it from the Redshanks with which it often feeds, but it is a longer-legged, larger bird, and when it rises, though the white rump is very conspicuous, shows no white wing border, for its secondaries are brown. Its pose, too, is different, the body being held horizontal, at right angles to its legs, which has the effect of making it look a much longer bird. Though alert enough, it has little of the nervous ducking action so characteristic of the Redshank. In winter it is a greyer bird, and in summer its back is blacker. It flies quickly, and though quieter than the ever-noisy Redshank, has a clear and distinctive call-choo-tchoo-tchoo-each note well emphasised. Occasionally this is a double chee-weet on rising. The Greenshank reaches its Scottish breeding grounds early, and possibly those which first visit the western shores, sometimes by the middle of February, are Scottish birds, slowly working their way north. Passage migration continues throughout April and May. I have seen a returning bird on a Cheshire mere before the end of July, and from then until October migrants pass, singly or in small parties, sometimes halting for several days on the sewage farms or the shallower inland pools. The usual wader diet is varied by the capture of small fish; Macpherson noticed this on the Solway, and Dr. Patten found the bird feeding on sand-eels. Mr. C. Oldham watched 
a bird on a Cheshire reservoir chasing the small silvery fry of some fresh-water fish, and catching one at nearly every rush through the shallows.

The nest is a slight structure, little more than a depression in the turf, amongst rocks, in heather, or open grass-land, but usually near water. The four buff, beautifully marked eggs (Plate 154) are a temptation to collectors; they are generally laid in May. The young in down are light buff, blotched and streaked with black. The anxious parent reveals the presence of young by flying round with wild cries, or, like the Redshank, perches on a mound or rock and keeps up a continuous mournful warning note.

In summer the grey head is streaked with dark brown, the mantle is blackish, the rump white, and the tail is mottled and barred with brown, but never so distinctly as that of the Redshank. The under parts are white, with ashy streaks and spots on the breast and flanks. The bill is blackish, the legs are olive-green, and the irides dark brown. The whole of the upper parts are greyer in winter, and the under parts are a purer white. Young birds have light-brown or buff fringes to the feathers of the back and mantle, and the flanks and breast are lined with blackish grey. Length, 13 ins. Wing, $7 \cdot 5$ ins. Tarsus, $2 \cdot 25$ ins.

\section{Common Sandpiper. Tringa hypolenca Linu.}

The Common Sandpiper (Plate 6r) is a summer visitor to the British Isles, usually arriving in April, rarely at the end of March, and generally leaving in September. It breeds throughout Europe and northern Asia, and winters further south, occasionally reaching the Cape, Australia, and Tasmania. It nests abundantly in Scotland and the greater part of Ireland, and in all the northern counties of England, and the whole of Wales, is common, but except in the south-west is best known in southern shires as a passage visitor. 

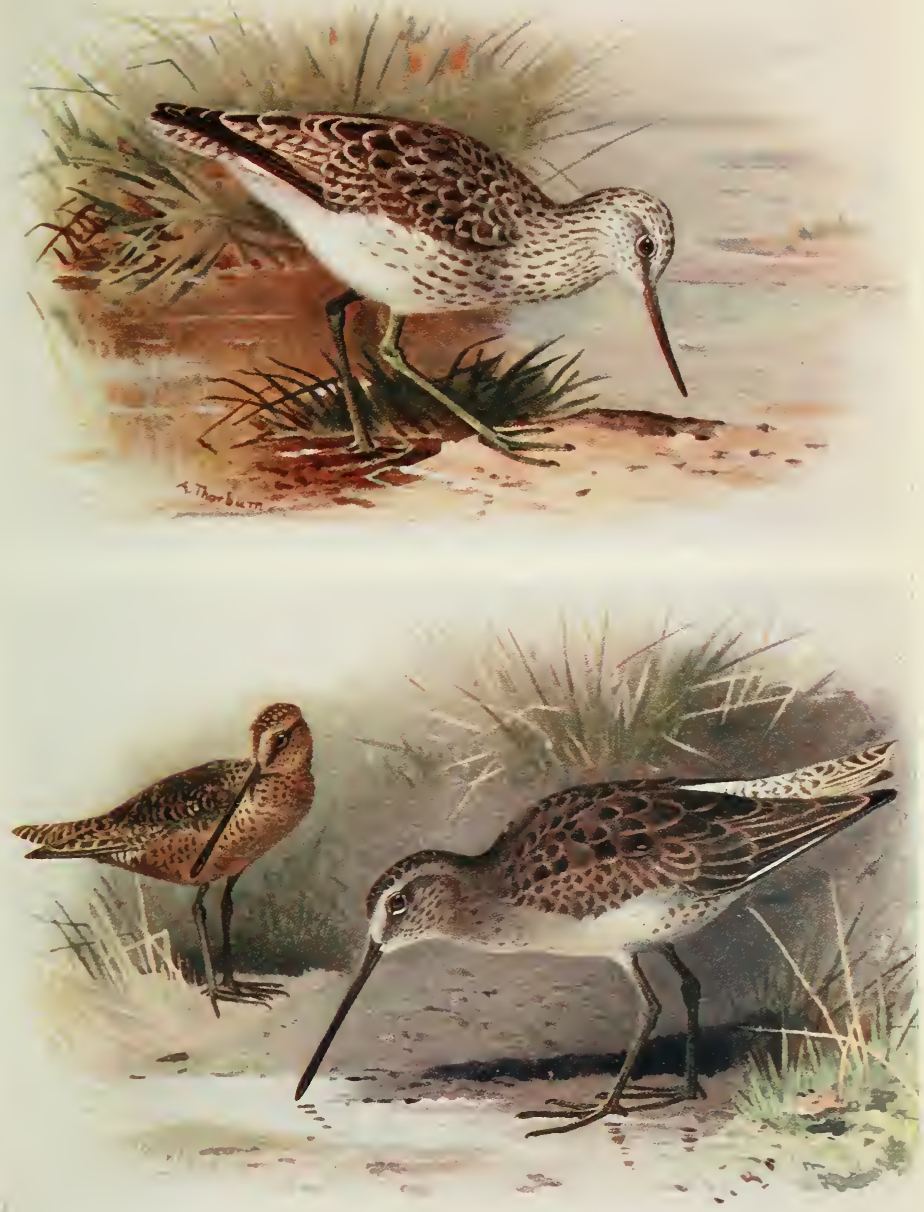

$2 \% \in 6$.

Greenshank.

Red-breasted Snipe. 


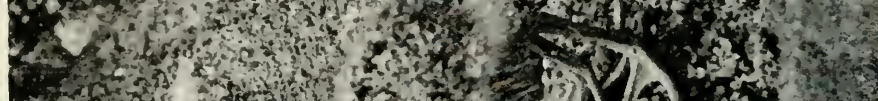

6.7. W

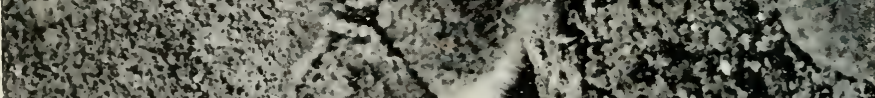

Wxint

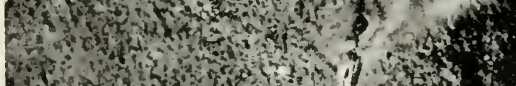
Writh

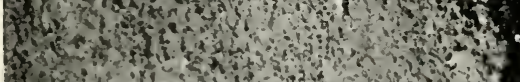

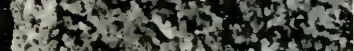
(.) (x) Axt 7 n 4.

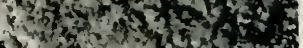
- $x^{2}$.

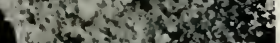

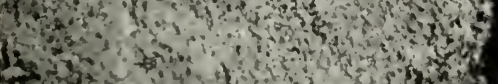

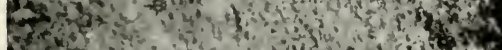
1.

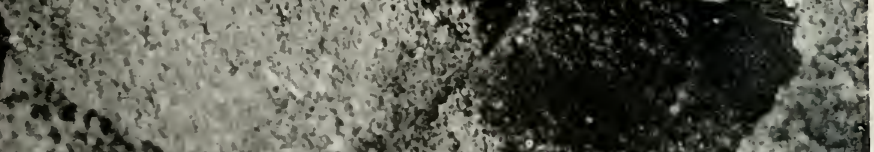

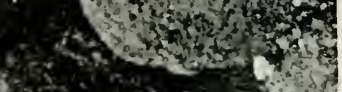
1 $x^{2}$ a 1.3. 
The graceful "Summer Snipe," with its cheery note as it skims over the northern river, lake, or loch, needs little description; the only birds with which it may be confused are the Green and Wood-Sandpipers, both of which have white rumps. Most of the Common Sandpipers have left before these autumn birds appear. Though nesting on lowland streams and pools this bird is the sandpiper of the hills, delighting in the clear trout-streams where its companions are the Dipper and Grey Wagtail. It seldom haunts the coast until autumn. The hills are usually deserted before the end of July; indeed, in this month small parties, probably families, reach the lowland streams and shore, and early in August emigration begins. Actual migration often takes place at night, for the familiar calls of birds keeping touch with one another are not uncommon on autumn nights. Most birds leave the north before the end of August, though stragglers may pass for a month or more ; in Cornwall and Devon a few occasionally winter.

When the Sandpiper reaches its summer haunts it settles on its own reach of the river or stretch of lake-side; there it wades in the shallows, catching gammarids and other crustaceans, small worms and the larvæ of insects. If approached it will stand jerking its tail and nodding its head. Suddenly it takes wing, its course over the water a semicircle, its wing-beats strong and decided, alternating with a sharp downward stroke when for a moment the down-bent primaries perceptibly quiver. During this characteristic flight the long rippling whistle is uttered, a call from which the bird gets two local names- "Kittie-Needie" and "Willy-wicket"; either of these, repeated quickly two or three times, gives a better idea of the note than many of the attempts to express it by a combination of letters. Courtship begins immediately after arrival. The male bird trills a lovesong, either when on the wing, when the down-pointed tips vibrate rapidly but actual progress is slow, or when running,

Series $I I$. 
with wings stiffly uplifted, along some wall or rail. He will circle round the female in wide sweeps, alight and trip towards her, wings uplifted, or chase her over the bank and sand; I have seen one run, following every turn and dodge she made to evade him, for fully ten minutes without a stop. When at last she took wing he followed, still trilling, and the two performed a high quick flight, in which the turns and swerves were almost as erratic as those of the Snipe. The trill, especially when the excited bird sings from an elevated perch, is varied by a plaintive pipe, a single note very like the warning call to the young.

The nest (Plate 65) is in various situations, but usually at no great distance from water. I have seen it, well lined with dead leaves, hidden beneath a thick patch of brambles, in the centre of a whimberry clump, amongst scree on a Welsh moor, in a dense wood, in grass close to a trodden pathway, and, a mere almost unlined hollow, on a garden lawn. The four buff eggs (Plate 54) are speckled or blotched, rather sparsely, with brown, and the shell has a decided polish; they are usually laid in May. The young, clothed in pale-grey down, marbled with black (Plate 67), crouch like other juvenile waders, but often betray themselves by a feeble pipe in answer to the parental clamour. The behaviour of the sitting bird varies; I have known one female shriek like an alarmed Starling as she squattered along the ground with trailing wings and expanded tail, and the following day slip quietly from the nest without demonstration.

The general colour of the upper parts is greenish brown, the feathers of the mantle having dark centres and margins. The barred secondaries are edged with white, forming a bar, con. spicuous in flight. The outer tail feathers are white, barred with brown, and the streaked breast, neck, and cheeks are light brown. A line above the eye, the chin, and under parts below the breast are white. The bill is brown, the legs greenish, the 
irides almost black. The young bird is a darker brown, and the sexes are alike, though the breasts of some males certainly look darker in the field. Length, 8 ins. Wing, 4.25 ins. Tarsus, $0.8 \mathrm{in}$.

\section{Spotted Sandpiper. Tringa macularia Linn.}

Truth owes much to Mr. J. H. Gurney for investigating the history of the Spotted Sandpiper. The result is astonishing; record after record was discredited, due to error in identification or deliberate fraud. The bird nests in Canada and the States, and winters in the West Indies and South America, and, as Mr. Gurney points out, is as likely to wander as many other waders which have certainly reached us from America, but as it has been confused with so different a bird as the Green Sandpiper, and in certain cases American skins have been palmed off as British, every record is suspicious. Two of the birds, provisionally accepted by Mr. Gurney and Seebohm, though correctly identified, I have reason to doubt; these are the Lancashire specimens. Seven or eight are accepted as genuine by the B.O.U. Committee. Seebohm, however, points out that if any of the adult birds are genuine it is probable that some reach us in immature dress and are unrecognised, since the majority of American wanderers are immature.

The bird is a little smaller than the Common Sandpiper, which it closely resembles, except that in summer its back and wings are more decidedly barred with brown, and its under parts are spotted with black. These spots are less distinct in winter, and are absent in the young bird, but the most constant distinction is that the broad brown bar on the secondaries is continuous in the Spotted Sandpiper, but interrupted in the Common, which has the eighth and ninth feathers nearly white. A photograph of the wing is shown in "British Birds" (Mag.), vol. iii. p. 377. The bill is greenish, yellower at the base, 
the legs pinkish, and the irides brown. Length, 7 ins. Wing, 4.2 ins. Tarsus, 0.75 in.

\section{Green Sandpiper. Tringa ochropus Linn.}

As a passage migrant the Green Sandpiper (Plate 68) occurs in all parts of the British Isles, including the island outposts. It breeds throughout northern Europe and central Asia and winters in Africa and southern Asia, occasionally reaching Australia. It is an uncommon winter visitor, and, rarely, remains all summer; indeed, it has occurred in every month in the year.

Reports that the Common Sandpiper has been seen in winter are generally referable to the Green, though it is larger, and can, even when at rest, be told by its white upper tail-coverts and strongly barred tail. On the wing the white lower back shows very clearly; this, contrasted with the dark back and wings, makes the bird look black and white. In flight it may be distinguished from the Wood-Sandpiper by the sooty under surface of the wing; in the Wood it is greyish white. The Green Sandpiper seldom frequents the shore; it is an inland species, haunting the borders of rivers and small streams, lakes, and even small ponds. Easily flushed, it rises high, towering to a great height with strong beats of its sharply angled wings, and with many Snipe-like turns and careens. Almost invariably it calls on rising, a loud, clear toie, toie, toie, with a rounder, fuller $o$-sound than the call of the Redshank. Though it does not as a rule alight within sight, it will return to the same spot when the coast is clear, sometimes in less than half an hour; day after day it frequents one pond or river reach. Occasionally two or three birds will feed near together, but as a rule it is solitary; flocks, very rarely large, are only seen during migration.

In Nay and June, August and September, the bird is commonest, but wintering Greens will haunt one spot for 
weeks at a time; in some years-for it is irregular in appearance-I have been sure of a bird in certain places any day during December, January, and February. Not only are there many records for July, but it has often been suspected that pairs were nesting, and there is circumstantial evidence that young have been seen. Perhaps the best evidence, though unfortunately second hand, is that of Mr. H. W. Robinson and Mr. J. H. Gurney, who believe that young were seen in Westmorland and Norfolk in 1917. In Yorkshire a Green Sandpiper was shot when flying down from an old nest in a tree, but the gamekeeper who killed the bird had no idea that the normal habit of this species is to use a deserted squirrel drey or bird's nest as a platform for its eggs. Many sandpipers perch on branches, but this is the only regular arboreal nester.

The streaked head of the Green Sandpiper is greyish brown, its back and wings greenish brown with a bronze gloss and numerous white spots. The upper tail-coverts are white, and the central tail feathers white with broad blackish-brown bands towards the tip; the outer pair are white and those between have less complete bars. In the hand the bird can be dis. tinguished from the Wood-Sandpiper by its axillaries, which are black with fine white chevron bars, whereas in the Wood they are white with grey specks and a narrow subterminal chevron. The breast and neck are greyish brown, the chin and rest of the under parts white. The bill is dark brown, the legs green, and the irides almost black. The white spots are smaller and fewer in winter, and the under parts are purer white, and in the immature bird the spots are buffish and the feathers of the mantle are margined with yellowish brown. Length, $9 \cdot 5$ ins. Wing, $5 \cdot 5$ ins. Tarsus, $1 \cdot 25$ ins.

\section{Wood-Sandpiper. Tringa glareola Linn.}

The range abroad of the Wood-Sandpiper roughly corresponds with that of the Green, but in the British Isles it is 
a less regular and frequent passage migrant, and though an annual visitor to Fair Island, is rare in Scotland and Ireland.

The Wood-Sandpiper (Plate 68) is a little larger tinan the Common and smaller than the Green, but, in proportion to its size, its legs are much longer; it resembles a small, slender Green Sandpiper with very long legs. On the wing it is not so black and white in appearance, for though the upper tailcoverts show as a white patch their centres are darker, and the feathers of the tail are barred throughout, whereas in the Green the bases are white. In flight, however, the much lighter under stirface of the wing is apparent. Like the Green it haunts inland pools, streams, and marshes rather than the shore, but often near the coast. In western counties, where it is more regular than books suggest, it occurs on the borders of meres and in sewage farms ; the food of both Green and Wood differs little from that of other waders. On the mud it runs quickly, showing its barred flanks, and if flushed rises smartly, often to a height, but with less twisting and dodging. One that I put up gave a triple call when it rose, sharper and less full than the alarm of the Green, but not unlike a feeble imitation of the Redshank. When on the ground it dips and jerks like a Common Sandpiper.

The bird seldom arrives in spring before April or lingers until June, but immature birds have been recorded in July and passage continues until October. It does not winter with us; but not only has it been seen in summer, but there is evidence that it was at one time a nesting species in one or two localities. A nestling was taken in Norfolk in 1846, and in 1853 Hancock discovered the eggs in Prestwick Carr, Northumberland, and the bird was shot to prove the species; a report of the nest in Elgin is not generally accepted. Like other sandpipers the bird often perches, and on the Yenesei Mr. H. L. Popham and Miss Haviland found it nesting in trees. Seebohm heard something in the nuptial trill which suggested 

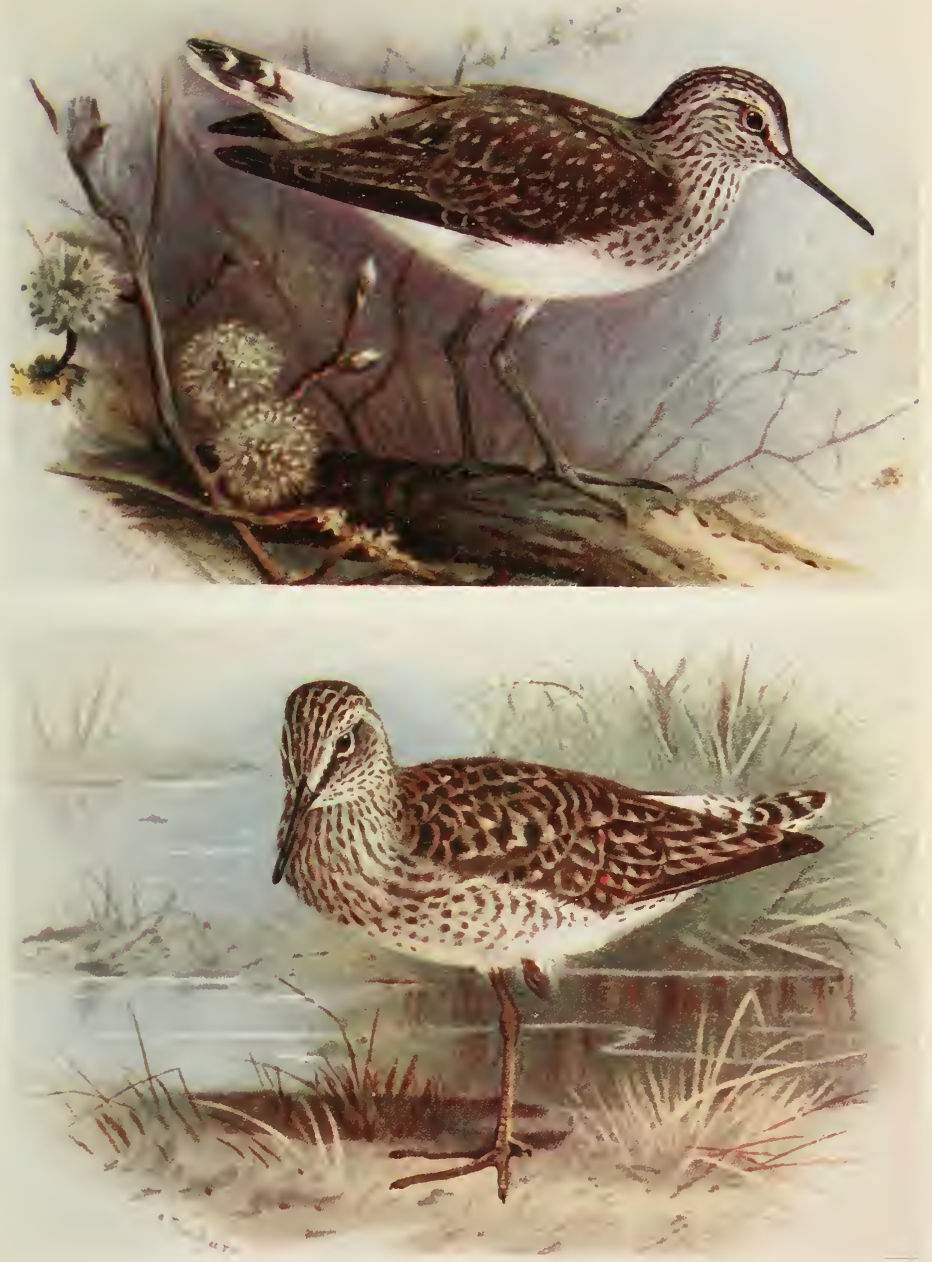

2 Pl. 68.

Green Sandpiper.

Wood Sandpiper. 


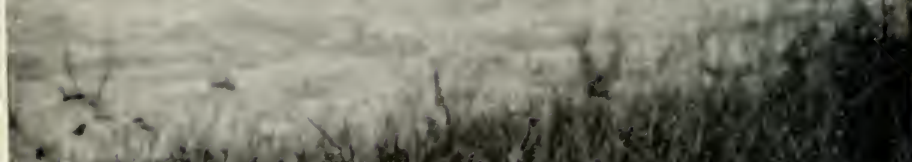

at) 170 (1)

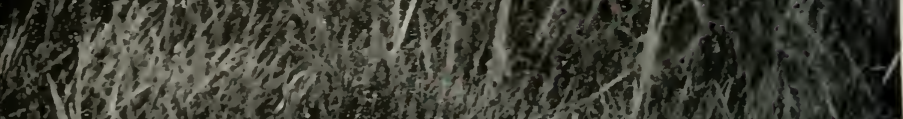
the

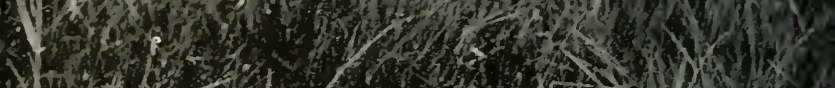
H. 8. 1 (1)

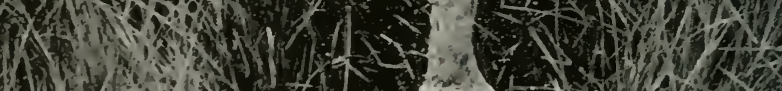

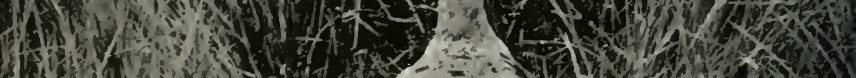
(⿻)

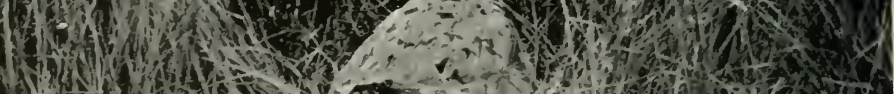

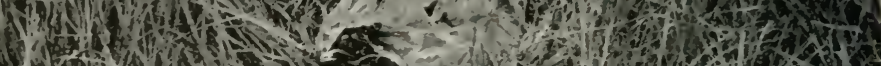

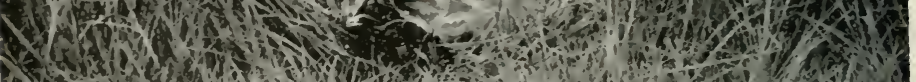

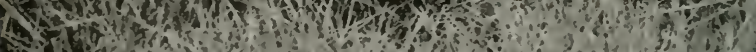

Nines

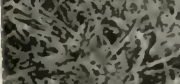

2.

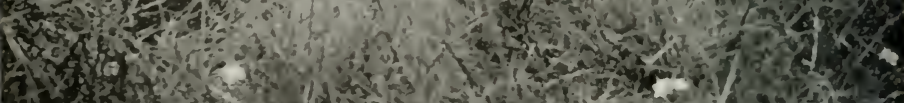

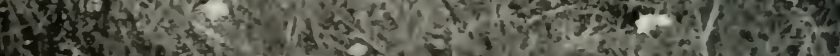

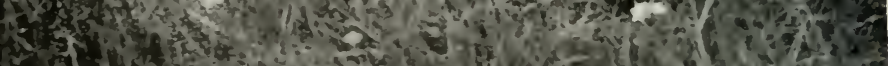
a two

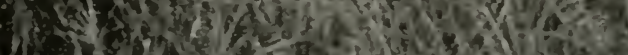


to him the Grasshopper Warbler, but to Adamson's ears, when he heard it in Northumberland, it sounded like the twittering of the Swallow.

The general plumage resembles that of the Green Sandpiper, but has less gloss, and the white spots are more profuse and larger. The outer primary has a white shaft; in the Green this is dusky; the axillaries, as already explained, differ. The spots on the back of the young bird are larger, and the axillaries are without brown marks. The bill and irides are dark brown. The legs, variously described as clay-coloured, olive, and yellow, were yellowish green in a bird I examined immediately after death. Length, 8.8 ins. Wing, 5 ins. Tarsus, I'5 ins.

\section{Solitary Sandpiper. Tringa solitaria Wilson.}

The Solitary Sandpiper is a small American Green Sandpiper which has occurred about half a dozen times in England and Scotland between the months of July and October as a rule, but it has been reported in April and May. It is the "Wood-Tattler" in some part of America.

The main points in which this bird differs from ours are that its rump and central tail-coverts are very dark brown, almost black. This character shows when the bird rises, and by it the Duchess of Bedford identified a bird in Kent, which until it rose she thought was a Green. The central tail feathers are olive-black, notched with white along the margins, the outer ones broadly barred with black, and the white bars on the dark axillaries are wider than in the Green. The habits of the bird appear to correspond closely with those of our Green and Wood-Sandpipers. The bill and legs are greenish, and the irides dark brown. Length, 8.25 ins. Wing, 5.2 ins. Tarsus, $1 \cdot 2$ ins. 
Grey-rumped Sandpiper. Tringa incana brevipes (Vieill.).

In I9It a male and female Grey-rumped Sandpiper were reported as killed in Sussex, and the species was added to the British list. It is an eastern Siberian species, which $\mathrm{Mr}$. Witherby says resembles the Knot in winter dress, except that it lacks the barring on rump and tail-coverts. Length, 95 ins. Wing, $6 \cdot 5$ ins. Tarsus, $1 \cdot 4$ ins.

Red-breasted Snipe. Macrortamphus griseus (Gmelin).

The Red-breasted Snipe (Plate 66), the "Dowitcher" of some parts of America, nests in the northern parts of that continent and migrates to the West Indies and Brazil. Over a score have wandered to the British Isles since it was first recorded in Devon in I8or. All the occurrences have been on autumn passage.

In its marked seasonal change of plumage this bird is like the Godwits and Knot, but it is from its long bill, with a swollen and pitted tip, and from a superficial resemblance in its summer dress, that it has been named Snipe. The general colour of the upper parts in summer is blackish with chestnut mottles and feather edgings, on the face and under parts it is rufous and spotted with black; the wings are greyer, and the lower back and tail white barred with greyish black and buff. In winter the upper parts are ashy grey, and the under parts white, tinged with grey on the breast. The plumage of the young bird is not unlike the summer-dress, but rather greyer, and with more conspicuous pale brown or chestnut markings; there is a tinge of buff on the breast. The bill and legs are olive, the irides dark brown. Length, 10 ins. Wing, 5.5 ins. Tarsus, $1 \cdot 5$ ins. 


\section{Bar-tailed Godwit. Limosa lapponica (Linn.).}

The two Godwits are birds of passage, one, the Bar-tailed (Plate 7I), abundant, the other, the Black-tailed, comparatively scarce; yet the latter formerly bred in England and nests in western Europe, whilst the former, though nesting only in the far north in Europe and Asia, is sometimes present at all seasons. Many of the birds which visit us winter in Africa, but in most years some go no further south than Britain. Plentiful though the Godwit is, its visits are irregular; under certain circumstances, probably due to the wind being in the wrong quarter, the migrating Bar-tails seem to miss our shores, or to pass without stopping to rest.

The Godwits are tall waders, distinguished, when at a distance, from Curlews by their straight, actually uptilted, and not downward curved bills. There are no other shore birds like them, but it is not always easy to tell one from the other. The tail marks, as implied by the names, are good characters, if visible, but a bird on the shore makes no special effort to advertise its salient points; the tail of the present species is not always barred, the actual tail feathers are grey in winter, but the black tail is constant and usually conspicuous. If the two species are together there is no difficulty, for the legs and, usually, the bill of the Black-tailed Godwit are longer than in the other; it towers above its companions. Even in winter, however, the upper tail-coverts of the Bar-tailed show bars, and the young birds, which form the bulk of the autumn flocks, have decided bars. The bills of Bar-tailed Godwits vary greatly, as a rule from three to five inches.

In East Anglia the Godwit seldom appears in numbers until early May, but on the Lancashire seaboard, where it is far more abundant than most accounts suggest, very large numbers appear in April, and the regular winter flocks are by no means small. In June there are few left, though a sprinkling of non. 
breeders often remain until, in August, the buff-breasted young of the year appear. From then until well into October, on all suitable parts of our coasts, Godwits abound; often flocks number thousands of individuals. Tidal ooze or sandbanks are the favourite feeding grounds of the Godwit. The food, marine invertebrates, may be picked up with the tip of the bill and rapidly jerked up until swallowed, be intercepted as they seek to hide themselves in the sand, or be probed for nostril deep. The upward tilt of the bill, as well as its length, varies, but it is always visible; at times the bird sweeps its bill through the shallow pools like an Avocet. As the tide rises Godwits congregate with Knots and Oyster-catchers along the sand at the edge of the water, and, until the ebb, rest in dense packs. As a rule they keep on the sea side of the crowd, their long legs allowing them to wade deeply ; they will stand on one leg, slowly hopping sideways up the shore as the water rises. When the tide turns the pack rises with a great rush of wings and flies, with strong wing-beats and with neck bent and head sunk in the shoulders, to the exposed banks, and there, walking rather deliberately with bill more or less horizontal, scatter to feed. Before alighting the flock will often perform rapid and complicated evolutions, turning and twisting, and shooting diagonally towards the beach with an angular twist before alighting, which a friend aptly calls "sicle-slipping." Reefs and rocky islets are often crowded with Godwits at high tide, and, as the birds are driven from the banks, become congested areas; yet fresh arrivals come in and, lowering their long legs, drop into the mob. Those on the outskirts leap into the air, and with a flicker of vings drop where the crush is already great, so that these "resting" packs are in a continuous state of disturbance. Perhaps it is from this habit that the bird gets a misleading local name- "Stone-Curlew." Red birds, in almost full summer dress, are in the grey packs in April, and in Norfolk I have 
1
¿े

M.

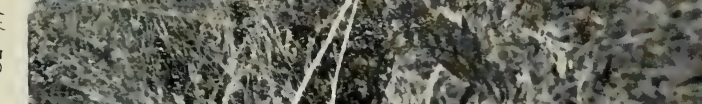

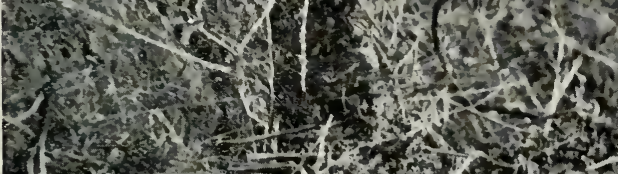

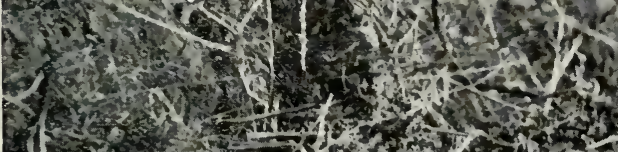

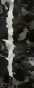

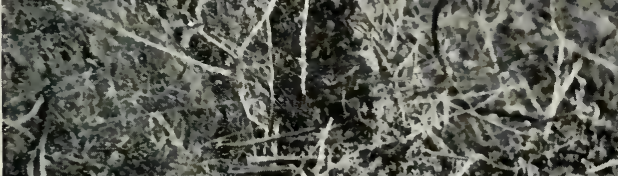

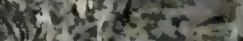

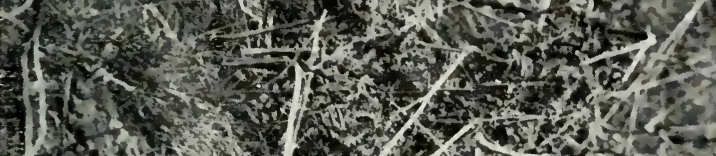

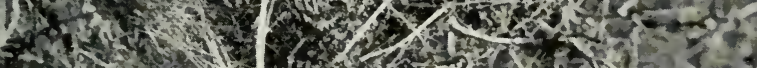

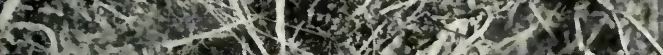

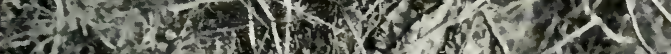

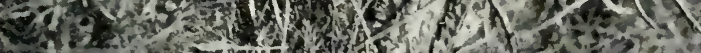

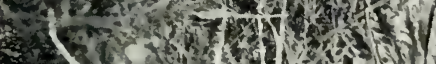

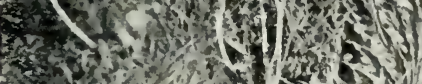

3
$\frac{3}{2}$
2
3
3
3
8
8

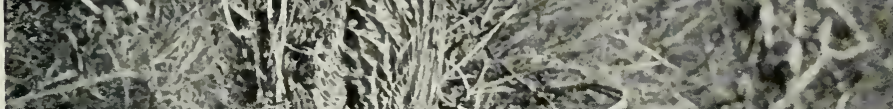

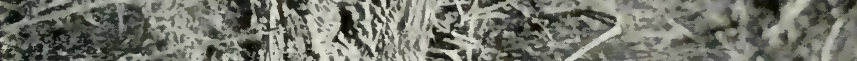
C. F.

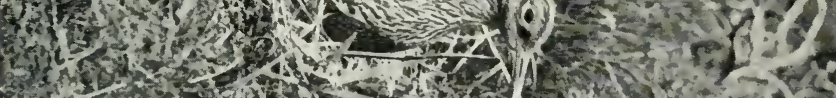

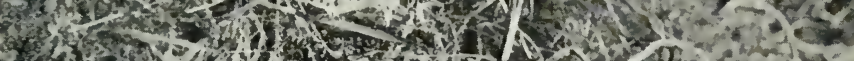

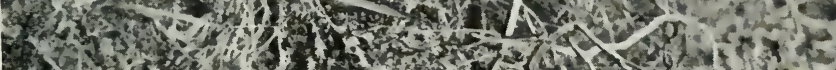
5.5.

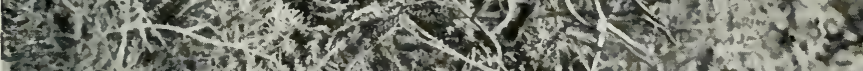

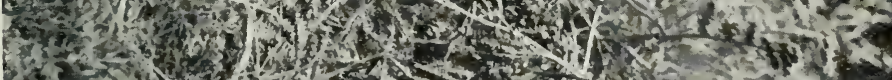

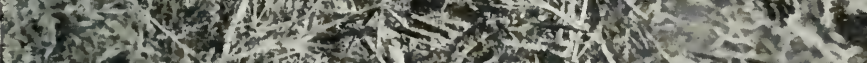

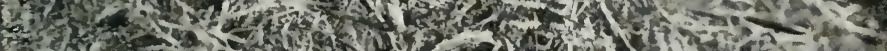

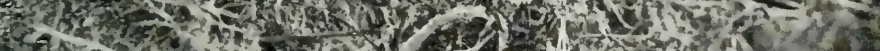

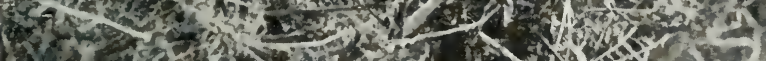

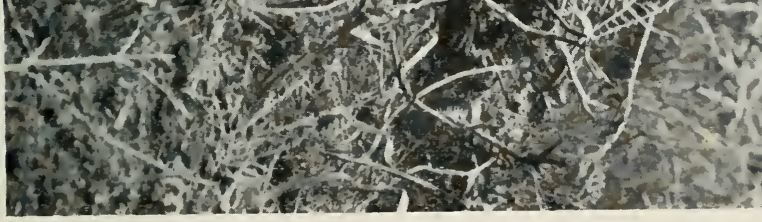



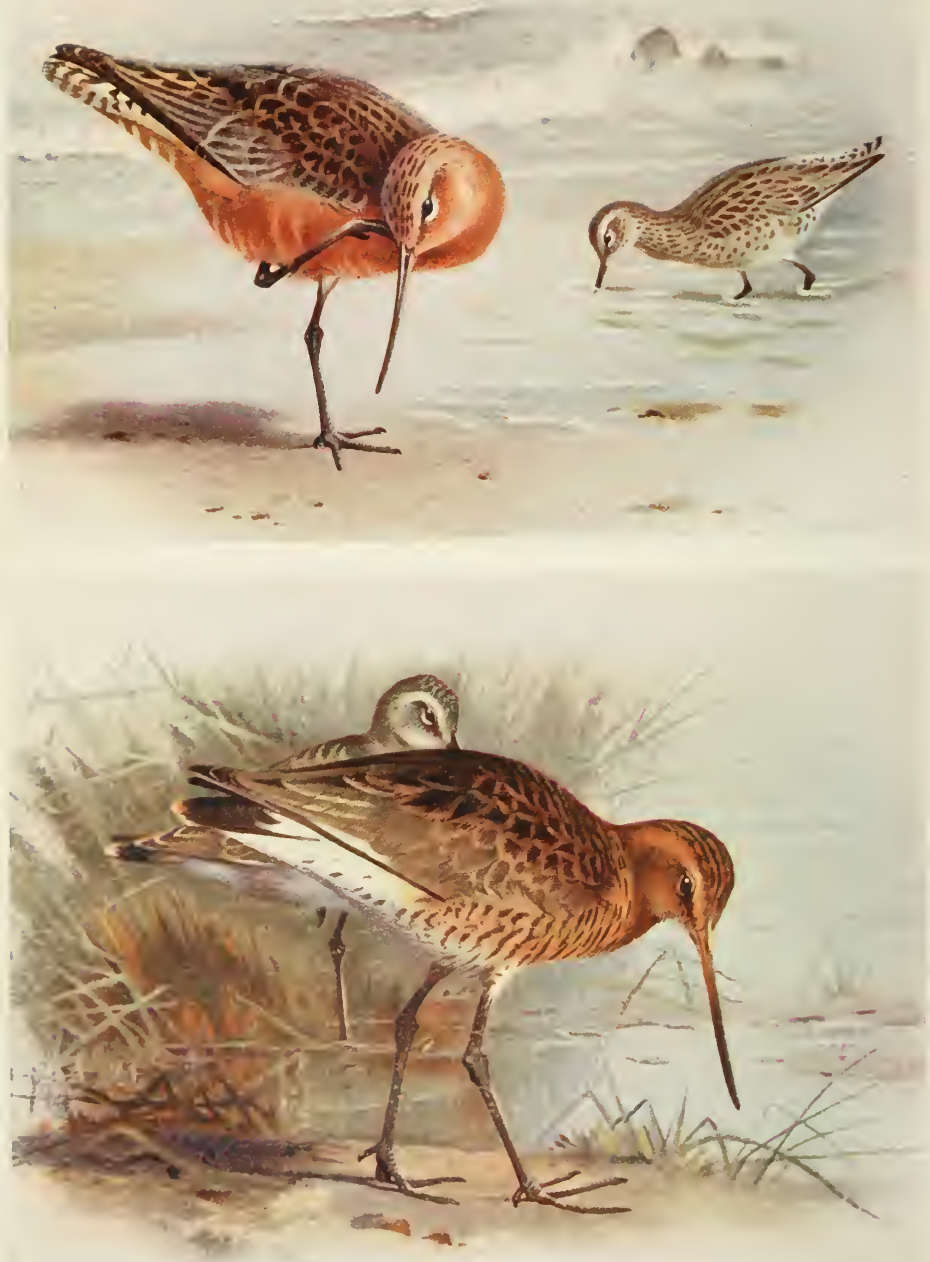

21\%. 71.

Bar-tailed Godwit. 
seen grey and red birds together in early May; those in grey plumage look larger. Even in September a few have not lost the summer red, for, like the Knot, the Godwit is irregular in its changes. The birds on the rocks and when feeding keep up a wheezy undercurrent of notes, quite distinct from the rather harsh double flight call. None of the many attempts to describe this barking note is satisfactory.

In summer the Bar-tailed Godwit is a red bird. The upper parts are a mixture of blackish brown and reddish chestnut, the under parts chestnut-red. The head is streaked, the coverts are greyish, and more decided streaks show on the back than in the Black-tailed Godwit. The upper tail-coverts are white streaked with brown, and the tail is barred with brown and white. In the strikingly different winter dress the upper parts are ash-grey and the under parts white; brownish streaks show on the mantle. Though the tail is partly grey, the upper tail-coverts are barred with brown. Most birds in the early autumn flocks are immature, more tawny yellow than the winter old birds ; the breast is buff and slightly streaked. The upper tail-coverts are white blotched with brown, and the tail is barred with brown and white. The colour of the bill is often described as brown; Sharpe, however, says "bill fleshcolour, dusky on its terminal half ; feet greyish blue." I have not handled a summer-plumaged bird, but those I have seen at fairly close quarters seemed to differ little from autumn birds that I have examined. The bill in these is delic ate rosepink for the proximal two-thirds, the tip black; the legs are plumbeous, the irides very dark brown. Length, 14 to 18 ins. (according to length of bill). Wing, 8 ins. Tarsus, 2 ins.

\section{Black-tailed Godwit. Limosa limosa (Linn.).}

The breeding range of the Black-tailed Godwit (Plate 7I) extends from Denmark and Holland across central Europe to 
western Asia, and in winter it occurs in northern Africa and India. Until the beginning of the last century the range included the eastern counties of England from Yorkshire to Norfolk, but the bird was useful for the table and, when fowlers had reduced its numbers, collectors did the rest; the last nest is believed to have been taken in or about I 847 . Now it is an uncertain and rare visitor on migration, most frequent in the south-east. In the west of Scotland and in Ireland it occurs from time to time, and the statement made by Saunders that it is "seldom obtained on the west side" of England is, I hope, true, though it is more frequent as a migrant and winter visitor than this suggests. Indeed, its visits are fairly regular.

The Black-tailed Godwit is an easy bird to recognise when alongside its shorter-legged relative, but when by itself may be known by its white wing bar-less distinct in young birds -and by the long legs extending far beyond the tail in flight. When watching Bar-tails collecting on a rocky islet, five Blacktails flew round, and the trailed legs caught my eye before I saw the darker back and the black tail contrasted with the white coverts. When feeding it is a slender, graceful bird, stalking deliberately, and bending its noticeably long neck in almost swan-like curves. Its flight is strong and less erratic than that of the Bar-tail. Mr. F. IV. Holder saw one bird, however, join a flock of Knots, and keep time with all their aerial gymnastics. I have seen a fair number of Black-tails with the autumn flocks of Bar-tails, Mr. Holder has noticed them in every month from December to March, and Mr. G. Marples saw the bird on the Cheshire shore in winter. In Scotland it has been also noticed in winter and, occasionally, in summer, once at any rate under circumstances which suggested nesting. The nest (Plate 69) is usually in marshy ground, sometimes in a very wet situation; if left alone by collectors there is no reason why the bird should not re-establish itself in some of the many undrained marshes. The call is 
quite distinct from and much more musical than that of the Bar-tail ; it is more like the triple whistle of the Redshank.

The summer dress is reddish brown mottled with black on the upper parts; the lower back is black, and the upper tailcoverts and base of the tail are white, but the distal portion of the tail feathers is crossed by a single broad black band. The under parts are reddish brown or bay on the breast, and the flanks and abdomen are whitish with bars of black and brown. In winter the bird is ashy brown above and whiter below, the breast and neck being grey. Young are not unlike the adult in summer on their upper parts, but the under parts are paler, buff instead of bay. The bill is pinkish, darker towards the tip, the legs greenish black, and the irides dark brown. Length, i 6 to I 8 ins. Wing, 9 ins. Tarsus, $3^{\circ} 8$ ins.

\section{Curlew. Numenius arquata (Linn.).}

The Curlew (Plate 73) has a wide range in northern and central Europe and Western Asia, and in winter reaches South Africa and southern Asia. In the British Isles it is a moorland resident in all parts, though only a few scattered pairs nest in southern counties. On all coasts it abounds as a passage migrant, a winter visitor, and summer bird.

The long, curved bill, which varies from four to seven inches in length, the bulky brown body, and the wild whistle, make the Curlew a familiar shore bird ; the smaller Whimbrel, itself a curlew, has a much shorter bill and distinctive dark streaks on its crown. At all seasons suitable feeding grounds are frequented, and as the bird is catholic in its tastes it may be seen amongst rocks as well as on mud or sand. It is as well known to the shepherd as to the fisherman, for in spring and early summer its haunts are the moors, often at a great distance from the coast. Early in March the resident birds repair to the hills, leaving behind immature and non-breeding individuals 
and winter visitors from more northern haunts. Northward passage reaches its height in April and May. By July the breeders are returning from the hills, and at the end of this month there is at times noticeable passage movement; from August until October passage and the arrival of winter visitors continues. What proportion of our home-bred birds go south in autumn cannot be ascertained; many English and Scottish birds winter in Ireland. The Curlew is at all times gregarious and sociable, crowding on banks and rocks when the tide is full, but when on migration its numbers are often immense. It frequently migrates at night, when only a feeble estimate of the passing hordes can be guessed at from the babel of voices of invisible travellers.

At all times the bird is noisy; its call-kour-lee-is perhaps the best-known wader note, but this cry has a number of modulations and, variations, the meanings of which the bird knows best. On the moor the call of the "Whaup" may have an amorous inflection, or, as it rises to a startled and startling scream, mean that our presence has been suddenly detected. From the guardian of the nest, standing sentinel on the skyline, it is a warning to the sitting mate, who silently slips from the nest and suddenly makes his or her presence known from a different quarter, and the two birds, so long as an intruder is about, keep up an incessant whoo-wee, whoo-wee, whoo-wee, distinct from the other notes. On the moors, before the eggs are laid and even when birds are sitting, the male indulges in a nuptial flight, a rising and falling aerial dance, accompanied by a trilling song, which has much in common with that of the Redshank. Here, too, may be heard the long, liquid bubbling call, which has no resemblance to the ordinary cry, but which is by no means only a breeding note, and is constantly uttered by birds in winter on the flats; I have heard it from night migrants. When the young are crouching in the heather the parents have two other notes, the first, a warning, very similar 
to the titter of the Whimbrel, and the other a savage bark of anger as the bird flies and sometimes hovers overhead.

The flight of the Curlew is more gull-like than that of most waders; it rises rather heavily, but is quick on the wing, though its slow and measured beats do not suggest speed. Flocks, especially when travelling for a distance, adopt the chevron formation or fly in well-ordered lines. The bird has been met with far out at sea, but as it can swim well it would have no difficulty in taking rest. Mr. L. N. Brooke saw one flying with a party of IVigeon, and twice when the ducks settled it also alighted and swam with them, picking up some food from the surface of the water. On the coast the bird feeds with the tide, either by day or night; when on a boat at anchor off a muddy estuary, I heard the birds calling, bubbling, and, judging by the barking cries, quarrelling all night long. The sickle-shaped bill can be thrust into the mud, but often the bird delicately picks up a mollusc or other animal, jerks its head, and so passes the food up to the gape. On the moors insects and worms are eaten, and berriesblackberry, whimberry, and crowberry, for instance-are appreciated.

Occasionally the Curlew nests on a low-lying heath, or in the upland pastures, but its true home is "the tops," where cottongrass, crowberry, and stunted ling crop out amongst the sphagnum. The nest, often a mere apology, is placed amongst the tussocks (Plate 70), and the three or four large eggs (Plate 57) brooded in April and May. The bird on guard, after warning its mate with a loud cour-lieu, will run towards a man, when the young are hatched, and strive to draw him from the danger zone, but a passing Raven, gull, or hawk is fiercely assaulted and driven away with angry barks. The down of the nestling, pale brownish white, mottled with chestnut and a few rich brown blotches (Plate 7:2), is inconspicuous in certain surroundings, but does not always hide the 
crouching bird. It has a short, straight, lead-blue bill, slategrey legs, and brown irides.

The adult bird in summer is streaked on the head, back, and breast with dark brown and buff; the wings and tail are barred with dark and light brown, and the white lower back has a few dusky streaks, whilst on the flanks are sagittate spots. There is a distinct pale eye-streak, and the chin, abdomen, and under tail-coverts are white with a few dark markings. In winter the colours are paler, and the immature bird is more tawny. The bill is brown, reddish at the base of the under mandible; the legs are green, and the irides brown. Length, 23 ins. IVing, 12 ins. Tarsus, 3.25 ins.

\section{Whimbrel. Numenius phceopus (Linn.).}

The breeding range of the Whimbrel (Plate 73) is more northerly than that of the Curlew; it extends from Iceland and the Færoes to north-western Siberia, and its winter range to the Cape. In the Orkneys, Shetlands, and a few of the Outer Hebrides, the Whimbrel is a summer visitor, nesting sparingly, but to most parts of the British Isles it is a regular and common passage migrant. A few non-breeding birds linger through the summer, and occasionally wintering is recorded.

The Whimbrel is often called the "Jack Curlew," Jack being a diminutive ; it differs from the larger bird in having a shorter, rather less curved bill, and in its much darker crown, which is not brown with narrow streaks, but has two broad brown bands divided by a median narrow buff stripe. "May-bird" is one of its popular names, for its arrival is expected in this month. Though a bird of the shore, the passage, especially in spring, is often overland, and the distinctive rippling or tittering call of the incoming birds may be heard at night in April as well as May. "Titterel" is a name derived from this call, and from the notion that the notes are always uttered 


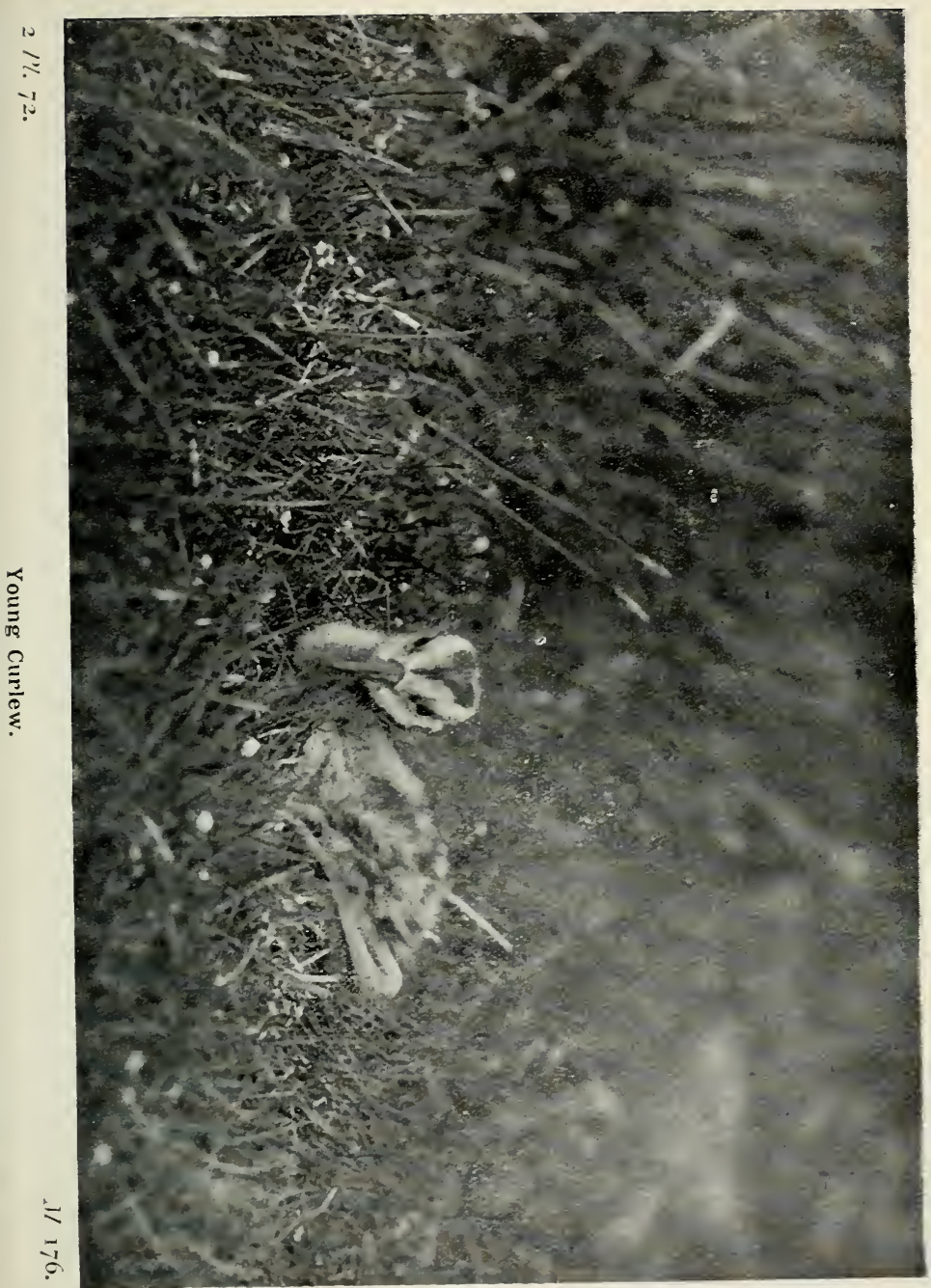


seven times in succession it is called the "Seven Whistler"; seven, however is a mystic number. Though passing inland, the bird less frequently halts to feed on fresh-water pools than the Curlew; it appears to hurry to reach the coast. Return migration begins in July and continues until October, very few lingering until November; from December onward the bird is very rare. I have only once met with the Whimbrel in winter, on the Solway on the last day of the year. When travelling, small flocks of Whimbrel often adopt the line or V-shaped formation ; the flight is steady and straight, but the wing-beats quicker than those of the heavier bird. Low rocky shores are as much frequented as mud-flats ; the brown bird, often almost invisible on the tangle, feels with its bill amongst the weed for molluscs and crustaceans, or hunts in the rock pools for prawns, gobies, or butterfish; I have watched it testing the size of crabs, swallowing the small ones and reluctantly throwing aside those which were too large. On the flats it eats the usual marine creatures, and inland adds berries to its diet of worms, land snails, and insects; "leather-jackets" have been found in its stomach. The bird is by no means shy; when the wary Curlew warns other waders, the Whimbrel will continue its meal unmoved.

The nest is a slight hollow in the moss or amongst rough grasses, lined with a few bents or bits of moss. The three or four eggs, similar to small eggs of the Curlew, are not usually laid until June. At the nest the alarm note resembles that of the commoner species, and the Whimbrel is just as plucky in its assaults upon possible foes. The nestling plumage closely resembles that of the Curlew, but the head shows in its streaks some suggestion of the later character.

The adult plumage, with the exception of the crown, is little different from that of the Curlew; the female, as in the last species, is the larger bird. The young show both blacker and buffer mottlings than those of the old bird. The bill is brown,

Series $I I$. 
the legs pale slate-blue, and the irides dark brown. Length, 17 to 19 ins. Wing, 10 ins. Tarsus, $2 \cdot 2$ ins.

\section{Eskimo Curlew. Numenius borealis (Forster).}

The Arctic American Eskimo Curlew migrates to, or used to migrate to South America, reaching Patagonia and the Falklands, and when wandering has been obtained in England, Scotland, and Ireland at least eight times. Packard writes of immense flocks on migration along the Labrador coast in autumn, and how the bird, fattening on crowberry, was slaughtered for food. Coues tells how it returned again and again to its food, heedless of the shooting, and so the bird was reduced in numbers until it is doubtful if any have survived. The last recorded for Britain was one which reached the Scilly Isles in I887. The Eskimo Curlew resembles a small Whimbrel with dark lower back and tail-coverts, and with sagittate marks on the breast. Length, 14 ins. Wing, 8.25 ins. Tarsus, $1 \cdot 75$ ins.

\section{Slender-billed Curlew. Numenius tenuirostris Vieill.}

The Slender-billed Curlew nests in western Siberia and winters in southern Europe, occasionally wandering west on migration. A small flock was reported in Kent in September, I910, and three were shot; in I9I4 another bird was recorded for the same county. It is about the size of the Whimbrel, but with the Curlew head streaks and with black "pearshaped" spots on the flanks. Its short bill is brown, its legs plumbeous, and its irides brown. Length, 17 ins. Wing, 9.9 ins. Tarsus, 2.5 ins.

\section{Sub-family HIMANTOPODIN Æ.}

Bill long, slender, straight, or recurved; legs very long ; toes three or four, anterior toes slightly or considerably webbed. 


\section{Black-winged Stilt. Himantopus himantopus. (Linn.).}

The Black-winged Stilt (Plate 74) breeds in southern Europe and Asia, in some parts in great numbers, ranging eastward from Spain and the south of France ; it is also widespread in Africa. In the more northerly portion of its range it is migratory, but when the bulk of the birds are travelling in a southerly direction, some, chiefly birds of the year, seem deficient in sense of direction and ramble north. For more than 200 years the Stilt has been accepted as a British bird on the strength of these repeated occurrences. Sibbald's drawing of the first recorded bird, shot in 1684, reproduced by Mr. H. S. Gladstone in the "Birds of Dumfriesshire," though quaint, leaves no doubts as to correct identification. By no means all the records for this species, which are widespread, ranging - from the Shetlands to the southern shires, are autumnal; Gilbert White saw the bird at Frensham in April, and there are several dates for May and June, as well as a number in. winter.

A novice could identify this very long-legged black and white sandpiper ; indeed, I could safely add a recent Anglesey record to the ancient one of Montagu, though the fowler who shot the bird and threw it away because he did not know what it was only gave a short description; ten inches of leg on a thirteen-inch bird is not usual. The use of these long shanks is apparent when the bird is feeding; it wades deeply in the marshy pools, for it is a bird of the open marsh, and snaps right and left at the hovering aquatic flies, or catches the beetles and tadpoles when they come up for air. In flight it is a striking bird with its outstretched neck and bill and legs trailing behind; its wings are narrow, angled, and pointed. When a nesting colony is invaded the birds will hover with dangling legs, uttering repeated cries of excitement.

The back and wings of the fully adult bird are glossy 
greenish black and its tail is greyish; the rest of the plumage is white faintly tinted in places with pink. The bill is black, the legs pink, and the irides crimson. Young males, however, breed before they have lost the last mark of immaturity, blackish grey on the back of the head and neck. In the still younger birds all the blacks are replaced by brown, and the legs are brownish rather than pink. Length, 13.5 ins. Wing, $9 \% 5$ ins. Tarsus, 477 ins.

\section{Avocet. Recurvirostra avocetta (Linn.).}

The too conspicuous Avocet (Plate 74) is indeed a "lost British bird," for a century ago it nested in some numbers in the eastern counties from the Humber southward. Many of its former European colonies have vanished before the advance in "civilisation"-mainly the introduction and perfection of the breechloader-but a few remain in Holland, Denmark, and Spain. Its range is wide in Europe, Asia, and Africa, and in the more northerly portion the bird is a migrant. To England it was a summer visitor, now it is a rare spring and autumn migrant, and there are one or two records of birds in winter. Some of the spring visitors might nest if allowed, but the bird is slain whenever it is seen. For instance, a party of seven were seen at St. Leonards, and within a few hours four were taken to a taxidermist. Only where there is protection, as at Breydon, are there many records of birds seen, but not shot. On migration the Avocet has occurred in various places from the Shetlands southward, but its most frequent visits are to its old breeding haunts.

So black and white a bird, with a unique uptilted bill, from which its ancient local names, "Cobbler's-awl," and "Shoohing horne" of Sir Thomas Browne, are derived, should be easy to recognise. Yet Mr. A. H. Patterson says that when with Black-headed Gulls it is not easy to distinguish, that on the 
wing it may be taken for an Oyster-catcher, and on the water, swimming buoyantly, is not unlike a Tufted Duck. He remarks that "it appears to delight in associating" with gulls, but in Holland Miss Best found that it did not trust them near its eggs, boldly driving them away, striking with wings and feet but not with its delicate and pliable bill. The Avocet is a bird of the ooze and shallow pool ; it may, perhaps, occasionally probe the mud with its needle point, but the usual method of feeding is to scoop the surface with a side-to-side action, which as it walks leaves a wavy track behind. On land insects are captured deftly in the upturned tip. Small crustaceans are scooped from the pools or skimmed from the mud. It wades deeply, its partly webbed feet preventing it from sinking in the ooze, but it swims well, alighting on water intentionally. On the mud it often runs with wings uplifted, perhaps ready to fly if the feet sink too deeply. Like the Redshank it used to be called "Yelper," for it is a noisy bird when alarmed, uttering a clear kluit or tu, tu, tweet, as spelt by some writers.

The Avocet nests in colonies, usually on open stretches of sand or mud, sometimes on water-surrounded tussocks. More or less-usually less-litter encircles the nest hollow; often only a few dead bents or shells are collected (Plate 75). The three or four buff, black-spotted eggs are not unlike small eggs of the Oyster-catcher.

The plumage of the mature bird is white and black, the latter confined to the head to below the eye, the back of the neck, and parts of the back and wings. The distribution on the primaries and coverts gives a black-streaked appearance to the closed wing. The black is browner and edged with rufous on the immature bird. The bill is black, the legs blue-grey, and the irides brown. Length, 18 ins. Wing, 9 ins. Tarsus, 3 ins. 


\section{Sub-family CHARADRIINÆ. Plovers.}

Bill short; legs moderate; hind toe, if present, short and elevated, usually absent.

\section{Golden Plover. Charadrius apricarius Linn.}

The Golden Plover (Plate 77) is found throughout northern and central Europe and western Asia, and in winter in Africa and southern Asia. In the British Isles it is a widespread resident, probably summer visitor, and abundant winterer and passage migrant. It nests sparingly in Somerset and Devon, but throughout Wales and from the Derbyshire Peak northward to the Scottish islands, as well as in Ireland, it is common on all suitable moors.

The Golden Plover is a typical plover, far more so than the round-winged Green Plover or Lapwing; it has sharply pointed angled wings and rapid flight, and is a plump, bullet-headed, short-billed bird with a high forehead, which runs lightly over pastures or coastal mud. It is a more inland bird than the Grey Plover, its nearest relative, from which it can be distinguished by the absence of the hind toe. In the field, apart from its yellower dress, it may be recognised by its white axillaries; when it raises the wings and holds them for a second stiffly, which it frequently does when stretching, and also when it alights, the Golden shows a white under surface, but in the Grey the axillaries are a dark patch on a dusky ground.

During spring and summer the moors are the haunt of the "Whistler," a name given from its frequently repeated liquid call. On the Pennines the shepherd knows it as the "Sheep's Guide," for it warns his flock if a man appears. On the shore and in the lowland fields in February some birds show traces of the black under parts of summer, and by April all have attained full breeding dress. The birds move to the 

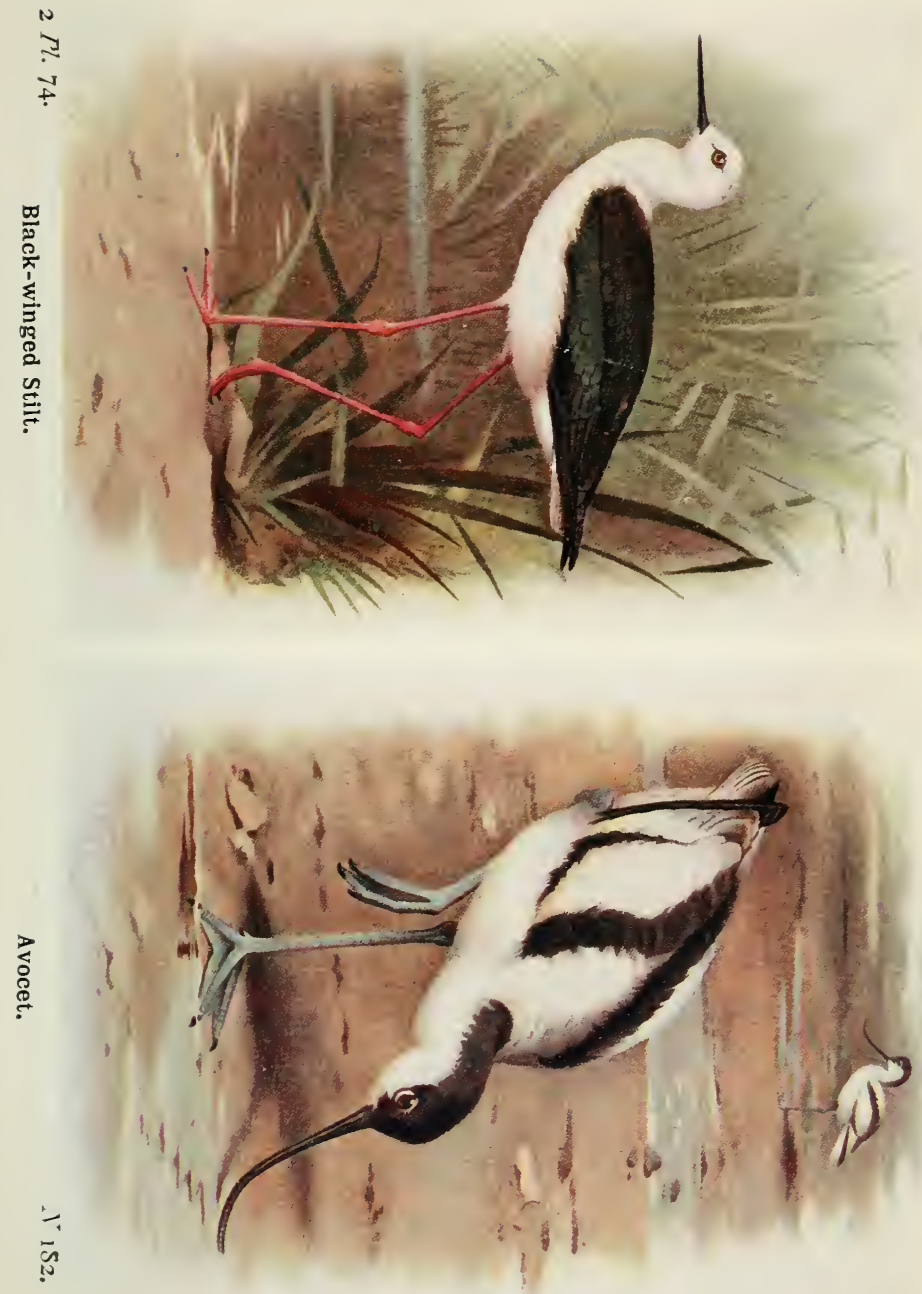


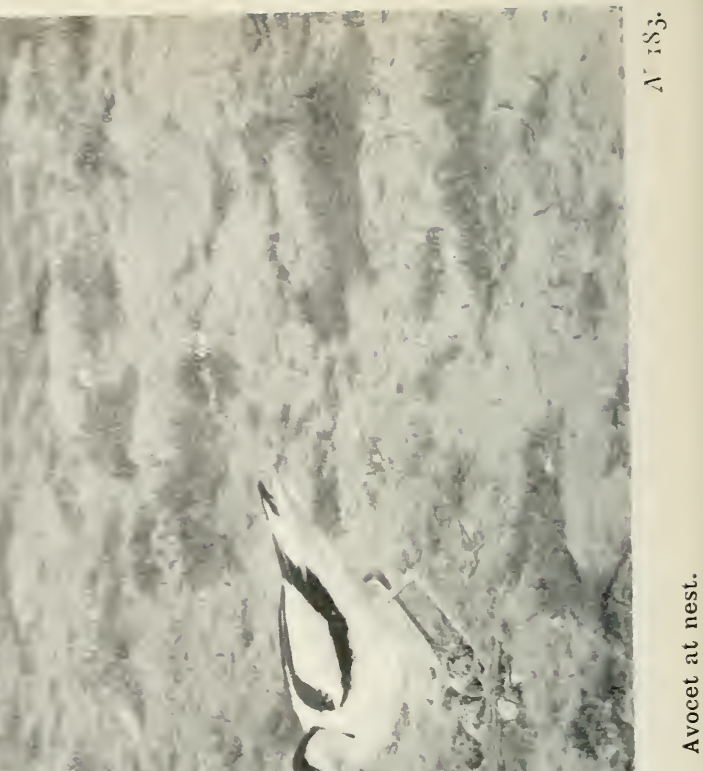
)

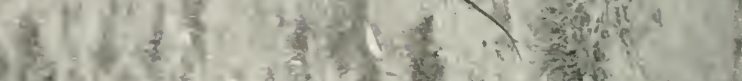

(2)

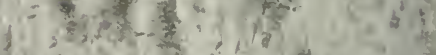

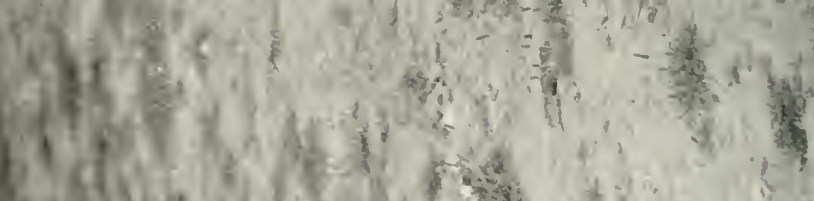

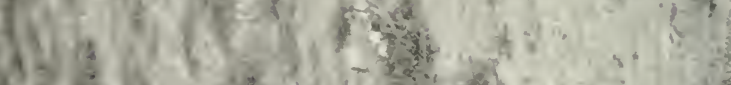
$\Rightarrow$ A

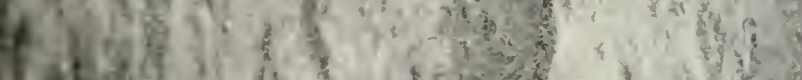

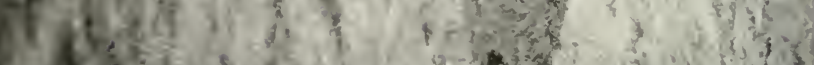

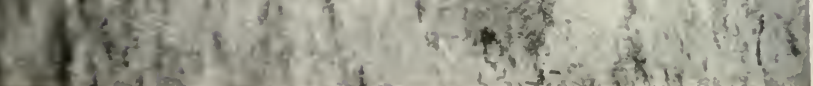
in $\underset{2}{2}$ 
hills in March, but long after this, even until May or June, certain lowland fields are visited by passing flocks, replaced by fresh arrivals so soon as one lot leaves for the north. The Golden Plover is partial to particular feeding grounds, seldom visiting other fields in the immediate neighbourhood. By the end of July the first adult birds are returning, still with their under parts mottled with nuptial black; in September the white-breasted young appear. Most of these flocks pass south, but in October and November the wintering birds join forces with the Lapwings. On the wing the species usually separate, the sharp-winged Plovers out-flying the slowly flapping Lapwings.

The gregarious Golden Plover whistles frequently when on the wing, but is silent when at rest. The normal call is a clear thii, heard at all seasons. Towards evening the flocks indulge in elaborate aerial performances, turning, twisting, and diving in pure enjoyment of air mastery. When all descend, and for a moment their white underwings flash in the light of the setting sun, the settling flock warbles a low, murmuring, long-shore chorus, and then as the wings are closed the yellow birds melt into their surroundings and vanish. On ploughed land the Golden Plover is almost invisible. On the moors the male trills a love-song as he sweeps round above his mate, and in March I have heard birds on the ground suddenly raise a trill of welcome to a party passing over-ri, toori, toori, toori-but relapse into silence when the visitors moved on. When changing ground or on migration the $\mathrm{V}$-formation is common ; nocturnal migration is often detected by the calls of the bird, but diurnal movements have often been observed, even at a great altitude. An ornithologist airman told me that he sighted Golden Plover passing far above him when he was flying at a height of 6000 feet. On the moors the pairing birds, in addition to the trill, have a nuptial call. Two birds flew swiftly past me over a Welsh moor, each uttering the normal call, but a third, when it overtook them, suddenly slowed down, and with 
measured beats of flexed wings, repeated a call which I wrote down as taw-tu-you, as all three alighted. The animal food is that of other waders, varied with a few moorland seeds and berries.

The upper moor, bare or clothed with coarse grass and stunted ling or crowberry, is the usual nesting site, and the nest itself is often exposed, but by no means easy to find, for when the four mottled eggs (Plate 80) are laid, the sitting bird, warned by the watchful mate, slips quietly off and runs for some distance before taking wing. One of the pair, usually the male, though both are known to sit, stands sentinel on the skyline, and gives a long warning tooee if any one appears within sight. When the mate is at a safe distance from the nest it answers the call, and both will fly round the intruder with plaintive cries, and long after the danger zone is passed will stand watching, repeating a single mournful too. The eggs are generally laid in May, and by the end of the month the downy nestling (Plate 76 ) crouches in the herbage. When first hatched the little bird is a wonderful golden yellow, with dark mottles and whitish streaks.

In summer the upper parts of the adult bird are mottled with black and golden yellow, and the tail and coverts are barred with brown and yellow; the under parts to the abdomen, and including the cheeks, are black, and between the yellow and black, from the forehead, over the eye to the flanks, runs a conspicuous band of white. The under surface of the wing and under tail-coverts are also white. There is rather less deep black on the under parts of the female. The bill and irides are blackish brown, the legs blue-grey. The black portions are white in winter, the colours are less golden, and the cheeks, greytinged breast, and flanks are mottled with brown and yellow. The plumage of the young resembles that of the adult bird in winter, but the flanks are more mottled and back more spotted with yellow. Length, II ins. IVing, $7^{\circ} 5$ ins. Tarsus, $I^{\circ} 6$ ins. 


\section{American Golden Plover. Charadrius dominicus Müll.}

\section{Eastern Golden Ployer. C. dominicus fulvus Gmel.}

The eastern race of this small Golden Plover ranges through eastern Siberia to Alaska, where it meets the Arctic American form. The American bird is known to travel in autumn to South America by an oversea route of about 2500 miles, not always breaking the journey at the Bermudas, but its return in spring is through Central America and overland. The Asiatic race reaches New Zealand, whilst some birds wander westward, not infrequently into Europe. It is not surprising that occasionally the Atlantic travellers are wind-drifted eastward, and that some of the eastern birds reach Britain; indeed, it is possible that many are unrecognised amongst the large flocks of our winter birds. On about four dates the American Golden Plover has been recorded from England, Scotland, and Ireland, all in autumn, but nearly twice as many Asiatic birds have been met with in autumn or winter in the south of England and once in the Orkneys; there is one spring record.

Beside being smaller birds, both sub-species differ from our Golden Plover in having smoke-grey and not white axillaries. The legs are proportionately longer. In winter the feather margins are paler, so that it is not unlike the Grey Plover in winter dress. In summer dress, $\mathrm{Miss}$ Haviland points out, the Asiatic bird is brighter in its yellows and more intense in its blacks than ours. The most noticeable difference between the two races is in size, but the larger American bird is duller in its colours. The bill is olive-brown, the legs lead-grey, and the irides dark brown. American: Length, 9.5 ins. Wing, 6.75 ins. Tarsus, $I^{\cdot} 6$ ins. Eastern: Length, 9 ins. Wing, 6.5 ins. Tarsus, $1 \cdot 5$ ins. 


\section{Grey Ployer. Squatarola squatarola (Linn.).}

The Arctic breeding range of the Grey Plover (Plate 77) is circumpolar, and its winter travels take it as far as the Cape, Australia, and South America. In the British Isles it is a regular and plentiful passage migrant and winter visitor, and has been met with in every month of the year. It is uncommon in Scotland and Ireland and less plentiful on the west than the east coast of England, but it is far from rare on the Lancashire and Welsh shores.

The Grey Plover is a shore bird, infrequent inland, and though its flocks are not so large as those of the Golden Plover it is often present in great numbers; I have seen the Humber clays sprinkled with Grey Plovers as far as my glass would range, yet nowhere could I see more than two or three in a group. The old bird is always greyer than the Golden Plover, and in summer well deserves the name "Silver Plover," but young, washed with yellow, are less distinctive, unless in the hand, when the presence of the small hind toe settles the matter. But, like the Golden, this bird frequently raises its wing, and will even run with uplifted wings, and then the black or very dark axillaries show plainly on the under surface ; these dark marks may be seen on the flickering wings of a passing bird. Further points are the whiter rump and upper tail-coverts, and the black and white barred tail. The Grey Plover is as a rule a lively and noisy bird, running quickly when feeding and constantly calling from the ground or on the wing. Its note is less liquid than that of the Golden, and is shrill and penctrating. Its wing-beats are rather deliberate, but it is swift and strong in flight. It is not always nervous, and young birds are at first absurdly tame, a common fault of Arctic nesters. If approached they will run for a few yards, turn to see if they are followed, and seem reluctant to fly; old birds, 


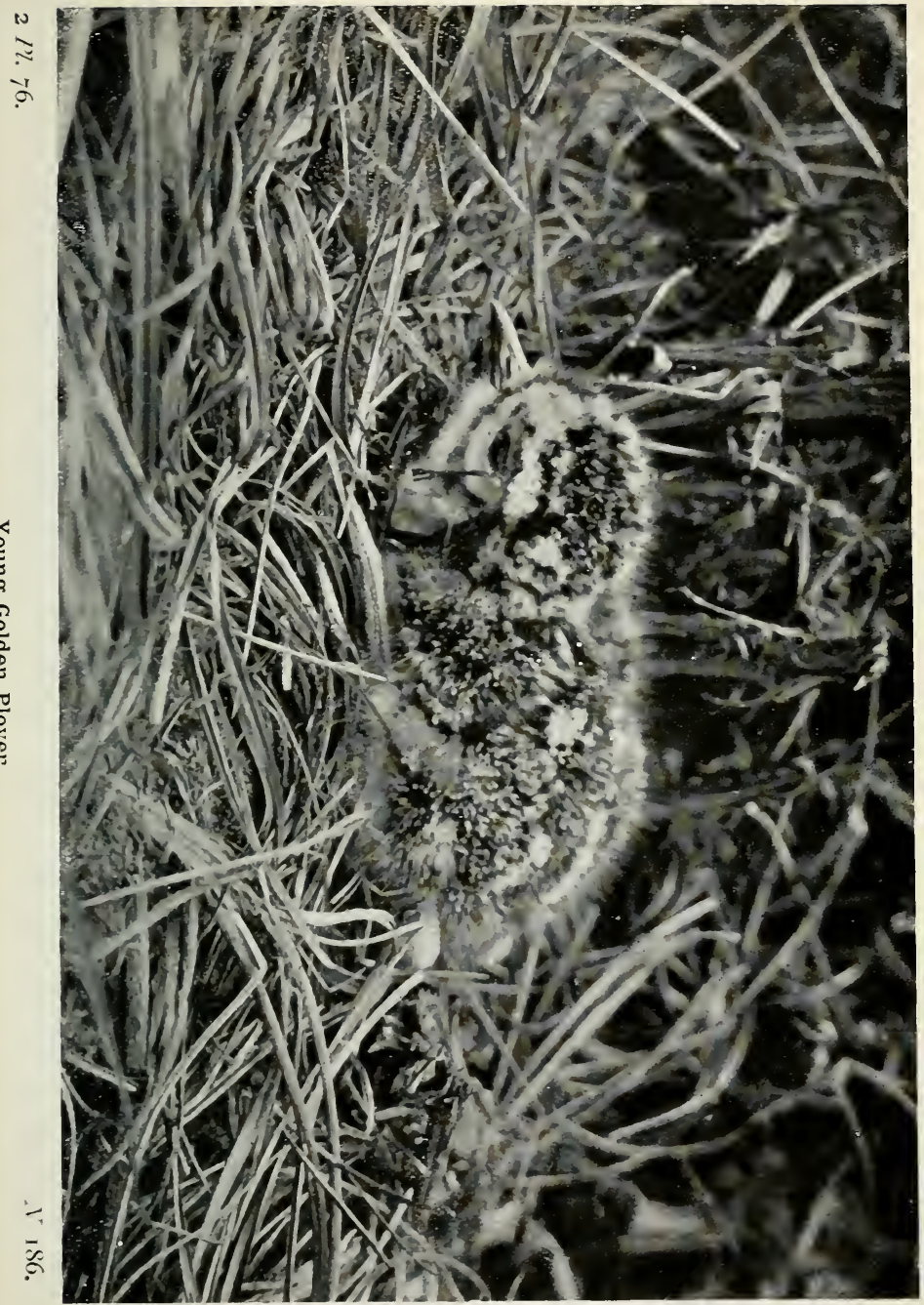


too, will stand solitary, resting, but not asleep, when waiting for the tide to turn, and not pack with other waders.

The majority of the autumn birds come in September and October, but many arrive towards the end of August and some even in July. August birds are often in breeding dress; indeed, I have seen one with a very black breast early in October. Most of the September immigrants are immature, and the adults in winter dress soon follow. The bulk of the visitors move south, but a fair proportion winter, and from March until the middle of May, and exceptionally until early June, parties are constantly passing.

The full breeding dress is striking. The upper parts are chequered brownish black and greyish white, the under parts to the lower breast are deep black. The colour pattern is as in the Golden Plover, but the white band separating the extremes is broader ; indeed, the bird is altogether whiter, for the forehead is white, and the streak wide above the eye and wider still where it margins the breast. The abdomen, as well as the under tail-coverts, is white, and there is a good deal of white on the quills and wing-coverts. The black is lost in winter, and the upper parts are browner, whilst the sides of the face, neck, and breast are streaked and mottled on a pale ashy brown ground. Young birds have much pale yellow on the upper parts, and the top of the head is browner; the under parts are streaked with brown. The axillaries, though dusky brown, are still distinctive. The bill is black, the legs bluegrey, and the irides dark brown. Length, I I ins. Wing, 8 ins. Tarsus, $1 \cdot 9$ ins.

\section{Ringed Plover. Egialitis hiaticula (Linn.).}

That there are two races, large and small, of the Ringed Plover, and that both appear on our coasts, is well known, but the actual range of the two forms is not worked out, and they 
must be considered together. It is the larger bird (Plate 78) which nests in the British Isles, and also is, apparently, the more northern form. The Ringed Plover breeds in Arctic America, Greenland, and northern and central Europe, and winters in Africa, even in the south. As a nesting species it occurs on all our coasts and in a number of inland localities ; probably most of our birds are resident, though there is an extensive autumnal immigration and at the same time emigration from the south coast; some portion of the home-bred birds may go south.

On the shore there is no more familiar wader than the lively Ringed Dotterel, as it is often called; it is a little larger than its constant companion, the Dunlin, and has distinctive black markings on its head and face, framing a prominent white forehead. On a pebble beach these markings and its sandy-drab back are by no means conspicuous, but on mud or grass the bird shows up well. Five other members of the genus are on the British list, but all are rare; the distinctive characters of each are stated later. Except in the breeding season the Ringed Plover is eminently sociable, and even in its nesting it shows a tendency to colonial habits. Sociability is not limited to its own species; it consorts freely with Dunlins, Sanderlings, Stints, and other waders, flying and feeding with them. In April and May, when large numbers are on passage, after the residents have settled down, and on the return in autumn, wonderful flights of these mixed waders may be witnessed when the birds are awaiting the turn of the tide. The Ringed Plover is as skilful and agile in its turns and twists as any, and its white plumage as silvery when with sudden swoop the flock showers earthward. At a distance these suddenly rising and dropping flocks look like showers of sunlit spray. When little parties sweep past along the beach, skimming low over the sand, the noise of wings sounds like the rustle of silk. The wing-beats are regular, rather deliberate, 
and when about to alight the bird glides, and finally trips forward with uplifted wings; the speed is never slow, but when amorous pairs indulge in nuptial flight, or when the Merlin strives to fly it down, few birds can excel it. Its actions on the beach when feeding are more energetic and spasmodic than those of the Dunlin, more erratic than the Sanderling's. Its legs twinkle as it runs for a few yards, stops and tilts forward to pick up some tiny crustacean, worm, or mollusc, and at once is off for another run. It will stand, observant, jerking its bullet-head, or for a second raise its wings straight above its back, when the great length of the pointed flights magnifies its size. If nervous it utters a low, musical, but querulus tooe, or tooli, and when numbers are calling together in a flock, this becomes a long, harmonious tooli, tooli, tooli, tooli, which, though often running into a trill, is the nuptial song, usually uttered on tlie wing. "Tullet" is a name it gets from its note, "Grundling" (groundling) and "Stone-hatch" from its habits. On migration it frequently visits the banks of rivers, meres, and lakes, and is common on sewage farms; it often nests inland.

When the nesting site has been selected, and a few preliminary scrapes made in the sand, the male tempt the female to sit, and, trilling the breeding call, will run and sit in one of the hollows. Rivals are boldly attacked then and even after the young are hatched; the guardian male, with lowered head, trailed wing, tail expanded and depressed, and the feathers of his back raised like the dorsal crest of an angry dog, will boldly attack all comers. In the site and decoration of the nest the bird shows variety and decided asthetic taste. The pebble ridge above high-water mark is favoured, and there, when eggs are in the depression, the nest is hard to see, but without eggs the lining or paving of smaller stones or bits of broken shell often gives it away. On sand or grass this lining is even more conspicuous, but often none is used, or only a few bits of weed or chips of wood are 
collected. The bird is an anxious and fussy parent, often betraying the presence of eggs or young by its persistent plaintive pipe; the sitting bird slips from the nest at the first hint of danger, runs with head low, and joins its mate at the water's edge. The young in grey and sandy down has a broad white collar and a black band above its white nape, but as it crouches, an expert at "freezing," the drawn back head hides these marks (Plate 79); its olive legs are hidden, but the bright black eye is open. If handled it will at first remain still, but if it feebly pipes the old birds become wild with excitement, and after flying round will fall and tumble with assimilated disablement. The nestling, if placed on the ground, runs on unsteady legs, falling often, holding its wingstumps uplifted; suddenly it vanishes, having crouched once more. One brood that I watched would crouch at once when on the shingle at high tide, but on the mud, where stones were freely scattered, they ran for safety, swam the tide pools round the stones, and hid, often in the water, amongst the weeds. When the parent thought the coast was clear it would alter the note, and at once the young appeared and ran to it. The three or four yellowish, brown-spotted eggs (Plate 57) are only conspicuous when laid on grass, but more usual surroundings are sand or shingle.

The general colour of the upper parts of the adult bird is mouse-grey to drab, of the under parts white. A black band passes through the eye, and another crosses the top of the head, framing the white forehead; below a white collar is a black gorget, deepest in front. A white streak above the eye and a white wing bar are conspicuous. The bill is orange at the base, blackish at the tip, the legs are chrome-yellow, and the irides practically black. The young bird is hair-grey, and the brown gorget is incomplete in front; the face stripe is brown, and the band across the crown absent. The bill is black, lighter at the base, and the legs are brownish yellow, 
but always light enough to distinguish it at any age from the Kentish Plover. Length, 7.75 ins.- Wing, 5.25 ins. Tarsus, $\mathrm{I}$ in.

\section{Kentish Plover. Egialitis alexandrina (Linn.).}

The Kentish Plover (Plate 78) is a summer visitor with a very restricted English breeding range, this being a portion of the Kent and Sussex coast; elsewhere in England, Ireland, and Wales it is only a very rare visitor on passage, but has occurred as far north as Durham. In Europe it nests from the south of Siveden to the Mediterranean, and in parts of Africa and Asia, migrating south in autumn.

Protection was just in time to save the Kentish Plover; it nearly came too late. As Dr. N. F. Ticehurst points out, the shooting of birds during the breeding season, which apparently goes on unchecked, has done more damage than egg-collecting, ruthless though this is away from specially watched areas. The bird, which normally nests in May, has been found sitting in August, its earlier efforts having failed. The demand for British-killed birds and British-taken eggs always exceeds the supply. The Kentish is smaller than the Ringed Plover, and may be distinguished by its incomplete pectoral band and its black bill and legs. The bird, especially the female, looks more sandy than the Ringed Plover; there is, too, something distinctive in the flight. Young Ringed Plovers often have the dark band interrupted on the breast, but their legs are always yellowish. The female Kentish is a browner bird than the male, the black patch on the lower neck being noticeably brown; indeed, on a bird I watched at close quarters it looked but slightly darker than the mantle, and no darker than the patch at the angle of the wing. The habits and food differ little from those of the last species; the note is shriller and more "flutelike," a plaintive whistle when alarmed. The birds arrive as 
a rule in April, though occasionally in March, and in July begin to flock ; by the end of September few are left, and Dr. Ticehurst's latest date for Kent is October Ioth, and a bird was killed against the St. Catherine's Light on October 9th.

The nest is usually a depression in sand or amongst shingle, and occasionally in dry weed at high-water mark ; little attempt is made to provide lining or decoration (Plate $8 I$ ). The yellowish-buff or stone-coloured eggs (Plate 57 ) are as a rule curiously streaked with black; they are generally three in number and are laid in May, and often placed vertically, their smaller end deeply buried in the sand, a method at times adopted by the Ringed Plover. Both sexes incubate, though it was formerly thought that in this habit they differed from the common bird. The nestling (shown on Plate 8I) has grey and buff down, but lacks the characteristic dorsal streak of the last species, and the dark band on the hind neck is also absent.

The male in summer is sandy drab on the upper parts; the crown has a rufous tinge. The forehead and a streak above the eye, the collar and under parts are white. There is a black mark above the forehead, and a streak through the eye to the cheeks, and a black patch on the neck. The only black on the female is a streak from the bill to the eye. The bill, legs, and irides are black. In winter there is practically neither black nor rufous in the plumage, and the young has a similar dress, but with buff margins to the feathers of the upper parts. Length, 6.75 ins. Wing, 4.25 ins. Tarsus, $0^{\circ} 9$ in.

The Semipalmated Ringed Plover, Egralitis semipalmatus (Bonap.), an American bird, is recorded as having been killed in Sussex in April, 19r6. In its summer plumage it closely resembles the Ringed Plover, but there is rather more webbing between the toes. 

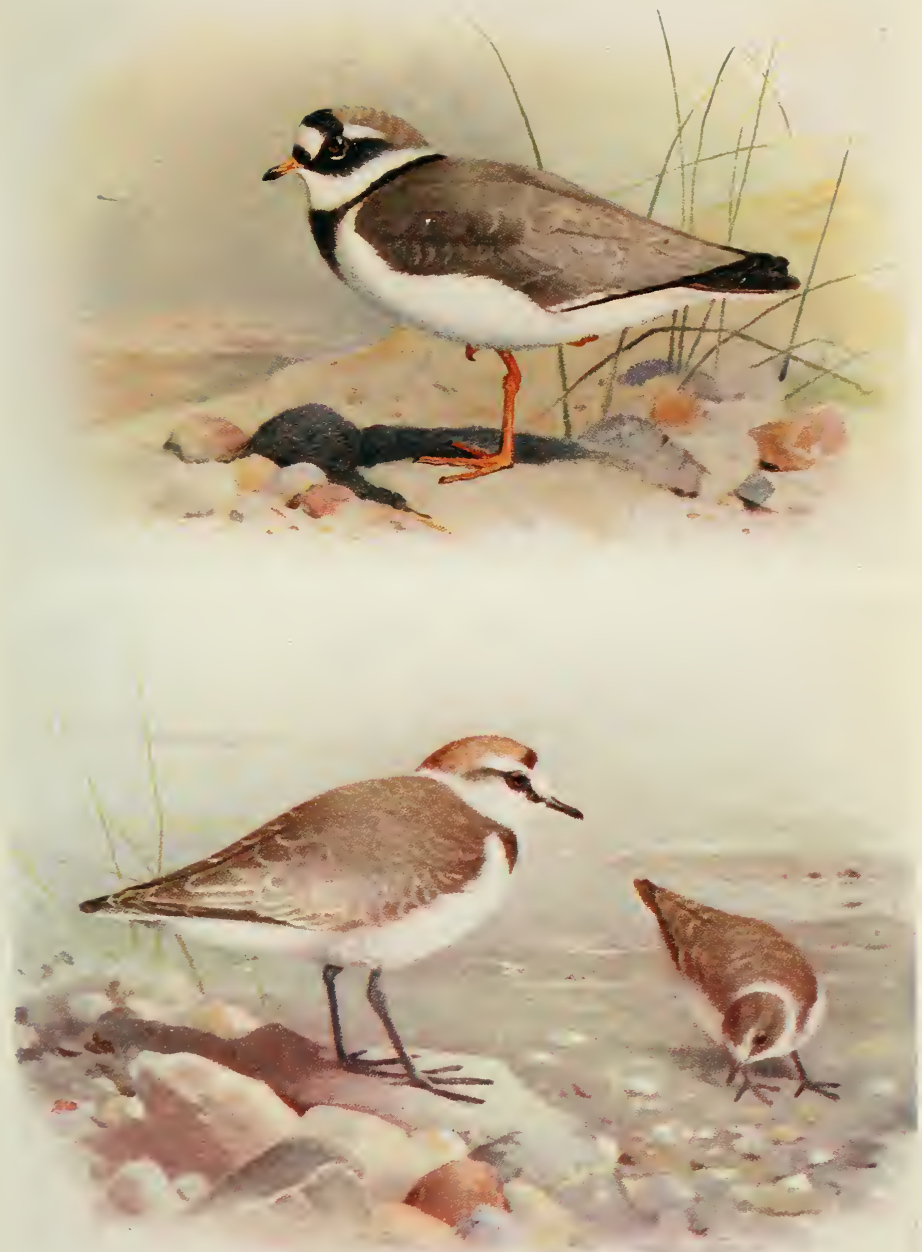

$2 \mathrm{Fl} .78$.

Ringed Plover.

$N^{\top}$ I92.

Kentish Plover. 


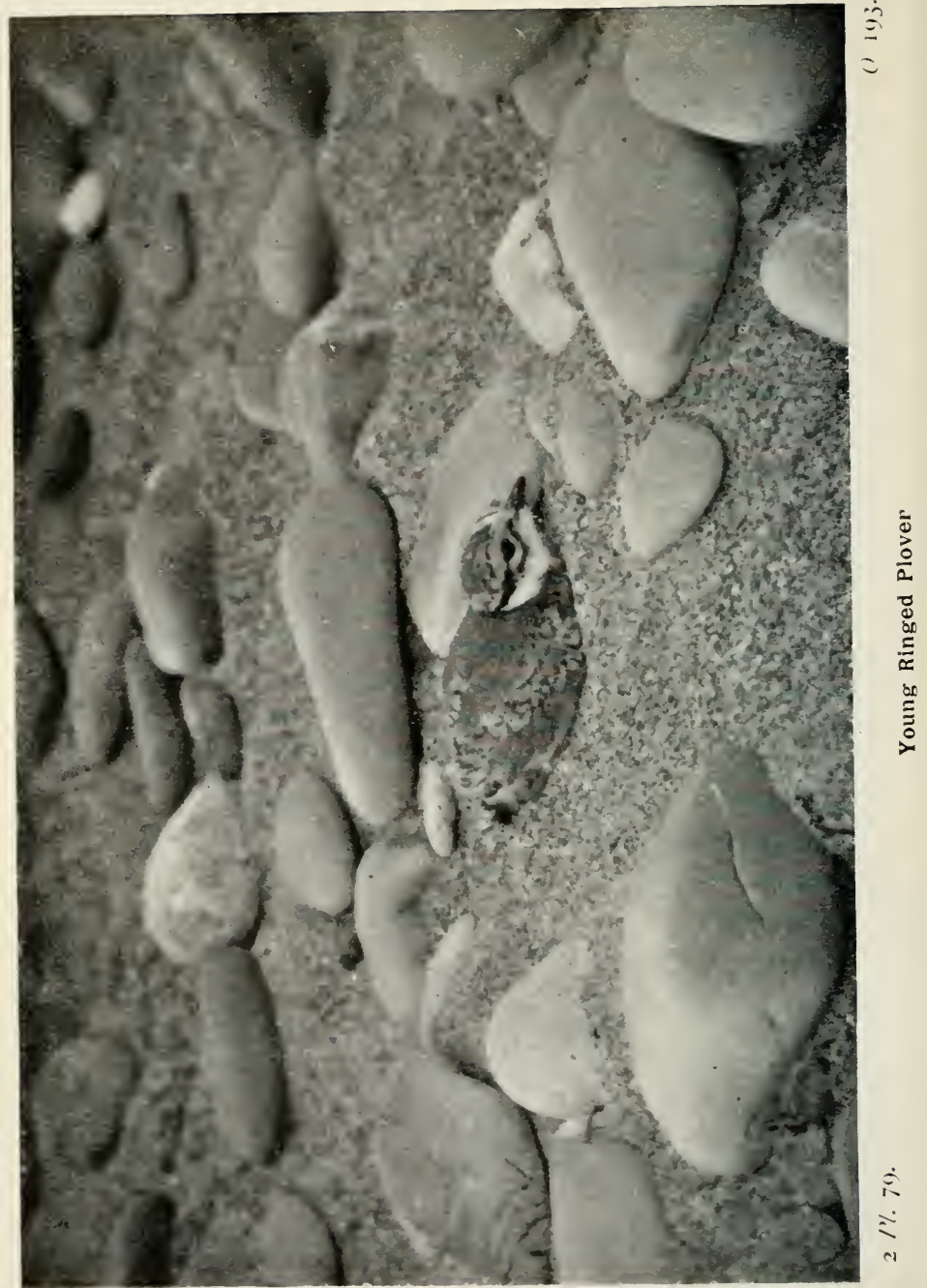




\section{Little Ringed Ployer. Egialitis dubia (Scop.).}

The Little Ringed Plover has been often reported, but it closely resembles the larger bird, and the majority of the records are erroneous. It is a very rare wanderer on migration, and, with the exception of one shot in North Uist, has appeared less than a dozen times in southern counties; most of the dates have been during autumn migration. Yet in Europe, where the bird has a wide range, it breeds in Holland, Belgium, and France, and migrates to Africa; its normal migration route must be east of Britain. It is more of an inland than a coastal species, nesting on river margins.

As its name implies, it is smaller than our bird, but the best distinction is in the wing; the inner primaries are uniform brown. In the Ringed Plover the inner webs are white, and show as a white patch when the wing is closed, as a bar when it is open. The bill is black, only slightly yellowish at the base of the lower mandible, and the legs are paler, rather pinkish yellow. The irides are dark brown. The black of the adult bird is replaced by brown in the young, and the upper parts are buffer. Length, 6.5 ins. Wing, 4.5 ins. Tarsus, 0.9 in.

\section{Killdeer Plover. Egialitis vocifera (Linn.).}

Both specific and popular names of this common North American plover refer to its loud, clear note, kill-dee; it is noisy and, in the eyes of the hunter, a spoil-sport. It is found throughout North America, and in winter Central Ainerica and Peru. It has occurred in England and Scotland about half a dozen times. Its colour scheme closely resembles that of our Ringed Plover, but it has two bands across the breast, the upper one forming a collar. The general colour of the upper parts is browner, and this is specially noticeable on the facial

Series $I I$. 
streak and cheeks. The lower back and wedge-shaped tail are rufous brown, with a subterminal black band to the latter. It is a rather larger bird than ours, with legs and tail longer in proportion; the bill is black, the legs yellowish green, and the irides brown. Young birds have rufous margins to the feathers of the upper parts. Length $99^{\circ}$ ins. Wing, 6.5 ins. Tarsus, 1.4 ins.

\section{Caspian Ployer. Egialitis asiatica (Pallas).}

The Caspian Plover, which breeds in south-eastern Russia and western Asia, and winters in Africa, has wandered to southern England two or three times in spring and summer. It has occurred elsewhere in western Europe. The adult bird is, roughly, brown above and white below, and has a broad chestnut band bordered with black across the breast. The face and neck are white, and a dark line through the eye throws up the broad white superciliary stripe. In winter the face is suffused with buff and the pectoral band is pale brown, and the young are still more buff on the face and wings. The bill is black, the legs are olive, and the irides dark brown. Length, 7.5 ins. Wing, 5.6 ins. Tarsus, $1 \cdot 35$ ins.

\section{Dotterel. Eudromias morinellus (Linn.).}

The Dotterel (Plate $\delta_{2}$ ) breeds in northern Europe and Siberia, and winters in north Africa and western Asia. In the British Isles it is a summer visitor and passage migrant, regular in its visits, but never numerous. In spite of centuries of persecution it still nests in small numbers in the Lake District, and in the Grampians and other Highland mountains, but in most parts is only known as a scarce spring and autumn visitor.

The plumage of a Dotterel in a specimen or picture looks very conspicuous, but in its favourite haunts, wild barren 


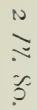
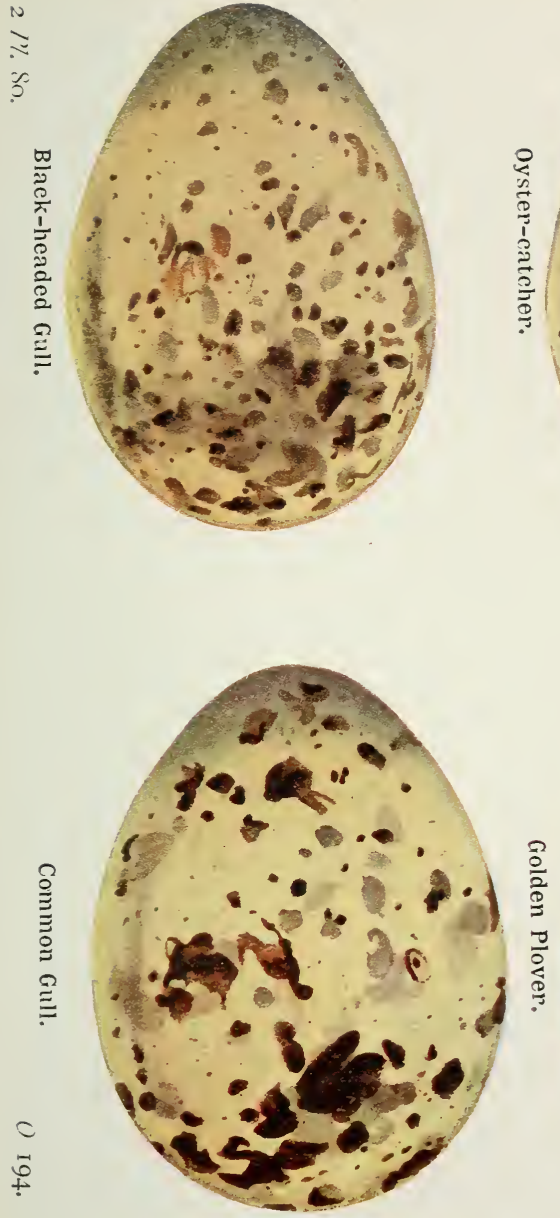
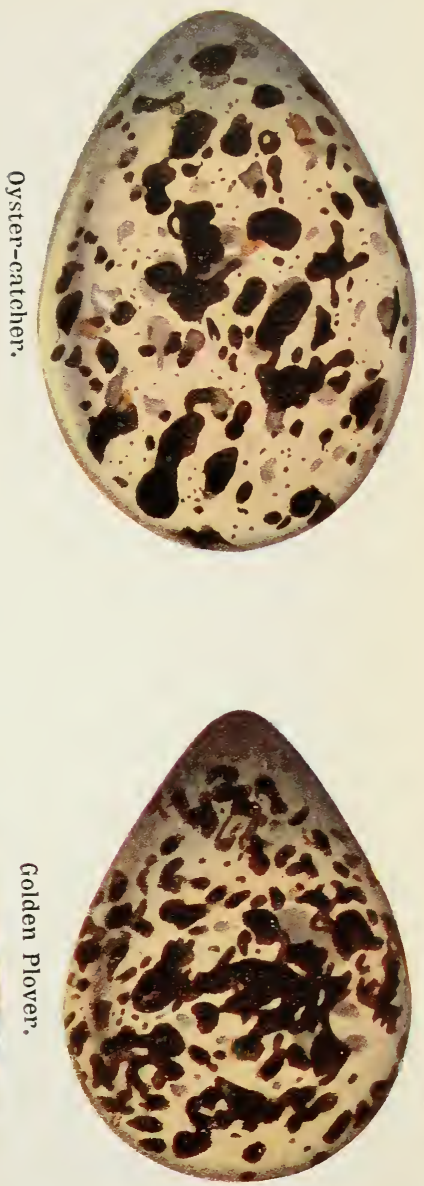


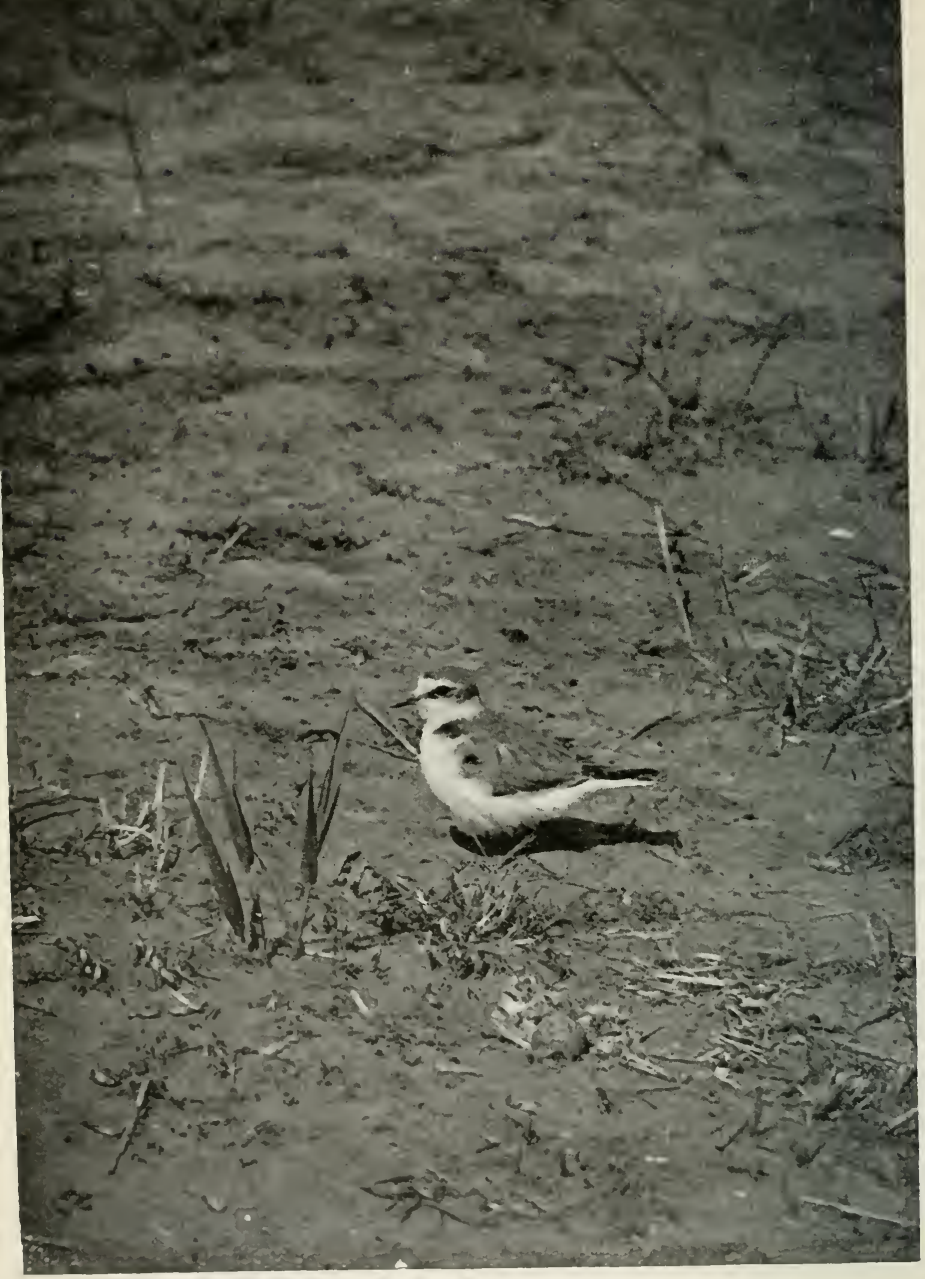


uplands, the bird is most difficult to see. It is a squat and plump, round-headed, short-billed plover ; its most characteristic markings are the curved white streak above the eye which meets its fellow on the nape, and the white band that divides the slaty-brown upper breast from the chestnut and black below. What the bird gains from the protection of its coloration it loses through its stupid tameness; it is one of our easiest birds to approach. Towards the end of April or early in May "trips," as the small parties are called, arrive in England; some, probably passage birds, travel slowly along the coast, but others follow ancient inland routes, halting at certain oft-frequented spots to feed or rest. The trips comprise from five to a score of birds, and their arrival is, or was, watched for keenly, for the Dotterel has always had a high money value, originally for its flesh, but later for its plumage ; inconsiderate fishermen demand certain feathers for artificial flies. The travellers are tired and stupid, and if shot at will settle again at once; it was not uncommon for the whole trip to be wiped out; within recent years similar massacres have come under my notice. The birds are regular visitors to the Pennines, the Yorkshire moors, and the Cheviots, and certain spots on the Lancashire coast are used as annual halts. Egg collecting is responsible for further diminution in numbers, but is less to blame than the wholesale destruction of the recently arrived immigrants. The return passage is in August and September.

The food either on the hills or the rough pastures, when on migration, mainly consists of insects and their larvæ, though worms and molluscs are also eaten. Like other plovers the Dotterel runs for a foot or two, then stops and tilts forward to pick up its food, and between its runs often stretches its long wings above its back. Ancient myth affirms that the wing and leg stretching was imitation of the actions of the fowlers as they lured or drove the bird to its doom. On the wing the 
bird is not unlike the Golden Plover, swift and graceful, with powerful strokes. Its notes vary according to circumstances, but the attempts to formulate them convey little; a low, plaintive whistle and a harsh call of alarm are the best known, but at the nest there is a soft, parental twitter.

Typical Dotterel ground is barren, stone littered, and almost without vegetation; the bird nests on the black soil near the wind-swept tops, seldom below the 2000-foot contour. The three buff or stone-coloured, brown blotched eggs (Plate 57), less pyriform and more tern-like than those of most waders, are placed in a shallow scrape, usually lacking lining or decoration. Eggs are sometimes laid before the end of May, but the middle of June is the normal time for incubation. Though the sitter will sometimes rise with a cry of alarm it usually slips away quietly, and at once begins by spreading and trailing wings and tail, and falling as if disabled, extravagant performances to lure the intruder from the nest. But if the eggs or young are handled the parent returns to within arm's reach and falls about in a frenzied effort to attract attention. If, however, the nest is undisturbed the bird will return and brood eggs or young at the very feet of the observer. The down of the nestlings is grey, mottled and streaked with buff, chestnut, and black ; there is a white band on the nape ; the legs are at first.lead colour, but soon show yellow on the feet; the bill is black and the irides brown, as in later life.

Some dogmatically affirm that the female, which is the larger bird, is also brighter in her colours, whilst others are as emphatic that she is duller; examination of sexed birds proves that there is little difference. Both sexes incubate, which may explain the confusion. The back and wings of the adult bird are brownish grey, neatly patterned on the coverts with rufous margins. The top of the head is brownish black, and below this is the curved white stripe from the forehead to the nape; the face and throat are white, and a dark streak passes through 
the eye and widens on the sides of the neck. The upper breast is slaty brown, bordered below with bands of black and white; the lower breast is bright chestnut, shading to black on the abdomen and white on the under tail-coverts. The heads of young birds are more rufous and streaked on the crown, the eye-stripe and the blacker upper parts are tinged with buff. The under parts, buff on the breast and flanks, and white on the abdomen, are mottled with brown. The bill is black, the legs are dull yellow, and the irides dark brown. Length, 9 ins. Wing, 6 ins. Tarsus, $\mathrm{I}_{4} 4$ ins.

\section{Sociable Plover. Chettusia gregaria (Pallas).}

The Sociable Plover, a native of southern Russia, the Caucasus, and Mongolia, winters in India and south-western Asia, and north-eastern Africa; it has been met with in Lancashire and Ireland in autumn, and in Kent and Sussex in spring. The Lancashire bird was consorting with Lapwings, and like them it is a round-winged plover. The adult bird is ashy brown, with a black crown and a streak through the eye, and between these a conspicuous white stripe from the forehead to the nape. The primaries are black, the secondaries white, the tail mostly white with a subterminal black-brown band. The cheeks and throat are buff, the lower breast brown, shading to black on the belly, the abdomen and flanks rich chestnut. The under tail-coverts are white. The crown of the young bird is brown and its superciliary stripe buff; the under parts are buffish white, with a few dark markings on the breast. The bill and legs are black, the irides dark brown. Length. 135 ins. Wing, 8.5 ins. Tarsus, 2.5 ins.

\section{Lapwing or Green Plover. Vanellus vanellus (Linn.)}

As a nesting species the familiar Lapwing (Plate 85 ) is found throughout the British Isles, and in winter its numbers are 
greatly increased by immigrants from Europe. It breeds in Europe, Asia, and some parts of Africa, and is partially migratory.

The erectile crest, round wings and call, and seemingly black and white dress, are well known, but the Green Plover is not really black and white; at close quarters in sunshine the glossy green back and the rich chestnut patches above and below the tail are wonderfully beautiful. Marshy fields and rough upland pastures are typical haunts, but its choice of habitat is catholic ; it feeds, a shore bird, on the tidal flats, it flocks on cultivated land, it is companion of the Curlew and Golden Plover on the bleak moor. Indeed, it is everywhere and often abundant. In the nesting season it is scattered, large lowland fields usually having their pair or pairs of birds, but so soon as the young can fly they form small parties, and from June onward the bird is gregarious. In autumn immigrants arrive from the north and east, and throughout the winter the flocks are often immense, though there are frequent southward movements after the usual time for passage. After accumulating a large amount of information, Dr. W. Eagle Clarke strove to formulate the various Lapwing movements, but the bird is capricious, and weather conditions or overabundance in any place may cause extra and erratic migration. Theories that all immigrants winter here, or that all home-bred birds remain or depart, are unsound; indeed, the recoveries of "ringed" birds show great variability in habit. Birds ringed abroad are found here in winter, but nestlings marked in England and Scotland may be recovered in their first or subsequent winters anywhere. An analysis of recoveries proved that a fair proportion remained near home, and that the majority that emigrated went westward into Ireland; others reached France, the Spanish peninsula, and Africa, and of those which did not leave England most went south, but a few wandered north. 

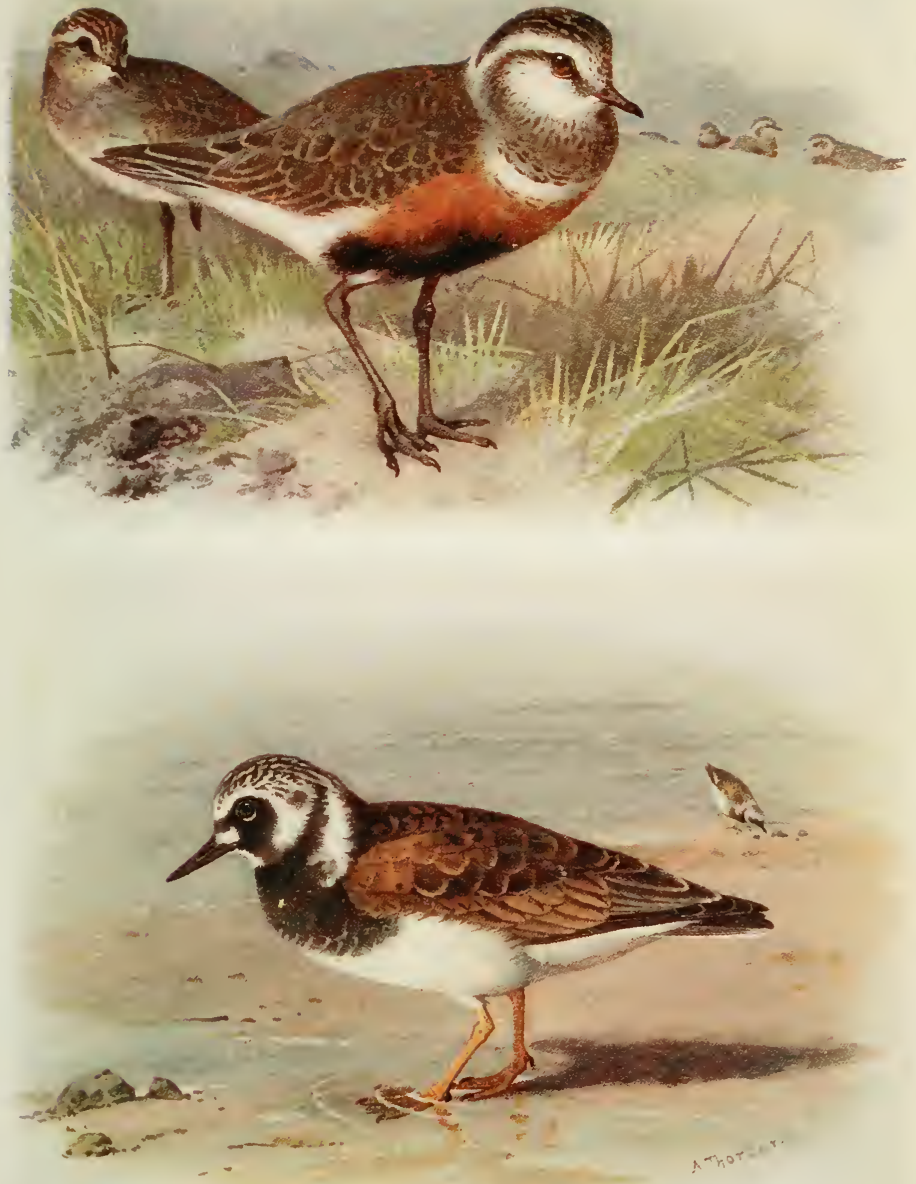

2 Pl. 82.

O I 98.

Dotterel.

Turnstone. 
As a check to pests the Lapwing is our most useful bird, for though it does not discriminate between harmful and beneficial insects and worms, examination of a number of stomachs shows that it devours more wireworms, tipulid and lepidopterous larvæ, and snails than useful carnivorous insects and worms, and there is no evidence that it ever attacks crops. It is nominally protected and the gathering of "plovers' eggs" regulated, but nothing is done to enforce the law. The stock of summer birds is large, but it should be larger. In flight the broad round wings flap slowly; the bird moves fast, but without the dash of the sharp-winged plovers; Lapwings flying high flicker black and white. They can fly high when migrating; one airman ran into a flock at 6500 feet. Such flights, at a height above range of vision, detract from the value of theories founded on visible migration, when the birds are often forced to low altitudes by adverse winds or other untoward conditions. The birds travel, when changing ground, straight, but without the ordered formation of many waders; lines are rare, and leaders frequently alter. Towards dusk in autumn and winter the flocks indulge in aerial exercise, wheeling and changing direction, as they rise and "tremble up to cloud." Their evolutions, though concerted, are without the quick turns and swaying swoops of sharp-winged waders. The air mastery of the Lapwing is seen in its nuptial flight.

The ordinary call is a wheezy pee-zvee, from which the bird gets the name "Peewit," with many local variants, but in February or early March both note and actions change. Before the winter flocks have dispersed, the males begin their erratic aerial dances, accompanied by a long, undulating, wild, but musical whistle, utterly impossible to put into words; the bird rises almost heavily, sweeps round in a wide circle, suddenly dashes upward, and calls. As suddenly it hurtles earthward, turning and twisting, throwing its broad wings anywhere, but never losing control, and often with the last excited 
hoo-00-ce, it drops lightly and runs forward with crest erect. During aerial display the Peewit often flies round in curves and circles, swinging from side to side and beating the air with a loud humming or soughing sound. This is not all the performance; the male scrapes and sits in imaginary nests, turning in them as he scratches the hollow in frenzied haste, or bending forward, breast to ground, raises and exhibits the chestnut coverts and banded tail. In May I have heard the spring call before daybreak.

So long as the site is open the nest may be anywhere, a shallow scrape in grass, on the ridge between furrows, in moorland ling, even on a cinder spoil-bank. A few bents or straws are collected as decoration by the sitting bird, and occasionally mild efforts at nest construction are made. Four olive or darkbuff eggs, richly mottled (Plate 57), are arranged end to end; clutches of five are rare. They are often laid in March, but so systematically are the nests robbed that young birds may be still unable to fly in August. The sitting bird leaves the nest silently, running for a few yards, and artlessly pretending to feed; then the pair will fly overhead, wailing, and, if the nest is threatened, dashing with a loud, angry peet at the head of the enemy. The rufous, black-marbled down of the nestling is protective, and at the first warning call it crouches with head back, but not always hiding the white collar (Plate 83). I have lain beside the chick and watched the old bird run toward me, stopping every few feet to peck at imaginary food, until within four yards, and after I have ringed and released downy young they would run off and pretend to feed. Nestlings disturbed in the open will run for shelter. Though the parent birds will swoop at and strive to drive away a man, a dog, or even a cow which crosses their domains, it is incorrect to affirm, as many do, that they never feign disability in order to lure the enemy away. Commander Lynes saw one bird thus tempting a stoat away from its young, and I have seen a similar performance. 
The crown, crest, face, throat, and breast of the male Lapwing in summer are black, the back and wings are metallic green glossed with bronze and purple; the sides of the neck and under parts below the breast are white. A broad black subterminal band crosses the white tail, and the upper and under tail-coverts are bright chestnut. The bill is black, the legs fleshy red, the irides dark brown. The female has a shorter crest, and her wings, as pointed out by Mr. Frohawk, are narrower and less rounded. In winter the throat is, usually, white, and the upper parts show buff margins. The legs are much darker, dull purplish red, a fact which seems to be generally overlooked. The crest is shorter on the still buffer young, and their chins and throats are white; females will breed before they have attained full black chins. The legs of the nestling are pale flesh. Length, 12 ins. Wing, 8.75 ins. Tarsus, $I \cdot 6$ ins.

\section{Sub-family HÆMATOPODINÆ.}

Bill long, stout, and compressed ; toes united at base ; hind toe absent.

\section{Oyster-catcher. Hamatopus ostralegus Linn.}

The Oyster-catcher (Plate $\delta_{5}$ ) is resident in Europe and central Asia, but a large number move southward in autumn; many reach the. British Isles, where there is also a southward migration, but on most of our shores, whether rocky or sandy, birds are present at all seasons. It nests freely on the Welsh and north-western coast, and in Scotland and Ireland, but is thinly distributed on the east and south shores of England.

The long, stout, and compressed orange bill, the fleshy legs, and black and white plumage make the "Sea-pie" an easy bird to recognise. At all seasons it is sociable, and little parties of 
non-breeding birds feed on the shore when the residents are nesting; in winter, when the migrants have arrived, the flocks are often immense. With the advance of the tide they pack on the lessening banks, or crowd on reefs and islets, and when forced to move rise with a chorus of calls, kleep, kleep, kleep, and fly, low over the water, to a drier refuge. When they scttle, the clamour rises in volume for a few seconds and then dies away. Long before the flocks break up in spring, the amorous males may be seen running on the banks or standing in groups with heads lowered and bills touching the ground, piping the trilling nuptial song. When the tide falls the birds scatter over the ooze or rocks, plunging the bill deeply for cockles or worms, or wading over the still submerged musselscalps to catch their victims before they close their valves. There is little evidence that the bird ever opens oysters, but it forces back the valves of mussels and smaller bivalves with skill, as well as smartly knocking the unsuspecting limpet from its hold. On rare occasions a bird will fly up with a shell and drop it on hard sand or rock until it is fractured. Crabs and other crustaceans and small fishes are eaten. The call is a clear, ringing feet, feet, and the alarm a sharply emphasised and repeated pic, pic, pic. Nesting birds are bold, mobbing human beings as well as avian visitors; I have seen a pair drive away a Carrion-Crow, and another pair, when guarding young, chased the passing Herring-Gulls until they squawked in alarm, dodging the fierce assailants. They even flew out over the water to mob a passing steamer!

The choice of the nesting site varies considerably, as does the quantity and quality of the nesting material. In England and Wales the nest is usually near the shore, but in Scotland the bird also nests on the banks of rivers and lochs. I have found nests in the micldle of a field, on the cliff edge, on rocky reefs and islands, on sandhills and pebble ridges. I have seen them unlined, or with a plentiful lining and wall of bents or 


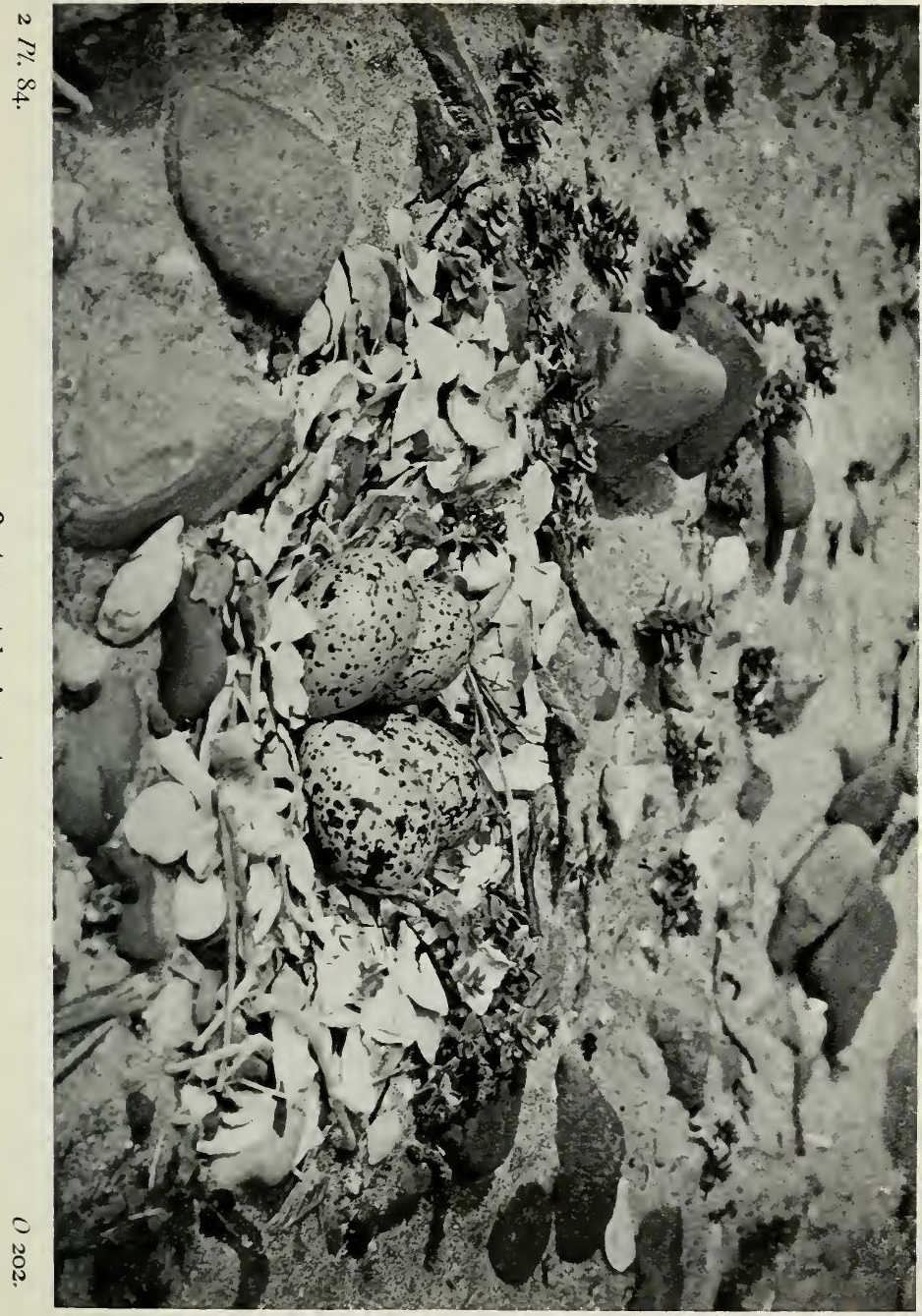


seaweed, and in some cases with a selection of small pebbles and broken shells (Plate 84). One scrape in light soil, two inches deep, was lined with dead thrift; another, on a pebble ridge, was entirely lined with Patella shells, and one in turf with bits of stick and a few shells of a small Helix. The most eccentric surrounding wall I have seen was composed of the bones of a rabbit and a Puffin. Three is the usual number of the yellowish, blotched, or streaked eggs (Plate 80); they are laid as a rule in May, and are not placed end to end. The down of the newly hatched chick (Plate 86) is close and plushy, light grey with darker stripes and mottles, down the centre of the back, on the head, and stumpy wings. The bill is short and dark, reddish at the base, and the legs blue-grey with a slight fleshy tinge. In a few days the bill is dull orange, blackish at the tip, in curious contrast with that of the adult, which is orange with a lighter tip. The legs are browner. A halffeathered young bird in the middle of July had the bill red at the base, then yellow, and the tip black. The behaviour of birds when guarding eggs or young, varies individually, but at the least suspicion of danger the sitting bird slips silently away, and the first evidence of the vicinity of a nest is the monotonous pic, pic, of the pair, standing on rocks, mounds, or walls some distance apart.

In summer the upper parts, except the lower back and upper tail-coverts, a patch on the wing, and a small streak below the eye, are black, as are the neck and throat; these exceptions and the rest of the under parts are white. In winter there is a half collar of white on the throat and the sides of the neck are also white, and this is still more noticeable in immature birds, which are browner on the back and wings. The bill varies from orange-red to vermilion, the colour of the narrow rim round the blood-red eye. The legs are fleshy pink in summer, but rather more livid in winter. Length, 16.5 ins. Wing, 975 ins. Tarsus, $I \cdot 8$ ins. 


\section{Sub-family ARENARIINÆ.}

Bill short and conical; anterior toes with narrow lateral membranes; hind toe present.

\section{Turnstone. Arenaria interpres (Linn.).}

If we include as one the Old and New World forms, which are close allies, the Turnstone (Plate 82 ) is circumpolar in summer and cosmopolitan in winter. It breeds as near to Britain as Iceland and southern Scandinavia, but though often suspected of nesting in our islands no nest has ever been found; it may be called a non-breeding resident, since it is present at all seasons. It is a common passage migrant and winter visitor, and many birds, even in breeding dress, linger on our shores all summer.

The Turnstone is a wader of the rocky shore, though on sandy beaches it may be seen hunting along the tide-wrack. In full summer dress it is a tabby, short-legged shore bird, very black and white about the head and neck, with noticeable orange legs and a short, slightly uptilted bill. In immature and winter plumage it is more indefinite in its coloration, suggesting irregular black, white, grey, and brown markings; it looks more variegated than other waders. When consorting with other birds it may be recognised by its actions as well as appearance. The pose is characteristic when a flock rests, often accompanied by Purple Sandpipers, on some rock just out of reach of the waves (Plate 88). Immigrants begin to appear in July and August, but before the end of September the wave of passage migration has spent its force, for many of our visitors may be bound for the southern hemisphere. From the latter half of April until June northward passage causes increase on our shores. The bulk of the birds which remain to winter, and also those about in summer, are immature. 
Although, on passage, the Turnstone occasionally visits inland waters, its favourite haunts are at the edge of the waves, either on tide-washed reefs or rocks. In its feeding habits it proves the value of its short pick-axe bill, using it as a lever to tip up and throw over large stones, hence its name, and with an upward sweep jerk the long strands of tangle aside, and quickly pounce on the astonished sandhoppers, small crabs, and molluscs. I have watched it hunting with Purple Sandpipers when the surf churned over the rocks, lifting the weed and submerging its orange legs; its movements were then deliberate, but on the litter at high-water mark it runs quickly, its keen eye detecting any stone or bit of weed beneath which crustaceans may be sheltering. Never, so far as I have noticed, is a stone turned a second time. There are several oft-repeated stories of co-operation or "mutual aid" when the stone or dead fish was too heavy for the efforts of one bird, but I have once only seen two work at the same stone, and it appeared to me that competition rather than combination had attracted them to a likely food spot. Dr. Patten tells how a Turnstone in his aviary killed three newly hatched Californian Quails by turning them two or three times a day, possibly mistaking them for fluffy weed. On shingle the variegated plumage is a useful protection; the bird is almost invisible. It is tame or indifferent, and will permit close approach before it takes wing with a short, Redpoll-like trill; as it flies the white on the wing and lower back are conspicuous, the bird flickering black and white.

In summer dress, fully attained by the end of April, the head, lower back, and under parts are white, banded and blotched on the cheeks, neck, and breast, and streaked on the crown with black ; the back and wings are variegated with black and warm chestnut. The bill and irides are blackish brown, the legs bright orange. In winter the bird is darker and browner, the blacks replaced by greyish brown, and the whites on head and 
neck much suffused and speckled with brown; the legs are duller. Immature birds resemble adults in. winter, but are buffer, and their upper parts are speckled with greyish white. In the same flock birds in various stages of immaturity or seasonal change may be noticed, for all do not attain their various plumages at the same time. Length, 9 ins. Wing, 6 ins. Tarsus, $\mathrm{I}$ in.

\section{Order LARIFORMES, Gulls, Terns, and Skuas.}

\section{Family LARID $A$.}

Bill strong, tip recurved (Gulls, Skuas), straight and tapering (Terns); cere present (Skuas); anterior toes webbed; hind toe present.

\section{Common Gull. Larus canus Linn.}

The Common Gull (Plate 89) ranges over northern Europe and Asia, and, in winter, north Africa and the Chinese seas. In the British Isles it is resident, a winter visitor, and a bird of passage; it breeds abundantly in Scotland and Ireland, but not, usually, south of the Border. There are recent records of isolated nests on the Farnes, the English side of the Solway, and kient.

Gulls as gulls are familiar, but the various species, owing to changes of plumage and variability in size, are difficult to identify ; the name Common Gull is a frequent source of error. In most parts, especially in England and Wales, the Black-head is the common gull, and as it loses its distinctive brown hood in winter is confused with the present species. The Common Gull is more robust, a stouter bird than the Black-head, but is 


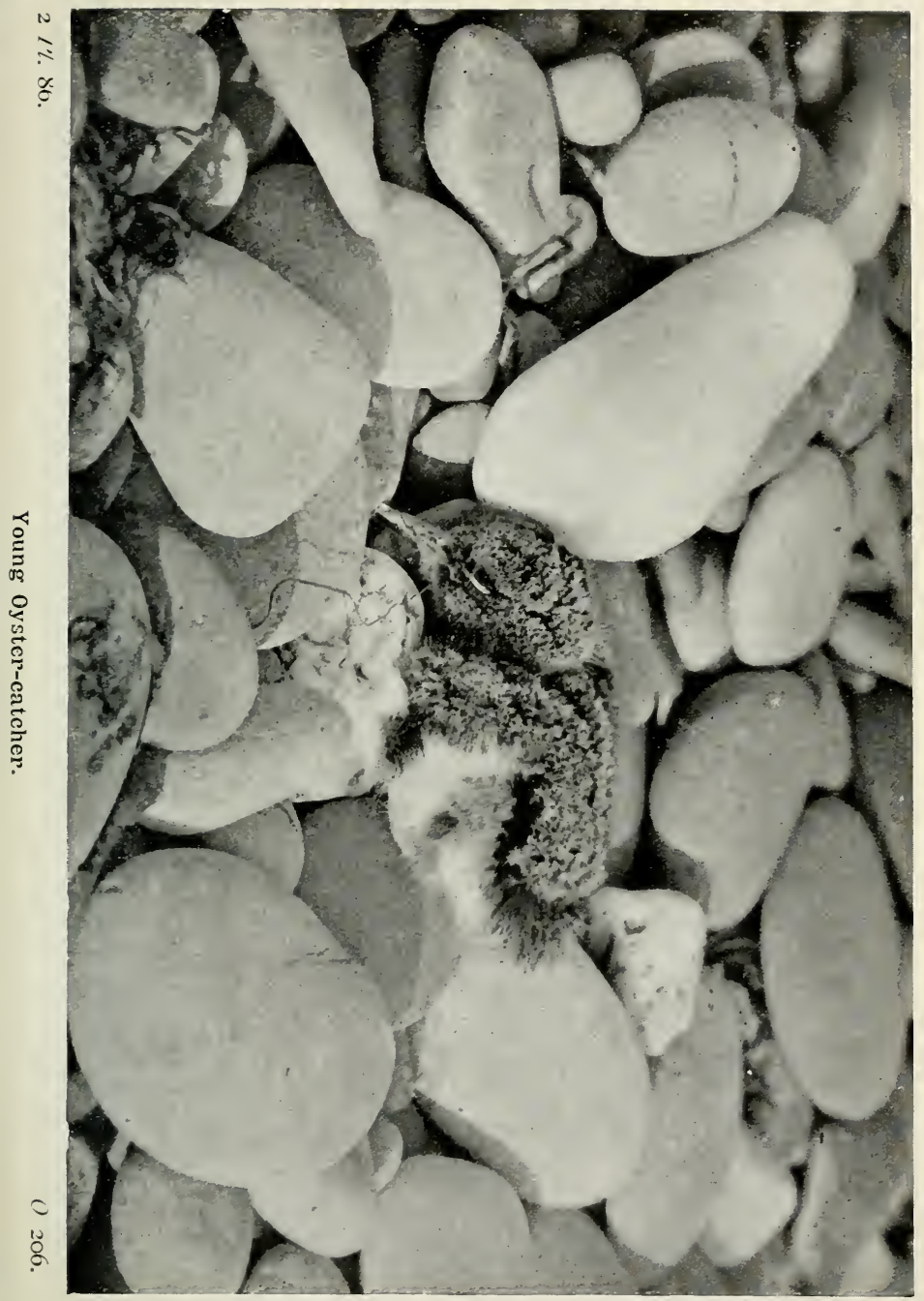




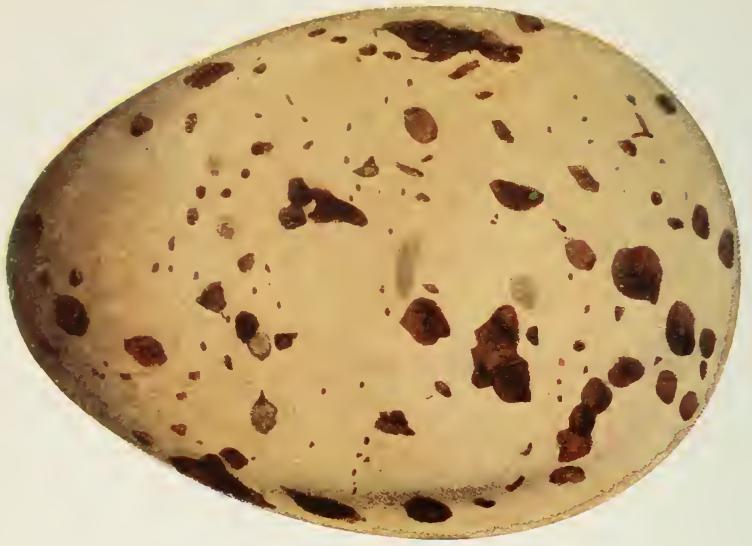

Great Black-backed Gull.

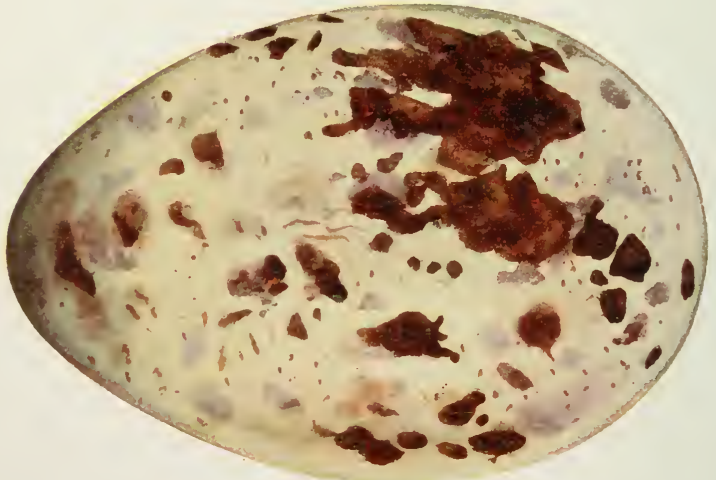


considerably smaller than the Herring-Gull, which it resembles in its white and French grey plumage. When they can be seen the colours of bill and legs are useful distinguishing characters in gulls; in the adult Common Gull the bill is greenish yellow, without the splash of red or orange, and the legs are yellowish green. In the flying bird white spots or "mirrors" show near the tips of the two first primaries; these are not present in the Black-headed Gull or Kittiwake, which approach this species in size. Except for occasional immature birds, distinguished by the black band on the tail, the Common Gull deserts England and Wales in March or April, and as a rule does not return until August, though a few sometimes appear in July. It frequently visits inland waters, by no means only when storm driven, but is never so common away from the sea as the Black-head; near the coast, however, it may be seen following the plough, or resting, preening its feathers or washing in fresh-water pools, on the cultivated iand.

Like other gulis, this bird is omnivorous, picking up garbage, animal for choice, on the shore, catching small surfaceswimming fish, and searching the sand and banks at low water for molluscs, crustaceans, and worms; on land it eats earthworms and insects and their larvæ, and occasionally a little grain. It will paddle in shallow water or wet sand, dancing or marking time to bring worms to the surface, and is more regular than other gulls in the habit of dropping bivalves in order to smash the closed shell. I have often watched the bird hunting for cockles and rising with one in its beak; when at a height of from fifteen to thirty feet it will droop the head, hold the wings motionless for a second, and deliberately drop the mollusc on hard sand or rock, stooping at once to recover its treasure. If the shell is not cracked at the first attempt it will try again; sweeping round until above the same spot, but never, so far as I have seen, rising to a greater height. This lack of reasoning power is strange, for in other ways the 
bird shows remarkable sense. I saw one Gull drop its cockle ten times in one spot, and another only smashed it after eleven attempts; in both cases the molluscs were dropped on sand; yet three different birds, after a first unsuccessful attempt on sand, deliberately carried their cockles to above some flat sandstone rocks and dropped them. These rocks were littered with broken shells.

The fight of the Common Gull is leisurely, its wing-beats more deliberate than those of the Black-head. It sails frequently, careening so as to benefit from every air current, and adjusting its balance with its tail. It swims gracefully, but only submerges itself when excited by the pursuit of a shoal of fish. Its usual calls are a sharp $k a k, k a k, k a k$, an alarm note or threat, and a resounding $k y a h$, but it has other calls difficult to express and impossible to interpret. One note, however, is either a love signal or challenge, but may be heard long before the bird leaves our shores; the head is lowered and then raised, the bill pointed upwards, and, with the mandibles wide open, the bird gives vent to a series of clarion, laughing cries.

At all seasons the Common Gull is gregarious, and though isolated pairs are met with in inland localities, the nests are usually in a colony on a cliff, an island either at sea or on a loch, or on the moors, even at over 2000 feet altitude. The nest is at times a scratching in short turf or on a ledge, but is often in thick heather or coarse herbage (Plate 90); it is seldom lined, but usually walled with grasses, ling, or rushes, and on the cliffs seaweed. Three is the normal number of eggs, which vary greatly in ground colour and markings; a usual type is olive or buff, sparsely spotted with black (Plate 8o), but I have seen unspotted blue eggs. Incubation begins in May, and the first young leave the colony as a rule in July. The nestlings, which like other juvenile gulls vary greatly, are greyish buff, mottled and streaked with black or brown.

The adult bird in summer has pale grey back and wings, and, 


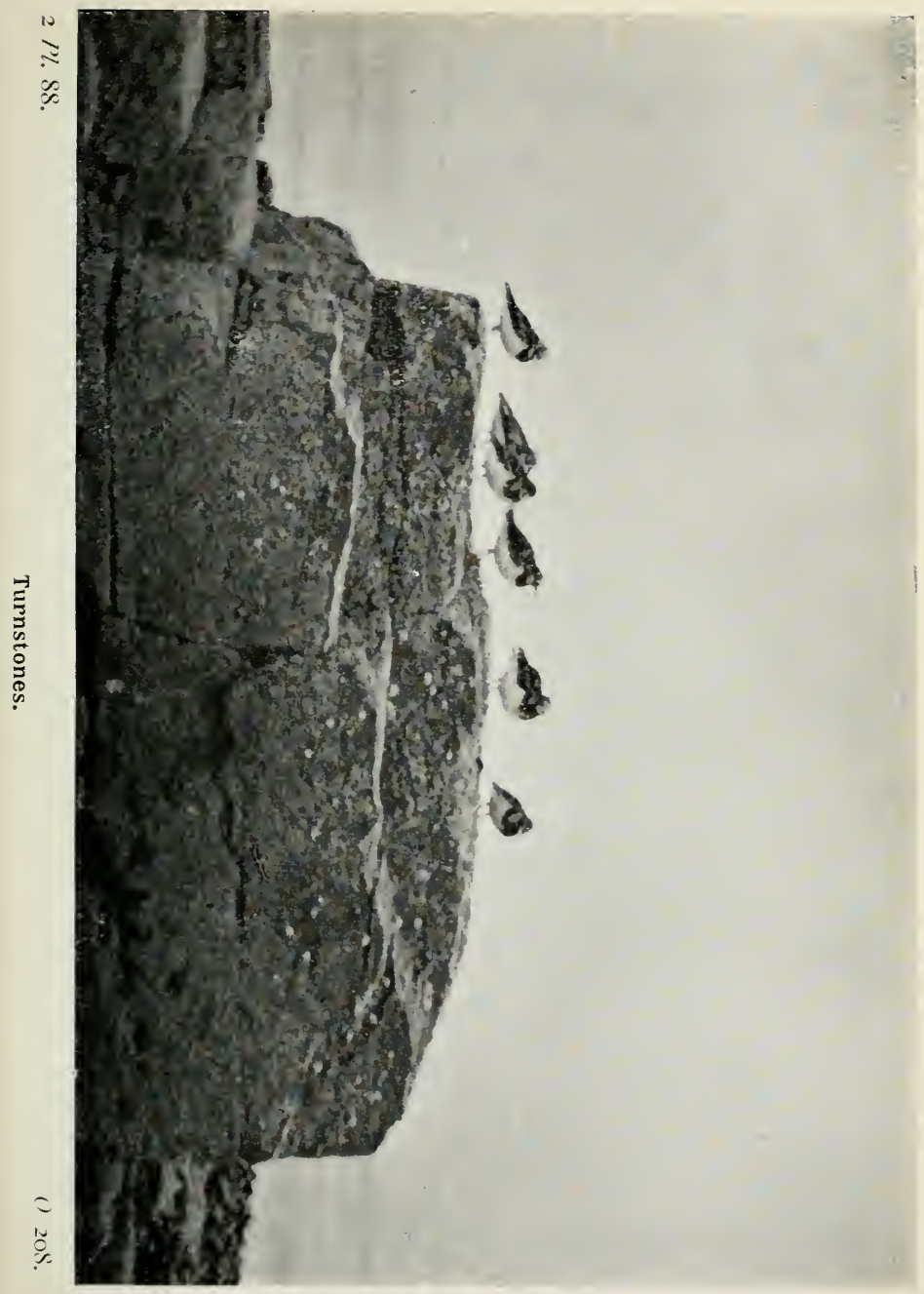



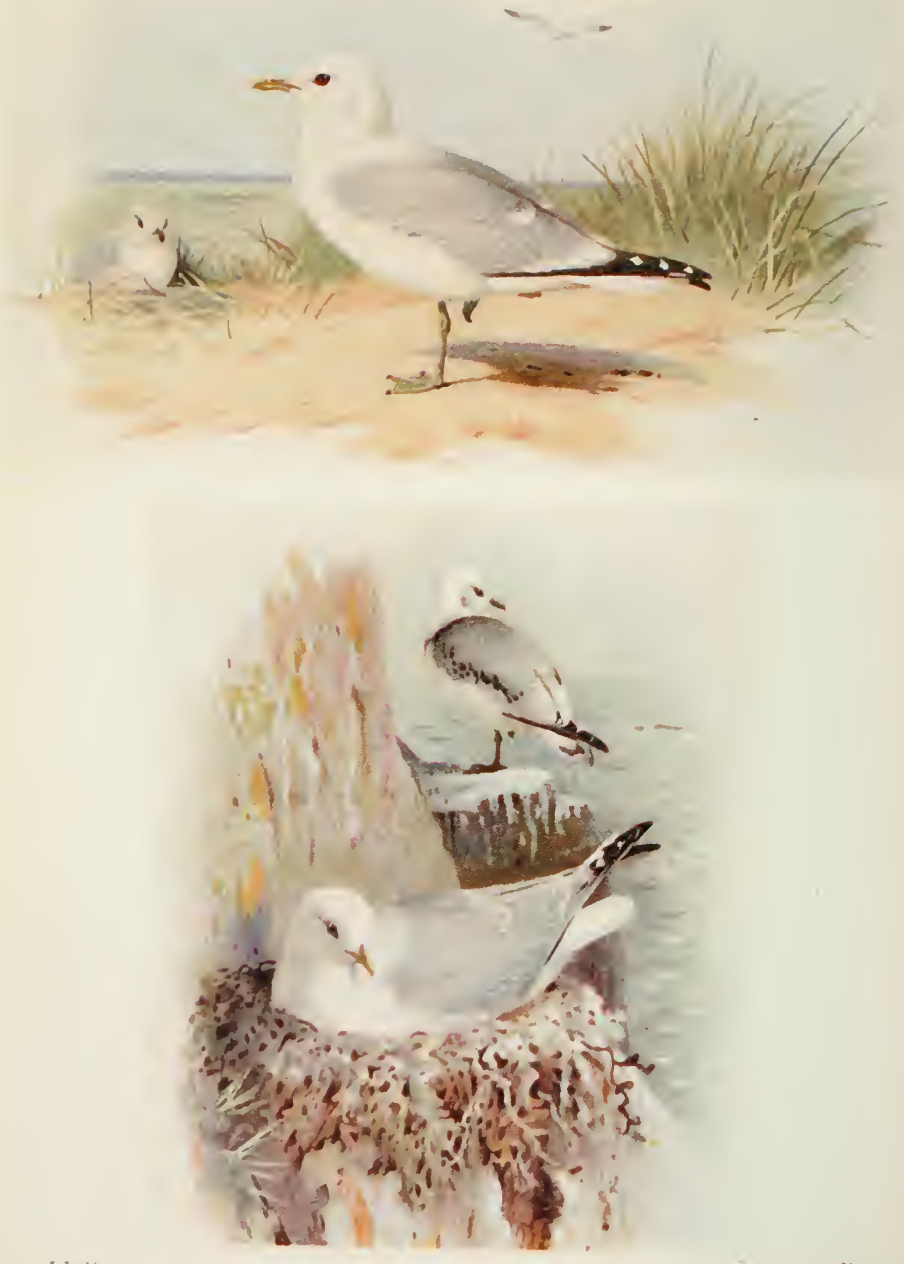

$2 H . \mathrm{Sg}$.

Common Gull.

Kittiwake. 
with the exception of the black outer primaries and blackbanded, white-tipped inner quills, is elsewhere snowy white ; the bill is green at the base, yellower towards the tip, the legs are distinctly greenish, and the irides blackish brown. In winter the head and hind neck are streaked with grey, but not blotched as in the winter Black-head. The young have mottled brown mantles with greyish feather edges, and their heads, under parts, and flanks are spotted with grey and brown; their primaries are brown and lack the white mirrors and tips, and the tail is broadly banded with black. The bill is brown, black at the tip, the legs pale brown. As they advance towards maturity the grey feathers appear in the mantle. Length, $17 \cdot 5$ ins. Wing, 14.5 ins. Tarsus, 2 ins.

\section{Herring-Gull. Larus argentatus Pontopp.}

Though it frequently wanders inland, the Herring-Gull (Plate 9I) is the typical gull of the British coast. It nests on all suitable cliffs and islands, on Scottish lochs, and a few inland marshes. It has an American and western European range, breeding so far south as northern France, and is partially migratory, reaching the Mediterranean and other southern seas in winter.

The Herring-Gull roughly agrees with the Lesser Blackbacked in size, but its mantle is pearl-grey, not dark, and its legs flesh-coloured, not yellow, as in the latter bird. Its black outer primaries have "mirrors" like those of the Common Gull, but they have white tips and grey inner edges; the yellow bill has a red mark or splash on the angled lower mandible. Mottled brown birds in various stages of immaturity, for full plumage is not attained until the fourth or fifth year, are common at all seasons, and through an optical illusion appear larger than the grey and white old birds. Only by careful expert examination can these young be distinguished 
from those of the Lesser Black-backed Gull, though as they grow the paler mantle serves to distinguish them. Although the Herring-Gull is certainly resident, it is also a partial migrant; there is a marked northward movement at the end of April and in early May, though the diurnal movements to and from feeding and roosting grounds are easily confused with migration. In autumn British-marked birds have been recovered in Germany, but the species is decidedly less migratory than the Lesser Black-back.

The flight of the Herring-Gull is typical of all the larger gulls, and can be studied when clouds of these birds follow in a steamer's wake. It drifts or sails, without noticeable wing action, even in the teeth of the wind, automatically adjusting its pose so as to benefit from every change of air current ; thus it will poise above the stern, travelling exactly at the rate of the ship, and glancing with yellow eye to right or left, ready to swoop to pick up from the waves any morsel thrown over or churned to the surface by the screw. After it has settled and been left far behind it rises, and in a few strong but never hurried wing-beats recovers its position and again sails. I have frequently seen birds drop one foot as if to adjust the balance whilst they scratched the beak with the other, and neither lose altitude nor speed. Indeed, all its graceful aerial actions are perfectly controlled. Often a number will rise for high flights, wheeling, mere specks in the sky. With the Black-head it comes to harbours and coastal towns, wrangling amongst the fishing boats for the garbage and offal, a useful scavenger. In the Mersey it floats with the tide past the anchored liners, flying back again and again to keep a watch for the appearance of cook or steward disposing of scraps. In rows it lines the dock sheds, or perches on the chimneys and pinnacles of high buildings. On its native cliffs it will stand, looking seaward, and at Tenby and other towns where the houses crest the cliffs it is just as ready to use the roof 


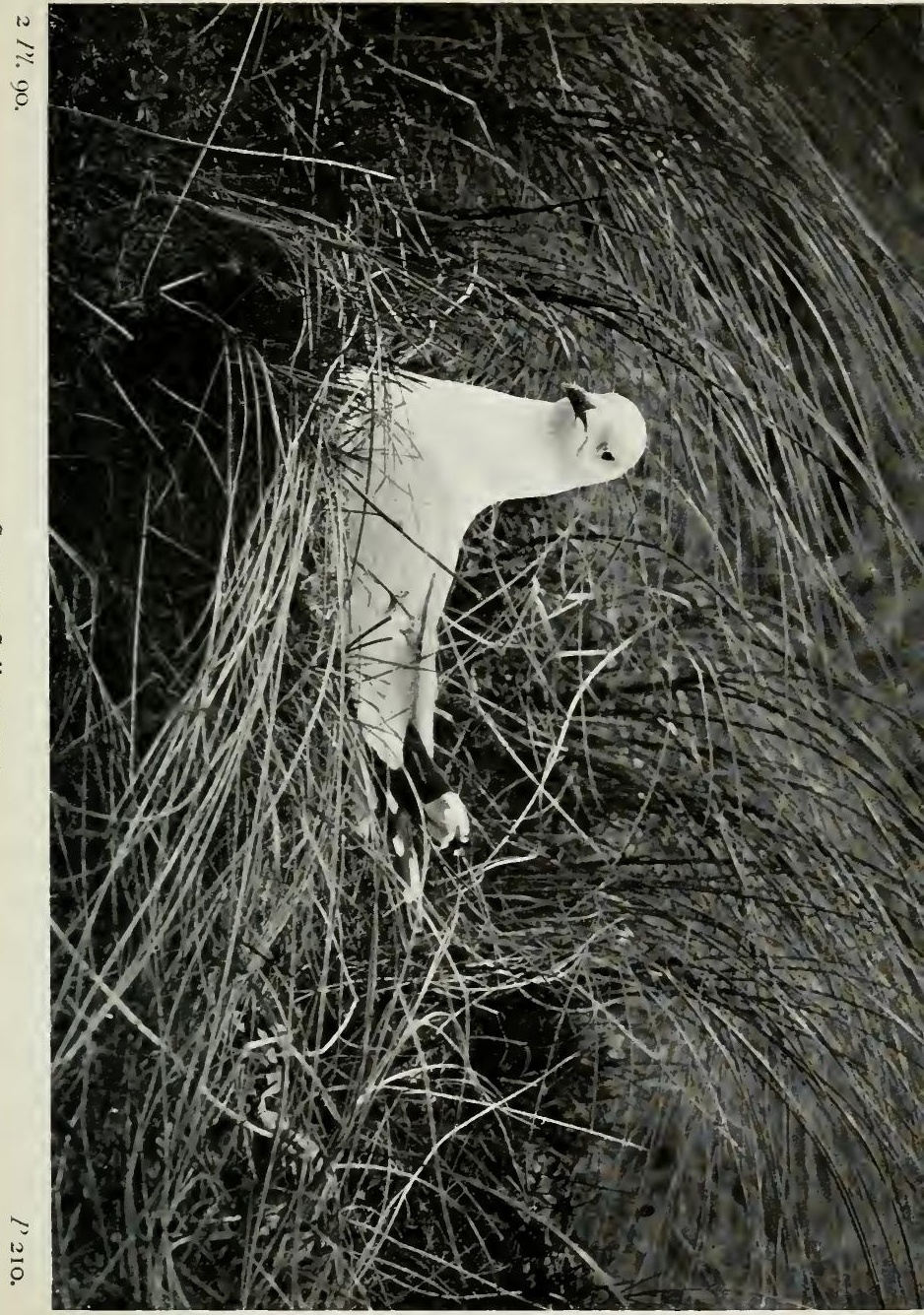



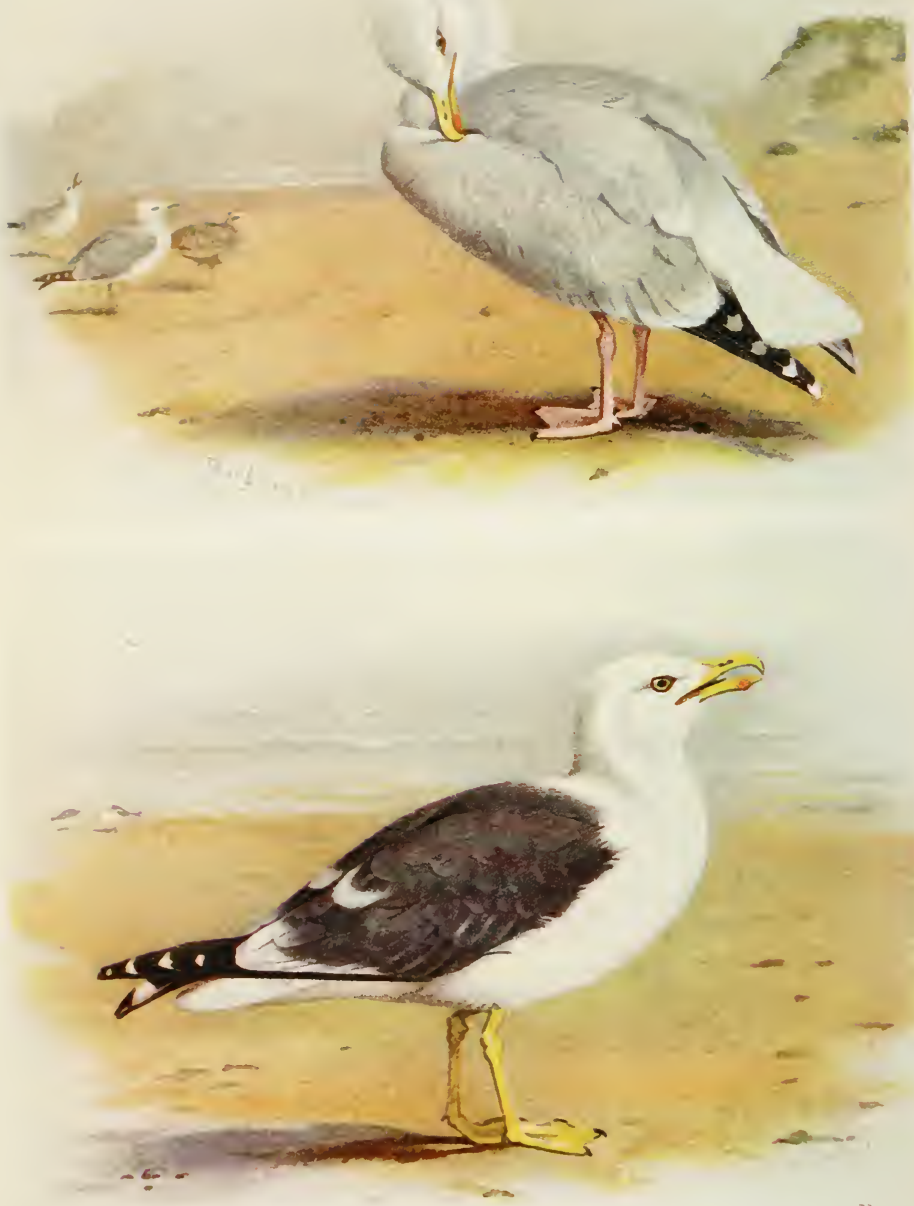

2 I\% $9 \mathrm{I}$.

P'2II.

Herring-Gull.

Lesser Black-backed Gull. 
parapet. In some seaside resorts-Llandudno, for examplethe charity of visitors is rewarded by confident familiarity; both young and old birds have taken food from my hand as they stood on the sea-wall. The bird usually rests on one leg, the long body horizontal, the head sunk in the shoulders, and when on the beach, head to wind.

Its feeding habits are similar to those of the Common Gull ; it drops crabs and molluscs to smash them, though in my experience less frequently than the other species; it also dances in wet sand or at the edge of the waves; I have seen it marking time and swaying slightly until its legs were entirely hidden in the sand. It will occasionally dive for food, though somewhat awkwardly. On fields near the shore it follows the plough, but on cultivated land does not confine its attention to "pests," for its cast-up pellets, which with broken shells and claws of crabs litter the cliff-top, often contain husks of oats or other grain. All gulls are egg-robbers, looting unguarded nests of other sea-birds, and occasionally scouring the moors and fields; the Herring-Gull is no exception. The bird has a loud and strident voice, which may trail off into a mournful wail ; usual more cheerful notes are a plaintive, cat-like mew and a round full hoh, hoh, hoh. It has a defiant kehoh, and a harsh $h a, h a, h a$, a threat rather than alarm note when the breeding colony is invaded, but when the bird is specially annoyed this becomes a barking and rapid wow, ow, ow. The challenge, uttered with uplifted, wide-open beak, is clear and ringing.

The nests are in colonies on the grassy slopes and ledges of high cliffs, or on grassy islands. At times the nest is sheltered by a rock, but is often in the open, and in one colony many were in thick alexanders, and others amidst cushions of thrift, surrounded by hyacinths; the flowers of the last plant had been picked to decorate the edge of one nest. Some nests were close to a trodden path, others on the wall of a ruin.

The nests are built of a variable quantity of roots, grass, and 
seaweed, and often have a little sheep's wool mixed in the lining ; they are shallow and untidy as a rule. Three is the normal number of eggs, which are dark olive or pale brown, plentifully blotched with dark brown (Plate 87). I have found five eggs, but of two distinct types, probably laid by two females ; incubation begins about the middle of May. The down of the nestlings (Plate 92) varies greatly; in one nest I have seen two very grey and black chicks, and one very dark brown. At an early stage the bill is black, pale at the tip, and the legs reddish black. The irides are dark brown at first, and remain brown until at least the second year, but those of the mature bird are bright yellow, surrounded by pale-yellow rims to the eyes. The young are fed by regurgitation (Plate 95), and long after they can fly they follow the old birds with outstretched necks, whistling demands; they have also a shrill and plaintive cry. In the first autumn the mottled greyish-brown young with white, brown-banded tails, have black bills, slightly fleshy at the base, and slate-grey legs with pink webs. As the pearl-grey feathers gradually replace the brown, the colour of bill and legs changes. In winter the adult bird has greyish streaks on its white head and neck. The sizes of mature birds vary considerably. Length, 24 ins. Wing, $17 \% 5$ ins. Tarsus, $2 \cdot 5$ ins.

\section{Yellow-legged Herring-Gull. Larus cachinnans Pallas.}

The Yellow-legged Herring-Gull, an inhabitant of southern Europe and western Asia, has been obtained in Norfolk and reported as seen in Kent. In February, I9I8, Mr. F. W. Holder watched a bird near Southport which, from his description, I believe was of this species. When mature it has a darker mantle and brighter bill than our bird, and very yellow legs; the irides are yellow, the eye-rims orange. The grey on the head in winter is obscure. Length, 23 ins. Wing, 16 ins. Tarsus, $2 \cdot 2$ ins. 


\section{Great Black-backed Gull. Larıs marinus Linn.}

The Great Black-backed Gull (Plate 93) ranges over northern Europe, Greenland, and eastern North America, and migrates south in winter, reaching the Mediterranean and Florida. It. breeds plentifully in Scotland, the Scottish islands, and north and west Ireland, even in some inland localities, but in western England and Wales it is not abundant in summer, and on the south coast there are few nesting pairs and none on the east. In winter it is present in estuaries and along the coast in considerable numbers, for there is a general southward movement.

The size of the bird and its very dark mantle distinguish it from the Lesser Black-back and all other gulls. When resting with other gulls on the banks or sand it stands, a blackbacked giant, dwarfing even the Herring-Gulls, and making the Black-heads look mere pygmies. Considering its tyrannical and predacious habits, it is extraordinary how peacefully small gulls will stand or rest beside it ; it is a confrrmed bird eater. On the wing its movements are easy and deliberate; it sails lightly in spite of its bulk, and often soars to an immense height. It is rarely met with inland. Little is known about its migrations beyond the fact that there is a great increase in numbers in all parts after the nesting season. For over a week in early October I watched the passage of this and the smaller bird, and though the Great Black-back was not so abundant as the Lesser, very large numbers passed all day and every day. Many of these rested on the wide expanse of the Humber "clays," which, as far as the eye could reach, was spotted with the conspicuous birds; all, however, were coasting south, and did not appear to have crossed the North Sea. In winter the bird is common in the Lancashire and Cheshire estuaries, and along the sandy shores, though only a few scattered pairs nest on the North Wales coast. 
The hoarse, barking $a g h, a g h, a g h$, differs from the notes of other gulls, and when I have been at the nest, the old bird wheeled high overhead with deep guttural, angry barks, ugh, ugh, more emphatic than the normal note. The challenge, however, uttered with head raised, differs but little from that of its congeners. After this vociferous call, the bird lowers the head below the level of the raised shoulders, and peers from side to side as if expecting a reply. All gulls are omnivorous, but the Great Black-back prefers its meals to be of flesh, either recent or ancient. A dead rat, dog, or whale is alike acceptable to the "Corpse-eater"; where the carcase is there will the Black-backs gather, keeping the smaller fry away. It will pounce upon and half devour the "cripple," before the wildfowler can gather it ; it ruthlessly slays its neighbours, the Puffins and Shearwaters, tearing out their entrails and leaving the rest for the rats; it has been known to bolt whole so large birds as Redshank and Little Auk. Mr. J.A. Dockray saw one chase and capture on the wing a passerine bird which was crossing the Dee estuary. I have not seen the Great Blackback drop molluscs, but it has been known to lift and drop the Puffin which it had been worrying, after shaking it as a dog shakes a rat.

In England and Wales this bird usually nests singly on the top of some stack or rocky headland, but in Ireland and Scotland there are some large colonies. It occasionally nests in the centre of a colony of Lesser Black-backs. On Puffin Island, though no Great Black-back was visible, Miss E. L. Turner and I examined a nest which contained three eggs, two of them typical eggs of the Lesser Black-back, and one which measured 76 by $58 \mathrm{~mm}$., about the size of the egg of the Greater Black-back. It was long doubted if the bird nested in the Isle of Man ; Mr. T. Taylor, however, found and photographed the nest shown on Plate 97. The nest is an untidy collection of seaweed, thrift and grass torn up by the roots, sticks, and 


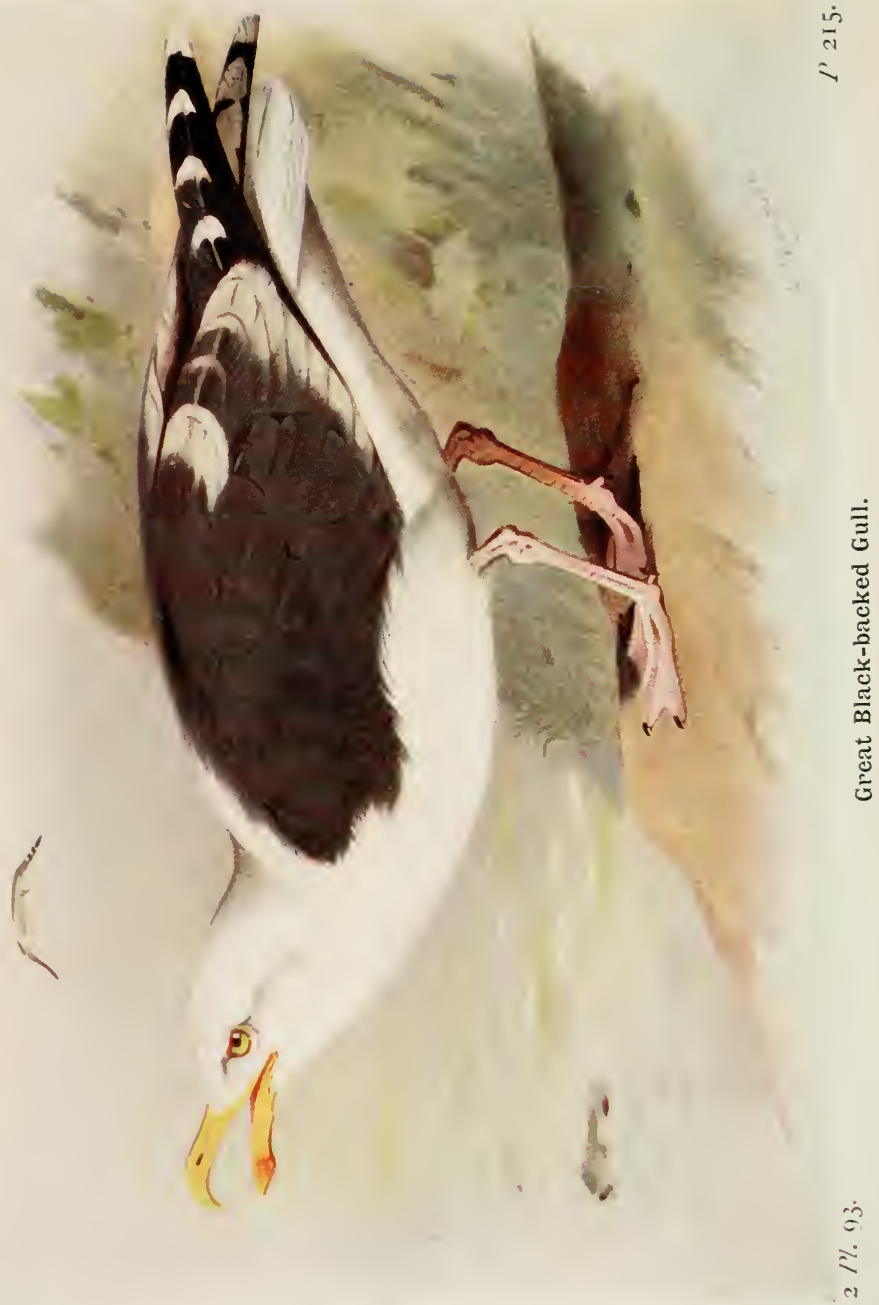


litter, placed either on turf or the bare rock. The eggs (Plate 87), as frequently two as three in a clutch, are buff or olive, usually boldly but not profusely spotted with brown and grey ; they are laid in May or early June. The nestling, which is fed by regurgitation, has pale-grey, often yellowish down, boldly spotted with black; its bill and legs are lead-blue, its irides dark brown. At a very early age it leaves the nest and runs for shelter if approached, crouching under a rock or amongst herbage.

The quills and scapulars of the mature bird are white tipped, the second primary usually has a "mirror"; the bill is yellow with red on the deeply angled under mandible, the orbits are red, and the irides yellow. The legs vary from flesh colour to pink-tinted white. In winter there are brownish-grey streaks on the head and neck, but these are often lost before the end of the year. In the first plumage of dappled brown and grey, the bird is paler than the young Herring-Gull, but in its second year there is some indication of the dark mantle. Observations on the changes of plumage of birds in captivity give such different results that it seems unsafe to take them as a guide, and the actual date at which maturity is reached is uncertain, but probably about the fourth year; the bill changes from blackish grey to yellow, but during the change shows a pinkish tinge at the base, and the black remains longest as a band towards the tip. Length, 29 ins. Wing, 19 ins. Tarsus, 3 ins.

\section{Lesser Black-backed Gull. Larus fuscus Linn.}

In 1912 Mr. P. R. Lowe called attention to the paler slategrey mantle of the British Lesser Black-backed Gull (Plate 9I), as compared with the slate-black of the Scandinavian bird. The dark Larus fuscus fuscus Linn., nests in Scandinavia and eastern Russia, and in Siberia is replaced by yet another forn, 
but the lighter L. $f$. affinis Reinhardt, breeds in the British Isles, the Freroes, western France, and perhaps elsewhere; both races are migratory, and both occur on passage and, occasionally, as winter visitors. How freq'ently the dark bird occurs is not certain, for it is often difficult to judge the depth of shade of a flying gull. The winter range of the two forms is not known with certainty, but that a large number of our birds leave is proved by the frequent recovery of ringed Lesser Black-backs in France, Spain, Portugal, and north-west Africa. The largest colonies of the British bird are in Scotland, Ireland, the north-east and western shores of England, and Wales.

The Lesser Black-back is a smaller and slighter edition of the Great Black-back, but differs from both this and the Herring-Gull in its yellow legs. In immature plumage, though at first it closely resembles the Herring at the same age, the darker mantle soon becomes apparent. In spring and summer, especially near nesting colonies, this gull is common, though never so abundant as the Herring-Gull, but in spring and autumn it is a far more familiar bird inland, for there are regular overland as well as coastal migratory movements. From about the middle of March until June birds are going north, and from July or August until October, passing south. In inland localities the birds often travel singly or in twos or threes, but on the Yorkshire coast, early in October, I have seen huge passages. On October 6th, one year, Lesser and Great Black-backs passed practically continuously from 9 a.m. till 6 p.m., often 50 to 100 at once; the smaller birds far outnumbered the larger. After timing the birds at intervals I found that the average rate was about 50 per minute; 20,000 a day was a low estimate, and this passage continued for over a week. Most of the Lessers came in from off the sea, from the northeast, but at that time I was unaware of the racial characters. In spring in Cheshire I see most birds passing between the 
first and third week in April, but in Norfolk have noticed steady northward passage early in May.

The Lesser Black-back joins the Herring-Gull in its watchful and sustained flights behind steamers, remaining on the wing for hours, also in the frenzied raids on shoals of fish, when the water is churned by the plunging and superficial dives of the excited birds, and the air rings with their cries; it is an equally useful scavenger in rivers and harbours. It is as omnivorous as the commoner bird, but its reputation, like its back, is blacker; so emphatically did the game-preserver accuse it of egg robbery that it was excepted from the protection given to most other gulls. At its nesting colonies the disembowelled corpses of Puffins and Shearwaters prove it as murderous as its larger relative; certainly on Puffin Island I have seen more bodies in the Black-back colony than on Herring-Gull ground. It delights, too, in a large carcase, only yielding its place to the Greater Black-back. Its manner of flight, its pose on land, and its habit of perching on an elevation agree with the Herring-Gull, but its calls differ slightly. The

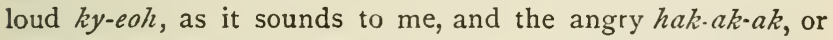
wow-ow-ow, when it swoops with a rush toward the head of an intruder, sound more ferocious than the usual wails of the Herring-Gull; but both birds have a wailing mew and an irate bark. The normal ow or owch is deeper and more melancholy than the call of the other bird.

Though I have found odd pairs of Lessers nesting with Herring-Gulls, it usually keeps in a colony by itself. Loud though the clamour is when a colony of the latter bird is invaded, the medley of angry voices and the frequent threatening swoop of an anxious parent is more marked on Black-back ground. The bird may be slighter in build and weaker in bill than the Herring-Gull, but, in my experience, it is much bolder. Grassy islands and marshes are more usual nesting sites than steep cliffs. The nests vary in size and construction, but 
though often smaller, closely resemble those of its constant neighbour; I have found the eggs in a scratched hollow without a vestige of nesting material. The eggs (Plate 94), two or three in number, are sometimes greenish, but usually stone-coloured or buff in ground, and boldly spotted; they are laid in May. I doubt if there is any certain distinction between the mottled nestlings (Plate 99) and those of the Herring-Gull; the down, often greyish, is sometimes warm in tint, but varies greatly. The blackish bill is at first pale at the tip, but soon darkens; the legs are dull slate but become browner, and the irides, dark brown at first, grow paler and more yellow during the three or four years of immaturity. In the first brown dress the two can only be distinguished by close examination, but after a moult or two the darker mantle becomes evident. The bill grows yellower, the black remaining on the angle until replaced by red when almost mature plumage is attained, and the banded tail becomes mottled before it is finally pure.

The adult bird, slate-grey and white, has "mirrors" on the first two primaries; the bill is yellow with red on the angle, the legs and irides are yellow, and the orbital ring vermilion. In winter the head and neck are streaked with grey. Length, 22 ins. Wing, 16 ins. Tarsus, $2 \cdot 6$ ins.

\section{Glaucous Gull. Larıs glancus Brünnich.}

The pale plumage of the Glaucous Gull (Plate 96) is suggestive of an Arctic species, for not only does this gull nest north of the Arctic Circle in both hemispheres, but it often remains for the winter. It is, however, also a migrant, and wanders south as far as the Mediterranean, and, in America, Florida ; to the Orkneys, Shetlands, and Outer Hebrides it is a regular autumn visitor. Both mature and immature birds reach the Shetlands in October, and some, mostly young, remain all winter. On the east coast it is a frequent "hard-weather" 


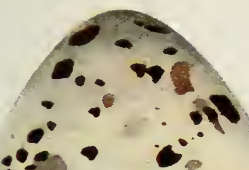

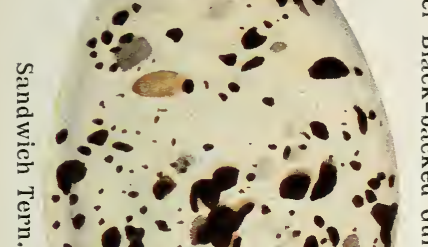
08 o $1 \%$ Q

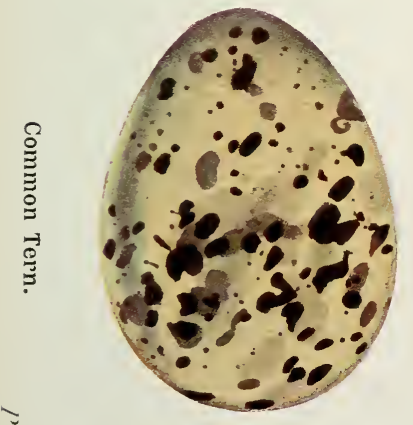

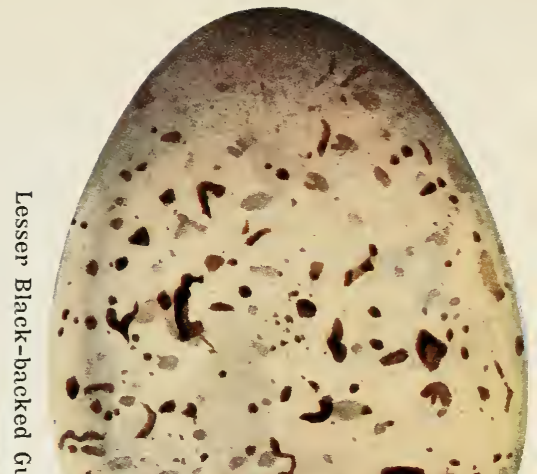

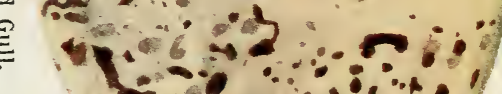
$1+00, \cdots 1,0$

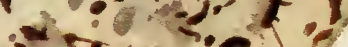
5.:- - -$$
\text { (-):- }
$$

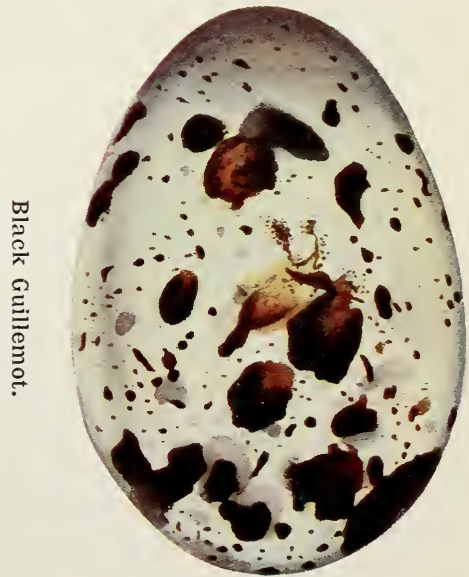



bird, and it also occurs regularly in the north-west of Ireland. Elsewhere it is an uncommon straggler, but is doubtless more frequent than would be supposed from the records; it occurs occasionally on the west coast.

In size the Glaucous or "Burgomaster" Gull corresponds with the Great Black-back, and may be distinguished from all other large gulls, except the Iceland, by the absence of black on the primaries; the Iceland is about the size of the HerringGull. The Glaucous is a very white-looking bird when mature, and at all ages is pale ; its light-grey mantle is several shades paler than that of the Herring-Gull. When at rest it may be distinguished from the Iceland Gull by the relative shortness of its wings, which when closed rarely project beyond the tail. From even the Great Black-back it differs in its "steady soaring flight," for it shows less angle in the wing than any other gull ; indeed, its shape when at a height resembles rather a Buzzard or other raptorial bird. There are "good " and "bad" years for this species, and doubtless the irregularity in its numbers is due to abundance or shortness of food caused by climatic variation in the Arctic. Though it delights in dead meat, and helps to dispose of the refuse turned out from the whaling stations, it is even more predacious than the Great Black-back; it worries all birds smaller and weaker than itself, ripping them to bits with its massive beak. It has been known to swallow a Golden Plover without troubling to dismember it. Its calls differ little from those of its congeners.

The adult in summer is very pale grey on the back and wings, and the rest of the plumage is white, including the tips of the quills. In winter the head is faintly streaked with brownish grey. The bill is yellow with an orange patch at the angle; the legs are pink, the irides yellow, and the eye-rims vermilion. At first the young bird is pale buff, mottled, barred, and streaked with ashy brown, lighter than any other gull in corresponding plumage. With each moult the colour pales, 
and the bill, legs, and irides, which are at first brownish, approach nearer to the colours of maturity. Length, 29 ins. Ving, $18 \cdot 5$ ins. Tarsus, $2 \cdot 75$ ins.

\section{Iceland Gull. Larus leucopterus Faber.}

The Iceland Gull (Plate 96) nests in Greenland and part of Arctic America; its breeding range and its winter wanderings are more restricted than those of the last species. It is not a native of Iceland, but winters there, arriving in September and leaving in May. Annually some reach the Shetlands, and usually other northern islands and the Scottish coast, but elsewhere it is a rare straggler, except during an invasion of the species, when it is met with in all parts.

The main difference between this whitish gull and the Glaucous is size; it is about the bulk of the Lesser Blackback. From all other gulls, except the rare Ivory Gull, which has black legs, it can be told by its whitish primaries. In its later stages of immaturity it is dull or dirty white, and though in its first winter it is said to be darker than the firstyear Glaucous, it is paler looking than other young gulls. Mr. H. G. Alexander, who watched a bird at Dungeness, noted its peculiar cry. It frequently consorts with Herring or other gulls, and even feeds with them on insects and grain in the fields; it does not appear to be specially partial to carrion, and certainly is less predacious than the fierce Glaucous.

The proportionately longer wings, which project well beyond the tail when the bird is at rest, look long and narrow in flight; it flies with ease and buoyancy. The very pale-grey and white bird has the head streaked with greyish brown in winter. The yellow bill has red at the angle, but the legs are flesh-coloured, as are the eye-rims, different in both cases from those of the Glaucous; the irides are yellow. The immature stages, so far as they have been worked out, appear to 
correspond with those of the larger bird, and it is said that maturity is not reached until the fourth year. Length, 22 ins. Wing, 17 ins. Tarsus, $2 \cdot 4$ ins.

\section{Great Black-headed Gull. Larus ichthyaëtus Pallas.}

The Great Black-headed Gull, a native of the eastern Mediterranean and central Asia, has wandered to England; one having been obtained in Devon in the spring of 1859 . There is a more recent report for Kent. It is a large gull, about the size of the Great Black-back, with a black, not brown hood, and a slightly darker mantle than our small bird. The white-tipped secondaries form a bar on the wing, and the primaries are white, broadly barred with black. In winter the hood is replaced by dark streaks. The yellow bill has an orange patch or band across both mandibles, and a black line crosses this band; the legs are greenish yellow, the irides dark brown, and there are whitish lines above and below the eye. The female is often much smaller than the male. Length, 26 ins. Wing, 19 ins. Tarsus, 3 ins.

\section{Mediterranean Black-headed Gull. Larıs melano- cephalus Temm.}

This Black-headed Gull is a bird of the eastern Mediterranean and Black Sea, and occurs in the south of France and Spain. On three or four, possibly more, occasions it has been taken as a wanderer in England, usually in autumn or winter in southern counties, but once as far north as Yorkshire. The head in this species is really black, and extends further on the nape and neck than in most hooded gulls; the mantle is light pearl grey, and the primaries white towards the tips, but there are black lines down the webs. The bill and legs are scarlet, the former crossed by a narrow dark band. The irides are brown, 
the eyes rimmed with red, and above and below the eye is a small white streak. The distribution of brown and grey on the white head in winter, and the mottles on the wings and streaky head of the immature bird, closely correspond with the seasonal and age changes of our Black-headed Gull. Length, $15 \% 5$ ins. IVing, $11^{\circ} 75$ ins. Tarsus, $1 \cdot 9$ ins.

\section{Bonaparte's Gull. Larus philadelphia (Ord).}

Bonaparte's Gull breeds in northern America and migrates so far south as the Gulf of Mexico ; it has occurred six or seven times in Ireland, Scotland, and England, apparently as a wanderer rather than a migrant out of its course, since it has appeared at various seasons. Its flight is light and ternlike, so much so that Ord first classed it with the terns; it swoops towards the water to catch insects, and flutters after them in the air. Its voice, according to American writers, differs from that of other gulls, being faint, shrill, and often repeated.

Its size is between that of the Black-head and the Little Gull. The hood is slate-black in summer, but in winter the head is nearly white; the first primary is white with a black outer margin and tip in mature birds, and dusky-brown margins, on either side of the shaft, in the young, but the white inner web of the first two primaries is a good diagnostic character. The bill is black, the legs are red, and the irides brown. Young birds, except in the primaries, resemble young Black-heads. Length, 14 ins. Wing, 1025 ins. Tarsus, $\mathrm{I}_{4} 4$ ins.

\section{Black-headed Gull. Larus ridibundus Linn.}

The range of the Black-headed Gull (Plate 98) extends over Europe and most of Asia, and in winter includes northern Africa. In all parts of the British Isles it is resident and 

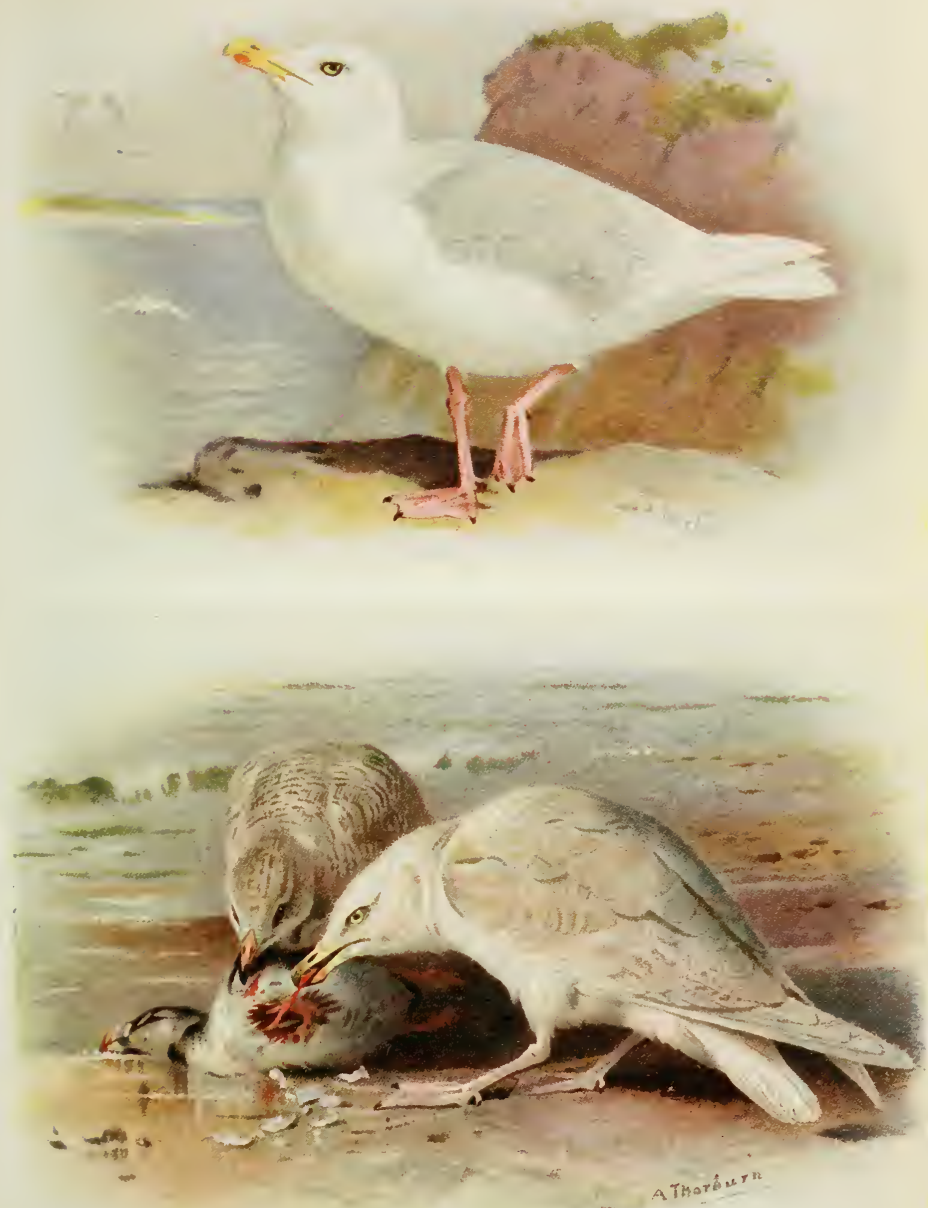

2 Pl. 96.

Glaucous GulI.

Iceland Gull (immature). 


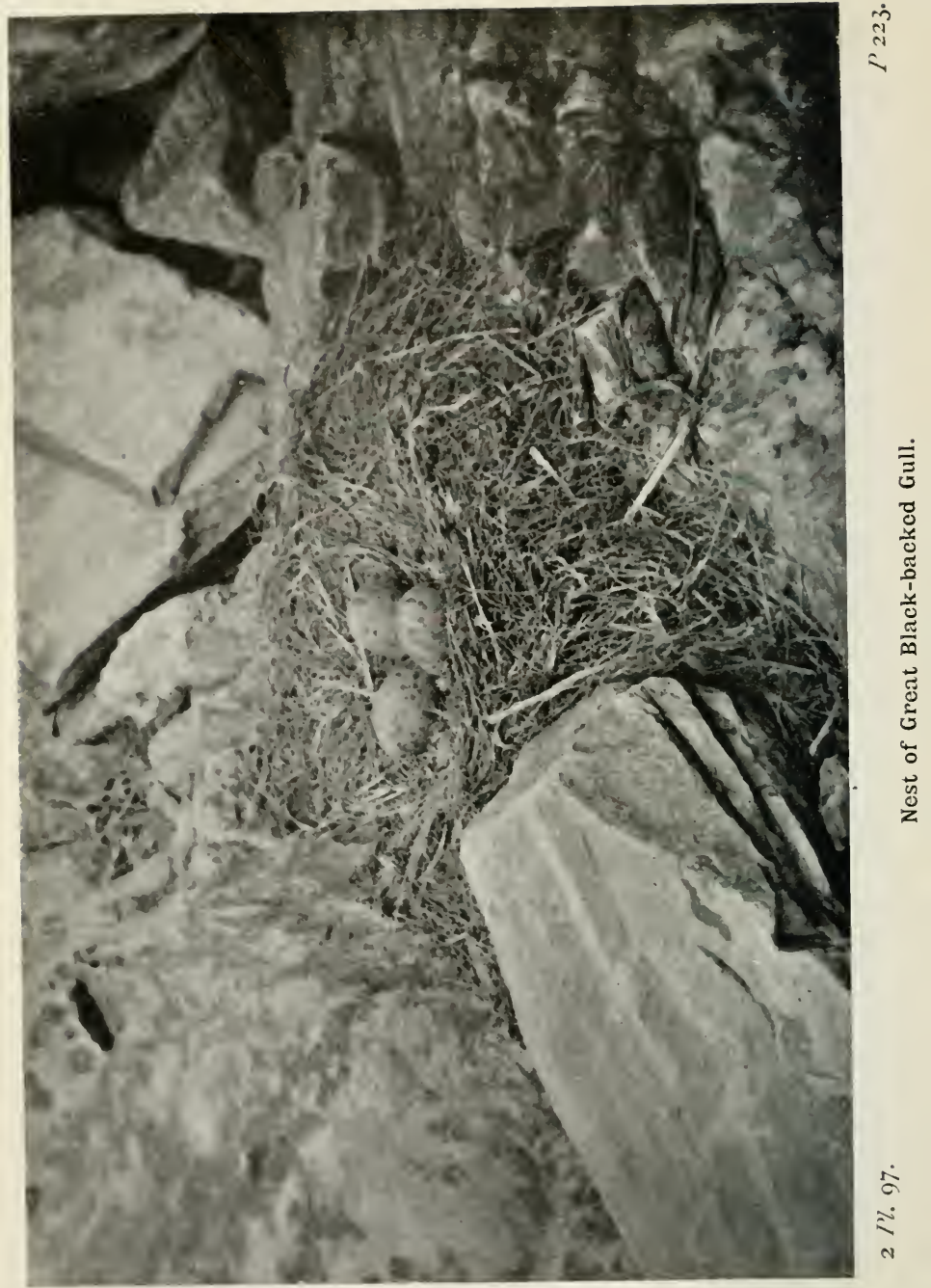


migratory, for many of our birds go south in autumn, and gulls from the north and east come as winter visitors or birds of passage.

Lilford and others tried to alter the name to Brown-headed Gull on account of the coffee-brown and not black nuptial hood, but the old-established name should stand. Amongst those whose interest in birds is superficial the fact that this is our commonest species causes confusion; they call it the "Common Gull," and insist that its head is not black, ignoring the seasonal change of plumage. The brown hood is worn in spring and summer, though exceptionally it is retained all winter, or regained before the end of the year; most birds lose the hood in August. The Black-head is an inland as well as coastal gull ; it is never pelagic and is seldom seen far from land; it nests as far from the sea as the Pennines, and feeds regularly in fields and sewage farms at fifty miles or more from the coast. Yet the old notion that a gull inland is a sign of bad weather dies hard. The adult bird in summer may always be recognised by the brown hood, blood-red bill and legs, and at any season by the white outer fringe of the wing contrasting with the pearlgrey of the mantle; the dark inner webs of the outer primaries are hidden, though the black tips are not. In winter the white head is blotched with brownish grey on the ear-coverts and near the eye ; the head of the Common Gull at this season is streaked with grey. Young birds have the wings mottled with chestnut-brown, and can always be told by the band on the tail ; their bills and legs are yellowish red.

The wing-beats of the Black-head are quicker than in larger gulls, and its build is slimmer ; there is a suggestion of relationship to terns in many of its movements. It has a desultory uncertain flight; it wavers, careens, and drifts, but when migrating or hurrying often flies steadily, and a party will adopt chevron formation. When about to alight on water the bird will "shoot" like a Rook, darting down with half-open wings, 
turning and twisting as it descends. The quickest flight is when in pursuit of some favourite food ; a big rise of May-fly, the emergence and nuptial flight of crane-flies, "coch-a-bonddu," or winged ants, excites the greedy birds. I have seen the air a maze of dodging, screaming gulls, their white wings fluttering as they checked their hurried rushes and swoops after the erratic insects. Although omnivorous like other gulls, the Black-head is undoubtedly a useful bird, especially inland; it follows the plough, wrangling with the Rooks and Starlings, or with its companions, as it hastens almost to the ploughman's heels. Stomach examination proves that though many worms and some harmless insects are eaten, great numbers of "leatherjackets" and wireworms are taken from the newly turned ground, and Prof. Newstead's examination of a number of pellets, picked up after a plague of crane-flies, was convincing evidence of its value. In rivers and on the shore it devours insanitary garbage, and is a faithful attendant on the fishing fleet when the catch is sorted. It is true that a little grain is picked up, and that a small percentage of fishy matter has been found in the stomach, but the good it does far outweighs the harm; indeed, it is a poor fisherman, lacking speed and diving skill, though I have seen it clumsily submerge when attempting to capture fish. At dusk on the IVelsh uplands, far from the sea, I have watched it sweeping to and fro with undulating swoops, picking off the male ghost moths as they hovered with their strange pendulum-flight above the long grass - both birds and moths ghostly in the gloom. It will paddle to bring food to the surface like other gulls, either in the shallow tide-pool or the mud of a harbour.

Inland, after feeding all day, it retires to some lake to roost, bathing and preening before settling down; on one Cheshire mere considerably over a thousand collect nightly in winter; it will wash in the sprinkler tank on the roof of a cotton mill in a busy Lancashire town. The corvine call note is harsh and 
scolding; from this, or its habits in the fields, it is called the "Sea-Crow." "Peewit-Gull," because it nests in marshes, is another name. The idea that any of its calls are "laughing" is strange ; they are often peevish or quarrelsome in tone, and when a nesting colony is visited the angry $k i k, k i k, k i k$, is usually the prelude to a fierce swoop at the head of the visitor. I have never been struck by the descending bird ; it has always swept upward with fluttering wings, and a harsh screaming kraah, a foot above my head. Since the passing of the Bird Protection Bill in 1880 , this gull has increased enormously, in some measure owing to the checking of ruthless shooting of young birds, but the eggs are still gathered for food, and sold as "plovers' eggs"; the adaptability of the species" is an important factor.

At all times the bird is sociable, consorting with waders and other gulls on the shore, and with Lapwings, Golden Plovers, and Rooks inland, but it is most gregarious in its nesting habits. The marshy edge of a lake, or the islands and tussocks in a shallow pool, are the most favoured nesting sites, and these may be close to the shore or on the moors at over 1000 feet. Some of the largest gulleries are on sandhills, where I have seen nests thick in the marram; one I have visited is on saltings flooded by spring tides, but the birds persist in their annual attempt in spite of repeated catastrophes. When a gullery is approached the gulls rise and whirl overhead with an angry and anxious clamour, the boldest making repeated threatening dashes, but they soon quiet down. When watching the gulls I have repeatedly seen a strange manœuvre, also noticed amongst terns; suddenly the noisy bickerings will cease, and the whole colony fly off in a cloud with a weird hush; in a few seconds the flock breaks up, the birds drift back, and the normal clamour is resumed. I have seen three of these departures in an hour. The nest is a mass of sticks, sedges, rushes, or grass, often large when on wet ground; it Series 11 . 
is placed on a tussock in the water, on level dry ground, on a rock or wall, exceptionally in a tree; indeed, the bird builds anywhere. The eggs (Plate So) are two or three in number, more rarely four, and vary greatly in ground and markings; some are bluish, others olive, green, buff, or brown, with blotches, spots, or zones of black, grey, and brown. The nestlings are almost as variable, the down being grey, buff, or brown, mottled and striped with irregular lines of black and brown. At one gullery I found that the legs of various birds of only a few days old were salmon-pink, brown, leaden, or blue-black. The young bird (Plate IOI) is at first suffused with brown and shows but little white, most of its mottlings being on the wings and back, but by the autumn the head is whitish with semi-lunar bands of grey on the crown and nape and blotches on the ear-coverts; the sides of the neck, upper tailcoverts, under parts, and tail are white, the last crossed by a broad brown band, the back is pearl-grey, and the wings and coverts tipped and mottled with grey and brown. The outer primaries show a white centre. The plumage of the adult bird is described above; the irides are brown. Length, 16 ins. Wing, $I I^{\circ} 75$ ins. Tarsus, $1 \cdot 75$ ins.

\section{Little Gull. Larus minutus Pallas.}

The Little Gull (Plate 100) breeds in northern Europe and Asia, and winters as far south as northern Africa. Its autumnal migrations appear to trend westward, and as within recent years it has also extended its breeding area westward, it is hardly surprising that to our eastern seaboard it is a fairly regular winter visitor or passage migrant in spring and autumn. In some years it is even plentiful. On the west coast and in Ireland it is more occasional, but is doubtless often overlooked amongst the numerous Black-headed Gulls.

In flight this bird looks smaller and more round-winged than 

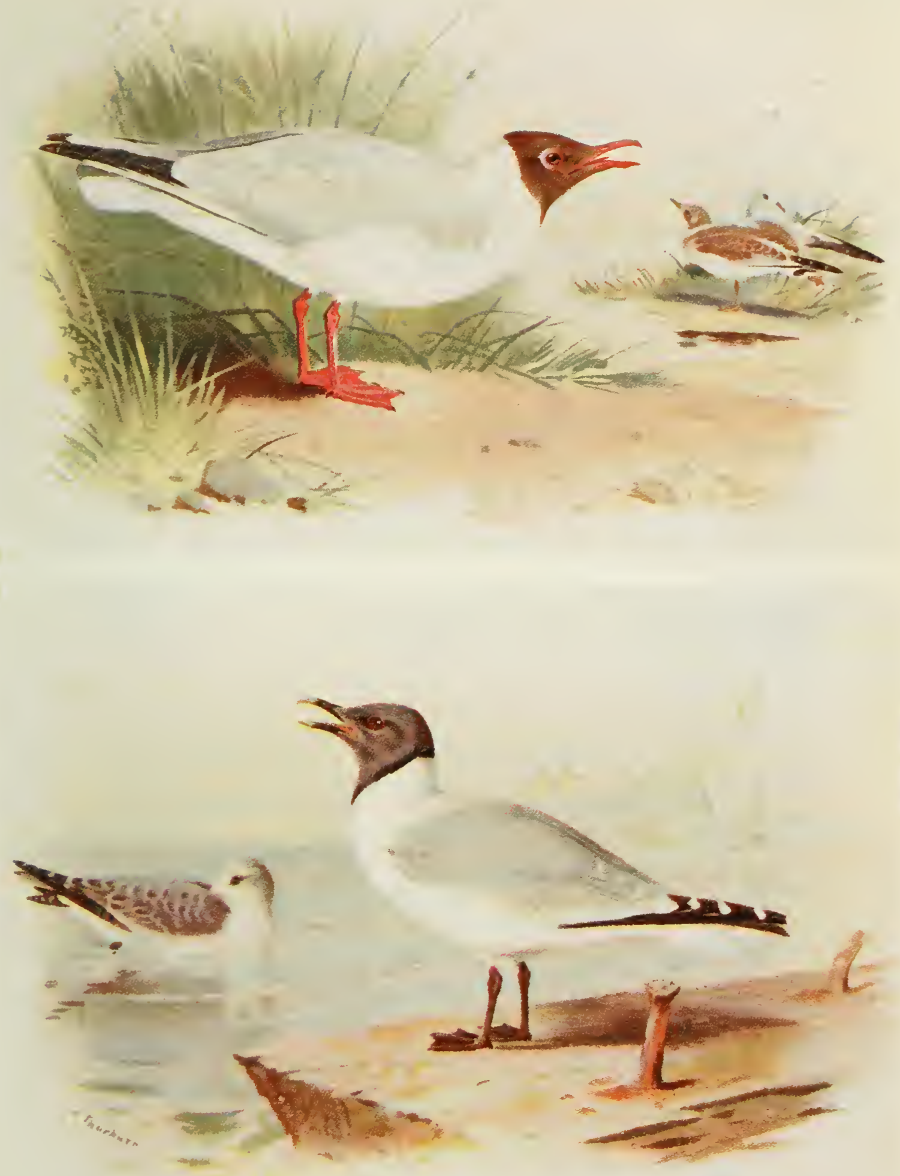

2 Pl. 98.

Black-headed Gull.

Q226.

Sabine's Gull. 


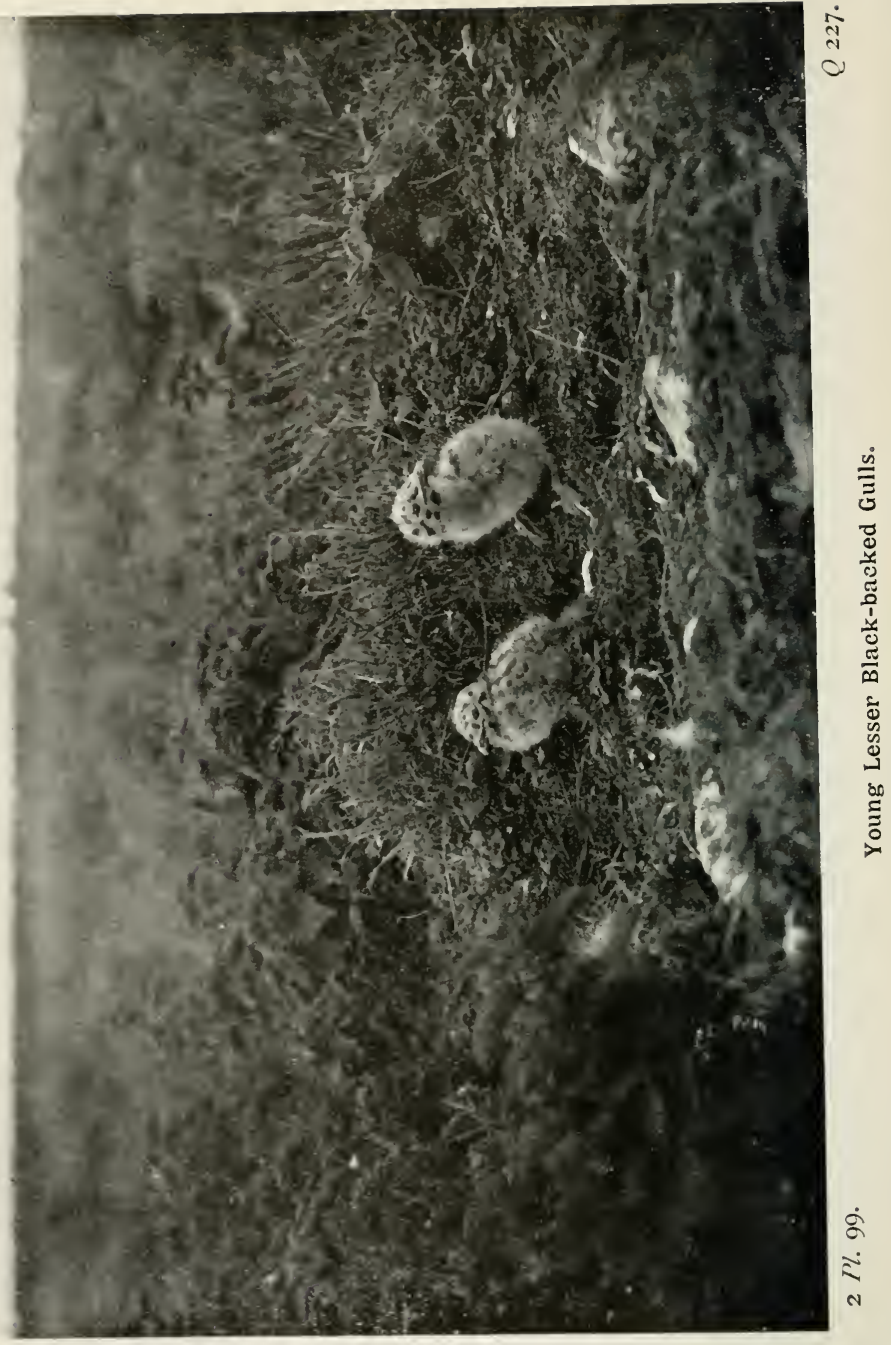


the Black-head; I have seen the two flying near together. It has been likened to a tern, but there is nothing tern-like in its much less pointed wings. In the adult bird the primaries are grey with white edges and tips; the outer primary looks white in flight, and the pale upper surface of the wing throws up the smoky under surface, as the bird loiters through the air, for it has a peculiarly hesitating, desultory flight. Its slightly forked tail is also noticeable when expanded, as it checks its speed or turns to snatch at a flying insect. Insects, even so small as gnats, form a considerable proportion of its food, though it catches small fish. Its call, said to be sharp and harsh, I have not heard; it is not a noisy bird in winter.

In nuptial dress the Little Gull has the whole head, including the nape, black; the back and wings are very pale grey, and the rest of the plumage is white. There is a rosy tinge on the abdomen, a character which is often present in other small gulls during life, but fades at once on a skin. The bill is dark red, the legs are vermilion, and the irides brown. In winter all that remains of the black head is a few streaks on the nape ; the legs and bill are duller. In first plumage the crown, nape, cheeks, and back are brown, streaked and mottled, and the back is mottled with buff, white, and grey; the primaries are sooty except on the inner edge, and the under wing is white. Later the crown is flecked with grey and the ear-coverts and a line round the eye are blackish, there is a half-collar of grey and a sooty bar on the wing. As the bird advances towards maturity the back becomes purer grey, and the central tail feathers white, leaving a few half-bars on the outer tail feathers, a remnant of the original band. In a second-year bird examined the bill was still black, but the legs were yellowish red. Length, $I I$ ins. Wing, $8 \cdot 5$ ins. Tarsus, $I$ in. 


\section{Ross's Gull. Rhodostethia rosea (Macgill.).}

Ross's Gull is a bird of Arctic seas, and so far has been found nesting in one place only, in north-eastern Siberia. The bird has been included as British on the strength of a single occurrence in Yorkshire in 1846 or 1847 , but the history of this specimen is marred by discrepancy, and it was "discovered by a dealer" who promptly sold it. Saunders was doubtful about including it, but Nelson thought that it really had been killed in the country, though the editors of the Field expressed a healthy scepticism. The best evidence brought forward was that the bird was recorded for Heligoland, but may not German dealers have found credulous purchasers even on Heligoland? The most likely locality to be exploited is one where rarities are known to occur. The bird is pale grey and white, the head and under parts suffused with a rosy tinge; the outer primary has a black outer web. The short bill is black, the legs are coral-red, the irides brown. In summer only, the neck is encircled by a narrow black collar. Immature birds are mottled with greyish brown and white on the wings. Length, 13.5 ins. Wing, 10.25 ins. Tarsus, 1.25 ins.

\section{Sabine's Gull. Xema sabinii (Sabine).}

Sabine's gull (Plate 98) is a circumpolar Arctic species which visits western Europe in winter with some degree of regularity; it is recorded almost every autumn or winter from the east coast of England, and has been met with elsewhere in England, Scotland, and Ireland as an occasional visitor. The majority of the birds which reach us are immature.

Apparently the wind or other agency that drives Sabine's Gull to our shores is the same which affects the Grey Phalarope and Little Gull; when these two are here we may look out for the rarer bird. On the wing it is graceful and tern-like, and its 
forked tail is much more pronounced than that of the Little Gull. Many of its visits have been when terns were on the move, and it has been seen associating with them; indeed, Mr. Caton Haigh was reminded of the note of the Arctic Tern when he heard a young Sabine call.

In its nuptial dress, which is occasionally seen in England -ten or a dozen have been noted in this plumage in Yorkshire alone-the head and neck are slate, with a black line where the hood meets the general white plumage. The back and wings are dark pearl-grey, the outer primaries are black tipped and inwardly margined with white, and the inner primaries and secondaries are mostly white. The yellow-tipped bill is black, the legs are brownish black, and the irides, at any rate in some examples, red. In winter the head is only marked with grey streaks and suffusion. Young birds have the back, wings, and a patch on the side of the breast ashy grey with brown bars; the nape is dusky and the forked tail broadly bordered with dark brown. Length, 13 ins. Wing, $10 \cdot 7 j$ ins. Tarsus, $1 \cdot 3$ ins.

\section{Ixory Gull. Pagophila eburnea (Phipps).}

The Ivory Gull (Plate I03) is another circumpolar bird which is almost an Arctic resident, but wanders south occasionally, and has reached most parts of our islands, though it is best known in the Orkneys and Shetlands. Though a winter visitor it has remained so late as June; unlike the last species, as many mature as immature birds are met with.

In its adult dress, whether in summer or winter, this gull is white; the white mantle distinguishing it from all others. The white of immature birds is spotted with dark grey or black to a variable degree, possibly due to age; in some the upper parts only are sparsely spotted, but in others the under parts are similarly marked. The primaries have black tips and the tail a subterminal brown-black band. Col. Fielden thought both 
call and flight like those of the Arctic Tern, and Miss. M. Haviland, who saw a little party in the Kara Sea in September, writes-" Their wings built to battle with the gales that blow over the polar seas, met this little wind with a contained strength that gave their flight a curious butterfly buoyancy. Their voices, which reminded me of the talk of the common terns on our English dunes, were gay and careless as the wind they conquered." Fish, lemmings in the north, crustaceans, and garbage are eaten, and the "Snowbird" is well known to the whalers as a scavenger. Like other Arctic birds it is foolishly confiding when it visits Britain, and is easily shot, usually before observations are made of its habits. The bill is greenish grey with a reddish-yellow tip, the legs are very dark grey, the eye-rims red, and the irides brown. Length, 18 ins. Wing, 14 ins. Tarsus, I' 5 ins.

\section{Kittiwake. Rissa tridactyla (Linn.).}

In both Old and New World the Kittiwake (Plate 89) is an abundant Arctic and northern Holarctic bird, nesting in large colonies in suitable places. In the British Isles it is resident; plentiful on rocky coasts in Scotland and Ireland, and locally abundant on the west coast of England and Wales, but rare in the east. In autumn and winter numbers of immigrants appear off our shores; there is a general southward movement.

In summer the Kittiwake is a gull of precipitous cliffs, in winter of the open sea. It has a clean and neat appearance, its mantle and quills bluish grey, the rest of its plumage snowy white except for the tips of the outer primaries which are black, and show on the open white wing as a triangular black patch. On the first two or three there are neither white tips nor mirrors; thus the flying bird can at once be told from the Common Gull which it rather resembles; a black line at the edge of the wing - the outer web of the first quill-distinguishes 

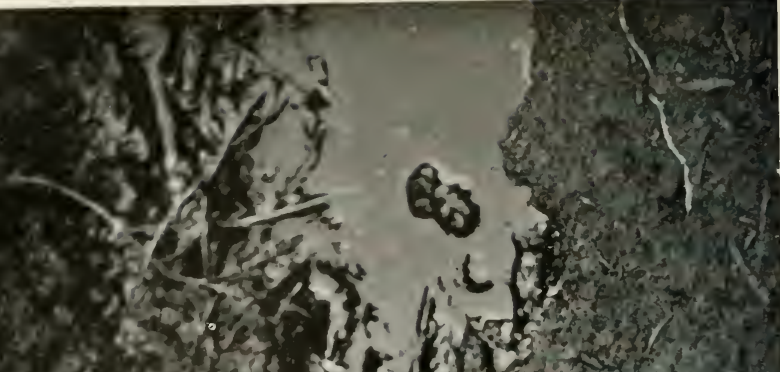

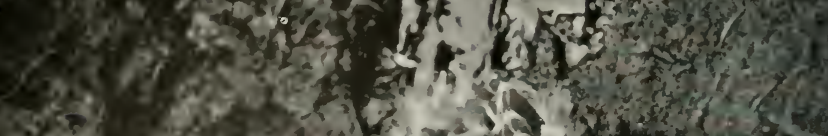

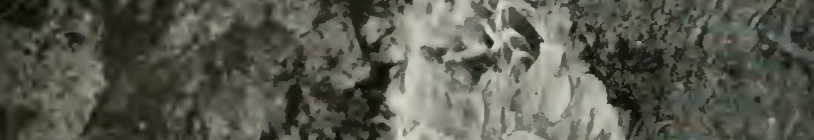

$x^{3} 8^{2}$

$$
\text { 4.8. }
$$

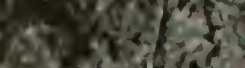

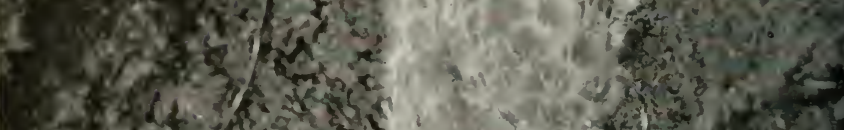

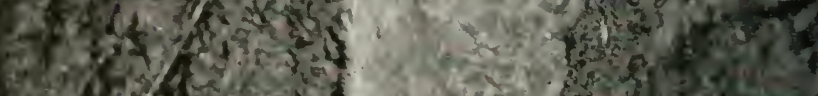

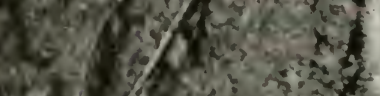

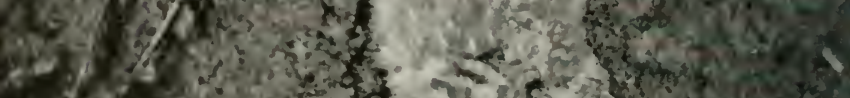

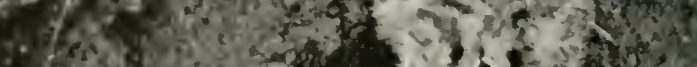

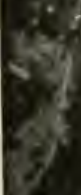

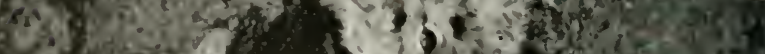

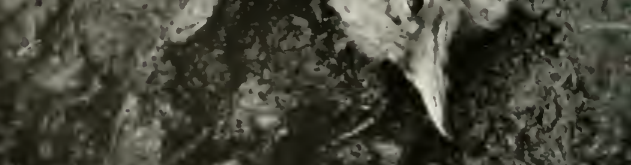

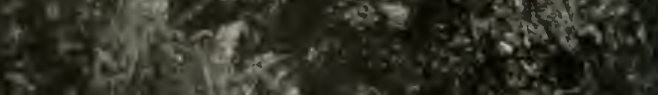

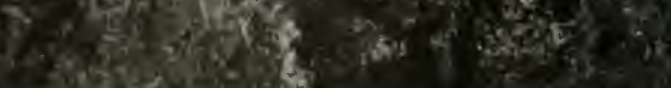

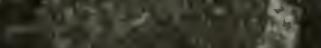

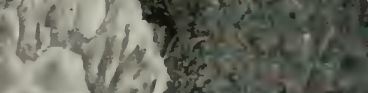


it from the Black-head in winter dress. The bill is greenish yellow, but the legs are so dark that they look black. In the hand it can at once be told by the practical absence of the hind toe, this being represented by a mere vestige. The inner primaries are white tipped, and show on the closed wing. Immature birds, still known as "Tarrocks," have a distinct dark half-collar, a band of mottled brown across the wings, and banded tails. The flight is easy and graceful; its gentle buoyancy hardly suggests battles with winter gales, yet, unlike other gulls, it selects the open sea for its winter home; its power of sustained flight is proved by its habit of following steamers, for it has been known to accompany liners across the Atlantic. It swings gracefully astern with wide down-wind swoops, even lighter in flight than the Black-head.

Surface-swimming fish and the larger crustaceans or other planktonic animals are its chief food, and for these it dives with more skill than other gulls. I have never seen it plunge into the water like a tern, but it beats about near the surface until it sights prey, then alights and dives, remaining below for a short time, swimming under water. Even a rough sea it rides lightly, mounting the steeply advancing waves, head to wind, and either plunging through the crest or fluttering over to avoid a crashing curl. A winter gale of long duration tries it, driving down its food ; immature birds especially are weakened and driven ashore, only a few saving themselves by flying inland before the storm. After a gale the shore is often littered with corpses.

The Kittiwake, is as a rule a silent bird, only uttering a sharp kit, kit, when wrangling for food, but is lively enough at the nesting colony. The colonies, often very large, are in caves or on steep cliffs, the nests being stuck on most insecure-looking ledges, often many close together. In March the pelagic birds begin to gather at the nesting place, but nest building is not hurried; eggs are often laid in May, but incubation seldom begins until June. The nest, a small collection of seaweed and 
grass (Plate 102), looks as if a puff of wind would dislodge it from its narrow base, but really it is a work of art. Both birds collect material, which consists of clay and mud as well as weed, and this, well trodden by the patient architects, forms when dry a firm, almost solid foundation. During courtship, nest building, and incubation the colony rings with pleasant calls of kitti-waake, kitti-waake, with an ascending emphasis on the last syllable.

Though there is frequent sparring between the various occupants of a ledge, the paired birds are most affectionate, caressing one another and expressing their feelings in head and throat movements, which Mr. Kirkman rather happily describes as "gulping." The male frequently feeds the female, and takes a share in incubation. In the evening I have watched the birds changing places, when many exchanges of compliments and a cheerful volley of kitti-ruaakes accompany the "relief." About the end of August the majority of old and young are ready to depart, but for some time after that remain at sea near the cliffs. The two or three eggs (Plate IOS) are usually lighter in ground-greyish, pale buff, or stone colour-than the eggs of most gulls; they are blotched and zoned with brown and grey. The nestlings are also paler than those of gulls which nest in more accessible situations; their heads are greyish white, and the marks on their grey backs are very faint. The parent does not regurgitate and present the young with food, but allows it to fish in its open mouth for what it can find, after the manner of a Cormorant.

In first plumage the crown and nape are grey and the back and wings mottled with brown, but the "tarrock" dress is acquired in the first autumn and retained for at least a year; I have seen birds in this plumage at the nesting colony. The bill is then black and the legs much browner than in the adult bird. The brown irides are surrounded in the young bird with a paleycllow eye-rim, but when mature this is red. The nape and 
back of neck of the adult bird are bluish grey in winter. Length, 16 ins. Wing, 12 ins. Tarsus, $1 \cdot 4$ ins.

\section{Common Tern. Sterna hirundo Linn.}

The Common Tern (Plate 103) has a wide Palearctic and Nearctic range, and in winter migrates far south. In the British Isles it is certainly the commonest tern in most parts; it nests all round our shores, least plentifully in the north, and large numbers visit us on passage.

"Sea-Swallow" is a name given to all the commoner terns, but except in the long, pointed wings and forked tail with streamers, there is little to suggest a Swallow. The Common and Arctic Tern can with difficulty be distinguished on the wing, though in the hand the characters are clear. Broadly speaking, the bill of the Common is red with the distal third dusky or almost black, and that of the Arctic coral-red throughout or with only the extreme tip dark. The safest guide is the white-shafted outer primary, dark slate in both on the outer web, but with a paler slate stripe on the otherwise white inner web. In the Common this stripe is twice as wide as the outer web; in the Arctic the two are about the same width. The Common Tern has a slightly longer tarsus, and therefore stands a little higher, but this is difficult to judge in life, as is the paler greyish suffusion of the under parts. On the average the wings of the Common are longer and its tail streamers shorter than those of the Arctic, but the position of the tips when the wing is closed varies according to the pose of the bird and is an unsafe guide. The difference in the voice can only be learnt by experience. The Common Tern is one of our bestknown sea-birds. It beats over the waves with slow and deliberate but powerful strokes; the determined down-strokes look as if they should jerk the slender, cigar-shaped body upward. It poises in the air with upraised wings vibrating, 
tail depressed and expanded, and bill pointed seaward, then half closing its sharply angled wings, dives obliquely, often with a slight screw twist, entering the water with a splash. In a second it is up again, for frequently its wing tips are not submerged, and rises with or without a struggling fish. It sports in the air with companions, the call kierie, or a sharp kit, often changed to pierre of mock annoyance; a clamour of voices announces the discovery of a shoal of fry, and excited terns hurry from all directions, hover, a snowy cloud, and rain upon their silvery victims. Terns rest upon the shore, but walk little and badly; the crossed tips of the long wings are usually held well above the tail. They are easy though not quick when swimming, but are certainly most at home in the air.

Towards the end of April the immigrants arrive, for they are summer visitors; many travel overland and halt to feed on inland waters ; there they catch insects as well as fish, swooping gracefully and taking them on the wing either from or near the water. From the middle of May until August they remain near the nest colony, but by the end of September most have left our shores, though passage birds drift through in October. Young birds when able to fly wander at first ; ringed Common Terns have been recovered in their first autumn far to the north of the ternery, though others have been reported in France and Spain. The breeding colonies are in various situations; three of the largest that I have visited are on coastal dunes, others on rocky islets, where thrift, wild beet, and tree-mallow is the only vegetation. One colony was on gutter intersected saltings, the nests on the sheep-cropped grass or in beds of sea-aster; I doubt if it survived the next high tide, for it had been submerged shortly before my visit. Other colonies are on shingle or the sand above high-water mark.

Nests may be lined or unlined, eggs being laid on bare rock or soil, in neatly rounded depressions, or in nests of consider- 


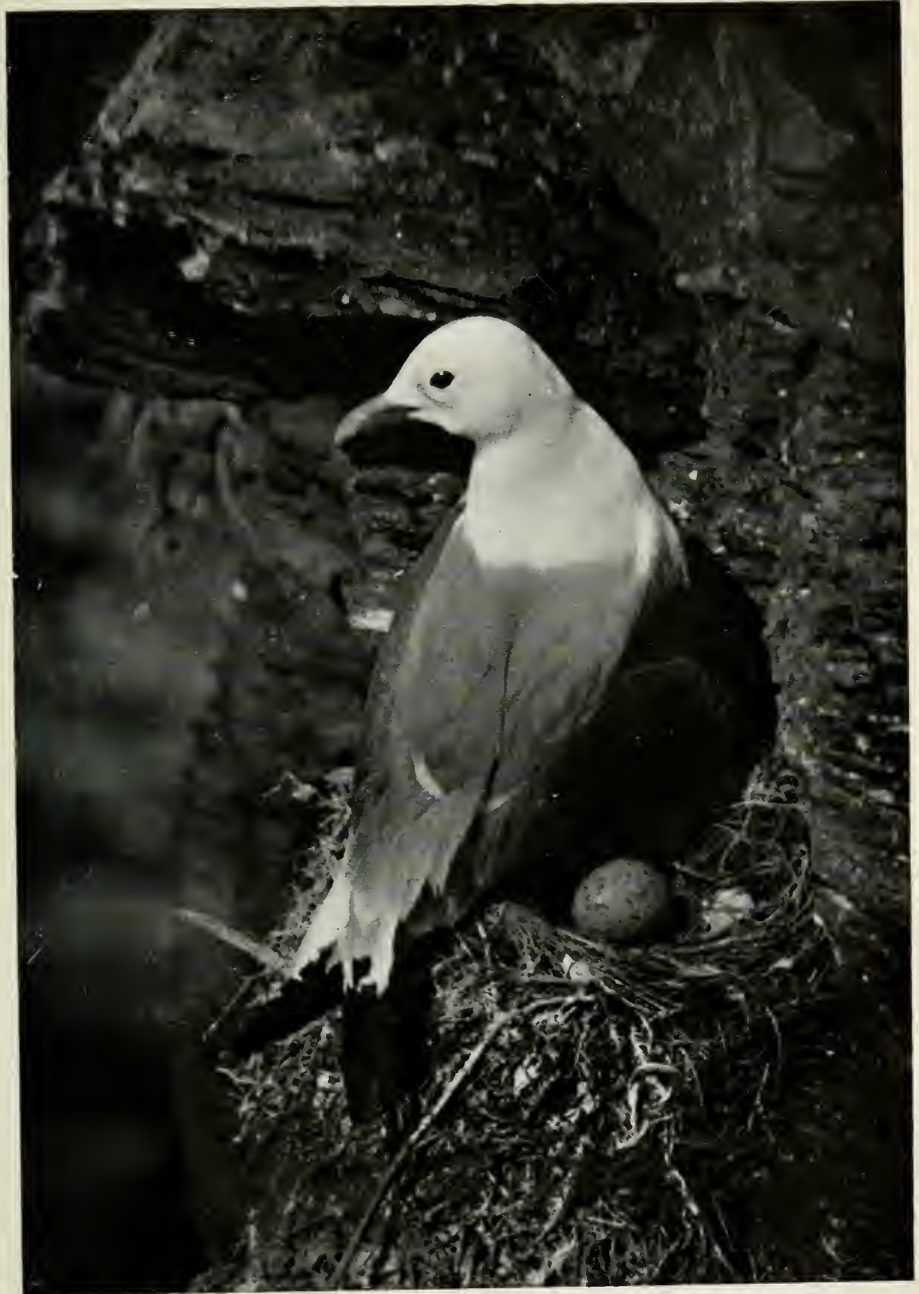

2 P. 102.

Kittiwake at nest. 

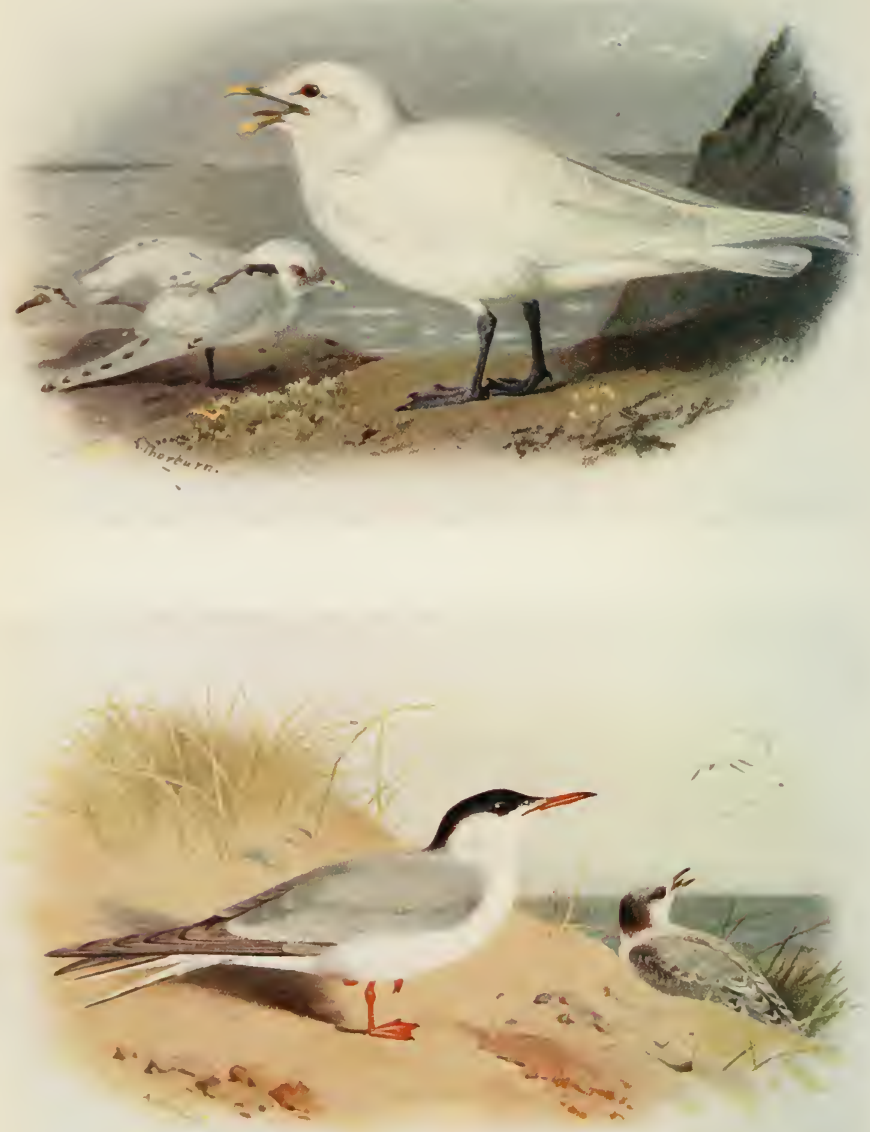

$2 \mathrm{Pl} \cdot \mathrm{IO}_{3}$.

Ivory Gull. 
able size. The two figured (Plate 104) are from the same colony, on sand dunes, one on sand, the other amongst dwarf willow. The female often lays and adds lining after incubation has begun. The materials vary as much as the site; I have seen the following used-marram, thick stems of beet, fresh sprigs of ragwort, bits of stick, straw, seaweed, pebbles, broken and perfect shells, and crab-claws. In but few cases were these materials mixed; each bird seems to select its special decoration. The male feeds the female before and during incubation; indeed, with all terns, the presentation of a fishy offering is the most important nuptial preliminary. The male depressing his half-spread wings, and elevating head and tail, dangles his gift before the crouching, expectant female, but only delivers it if she accepts his overtures. When the ternery is first approached the birds rise and fly to and fro overhead, many at a great height, filling the air with a maze of white wings and harshly screaming voices, most prominent the long drawn pieerah, or the sharply repeated kit, kit, of some specially anxious parent; but the tumult soon subsides and the life of the colony may be watched from close quarters. I have often seen, after they have settled down, the strange simultaneous departure of the birds, a habit shared by Black-headed Gulls and Sand-Martins. A sudden cessation of the normal clamour is followed by an uncanny hush as all wing seaward, but before out of sight a bird calls and the whole body drifts back to resume activities.

Irate birds will dive savagely at and occasionally strike the head of any one walking amongst the nests. Others than human trespassers are assaulted, even killed. At Ravenglass I have examined the bill-pitted skulls of young rabbits and the juvenile Black-headed Gulls which had foolishly wandered from their own domain. Passing birds, innocent as well as would-be thieves, are driven off or overwhelmed, and even cattle are mobbed. 
The colour of the eggs (Plate 94) varies greatly; some are pale, greenish or buff, others deep brown in ground, and the marks of black, brown, or grey may be speckles, spots, or blotches; some are thickly zoned with markings, others have a black or brown patch at the larger end. It is practically impossible to distinguish between the eggs of the Common and Arctic Tern. Three is the usual number, but clutches of two are common; only a small proportion are hatched. Out of some 300 nests in one Lancashire colony, Mr. F. W. Holder found only eight from which all three chicks emerged. Eggs and nestlings are destroyed by rats, weasels, and stoats at night, but diurnal robbers get a warm reception. Most eggs are laid in June. The nestlings have been described as dimorphic; polymorphic is more correct; the down varies from grey to deep brown, sandy buff is most usual ; the black markings and mottles are irregular. Some have white, others black chins; they may grow paler with age. The bill is light red or almost black, the legs salmon-pink, reddish, or yellow. The nestlings are fed by the parents on small fish-sand-eels, dabs, and coal-fish fry being common. I have seen the old bird drop the fish, but I think unintentionally; Saunders thought that food was deliberately dropped in front of the nestling, but it is usually delivered to the young, when the old bird, with wings uplifted, daintily alights beside it. One of the dropped fish was the venomous lesser weever. The young (Plate 106), which follow their parents with repeated insistent cries, chik, chik, chik, are at first much mottled with buff and slate on the upper parts, and their foreheads are buff, but after the autumn moult the forehead is white, the crown speckled, and the nape brownish black; the back and mantle are then marked with grey and buff, and the shoulders show a greyish band. The bill is almost black, and the legs dull red. The mature bird has a black cap, pearl-grey back and wings, primaries edged with dark grey, and a white tail with greyish borders to the 
streamers. The under parts are slightly suffused with grey, sometimes showing a pinkish blush, but they are white in winter, when the cap is also mottled with white. The red bill is black tipped, the legs coral-red, and the irides very dark brown. Length, $14^{\circ} 25$ ins. Wing, $10^{\circ} 5$ ins. Tarsus, $0.8 \mathrm{in.}$

\section{Arctic Tern. Sterna paradisea Brünn.}

Few birds, if any, have a greater range than the Arctic Tern (Plate 105), for it nests far north of the Arctic circle, and, as proved by Dr. Eagle Clarke, occurs in winter in the Antarctic, unless, as has been suggested, there is a southern form. In the British Isles, the southern limit of its breeding range in Europe, it outnumbers the Common Tern in Scotland and Ireland, but has only a few colonies in England and Wales. In some of these, for instance the Farnes and Walney, the two species nest close together, but even there the colonies are more or less distinct.

As a summer visitor the Arctic Tern arrives a little later than the Common; it is often May before the birds appear, and well into June before eggs are laid. The characters by which it can be recognised-the blood-red bill, deeper grey under parts, short tarsus, and narrow grey stripe on the primaryhave been already stated. In general appearance, manner of flight, food and feeding habits, and to some extent voice, it closely resembles the previous species; its usual call is shorter -a harsh kleeah. Rocky islands and stacks are more frequently occupied as breeding colonies than sites on the mainland, but there are some large terneries on dunes, sand, and shingle, and a number on inland lakes. Of late years there has been some extension southward of its breeding range, and small parties have appeared in terneries which previously contained only Common Terns. Though there is much variation in the site and construction of the nest, eggs are frequently laid on 
bare rock, or on the ground without surrounds or lining; nests as bulky as many of those of the Common Tern are rare. On one small group of stacks on the Welsh coast most eggs are in cracks in jagged rock, some with a few ripped-off strips of lichen around them, but I have seen them in circles of grass and rabbit bones, both of which had certainly been carried from the land.

Three eggs in a clutch is perhaps normal, but two is common. It is only possible to figure one type (Plate ro8), but they vary quite as much as those of the Common Tern, though the average size is smaller. The nestlings are at least dimorphic, there being creamy-white and dusky-brown phases; the dark markings roughly correspond, but are more distinct on the paler ground. Like the young of the Common Tern they soon leave the nest, and at first stagger, but soon run fairly quickly on their short and thick, light or dark reddish legs, crouching under shelter of rocks or vegetation for protection if alarmed. The parents feed them on fish, usually bringing only one at a time, but in an Irish colony have been seen to supply them with insects, mostly crane-flies. When leaving the colony to fish the old birds fly lo:v over the water, but return at a higher level, and in Scotland are not infrequently robbed of their load by the bullying Skua. The Arctic Skua is one of the few birds which is too much for the terns, for in defence of the young the Arctic Tern is even bolder than the Common; it will frequently strike the head of a human visitor to the ternery, though I have not personally experienced this, the assaulting bird always sweeping up with a sharp angry cry when within a few inches of my head. The violence with which the bird can strike and then recover itself without breaking its neck is really remarkable; this power of a sudden reversal of position is shown by its rapid emergence when diving for food.

The young bird has a whitish forehead and buffish neck and cheeks, whilst its back and wings are mottled with buff; but 

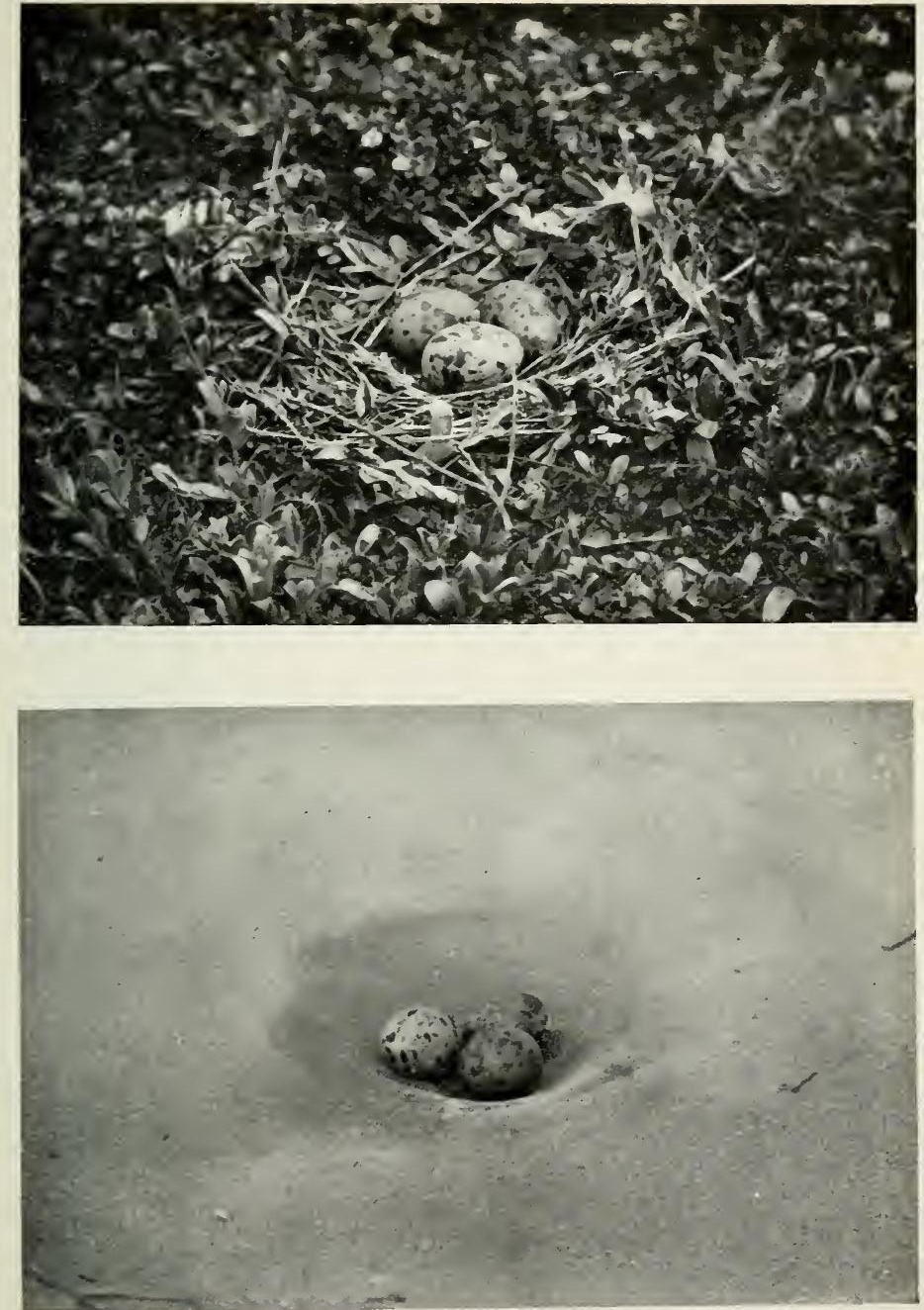

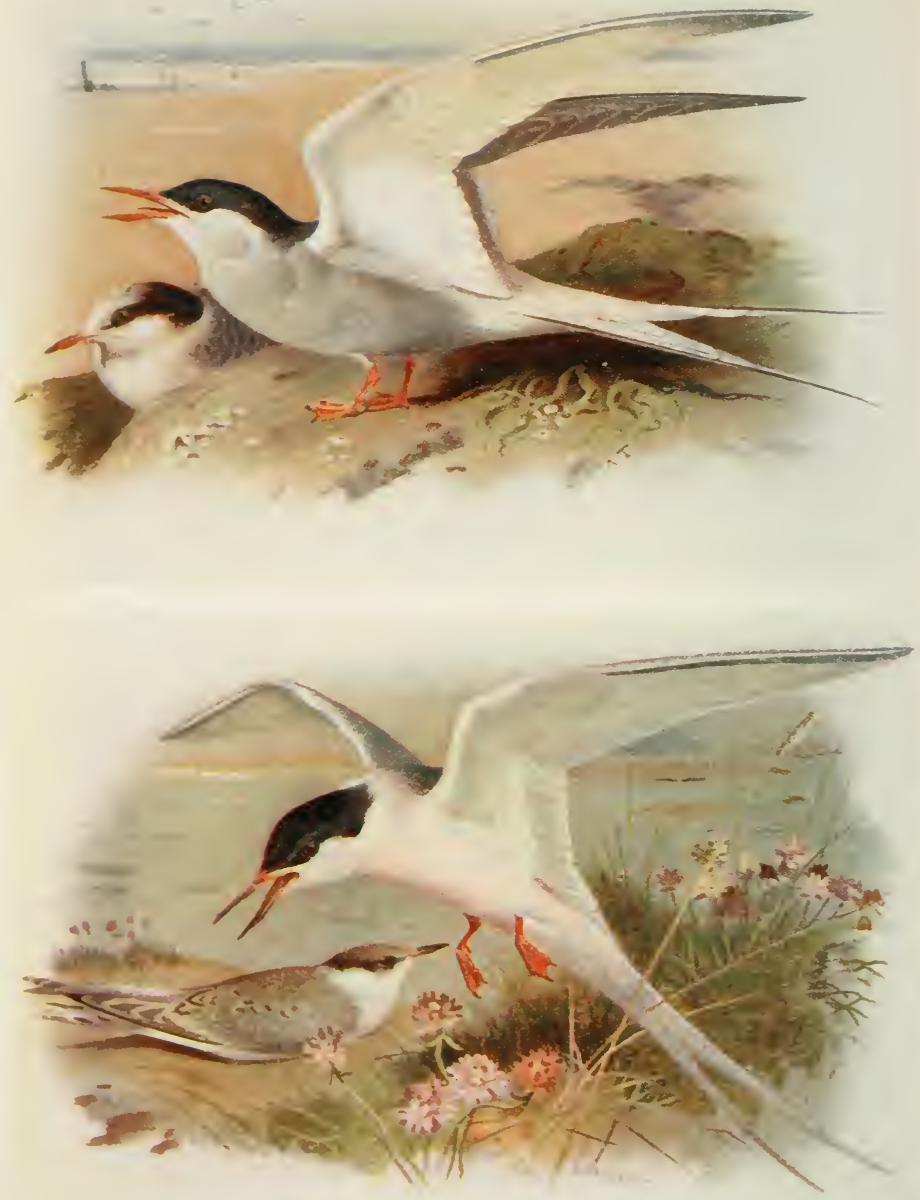

2 I\% 105.

Arctic Tern.

C 239.

Roseate Tern. 
after the autumn moult the forehead is white, the crown speckled, and the nape brownish black, but the pearl-grey upper parts are purer, though marked with a dusky band on the shoulders. The bill and legs are much darker than in the mature bird; indeed, the former is almost black. The grey breast of the adult Arctic Tern is without the vinaceous tinge sometimes noticed on the Common Tern, and the cheeks and throat are suffused with pale grey. The bill is blood-red, the legs are coral, and the irides blackish brown. Length, I45 ins. Wing, to ins. Tarsus, $0.7 \mathrm{in}$.

\section{Roseate Tern. Sterna dougalli Montagu.}

The Atlantic breeding range of the Roseate Tern (Plate 105) is more southerly than that of the Common Tern ; closely allied sub-species are found scattered over the Indian Ocean, Pacific, and other seas. In the northern part of its range it is migratory, and is a summer visitor to Britain in small numbers. Many of its former nesting haunts in the British Isles have long been deserted, but there is one flourishing colony and a second, much smaller, in Wales, and a few pairs nest on the Farnes, and perhaps still in Scotland. In Ireland it was thought to be extinct, until one small colony was discovered recently, and there is evidence that pairs have occasionally nested in other parts of England and Ireland.

The evanescent salmon-pink tint of the under parts of the Roseate Tern is not always easy to see; in direct sunlight it is usually plain. Better characters are the much blacker bill and the noticeably long tail streamers. I have watched it flying amongst a screaming mob of Common Terns, heard its call, and had no difficulty in picking it out; the body looks long and slender, the wings are shorter, and the tail much longer than that of its companions. Although several reliable observers affirm that the wings move more rapidly than those 
of other species, the flight has always appeared to me more deliberate, and I have visited one colony several times; in the down-stroke they are not brought so far beneath the plane of flight as in other terns. The black hood appears to extend further on the neck than in the Common Tern. The alarm or cali of annoyance is a long aaack, or a sharper $a g h$; it has too a long craak or creee. The call note is a clearer chew-it. A pair of birds sporting in the air at a great height, in what appeared to be nuptial flight, varied the chew-it with a harsher achrr, as I entered it in my notes at the time.

Persecution nearly exterminated our Roseate Terns, but protection saved the situation in some places. Colonies of this and other terns were harried out of existence by plumage hunters, and egg collecting has swept clean many a colony. There are, however, other factors which make the Roseate's position unsatisfactory, the worst being its competition with more go-ahead species. On congested stacks the best sites for nests are monopolised by the earlier breeding Commons or Arctics, though I have seen Roseates, on the same stack with the other three species, busily engaged in courtship without any suggestion of interference. The Roseate arrives late in April, nests often late in June, and seldom remains in British seas long after the end of August.

Most of the colonies are on rocky stacks occupied by other species, but, except for occasional pairs, the nests are in one area. Some of the now extinct colonies were on dunes or shingle banks, and recently a few pairs have nested in Common Tern colonies on the mainland. Very little nesting material or lining is used, most eggs being laid on ledges, or in cracks and hollows in the rock. Mr. Jourdain points out that water often collects in these hollows and chills the eggs; I have seen many swamped clutches of eggs of the Arctic Tern. Either one or two eggs (Plate IOS) are laid, but a single egg is more common than two, and from observations made 


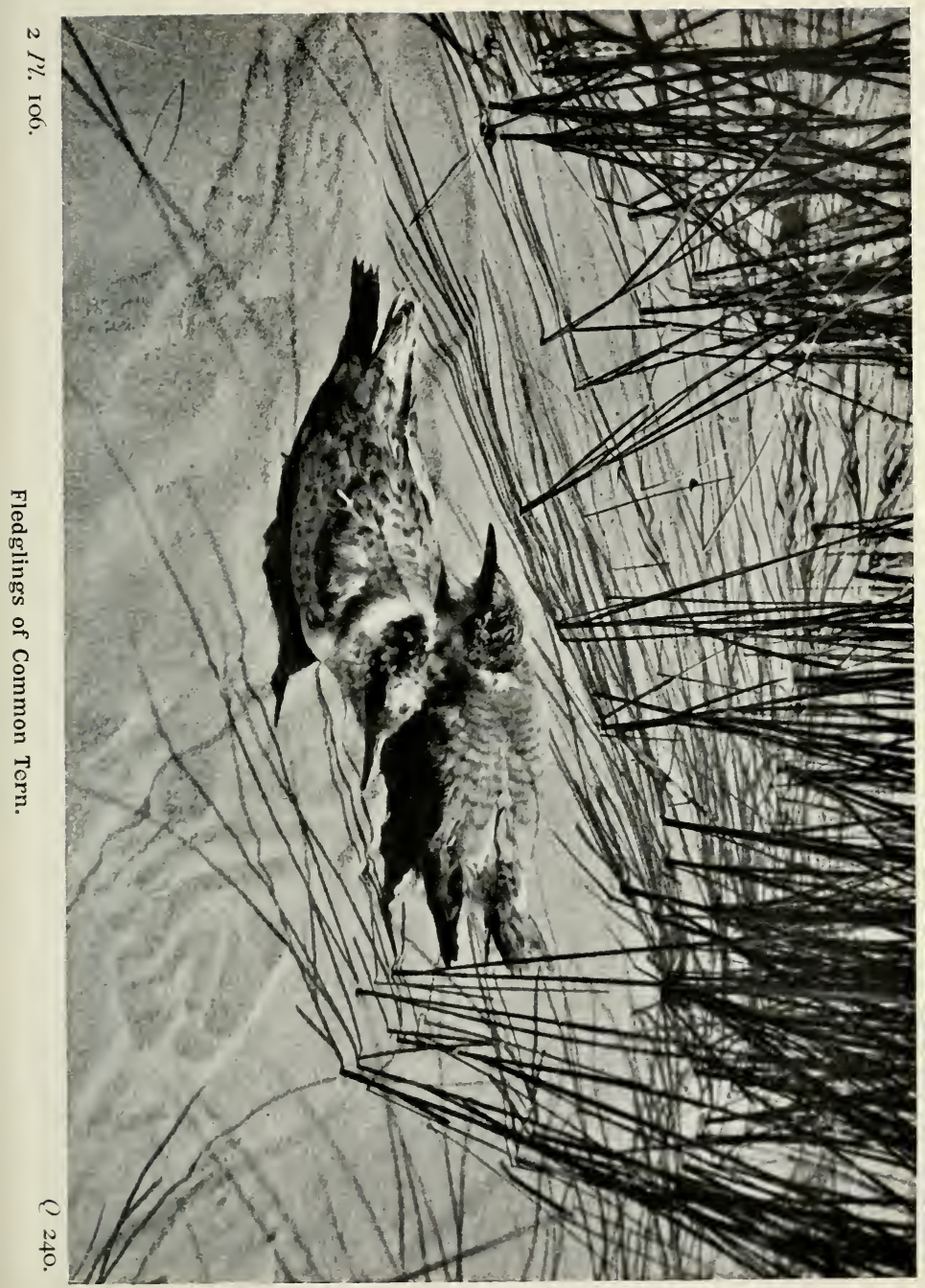



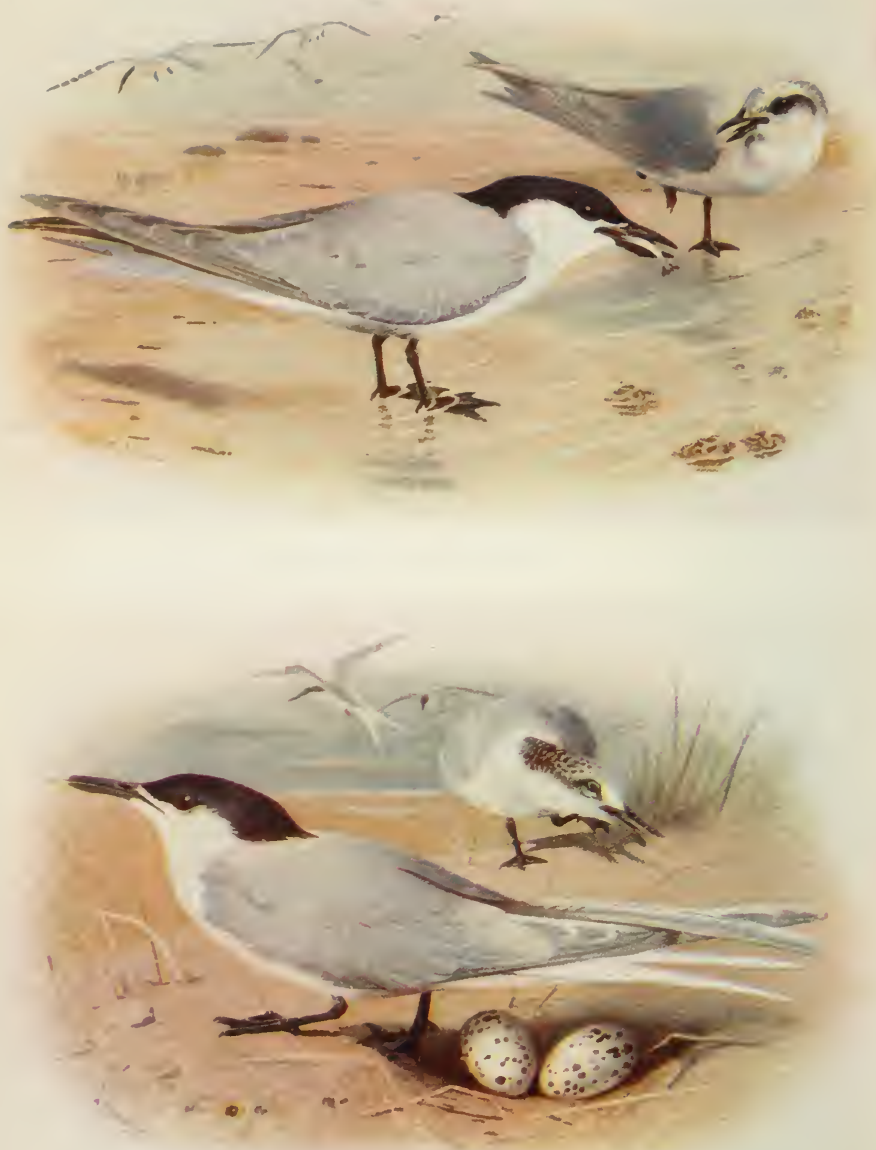

$21 \% 10 \%$.

Gull-billed Tern. 
in an Irish colony it appears that but one chick is the rule. Variation is less frequent than in the eggs of Common or Arctic Terns, and most oologists affirm that they can at once distinguish the eggs by their light stone or buff ground and small spots of varied browns and greys, which often form a zone towards the larger end. On the average they are slightly larger and longer than those of the Common, but many eggs would puzzle the most expert sorter. The nestling is paler buff than most juvenile terns, and its greyish-brown markings are streaks rather than mottles ; the bill is at an early age, at any rate, pinkish flesh, and its legs " purplish flesh," but Dr. Bureau, who carefully studied the changes, says that they are at first blackish brown, and in a few days turn black.

The adult bird has the top of the head and back of the neck black in summer and speckled with white in winter; the outer margin of the streamer is white. The white streak on the primaries, even extending round the tip, is present in the young bird, which has also a white-streaked forehead, brownish nape and crown, and ashy-brown speckles on the back and wings. The bill of the adult bird is black, except for a red patch at the base; the legs are orange-red and the irides dark brown. The length of the streamers varies greatly; in one bird I measured they were eight inches long, but others were much shorter. Length, $15-17$ ins. IVing, 9.25 ins. Tarsus, 0.87 in.

\section{Little Tern. Sterna minuta Linn.}

The Little or L.esser Tern (Plate I00) breeds on the coasts and inland waters of the Palrearctic region, and closely allied races occur in other parts of the world. To the British Isles it is a summer visitor, nesting in small and scattered colonies in all parts. It reaches the south coast about the middle of April, and birds are passing north in early May; it is seldom seen after the end of September.

Series $I I$. 
Apart from its size, for this is our smallest tern, it may be recognised by its broad, semi-lunar white forehead. The white extends to above the eye, and is emphasised by a black streak from the bill through the eye. The legs and bill are yellow, the latter with the tip black. Its wide wing-stretch magnifies its size, and its wing-beats are quicker than those of other terns; it beats above the waves at a height of from ten to fifteen feet, with head drooped, scanning the surface. At intervals it checks its pace, poises with wings uplifted and vibrating, and tail depressed and expanded. Its body is held well upright, and as its streamers are short, its spread tail is almost triangular. Suddenly wing movement ceases, and as the bird drops it reverses, and with wings almost closed bores through the air with a half turn, throwing up a shower of spray as it strikes. Instantly it reappears, and with a few strong strokes mounts again, but at times it checks its descent and rises without touching the water. By no means every dive brings reward; one bird I watched averaged a catch to every six dives. Complete submersion is common, but the bird is up again before the splash has subsided. Small crustaceans as well as fish are eaten, and these, even when in shallow tidepools, are obtained by diving, the bird checking the impetus of descent with skill. I have seen many fishing in tidal gutters on "slob" land, the snowy plumage distinct against the dark green of the sea-grass. The call-pee-e-err-is neither so harsh nor sustained as that of the Common Tern, but the bird is very loquacious on the wing. It has, in addition, a short zit, zit, and a long tirrue, tirrue, tirrue. On migration the Little Tern often visits inland waters, fishing occasionally, but usually swooping for flying insects after the manner of the Black Tern; young birds are not uncommon on the Cheshire meres in September.

The nesting colonies are small and the nests seldom close together; favourite sites are shingle banks or stretches of sand 
above the tide-mark. It seldom if ever nests on rock, and bare ground is preferred to grass-grown flats. Some colonies are foolishly near the water; high tides destroy many eggs, yet the bird returns annually to these danger zones, and never seems to learn by experience. Courtship gifts of fish to the female and the postures during presentation are as common with this species as with others, and a pair will indulge in high nuptial aerial chases, the air ringing with excited cries. The eggs may be placed amongst pebbles without any attempt at a nest, or laid in an unlined scoop in fine sand; only occasionally is grass or other soft lining used, though the eggs are frequently on a paving of small pebbles or broken shells. When these are collected from the immediate vicinity the denuded ground forms a distinct zone round the nest; paved nests are conspicuous when on sand. Indeed, on sand the sitting bird (Plate I09), and even the two or three light stone-coloured eggs (Plate I08), spotted, blotched, or smeared with brown and grey, are easy to see, but amongst fair-sized pebbles the bird is inconspicuous, and the eggs most difficult to discover.

On returning to the nest, which it does very soon after being disturbed, the bird descends direct, and can with ease be marked down. Yet it is a plucky defender of its property, chasing away with fierce cries of $k i, k i, k i$, any marauding gull, crow, or more innocent bird which approaches the colony. Like other terns it dives at the human head, rising first to a great height, and plunging down with three or four strong beats before the wings are half closed, but with a few hurried and angry notes it sheers off without striking. In Lancashire and Wales eggs are usually laid about the middle of May, and one brood is usual, but where the bird is persecuted fresh eggs in July are not uncommon. The grey or yellowish down of the young helps concealment when they crouch either on sand or amongst stones; the head is speckled with black, and there are irregular longitudinal lines on the back. Young in autumn 
have the back and wings mottled and barred with brown, the cap is brownish, and the white on the forehead wide; on the carpal joint is a dark patch, which persists until the second year. The bill is yellowish brown, the legs much duller yellow than in the mature bird; the irides in young and old are dark brown. The white frontal patch of adult birds is broader in winter than in summer. The outer primaries are black on either side of the dusky shaft in mature birds, the inner web having a pale margin, but in the young they are light slate. Length, Io ins. Wing, 6.75 ins. Tarsus, 0.6 in.

\section{Caspian Tern. Sterna caspia Pallas.}

Rather more than twenty examples of the Caspian Tern have been recorded from the east and south coasts of England; the largest number from Norfolk. As it nests in Sweden and Finland, as well as Spain and other parts of Europe, it is surprising that it has not more frequently wandered on migration. It has a wide, almost cosmopolitan distribution, and does not appear to vary greatly in different parts of its range.

It is a large, rather heavily built tern with powerful flight, easily distinguished by size alone. Its tail is short, its bill, strong and slightly angled like that of a gull, is vermilion, dark at the tip, and its legs are black. The cap, which extends to below the eye, is greenish black, and the dark grey primaries have a frosted appearance ; the irides are almost black. Hume states that its Indian name is "Keykra," which as pronounced by the natives approximates to its call. In autumn the black cap is replaced by black streaks, as it is in the young, which have the bill yellowish orown and the legs brown. Length, 20 ins. Wing, $16 \% 5$ ins. Tarsus, 106 ins.

\section{Gull-billed Tern. Sterna anglica Montagu.}

The Gull-billed Tern (Plate 107) breeds on the western shores of Europe from Denmark to Spain; it also nests inland. It has 
a wide distribution in Asia, Africa, and America, and a closely allied race is found in Australia. It occurs from time to time on our southern and eastern shores, and has once been recorded from Lancashire, and more recently from the Pentland Skerries. The majority of the records are in spring or summer.

The heavy angled bill of this bird is black, as are its legs, and its colour scheme is that of other terns; the frosted primaries are a darker grey than the mantle. Saunders gives the alarm note as af, af, af, and Legge says that its call is che-ah, though Irby spells it $k u k-r u u k$, neither of which convey much to those who have not heard the note.

In India and Africa it feeds largely on insects, catching them on the wing, but it also eats fish and frogs.

The young bird has the head spotted and streaked with brown, and the back and wings mottled with brown and buff; the bill and legs are browner than in the mature bird. Length, 15 ins. Wing, $12^{\circ} 5$ ins. Tarsus, $1 \% 5$ ins.

\section{Sandwich Tern. Sterna sandvicensis Latham.}

Together with its American sub-species, the Sandwich Tern (Plate 107) is practically a bird of the North Atlantic and southern European seas, migrating so far south as Natal and Brazil. Small colonies are scattered round the British coasts, and in Ireland on at least two inland loughs; the largest colonies, all now protected, are at the Farnes, Ravenglass, and Walney. The statement that the last of these is now deserted was certainly incorrect a few years ago; I saw both birds and eggs in 1914. Other small colonies have been established recently, for the bird is increasing, and possibly has benefited by the preoccupation of collectors during the war.

The Sandwich is the largest of our breeding terns and one of the easiest to recognise; its greater stretch of wing, shorter forked tail, and heavier build, separate it at once from the 
slender, long-streamered birds. It is, however, graceful and easy in flight, often rising high, and in a good light a rosy tinge shows on its white under parts, for this adornment is not a monopoly of the Roseate Tern. On the ground the very black cap is striking, and as the feathers of the nape and neck are pointed they often stand out as a mane or crest, especially when raised under excitement. The black bill with a yellow tip can generally be seen on the flying bird; the legs are also black. Fishermen on the north-east coast know it as the "Tern," dis- " tinguishing it from the "Sea-Swallows." The call-kirr-whit or troo-it-is less harsh than the notes of Common and Arctic Terns, and sounds almost musical when many are calling; the alarm or threat is a sharp gwit or whut. When hovering before a dive the tail is not, as a rule, depressed as in the other terns, and when it enters the water it is frequently submerged for an appreciable interval. The habit of the male presenting fish to the female during courtship is very noticeable at the nesting colony ; he struts with wings expanded and depressed, dangling his gift from the tip of his uplifted bill, sometimes, it is said, offering it to several females in turn until it is accepted. The upstretched neck and skyward pointed bill is evidently an amatory salutation.

Many birds reach the breeding grounds before the end of March, and eggs are often laid early in May ; by the end of July most birds are at sea, and south ward departure is in August and September. The majority of the British colonies are on sand dunes or sandy shores; indeed, it has been asserted that the bird always nests on sand. There is, however, one west coast colony on a rocky stack, where many of the eggs are laid on bare rock. Nests on sand are often mere scoops without any attempt at lining or rim, but round others a thin scattering of bents is arranged. Finished structures are uncommon. The colonies, or rather colonies within the colony, for little groups are often scattered around or even on the ground occupied by 

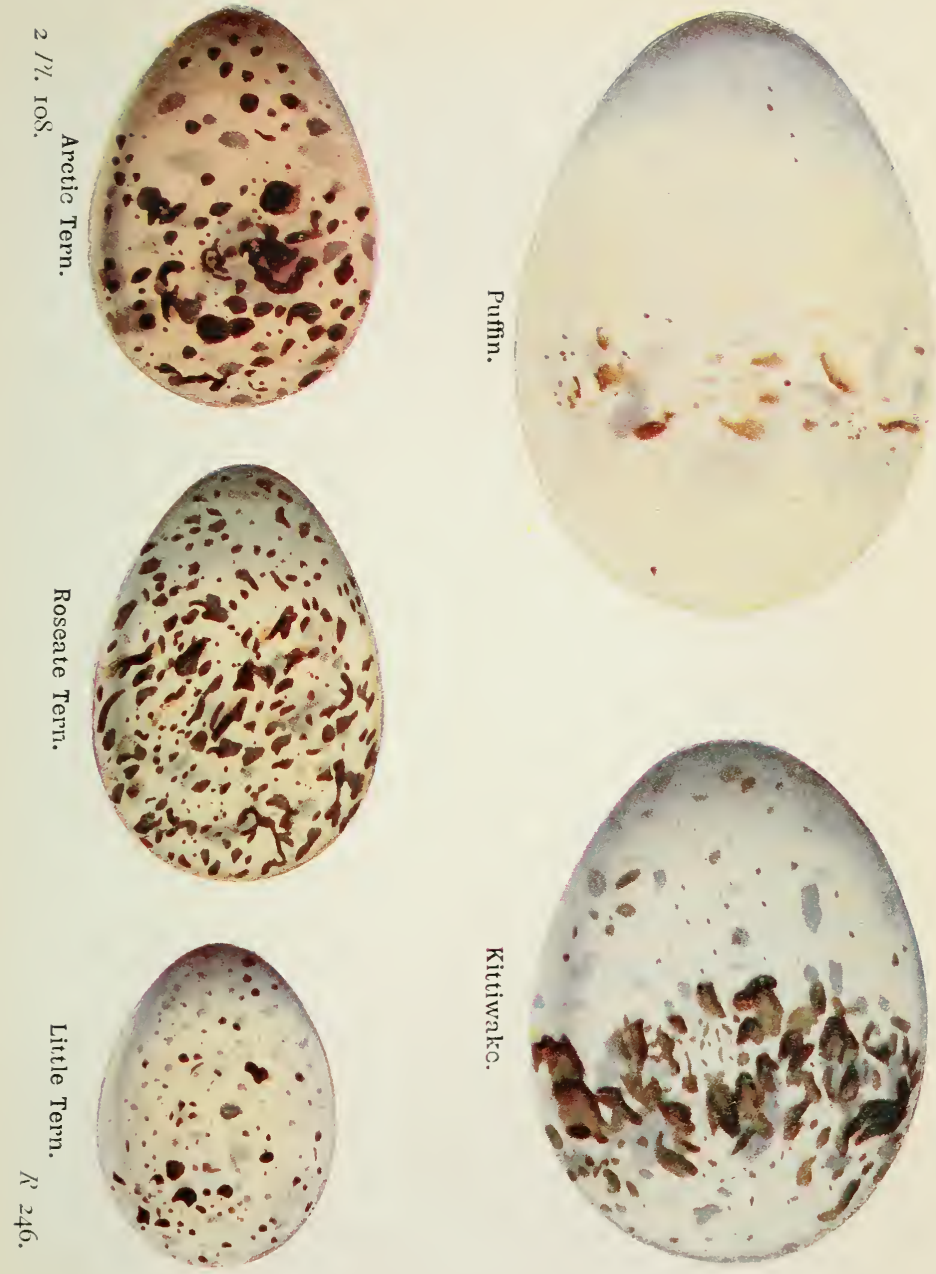


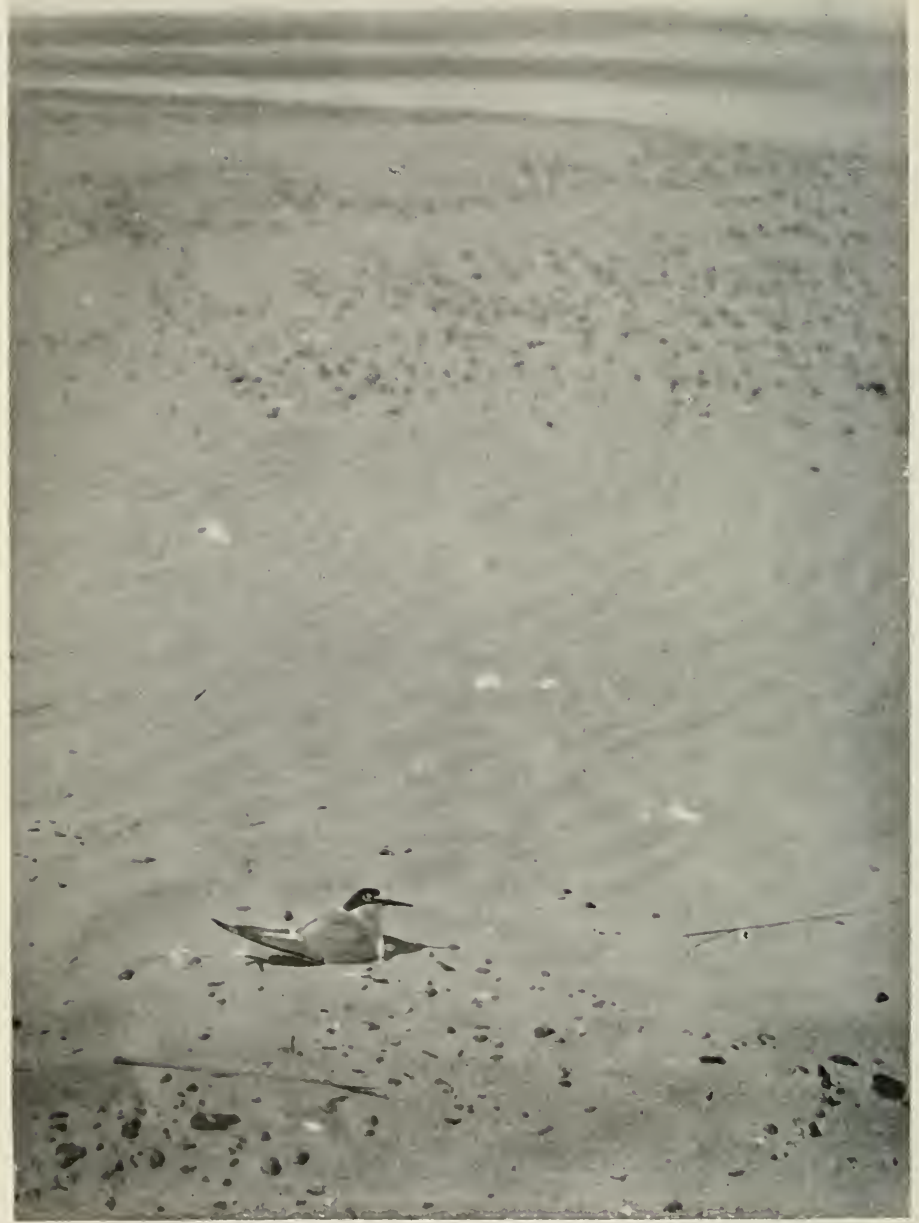

$21 \%$ I09.

K 24 .

Little Tern on nest. 
other terns or Black-headed Gulls, consist of half a dozen to fifty nests, usually close together. At Ravenglass most of these groups of nests are on the slopes of the dunes amongst sparse marram grass. As incubation proceeds the nests (Plate IIO) become more and more evident, owing to the insanitary habits of the sitting bird, and often they are surrounded by scattered feathers.

The eggs (Plate 94) are light in ground-creamy white to rich buff-and are beautifully speckled, streaked, or blotched with black, brown, and grey; two is the usual number, but single eggs are common. The light ground shows up the markings, and they are much sought for on account of their beauty by collectors, and for other reasons by Black-headed Gulls. The parent birds are said to be less demonstrative in defence of eggs and young than other species, but they certainly stoop at the head of visitors to the colony with considerable show of ferocity. The nestling in down is better protected by its colour than the eggs, and though there are light and dark phases, are on the whole lighter than other juvenile terns; light and dark young may be found in the same nest. The paler birds are creamy white with a few black specks and dashes, darker ones are rich buff, but in both forms the quantity and depth of the markings varies. The bill is blackish, yellow, yellow tipped with black, or even dull red; the legs may be greenish, purple, or plumbeous. When only a few days old the young leave the nest and ramble, and, as Mr. C. Oldham pointed out, conceal themselves by partially burying themselves in self-made scrapes, exactiy fitting their bodies, in the loose sand. The habit is most marked with the older young, the scoops being deeper; Mr. Oldham found birds thus concealed when partly feathered. In the first plumage the greyish-buff head is finely barred and speckled with black, and the mantle broadly barred with black and buff. Their legs are leadcoloured or purple, and bills yellowish horn or black with a 
yellow tip. The cap of the mature bird is very black, but in the immature after the moult it is brown, barred and spotted with white; white streaks and spots appear at times on the foreheads and crowns of adult birds before they leave the ternery, for in winter the top of the head is merely streaked with black. The mantle and tail of young birds have angular black and brown markings. The irides are dark brown. Length, 15 ins. Wing, 12 ins. Tarsus, $1 \cdot 2$ ins.

\section{Sooty Tern. Stcrna fuliginosa Gmelin.}

Rather more than half a dozen examples of the Sooty Tern have wandered north from tropical or subtropical seas, and fallen exhausted on our shores or in inland localities; some were shot, but most have been picked up dead or barely alive. The visits have been in both spring and autumn. The crown, back of the neck, and a streak through the eye of the adult bird are black, the back, wings, and tail-except the outer web of the streamer-are sooty black; the rest of the plumage is white. The bill and legs are black, the irides blackish brown. The young bird has the dark back feathers tipped with white, and the under parts are sooty brown. Length, 16 ins. Wing, 1175 ins. Tarsus, $0^{\circ} 9 \mathrm{in}$.

\section{Black Tern. Hydrochelidon nigra (Linn.).}

About a hundred years ago the Black Tern or "Carr-Sivallow" (Plate III) nested freely in the east coast marshes, but now it is a passage migrant only, halting for food in April and May, August and September. A Black Tern in June or October is unusual, in other months very rare. On passage it is regular and sometimes numerous in eastern counties as far north as Yorkshire, crossing south-eastern England on migration to and from its breeding grounds in Denmark, 
Sweden, and the Baltic. It is found throughout a great part of Europe and western Asia, and in winter visits tropical Africa. Knowledge of the British distribution of this, and many other passage birds, depends largely upon scattered notes of observers who cannot regularly watch one spot; consequently it is counted rare and irregular in the west and inland. In Wales, Lancashire, Cheshire, and various scattered inland waters, closer attention proves it to be far more frequent than most authorities affirm ; indeed, on the Cheshire meres it is a regular visitor in spring and autumn, often appearing in little parties. North of Cheshire in the west, and south Yorkshire in the east, and in Ireland, it is less frequent, though it has been noted in Orkney and the Outer Hebrides.

Though drainage destroyed some of its former nesting haunts, there remain many wild marshes where it could be secure. Collectors in this case have been unjustly blamed for its departure, nor is it probable that it was badly harried for its flesh or plumage; the desertion of the haunts seems to have been deliberate, an intentional restriction or change of habitat, possibly due to the increase of population and consequent more frequent disturbance on the marshes. The last recorded Norfolk nest was in 1858 .

In summer plumage the Black Tern is a very dark bird, its slate wings, back, and tail look almost pale compared with the deep blue-black of its head, neck, and breast. From both White-winged and Whiskered Terns, its nearest allies, it may be told by its black bill and blackish legs, red in these birds. From the former, when both are mature, its darker wings and grey tail and tail-coverts are distinct when in flight, and the latter is a larger, paler tern with a black cap and not wholly dark head. The immature plumages are more puzzling. The Black Tern does not hurry through England, but stays for a few hours, and often days, about some inland water where food is abundant. It beats up and down with desultory flight, swooping 
when it sights food on or near the surface ; sometimes its descents and ascents are long, graceful swinging curves, varied with a check and flutter as it intercepts some dodging fly or gnat, but often it dives obliquely with a half turn, lightly touches the water with its bill, leaving a circle of ripples where an insect swam or drowned, and banks smartly. Its loitering flight is broken by a series of deep $\mathrm{U}$-curves. But rarely it strikes the water with its body, and I have only once seen a bird submerge. Like the Swallow it feeds against the wind, sweeping down wind to repeat the process when it reaches the limits of the pool. When tired it settles on some rail or mooring-post; on this it perches head to wind, its head and neck depressed, its long wing tips crossed above its short tail and slightly raised; it tilts forward in its resting position. It is sociable rather than gregarious on migration, often flying with Common and Lesser Terns, when its even more buoyant flight is very marked. Large numbers have, on rare occasions, been recorded from the east coast, but more than fifty in a party is unusual; in Cheshire, twelve and twenty-four are the two largest flocks observed.

The Marsh Terns, as the members of this small group are called, are inland rather than sea terns, more frequent over fresh than salt water; even when travelling along the coast of Lancashire they keep to the dunes, feeding over the "slacks," rather than the shore. They seldom swim, the webs being more deeply indented between the toes than in other terns, the feet better fitted for walking. The Black Tern nests in extensive and treacherous marshes, the nest itself (Plate I 13), built of sodden and often rotten vegetation, is frequently surrounded by water, placed on a quaking platform of dead aquatic plants. The bird is demonstrative at the nesting colony; Pennant, writing at the beginning of the nineteenth century, says - "They are found during spring and summer in vast numbers in the fens of Lincolnshire; make an incessant 


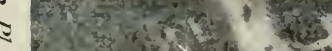

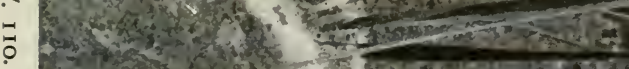
or y. $x^{2}$.

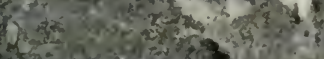

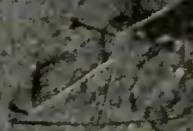
$x^{2}+\mathrm{CH}^{2}$

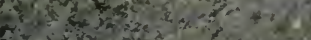

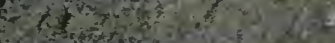

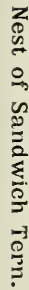

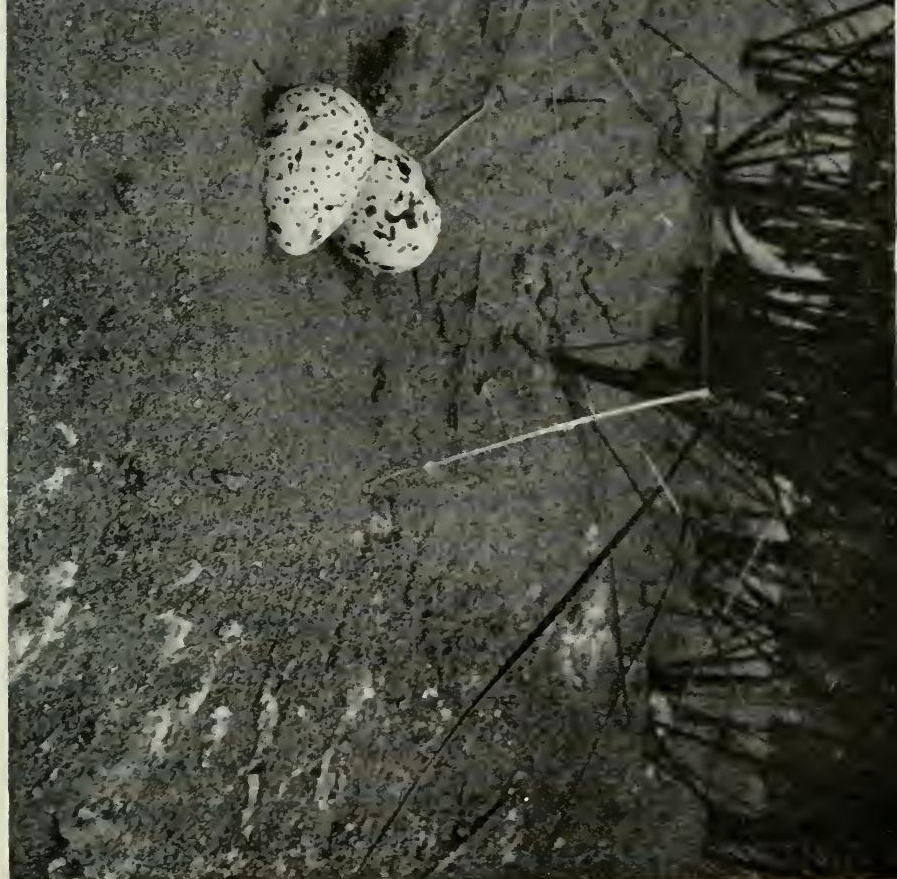



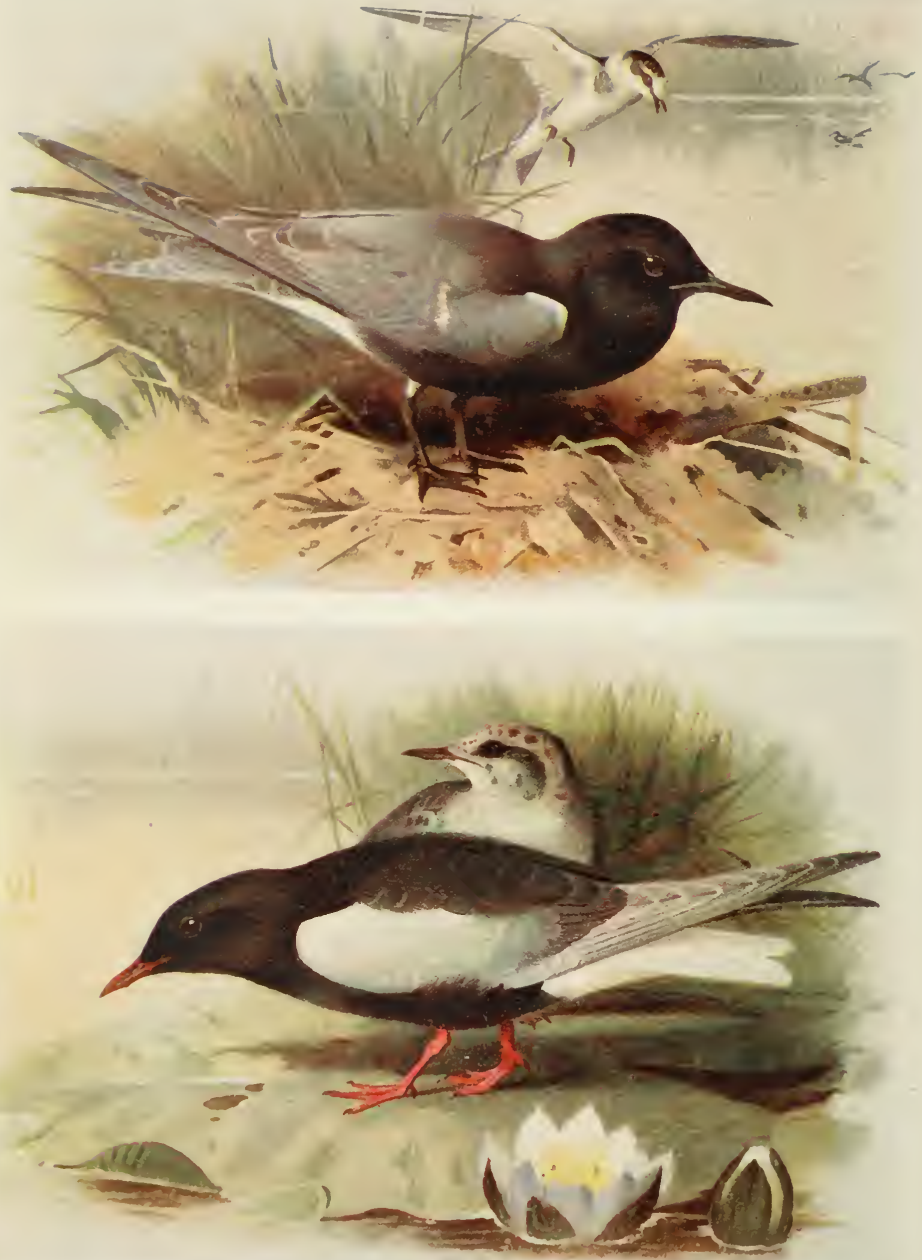

$21 \%$ III.

Black Tern.

l 251.

White-winged Black Tern. 
noise, and feed as well on flies as water insects and small fish." Dr. Patten says its note is "shrill and powerful," and Saunders calls it "a shrill crick, crick," but on migration it is a silent traveller.

The head, neck, and breast of the mature bird are black in summer; the rest of the plumage, except for white on the carpal angle and the under tail-coverts, is slate-grey, varying in depth. The bill is black, the legs are dark reddish brown, the irides blackish brown. After the autumn moult the forehead, sides of face and neck, a collar, and the under parts are white, tinged and speckled in places with grey, and the bill often shows a trace of red at the base. The greyish upper parts of young birds are suffused and mottled with brown and buff, and the face, nape, and a patch on the side of the neck are dark grey; there is a dark patch on the shoulder, which is still present in the second autumn when the back and wings have lost their brown splashes. The bill is brown, darkest at the tip, and the legs are reddish brown. Length, 9.6 ins. Wing, 8.5 ins. Tarsus, $0.6 \mathrm{in}$.

\section{White-winged Black Tern. Hydrochelidon leucoptera (Temm.).}

The White-winged Black Tern (Plate II I) breeds in central and south-eastern Europe and western Asia, and winters in southern Asia and Africa, yet it occasionally wanders northwest and appears in spring and, more rarely, in autumn in our southern and eastern counties. It has been met with as a vagrant in Ireland and inland in England.

There is no difficulty in identifying the adult bird in summer, for the white patch on the carpal joint is, naturally, conspicuous against the deep black head, back, and breast, and more noticeable still are the white upper and under tail-coverts and tail. The rest of the plumage except the wings is blacker than in the 
Black Tern, and the bill and legs are strikingly red. The wings are greyish slate, almost pearl-grey on the secondaries, and the primaries, though really blackish, are so frosted as to appear pearl-grey; thus the whole wing, apart from the white patch, is consiclerably lighter than that of the Black Tern. This difference is reversed in the under wing, for the under wing-coverts and axillaries in this bird are black, and in the last species suffused with grey; the effect is that as the bird cants in flight the upper surface shows lighter than the under in the White-winged Tern, and vice-versa in the Black. Its habits, at any rate when on migration, closely agree with those of its congener; it catches insects and small fish, stooping to the water or taking the former in the air, and its flight is equally slow and desultory.

In winter the head, except for the blackish nape, the neck, and under parts are white, but the tail is suffused with grey and the under wing becomes paler, but not so pale as that of the Black Tern at the same season. The young bird is at first mottled with brown and buff on the head and upper parts, but during its two years' progress to maturity it gradually loses the brown feather edgings; the back of the head and neck become sooty, a greyish patch shows on the cheeks, and the wings become a purer grey. The upper tail-coverts in the second year are very nearly white, sufficiently so as to contrast with the pale grey tail, whereas in the Black Tern there is no appreciable difference. The bill and legs of young birds are brownish, the irides at all ages brown. Length, 9.3 ins. Wing, 8.25 ins. Tarsus, 0.75 in.

\section{Whiskered Tern. Hydrochelidon leucopareia (Temm.).}

Southern Europe and north Africa, eastward to India, is the summer range of the Whiskered Tern, and it winters further south; it is harclly surprising that it is a rare bird in Britain. 
Out of rather more than a dozen which are known to have wandered north as vagrants to our islands, single birds only have reached Scotland and Ireland.

Though the under parts are dark-almost black on the bellythe mature bird in summer is distinct from either of its congeners, for only the top of the head and nape are black, the chin, cheeks, and throat are white. The mantle and wings are slate, darkest on the shoulders ; the primaries, really black, are frosted with pearl-grey. Pure white under wing-coverts are a good distinctive character, for the bird flies slowly though buoyantly and its wing-beats are deliberate; when it cants over, the under wing is visible. The bill is blood-red, the legs are vermilion, and the irides dark brown. The food, as in the other marsh terns, consists of insects, small fish, and frogs. Birds have been met with in both spring and autumn, and after the autumn moult the mantle is lighter and the under parts, as well as the forehead, are white; the black on the head is streaked and spotted with white. The upper parts of young birds are at first mottled with brown, and even when the back is nearly grey the scapulars and tail are still brown towards the tip. The bills and legs of the young are brown. Length, $\mathrm{II}^{\circ} 5$ ins. Wing, ro ins. Tarsus, $0^{\circ} 9 \mathrm{in}$.

\section{Great Skua. Catharacta skua Brünn.}

Skuas differ in form and habits from gulls and terns; the strongly hooked bill has a horny "cere," and the curved claws are sharp; the birds look predacious, though they are not regular flesh eaters, and are piratical rather than parasitical, robbing others of their food. Largest, fiercest, and most powerful is the Great Skua (Plate II2), a bird of the North Atlantic, nesting in Iceland, the Færoes, two large and some small colonies in Shetland, and one at least in Orkney. In autumn these haunts are deserted and the bird becomes pelagic, 
only occasionally visiting the shore. It does not wander far south, but is met with at sea on both sides of the Atlantic, and it is affirmed that there is one breeding station off the Canadian coast. The breeding stations are returned to in March or April.

The Great Skua is a large, heavily built bird, umber-brown in general colour, about the size of a Herring Gull; at a distance it may be taken for a young Herring or Lesser Blackback in mottled plumage. It is, however, browner-less greyand on the outspread wing is a large white patch, formed by the white basal inner webs of the primaries. In all the skuas the central tail feathers are elongated ; in the "Bonxie," as the bird is called in Shetland, they only just project beyond the outer ones, yet sufficiently to give a rounded appearance to the tail. The white patch may be concealed by the flank feathers when the wing is closed, but shows immediately the bird rises. Normally the Bonxie has a gull-like, drifting, aimless flight, but it becomes direct and powerful when the bird has sighted chance of food, a clamorous cloud of gulls harrying an unlucky shoal of fish. When from amongst the flock it has singled out some victim, gull or tern, its true speed and aerial agility is shown. It has also a gliding flight, often associated with courtship; with wings raised at an angle of about $45^{\circ}$, it floats like a harrier. The method of obtaining a meal, shared by other skuas, is to select its victim and give chase with ferocity and terrifying cries, following every turn and dodge relentlessly, threatening to strike with wing, beak, and foot. As a rule, at any rate, there is no need to actually buffet the screaming fugitive, which sooner or later reluctantly disgorges its latest meal, sometimes half digested, or the fish it has just captured. Instantly the Skua stoops like a falcon, usually catching the fish before it strikes the water. The cry during the chase is skeerr or skua; from this the name is derived; in ordinary flight it has a deep gull note, and a barking cry of alarm or anger. Any gull or tern is hunted, and Hewitson saw 
a Gannet chased. Vicariously caught fish are not the only food of the Great Skua, for it will pick up offal, gorge on a carcase, and even slay smaller birds and devour them; it is also a robber of the eggs and young of other birds.

In the Froes the Great Skua had a bad name and was at one time in danger of extermination, but in Shetland the shepherds look upon it as a friend, for it boldly drives away other predatory species, even attacking and defeating the eagles; thus it unconsciously protects the flocks. But its restricted breeding ground brought collectors to the Shetlands, amongst them a dealer, and in $183 \mathrm{I}$, it is said, but two pairs survived at the Unst colony. Since then, both at Unst and Foula, protection has been afforded by the owners of the islands, and now, though there have been some lean years, the numbers are well maintained. The fact that within recent years small branch colonies have been established in the Shetlands and Orkneys is a hopeful sign. The Foula and Unst colonies are on hills, one at any rate at over $\mathrm{I} 400$ feet ; the nests are scattered over the moor. The nest is usually a trodden depression in ling or rough grass, somewhat loosely ${ }^{\circ}$ built of grass, and littered around with feathers, remains of recent meals and castup pellets of feathers, scales and bones. Two eggs (Plate I 16 ), light or dark olive-brown or buff, sparsely spotted with darker brown and grey, are laid late in May. The down of the nestlings is buffish sepia, and is without distinct markings ; the bill and legs are leaden. In defence of eggs or young the Bonxie is at its best, boldly attacking an invader of its territory, though by no means always striking, but sweeping past with a rush of wings. Those who have actually been struck give different accounts, some declaring that it was the wing, others the feet that hit them. The legs are lowered threateningly when the screaming bird attacks, and Mr. R. Kearton believes that the blow was delivered with the back of the foot.

The adult bird has its umber-brown plumage streaked and 
speckled with yellowish brown, and the neck, where the feathers are pointed and have light shafts, is lighter than the head and back; the under parts are more cinnamon-brown. The bill and legs are black, the cere blue-black, the irides dark brown. Length, 22-25 ins. Wing, 16 ins. Tarsus, $2 \cdot 5$ ins.

\section{Richardson's or Arctic Skua. Stercorarius parasiticus} (Linn.).

The Arctic Skua (Plate II4), is a circumpolar bird, but though it nests in the Arctic in both hemispheres, its range is really more southern than that of two of its congeners, and extends to northern Scotland; in winter the bird inhabits warmer seas, but though recorded far south is normally a northern species. It nests in colonies in the north of Scotland, the Orkney and Shetland Isles, and some of the Hebrides. On migration it is at times noticed in extraordinary numbers, especially on the east coast, the most extensive movements being after or during stormy weather. Saunders' "comparatively irregular in the western sea," has been mutilated and enlarged upon in various text-books by naturalists with no experience of the west coast, until the impression appears general that the bird is a mere vagrant. This is quite a mistake; though usually off shore, the autumnal passage from August to October is regular though less extensive than in the east. Mr. R. W. Jones on one occasion counted forty-two passing the Great Orme in the course of a three hours' watch.

Richardson's Skua, as some prefer to call it, is dimorphic, having more or less stable dark and light forms which interbreed. It is, however, a variable bird, and all manner of intermediate forms occur. The dark phase is perhaps the commoner in our seas, and in this the bird resembles a small Great Skua with much more elongated and pointed central tail feathers, projecting in adult birds about three 


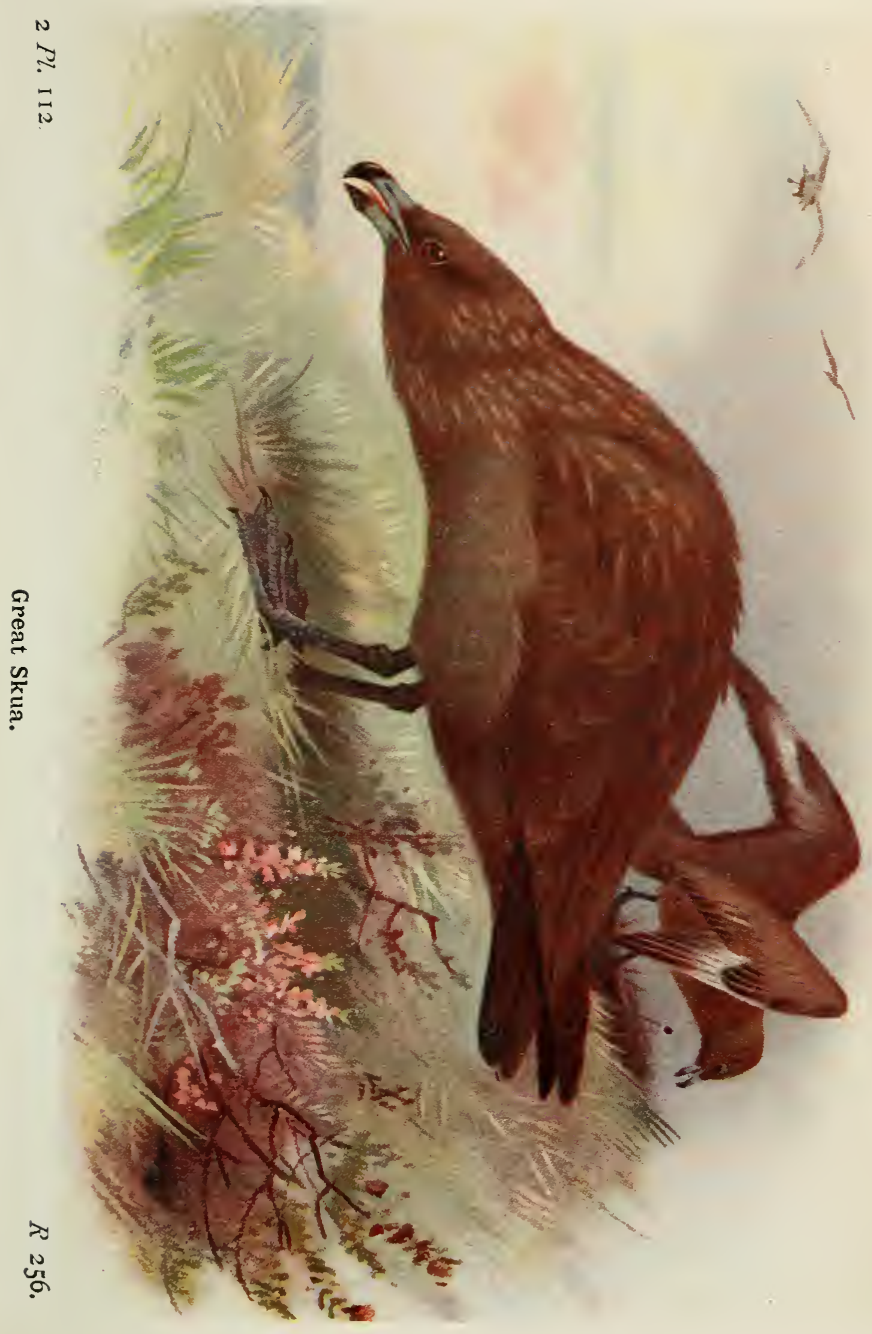



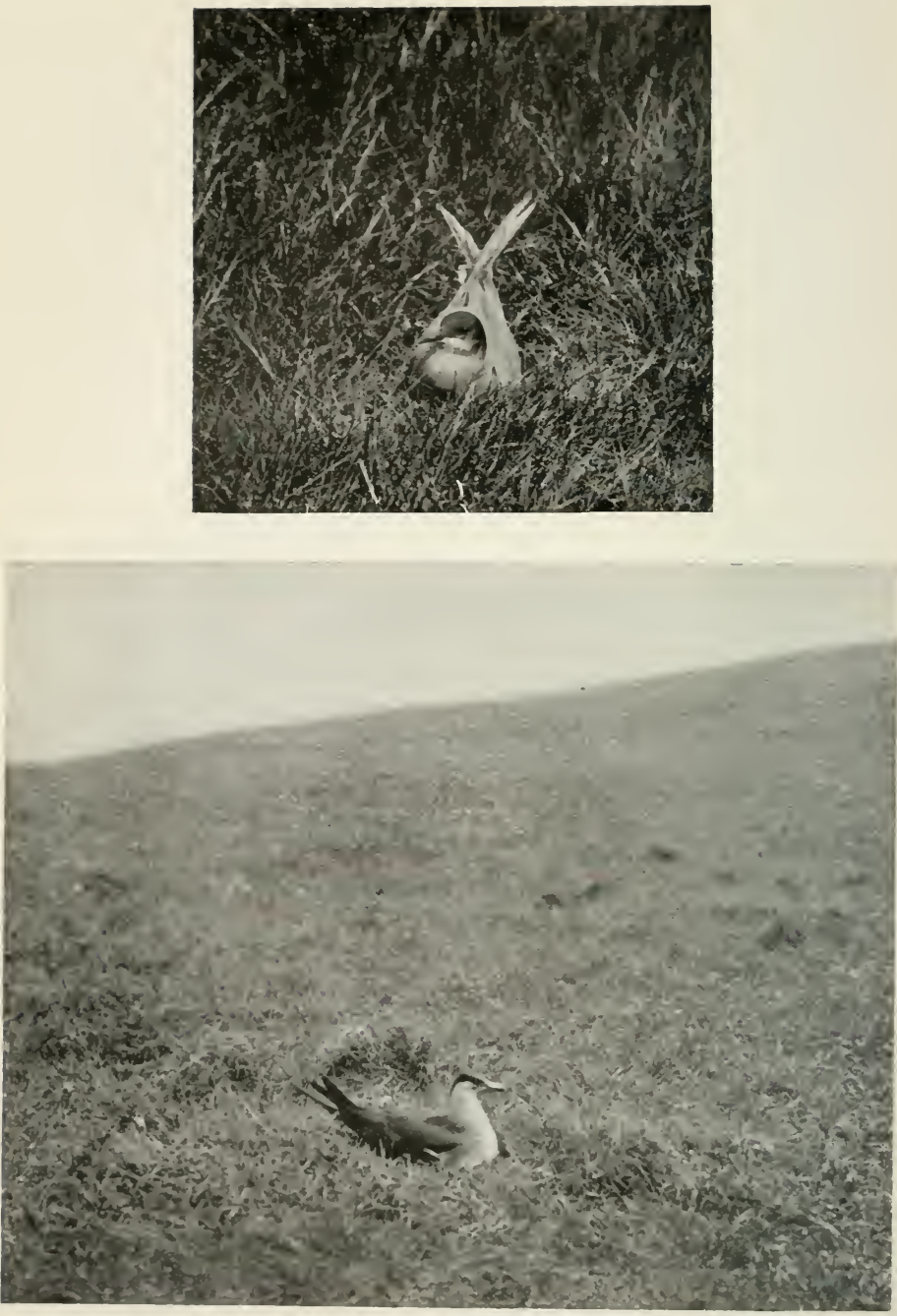
inches beyond the others. It is smaller than the Pomatorhine, which has the elongated feathers rounded, and larger than Buffon's, which has very much longer streamers. Immature birds, before the tails have lengthened, are very puzzling, especially when in flight, but in the hand one character usually holds good-the shafts of the primaries. Saunders points out that in the Arctic all the primaries have white shafts, but in Buffon's only the first two, those of the inner primaries being dusky; after examining a number of skins I am inclined to agree with his American critics that this rule has exceptions, and that the distinction between white and dusky is at times fine.

On the wing the Arctic Skua is graceful, its flight being steady and regular, varied with hawk-like glides, but when chasing a gull, tern, or diving bird, for it victimises the Guillemot and Puffin, it is erratic, swift, and powerful. When the hunted bird throws up food, the swoop of the Skua is wonderfully smart, yet if it misses the desired tit-bit it seldom tries to recover it from the water, but turns its attention to another victim. Some assert that it always hunts in couples, one bird worrying its dupe and the other fielding the food, but I have often seen a single Skua following a tern. When, however, a shoal of sand-eels or fry has attracted large numbers of gulls, terns, and auks, three or four Arctic Skuas will attend on the outskirts of the noisy crowd, commandeering whenever opportunity offers. On the moors insects and berries are eaten, and Saxby states that small waders are killed and devoured. On several occasions I have noticed a light, even white patch, at the base of the primaries of the flying bird, and Mr. R. W. Jones and Mr. T. Hadfield have observed the same. In most skins the white basal portion of the primaries is concealed by the coverts, but in one I could just see it; this white is often exposed when the wing is extended as in the Great Skua. The ordinary call is well described as mewing, but it is Series $I I$. 
sharper and more ferocious when the bird is engaged in piracy.

The Arctic Skua is a moorland nester; its colonies are scattered, nests being seldom near together. The nest (Plate 113) is little more than a hollow scraped or flattened in the grass or heather, and has very little, if any, lining. The eggs (Plate II6), laid at the end of May or in June, are usually two in number, and are dark or light olive-green or brown in ground, blotched and suffused with darker brown and underlying grey. An invader on the moor may be attacked and struck, usually with the feet, but sham disablement is a trick of the bird to lure the visitor from the vicinity of the nest; as the seemingly damaged bird struggles along the ground it beats with the extended wing, exhibiting the white shafts. The nestling is greyish brown, and shows little indication of the phase into which it will develop.

The dark phase is dark brown, with a distinct slate tinge in many examples, darkest on the head and paler beneath, but often showing yellow on the ear-coverts. The light birds have the neck and under parts white, often with a creamy or pale brown band across the breast, and at times with all the white suffused with cream; one of the most beautiful birds I have seen was slate-brown above, and rich chocolate beneath. Light birds may have the back of the neck suffused or streaked with yellow. Immature birds of either form are barred and streaked with brown and reddish buff, and the barring is most noticeable on the lower back. The bill and legs of young birds are brownish black, in old birds black with the cere bluish. The irides are dark brown. Length, 23 ins. Wing, 13 ins. Tarsus, $1 . t$ ins.

\section{Buffon's Skua. Stercorarius congicandus Vieill.}

Buffon's Skua (Plate i I5) has a more Arctic circumpolar range than the last species, and in winter is not met with far 
south in northern Atlantic and Pacific oceans. It is less frequent than the Pomatorhine and much rarer than the Arctic Skua, appearing as a passage migrant in autumn, and occasionally in spring, off our shores and inland. At times, in "skua years," numbers arrive, stormy weather causing invasions ; the greatest numbers have been observed on the east coast from Yorkshire northward, but there are scattered records from all parts.

Long-tailed Skua is a descriptive name, for the literally outstanding feature of the mature bird is the extraordinary elongation of the two central tail feathers, which project for from six to nine inches beyond the others. In general colour pattern it resembles the light phase of the Arctic Skua, but is rather greyer; dimorphism has been recorded in this species, but it is less variable than the last named. In young birds, and all skuas take some years to attain perfect plumage, the streamers are shorter, and, according to some authorities, are more obtuse at the tip than in the Arctic, but this is difficult to see in a living bird. The rule, however, that the shafts of the two outer primaries only are white, the others dusky, holds good in most cases. The Long-tailed is the smallest and most elegant of the skuas; its flight is lighter and more graceful; it glides through the air without effort, and often hovers like a tern. Indeed, there is much that is suggestive of a tern in its build and behaviour. Mr. J. A. Dockray, who watched and photographed a bird at close quarters in Ireland in the spring of 1914 , when others were met with in various places in England, noticed a peculiarity which is difficult to explain. The tips of the long streamers turned up and forward when the bird was alighting, though held straight when on the water; the bird alighted and swam against a very light wind, which he was sure did not influence the curve. In May, I9I6, Mr. F. W. Holder and a friend watched one in the Ribble estuary, and without knowledge of Mr. Dockray's observations, 
told me that "these elongated feathers curled in a most peculiar way as the bird progressed," and were sure that it was in no way due to the slight north-west breeze.

The bird swims buoyantly, holding the neck straight ; indeed, on land as well as water the skuas generally have an alert pose, the neck held at right angles to the horizontal body, though they are by no means nervous or shy. Piratical feeding habits are common with this species, though terns and Kittiwakes and not the larger gulls are most tormented; the Long-tailed Skua enjoys the chase, and will hunt small waders and even its own kind for pure love of sport. Indeed, as recorded by Dr. Eagle Clarke, during one invasion of this and the Pomatorhine, the two were observed chasing one another and occasionally nipping off the ends of the pursued bird's streamers. On the wing Buffon's seems to be less noisy than other skuas, but at its nesting place it is clamorous. On the tundras and fjelds it subsists upon lemmings, insects, berries, and other vegetable food, and here it varies its second-hand fish diet with insects, crustaceans, and worms. The bird Mr. Dockray watched joined with many other species in a wild orgy during a heavy rise of May-flies, and Stevenson records that a bird shot in Norfolk disyorged living earthworms.

The mature bird has the upper parts of the head dark brown, and the back, wings, and tail shading from dark grey to slaty brown; the rest of the plumage is whitish, purest on the neck and breast, tinged with yellow on the cheeks, and with greyish brown below the breast. The bill is blackish at the tip, blue tinged on the cere, the legs are greyish olive, and the irides dark brown. Immature birds are profusely barred with brown and grey on the upper parts, but are less rufous than Arctics. Length, 23 ins. Wing, $12 \% 5$ ins. Tarsus, $1 \cdot S$ ins. 

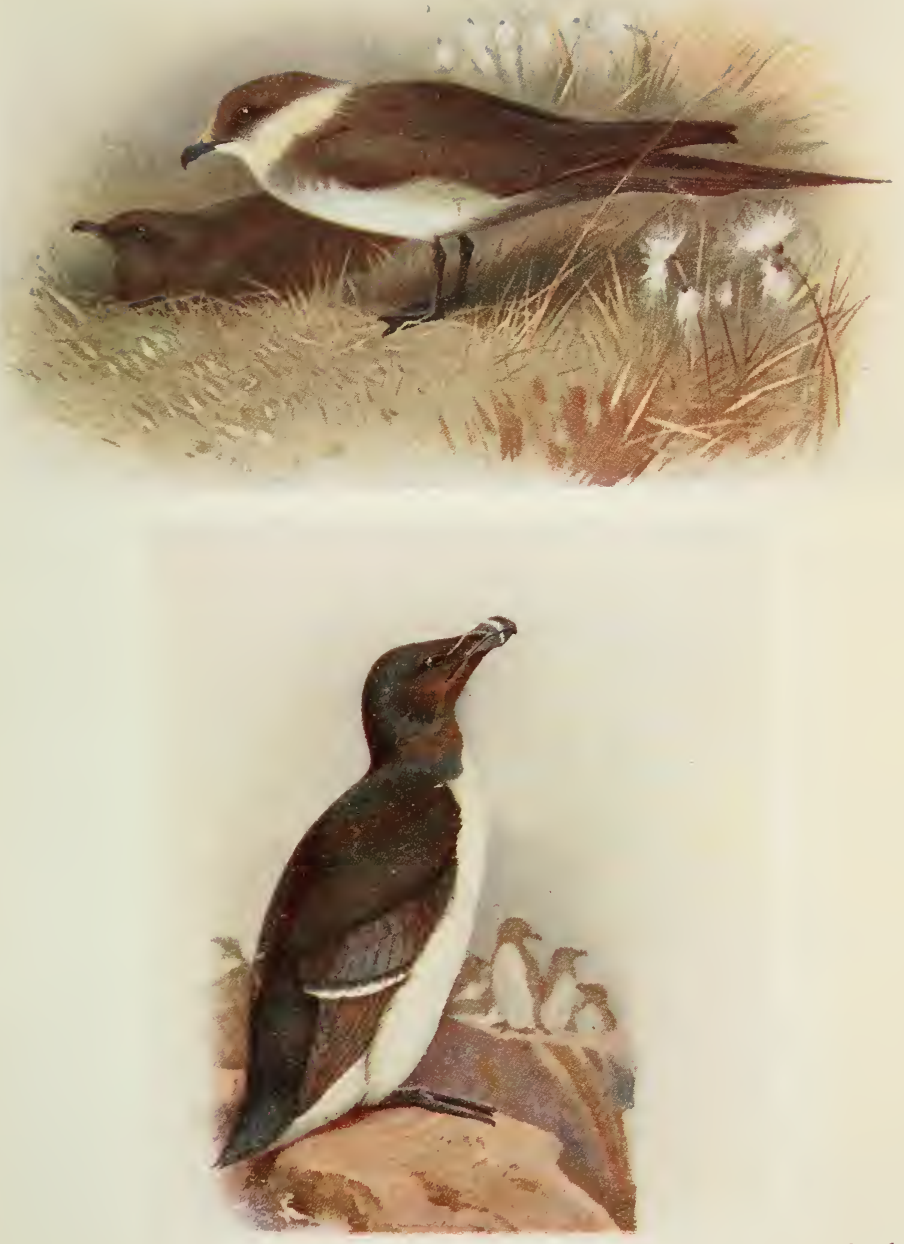

2 Pl. II 4 .

Richardson's Skua. 1/8th.

$S 260$. 

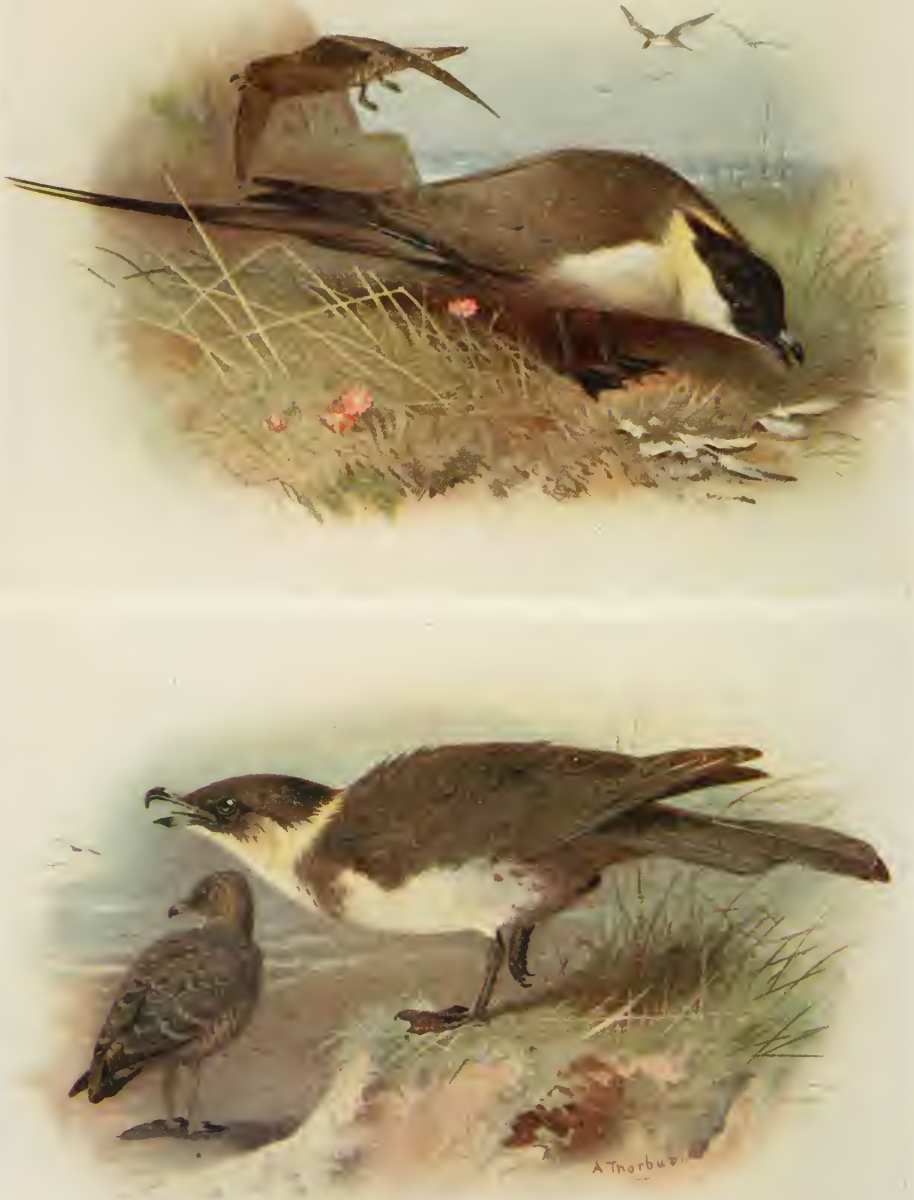


\section{Pomatorhine Skua. Stercorarius pomarinus (Temm.).}

The Pomatorhine, Pomarine, or Twist-tailed Skua (Plate I I 5) is another skua with an Arctic circumpolar range and a southward pelagic migration in autumn. It visits our shores in autumn, sometimes in spring, and young birds have been observed in summer; as a winter visitor it occurs at sea near the south coast. In the so-called skua-years many hundreds have been driven shoreward, and not a few picked up inland. The most noticeable of these invasions were in the autumns of 1879-188I, and were very marked upon the Yorkshire coast. Though looked upon as irregular in its visits, it appears that this and other species migrate normally at some distance from the land; adverse conditions explain their appearance on the shore.

The Pomatorhine is intermediate in size between the Great and Arctic Skua, and, though it occasionally exhibits dimorphism, is usually of the same brown and whitish pattern as the Longtailed and light phase of the Arctic. The tail of the mature bird differs from that of all others, for not only are the two central feathers rounded at their tips, but they are twisted so that they are at an angle, sometimes almost a right angle, to the outer feathers. The effect is curious, and when in its chases the bird hovers over its dodging victim, the tail is expanded or closed like a fan. When open it looks square, the twist of the shafts of the streamers giving them a paddled-shaped appearance as they project beyond the fanned-out outer feathers. I have only twice seen the mature bird on the wing, but the rounded paddles caught my eye at once. Barrington believed that the tips of the tail were broken off by rough winds, weakened by the twist in the shaft, as he came across many specimens thus mutilated; he thought that this was more likely than that they had been nipped off by other birds. In young birds the central feathers are but little elongated. The flight is hardly so free and rollicking as that of the Arctic, nor so graceful as Buffon's, but 
its piratical habits are the same. It is said to fish at times for itself, and will feed on carrion, small birds, and, in its breeding quarters, mammals and berries. The note is harsh, and E. T. Booth, who kept the bird in captivity, found that the young, at any rate, had a variety of screaming and whistling calls.

The age variation of this and other skuas is puzzling; almost every bird seems to depart from the normal. Booth was of opinion that maturity was not attained until the fifth year, but little is known of the plumage changes of birds in the free state. The mature bird has the head black on crown and nape, and the cheeks and neck, where the feathers are pointed, streaked or suffused with yellow. The back, wings, and tail are umberbrown, the breast and front of the neck white, and the lower abdomen brown. Immature birds are brown above and below, barred and mottled with rufous and brown, but birds showing more or less elongated tail feathers, and therefore approaching maturity, have a wide pectoral band, which in younger birds is almost self brown, but in those a little older is formed of brown streaks and blotches. The primaries have white bases, and the white extends further on the inner web than in the Arctic, a useful distinction in immature birds. The bill in adult birds is greyish black, bluer on the cere, but browner in young birds; the legs are brown, but often show bands or blotches of blue-grey, a sign of immaturity; and in the young, as in other skuas, the webs usually differ in colour from the tarsi and toes. The irides are dark brown. Length, 2 I ins. Wing, 145 ins. Tarsus, 2 ins.

\section{Order ALCIFORMES.}

Family ALCID $A$. Auks.

Stout, short-winged, web-footed diving birds. Bills variable in shape ; legs set far back and short; hind toe absent. 


\section{Razorbill. Alca torda Linn.}

Although the Razorbill (Plate II 4 ) is classed as a British resident, it is only from about the end of March to the beginning of August that it willingly comes to land ; the rest of its lifeday and night alike-is spent at sea. It is a pelagic inhabitant of the North Atlantic, nesting so far south as the Channel Islands in the east, and New Brunswick in the west. In winter it enters the Mediterranean and visits the seas of the Canary Islands and Azores. In their breeding haunts all round the British Isles the Razorbill and Guillemot are usually near neigh. bours. In autumn and winter the Razorbill keeps well away from the shore, but stormy weather drives it in ; after continuous rough weather, when it finds difficulty in obtaining food, large numbers of weakened birds are beaten to death by the breakers.

The boat excursionist, seeing a small black and white ducklike bird swimming in front of the steamer and adroitly diving under the bows, calls any auk a "Diver," but the bird may be a Razorbill, one of the Guillemots, or a Puffin. In the shape of its bill the Razorbill is intermediate between the two; it is deep and laterally compressed, far more so than the long pointed bill of the Guillemot, but shallower and less smartly decorated than that of the Puffin. It is black and transversely grooved, the deepest groove being sharply lined with white. The swimming Razorbill looks black on the back and wings, the Guillemot brown; it floats buoyantly, tossed like a cork, its head rests easily on its stout neck, its short, pointed tail is slightly elevated. It can paddle quickly, and does so as the cutwater approaches, glancing back over its shoulder to judge the right moment to duck; when the curl from the bows threatens to swamp it, the bird neatly dives, leaving a trail of bubbles from its now open wings, for it flies under water. When swimming under water the bird inclines downward to react against the uplift of its air-filled body, and 
the wings propel it rapidly forward, the feet being only used as rudders when turning. Small fish, its chief food, are captured and swallowed under water, but when hunting for its young are brought to the surface, and it is then that it has to dodge the unwelcome attention of thieving gulls. For so short winged a bird its flight is rapid, but it splashes a little when rising from the water; when once fairly on the wing it flies straight with whirring pinions, usually near the surface, but can rise high by a gradual ascent. No combination of letters expresses its curious and often querulous growling note; the young, when following the old birds on the water, have a plaintive whistling mew.

Early in March or even in February the birds return to the neighbourhood of the nesting colony, but remain on the water for some time before they visit the ledges. In April and May they line the face of the cliffs, resting on the whole of the foot-the tarsus and toes-but seldom walking, for they are poor pedestrians. The eggs are laid during May, usually late in the month, and both birds share in incubation. Before and during incubation the pair exchange compliments, rubbing and playing with one another's bill, or gently nibbling at the dense plumage; squabbles in which there is much bill biting and growling are frequent between neighbours and perhaps paired birds, but on the whole the life on the ledges is peaceful. Razorbills and Guillemots incubate in close proximity, but the latter places the egg on a more open ledge, sitting upon it in an upright position, whereas the former selects a crack or overhung ledge, and incubates with the egg lengthwise beneath the recumbent body. The cranny or sheltered ledge is usually on a steep cliff face, but holes amongst broken rocks near the top of the cliff are sometimes occupied.

There is no attempt at a nest, the single large egg resting on the rock. It is more conical, less pyriform than that of the Guillemot (Plate 117), and though showing a wide range of 
variation, conforms a little more to regular types; a single figure can give no idea of the wonderful variation of the eggs of either species. The spots, streaks, lines, and blotches differ in size and quantity, the ground may be white, cream, blue, green, or brown. Apart from the shape and, on the average, smaller size, the eggs may be distinguished from those of the Guillemot by a simple test, which holds good in all but the blue and green eggs of the latter; if held to the light the inner shade, as seen through the hole through which the contents were extracted, is greenish in the Razorbill, cream or yellowish in the Guillemot. The nestling (Plate Ir8) has a short and shallow bill, a whitish head and under parts, and a velvety-brown back, but the first plumage closely resembles the summer dress of the old bird. The young is fed by the parent on fish, frequently sand-eels, and these are often brought several at once, held crosswise in the bill; Mr. F. W. Frohawk saw twelve brought by one bird. How the bird captures and packs fish after fish in its bill is a mystery. After two or three weeks on the ledge the young goes to sea, and does not return to land until the following spring. The ledges are often a hundred feet or more above the sea, yet young still unable to fly may be seen with their parents on the water. It has been asserted that the juveniles slither down the rocks or are jostled from their insecure homes by the old birds; fishermen and others declare that they are carried down in the bill or on the back of the old bird. Certainly in many places death would inevitably result if the young bird fell or was thrown over, and eye-witnesses believe that they have seen them carried ; further evidence is, however, desirable. The parents continue to feed them on the water, but the young soon learn to hunt for themselves.

The upper parts of the adult in summer are black glossed with green, the chin and throat are dark, rich brown, the under parts, a wing bar, and a line from the top of the bill to the eye are white. In winter the sides of the face, chin, and throat 
are white, and the line from bill to eye obscure. On the bill in summer there is a raised rim at the base of the upper mandible, but this and apparently part of the outer cuticle of the lower mandible is lost in winter. The bill of the young bird in autumn, when it has a plumage like the adult in winter, is short, shallow, and at first ungrooved. The legs of the young are dark brown, of the old bird practically black; the irides are brown, paler in the young. Length, 17 ins. Wing, $8 \cdot 5$ ins. Tarsus, $1 \cdot 25$ ins.

\section{Great Auk. Alca impennis Linn.}

From time to time popular interest is aroused in the Great Auk; an egg changes hands and brings a high price in a London sale-room, and a more or less incorrect account of the Garefowl appears in the Press. It is the money value of the egg-for oologists will give anything for a "British" egg-and not the bird that creates interest ; indeed, eggs are of more value than skins! The passing of the Great Auk occurred some eighty years ago; probably the last was killed in Iceland in I844. Mr. H. Evans has evidence that one was captured in St.Kilda four years earlier, and, as a storm followed, was done to death as a witch. A bird preserved in Dublin was caught at Waterford in 1834 , and one in the British Museum in Orkney in I8I3. Altogether some eighty skins and sixty-three eggs are supposed to exist. It has been proved that it bred in Iceland, the Færoes, Orkneys, Outer Hebrides, especially St. Kilda, Greenland, Funk Island, and other stations off the Newfoundland and Labrador coasts. As it did not range far north, it is unlikely that any unknown breeding place exists; it has gone for ever. It perished like other unadaptable species because it failed to compete with predacious man, who wiped it out at its breeding stations, killing it for food. In form it was a large Razorbill, about 32 ins. long, with wings absurdly out of proportion, no more 
than 5 ins. in total length ( $4 \frac{1}{4}$ from the carpal joint), serviceable enough in the water, but of no use for flight. The eggs, about 5 by 3 ins., are similar to large eggs of the Razorbill, and vary considerably. Descriptions of plumage and of the known history of this extinct bird can be found in the extensive literature of the Great Auk.

\section{Guillemot. Uria troille (Linn.).}

The Common Guillemot (Plate I I9) is a bird of the northern Atlantic and Pacific, breeding in the former from Greenland and northern Norway to Newfoundland and Portugal. It is an abundant and very gregarious breeder on all suitable steep cliffs or lofty stacks round our shores, and in winter is pelagic, keeping well off shore except when storm driven.

On the water the Guillemot, beside being a browner bird, lacks the compact, plump, and neat appearance of the Razorbill ; it is a longer necked, more slender bird, with a long pointed bill. It swims well, and may be seen sporting on the surface, splashing and rolling, sometimes with the white under parts upward. It dives swiftly, catching and swallowing fish below the surface, and uses the wings under water, only employing the feet to assist when turning rapidly. Its flight is swift and straight, and when moving to and from distant feeding grounds parties frequently form strings or lines, skimming near the surface. In February or March birds collect near the breeding cliffs, and long before the eggs are laid, in May, constantly visit the ledges, quarrel for sites or posture with bobbing heads and swinging necks in nuptial preparation. In late summer the young are induced to take to the water, but the method by which they are brought from cliff to sea is as uncertain as with the last species; throughout early autumn old and young remain near the ciiffs, though I have met with birds 200 miles from land early in July. In winter, though some remain off 
shore, many appear to journey south, but a spell of rough weather brings some, mostly immature, hungry and wave battered, and casts them dying on the beach. I have caught birds in shallow shore pools, apparently too feeble to fly, which showed no sign of injury. The note of the bird is a chattering growl, at times deep and angry in tone, at times shrill and querulous; from it the name "Murre" is derived, though this conveys little to most ears.

On most coasts the Guillemot is more abundant than the Razorbill, and in favoured haunts, such as the chalk cliffs of Bempton and Flamborough, the rugged headlands of Wales, and the stacks and crags of Scotland, its numbers are beyond all calculation. Long rows of white-breasted birds sit upright on the ledges at dizzy heights, those sitting eggs usually with their front to the cliff, but the others, well upright, rest on the tarsus, the toes bent over the lip of the ledge, and swing their snaky necks from side to side. On the Farnes the flat tops of the Pinnacles are crowded with birds (Plate $12 \mathrm{I}$ ), but the brown mass is constantly in motion, disturbed by the arrival of newcomers who fight for foothold, whilst a stream drops off to fish. When leaving the ledge neither Guillemot nor Razorbill habitually dives seaward as frequently depicted and described, but flies off maintaining a more or less horizontal position. The head and tail are depressed, the arched back is held highest by the whirring wings; the bird floats outward and downward, gliding ob?iquely forward. No nest is made; the single large pyriform egg lies on bare rock, often on a ledge which slopes dangerously seaward. The idea that its shape allows it to twist round in the wind is exploded, as is the egg when a careless sitter sends it hurtling to the rocks beneath; the frequent struggles for the rights of a ledge lead to many catastrophes; I have seen the rocks at the foot of the cliff yellow with yolks.

Only one type of egg can be shown (Plate 117), but the variation is endless; the ground may be white, cream, yellow, 


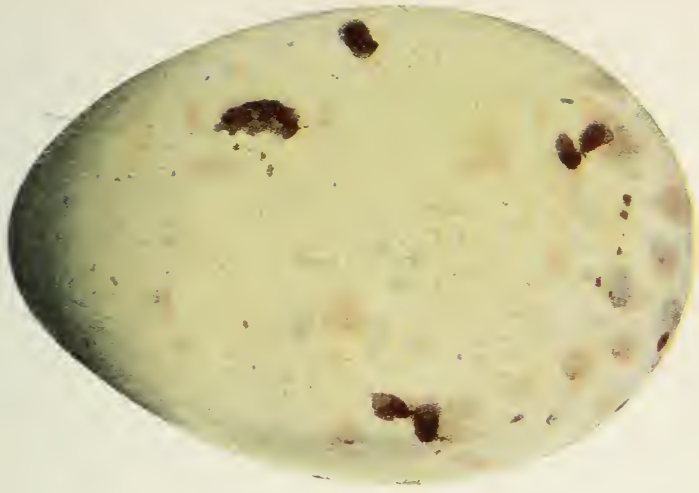

Great Skua.

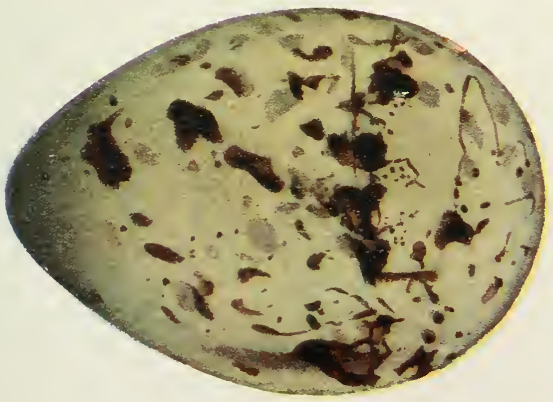

Richardson's Skua. 


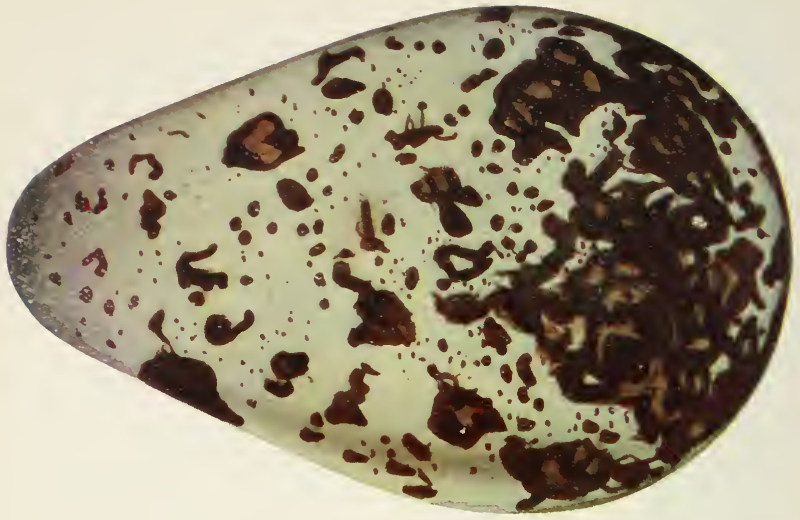

Guillemct.

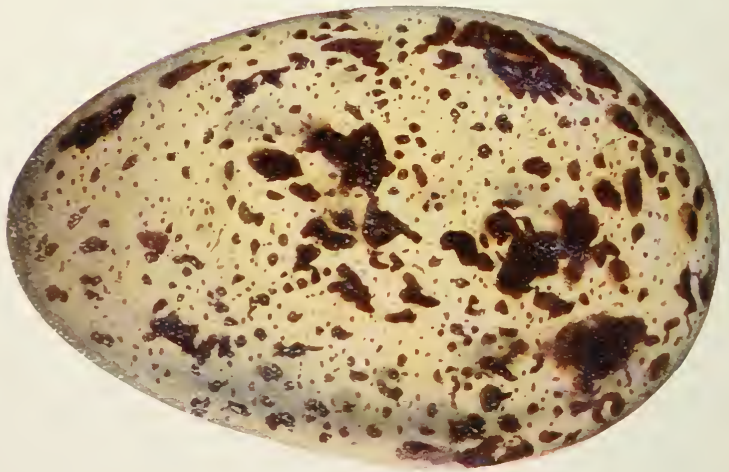

Razorbill. 
blue, green, purple, red, or brown, the spots, streaks, lines, smears, or blotches of any colour, light or dark. Some eggs are blue or green without a spot, others are blotched or zoned with solid black or brown; one type is covered with a maze of dark lines, and some have unspotted bands, though elsewhere densely coloured. The sitting bird is usually upright, though lack of head room may force it to lie prone; the egg is tucked lengthwise beneath the body and as much as possible of its surface brooded. When the downy young, dark brown above, greyish beneath, and with hoary heads, are hatched, the activity of the colony reaches its height; far as the eye can reach the water is spotted with birds busily fishing and others trail off to known distant feeding grounds, or speed to join with gulls and porpoises in decimating a passing shoal of fry. The air is full of ascending and descending birds, and when a fish, for usually but one is brought at once, is carried up for the young, the captor alights on the slippery ledge with a flutter of wings as it strives to secure a balance. It is then that a bad-tempered neighbour will snatch its prize, or with a dig topple it backward and force it to make another attempt to land. Growling unamiable remarks greet these newcomers, and often with bills interlocked two will struggle for foothold. The call of the young is said to have given origin to the name "Willock," a name also applied to Razorbill and Puffin. When in September the half-grown young eagerly follow their diving parents, swimming with head low and short bill pointed forward, they pipe a shrill pee-oo, pee-oo. "Scout" is another common name, and in Yorkshire the Bridled Guillemot, a sporadic variety with a white eye-rim and line towards the nape, is known as the "Ring-eyed Scoot."

The adult bird in summer is slaty brown on the upper parts, and more rufous brown on the cheeks, chin, and throat; the under parts and a narrow wing bar are white. In winter the plumage is browner, and the sides of the face, chin, and throat are white, a dark line passing through the eye to the cheeks. 
The first plumage of the juvenile resembles that of the adult in summer, but in autumn one more like the winter dress is attained, but the sides of the face and neck are mottled with brown. The bill is blackish horn, the legs and feet blackish brown, and the irides brown. Length, $18 \cdot 5$ ins. Wing, 7775 ins. Tarsus, 1.25 ins.

\section{Brünnich's Guillemot. Uria lomvia (Linn.).}

Brünnich's Guillemot is an Arctic bird, which nests as far south as Iceland, and occasionally wanders in winter to our shores. Four were obtained in the winter of 1894-95, three of these in Yorkshire and the other in Cambridge; others have been taken since and probably some before, but the evidence is not always conclusive; at any rate the majority have been met with on the east coast in England or Scotland. The bird has been reported in June at Bempton and the Farnes, but was only identified through glasses. It is a blacker bird than ours, and the bill stouter and deeper; the mature bird has a pale unfeathered line from the nostril to the gape; the legs are brownish. Length, 18 ins. Wing, $8 \cdot 5$ ins. Tarsus, $1 \cdot 3$ ins.

\section{Black Guillemot. Uria grylle (Linn.).}

In so many ways the Black Guillemot (Plate IIg) differs from other auks that it is placed by some systematists in a separate genus; it has a very distinct seasonal change of plumage, lays more than a single egg, and is much less gregarious. It is found, seldom in large numbers, throughout north-eastern America, Greenland, Iceland, and western Europe to the White Sea ; in the British Isles it is local in Scotland and the western islands, more plentiful in the Orkneys and Shetlands, scattered over the north and west of Ireland, and the Isle of Man. It formerly nested in one or two localities in North Wales and on 
the cliffs at Flamborough, but it is capricious, and has deserted without apparent reason some of its old Scottish haunts. In winter, though pelagic, it wanders south and is occasionally met with in bays and inlets on all parts of the coast, but is never common. In early spring an odd bird will remain on a rocky shore, its summer dress suggesting nuptial intentions, and it is always possible that some of its old stations may at times be occupied. Inland it is very rare, and its storm-beaten corpse is infrequent in the tide wrack.

Few birds are more easy to recognise than the Black Guillemot in summer dress, for the glossy brownish-black plumage is set off by the big white patch on the wing; as it flies, even at a distance, or when like a duck it rises in the water to flap its wings, the flicker of this patch and of the white under wing attracts the eye. Its legs are brilliant red, and when it calls, its bill, though really black, appears red, for the inside of the mouth is conspicuously orange-red. The white and black dress of winter is almost as noticeable. The plumage has a soft, blended look, the black and white bars on the upper parts merge without sharp dividing lines; the white patch on the dark wing remains unchanged. Age explains much of the variation in winter dress, for in many birds the head is almost white, merely flecked with black, but in others is well marked with dark streaks. The black dress is not invariably lost in winter, and Grant considered its retention a sign of old age. There is something in this soft, hoary plumage which suggests the doves, for one of the old names for the bird, especially amongst the whalers, was "Greenland Dove," shortened at times to "Dovekie," and in the Isle of Man the bird is still the "Sea-Pigeon."

Less sociable than other auks, the Black Guillemot straggles to its nesting haunts in February, but comes little to land until April. It swims lightly and dives with skill, but I have never been near enough to see under-water progression, when it is 
said to use the feet as well as the wings. In flight its wings beat quickly; it flies close to the water as a rule, straight and with considerable speed, but finds the same difficulty in rising as other auks, splashing with feet and wings. On rocks it is more agile than the Common Guillemot, often standing on the toes alone, walking well with the body upright. When resting it sinks on to the tarsus or lies prone, the position during incubation. The common Orkney and Shetland name is "Tystie," probably derived from the whistling love-callNaumann's ist, ist, ist, and not from the "dreary whining cry," as Mr. P. G. Ralfe well describes its normal call. Fish are eaten and brought, one at a time, to the young, but crabs and other crustaceans, hunted for at the bottom or amongst the tangle of submerged rocks, are perhaps its chief food.

The two eggs (Plate 94) are placed in a crack or fissure seldom at any great height on a cliff face, or are beneath loose stones in the fallen masses at the foot of a crag and sometimes in a cave. No nest is made. The colour is white or slightly tinted with green or cream, blotched and spotted towards the larger end with brown and lavender; they are laid late in May or in June. The nestling has sooty-brown down, and the young bird a mottled dress of grey, black, and brown, darker than that of the barred winter plumage of the adult bird. The white wing patch is splashed with brown, and in the second year brown marks still indicate immaturity. Between the mottled dress and the glossy black of summer or the hoary plumage of winter are a variety of complicated gradations. In the young bird the bill is dusky, and the inside of the mouth duller; the legs are at first brown. Apparently at all ages the irides are dark brown. Saunders gives the total length as 14 ins., but 12 is nearer the average. WVing, $6 \cdot 5$ ins. Tarsus, $1 \cdot 25$ ins. 


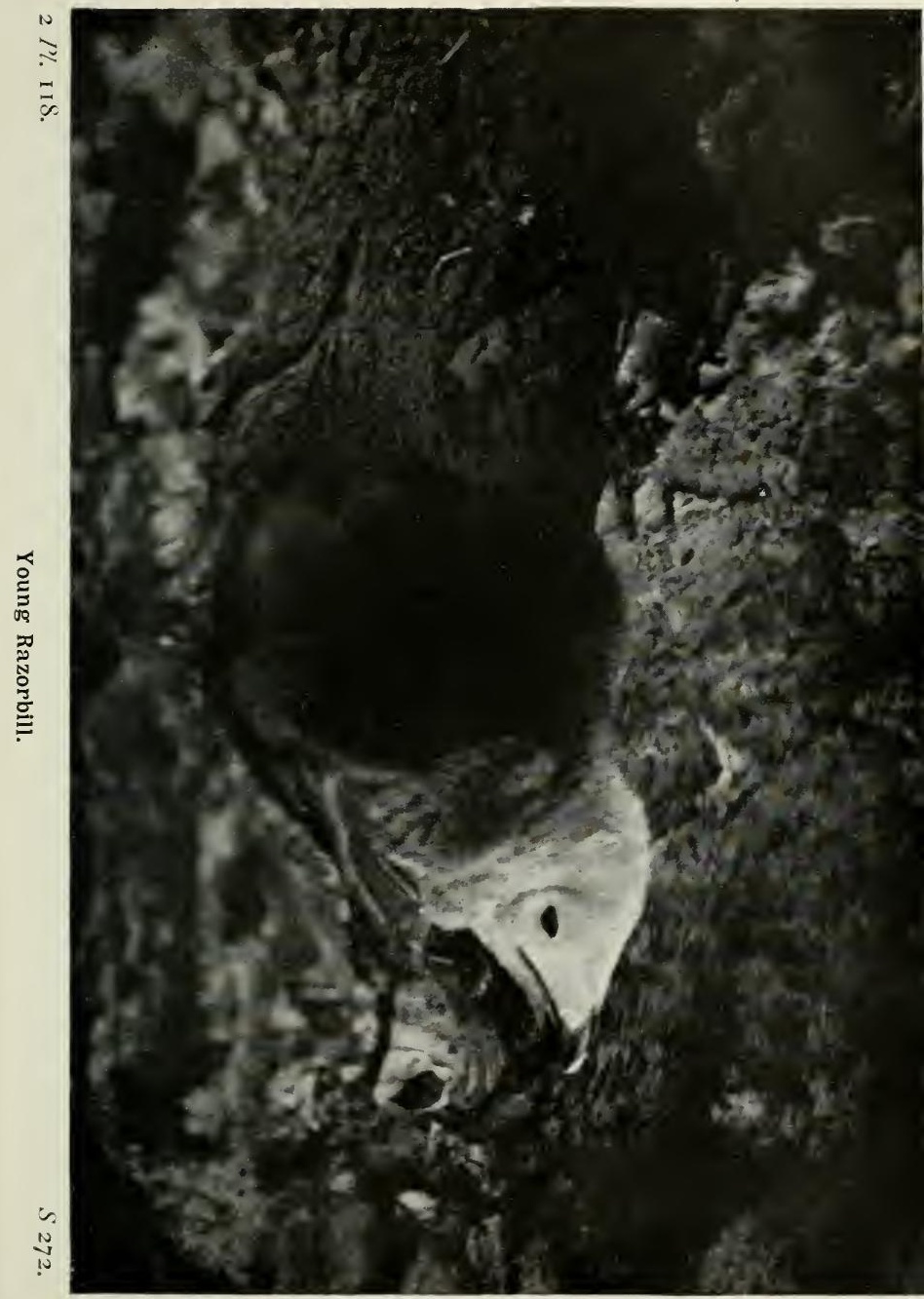



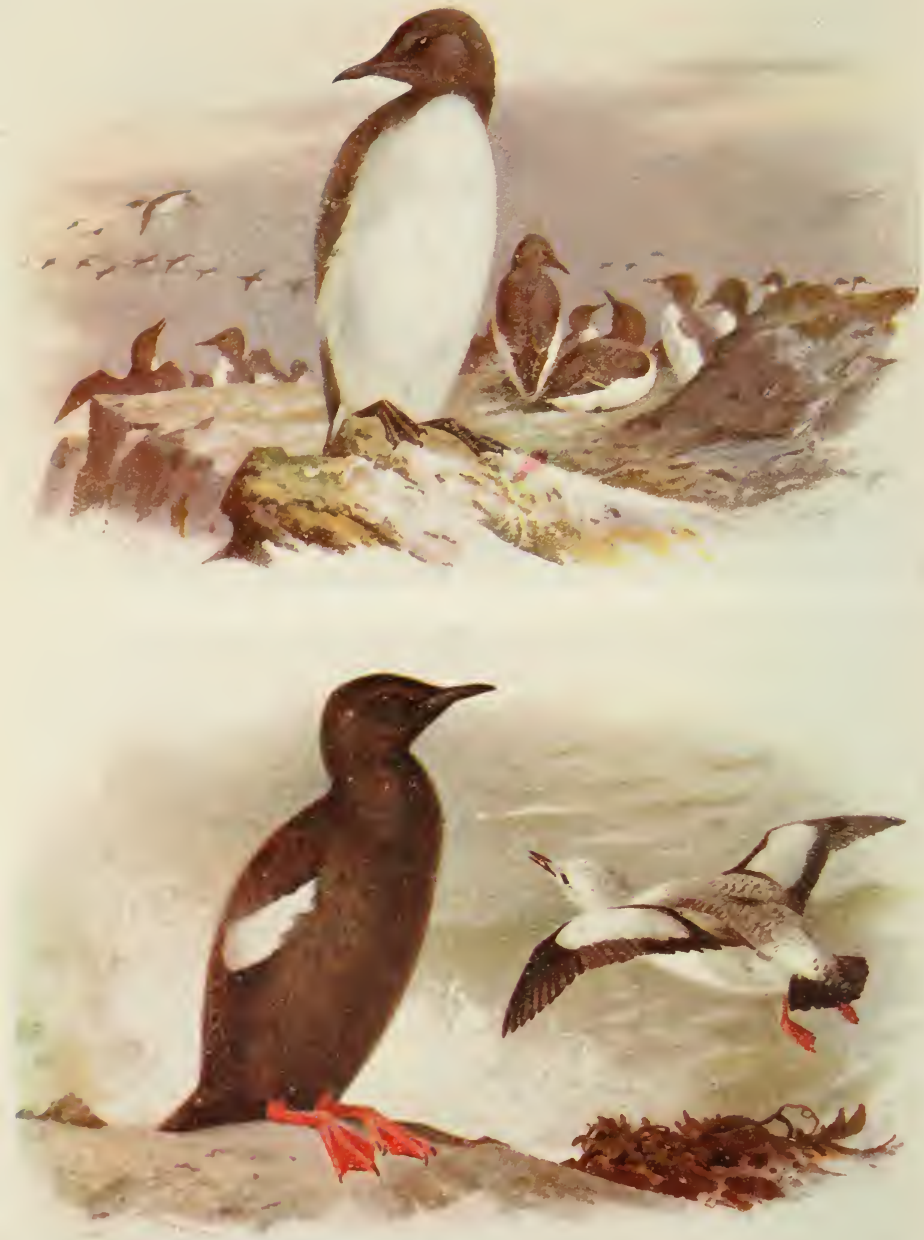

$21 \%$ I 19.

Common Guillemst. 17 th.

Black Guillemot. 1 sth. 


\section{Little Auk. Alle alle (Linn.).}

The summer home of the Little Auk (Plate 120) is on Arctic islands and in the seas around them, the nearest of these to Britain is off the coast of Iceland ; its winter pelagic wanderings take it at least so far south as the Canary Islands and Azores, and almost annually a few are met with on our coasts during the colder months. Exceptionally birds in summer dress have been recorded as late as June. From time to time blizzards or fierce gales hurl hundreds upon our shores or whisk them far inland, even, during a north-easterly gale, across England from the east to the west coast ; there are few counties which cannot record some of these unfortunates.

On the water the Rotche, another name of the bird, swims well but deeply, "by the stern," Mr. Abel Chapman calls it. It looks short-necked and stumpy, but neat and compact; its small size and short, conical bill prevent confusion with its congeners. It flies fast and straight, its wings whirring rapidly, and seems always in a hurry; if alarmed when swimming, it scutters along the surface and dives headlong into an advancing wave. I have only once seen it diving, in the tank at Regert's Park in $188 \hat{3}$, where for a short time one was kept alive on fish. It easily overhauled its prey, swimming with its short wings like a penguin, and steering as it turned with the spread webbed feet. Like other auks it swallowed its food under water. Crustaceans and not fish seem to be the chief food of the Little Auk; at the breeding stations, its pouch-like cheeks are often loaded with small planktonic CrustaceaEuphausia in particular. Mysids, shrimps, prawns, and small crabs are also captured, and the bird has been known to feed on offal thrown overboard from whalers and deep-sea trawlers. In its breeding colonies, where it congregates in immense numbers, the loud chorus of chattering cries has been commented upon, but the note heard off our shores is variously Series $I I$. 
described. Dr. Patten, following Seebohm, says that it utters "a sound like alle, alle, from which its specific name is taken."

During these invasions or, more correctly, "wrecks " of Little Auks, the bird comes prominently before the public; the year I 895 witnessed a noteworthy wreck, but a more recent one was in the winter of I9II-I2. During the early months of I9I2, I handled several of the birds, and heard of many in the west in addition to the hundreds recorded on the east coast. The local papers everywhere were full of references to the strange bird which some one had found dead in the road, or whose inevitable end had been hastened with stick and stone by village lads. The Little Auk comes, to us to die. A few find temporary refuge on inland pools, or, if more fortunate, reach quieter seas and may survive, but most if wind driven far beyond the fatal lee shore finally drop exhausted-one even entered a surgery in Finsbury Park; if found by kindly folk they are ineffectually tempted with unsuitable viands until nature claims its own. Dr. P. R. Lowe has hit upon the probable explanation of the wreckage. Lowered temperature, disturbed surface water, or other change may drive down beyond reach the planktonic food. Weakened by lack of food, the bird, normally hardy enough, is unable to cope with a gale and is driven to its death.

In summer the upper parts are glossy black, the lower part of the face, chin, neck, and throat more sooty; a small semicircular spot above the eye, the tips of the scapulars, a wing band, and the under parts are white. In winter the chin and throat are white, and there is a more or less marked white collar. Immature birds resemble the adult in winter, but lack the eye-spot. In spring and autumn, during plumage change, the chin and throat are mottled. The bill is black, the legs are greenish grey, and the irides dark brown. Length, 8 ins. Wing, 5 ins. Tarsus, $0^{*} 9$ in. 


\section{Puffin. Fratercula arctica (Linn.).}

No bird is more distinctive than the Puffin (Plate I20), and it is an abundant species, yet few accounts of its appearance and life history agree. It inhabits the Arctic seas and North Atlantic, breeding as far south as Portugal, but though a few birds remain off our shores all winter, there is a general southward migration. Colonies are scattered on suitable cliffs or islands round the British Isles, but there are only a few on the east and south coasts of England; some in Scotland, Wales, and Ireland contain many thousand birds.

It is not the black and white plumage, the large particoloured bill, the upright carriage, nor the orange legs that give the Puffin its quaint appearance, but its eye; no bird has caused more unjustifiable hilarity than this "big-nosed" dumpy auk. Mr. F. Heatherley calls the eye Chinese, but it is not oblique; it is set deeply above the round, full cheek, and from it a conspicuous groove curves backward. Around the eye is a crimson ring, above it a triangular steel-blue plate, and below a small bar of the same colour. As we look at the serious birds, for they do look very serious, standing in solemn rows at the edge of the cliff or scattered over the thrift-grown turf (Plate 122), we unconsciously smile, but do not realise that it is the fixed expression caused by the eye that entertains us. The Puffin is no clown, but a business-like, beautiful little auk; it is our conceited ignorance of serviceable avian proportions which misleads us. From its deep but shapely bill the bird receives semi-humorous names - "Pope," "Sea-Parrott," "Bottlenose," "Tommy Noddie," or the more descriptive "Coulterneb"; there is something suggestive of the coulter of a plough in its shape, but nothing to justify bottle-shape, parrot bill, or papal. It can catch and hold a slippery fish and nip severely.

In March the far-scattered Puffins turn towards our islands, 
but the return, though regular, is not annually on a given date, as lighthouse-keepers, and even Prof. Newton, would have us believe. A few arrive in March, but the majority come later, and departure, which begins in August, often drags on until the midrlle of September. Holes or burrows, not exposed ledges, are the nesting sites, consequently the biggest colonies are on turf-covered islands, or the grassy slopes of cliffs. At the colony the birds swarm, many loitering aimlessly, others excavating, or attending to various domestic duties. The Puffin stands on the toes-popularly called the foot-and does not rest upright on the whole length of the tarsus like a Guillemct, in the attitude often pictured and even recently described; I have never seen the bird sink on to the tarsus except as a preliminary to its position of ease, when the breast rests upon the ground. When walking it has a nautical roll, due to its short legs and the position of the feet, but it walks without labour and can run quickly. A bird may often be seen chasing another with head held low, and if the pursued is overtaken the big bills will be interlocked, and with much growling each appears to be striving to wring its rival's neck. On the sea near the colony the birds swim in hundreds; the brightly coloured bill alone serves to distinguish them from their companions, Guillemots and Razorbills.

The Puffin dives without effort, and under water swims with wings alone. The flight differs from that of other auks. When turned out of its burrows the bird runs down the slope towards the sea, often tumbling in its haste, and with open and quivering wings slowly rises like a starting aeroplane. Mr. O. V. Aplin points out that when the bird rises clear the feet are gathered beneath it with "unctuous palms" meeting, but as it descends towards the water are extended on either side of the tail. In the oblique descent they function as rudders and balancers, but are again drawn together when it skims out, perhaps for half a mile, low over the water. The pose of the body during the aerial dive 

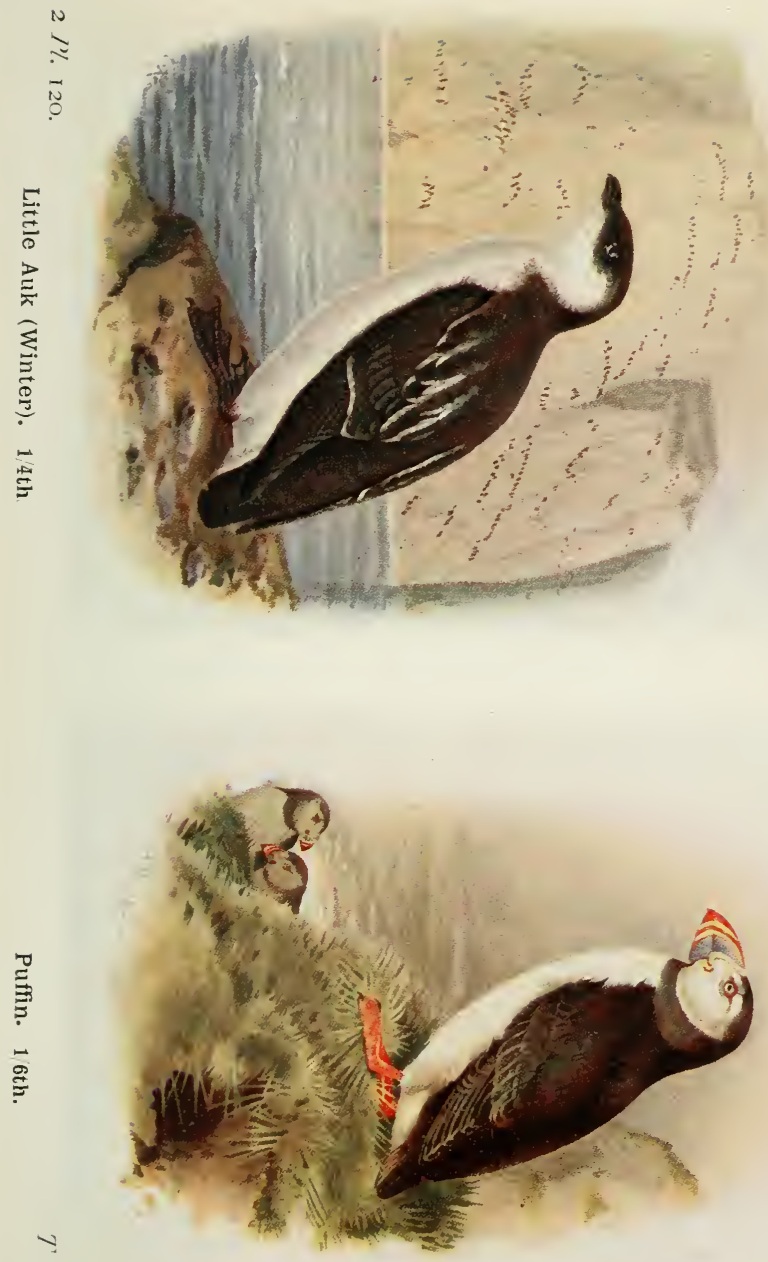

Nㅗㅇ 


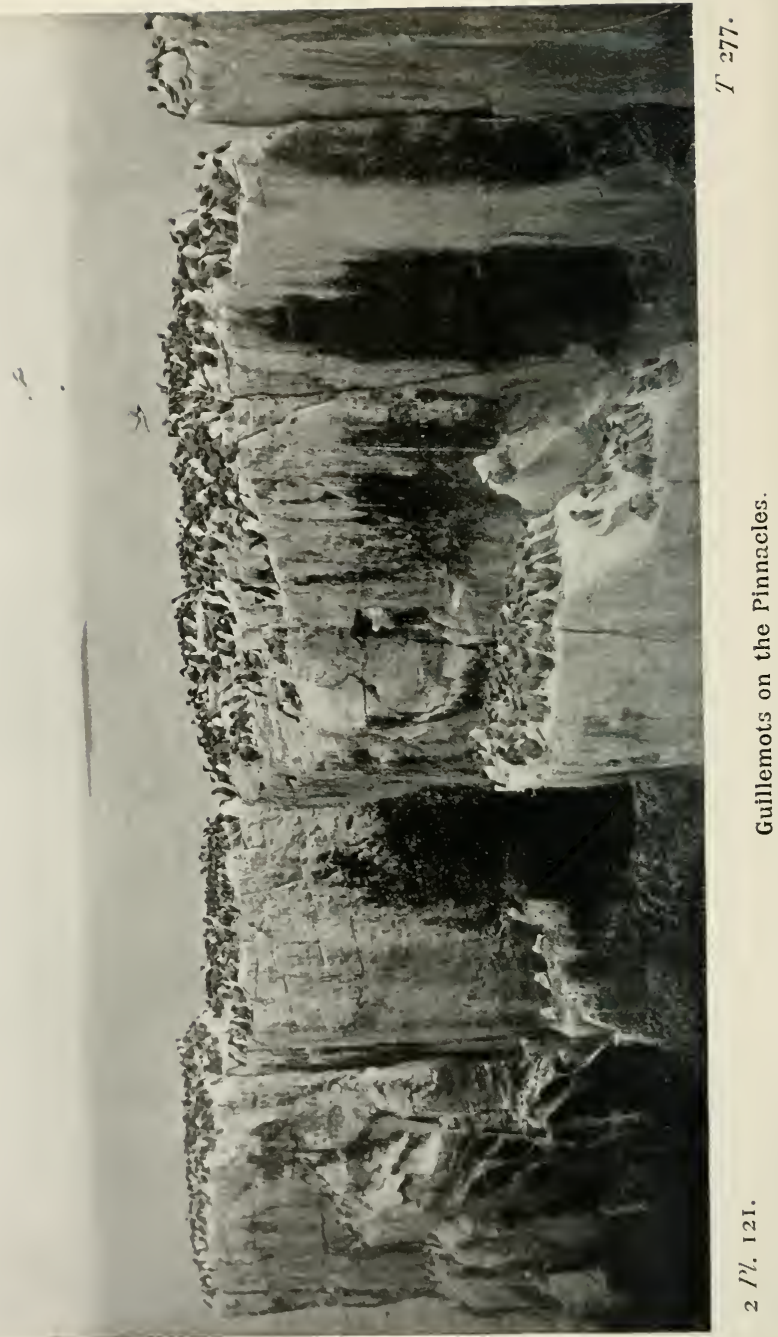


is more diagonal than that of the descending Guillemot, and the wings vibrate rather than beat; the bird looks like some thickbodied dragon-fly. This curious vibrating flight is noticeable at other times, especially when clouds of birds wheel in accord; indeed, the Puffin is an active and agile bird on the wing, turn. ing smartly with a steep heel over. The deep guttural arr is heard in the colony and on the water; it is a discontented and complaining sound, and has an angrier ring when the bird is rudely evicted from its burrow. The note varies or the bird has distinct calls, but all are deep, and at times, as Mr. Aplin aptly describes it, is "like one of the nocturnal calls of the cat." Naumann says that the bird does not retaliate if handled so long as it is in its hole, but though it will strive to shrink away from an intruding hand, the first evidence of occupation is often a savage and painful nip.

It is true that a rabbit burrow is occupied if one is handy, but most of the tunnels are excavated by the birds themselves; in a large colony the springy cushions of thrift and the turf are undermined by a labyrinth of burrows; the foot sinks into the superficial tunnels. The Puffin digs vigorously, scratching the soil backwards with its feet. A heavy, peculiar smell hangs over this densely crowded colony; the bird is not particular about sanitation. Many holes have more than one exit, and the position of the nest, when nest is made, may be a few inches from the entrance or many feet beyond reach. Holes under rocks or amongst loose stones are occupied; indeed, all the Puffin demands is a hole. The egg may be laid on the bare soil or an untidy nest of wet grass, seaweed, thrift, and feathers be collected in a rounded chamber. The single egg (Plate 108), laid in the latter half of May, is dull white, rough in texture, and usually faintly zoned with grey or reddish spots; it becomes much soiled from the wet feet of the incubating birds. The nestling has long sooty down, with a whitish patch en the under palts; its short bill and legs are slate-grey. It 
grows rapidly, and a little later has greyer down (Plate 125), and its legs show a pinkish tinge; it is active, runs well, and quickly bolts into its burrow if placed near the entrance. It has a piping note when handled, or when the old bird arrives with its beak full of fishes, neatly arranged in a row.

The adult Puffin has the upper parts and a collar greyish black, darkest on the back; the under parts are white. The cheeks and throat are delicately shaded with art grey. At the base of the upper mandible is a pale-yellow raised rim, on the lower a narrower vermilion line ; the basal portion of the beak is blue-grey, the outer portion orange and vermilion, more or less in transverse streaks; at the angle of the gape is a rosette of orange skin. The legs are orange, the irides pale brown. Some birds have vermilion, others lemon-yellow legs; indeed, the colours of beak and legs show considerable variation. In winter the raised rim, most of the outer covering of the bill, the rosette at the gape, and the decorations above and below the eye are shed; the bill becomes smaller and less brilliant. It is frequently stated that the cheeks are greyer in winter, but this may be due to age, for the young bird not only has the cheeks darker, but in front of the eye is a blackish patch; the bill in the young is at first short and more conical. Length, I 3 ins. Wing, 7 ins. Tarsus, $I$ in.

\section{Order PROCELLARIIFORMES. Petrels and Shearwaters.}

\section{Family THALASSIDROMIDÆ.}

Small, long-winged, web-footed birds; bill short, hooked, nostrils in one double tuibe. 


\section{Storm-Petrel. Thalassidroma pelagica (Linn.).}

The sailor is well acquainted with the Storm-Petrel (Plate I23); he calls it "Mother Carey's Chicken," and by no means always looks upon it with superstitious dread, for the bird follows in the steamer's wake in any weather. During the greater part of the year the ocean is the Petrel's home ; it is a bird of the eastern Atlantic, but how far it normally ranges south is uncertain, for though it is said to have rounded the Cape, there may have been confusion with other petrels. Its British breeding colonies are on islands off the Scottish and Irish coast, and on some in South Wales and the Scillies. There is a general southward movement in autumn, but the bird is scattered far and wide in winter, and only continuous bad weather brings it to land. Strong gales not only drive it ashore, sometimes in such numbers as to be classed as "wrecks," but often carry it far inland, dropping it, storm battered, in towns or other unlikely spots for an oceanic bird, where starvation hastens the end.

The Storm-Petrel is a small sooty bird with a white patch above and below the base of the tail; the tail is square, not forked as in its nearest allies. Its wings are long and narrow ; its flight buoyant, swift, and erratic ; as it follows a steamer, a frequent habit, it looks like a long-winged House-Martin; the white back patch helping the resemblance. It swerves and twists, and occasionally lowers its long legs and patters on the surface-from this the sailors coined the name--Little Peter striving to walk on the waves. During this pattering, halfrunning flight it dips its head for food, sometimes erroneously described as "insects," sometimes as the oily offal thrown overboard, whatever this may mean. It will eat oily matter, skimming it from the surface; Mr. T. H. Nelson kept a bird for a few days, and fed it on oil floating on water in a saucer; the bird flew over it like a Swallow and skimmed off the oil. The 
chief oceanic food, however, consists of small crustaceans and cephalopods, and for these, churned up by the screw, it follows a steamer, and not, like a gull, hoping for scraps. Small fish are eaten, and during the nesting season a considerable amount of sorrel, but there is no evidence that insects are taken, though the bird's actions suggest fly-catching. In a rough sea it swims easily, rising on the advancing wave and apparently glissading to the trough. Its wing-beats are not hurried, it skims and glides, beating deliberately, more like a tern than an auk.

In most books the petrels generally are figured standing on their webbed toes, and specimens are usually mounted in this position, yet it is doubtful if the Storm-Petrel and others of its relatives can stand. A captive bird in the possession of Dr. C. B. Ticehurst never stood, but rested on the tarsus or whole length of the foot, and even walked or shuffled in this position. When rising on the wing it raised itself to the toes with forward steps and uplifted wings. Audubon says of Leach's Petrel that it "walks as if about to fall down, but with considerable ease, and at times with rapidity," probably referring to this forward shuffle. Detailed observations of the habits of the StormPetrel on land are difficult to obtain, for during the breeding season the bird is largely nocturnal; storm-driven victims are usually so weak as to be unreliable.

The bird comes ashore in April or May, and the single egg is laid as a rule late in June, in a burrow in turf, a hole in rock, or beneath a litter of stones. The nest, when any is made, is a small collection of wet grass. The chalky-white egg is usually zoned with fine reddish specks (Plate 153). In large colonies the turf is honeycombed with burrows, some superficial. On the water the Petrel is a silent bird, but at night at the nesting colony it is noisy in flight ; Mrs. Gordon says its note is "very husky, and sometimes ends in a sort of shriek," a repeated cuch-ah. Mr. N. H. Joy heard no sound from flying birds, but a purring noise, like the churr of a distant Nightjar, came after 
dusk from incubating birds in the holes. This churr often ended in a sharp wit. Nearly two hours after sunset the birds emerged and flitted round in the dusk. Dr. Eagle Clarke found one colony deserted in the daytime, for the young were hatched, and concluded that the birds go off for food during the day and feed the young at night; the food is regurgitated oily matter, probably half-digested squids. An oily smell pervades the colony, and the bird itself reeks of oil ; if handled its first act of retaliation is a jet of oil, squirted from beak or nostrils. The down of the sooty brown nestling is long and on the under parts hoary, its bill and legs are at first white, but soon darken. There is little difference between young and adult birds, though the slight white wing bar is perhaps more noticeable in the former. The bill and legs are black, the irides blackish brown. Length, 6.5 ins. Wing, 4.7 ins. 'Tarsus, $0^{\circ} 9$ in.

\section{Leach's Petrel. Oceanodroma leucorrhoa (Vieill.).}

The North Atlantic breeding range of Leach's Petrel (Plate I23) is more to the north and west than that of the StormPetrel, and it also occurs in the north Pacific; the only known European stations are in the British Isles-on St. Kilda, the Flannans, North Rona, and a few islands off the west coast of Ireland. Yet the bird, on the whole, is more frequently seen off our shores, for a number pass south in autumn over our seas; westerly gales often drive them inshore, and not infrequently whirl them helplessly far inland. As a derelict it is not uncommon, even at a distance from the coast.

The full name is Leach's Fork-tailed Petrel, for it is the decidedly forked tail which distinguishes it from the Storm, though not from all its congeners. It is larger, but in the main its sooty dress and white back patch agree with those of the last species; the median wing-coverts are pale brown, and show on the flying bird, as Mr. R. W. Jones points out, as 
two brown patches converging above the white rump. The manner of flight, the habit of following steamers, of picking food from the water, holding its long wings elevated above its back as it almost alights, paddling with its feet, and the nature of its oily planktonic food agree with those described for the Storm-Petrel. I followed one storm-driven bird along the shore, and never once saw it stand. When it stopped for a moment, it sank upon the breast, its tarsi doubled beneath it, but it persistently strove to rise against the fierce west wind. Raising its wings, but beating them but little, it ran into the teeth of the wind until it was lifted, but immediately this happened the gusts heeled it over and whirled it a few inches above the sand towards the dunes; in a few yards it came to the ground and was helplessly rolled over.

The nesting holes, the habits during the breeding season, and the nocturnal note, appear to be as in the other species, but actual information is scanty. The single egg is very like that of the Storm, though slightly larger; eggs are often laid at the end of May, a little earlier than those of the other bird. The mestling has long sooty-black down, darker than that of the Storm. There is no marked difference between mature and immature dress. Length, $8 \cdot 5$ ins. Wing, 6 ins. Tarsus, $0^{\circ} 9$ in.

\section{Madeiran Petrel. Oceanodroma castro (Harcourt).}

Harcoutt's Petrel, as it is often called, nests in the Azores, Madeira, and other islands off the west African coast, and also in the Hawaiian and Galapagos groups in the Pacific. In winter it has strayed to western Europe and has three times been met with on the south coast of England, twice in Kent and once in Hampshire. Except that its tail is less forked, and that some of the white upper tail-coverts have black tips, this bird differs little from Leach's Petrel. Its bill and legs are black, its irides dark brown. Length, 8 ins. Wing, 6.1 ins. Tarsus, 0.82 in. 


\section{Wilson's Petrel. Oceanites oceanicus (Kuhl).}

Wilson's Petrel inhabits the Antarctic and migrates north at the approach of the southern winter ; thus, when it reaches our islands, which it does on rare occasions, its visits are in summer. Most of the occurrences have been on the south coast, but it has reached the Hebrides once and Ireland twice, as well as Cum. berland and Yorkshire. Gould saw some numbers off Land's End in May, 1838 , and apparently some remained all summer, as a bird was obtained in Cornwall in November of that year. So far as is known its habits and flight are similar to those of nıost petrels. Dr. E. A. Wilson saw it, flitting "apparently never tired " over the Antarctic ice like a House-Martin hawking for flies. Its plumage is black, with the white lower back of other petrels, but its legs are long, and the black toes have yellow webs. The tail is variable, sometimes square, sometimes slightly forked. Length, 7 ins. Wing, 6 ins. Tarsus, 14 ins.

\section{Frigate-Petrel. Pelagodroma marini (Latham).}

The Frigate-Petrel is a bird of the South Pacific and Atlantic, with colonies as far north as the Salvage and Cape Verde Islands. It has twice been known to wander to Britain, the first washed ashore after a gale at Walney Island in November, I890, where it was picked up together with an example of Wilson's Petrel and other oceanic birds. The second was captured in the Hebrides in January, 1897 . This bird is lighter in colour than the petrels previously mentioned; its forehead, a conspicuous eye-stripe, and under parts are white ; its head, cheeks, neck, and back are dark slate, and its lower back paler slate. Its wings are brown, its bill and long legs black, and its webs yellow. Length, 775 ins. Wing, 6.25 ins. Tarsus, $\mathrm{I} \cdot 6$ ins. 


\section{Family PUFFINID £. Shearwaters.}

Long-winged petrels; bill with united tubular nostrils.

\section{Manx Shearwater. Puffnus puffinus (Brünn.).}

The range of the Manx Shearwater (Plate 124), so far as is known with certainty, is restricted. It nests in Iceland and the Færoes, and is thought to breed in Madeira. In the Scilly Isles it is abundant, and also in several islands off the coasts of Wales, Scotland, and Ireland, including the Orkneys and Shetlands. Mr. C. Oldham and I discovered a small colony on the mainland in North Wales, and there are a few similar colonies on Irish headlands. In the Mediterranean the closely allied Levantine Shearwater, $P$. p. yelkouan (Acerbi), occurs, and numbers wander into the Atlantic in autumn; it is by no means uncommon off our south and east coasts between August and February. British birds, and probably passage migrants from further north, are common off our shores in autumn, and large numbers are picked up inland. Southward migration is a wellmarked movement.

The Manx Shearwater, no longer an inhabitant of the island from which it gets its name, is nevertheless a common bird in the Irish Sea; indeed, it is well distributed and often common in most of our coastal waters in summer, even at a distance from any known breeding ground. Its black upper and white under parts are a little like those of an auk, but its long, slender bill, with a strong hooked tip, and its narrow pointed wings are those of a petrel. Even on the water it looks more slender, has finer lines that the stout Guillemot or Puffin, and on the wing it is a very different bird as it skims or shears the waves. It glides upward, cants over at right angles, swoops with one wing just missing a crest, then skims the surface, rising and falling with the waves, then up again, now right wing up, now left. 


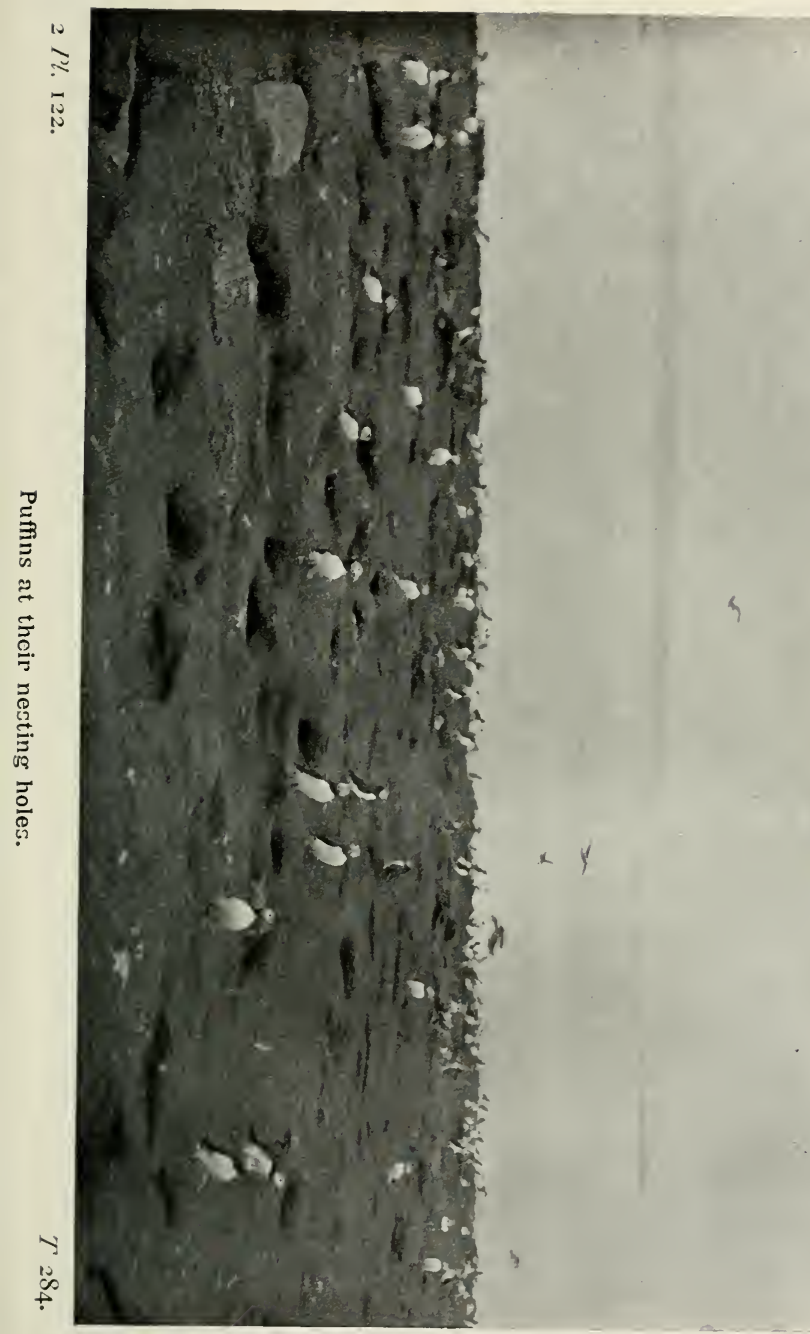



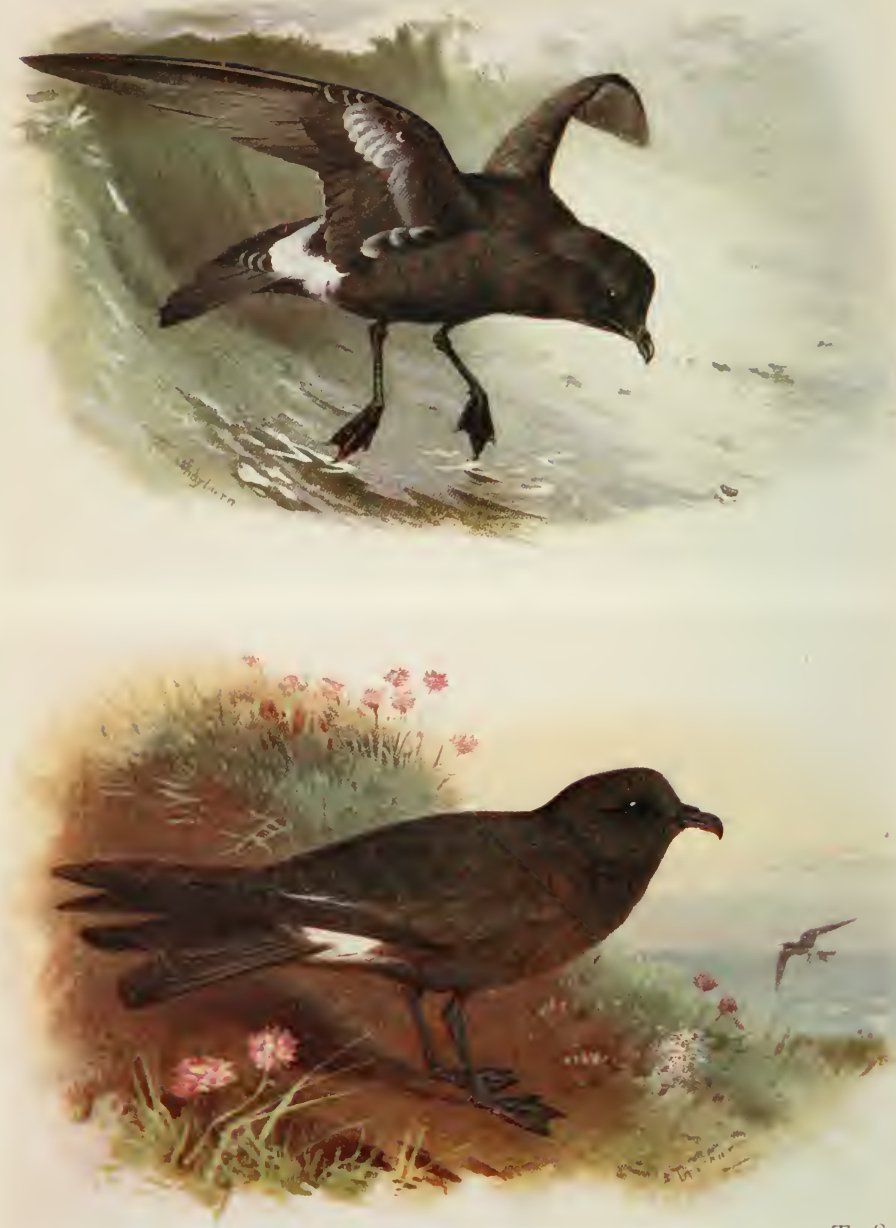

$21 \% 123$.

Storm-Petrel.

Leach's Petrel. 
There is little wing-beat, but an easy loitering glide; it does not hurry. Often, however, strings of Manx Shearwaters pass, bent on business; these birds fly straighter and with greater speed, but their longer wings are never rapidly moved like those of auks; the birds swing along and glide with easy grace, undulating just above the waves.

Off the North Wales coast these steadier flights are in the morning and evening, the birds passing to and from feeding grounds. These movements are puzzling; they are diurnal summer flights which have no connection with the larger southward autumnal migration. I have often observed them myself, but my main source of information is Mr. R. W. Jones, who first called my attention to their regularity in the neighbourhood of the Great Orme. From May to August the birds pass almost every evening in a series of flocks or strings, travelling west from the direction of Liverpool Bay towards and beyond the north coast of Anglesey; Mr. Jones counted I 44 in half an hour, and at Point Lynas I saw 270 pass between 6 and 6.30 p.m. I have occasionally seen parties going east in the early afternoon. In Liverpool Bay and the Irish Sea between Lancashire and the Isle of Man, Manx Shearwaters are common in the daytime all through the summer. I have seen the bird at this season in the North Sea and Scottish waters; the statement that it is nocturnal, in the breeding season and after, is certainly not entirely correct. Dr. Eagle Clarke's experience with the Storm-Petrel, which he found absent during the day when young were hatched, does not apply to this species, for I found birds brooding young in the daytime, but at three different colonies I saw no birds about by day. Probably some, perhaps one of each pair, goes off to a distance to feed by day, and at night injects the young with the oily half-digested matter upon which it certainly thrives. Those who know the coast and the position of the colonies will understand that the evening westward flight is from, not to the feeding grounds. 
In early August I have sailed amongst the feeding birds; they paid no attention to a throbbing motor, nor, on this occasion, to the refuse or "offal" from the trawl, but busily hunted, probably for squids, then plentiful in the surface water. They took short flights and picked food from the surface as they paddled, petrel fashion, with their feet ; they alighted and dived, remaining under for a few seconds only. They were quick and excited, but never dived in with open wings, as they have been described as doing, but I could not see how they swam under water. They floated, picking food right and left, between the short flights and dives. Young birds of the year were distinctly browner about the head and cheeks than the others. Planktonic crustaceans, squids, and other free-swimming molluscs, and small fish are the food, and at the breeding haunts they eat sorrel-Chaloner quaintly remarks - "for digestion's sake, as is conjectur'd."

The nests are in burrows in turf, often on steep slopes, in cracks or caves in rocks, or amongst the debris of scree and fallen rock. The single egg is white, and measures about 2.3 by 16 inches; it is laid in early May, and $I$ have seen apparently fresh eggs in the middle of June when there were many young in other burrows. Some eggs were on a small collection of dry grass, others in unlined scoops in the soil; some were within easy reach, others fully five feet from the entrance. The old birds pecked at my hand with chortling expostulation, but when taken from the hole uttered no complaint ; they bit, the hooked nail giving a powerful nip, and the sharp claws painful scratches. When released they bounded down the slope, fluttering and running, striking the ground heavily with the breast, but when clear of the cliff top, sailed easily, and did not alight on the water so long as they were in sight. The young are fed on oily regurgitated food, and are fat balls of long blue-grey down, with a fluffy tuft on the head; the under parts are bluish white, and the tips of the wing 
stumps white; the bill and feet are lead-blue, the webs fleshcoloured. When placed on the ground the young crawled on all fours, using the wing stumps and the weak tarsi. The old bird at rest, lies prone on the breast and tarsi.

Whether the bird makes any sound on the water or in diurnal flight I cannot say, but at night it is noisy at the nesting colony. The light-keepers told me that the "Mackerel Cocks" were most clamorous after rain, and certainly at one colony a heavy thunder shower enlivened them. At 10.30 p.m., when rain was still falling, the noise began and lasted most of the night. The birds flew fast, judging by the calls, for they were invisible in the darkness. The light-keepers said that the birds exclaimed"It's your fault," with emphasis on the "your," and this is an excellent simile. The calls vary, some being harsh and scolding, others soft and crooning: It-y-corka, kitti-koo-roo, kok-aliok (very quick), kok-a-roo-roo, It-is-yor-folt. The hard kok was most frequent. At the end of August the southward move begins, and in the first week in September, and at times a little later, many are seen moving in strings along our shores, and large numbers cross the land, dropping from their hosts the weaklings in places far from the coast. These birds are not storm driven, but have failed to keep up; the records at this season point to regular not occasional overland travels. In winter the bird is rare in our seas.

The adult Manx Shearwater is black above and white beneath, the black merging with the white in delicate greys; the bill is blackish, the legs are black on the outer side, pinker within, and the webs are blue; the irides are described as dark brown, but those of the birds I handled appeared to be closed with a bluish nictitating membrane, though they exhibited no daylight blindness when released. Length, 16 ins. IVing, $9{ }^{\circ} 5$ ins. Tarsus, 1.75 ins.

The Levantine Shearwater has the upper parts browner, the under parts more dusky, and the axillaries smoky brown; in 
the Manx the axillaries are white, or sharply tipped with brown. The Levantine is the larger bird. Length, 16 ins. Wing, Io ins. Tarsus, $1 \cdot 9$ ins.

\section{Sooty Shearwater. Puffinis griseus (Gmelin).}

Though the Sooty Shearwater (Plate 124) is a world-wanderer, it would indeed be strange if the large numbers which visit the Atlantic, even so far north as the Canadian coast and the Fxioes, were all reared in the one known breeding haunt, the Chatham Islands, in the New Zealand seas. Considering how plentiful it is in the southern Atlantic, it is more than probable that there are colonies on unexplored or partially explored oceanic islands, where, no doubt, the crepuscular habits during the breeding season have lessened the chance of discovery. At the termination of its breeding season this southern shearwater migrates northward, in our spring: and must, in the light of all the records, be looked upon as a more or less regular annual visitor to our shores. In mid-July it has been seen off the Butt of Lewis, and frequently from August to October on all parts of the east and scuth coast, and the west of Ireland, from the Orkneys to Land's End; it has seldom been noticed in the Irish Sea. Off the Yorkshire coast it is so well known as to be named the "Black Shearwater" by the fishermen; at a distance it looks very black as it flies with typical shearwater flight, skimming and swinging, now the upper, now the lower parts in view. From the Great Shear. water it can be told by its uniform brown colour. At times it flies in strings or lines; ten or a dozen together have several times been observed. Belated birds have been recorded in November and December, but as a rule the southward migration is at its height in September, the birds travelling south to breed when our northern birds are seeking winter quarters.

The general colour is deep brown, darkest on the upper 

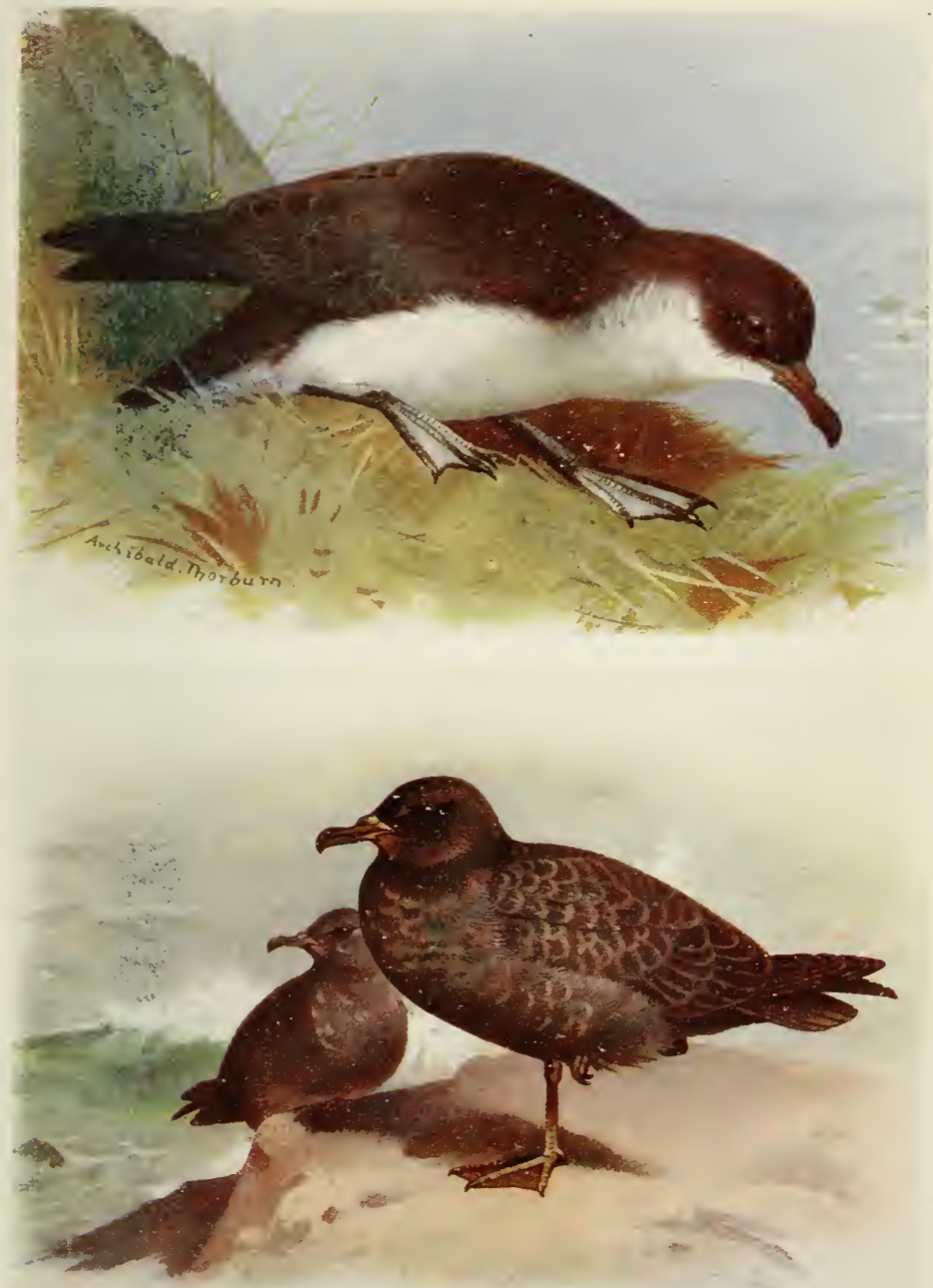

2 Pl. I 24.

Manx Shearwater. 14th. 


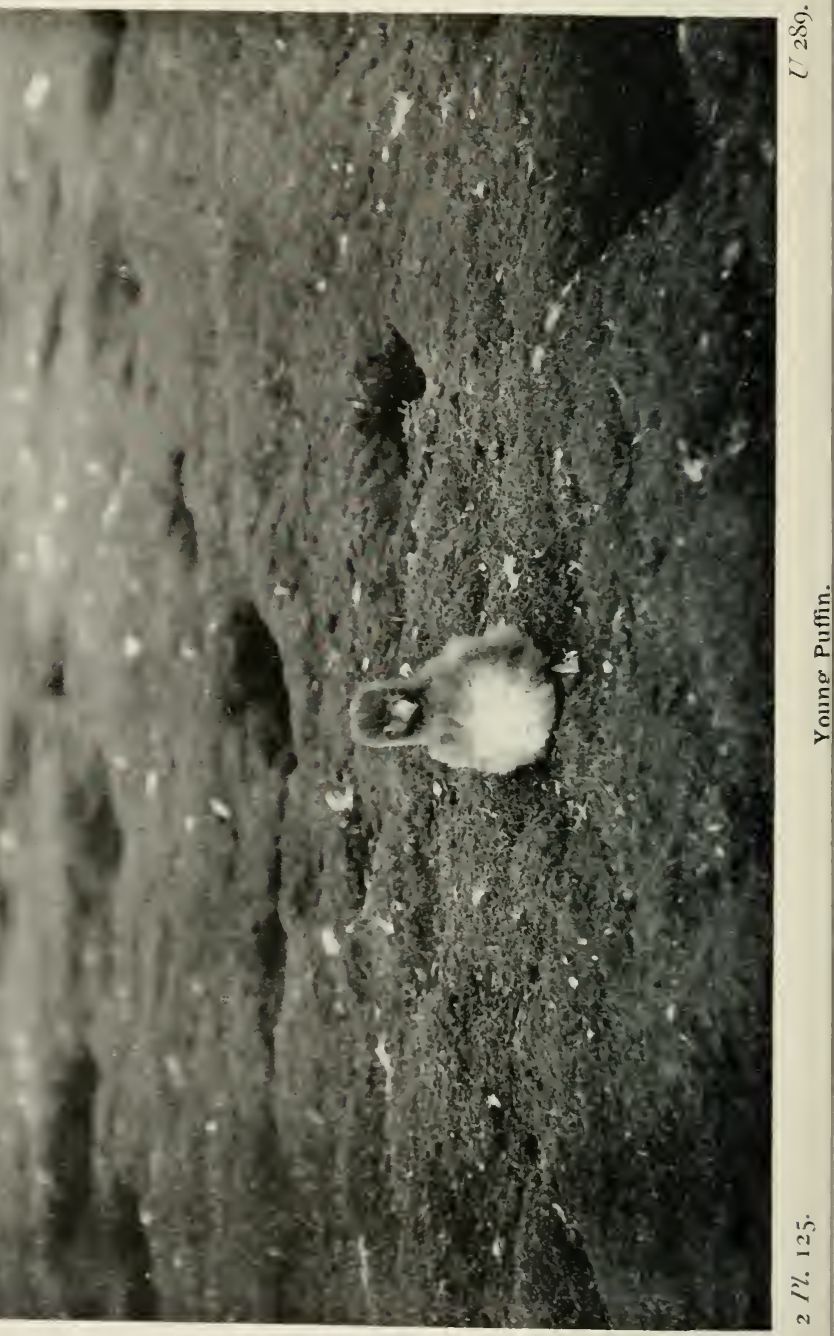


parts; the bill, legs, and irides are dark brown, but the inner side of the tarsi and webs are greyer. Length, 18 ins. Wing, 12 ins. Tarsus, 2 ins.

\section{Great Shearwater. Puffinus gravis O'Reilly.}

So far the only known breeding place of the Great Shearwater (Plate 126) is the Tristan da Cunha group in the south Atlantic, though probably other stations exist. In our springthe southern autumn-the bird migrates north and occurs throughout the Atlantic, even to the Greenland seas. Apparently the northward movements of this oceanic bird are even further from the shore than on its return, for in June and July it is fairly frequent off the Outer Hebrides, St. Kilda, and Rockall; on June 22nd, I912, Mr. R. W. Jones saw a large shearwater, flying with the Manx Shearwaters, off the Orme's Head, which from his description and the fact that he is familiar with the smaller species, can only have been a Great Shearwater, unless it was one of the much rarer forms of P. kuhli. From August until November the Great Shearwater appears with certain indications of regularity, slowly passing south, but usually well off shore ; it is commoner off the western than the eastern coasts, though the Yorkshire records are so frequent that it must be looked upon as an almost annual autumn visitor. It looks dark on the wing, but its light under parts, which show even when it is swimming, prevent confusion with the Sooty Shearwater; a dark tail-band and white upper tail-coverts are conspicuous as it turns in true shearwater flight. From the next species it may be told by its darker bill, wings, and back. The flight resembles that of other shearwaters, but it has been stated to have a rapid moult of the flight feathers in June and July, when it is for a time helpless. It is true that examples have been captured on the water, but at this season they have, often been seen in full flight; further observations on this point are desirable. 
The upper parts are ash brown, except on the tail-coverts; the quills and tail-band are blackish brown, and the sides of the face and under parts white, mottled with brown on the abdomen ; the under tail-coverts are sooty. The bill is yellowish green, the legs are greenish grey, and the webs flesh-coloured. Length, 20 ins. Wing, 12.7 ins. Tarsus, 2 ins.

\section{Mediterranean Great Shearwater. Puffinus kuhli (Boie).}

The North Atlantic and Mediterranean Great Shearwaters are subdivided as sub-species, $P$. k. borealis Cory, and $P . k$. kuhli (Boie), and other formes are recognised elsewhere in the Atlantic. The former nests in the Canary and Salvage Isles, Madeira, and the Azores, the latter in the Mediterranean, yet examples have only twice been recorded from our shores, though $P$. gravis is a regular visitor; birds in the warmer seas have less occasion to migrate or wander than those from the south. The Mediterranean bird was obtained in February, 1906, the North Atlantic form in March, 1914. Both are said to have been picked up dead on the Sussex beach, but to include drifted bodies as British is rather swelling the list on slender evidence. The upper parts are paler than those of the Great Shearwater, the sides of the neck are mottled, but the abdomen is without spots; the bill and legs are yellow. The main difference between the sub-species is in the bill, which is stouter in the North Atlantic bird. Length, 20 ins. Wing, $14^{\circ} 3$ ins. Tarsus, $2 *$ ins.

\section{Little Dusky Shearwater. Puffinus obscurus (Gmelin).}

Mr. T. Iredale, when discussing the nomenclature of this shearwater, which is distinguished from all others on our list by its small size, aptly remarks - "A more unfortunate little bird 
as regards names it would be hard to find." It is not within the province of the present book to discuss such controversial matter, especially as the various geographical races of $P$. obscurus (Gmel.) or $P$. assimilis Gould, are complicated. Two forms have occurred in Britain. The one which breeds in Madeira and some other eastern Atlantic islands, is called by the B.O.U. Committee, P. obscurus baroli Bonap., and by Dr. Hartert and his school, $P$. assimilis godmani Allen. It has occurred on about eight occasions, in April and May, and between October and December. Most of the occurrences have been in autumn on the south coast, but the first obtained was in Ireland in May, and a bird was taken in Suffolk in April. The Cape Verde form, $P$. a. boydi Math., has been twice recorded from the south coast, in December and January.

The upper parts of the Madeira bird are brownish black, with a bluer tinge than in the brown Cape Verde form. The under parts, including the tail-coverts, are white in the former, but in the latter the longer under tail-coverts are dusky, almost black. There are other minor, and perhaps more variable, differences. The bill is slate, the legs are blue-black, and the irides dark brown. Length, II ins. Wing, $7^{\circ} 5$ ins. Tarsus, 14 ins.

\section{Fulmar. Fulmarus glacialis (Linn.).}

Until 1878 the only known British breeding place of the Fulmar (Plate 126) was St. Kilda ; then a colony was established on Foula, and now the bird nests in large and growing colonies on many of the Orkney and Shetland islands, on North Rona, the Lewis and others of the Outer Hebrides, on the Sutherland and Caithness coasts, and in two or more places in Ireland. In June, I9I9, my friend Mr. G. W. Temperley saw two at Speeton, Yorkshire, where they had been noticed for some weeks. The increase in the last ten years has been extra- 
ordinary; in one Irish colony a dozen pairs nested in 1913 , but two years later there were over a hundred. Beyond our islands the range extends northward to the Arctic seas. Except during the nesting season-roughly May to August-the bird comes little to land; it is an oceanic wanderer, but during winter a few may be seen well off shore in our southern seas, and occasionally a bird is storm driven inland. Some birds return early to the neighbourhood of the colonies, or even linger in the north all winter.

The Fulmar, with its grey back and white head and under parts, is not unlike a large gull, but the bill, with its tubular nostrils, is that of a petrel. But the most skilful gull cannot compete with it, for "the Fulmar flying free" is one of the easiest, most graceful, and powerful of sea-birds. From time to time it takes a few strong strokes, but for the most part its flight is clever steady sailing with wings more outstretched than those of any gull, steady as the wings of an aeroplane. It sweeps round in huge arcs, catching the wind with the fine, almost imperceptible adjustments of the soaring bird, yet rising to no great height. Without effort it sails in the teeth of a gale that drives the great Atlantic rollers shoreward; it swoops into the trough, sweeps up to the crest, swings over at right angles, the tip of one wing just clearing the wave. Its neck looks short; it is compact and well proportioned, gleaming white against a green sea or lowering sky. When approaching St. Kilda I saw Fulmars immediately beyond the Sound of Harris, and the numbers increased mile by mile, until the air was full and the water dotted with the graceful birds.

St. Kilda exists more upon Fulmar than any of its other fowl; the bird provides oil and feathers for rent, food for winter consumption, and, since the islanders realised that collectors would pay, eggs for dealers. For centuries the bird has been exploited, but in spite of the annual Fulmar harvest the area is congested, and without doubt the new colonies are 
the result of overcrowding in the ancient home. The food of the Fulmar consists of fish, any floating oily refuse, cuttles, and, near the nest, sorrel; sometimes food is picked up as the bird swoops, but often it settles on the water to feed. The young, plunging the head into the parent's mouth, feeds on regurgitated oil; both old and young are so full of oil that they eject it on the slightest provocation, squirting it, often at an intruder, for three feet or more. When snared by the crag-climbing native of St. Kilda the bird is seized by the neck and made to disgorge its oil into a pouch, usually the stomach of a Gannet, which is carried slung to the waist ; then the bird's neck is wrung so as to avoid further loss. The oil is a beautiful clear amber colour, and has a penetrating but not unpleasant smell ; I fail to understand why it is often described as "musty." St. Kilda reeks of the smell, as do skins and eggs of the bird; blown eggs, twenty years old, retain this persistent odour. The flesh is oily; I have tried young birds both boiled and roasted.

At St. Kilda the birds are overcrowded on the ledges; the single egg is laid on the rock, in a rough scratching in soil, or in an apology for a nest-a few bits of grass or thrift, or on a slight lining of small flat stones. The white egg is rough in texture, and measures on the average $2^{\circ} 9$ by $1^{\circ} 9$ inches; incubation begins about the middle of May. At the nest the Fulmar has a low crooning note; I have detected no sound from the flying bird. Mr. Pike noticed that the egg was so deeply embedded in the breast feathers of the sitting bird, that it was often carried from the ledge by the startled parent and hurled to destruction. The nestlings have greyish white down and dark bills.

The adult Fulmar has two phases, but the dark one, in which the blue-grey extends to the under parts and head, is rare in British colonies, though said to be common further north; the natives know this bird as the "Blue Fulmar." The lighter or normal bird is white on the head, neck, and under parts, though 
usually with a slight yellowish tinge; the back, wings, and tail are blue-grey, faintly tinged, rather than mottled, with pale ashy brown; the quills are darker. Dr. Eagle Clarke corrected the many erroneous descrip:ions of the soft parts, and first described the colour of the young. Roughly the bill is greenish brown, tinged in places with blue and pink, and brownish horn at the tip; the legs are greenish grey, the irides dark brown. Young birds are a purer and a more silky white, and the grey is uniform, purer and paler than in mature birds; the bill is faler, the legs are livid white. Length, 19 ins. Wing, 13.25 ins. Tarsus, 2 ins.

\section{Capped Petrel. Pterodroma hasitata (Kuhl).}

Single examples of three species of the genus Pterodroma are known to have wandered to England or Wales, but their appearance was evidently purely accidental. The Capped Petrel, now believed to be extinct, probably killed by rats, formerly nested in some of the West Indian islands, but was, apparently, always rare. In spring, i 850, one, evidently exhausted, was found by a boy entangled in a furze bush near Swaffham, in Norfolk. It is about the size of the Manx Shearwater, more distinctly brown on the "cap," back, and wings, and with the forehead, back of the neck, and upper tail-coverts, as well as the under parts white; round the eye, and from the eye to the crown is brown, the tail is also brown. The bill is black, and the legs yellowish, the tips of the toes and outer edge of the webs almost black. Length, 16 ins. Wing, II 3 ins. Tarsus, $\mathrm{r} \cdot 5$ ins.

\section{Collared Petrel. Pterodroma brevifes (Peale).}

So far as is known, the Collared Petrel only nests in the western Pacific, but like all petrels is a great wanderer; if there are no undiscovered Atlantic breeding stations, the bird 

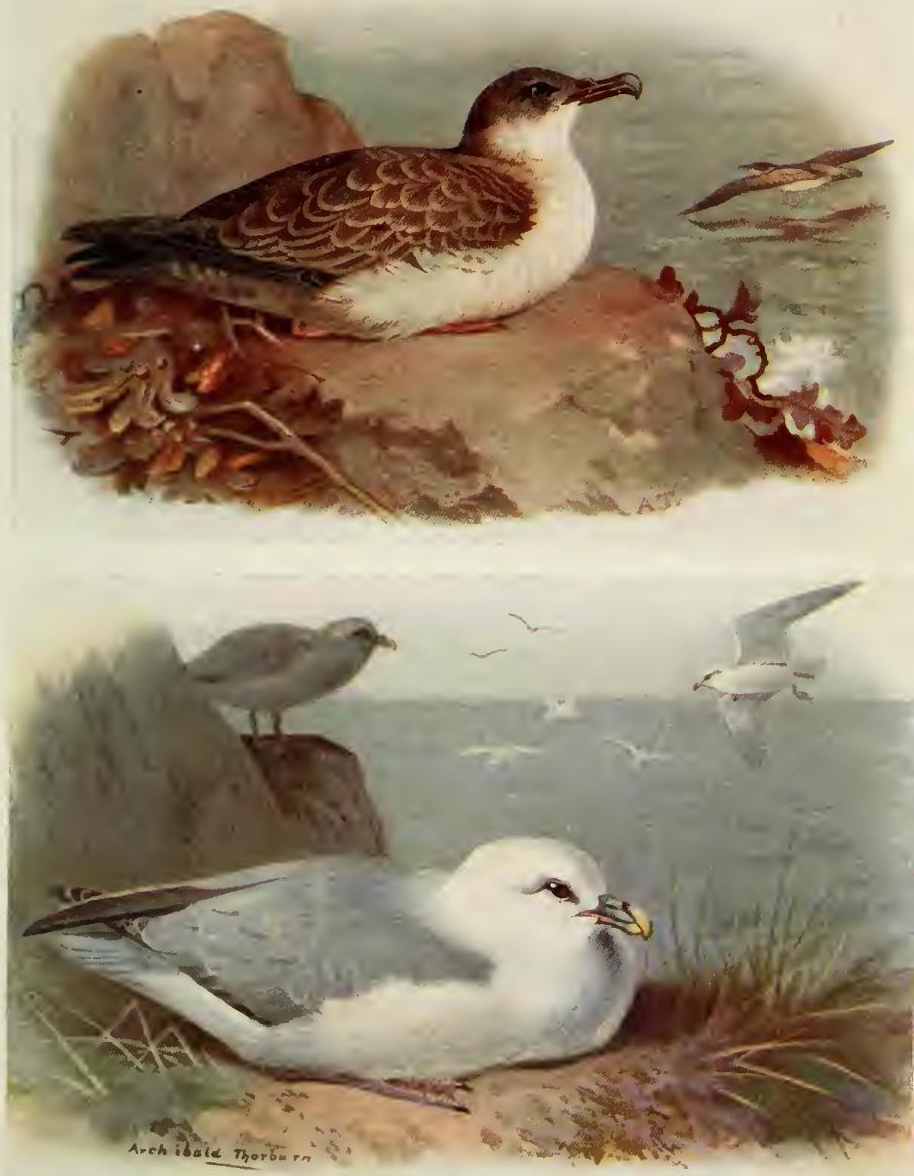

2 I\%. 120.

Great Shearwater. 1/7th, 


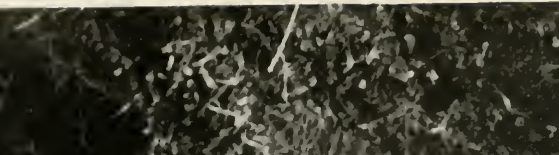

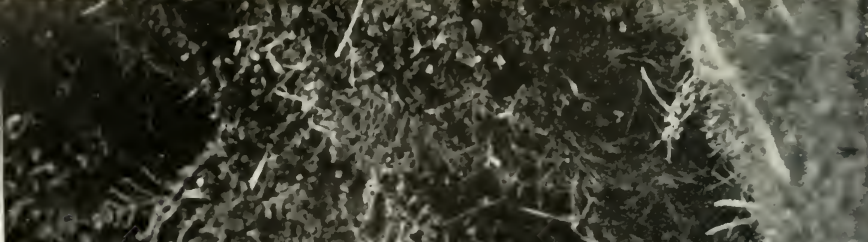

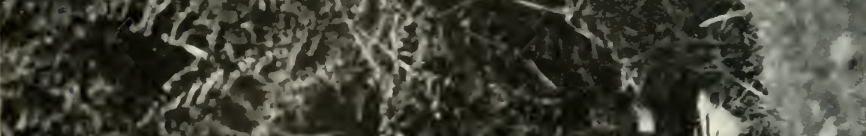
(20) in

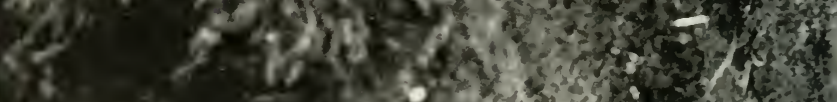

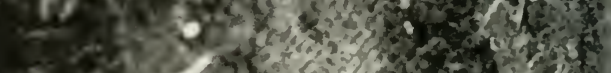

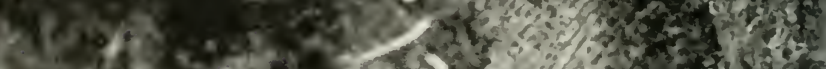

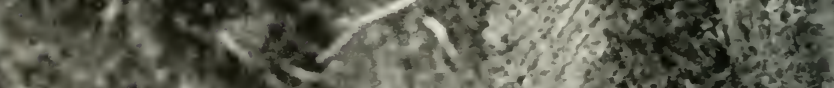

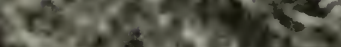

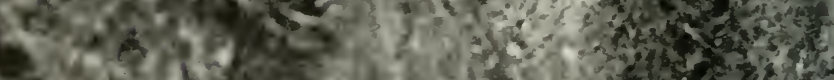
a.2. 2 .

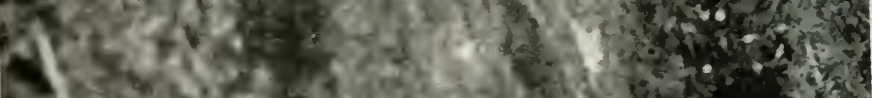

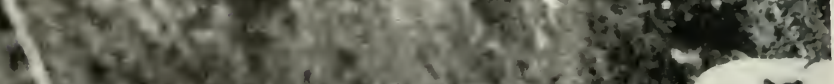
$3 \times$ 
which was shot in Cardigan Bay in November or December, I889, must have rounded Cape Horn and wandered north. The typical bird is slate-grey on the head, back, wings, upper tail-coverts, and tail, and there is a grey band across the breast; the mantle and coverts are slightly mottled with brown; the forehead, chin, and throat, and the under parts below the breast, are white. Some birds, however, have the whole of the under parts below the neck suffused with grey; the Welsh example is of this form. The bill and legs are as in the last species. Length, $\mathrm{I}^{\circ} 5$ ins. WVing, $8 \cdot 7$ ins. Tarsus, $\mathrm{I}$ in.

\section{Kermadec or Schlegel's Petrel. Pterodroma neglecta} (Schleg.).

The only known breeding place of this petrel is in the Kermadec group in the New Zealand seas, and like the last species the one British example had travelled far. In April, 1908, one was found dead, after strong south-westerly gales, beneath a tree at Tarporley, Cheshire. Prof. R. Newstead examined it in the flesh, and I saw it and the carcase a day or two later. Sharpe and Du Cane Godman, to whom I showed it, confirmed our identification, though the tarsi and proximal third of the toes were bluish grey and not yellow, as described by Salvin. The distal portion of the feet was black. This species, however, is known to be variable, and our specimennow in the Chester Museum-is of the dark phase, uniform brown, slightly paler on the under parts. The bill was black, the irides dark hazel. Length, 15 ins. Wing, $I x \cdot I$ ins. Tarsus, I'5 ins.

\section{Bulwer's Petrel. Bulweria bulweri (Jard. and Selby).}

In May, I837, a dead Bulwer's Petrel was picked up in Yorkshire, but the bird was not recorded again until 1903 ; since then four have been found in autumn or winter in Sussex. The 
bird nests in the Canary, Salvage, and Madeira islands, also in the Pacific; the Sussex birds were found after strong southwesterly gales. The general colour is blackish brown, greyer round the black bill; the legs are reddish brown, the webs dusky ; the irides are dark brown. Length, II ins. Wing, $7 \cdot 8$ ins. Tarsus, $\mathrm{I}$ in.

\section{Family DIOMEDEID Æ.}

Large, long. winged birds ; nostrils lateral in separate tubes.

\section{Black-browed Albatross. Diomedea melanophrys Temm.}

The oceanic wanderings of this southern Albatross, which nests in the Falklands as well as in New Zealand seas, have taken it far to the north of Britain, since it has been captured in the Arctic ocean. There is, however, but one British recordan exhausted bird, apparently immature, found in Cambridgeshire in July, 1897. Dr. Knud Andersen believes that one which was shot in the Freoes in 1893 had been living amongst the Gannets for thirty or forty years. In the mature bird the back and wings are brownish black, the tail is grey, and the head, neck, and under parts are white. A blackish band above the eye, less conspicuous in young birds, is the "brow." The bill is yellowish, as are the legs in old birds, though in the Cambridge example they were flesh-blue; the irides are dark brown. Length, 29 ins. Wing, 19 ins. Tarsus, 3.3 ins.

\section{Order COLYMBIFORMES. Divers. \\ Family COLYMBID E.}

Powerful diving birds; bill strong and straight; legs set far back, toes webbed, tarsi flat and capable of rotation. 


\section{Black-throated Diver. Colymbus arcticus Linn.}

The Black-throated Diver (Plate 129), ranges over northern Europe and Asia, and in winter visits the Mediterranean, and other southern waters. It nests in the north of Scotland and the Outer Hebrides, and exceptionally in Skye and the Orkneys. Some birds remain all winter in Scottish waters, but there is a general southerly movement in autumn, when, and on the return in spring, the bird is not infrequent off our coasts and on inland waters; it is rare in English seas in winter. On passage it is more regular on the west coast than is supposed.

There is little difficulty in distinguishing the three divers when in summer plumage; the fourth is very rare. In size this species is intermediate and may be known by its sharply defined, shield-shaped, purple-black throat, bordered on either side by wavy white streaks. There is a half-collar of black and white dashes above the shield, whereas the Great Northern Diver has in addition a second and larger streaked collar. The throat of the smaller species is red. The winter and immature plumages are more difficult, but the ashy brown upper parts are in this bird usually more uniform than in the Great Northern, and are sprinkled with a few white spots, but not so profusely as in the Red-throated. The best distinction is in the bill, which is less massive than that of the larger bird, and lacks the slight but perceptible uptilt of the Red-throated.

Compared with the bulk, the short wings of the Blackthroated Diver look feeble, yet it can fly with speed and power; it flies straight, close to the surface or at a considerable altitude. The neck is outstretched in flight, but looks short and thick, for there is little difference between the width of the head and neck; on the wing the bird is cigar-shaped. It swims low, often with the lower neck awash, and forges forward with great speed, turning its supple neck from side to side. At the 
least suspicion of danger it further submerges the body, and after a dive will expose head and neck only until sure that the coast is clear; it often raises itself high in the water, flapping its wings, and sometimes points the bill upward as if stretching. Quick though it is on the surface or in the air, its best speed is under water, when it can outstrip swiftly swimming fish, its main food. Many good observers say that it uses its wings as well as its feet when wishful to make a spurt, and though it has been seen flying under water, I believe that the greatest speed is attained when with wings held close to its sides it shoots forward with strong lateral and simultaneous strokes. The legs, set far back, move like those of a grebe, and are turned, so as to "feather" and offer little resistance, when brought forward. The freedom with which the tarsi can be revolved is shown by the habit of raising one foot above the back. Saxby saw the wings of a Great Northern Diver used when it towed a boat, swimming under water, but this is no evidence, for the bird was wounded, and was tethered to the boat by one foot; it could not use the feet simultaneously.

The dives are long, but their duration has at times been exaggerated; my own timing never exceeded fifty-three seconds, and thirty was frequent; two minutes has, however, been recorded. If the bird is diving to a depth it takes a header, first springing up in the water, but often it sinks with hardly a swirl. Probably small fish are swallowed under water, but I have seen a large flat fish brought to the surface, and not swallowed until it had been shaken and bitten, its bones well broken. After a dive it almost invariably sips water, and often turns its head and wipes the side of its face and probably the bill against its lower back. The call of the divers is discordant and weird; Seebohm likens it to the scream of a tortured child; it is a melancholy wail, an "uncouth shriek." Miss Haviland, from whom I borrow the last expression, also heard and saw the bird with uplifted bill utter 
$N$
$N$
$N$
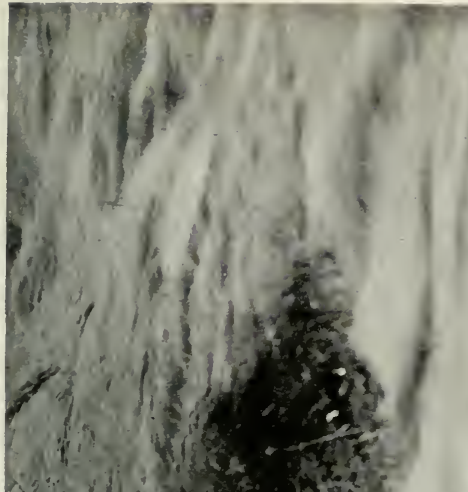

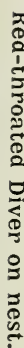

(3)

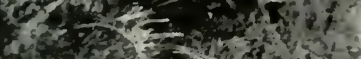

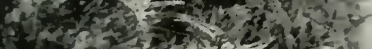

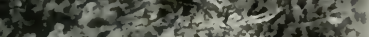

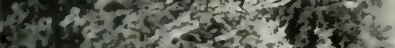

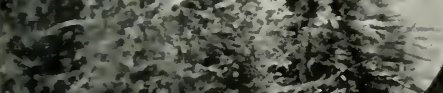

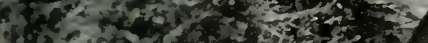
If

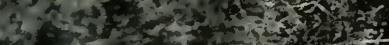

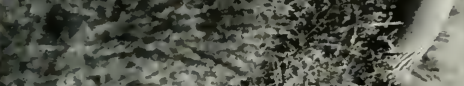

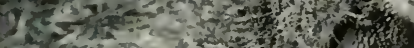

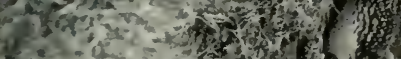

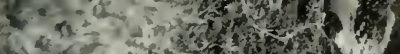

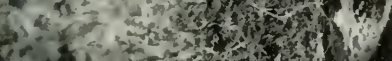
30 ta

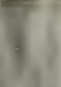




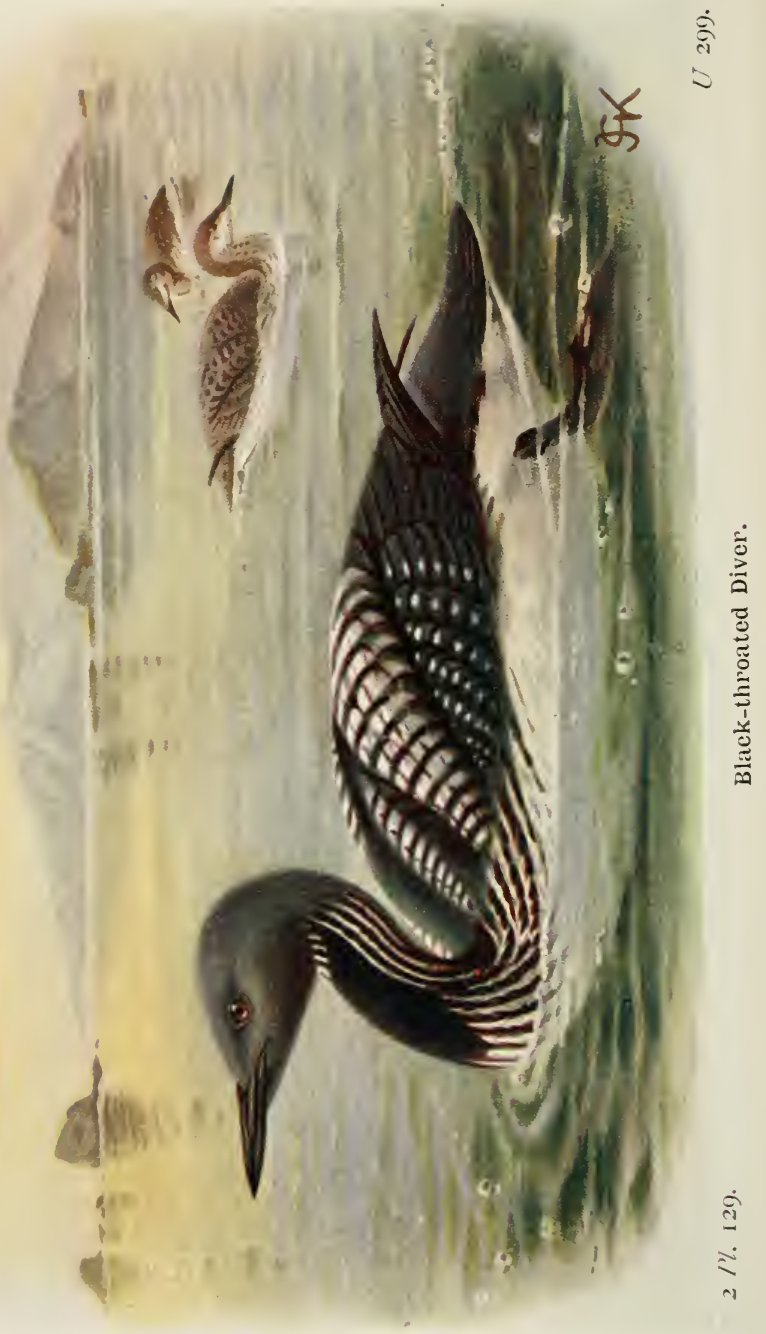


a "beautiful modulated whistle," which she concluded was the love-call; others describe a conversational chatter and a yelping cry.

The nest (Plate 127), for convenience, is close to water, for the bird cannot really walk; it shuffles on its tarsi and toes, raising its body and throwing it forward an inch or two at a time. Yet if chased on land it can travel fast in a series of quadrupedal bounds, making use of the wings as hands. The eggs (Plate 136 ), two as a rule, are laid in a simple depression, usually without nesting material. They are dark brown or olive, sparsely spotted with black and brown. The nestling has long, sooty brown down, and like the young grebe is frequently carried on the back of the parent bird.

Summer plumage often shows in March, and on April 2Ist I have seen the bird in full dress, but Mr. Jones saw one on the 3oth of that month with black throat, white collar, and grey head, but with a brown back devoid of white bars. Saunders states that "by the middle of September the autumnal moult is completed," but this is by no means always the case; I examined a bird in full dress which had been killed on October i6th. Full-plumaged birds are not uncommon on both spring and autumn migration. In summer the crown and nape are bluish grey, the cheeks sooty, and the chin black; below the chin is an evenly striped black and white cravat, and below that the black throat, showing a purple or green sheen according to position. On either side of the neck are black and white wavy lines, and the blacks extend to the sides of the breast as a series of lines or dashes. The back, scapulars, and wings are blue-black; on the scapulars are rows of rectangular white spots, forming distinct broad bars; on the coverts are a few round white spots. The abdomen is white. The strong bill is black, pinkish at the angle of the gape and on the lower mandible; the legs are black, sooty on the webs; the irides are crimson. In winter the head and upper parts 
are ashy brown and the under parts white; all the neck decoration is lost, but the top of the head is paler than the back and wings; there is a brownish patch on the side of the neck. Faint pale edges occasionally show, but these are more distinct, forming bars, on immature birds, which otherwise resemble old birds in winter. The bill of both adult in winter and young is bluish horn, the legs are browner, and the irides reddish brown rather than crimson. Length, $27 \cdot 75$ ins. Wing, $12 \cdot 8$ ins. Tarsus, $3 \cdot 1$ ins.

\section{Great Northern Diver. Colymbus immer Brünn.}

As a winter visitor to British seas the Great Northern Diver (Plate 130 ) is not uncommon; it has not been known to breed, even in the Shetlands, though a few non-breeding, apparently mature birds occasionally remain in northern waters for the summer. Iceland is the nearest breeding station to Britain, and from there the range extends westward through Greenland and northern Canada to the Asiatic coast. Birds have been seen off the English coast in August, but usually they do not appear until October, and most have returned north before the end of April, stragglers only passing in May.

Seebohm's " as big as a goose"-he does not say which goose ! - gives a very rough idea of the size of this handsome diver, yet it certainly is the size which commands attention when it appears, as it often does, on inland waters and swims amongst more familiar fowl. The bird in nuptial dress, which is usually lost in September, though one was obtained in Ireland in full plumage so late as October 3 Ist, differs from the Black-throated Diver; its head is glossy black, not slate-grey, and it has two half-collars of white spots on the neck instead of one, the lower and additional one being the larger. Though, when in winter dress, the large size and heavy, dagger-shaped bill are striking, such characters are of little use when it is solitary, and the bird frequently travels alone. Often, however, a dark mottled grey 
patch, an indication of the black of summer, shows on the side of the neck; I have not noticed this on the Black-throated Diver. It is possible that this patch is really a sign of immaturity, for the majority of the birds which visit inland waters in winter are immature, and those at sea give few opportunities of close observation as they bob about on the waves. A mature winter Great Northern is blacker grey, less brown than the Black-throated on the upper parts, and has a more mottled, less uniform, appearance. From the rare Whitebilled Diver it can be told by the colour of the bill, which even in winter is darker, and by the slight downward curve towards the tip of the upper mandible, which is straight in the Whitebilled and appears to tilt upward.

Except when on migration the "Loon," as it is called on the east coast as well as in America, is little on the wing, but owing to its large size its appearance in flight is even more remarkable than that of the last species. The wings, set far back, look inadequate to carry the torpedo-shaped body, yet the bird travels with speed. The thick neck, pointed bill, and position of wings prevent confusion with a goose, and even with its nearer but much smaller relation, the Great Crested Grebe. The short legs are trailed and usually point inward, and are only exceptionally extended on either side of the tail ; it is an error to say that they are habitually carried this way to serve as rudders. The normal swimming position is deep in the water, the lower neck awash ; if alarmed the back vanishes also, but when unsuspicious the bird will ride buoyantly, rolling like a grebe as it preens its plumage, nibbling at the feathers after moistening its bill. Often it raises itself upright in the water to flap its wings. When indolently floating, the short thick neck is carried in a graceful curve, or rests on the shoulciers; frequently a foot is raised above the back and shaken in the air. If swimming fast the neck and head are held well forward, and I have seen it with them extended along the water, a position assumed by 
the Great Crested Grebe during nuptial display. In ordinary slow progression on the surface the leg strokes are alternate, but when diving or swimming at great speed they are simultaneous and lateral, in the same plane as the body. The dive is its highest accomplishment; its existence depends upon great speed under water, the power to overtake swiftly swim. ming fish. The method differs according to circumstances; I have seen it spring forward, almost clear of the water, to take a deep header, and at other times submerge its body until the head and neck alone were visible, when, dipping these, it slid forward, hardly disturbing the surface. As a rule, during the dive, the wings are held close to the sides.

Holböll stated that the Loon would remain under water for eight minutes, and Payne-Gallwey timed one for ten, but he admits that the bird was wounded or alarmed, and under these circumstances it will protrude the head only and dive again at once; probably he missed one or more momentary appearances on the surface. My own times of an unsuspicious bird were, amongst many short periods of absence, two of two minutes and one of three; I do not think that the bird's head appeared, even during the long absence from sight. One very busy bird, timed for a quarter of an hour, was out of sight for $14 \frac{1}{2}$ minutes, only remaining on the surface for a second or two at a time; I did not see it bring up a single fish, as probably its prey was small. Large fish are brought up to be eaten and are swallowed head first. Crustaceans and cephalopods are also eaten. A little water is usually sipped immediately after the dive. Rising from the surface is only accomplished after thrashing the water with its wings, and it has not been seen to rise from the land, where indeed it can only shuffle along in a prone attitude; it does not sit up as frequently depicted. The Loon has the same distressful wail as other divers, and a milder, more musical love-call, as well as a deep guttural growl, which I have heard uttered by winter birds. 
The spring moult begins in December, but full dress may not be attained until May. The head and neck are then black, glossed with purple and green; under the chin and on the sides of the neck are bands of white streaked with black, and below the black on the sides of the white breast are wavy slate-grey lines. The upper parts are glossy black, plentifully spotted with white; on the mantle the spots are large and square, arranged in regular bands. The quills and tail are black. The bill is blue-black, the legs have a greenish tinge, and the irides are crimson. A bird in early January with the throat still white, had the back black with ordered rows of spots. In winter the only indication of the throat adornment is a dark patch on the side of the neck; the head and nape are sooty, and the upper parts ashy grey with obscure spots, giving a mottled appearance. The tail is tipped with white. The bill is bluish horn, much lighter than in summer, and the irides are reddish. Young birds have the crown and nape grey, the face suffused with brown, and the feathers of the upper parts show pale edges, often as regular but indistinct bars. The irides were brown in a bird I examined. Length, $3 \mathrm{I}$ ins. Wing, 14 ins. Tarsus, $3^{\circ} 6$ ins.

\section{White-billed Northern Dixer. Colymbus adamsi Gray.}

The White-billed Northern Diver breeds in the Arctic from Novaya Zemlya eastward to Alaska, and about half a dozen have been obtained in Great Britain, though it is possible that it has often been overlooked. Seebohm's supposed differences between this bird and the Great Northern in summer plumage are not sound; the green and purple gloss on the head and neck varies individually, and certainly in the latter species the number of the streaks on the neck bands is not constant. This bird is, however, larger, and has a deeper and more massive bill, which at all seasons is yellowish white; the colour alone is not 
enough, since many winter Great Northerns have very pale bills, but in the White-billed bird the upper mandible is straight, and the lower inclines sharply upward from the wellmarked "angle," giving the whole bill a suggestion of uptilt. Length, 33 ins. Wing, I $4^{\circ} 9$ ins. Tarsus, $3 *$ ins.

\section{Red-throated Diver. Colymbus stellatus Pontopp.}

The Red-throated Diver (Plate I3I) has a wide range, breeding in the north of Europe, Asia, and America. In autumn a general southward movement distributes it throughout warmer seas, even south of the Mediterranean, and to the British shores it is a common winter visitor and passage migrant. It nests, however, in the north of Scotland and in many Scottish islands, as well as in at least one locality in Ireland.

Much commoner than the other divers, this bird can be identified at any season by its smaller size and slender uptilted bill; it is about the size of a Mallard. The vinaceous red patch on its throat, from which it gets its name, is sufficient for identification in summer, and in winter the white speckles on its back set it apart from other divers. Many of its habits, though in the main similar to those of its congeners, approach those of grebes; it is a graceful, active, playful bird, when on the water assuming quaint but never distorted attitudes as it rolls and gambols. Though it swims low and when anxious submerges its body, it floats buoyantly, resting with the head on its back, the bill pointed towards its tail. It is sociable, and high flights of small parties are not unusual; from these it descends obliquely, sometimes almost vertically, hurtling down with turns and twists, but changing the angle of descent before it strikes the water, ploughing up a wave. The flight is rather grebe-like, and its head is carried a little below the 
level of the long axis of the body. The wings are sometimes, but not always, used under water, and the speed and skill when chasing fish is little inferior to that of more powerful divers. I have not seen the bird stop under water for more than thirty seconds, but Mr. P. H. Bahr records dives of a minute and a half. Fish are its chief food, though crustaceans and other aquatic animals are eaten; large numbers of medium-sized fish have been found in the gullet. All the divers have one habit, which is also common to the Cormorant; as they swim on the surface they sink the head below, and thus avoid the confusion of surface ripples. When they sight the prey-Dr. F. Ward thinks they see it flash when turning-they at once dive and follow it.

The usual barking kark, kark, of the "Rain-Goose," a call supposed to foretell bad weather, is distinct from other diver notes, but it has a loud wailing cry, and a guttural note of alarm. The Red-throated, more frequently than other divers, assumes the upright pose, though its normal method of progression on land is with breast to ground. Mr. Caton Haigh saw one walk upright, and another scuttled away in an almost upright position when disturbed by Mr. G. Bolam. One of Mr. Bahr's photographs shows a bird waddling to the nest, carrying the body inclined forward and the snaky neck curved. Miss Haviland was astonished with the speed of a downy nestling, which propelled itself on its breast with rapid jerks of its legs, but also used its wings as supports ; thus the normal prone position is adopted by the young. Miss Turner saw one bird raise itself at the edge of the water before plunging in, and it frequently stands when turning the eggs. The largest numbers pass northward in April and May, and even in March some have advanced far towards nuptial dress. The date of the assumption of summer or winter plumage is irregular; even late in October many still show red on the throat. In June and July few remain off the English shores, but some appear Series 11 . 
about the middle of August, and immature birds have been known to linger through the summer.

The nest, often on an island in a fresh-water lake, is never far from water, and, as is also the case with the Black-throated, there is a well-flattened pathway from the landing place to the nest, smoothed by the bird's advancing breast, which during the breeding season is stained with peaty soil. The egg (Plate 136) is smaller but similar to that of the Black-throated Diver, the spots on its dark ground being few; two are often laid, late in May or in June, but single eggs are common. Untidy nests of grass or other vegetation are not infrequent, though the eggs may be in a mere depression in the herbage. It is unsafe to say that the bird is a shy or close sitter; Miss Turner could do nothing with one nervous female which she tried to photograph, but the bird depicted (Plate I28) allowed her to stand within two feet and almost to touch it. Sitting birds, if scared by a passing Raven or Peregrine, crouch on the nest with head and neck extended, and are wonderfully inconspicuous in this position. The nestling, clad in thick sooty brown down, is often carried on the parent's back.

The plumage of the adult bird in summer is singularly beautiful; its graceful movements show off the white and black lines on the back of the sinuous neck. The head and neck are soft pale blue-grey, streaked on the crown and nape; the throat is red; the back and wings are ashy grey, slightly spotted with white, and the under parts are white. The bill is black, the legs are greenish black, and the irides ruby-red. In winter the chin, lower part of the face, and front of the neck, as well as the under parts, are white, and the upper parts are a browner grey, profusely speckled with white. The bill is horn, almost white. Immature birds have a few whitish streaks and obscure spots, and pale edges to the feathers of the greyish brown mantle; their throats and flanks are often mottled with grey. Length, 25 ins. Wing, 11 ins. Tarsus, $2 \cdot 6$ ins. 


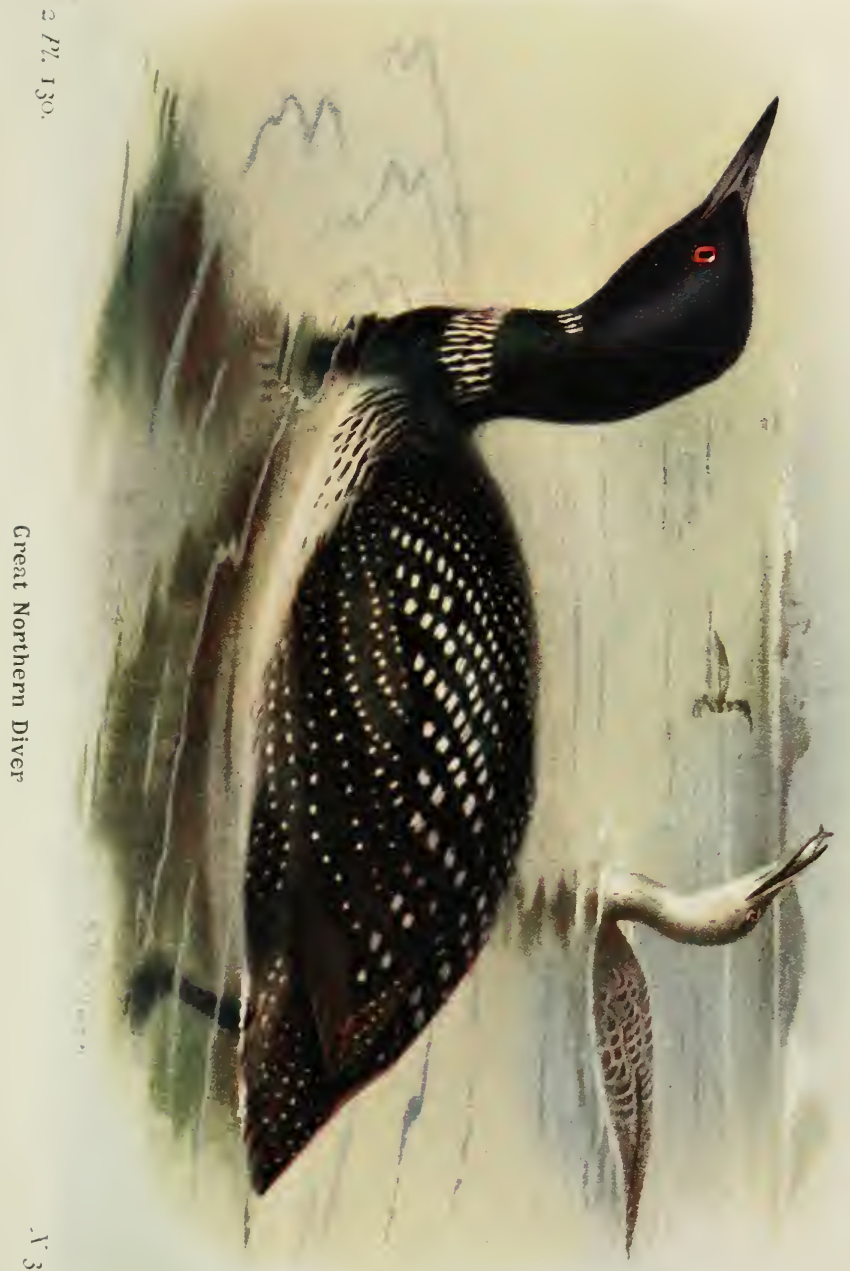


定

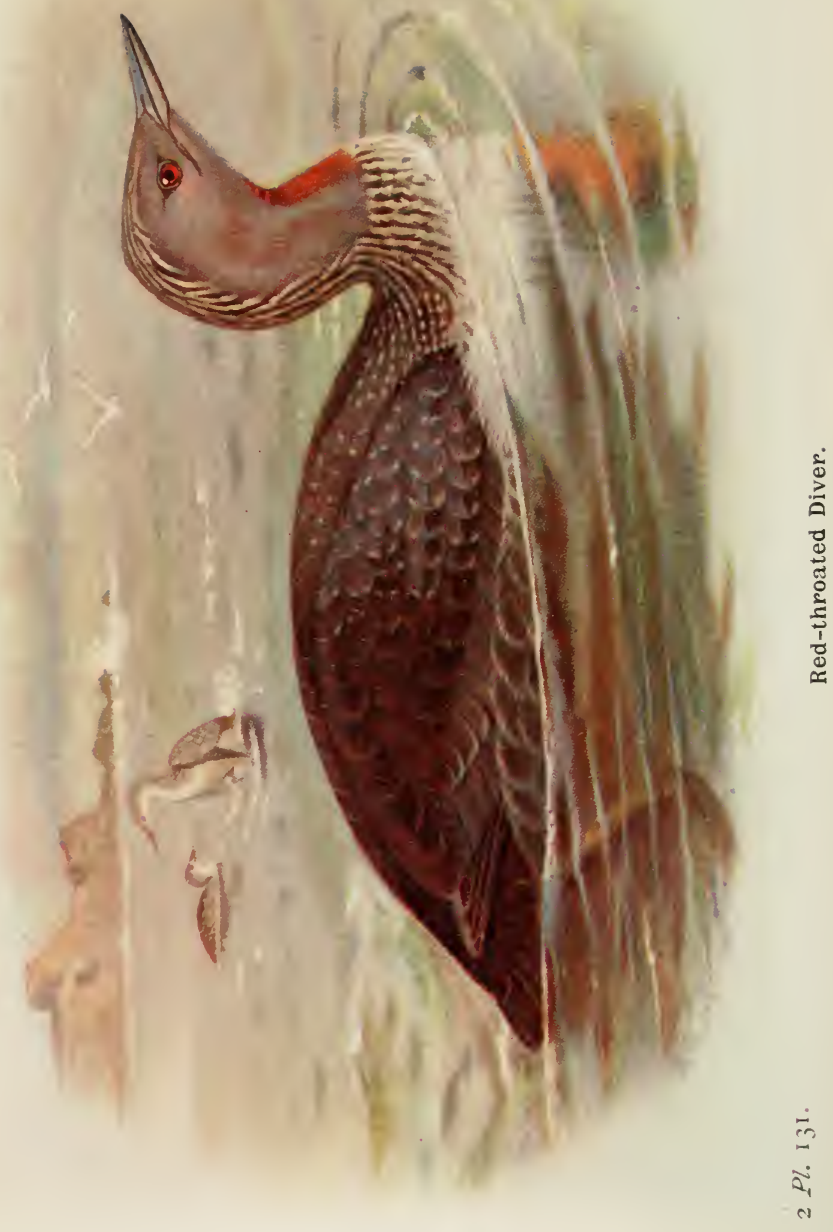




\section{Order PODICIPIDIFORMES.}

Family PODICIPIDÆ. Grebes.

Slender diving birds ; bill straight ; legs posterior, no visible tail ; toes lobed ; tarsi flat, capable of rotation.

\section{Great Crested Grebe. Podiceps cristatus (Linn.).}

Few once persecuted birds have made more rapid recovery than the Great Crested Grebe (Plate 132); it was at one time slaughtered for its satin breast-" grebe-fur"-and was almost exterminated, but it has not merely greatly increased in its old haunts, but has extended its range, and now nests in all suitable localities in England and Wales, and in many parts of Scotland and Ireland. It occurs throughout southern and central Europe and central Asia, and in winter in northern Africa. Nowhere is the bird more common than on the Cheshire and Shropshire meres, though the Broads are usually said to be its great stronghold. Cheshire is not a recently colonised area, but an ancient centre of distribution. In autumn there is a movement of migrants along our coasts, and many places, including the Broads, are deserted in early winter. But unless the Cheshire meres are frozen some birds remain. Early in January the numbers present are often large; I have seen between forty and fifty on one pool on January ist. Passage birds in small flocks appear as late as May, when the residents are nesting.

At any season this bird, known in various parts as the "Diver," "Loon," or "Gaunt," is distinct ; the erectile "eartufts" and frill of summer have no counterpart, and in winter its slender build and large size prevent confusion with other grebes. It swims low in the water, often with the lower neck 
awash, and seldom shows its white under parts below the "turtle back." Though the bird frequently rests its head well back on the shoulders, gracefully curving the neck, the usual position of the slim neck is rather stiffly erect; it appears slender below the ample frill. It can swim fast on the surface, the head forward, the straight neck inclined at about $45^{\circ}$, but if speed is necessary the bird dives; under-water progression, when the legs strike out simultaneously and laterally, is wonderfully swift. Except during courtship, when it takes frequent short flights, it is little on the wing, though it travels from mere to mere, or to the sea, flying high. In flight a white wing bar is very conspicuous. I have, however, seen a pair circling high, tippets expanded and legs held outward, evidently in nuptial exercise. The outstretched neck sags a little, but is raised, as are the feet, when the bird alights, striking the water with its breast. Grebes resting on the water frequently shake a leg above the back, or roll, their satiny under parts flashing, as they preen their feathers. The dive is almost invariably easy, a quick slip under water with little surface disturbance, though occasionally the bird makes a forward spring. The dive usually lasts from twenty to twentyfive seconds. The leg action is quick, but its power is more impressive than its speed; in the forward stroke the lobed toes lie together and the flattened tarsi are turned so as to cut the water; in the back stroke both expanded toes and flat tarsi grip the water. Newts, molluscs, and insects are eaten, but fish are the mainstay, and on fish the young are fed. The Grebe is little on land, but it walks easily and gracefully on the nest, its body well forward, and its tarsi raised at an angle.

The "Tippet-Grebe," as it was formerly called, is a noisy bird, especially in the pairing season. The most frequent call is a repeated $j i k, j i k, j i k$, often $j i c k c r, j i c k c r$, uttered by either sex, and a loud discordant gorr is common. This is often uttered by a male when, thrashing the water with its wings, it 
chases a rival. There is also a pleasant twanging banjo note and a rasping whirr. The hunger-cry of the young is a wheezy and insistent tcheep, tcheep, tcheep. Strange courtship antics begin in January, even before the frill is developed; the eartufts are never really lost ; the ruff is most pronounced in the male. Mr. E. Selous and Prof. J. Huxley have described these actions at great length, but some of the attitudes they mention are seldom seen. Often, however, two birds approach with necks stretched along the water, then rear themselves, breast to breast, stretching the necks to full extent and spreading wide the frills, whilst they gently fence with their bills. One or both will dive for weed and dangle it at the other, suggesting nest construction. During the upright caress both will suddenly dip their necks until the crown nearly touches the back; the head is usually vigorously shaken after the fencing. Wher the male approaches the female with head depressed, the ruff is closed and the ear-tufts at times loll over like wattles. Nest construction may begin in March, but eggs are laid from April until August; second broods have been recorded, but first broods frequently come to nought; I have seen young still following their parents for food in November. The nest (Plate I33) is a floating mass of wet decaying weed, moored amongst reeds, lilies, or other aquatic vegetation. The green or blue tinge of the elongated egg (Plate 153) is hidden by a chalky outer covering, which soon is permanently stained with vegetable juices. When disturbed the sitting bird raises itself, and with rapid right and left pecks covers the eggs with nesting material, then slides into the water and dives. Four is the normal number of eggs. Both birds incubate and tend the young, carrying them at first in a cradle formed by the slightly upraised wings; the pose of the parent is then distinctly higher than usual. The nestling has close cinnamon down striped with glossy black, the stripes most distinct on the neck; the crown is pinkish buff surrounded by black, and in front is a 
small bare vermilion triangle. The rose bill is crossed by a dark band, the legs and irides are cinereous grey.

The adult bird is greyish black on the top of the head and back of the neck, the upper parts elsewhere are greyish brown, and the under silky white. In summer the tippet is rich chestnut, shading to deep brown. The bill is yellowish, the legs are olive-green, and the irides crimson. The frill is lost in August, and begins to show again in December. Immature birds are ashy brown with longitudinal stripes on the neck; their irides are yellow. In the first autumn they show small ear-tufts even when the neck stripes are still retained. Full plumage is attained in the second winter. Length, 21 ins. Wing, 7.5 ins. Tarsus, $2 \cdot 5$ ins.

\section{Red-necked Grebe. Podiceps griseigena (Bodd.).}

The Red-necked Grebe (Plate 135), a regular but not numerous winter visitor, breeds in many parts of Europe and Asia, and ranges to north Africa in winter. It is not known to have nested in Britain, though it does so in southern Scandinavia, and is a less frequent visitor to inland waters than its congeners; it is, during winter, a salt-water grebe. A few reach us in August, but it is, on the whole, a cold-weather visitor. Most return in March or April, when some are in full nuptial dress.

In summer dress the distinctive characters are the warm chestnut neck, and the grey cheeks, bordered above by white, just below the eye. The bird is a little smaller than the Great Crested, and considerably larger than the Slavonian, the next in size. In winter, when it looks very black and white, the lower part of the face is still a good character, the white in strong contrast to the dark cap. If within range of glasses it can be distinctly seen that the cap extends to the eye, whereas in the Great Crested there is a white stripe above the eye. It is a stockier, less slender bird than the last, and its stout, short 


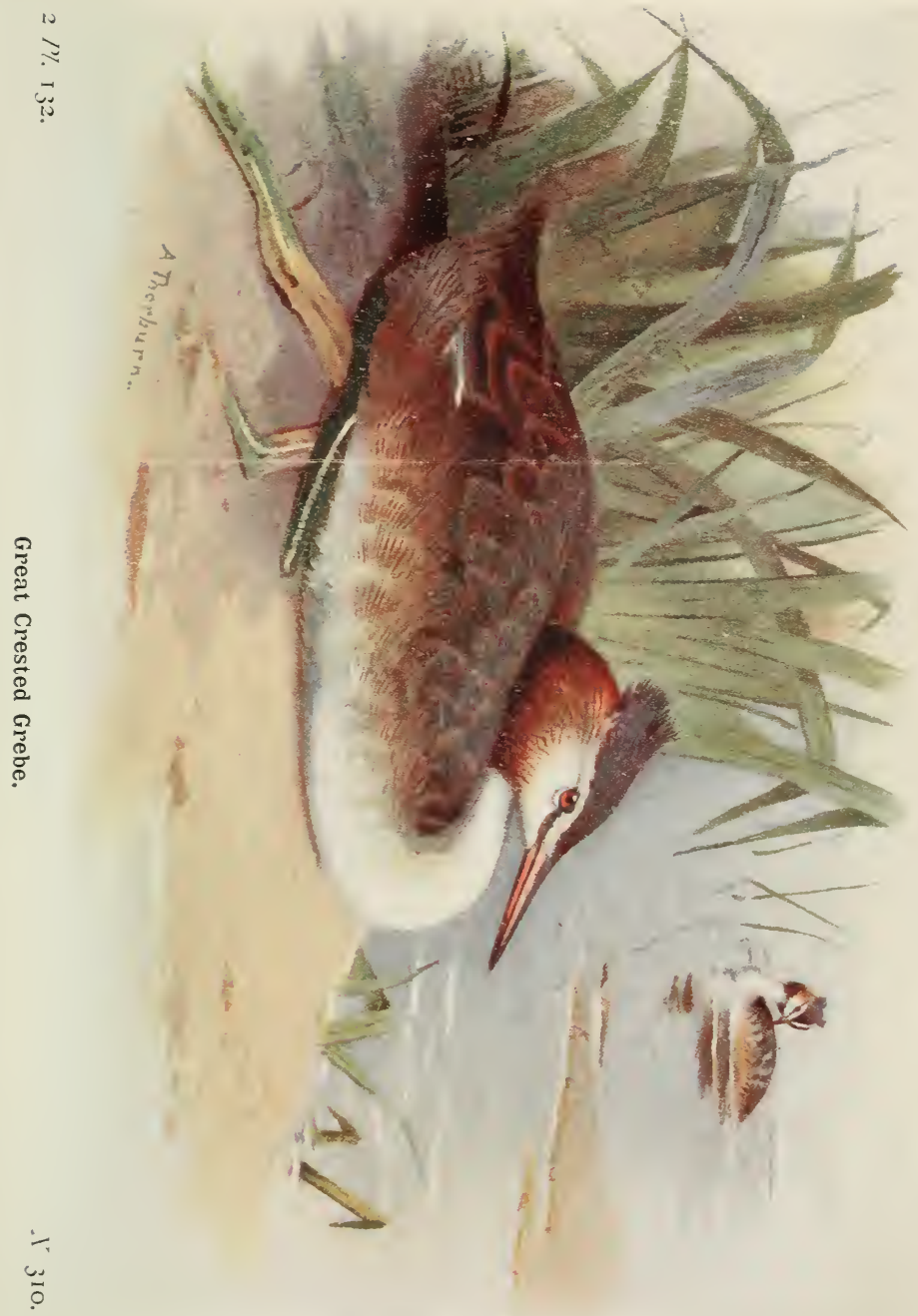




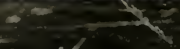

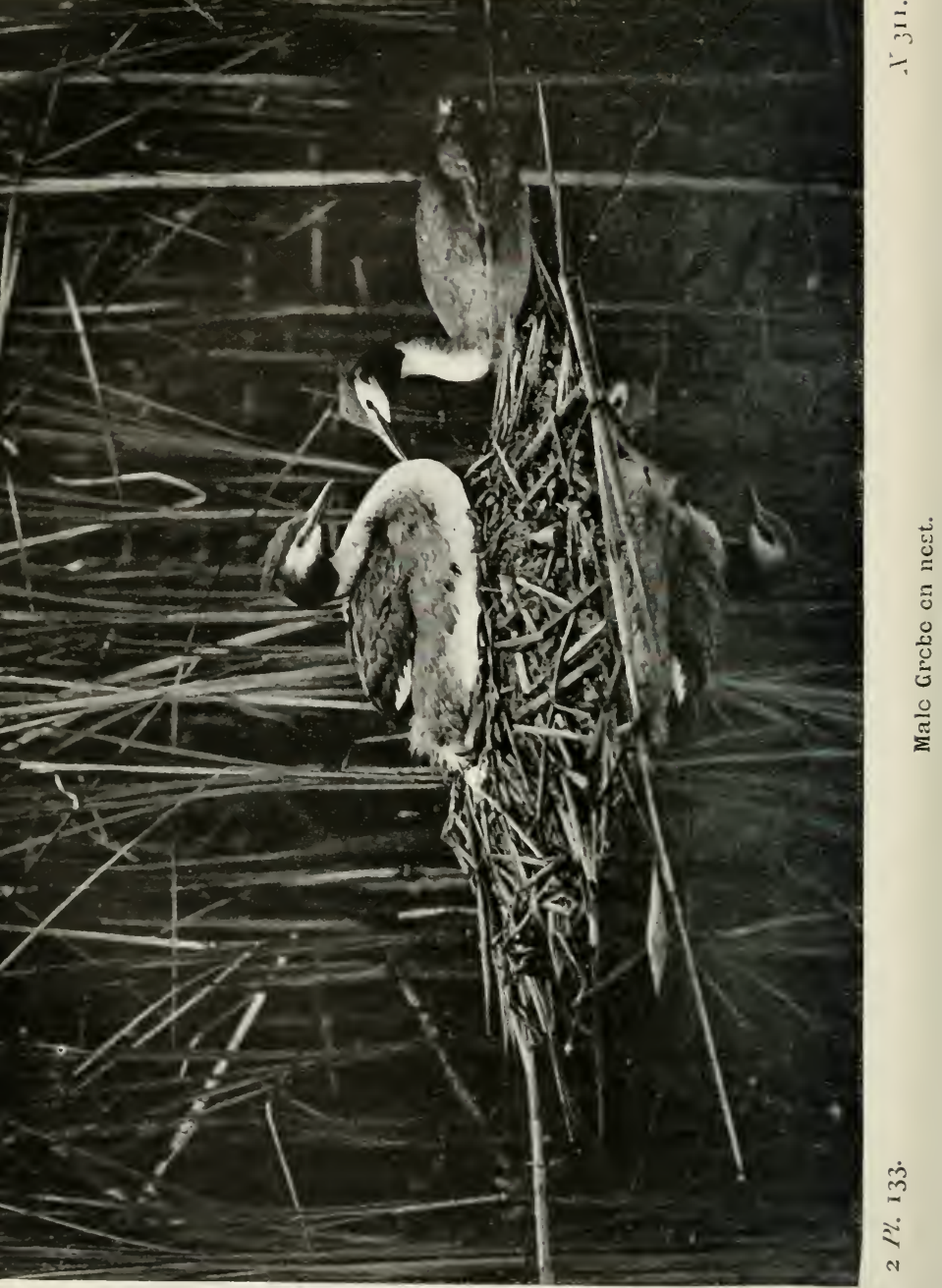


reck is carried well erect. A broad white border to the wing is very conspicuous in flight, and the forward edge of the wing is pale as far as the carpal joint. The swimming, diving, and feeding habits closely agree with those of the last species, and its voice, which is seldom heard in Britain, is said to be similar ; it is, however, less averse to terrestrial progression. Mr. G. Bolam says that it "walks upright," and saw one disabled bird hop rapidly down the beach. I have not seen the British bird on land, but a captive American Red-necked Grebe, $P . g$. holbcllii Reinh., stood with ease and grace, bending the tarsus but little, and walked as naturally as a duck. Crustaceans, molluscs, and fish are eaten, and in fresh water aquatic insects. When a fish is brought to the surface it is gripped until its struggles have ceased and then swallowed head foremost ; one bird I watched did not toss its prey, nor even jerk its head up, but shifted the captive in its bill until it slipped down.

The upper part of the head and back of the neck are glossy black in summer, when the ear-tufts are prominent; there is no ruff. The chin and cheeks are suffused with pearl-grey, bordered from the bill to the eye with pure white. The upper parts are greyish brown, the sides of the neck and breast rich chestnut, the flanks rufous grey, and the rest of the under parts silky white with underlying grey mottles. The bill is black, yellow at the base; the legs are greenish black, the irides carmine, but yellower in young birds. The ear-tufts are much reduced in winter, though the bird retains a flat-headed appearance, and all the neck colour is lost; grey flecks often show on the breast, and the bill is yellower. For.some time young birds show traces of the neck streaks; one, in which the red neck and ear-tufts were well developed, had the cheeks crossed by two pale brown bars. The size is variable; the American sub-species mainly differs in size, being on the average larger than ours. It is possible that large examples may have transAtlantic origin. Length, I 8 ins. Wing, 7 ins. Tarsus, 2 ins. 


\section{Slayonian Grebe. Podiceps auritus (Linn.).}

The B.O.U. Committee make a great mistake in trying to make the English name of the Slavonian Grebe (Plate 135) agree with the specific name; Eared Grebe has long been associated with the next species; Horned Grebe is the only accepted alternative. This bird has a northern range in Europe, Asia, and America, and it reaches the Mediterranean and Gulf of Mexico in winter. There is some evidence that the bird has nested in the Outer Hebrides and elsewhere, and proof from one Scottish locality, where in the year that the nest was discovered a bird was shot, and in the following year eggs were robbed by collectors. As a winter visitor and passage migrant the Horned Grebe is regular on most coasts, even in the west and south; inland, too, it is so frequently noticed on some waters that the old "storm-driven" idea must be rejected.

The Slavonian Grebe likes calm water, either inland or in estuaries and sheltered bays. There it swims, rather high in the water, with the neck straight, and, if uneasy, nervously glancing right and left. The erectile horns are tufts of buffish chestnut feathers, extending from the eye and projecting above the nape; they are darker than the tufts of the Eared Grebe and are not splayed out; there is also, in summer, a frill or ruff, but it is shorter and less noticeable than that of the Great Grested Grebe. The lower neck of this species is deep chestnut, in the Eared it is black, but the two look about the same size, and when the summer characters are lost are difficult to distinguish. Both appear black and white on the water, but the bill of the first is stout, and the upper mandible curves down towards the tip, whereas in the Eared Grebe it is slender and has a slight upward tilt. A Horned Grebe in the hand may be told by the absence of white on the primaries. A few birds appear late in August, and passage continues until November; from April to June northward movements are in progress, but 
in winter it is seldom numerous. Late in March some are in winter dress, though early in the month others have attained nuptial plumes; individual variation is remarkable, but probably Audubon was correct that old birds attain the summer dress sooner than the young. In winter mature birds have very white cheeks.

On inland waters, at any rate, the Slavonian Grebe readily takes wing, and when flying the neck does not always incline downward like that of the Great Crested; the wing bar-the inner secondaries are white-is broad and conspicuous on the open wing, but seldom shows as more than a small white line when the bird is swimming. It is a quick, expert diver, never long below the surface, and feeds on fish, crustaceans, molluscs, insects, and weeds. The smartmess of its dives is signified by its American name, also given to other grebes, of "HellDiver." One bird I watched dived superficially; its progress was shown by a ripple on the water. The nest is a mass of decomposing weed, floating in aquatic vegetation or built from the bottom in shallow water. Four eggs, laid in June, are usual; they are greenish white, averaging $I^{*} 7$ by $I^{*} 2$ inches (Jourdain), and are soon stained with vegetable juice. The young are striped brown and white, especially on the head and neck, and have a bare red patch. The statement, also made about the Dabchick, that the old bird dives for safety with the young under the wing is perhaps correct, though misleading; the young are carried on the back, and, when the parent dives, may be held there for a time under the secondaries or scapulars, but they soon come up to the surface like corks.

Except for the horns, the head, frill, and upper neck are glossy black in summer; the rest of the upper parts are browner; the lower neck, breast, and flanks are rich rufous brown and the abdomen silvery white. The head and neck decoration is lost in winter ; the under parts are white, but often show dusky mottles on the breast and flanks. Immature birds 
have the cheeks clouded. In mature birds the bill is blueblack, yellowish at the tip, red at the gape, and with a pink streak from bill to eye. In winter and immature dress it is bluish grey, with the base and tip yellow. The legs are greyish blue, the toes edged with yellow, and are greener in summer. The irides are reddish orange in mature birds, and there is a fine white circle round the pupil; they are pinker in young birds, and perhaps in winter. Length, 13.5 ins. Wing, 55 ins. Tarsus, $I \cdot 75$ ins.

\section{Black-necked Grebe. Podiceps nigricollis Brehm.}

The Black-necked or Eared Grebe (Plate 137) nests in central and southern Europe, in Asia and Africa, and is partially migratory. In the British Isles it is a winter visitor and regular passage migrant or summer visitor, for it is struggling to establish itself. It is more a fresh than salt water species and appears with some degree of regularity on certain western waters, which it may eventually colonise. The earlier history of its British nesting is obscure; the best evidence is from Norfolk, and there is reason to believe that it has nested in Oxford, Perth, and Ireland. How long the Welsh colony had existed before it was discovered in 1904 by Messrs. Cummings and Oldham is unknown, but when a few days later I was able to join them we found that several pairs were nesting, and already had young. For obvious reasons we kept the locality secret, only showing it to Mr. O. V. Aplin, Prof. Newstead, and one or two others; some years later it was discovered. In 1918 at least two pairs established themselves and brought off young on the reservoirs near Tring, where it is hoped they will be protected, though attempts have been made to rob the nests.

The Eared Grebe is siightly smaller than the Slavonian, and when swimming is, like a Dabchick, very broad in the stern, 


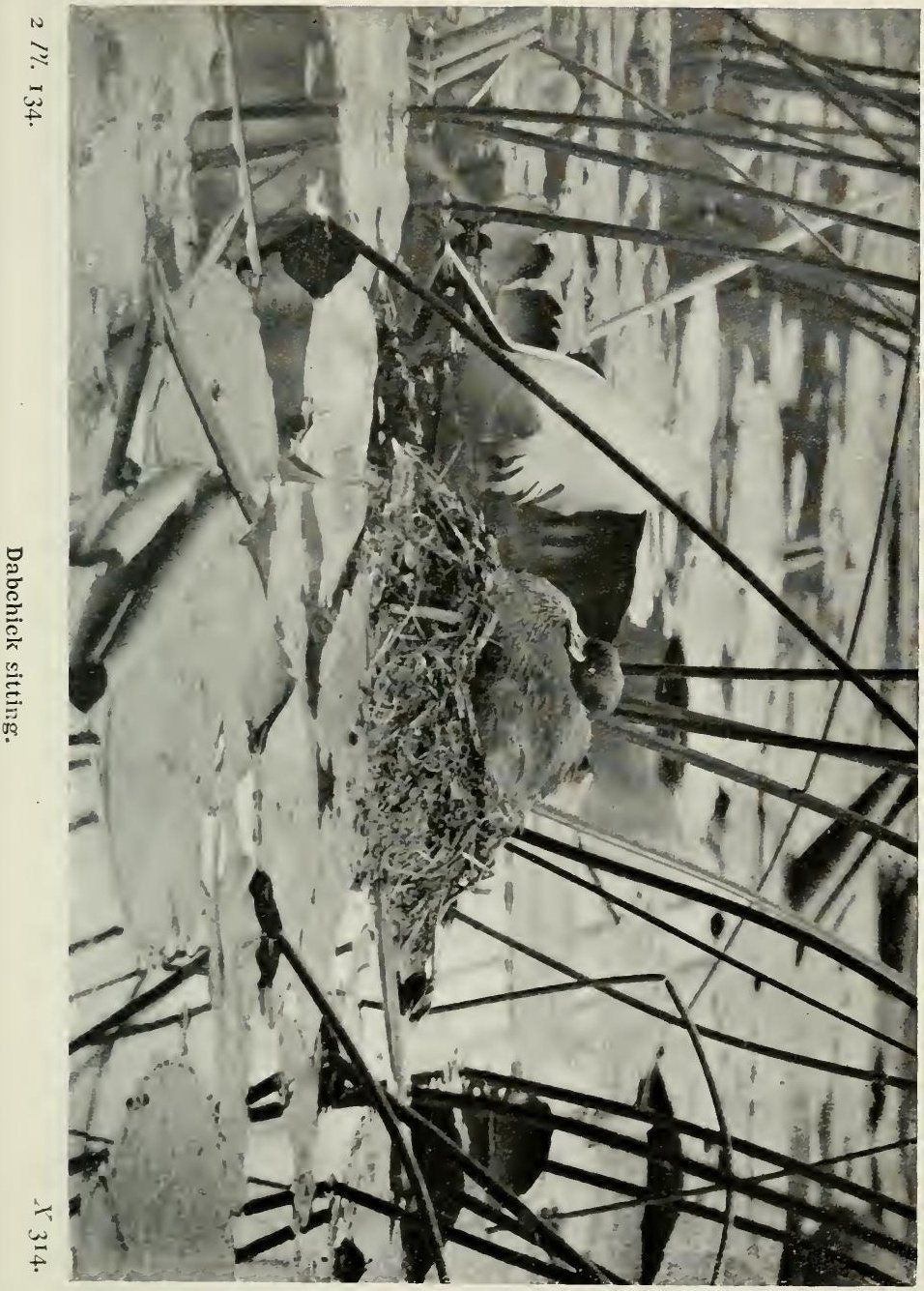




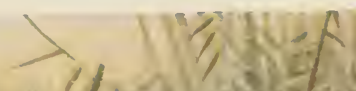


but carries its neck more erect. The distinctive summer characters, in addition to glossy black upper parts, are the silky golden-straw feathers which extend across the ear-coverts, fanned out over the cheeks, and the rich copper flanks. In winter the slender, uptilted bill distinguishes it from the Horned Grebe, and in the hand it can further be told by the white which extends from the secondaries to the inner webs of the primaries. This white is usually hidden by the puffed-out flank feathers when the bird is swimming, but shows plainly in flight or when the wings are flapped. The bird swims buoyantly, unless alarmed sitting high; the erectile feathers of the crown usually rise abruptly from the bill, giving the appearance of a very high forehead, but there are no distinct eartufts. The duration of timed dives was never more than thirty seconds, and when the bird dived amongst potamogeton and other water plants was often under ten. Molluscs and aquatic insects are eaten, and I have seen small fish given to the young. Insects are captured on the surface with the rapid right and left snatches of a Phalarope. I saw one bird feeding on caddis worms; it bit and shook the case until the larva was ejected. The calls are soft, and the trill, not unlike that of the Dabchick, is less of a rattle and rather short, though loud and clear. The hunger-cry of the young is milder and quieter than that of the Great Crested. The nuptial display, so far as I saw it, had much similarity to that of the larger bird; there was the same upright pose, breast facing breast, gently toying with one another's bills, dipping of the head and neck, and approach with necks outstretched on the water.

The nest, similar to that of the Dabchick, is a large collection of decaying weed, usually floating, moored amongst pond-weed, bog-bean, or other aquatic vegetation. Three or four eggs are normal; they are of the same blue tint as those of the Great Crested, and are coated with a chalky deposit which is speedily stained with brown and grecn. Mr. Jourdain gives the average 
size as $I \cdot 7$ by $I \cdot I$ inches. In Wales they are laid early in May. The nestling is ashy grey above and white below; the neck and head are streaked, there is a bare patch on the crown, and the bill is lead-blue. At first the parents carry the young, though they are often shaken off, and I saw one old bird repeatedly duck a nestling, as if trying to induce it to dive; they will, when young, dive a little for food, and three in down instinctively dived when a Black-headed Gull passed over.

In summer the head, neck, breast, and back are glossy black, and the wings have a greenish sheen; the cheeks are crossed by silky straw-coloured plumes; the flanks are coppery chestnut, and the under parts white. The male is distinctly larger and has more pronounced ear-coverts. The bill is blue-black, reddish at the base; the legs are blackish green, and the irides ruby-red. In winter the head often to below the level of the eye, the back of the neck, and mantle are brownish black, and the flanks are mottled with grey; except for a dusky band on the lower neck the under parts are white. In the young in autumn the cheeks and necks are dusky, and the irides are yellowish. A bird watched in spring was browner on the flanks in the middle of March, early in April the cheeks became dusky, and full plumage was attained in the third week, but probably, as in all grebes, the date of assumption of summer dress is variable. Length, 12 ins. Wing, 57 ins. Tarsus, $r \circ 5$ ins.

\section{Little Grebe. Podiceps fuviatilis (Tunstall).}

Dabchick is a widely used name for the Little Grebe (Plate 137 ), a familiar resident in most parts of the British Isles. It ranges through central and southern Europe, a large part of Asia, and northern Africa, and is partially migratory, though it is likely that its frequent collision with lighthouse lanterns is due to nocturnal wandering rather than regular migration. 
Frost drives the Dabchick to the coast, but it also visits estuaries and tidal gutters for food, independently of weather.

The smallest of the grebes is much rounder and squatter than its congeners, and usually swims with the neck curved; it is, however, the absence of tail, and its habit of fluffing up the feathers of the hinder end-tail-coverts by courtesy-which gives it a characteristically bluff finish. Macgillivray, speaking of the bird in flight, describes "its large paddles projecting beyond its blunt end." Its bill is short and stout. The bird is browner than the Eared Grebe, and has neither tufts nor frill; in winter it is still browner on the upper parts. It flies frequently, with a quick flutter of short, rather rounded wings, and if disturbed near the bank, will fly for a dozen yards and dive immediately it drops. The white on the inner webs of the secondaries hardly shows in flight, and not at all when swimming; it is concealed by the overlap. "Ducker," "Dowker," or "Dipper," of the vernacular, indicate its habits ; it is a persistent diver, slipping under without surface disturbance, or with a vigorous plunge, kicking up a little shower of spray with its lobed feet. Dives may last twenty-five seconds, or the bird may reappear immediately; I have seen it bob up stern foremost. In clear and shallow water its movements may be observed; I have exercised it in my bath and watched it in a stream, and never saw the wings used, even when turning; they are tightly held to the sides. On the surface, when not hurried, the foot strokes are alternate, but under water it progresses in a series of rapid jerks, vigorously rowing itself along. At the beginning of the stroke the feet are at right angles to the body, at the finish they almost meet behind the so-called tail, and the half rotation of tarsi and toes, already described, is very distinct; so lateral is the stroke that a bird swimming at the bottom does not stir the mud. Air bubbles clinging to the feathers give it a silvery, filmy appearance under water. After a dive a Dabchick, if nervous, protrudes the head and 
body only, and often swims to the side, sheltering under the bank with the bill alone above the surface, where it holds itself in position by gentle circular strokes. Birds thus hiding may be taken from the water; I have captured several. When held in my hand the feet stuck out at right angles, and remained in that position when the birds were placed on the ground ; they fell forward on to the breast. This impotence is delusive ; one bird, placed on the bank, took a sudden spring into the water and dived, and another, released further away, sprang up and ran rapidly on its toes, then flew to the water, struck with its breast and ricochetted two or three times before it dived. A captive Dabchick stood and walked well, its tarsi slightly bent, and when resting- $\mathrm{a}$ ball of feathers-held the legs well up, the toes forward, and the tarsus crossing the tibia, in the manner first described by Prof. Newstead. Fresh-water molluscs, crustaceans, and insects are the main food, but small fish are captured, and occasionally unwisely. I found one bird with a three-inch bull-head, Cottus gobio, fixed in its distended gape, the gill spines of the fish deeply embedded in the bird's mouth; I have heard of similar fatalities. The call is short, a soft, subdued note, not unlike the whistle of the Teal, but the rippling trill is loud and clear, a rapidly repeated double note, which begins suddenly and runs down the scale.

The nest (Plate 134), usually floating, is a large collection of weeds, mostly brought from under water, and the eggs are normally covered when the bird is absent. I saw one bird conceal the eggs with four smart right and left pecks, and slip into the water, in three seconds. Four to six white, but soon stained, eggs of the usual grebe type are laid in April, but later clutches are common; the size is about $\mathrm{I} 44$ by $\mathrm{I}$ inch. The young have brown and black clown streaked with white, and can dive as soon as they take to the water, but prefer to snuggle under the parental scapulars. The old birds dive when the young are on their backs, but the little ones rise like corks 

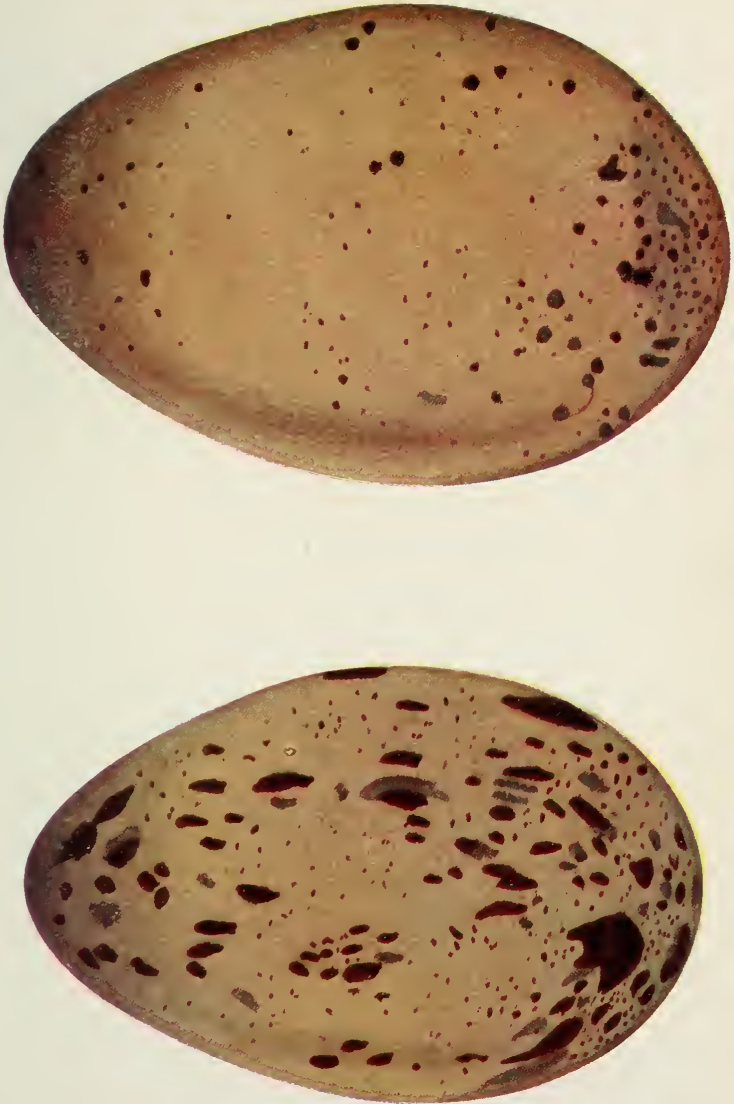

Black-throated Diver.

Red-throated Diver. 

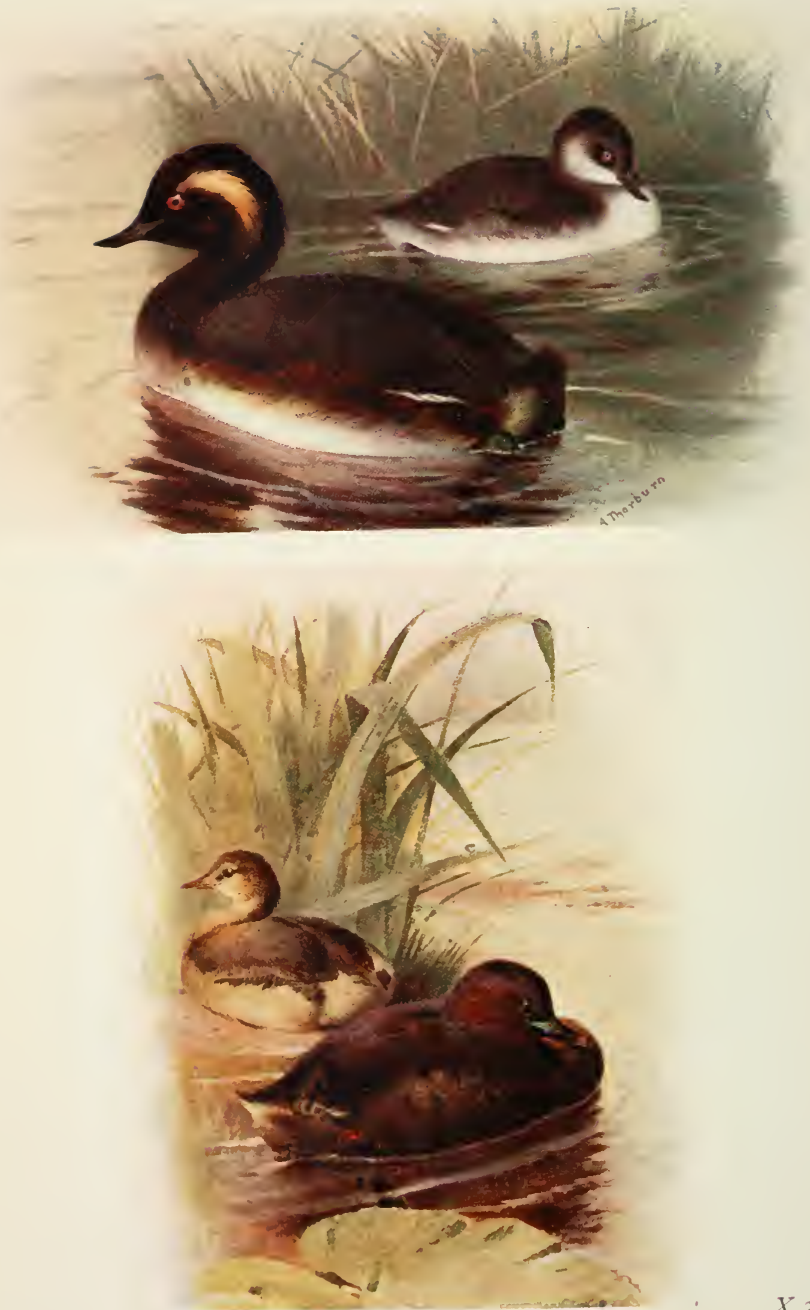

Black-necked Grebe (Summer and Winter). 
and anxiously look for the reappearance of their bearers, when they scramble back over the parent's tail. There is no proof that they are carried down under the old bird's wing.

The head and upper parts are dark greyish brown, almost black, in summer ; the chin and breast are black, but the cheeks, throat, and sides of the neck are warm chestnut, and the flanks are brown. The under parts below the breast are variable, blackish but with a silky, silvery sheen which gives the impression of grey. The bill is brownish horn, pale at the tip and base, and a fold of skin at the gape is greenish yellow. The legs are dark olive, and the irides dark brown. The upper parts are lighter and browner in winter, and the under parts, including the lower face, are silvery white, suffused with brown on the lower neck and breast. Young birds have dusky streaks on the head and are an even lighter brown. Length, ro ins. Wing, 4 ins. Tarsus, I*25 ins.

\section{Order RALLIFORMES.}

Family RALLID E.

Short, rounded wings; bills variable; feet large ; toes long, with (Moorhen, Coot) or without swimming membrane (Rails).

\section{Water-Rail. Rallus aquaticus Linn.}

Owing to its secretive habits so little is known about the Water-Rail (Plate 138 ) that its real status is uncertain. That some migrate is clear, but whether those which breed remain to winter or emigrate is unknown; as, however, birds frequently strike the lanterns, sometimes when travelling in parties, I believe that there is regular passage migration, but reserve an open mind about permanent residence and winter visitation. The Water-Rail is present at all seasons throughout England, 
Ireland, and the south of Scotland. Our race inhabits Europe, western Asia, and north Africa.

The presence of the Water-Rail is often unsuspected by those who are unfamiliar with its habits, do not know its voice, and fear to wet their feet. It is a bird of the marsh, hiding effectively from view in dense aquatic vegetation. Its laterally compressed body, for it has a remarkably narrow sternum, enables it to slip between closely set stiff reeds which would hold up a Moorhen. From other rails it can be recognised by its long, slightly decurved, red bill, and by the black and white transverse streaks on its flanks. These streaks aid concealment when the suspicious bird stands motionless in vegetation; instinctive "freezing" is common. Anxious and nervous, it hesitates to take wing, but if surprised flies heavily with its long legs limply dangling. That it can fly fast and for long distances is proved by its death against lighthouse glass, and the loss of a wing or other injury when, during nocturnal migration, it has struck a wire. Its gait is graceful; it lifts its long, widespreading toes, useful when tramping a quaking bog, with delicate, cautious deliberation. When unaware of human presence it holds its head up, and elevates its tail, frequently jerking it like a Moorhen, exposing the yellow and white under tail-coverts; but if alarmed the head and tail are depressed, and with a swift run the bird vanishes into cover. It swims well, swimming in preference to flying over water. Its calls are varied; one is half groan, half squeal, and another, tichif, tchuf, has a contented tone, and is rather deliberately repeated. But the most noticeable sound is a loud explosive yell, like the cry of an animal in mortal agony; this it will utter when startled by any sudden sound, and also, apparently, for the pleasure of making a noise. When I was at one nest I was startled by an awful groaning scream apparently at my feet, but it was some time before I put the bird up. Miss E. L. Turner heard both male and female utter a curious purring note when they were 
umaware of her presence. Insects, worms, molluscs, berries, seeds, and, occasionally, grain are eater.

The nest is composed of flags, reeds, sedges, or whatever vegetation is handy, and is supported on a platform of bent and broken stems, almost invariably in a very wet and treacherous situation; it is often raised six inches or more above the water. The bird approaches by well-trodden but narrow tracks (Plate I39), and always with a suspicious carriage. Seven to twelve light buff or brown, rather sparsely spotted eggs (Plate 153) are laid in April, and both birds sit. The nestling is a downy, blue-black ball with absurdly big feet and a short bill; it has a feeble cheeping cry. Miss Turner managed in the course of ten minutes to obtain a series of pictures of the female removing two chicks, and three eggs, after the bird had realised that the nest had been discovered; one unchipped egg gave her trouble, but she managed to carry it in her wide-open bill.

The upper parts of the Water-Rail are chestnut streaked with black, but the crown is tinged with olive. The sides of the face, neck, and breast are lavender, and the flanks strongly barred with black and white, above the buff abdomen. The bill is red, blackish on the culmen; the legs are greenish brown, and the irides claret-brown. In winter the bill is duller, more madder in shade, and the general colour is browner. Young are tinged with olive above and are buffer below, and the throat is slightly mottled with brown. Length, $11 \cdot 5$ ins. Wing, 475 ins. Tarsus, $1 \cdot 7$ ins.

\section{Spotted Crake. Porzana porzana (Linn.).}

The Spotted Crake (Plate 138) breeds in most of Europe, north Africa, and western Asia, and winters in Africa and India. It is decidedly migratory, and though some nest, as summer visitors, in England and Wales, and less frequently in Scotland and Ireland, it is best known as a regular passage migrant. A few remain all winter.

Series $I I$. 
Much smaller than Water-Rail or Moorhen, this bird may be distinguished by its spotted olive-brown dress and brown barred flanks; the other small crakes are not spotted on the face and neck. Even more skulking than the last species, the opportunity it affords for observation is usually brief-a fleeting vision of a running form which might just as well be a rat. Even a dog finds difficulty in flushing the bird from the deep bogs and marshes that it normally frequents, but it is a vigorous nocturnal migrant, and when it meets with a telegraph wire or other obstacle, or is attracted by the rays from . a lighthouse, it comes to grief. The "wired" corpse is more familiar than the living bird. When swimming it looks small, like a diminutive Moorhen, bobbing its head in time with its spasmodic forward jerks. I have not seen it on the wing for more than a few seconds, and only on land when running rapidly. Its food is both animal and vegetable, similar to that of the WaterRail. No doubt the Spotted Crake has various cries, but I have only heard one, a loud, ticking call, quite distinct from the squeal of the Water-Rail or other of its notes. It is not only nuptial, for I heard it from a bird which rushed into a reed-bed in November; - a loud, regular tchack, tchuck, was repeated two or three times. At about 3.30 on a May morning, at the edge of an impassable Cheshire marsh, I heard a low tick, tack, rather like the note of a Snipe, which rose quickly in pitch and volume until it throbbed like a piston-tchick. tchuck, tchick-tchuck, every second. It stopped suddenly, and after a pause again began low, ascending until the air seemed to vibrate. This throbbing repetition, with its sudden end, was continued for about half an hour.

The nest is in a marsh or bog, on a tussock or platform of broken stems; it is built of aquatic plants, and often has a concealing bower of living stems bent over it. The eight to twelve eggs, buff with dark red and sepia spots as a rule (Plate I 48 ), are laid in May. The down of the nestling is black. 

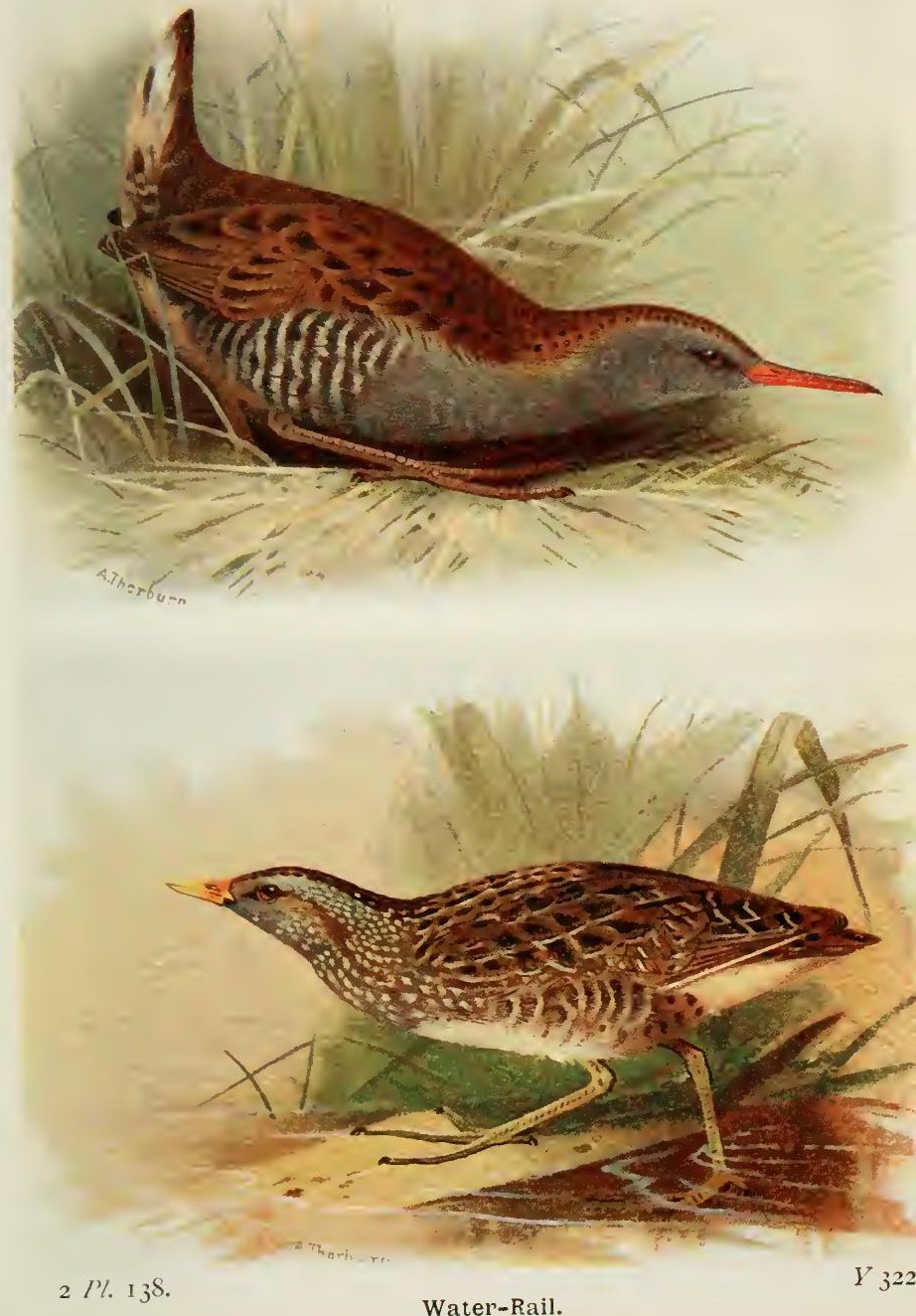

$2 \mathrm{Pl}{ }_{13} 8$.

Water-Rail.

Spotted Crake. 
The crown of the mature bird is dark brown, and the upper parts are chestnut, streaked with black and speckled with white ; the under parts and the side of the face are greyer, and the spots are most abundant on the face and neck. The outer web of the first primary is white, and the flanks are barred with brown and white. The bill is yellow, red at the base ; the legs are yellowish green and the irides reddish brown. The chins of immature birds are whitish and the spots are less plentiful. Length, 9 ins. Wing, 4775 ins. Tarsus, $1 \cdot 25$ ins.

\section{Carolina Crake. Porzana carolina (Linn.).}

The Sora, the American name for this rail, breeds in Canada and the northern States, and winters in Central and South America. It has been noticed as an accidental autumnal visitor to Greenland, and some five birds have, apparently, taken an eastward as well as southern course and reached the British Isles. The earlier records are from Berkshire and Glamorgan, but recent examples were obtained in the Hebrides and Ireland. The mature Sora has a black forehead, face, chin, and throat, and its upper parts are streaked rather than spotted with white. The cheeks, neck, and breast are bluegrey and unspotted, and the flanks are barred with black and white. The bill, legs, and irides are much as in the Spotted Crake. Length, $7 \cdot 5$ ins. Wing, $4 \cdot 2$ ins. Tarsus, $1 \cdot 3$ ins.

\section{Baillon's Crake. Porzana pusilla intermedia (Herm.).}

The two small crakes are frequently confused, and many early recurds of the Little Crake doubtless refer to this species, which, though uncommon, is less rare. Baillon's Crake (Plate 140 ) is a central and southern European species, and also occurs in Africa and western Asia, the eastern form being $P . p$. pusilla (Pallas). In the northern part of its range it is 
migratory, and passage birds occur from time to time, mostly in southern counties, though it has visited Scotland and Ireland. A few have been observed in winter, and rather more in summer; indeed, it is said that nests were taken many years ago in Cambridge and Norfolk. As the bird breeds in Holland, and as the localities from which the information came are suitable, there is nothing impossible nor even improbable about these statements, but collectors have been so freely exploited that without further proof the records will remain doubtful.

Like the Spotted Crake this nocturnal traveller turns up in unexpected places, often beneath telegraph wires. It differs from this species in size, being even smaller than the Little Crake, and in the fact that its neck, breast, and face are unspotted, and that its under tail-coverts are barred and not uniform buff. It agrees with it in having a white border to the first flight feather, and this distinguishes both from the Little Crake in which it is uniform brown; further, its flanks as well as its under tail-coverts are barred, though in the Little Crake the flanks are uniform grey. In habits, food, and appearanceor rapid disappearance-both have much in common with the last species; it is a shy marsh bird, swimming and diving for food, or walking daintily across the floating weed. The nest is a neat cup in a tussock, often concealed by bent stems, and usually surrounded by water. The eggs, six to eight, are yellowish, closely marked and speckled with greenish brown.

The upper parts are brown, streaked with black and white, the white being on back and scapulars and sometimes on the coverts; the under parts, including a stripe above the eye, are slate-blue, except on the flanks and under tail-coverts, where they are black barred with white. The female is a lighter brown, and the young bird has the under parts buff, indistinctly barred. The bill is green, red at the base ; the legs are greenish, and the irides red. Length, 7 ins. Wing, $3^{\circ}+5$ ins. Tarsus, $I$ in. 


\section{Little Crake. Porzana parra (Scop.).}

The Little Crake (Plate I40) breeds in southern Europe, southwestern Asia, and northern Africa, and winters in the southern part of its range as well as further south. It has occurred occasionally, chiefly on passage in spring and autumn, in various southern counties, and more rarely in Scotland and Ireland.

The absence of the white edge to the first flight feather, and of white spots or streaks on the wings, though present on the back, are characters in which it differs from its congeners. So far as the British Isles are concerned, its habits and appearance are similar to those of the others. It has not been suspected of nesting here, though recorded in summer, and its appearance in winter has been noted. The upper parts are olive-brown with dark streaks, and a few white dashes on the back; the rump is black. The under parts are slate-blue, and only the under tail-coverts are barred in mature birds. The female has the under parts buff, and her throat is white; the young bird is similarly coloured, but shows indistinct barring of brown on the flanks. The bill is green, red at the base; the legs are green, the irides red. Length, 8 ins. Wing, $4 \cdot 2$ ins. Tarsus, $1 \cdot 5$ ins.

\section{Corncrake or Land-Rail. Crex $\operatorname{crcx}$ (Linn.).}

The Land-Rail (Plate I43) is found throughout Europe and western Asia, and is a summer visitor to our islands, though, at any rate of late years, less plentiful in the south than further north and in Ireland.

Although its rasping voice is so well known that the Corncrake must be called a familiar bird, few who note its arrival in late April or early May have ever really seen it. They may have noticed its head above the growing grass, but like 
others of its kind it shows itself but little. Its general form suggests a game-bird; indeed, it is often called the "GrassQuail," and was included in the game list by the Act of 1860 . It is nominally protected by the Wild Bird Acts in England, but in Ireland may be shot from September 2oth to January Ioth, when, except for a few weeks, there is little chance of seeing it. Indeed, most leave during October, though a few remain all winter; instances of wintering, though occasionally recorded from the south, are more frequent in western counties, Ireland, and the Scottish islands. The Corncrake is a slender, brown, short-billed bird with barred flanks and rich chestnut wings, very noticeable in flight. Though really nocturnal in habits, the males in spring are so obsessed by nuptial instincts that they call day and night. If startled they will at times take wing, and occasionally fly from field to fie!d, though apparently with labour, the wings moving rapidly and the legs dangling loosely. In long-distance flights, however, the legs are trailed, though I have handled wired birds in which both thighs were smashed. There is a widespread popular notion that the bird cannot fly far, and must either hide all winter or hibernate; as a matter of fact it can fly fast and at an altitude, and is a long-distance traveller. Not only is it known as a winter visitor to South Africa, but it selects a long rather than a short Channel crossing ; it has been met with in Greenland, eastern Canada, Bermuda, and even in Australia. It is, however, fair to state that, like other rails, it can swim, and thus could rest on water.

The Corncrake walks with the head rather low and the neck drawn in, lifting its feet high like other rails (Plate $14 \mathrm{I}$ ), but it is a cautious, suspicious bird, and at the least sound cranes its neck for a better view, before running for cover. At times, like the Water-Rail, it stands still when anxious, allowing a near approach before it darts for shelter, and if captured will, at any rate occasionally, simulate death, hanging limply with closed eyes, but recovering instantly if opportunity of escape 

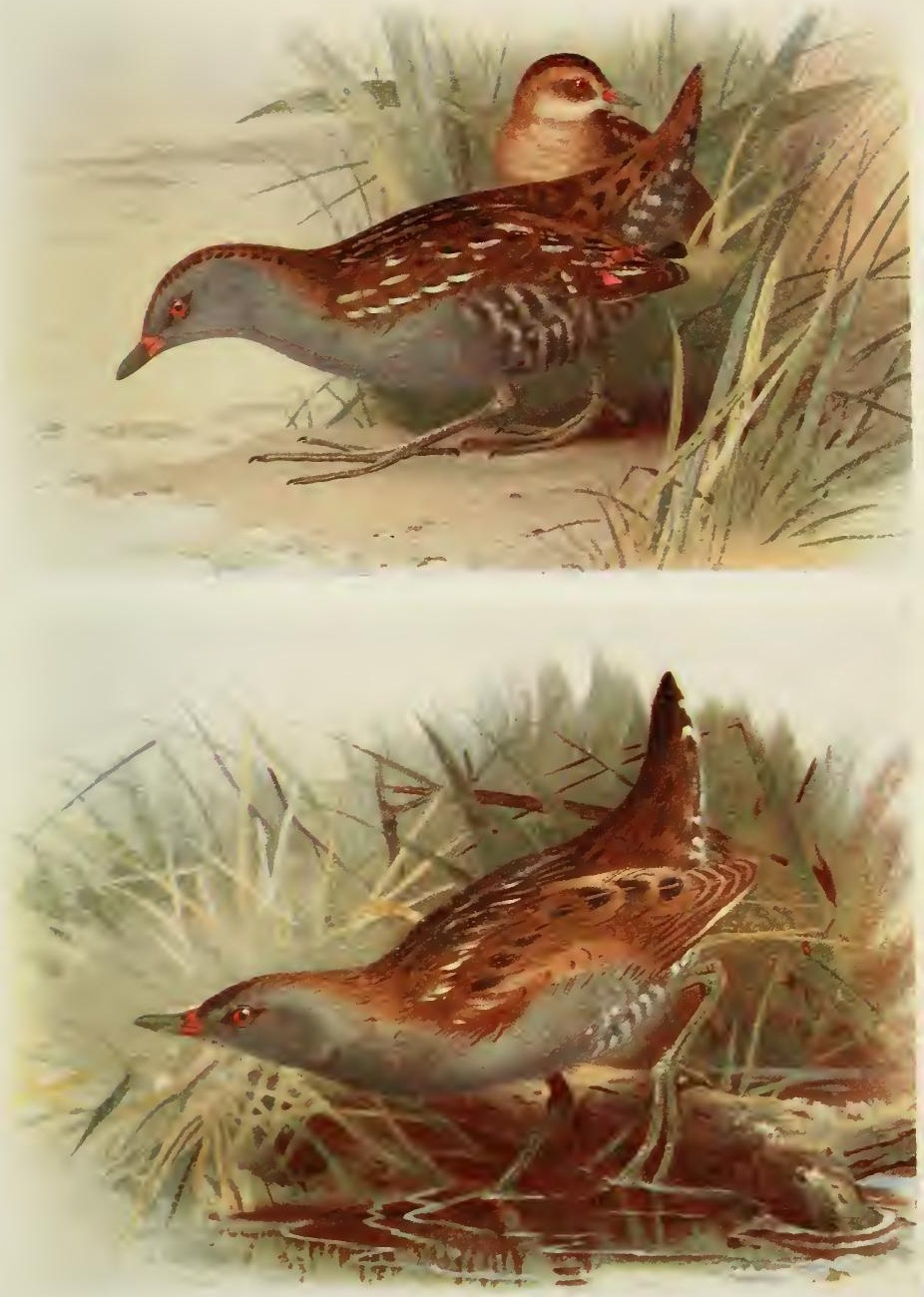

Baillon's Crake. 


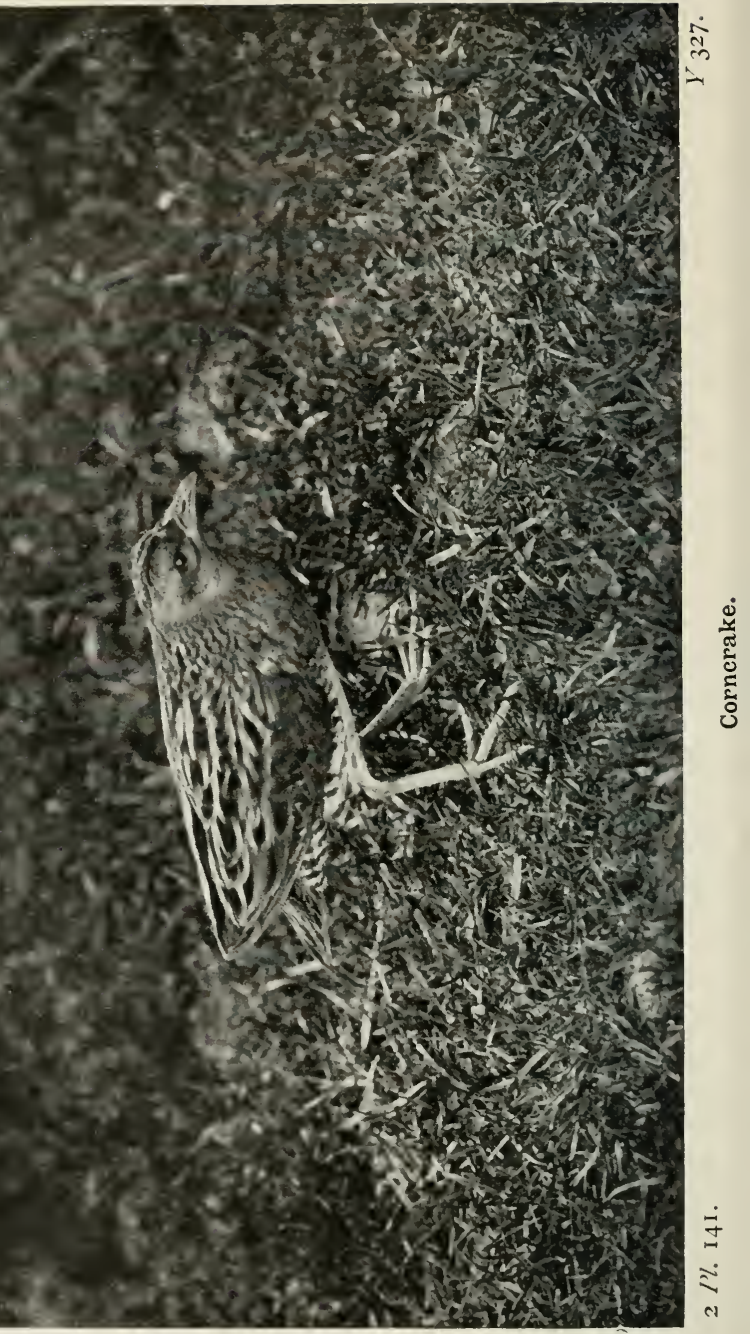


presents itself. Even when calling it keeps well hidden, though its head shows above moderately short grass when, pointing its bill upward, it calls its rasping crek-crek. Macgillivray says that in the Hebrides it often calls from a wall, but the habit is not common where there is long grass. In Wales, however, I saw, and very distinctly heard one, hurling its defiant double note heavenward from its perch on a high stone wall; every time it threw its head up its white chin was visible. The tone and appearance of the bird suggested challenge rather than love-call, for the males fight fiercely. The study of birds in captivity rather than field observation has proved that it has other notes; a grunting sound accompanies courtship, and an angry bird, attacking a rival or striving to drive away a predacious foe, will give a loud squealing threat.

The nest is commonly in a grass field, and often suffers when mowing begins, but it is sometimes in wet situations; the one figured (Plate I42) is in sedge. It is a grass-lined hollow, and at times the surrounding blades are bent over to help concealment. The eggs (Plate I48), usually eight to ten, or even more, are pale buff, sparsely spotted or splashed with reddish brown; they are laid from May onward, and though many nests are destroyed, it is probable that second broods are normal, for late nests are common. The nestling has long brown-black down, and is fed on insects, the chief food of the old bird, though worms, slugs, snails, and seeds are eaten.

The adult bird in summer is yellowish buff, streaked and spotted with dark brown; the wings are rich chestnut. The cheeks and a stripe above the eye are slate-grey, and the under parts buffish white with rufous bars on the flanks. In winter yellow replaces the grey on the face, as it does in immature birds, which have the flanks tawny and with only indistinct bars. The bill and irides are brown, the legs fleshy brown. Length, 10 ins. Wing, 5.25 ins. Tarsus, $1 \cdot 8$ ins. 


\section{Moorhen. Gallinula chloropus (Linn.).}

The Moorhen (Plate 145) has a wide range in Europe, Asia, and Africa, and is partially migratory. It is an abundant resident in the British Isles, and there are indications of passage migration.

Moorhen, really "Merehen," is descriptive, but less general than Waterhen. Any water-lake, pond, or river-suits the bird, the size regulating the number present in spring, for it is jealous of territorial rights, and two pairs cannot exist peacefully on one small water. The only birds with which it can be confused are the Coot, larger and with a white frontal plate, and the Spotted Crake, smaller and with no plate; in fact the vermilion bill and frontal plate give the bird its distinctive character. It has a perky, high-stepping gait, and a habit of flirting its tail and bobbing its head. It bobs and flirts when swimming as on land, progressing in a series of short jerks, usually holding the tail level with the water, but often raised so as to show the white under tail-coverts and the black line which centres them. If disturbed it scuttles over the water, half flying, half running, leaving a troubled trail behind as its toes splash the surface. Its long, slightly flanged toes enable it to walk over lily-pads and other floating weeds, and aquatic plants provide it with food, for it is practically omnivorous. Grain and seeds are sought for in the fields, even in the farmyards, at some distance from water, and berries, including garden fruit, are eaten. Animal food, however, is as welcome, and it has been, on slender evidence, accused of destroying eggs and young birds.

The Moorhen dives well, and is said to use the wings under water, not fully extended but held near the sides, half open; probably the feet are the chief organs of propulsion, as they certainly are in the Coot. Its power of partial submergence 
is well developed; it will swim under water to the bank, keep the body submerged, and protrude the bill only. I have seen the red plate amongst the grasses, and have cautiously lifted the hidden bird. Even newly hatched young will slip over the edge of the nest and submerge. The vocabulary of the bird is varied, and when males are fighting, a frequent occurrence, angry and explosive. The loud, metallic call, which sounds to me like fulluck, and another softer note, tcheco, are common; the young, begging for parental attention, have a squealing, complaining pitcheese, pitcheese. One cry, tit-a-tit, quickly uttered and not unlike a call of the Barn-Owl, is usually, though not always, a flight note. It is heard when the bird indulges in nocturnal wanderings, especially in spring and autumn, for the Moorhen has a curious habit of flying at night, even amongst houses, without apparent object. Display has been described, rather elaborately, but what I have noticed most has been the exhibition of the white under tail-coverts, as the bird swims with the fore parts low and the lower back and tail raised. Rival males fight like game-cocks, striking with both feet, even when on the water. Serious damage is sometimes done, and after pairing quarrels defeated males may be seen limping with broken toes and dislocated thighs. When pressing his attentions the male chases the female; as Miss Turner says, "he drives her from the open water, and then chases her up and down ditches, or through tangled grass" (Plate 144), though she probably has no real desire to escape.

The nest is a rather well-woven platform of flags, reed-blades or rushes, lined with grass, usually near the water's edge in low vegetation, or in the branches of an overhanging.bush. Sometimes it is in a tree at a considerable elevation and away from the water, its foundation being the old nest of some other species. I have seen it in a fir, and several times in rhododen. dron bushes many yards from water; the young in down toppled out of a nest in one bush, rolled down a steep slope and 
scattered, unhurt. Though the Moorhen looks rather awkward amongst branches, it keeps its balance well, even when on swaying twigs; indeed, it often roosts on a branch. Supplementary nests and platforms are constructed, though second broods are often in the first-used nest. The number of eggs varies, usually six to ten, and at times one or two eggs lie upon the others; they are buff or clay coloured with red and purple spots (Plate I48). Eggs in the middle of March have several times been recorded, but April is the usual month, and two or even three broods are reared; young of the first brood will, it is said, help to feed later nestlings. I have several times seen odd eggs of the Moorhen in the nests of Coots, and there are instances of Coots depositing an egg amongst those of the Waterhen. Exceptionally the bird covers the eggs when it leaves, but I have no recollection of seeing this myself, and only now and then have found a nest over which the blades had been drawn to aid in concealment. Most text-books, if they mention them at all, say that the nestlings are black, but for two or three weeks the coloration is remarkable. My description is from a bird just hatched. The down, for the most part, is black, though hoary round the eyes and on the chin and throat. Above the eye is a black line, and the crown is livid blue, passing through pink to orange on the nape. The sealing. wax red frontal plate tops an orange bill with a yellow tip and canary-yellow nail, and the legs are olive-green, much darker than in the adult bird. On the bastard wing is a distinct nail or claw, which, like that of the Hoatzin, is used in climbing. I saw a tiny bird scamble into the nest, using its wings as hands, and Mr. C. B. Moffat tells me that he watched a nestling climb from the water up a steep bank, three or four feet high, clutching the herbage with its wing-claw ; it repeated the climb after he had replaced it on the water.

The adult bird, and the young after the first autumn moult, is slate-black with deep brown wings, white under tail-coverts, 


\section{1) 100

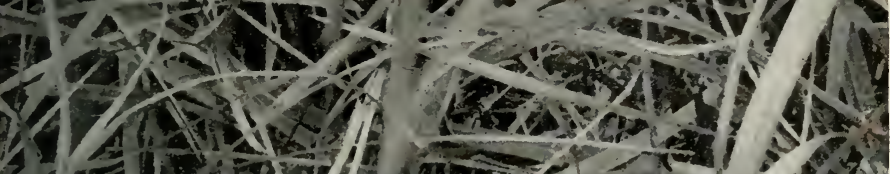

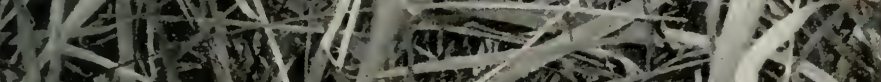

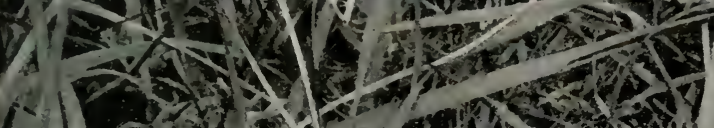

in

बा? $T$.

int

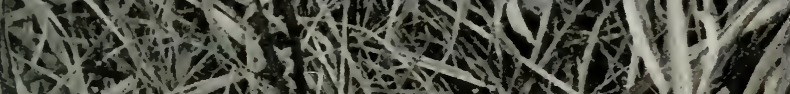

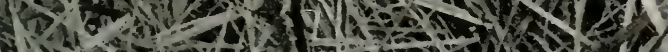

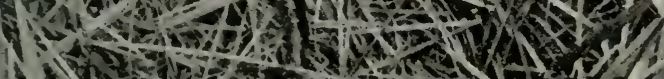

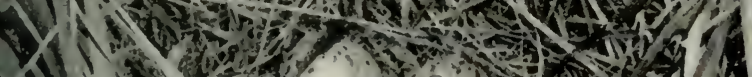
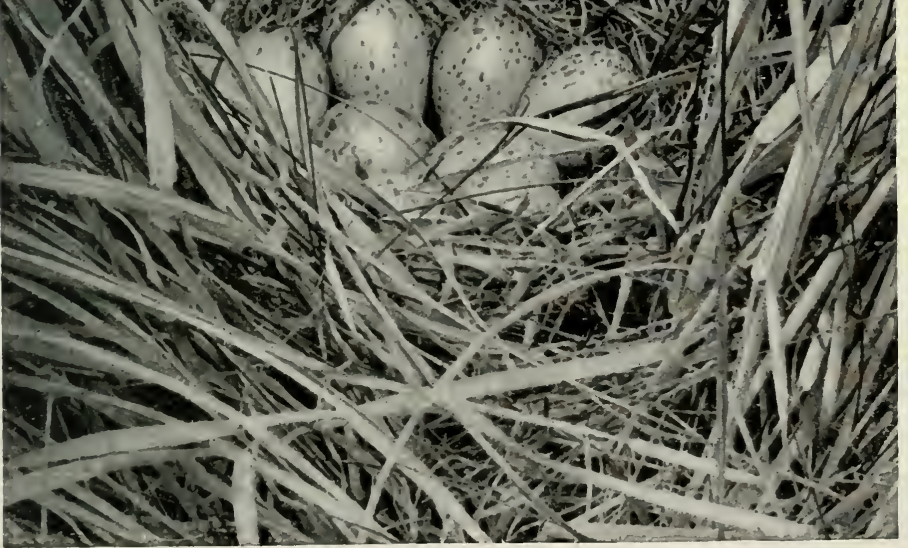

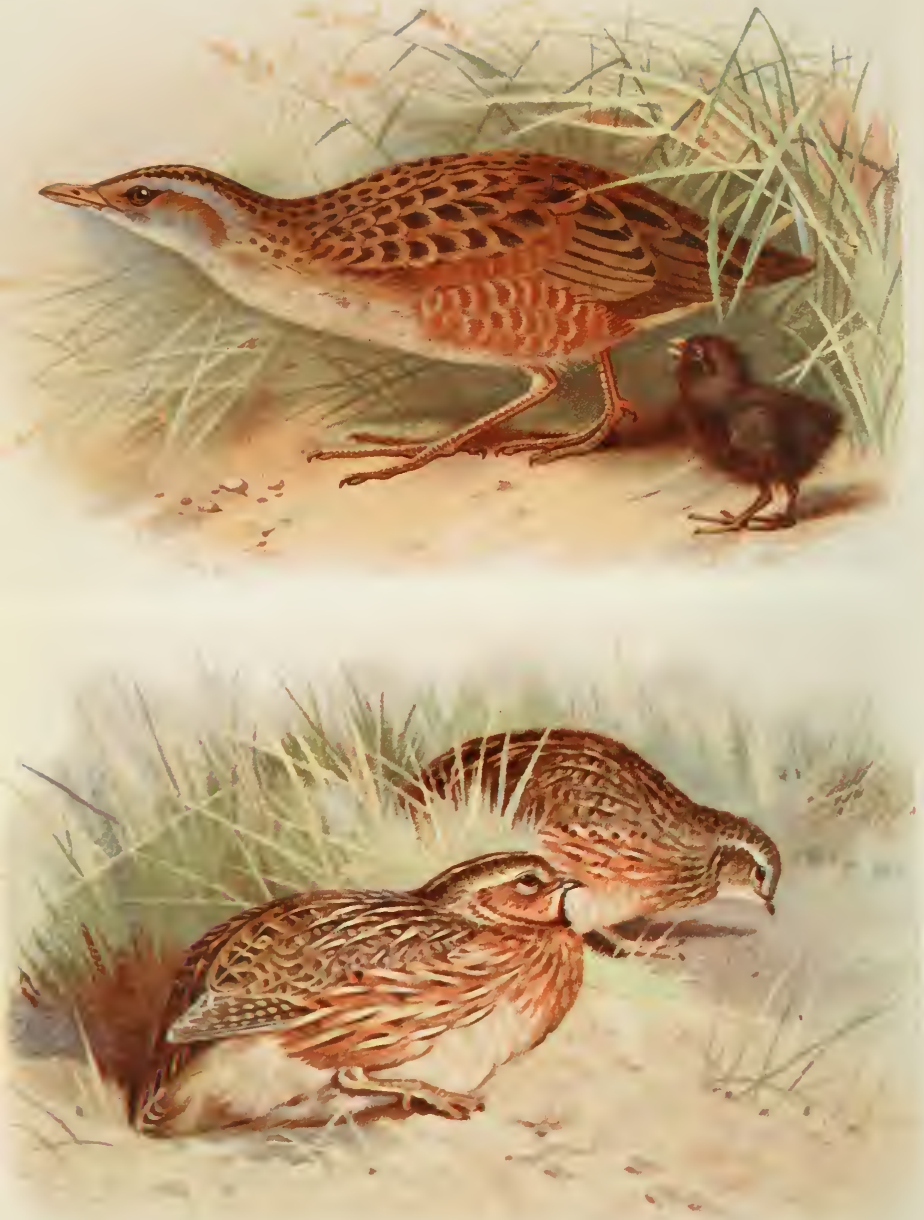
and a white line on the flanks. In first plumage the bird is rusty grey, whitish grey beneath. The shield and base of the bill are vermilion, and the tip yellow in mature birds, but the bright colour of these in the nestling fades in three weeks or so to green. The legs are green with a red and yellow "garter" above the heel, incorrectly called the knee. This band and the red frontal are not always developed in the first autumn. The irides, really banded, appear red. Length, I3 ins. Wing, $6 \cdot 75$ ins. Tarsus, $1 \cdot 75$ ins.

\section{Coot. Fullica atra Linn.}

The Coot (Plate 145) is found throughout Europe and temperate Asia and Africa; it is resident in all parts of the British Isles, but in the northern part of its range is migratory, and there is some movement south from Scotland and the northern isles. Its haunts are the larger waters, including slow rivers, and in winter many seek the coast.

The Coot is a heavy, rather clumsily built bird, slate-grey with a white bill and spear-shaped frontal plate, which though slightly tinged with pink looks Chinese white at a distance; this frontal is responsible for the name "Bald Coot." Swimming Coots may be told from dark ducks by the bobbing movements of their heads; if disturbed they run along the surface, splashing vigorously before getting clear, and this same splashing rush is common when one bird chases another. The wings move rapidly in flight, and the bird gets up some speed, flying straight, but always looks heavy; its legs trail behind its tail. It frequently feeds on grass or grain on the banks, but seldom ventures far from the water, and runs quickly with head low, and with beating wings, if it fears danger. Hard frost drives it to the sea, but it will remain after all grebes and ducks have left, and if then it attempts to alight on the ice, slides forward on its breast, and 
falls sideways when it attempts to walk on the slippery surface. Its method of alighting differs from the feet-foremost drop of a duck and the breast plunge of a grebe, for it alights on the breast with the feet lowered; it is intermediate between the two. It is a constant but not neat diver; it jumps from the water and plunges, going down with a splash, but quickly reappearing. Yet it can swim fast under water, striking with both feet at once, not alternately as on the surface, more under the body than those of the grebe, though visible when viewed from above. The lobes on the toes fall back and present little resistance to the water when the feet are brought forward, but automatically open out during the propelling back stroke. The wings of a bird I had in captivity were not used under water, though slightly opened when it wished to rise to the surface. The object of diving is to obtain the fleshy stems of weeds and aquatic molluscs, for both vegetable and animal food are taken.

If the Moorhen is quarrelsome, the Coot is a prize-fighter; it swims with head and neck low, shoulders hunched, and wings slightly raised, threatening a rival. Combatants sit high in the water, apparently balanced on their tails, and strike with both feet and wings; I have seen four fighting at once. The battles are accompanied by war-cries and much splashing, but seldom result in serious injury. The bird is bold in defence of eggs or young; I have seen it chase a Rook, and after much splashing and squealing emerge from a reed-bed, with a triumphant trumpet, immediately behind a defeated rat. In spite of its apparent bad temper it is sociable, and in winter gregarious; possibly augmented by immigrants, the numbers on Cheshire meres are often large in winter, and on the lagoon at Slapton Ley I have seen immense flocks. Its calls are varied and difficult to express. A bell-like kwong, and a softer tnewt are common, and a clinking metallic note is a warning or alarm when the nest is approached. As it swims from the nest, looking back apprehensively over its hunched shoulders, it 
utters an explosive tizz, a regular splutter. The hunger-cry of the young is a wheezy squeal-qucep, and the nestling has a faint whispering pipe. The Coot flies at night, but is less noisy than the Moorhen. In April one alighted on a greenhouse, probably mistaking it for water, and in February one dropped in a town back-yard; both these may have been migrants or the night flight have had nuptial significance. One, when I handled it, made repeated vicious dabs at my eyes.

The nest (Plate I46), a large structure of flags, reeds sedge, and rarely, twigs, is built in aquatic vegetation, but is seldom actually floating. If the water rises additions are made until a big stack remains when the water subsides. I have seen it built of green sedge, when the stone-grey, black-speckled eggs (Plate I $_{4}$ ) were plainly visible, but when old reed-blades, speckled with fungoid growth, are used, the result is very different. I have once seen the eggs partially covered, but the habit is not general. The eggs number from six to ten as a rule, and are laid late in April or in May. The head colour of the nestling in its early days is more vivid than that of the juvenile Moorhen. The bill is black at the extreme tip, the rest dead white shading to vermilion at the base and on the plate; round the bill the down is bright red, the sides of the face are orange, the crown is livid blue or ultramarine, and the nape may be orange, flame, or black, like the rest of the hairy down. Young birds I have examined showed much variation in the areas covered, but red, orange, and blue were always present. The remainder of the down is sooty with hoary filaments, and the legs are dull slate. One just out of the egg fell into the water and swam at once.

The mature bird has a slight wing bar, the rest of the plumage different depths of slate-grey, but velvet-black on the head and neck. The bill and frontal plate are white, faintly tinged with pink; the legs are olive-green, and the irides crimson. The 
back is rusty grey in first plumage, and the under parts, including the sides of the face and front of the neck, grey to white. The frontal plate is distinctly yellow until after the autumn moult. Length, 15 ins. Wing, $8 \cdot 5$ ins. Tarsus, $2 \cdot 3$ ins.

\section{Order COLUMBIFORMES. Doves and Pigeons.}

\section{Family COLUMBID $Æ$.}

IVings ample, bill short, nostrils in soft, fleshy membrane; feet arboreal, toes four, tarsus short.

\section{Stock-Doye. Columba anas Linn.}

In the northern part of its European and western Asiatic range the Stock-Dove (Plate 147) is a migrant, but, except on the east coast, there is little evidence of migration in the British Isles, where the bird is a well-distributed and ofter plentiful resident, gradually pushing its way north. Early in the 'eighties it was rare in Northumberland, now it breeds in Sutherland, and visits the Orkneys and Shetlands, and is also spreading in Ireland.

The three pigeons, though superficially alike, have very distinctive characters; the Ring-Dove may at once be told by the white on its neck and wing, but the Rock and Stock-Doves are more alike in size and plumage. The former, however, has a white rump, and two well-marked black bars on the wing, but the rump of the Stock is grey, and the bars are incomplete. The haunts of the Stock-Dove are in more or less open country, for though it often nests in trees it prefers park lands to thick woods; where it nests amongst rocks it is often called by the wrong name. It is common on coasts where the cliffs provide holes, and frequents sand-dunes, where it is known as the 


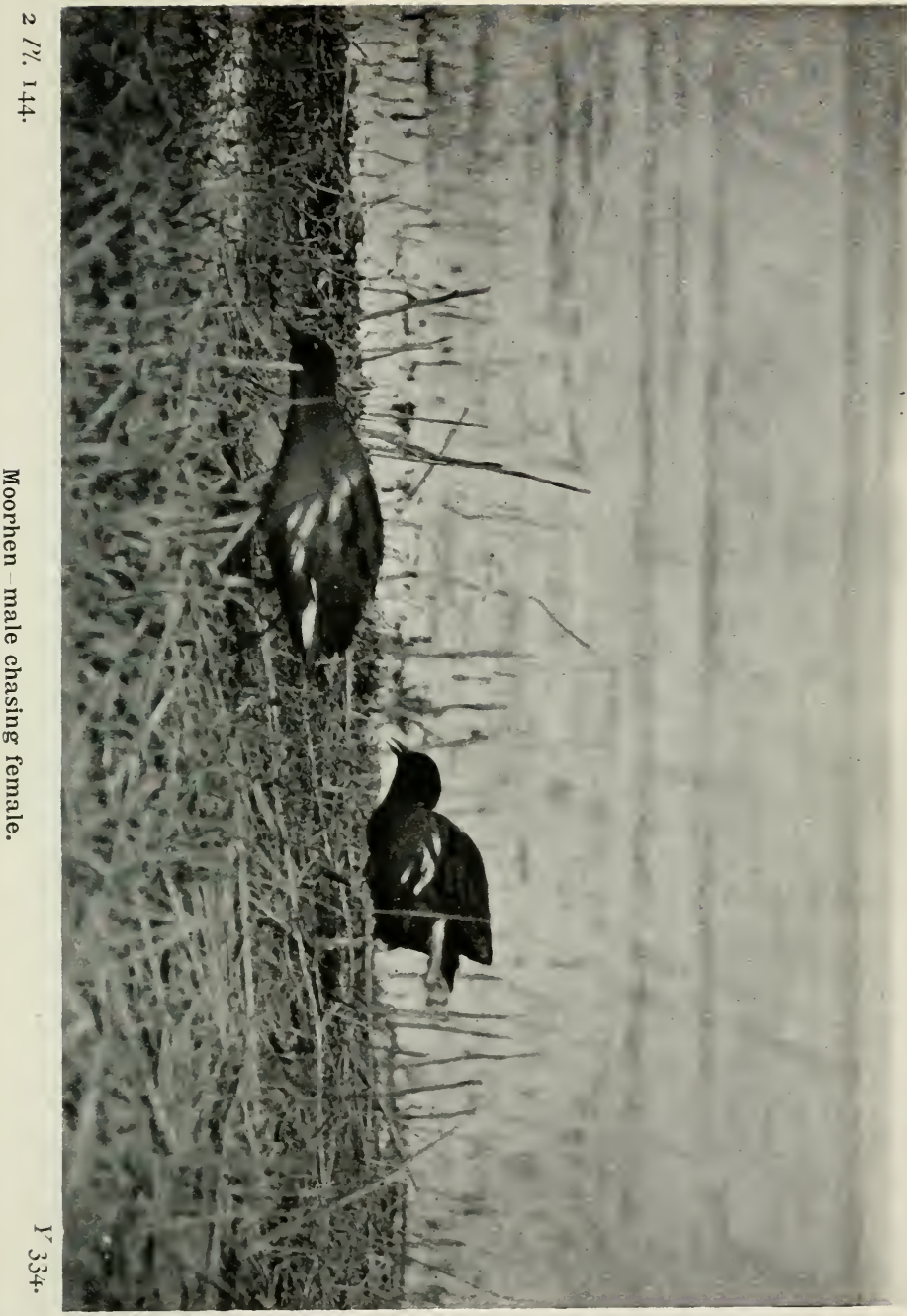



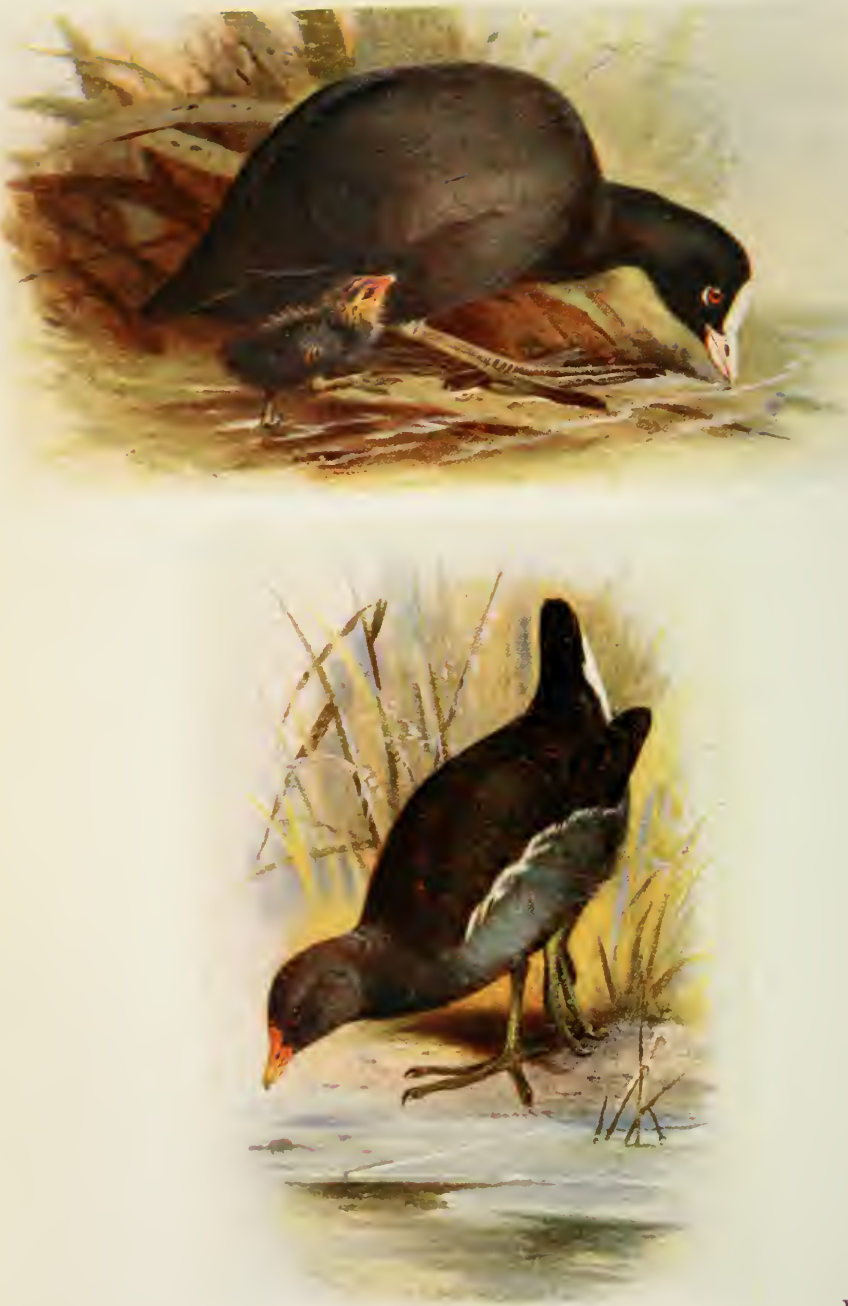

$21 \%$ I 4.5.

Coot. 
"Sand-Pigeon." Its flight is quick, performed by regular beats, with an occasional sharp flick of the wings, characteristic of pigeons in general. Indeed, there is so much of the domestic pigeon in its bobbing gait, appearance, and habits that there is excuse for the erroneous idea that it is the "stock" from which our tame birds are derived. It perches well, and in nuptial display walks along a horizontal branch with swelled neck, lowered wings, and fanned tail, just as tame birds swagger on the rouf-tree. I have seen a male bowing to the female, with his bill almost touching the ground and his spread tail elevated vertically. During the circling spring flight the wings are smartly cracked like a whip-lash.

The Stock-Dove is sociable as well as gregarious, often consorting with Ring-Doves, though doubtless it is the presence of food which brings them together. Something to its liking takes it to the shore, where it may be seen pecking at the sand on tidal banks, a common habit also of domestic pigeons. Its comparative scarcity, when compared with the vast hordes of migratory Ring-Doves, explains why it has not been accused of grain eating; it is defended by many as a destroyer of weeds. Weeds it certainly eats, especially the seeds of charlock, but it enjoys grain; Mr. J. A. Dockray found the crops of many birds filled with wheat and oats as well as charlock, at the same time that those of Wood-Pigeons were crammed with nothing but acorns. Most of its food is vegetable; young shoots and seedlings are favoured. The short, deep, grunting call is quite distinct from the modulated cooing notes of the RingDove; it is loud enough to be described, somewhat fancifully, as "roaring."

The nest, though it is seldom that any nesting material is used, is usually in a hole in a tree, a crack in a rock face, as in the limestone of Yorkshire, Derbyshire, and Wales, or in a rabbit-burrow, but the bird also nests in ivy, or in the thick growin round the boles of limes, as well as in deserted nests of 
other birds and squirrel dreys. Since its increase it has been found in ruins and large ecclesiastical buildings, sharing the crevices with the Daws. Two creamy-white eggs, measuring about $I^{\circ} 5$ by $I^{\circ} I_{5} 5$ inches, are laid practically at any time between March and October. The down of the nestling is yellowish, and its bill is at first dark, but later flesh-coloured. A young bird, taken from the nest, took kindly to captivity, and before it could walk would push itself across a table, shuffling on its breast, to take food from my mouth.

The upper parts of the mature bird are blue-grey, palest on the rump. The wing is crossed by two interrupted black bars, the quills are dark slate, and the tail shades from grey to almost black at the tip. The breast is vinaceous, and on the neck is a metallic green and purple patch, shining when the bird swells its neck in display. The rest of the under parts are pale blue-grey. The under wing is grey; in the Rock-Dove it is white. The bill is brownish yellow, red towards the base, but the actual fleshy basal portion is white. The legs are pink with a purple tinge; the irides are variously described, but I have found them dark brown. The young bird has at first little lustre on the neck or sign of bars on the wing, but the bird mentioned above, taken on May 25 th, when down was still present on head and breast, showed the patch and one bar distinctly on October 12th. Length, $13^{\wedge} j$ ins. Wing, $8 \cdot 8$ ins. Tarsus, $I \cdot I$ ins.

\section{Ring-Dove. Columba palumbus Linn.}

It is not proved that any of our resident Ring-Doves migrate, but too well known that birds in the northern part of its European and Asiatic range travel south when food supplies are precarious, for in autumn and winter great numbers arrive on the east coast. As a resident the Wood-Pigeon or "Cushat" breeds throughout the British Isles, in woodlands and even in 
city parks. By Ring.Dove many understand only the domesticated dove with a black ring on its neck, which when allowed its freedom makes itself at home in woods and gardens, but the name is correctly applied to the Wood-Pigeon.

Even in the London parks the Ring-Dove (Plate 147), the largest of our wild pigeons, is a familiar bird ; indeed, it is there so confiding that we have excellent opportunity of studying its portly figure and beautiful plumage ; in the country, where it is not beloved, it is shy. It walks, perches, and bows with swelled neck and fanned tail like a dovecot bird, but has certain characters and habits of its own. It can always be told by the white patch on its neck, and when flying by the transverse white bar on the wing. Its note, heard at all times, but most frequently in March and April, is often insufficiently represented by a series of coos. There are, however, two hard sounds and a double note in each phrase, which is usually repeated about three times. The old interpretation, "Tak' two coos, Taffy, tak' two coos, Taffy, tak'," or Mr. Bolam's "Tak' care noo, hinny," give a better idea, the first two words sharp, the third drawled. Almost invariably the bird ends with the hard tak or cuc. Bowing and cooing is often interrupted by a display of nuptial flight; the bird rises rather steeply with strong though not rapid wing-beats, then stiffening its wings, falls and rises in a series of undulations, at the end of which there is a sharp crack, caused by a strong down beat of the wing, and not, as so often stated, by the wings clapping together. The pectoral muscles are powerful; the bird fights with the wings, and even a "squab" in the nest will give a smart blow.

Sportsmen declare that the Wood-Pigeon is difficult to kill, the shot glancing off its feathers as if it were clad in mail ; certainly its pinions sound stiff and hard when with a clatter it dashes through the branches. But it is possible that it is the softness of its plumage which presents a cushion to the shot, for few birds have softer or looser covering. A keeper will 
strike a wounded bird with his stick, killing it before he attempts to pick it up, because in its struggles it litters everything with these easily shed feathers, and there are good retrievers which will not pick it up, having once experienced the unpleasant mouthful. Though some immigrants arrive in October, the biggest hordes come in during the next three months, and often return again in February. Fortunately the numbers vary in different years and the localities attacked are widespread, for a Wood-Pigeon invasion is a menace to food supply; the numbers sometimes observed coming in from the North Sea are beyond all calculation. Much grain is devoured by the greedy bird- -838 grains were counted from one cropbut acorns are its great stand-by; in years when the acorn crop is large, immigrants are most abundant. Beech-inast, nuts, haws, berries, young leaves of ash, beech, and oak are amongst the harmless foods; turnip-tops, young greens, Brussels sprouts, small potatoes, crops which it damages; but by devouring seeds of charlock, ragwort, and other weeds it does some amount of good. The crops of birds have been found full of caterpillars of the dotted border and mottled umber, both defoliating species, and certainly at times it eats harmful slugs.

The nest (Plate I 5 I) is a flimsy platform of intertivisted sticks, through which the light shows, and the eggs may be seen from below ; it is built in a tree or hedge at varying height from the ground; exceptionally it is on the ground or on a ledge. The two eggs are dead white and glossier than those of the StockDove; they measure about $\mathrm{I}^{\circ} 6$ by $\mathrm{I}^{\circ} 2$ inches. Winter eggs have several times been found, but from April onward is the usual time; two or even three broods are reared. The nestling or squab has sparse yellow down, and a broad, soft bill, the lower mandible broadest; it pushes its boat-shaped bill into that of the mother bird and sucks up the milky fluid she provides for its early nourishment. 


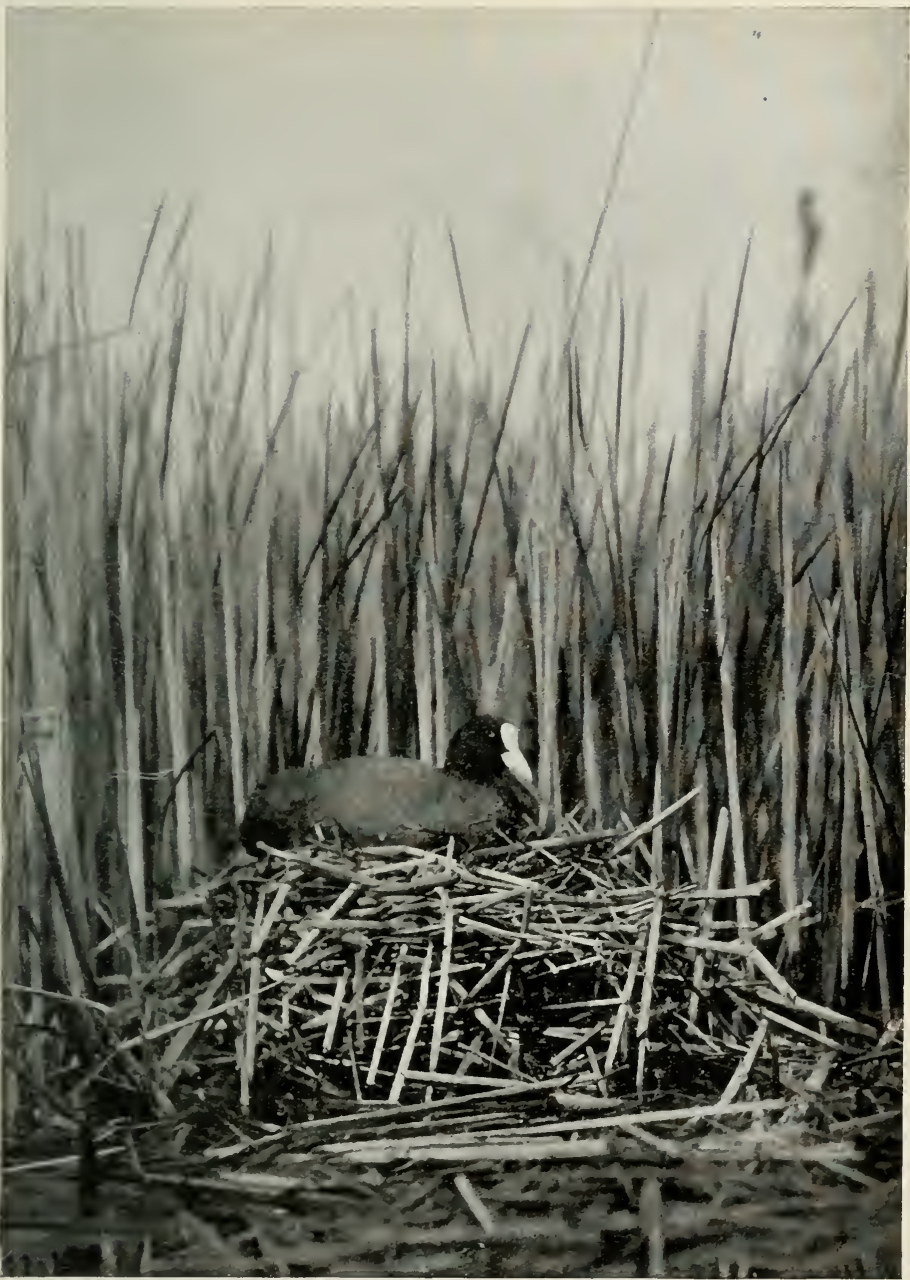

$2 \mathrm{Fl} .146$

Coot. 

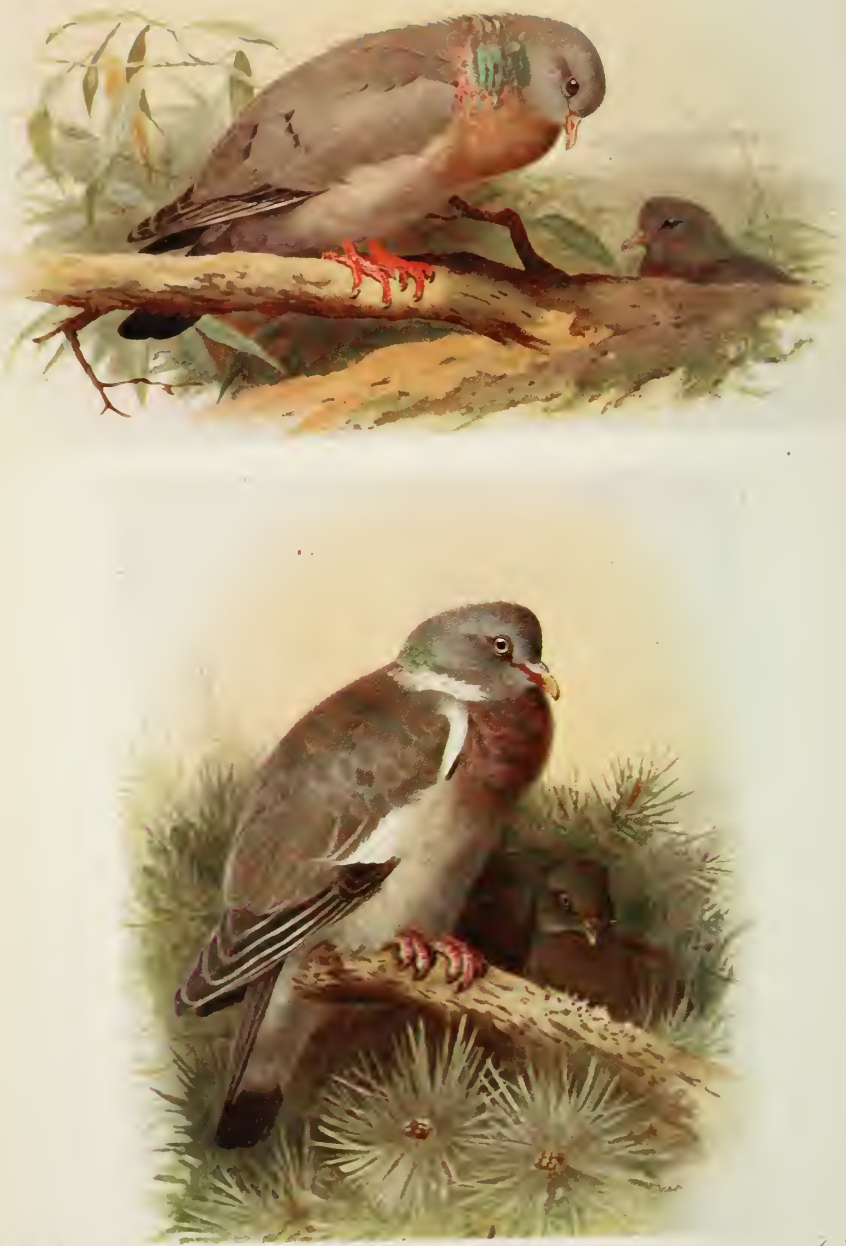

$-16+7$.

Siosk-D ove. 
The upper parts of the adult bird are lavender or bluish grey, the wings darker, and the white-bordered quills greyish brown. On the neck, which is shot with green and purple, are large white patches, and the white bar on the wing shows when the bird is at rest as a patch on the angle. The breast is vinaceous, shading to pale lavender on the abdomen. The upper surface of the tail is blackish, but the under has a bluegrey subterminal bar. The bill is yellow, red at the base, and white over the nostrils; the legs are red, often tinged with purple, and the irides yellow. The young bird has at first no white on the neck, and the wing bar is suffused with blue. Length, $16 \cdot 5$ ins. Wing, $9 \cdot 5$ ins. Tarsus, $1 \cdot 3$ ins.

\section{Rock-Dove. Columba livia Gmelin.}

The Rock-Dove (Plate I49) has a restricted range in western and southern Europe and Mediterranean countries; in our islands it is a local resident, even in Scotland, Ireland, and the western and northern isles, where it abounds in suitable places. It is plentiful on the Yorkshire cliffs, rare in Cornwall and Devon, and its present status in Cumberland is doubtful, but colonies of considerable size are scattered along the Welsh cliffs. It appears almost to have deserted Anglesey and the Isle of Man. All its haunts are maritime, and confusion with the Stock-Dove probably accounts for reports from inland localities; in Yorkshire the "climmers" call it the "RockPigeon," to them the Stock is the "Rock-Dove." This bird is the "Blue Rock" from which our domestic breeds are descended, and not only will the wild bird visit and feed with tame birds about the farms, but, pairing with them, induces them to cast off the fetters of domesticity. I have seen these wild "tame" birds flying with the Flamborough Rocks, and an undoubted "chequer" evidently mated with a wild bird in a cave in Scotland. 
The white croup or lower back of the Rock-Dove is its best character, but the two black bars on its pale-grey wing are distinct; the tail is margined with white. It is strong and quick on the wing, dashing out from the caves, flying low over the water, its white rump showing well from above. Little parties will circle over the sea and the cliff tops, when the white under wing is equally conspicuous ; in its flight, behaviour, and voice, which is more of a dovecot coo than the phrase of the Ring-Dove, it shows its relationship. Though fields are visited for grain and green food, it is nowhere so plentiful as to be a pest, and the good it does by devouring weeds probably balances the damage. Like other pigeons it often drinks; I have seen it alight on the sea, and apparently drink salt water; domestic birds will alight on water, even on the sea. The bowing courtship, when the metallic lustre of the neck is fully displayed, often takes place on ledges where Guillemots and Razorbills sit.

The nest is usually on a ledge in a cave; it is a slight structure of grass, heather, or seaweed. The two white eggs, more like those of the Ring-Dove than the Stock, measure $I^{\prime} ;$ by $I \cdot I$ inches. The nestling has pale yellow down and a fleshcoloured bill with a dark band. It is tended and fed on "milk" like other doves.

The head and neck of the mature bird are a darker blue-grey than the back and wings; the lower back is white. The green and lilac or purple patch on the side of the neck is larger than that of the Stock, and the tail is more distinctly banded. The bill, legs, and irides are as in the Ring-Dove. Young birds show little lustre and are duller. Length, $\mathrm{I}_{3} 5$ ins. Wing, 8.5 ins. Tarsus, $1 \cdot 2$ ins.

\section{Turtle-Dove. Streptopelia turtur (Linn.).}

The migratory Turtle-Dove (Plate I 50 ) has a western Palæarctic range, though it is rare in northern Scandinavia and 


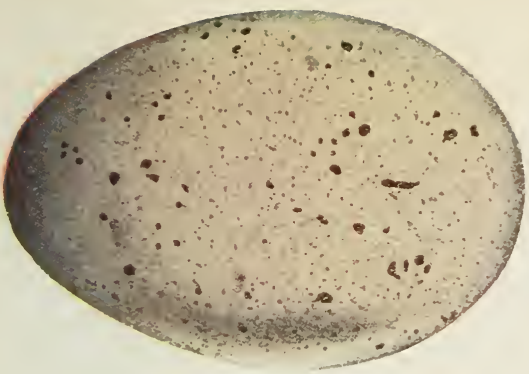

coot.

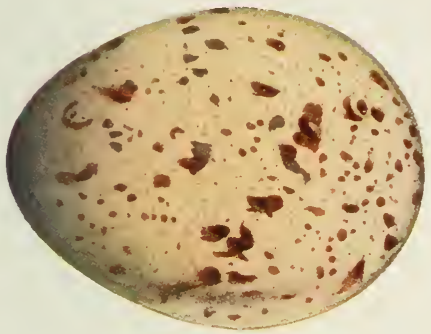

Moorhen.

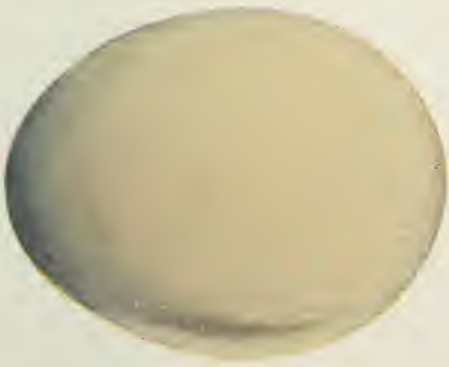

Pheasant.

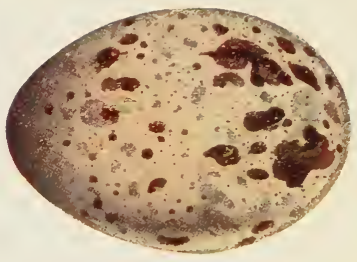

Spotted Crake.

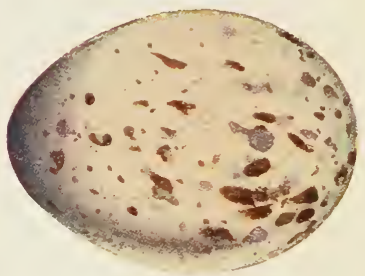

Cornerake.

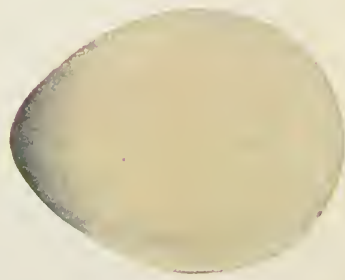

Partridge.

$2 \mathrm{Pl} . \mathrm{I}_{4} \mathrm{~S}$. 

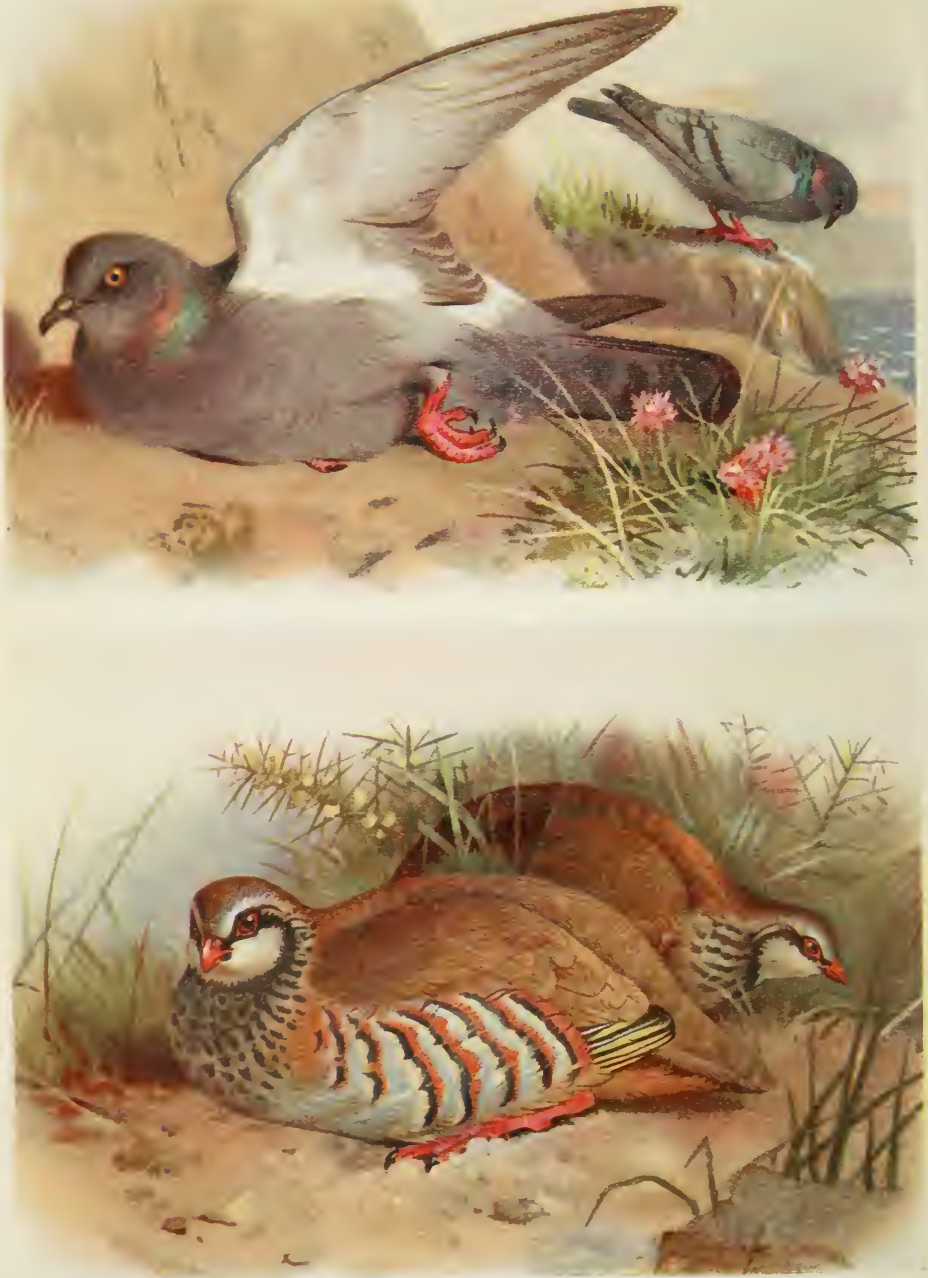

$2 \% 149$.

Rock Dove. 
Russia ; it winters in Africa. In the British Isles it is steadily extending its summer range, though it is still rare in Scotland and Ireland. In the north of Scotland and the Orkneys and Shetlands it is, apparently, a regular passage migrant in spring and autumn, and there are one or two instances of winter visitation. The regularity of the appearance on such out-ofthe-way places, as for instance Fair Island, are as yet unexplained migration problems.

Smaller and slighter in build than other doves, the Turtle may be recognised by its browner colour, and the black and white striped patch on the side of its neck, but it is its tail that catches the eye when it flies from the observer; it is wedge shaped, with a dark centre and white borders and tips. When viewed from below this pattern, owing to the white under tailcoverts obscuring the dark bases, is a blackish chevron on a white ground. This is noticeable when the bird stoops to drink, raising its spread tail. April is nearly ended before the Turtle, one of the latest migrants, appears ; it often is not here until May, whilst passage birds travel through in June.

It is a bird of open rather than dense woodlands, and frequently feeds on the ground (End paper 4); it will nest in gardens, and I have seen it feeding on scattered grain on a suburban cab-stand. The flight is often described as arrowy, but is not remarkably swift; in the open it is direct, but the turns and dodges are neat when the bird flies amongst trees. For so small a dove it is strong, performed with purposeful beats. The nuptial flight, high and circling, is rather like that of the Ring-Dove, but the undulations are less decided; it is accompanied by the whip-crack of the downward flicked wings. The arrival in spring is heralded by its purring notes, a rather deep, vibrating courrr, courrr. Seeds of various kinds and tender shoots are eaten, and where food is plentiful a number of birds may be seen together, but it is hardly gregarious in summer. It is a constant attendant at the Pheasant rearing 
field, helping itself to grain. Like other pigeons it will drink salt as well as fresh water, visiting the shore and marshes for this purpose. The increase and extension of its range north and west has taken place comparatively recently. I remember the first bird shot in eastern Cheshire, brought to me by a keeper who had no idea what it was. Now it is abundant in Cheshire and Lancashire.

The nest is even more flimsy looking than that of the RingDove, being built of more slender twigs, usually, at no great elevation, in a tree or old untrimmed hedge. Yet it is not loosely put together, for I have known it, in an exposed position, withstand a winter's storms. Two white eggs, about $I^{\circ} 2$ by 0.9 of an inch, are laid late in May or in June. The "gentle Turtle," even when a mere down-clad squab, will fight vigorously, striking with its feeble wing, pecking and snapping its soft bill in defiance.

The mature bird has the head, neck, flanks, and rump bluegrey, and the wings cinnamon, mottled with black. The breast is vinaceous, the abdomen and under tail-coverts are white. The bill is black, the legs and eye-rims are red, and the irides reddish brown. The black and white patch on the side of the neck is absent in the browner and duller young bird, which also has the legs brown. Length, II'2j ins. Wing, 7 ins. Tarsus, $0^{\circ} 9$ in.

\section{Eastern Turtle-Dove. Streptopelia orientalis (Lath.).}

A single example of the Eastern Turtle-Dove, which inhabits eastern Asia and has occasionally wandered west, was taken in Yorkshire in October, 1899, under circumstances which suggested that it was a genuine wanderer. It is a larger bird than ours, darker on the upper parts, has the neck-spot black and pale blue, and the lower parts more vinaceous; the under tail-cuverts are blue not white. Length, 13.5 ins. Wing, 77 ins. Tarsus, $I \cdot I$ ins. 


\section{Order PTEROCLETIFORMES.}

Family PTEROCLETIDÆ.

Ground birds ; bill short, curved; wings long, pointed ; tarsi short, feathered; toes three, united.

\section{Pallas' Sand-Grouse. Syrrhaptes paradoxus (Pallas).}

Few birds are more puzzling than Pallas' Sand-Grouse (Plate 150), for though the normal migration from its home on the Mongolian and central Asiatic steppes is southerly, sporadic westward irruptions or invasions scatter birds all over Europe. Theories about these abnormal westward movements are many, but do not explain the phenomena ; a surplus avian population, impelled by some unexplained instinct or force, strives to extend its range by emigration, and meets with even less success than the human Asiatic floods which from time to time have inundated western lands. In the most memorable of these invasions-1863, I888, and I908-small flocks were scattered over our islands, invading the east coast, but travelling to the west and even to Ireland. Museums and private collections contain evidence of these abortive raids. In most instances the birds reached Britain in spring, and a few, on sand-dunes and marshes, found congenial haunts and nested, but it is doubtful if any of the young survived long, though adult birds dodged gunners until the autumn, and in a few instances, winter.

In June, I908, I just missed seeing a covey in Cheshire; to a more fortunate observer they appeared like light-coloured Partridges with pigeon heads, long pointed wings and tails, and remarkably swift flight which immediately recalled that of the Golden Plover. The flight call was chack, chack, but he was not near enough to hear the whistling of the wings, 
commented on by others. The bird has short legs and feathered feet, in which the three toes-the hind toe is absent-are together and padded beneath, rather suggesting the foot of a rabbit. It walks awkwardly, with short steps. Like its relatives, the pigeons, it is a thirsty bird, drinking saline as well as fresh water. Seeds and shoots of all kinds of lowgrowing herbage are its food, of the salt-marsh type in its native haunts, but in Britain various grasses, clovers, and weeds are known to have been sampled by the analysis of stomach contents.

The nest is a hollow scraped in sand or loose soil, seldom with more than a few bents by way of lining or decoration. The eggs, usually two or three in number, are stone-brown or buff, speckled and blotched with darker brown (Plate 153), and the nestling in down is pale buff, streaked and speckled with a lace-work pattern of brown and black.

Both male and female are sandy brown in general colour, and have elongated central tail feathers, though those of the male are the more pointed. The head of the male is sandy grey, his cheeks and chin rusty; his back is barred with brown, and there is a large buff patch on the wing. The lavender primaries, particularly the first, are very pointed. The breast is greyish buff, crossed by a band of fine black markings; below the breast is a broad chocolate band. The female has smaller but more numerous markings on the upper parts; her head is streaked, and she lacks the gorget and buff wing patch. The bill, shaped like that of a game-bird, and the irides, are brown, Male: Length, 17 ins. Wing, 10.5 ins. Female: Length, 1475 ins. Wing, 9 ins. Tarsus $I$ in. 

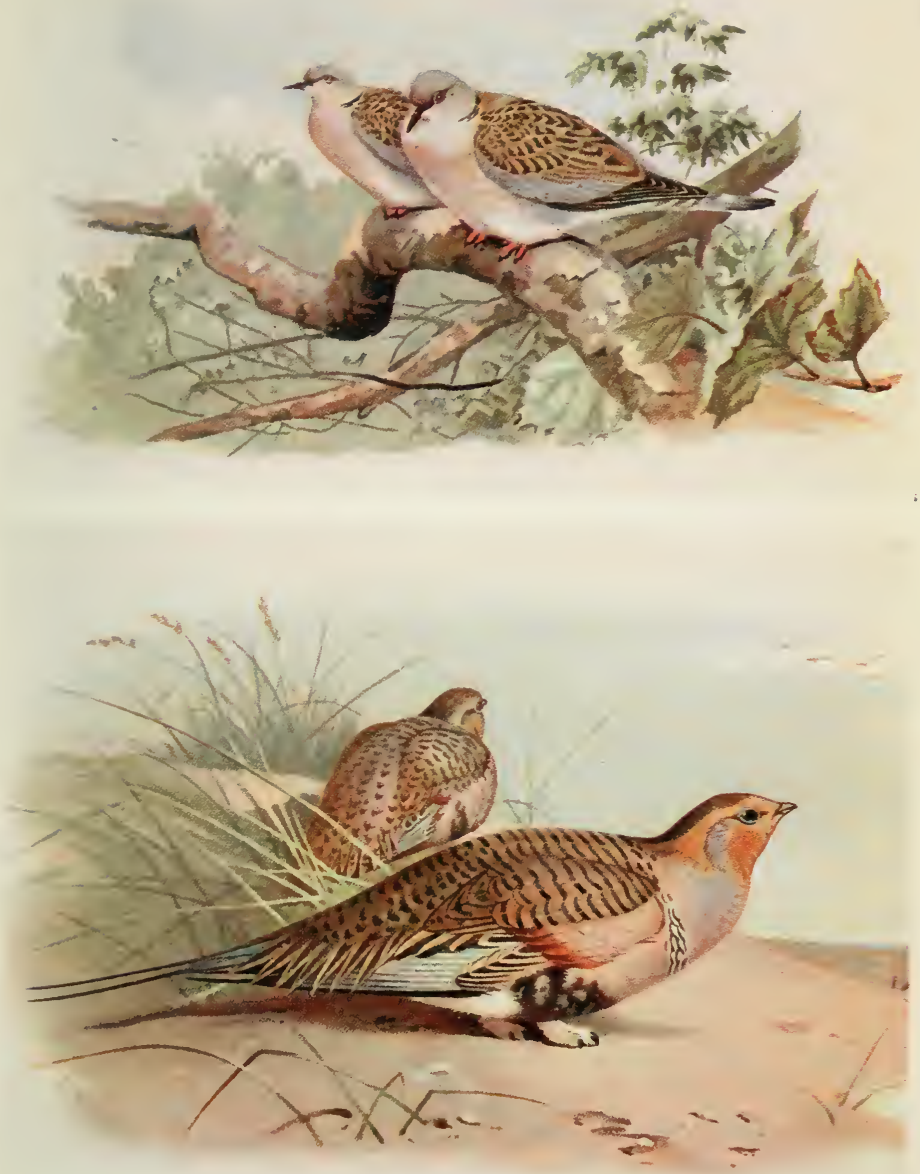

$2 P$ I jo.

Turtle-Dove.

17 th.

Z 344 .

Pallas's Sand-Grouse. 29 ths. 


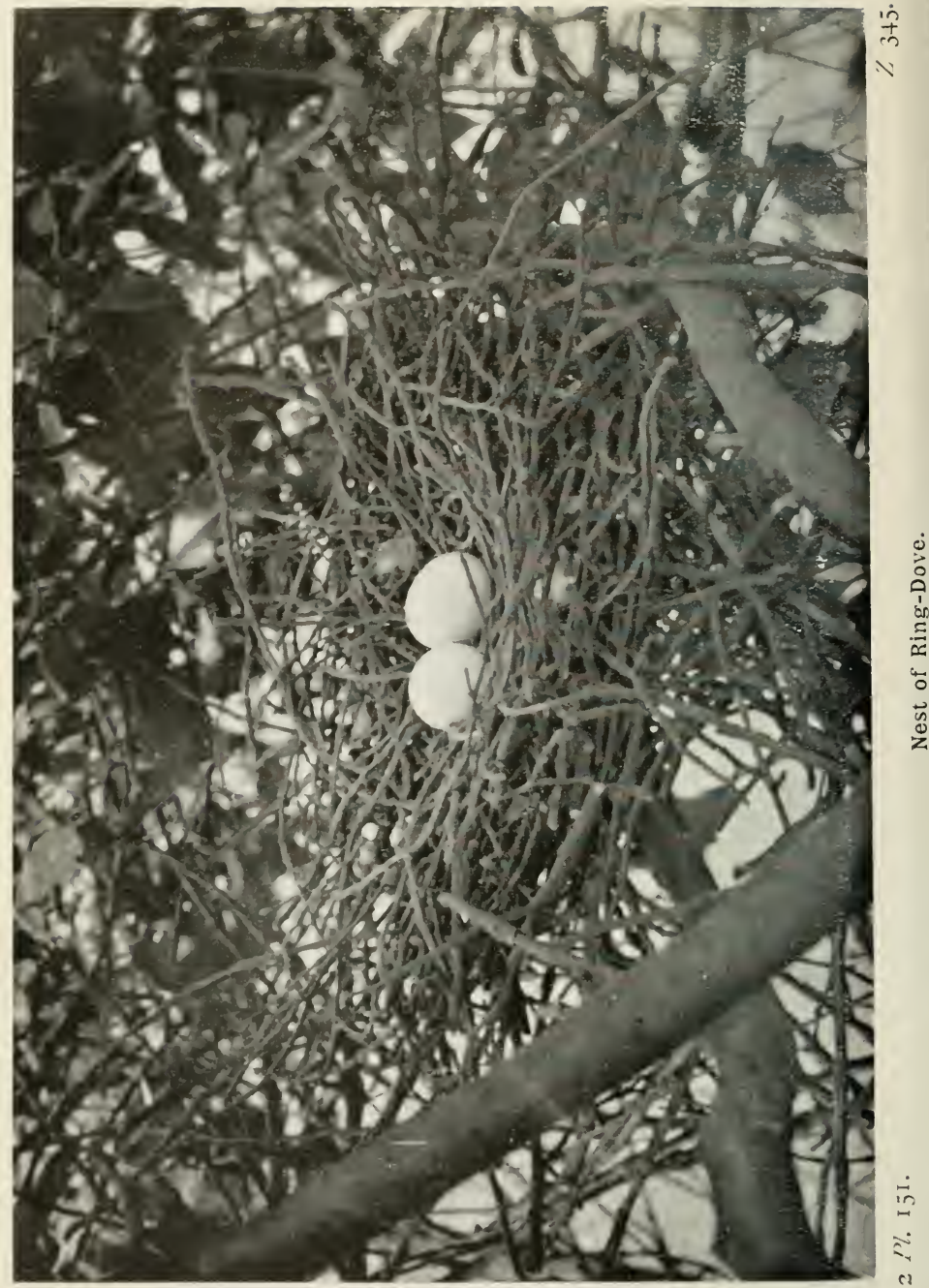




\section{Order GALLIFORMES.}

Family PHASIANIDE. Pheasants and Partridges.

Ground birds, with short, rounded wings; bill short and stout, toes four.

\section{Pheasant. Phasianus colchicus Linn.}

Only as a long-established alien can the Pheasant (Plate 152) be admitted as a British bird, though the date of introduction is unknown; it is first mentioned in 1059. More recently various pheasants have been introduced, and have interbred with the older stock; it is impossible to meet with a pure descendant of the original $P$. colchicus, though some of the characters survive. The Chinese $P$. torquatus, first introduced about two hundred years ago, has also left its mark, notably in the white neck ring, but as the blood of five or six other species may be intermingled, we can only look upon the semidomestic Pheasant of to-day as a mongrel. Crosses with more distantly related birds take place occasionally, even with Black Grouse and various breeds of domestic fowl. $P$. colchicus hails from the Black Sea area of western Asia, but many closely allied forms occur in other parts; the Romans, Phœnicians, or whoever first traded the bird on sporting Britain, may have brought different races. The two types, colchicus and torquatus, are figured.

Any description of the appearance or plumage of the Pheasant is unnecessary; the pictures, or the poulterer's shop, will supply details; every one knows that the cock is the smarter, the hen the browner, shorter-tailed bird. The male has erectile ear-tufts and a featherless red face; it is a gorgeous bird, but would it be here at all were it not almost sacred? The habits of this carefully tended bird have, undoubtedly, 
been influenced and altered by artificial conditions. It is a woodland species, thriving best in protected coverts; it roosts in trees for protection, but is, in other ways, a ground bird, nesting on the level and running swiftly to escape an enemy, unless forced to take flight, when it rises with a whirr of round wings, often "rocketing" over the tree tops; it is then swift, but incapable of really sustained flight. If it can sneak through the herbage with lowered head it tries this dodge, and will crouch in cover; the plumage of the female then gives her protection. Young birds, if alarmed, will run from the coops and crouch in the grass. The controversy about the economic value of the Pheasant is complicated by political and class bias; very opposite opinions have been expressed. As the bird is omnivorous, eating vegetable and animal food, much may be argued for and against it; certainly it is unfair to judge by individual cases. One bird's crop may be filled with germinating grain, and another with wire-worms. A favourite but apparently trivial food is the spangle gall on the oak, a mixture of animal and vegetable. Old birds will, with impunity, eat the froghopper nymphs in the "cuckoo-spit," and these, killed in hot water, do the young no harm, but when the froth is thick on the grass many downy young birds perish; they swallow the living insect, and are choked by the froth it exudes. The best natural food is the pupæ of ants, popularly known as "ants' eggs."

In spring the male indulges in display, showing off his charms as he runs round the hen with much of the sideling, wing-trailing action of the domestic cock. $\mathrm{He}$ is pugilistic, ever ready to use the spurs with which his feet are armed; before a fight the rivals face with lowered heads and ruffled necks, and strike like game-cocks with the back of the feet. The loud, sudden crow of the cock is immediately followed by a rustle of the plumage and flapping of the wings, a familiar woolland sound in spring. It is well know, that thunder, an 
explosion, or other loud noise will start the Pheasant's crow, and during the war, air-raids before audible to human ears were responded to by the agitation of the sensitive birds. My most remarkable personal experience was on the morning of January 24 th, I9I 5 , when, in a Cheshire wood, I was struck by the frequent crowing of the cocks ; in my note-book I wrote"Cock Pheasants crowing constantly, and wing-flapping after each crow." Two days later I commented on the fact in the Manchester Guardian, but attributed it to the mildness of the weather, and it was only when reports were received of similar disturbances in Norfolk, Lincoln, and Cumberland that I realised that the Cheshire birds had also been influenced by the air vibrations of the heavy guns in the North Sea battle, some 400 miles away.

Whether naturally the bird is polygamous or monogamous has never been settled; pedal armature is not conclusive evidence of polygamy. It is to the advantage of the hen as an egg-laying machine that cocks, which are acknowledged bullies, should not be too abundant, and man, trading on this, hatches the eggs under foster parents, pretending that the Pheasant is a bad mother. She, certainly, will deposit her eggs in the nests of the Partridge, Mallard, or other bird, and cheerfully leave them, but at times is attentive ; the less she is interfered with the better she does her work. The nest is a hollow in cover, lined with a little grass and a few leaves; the olive eggs (Plate 148 ) vary in number, ten or twelve are common, and are laid in April and onward. Occasionally the eggs are in old nests of other birds in trees. The size of the bird varies according to the breed and the length of the tail, that of the Mongolian race, one of the more recently established, being perhaps the longest. Length, 24 to 36 ins. Wing, $9^{\circ} 5$ ins. Tarsus, 2.5 ins. 


\section{Red-legged Partridge. Caccabis rufa (Linn.).}

The range of the Red-legged Partridge (Plate I49) does not extend beyond south-western Europe, though allied species occur in various parts of Asia and Africa. It is not a British native, and its introduction for sporting purposes much more recent than that of the Pheasant, indeed shortly before the close of the eighteenth century. In the north and west, where a few attempts have been made to establish it, no colonisation has been accomplished, but in south-eastern and midland counties it has settled, multiplied, and spread. Under the impression that determined colonisation was detrimental to the resident Partridge, sportsmen, regretting their haste, strove to wipe it out, but it refused to be evicted, and now that driving has largely replaced shooting over dogs, it is tolerated rather than encouraged. As exhausted birds have been found upon the shore, and others noted at sea, it has been argued that migrants may reach us from time to time, and that our birds may attempt to emigrate. Southwell and others were of opinion that these over-water excursions were merely abortive attempts to extend the range, due to wandering habits, or to coveys having been driven out to sea, and that the weary, disappointed birds were returning to the land they had just left. Dr. N. F. Ticehurst, however, is convinced "that occasional birds or coveys do wander across" the Channel, and believes that the early records of the species in Kent cannot be explained by spread from any area of introduction. His evidence cannot be lightly cast aside, but so far there is no suggestion of regular migration. Solitary birds, apparently wanderers, turn up in unexpected places, but Partridge as well as Pheasant eggs are bought for the purpose of stocking preserves, and it is always possible that eggs of the Red-leg might be included.

The plumage of the "French Partridge," as it is still called in East Anglia, is more striking than that of the common bird; 


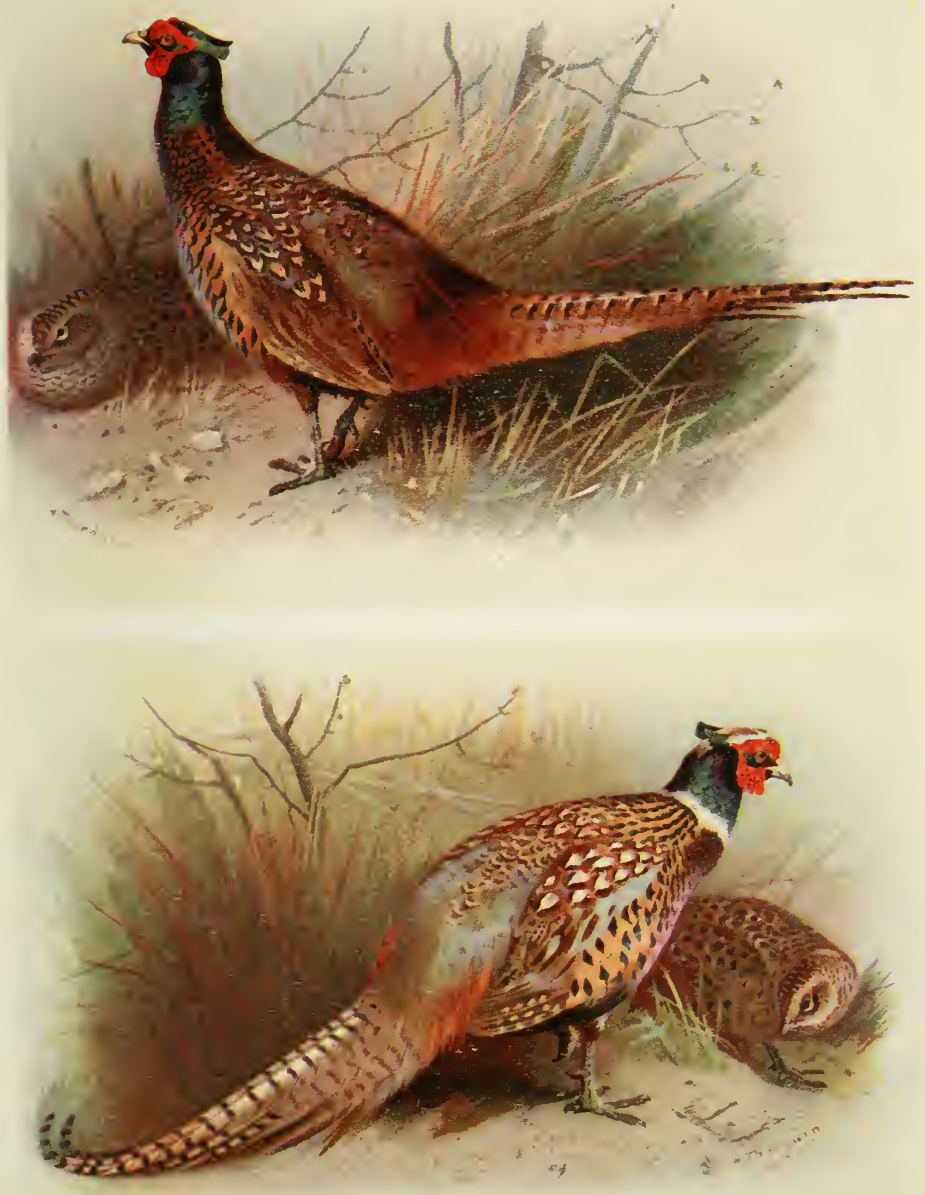

2 Pl. I52.

Pheasant. 

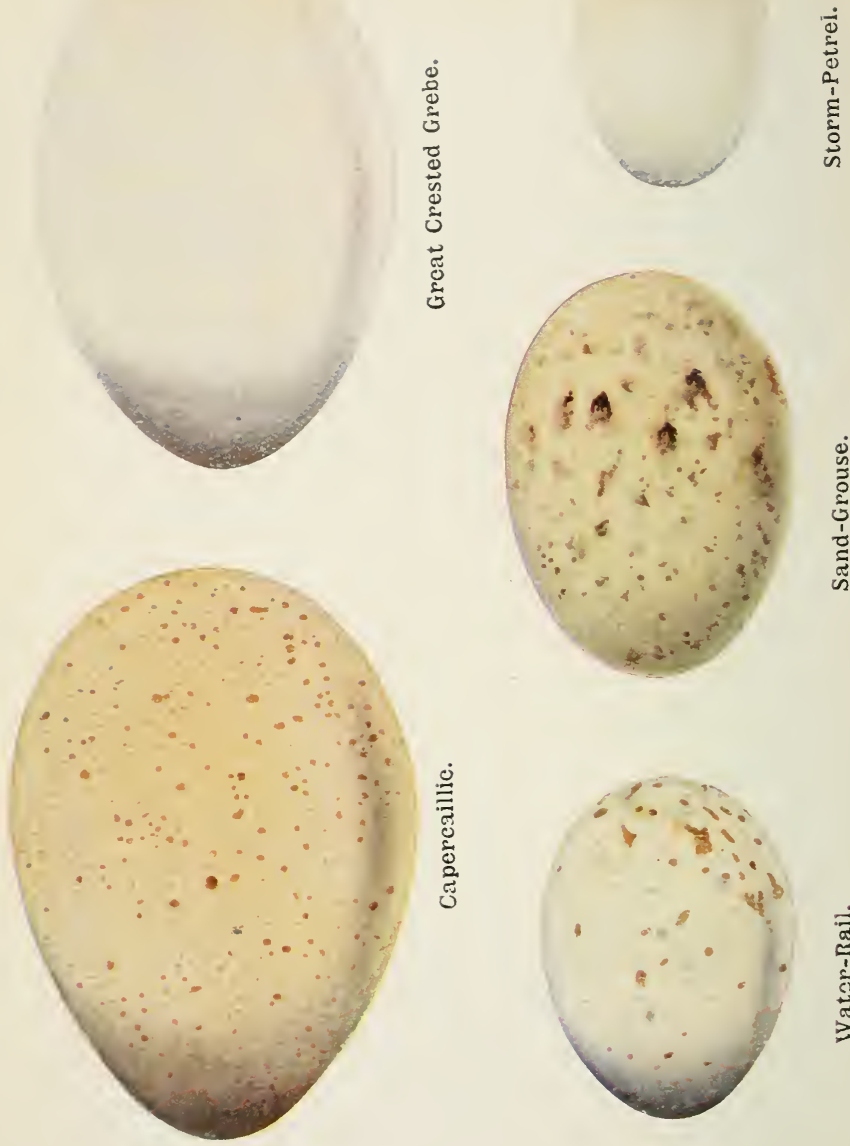

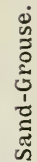

0
$\vdots$
0
0
0
0
0
0

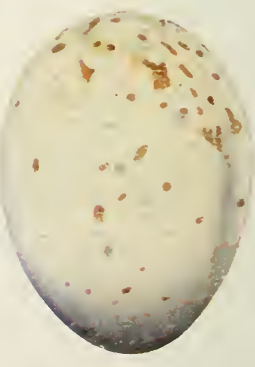

$\frac{1}{3}$
$\frac{\pi}{1}$
$\frac{1}{3}$
$\frac{\pi}{3}$
$\frac{\pi}{2}$ 
the strongly barred flanks and black-framed face and throat are its most conspicuous features. On grass or dark soil its light-brown upper parts are noticeable ; it looks a larger, paler bird than ours. The natural habitat is stone-strewn or sandy waste, and the chalky undulations of Norfolk suit it well; it delights in a sunny spot where it can lie on its side and enjoy a dust bath. It is, perhaps, more of a runner than the next species, though some Norfolk keepers tell me that this is a mistake, but it certainly seeks safety by foot rather than on the wing if long grass or other concealment is near ; its speed on the ground is remarkable. When put up it flies swiftly, whirring its wings, and rising just high enough to skim the hedges ; it provides a sporting shot when driven. The accusation that it kills the smaller bird is an exaggeration due to a misapprehension of inter-specific competition. Armed with blunt spurs, the males are ready to fight for their rights, marital or territorial, but a weak bird speedily knows when the odds are against it ; the Red-leg, however, is the more powerful and pushful bird and monopolises food supplies and suitable nesting sites. Grass, clover, buds and shoots, as well as insects, spiders, molluscs, and worms, are its food, and for the greater part of the year the bird is sociable, visiting the feeding grounds in little parties or coveys. The note is a crake-like chuk, chuk, chuk-ker; the Indian name for the Himalayan representative of the genus is "Chukar."

The nest is a hollow, often in a hedgegrow bottom or beneath a bush, sparsely lined with grass and leaves. Large clutches of eggs are common, and nine (Plate 155 ) is a small number; a full nest may contain double. The egg (Plate 154 ) is yellowish buff with fine reddish spots or blotches; late April and May is the time for the first eggs. Elevated nests are not uncommon, the top of a haystack having bzen recorded several times; in its ordinary life the bird rather likes an elevated stand, perching on walls and even branches. The nestling has reddish 
down, pale and unspotted on the head, but mottled with blackish brown on the back, where there are three yellowish longitudinal streaks. Dr. Bureau, in his elaborate work on the Partridge, gives details of the moults of the young, and shows how the age can be told at any time.

The mature bird has the upper parts hair-brown, tinged rufous on the back and grey on the forehead; the white face and throat are framed by a black line, which starts at the bill, runs through the eye, and then curves down the neck to form a gorget. Below this the lavender breast is speckled with black; the flanks, also lavender in ground, are barred with white, black, and chestnut. The bill, eye-rims, and legs are bright red. The black on the breast, and slate on the head and flanks, is mainly replaced by brown in the young bird. Length, 13.5 ins. Wing, 6.25 ins. Tarsus, I'7 ins.

\section{Partridge. Perdix perdix (Linn.).}

The sportsman is mainly responsible for the abundance of the Common or Grey Partridge (Plate 159), a bird of Europe and western Asia which is resident in the lowlands of Great Britain and Ireland, though decreasing in the latter island. Distinctly a bird of cultivation, it is most abundant on farm land, though thinly distributed on upland pastures and occasionally nesting on the moors. From the point of view of the sportsman who wants big bags it is a delicate bird, yet hardy enough to hold its own in small numbers where little protection is afforded. Coveys on sand-dunes and marshes, apparently unsuitable spots, are by no means rare.

The Partridge, like the Pheasant, is too familiar to need much description. It is a ground bird, running swiftly, and lying squat until we are upon it, then rising with a curious sound, a mixture of its creaking voice and whirring wings. Its aerial spurts are rapid and not long sustained, its flight an 


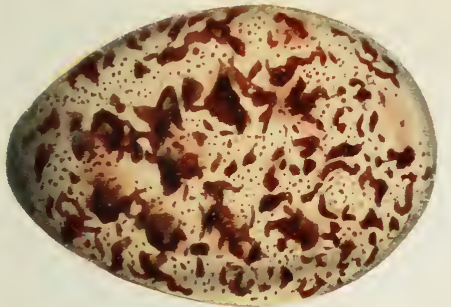

Ptarmigan.

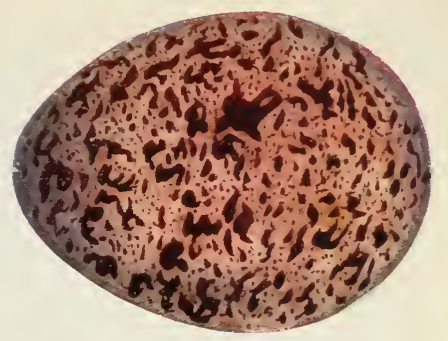

Red Grouse.

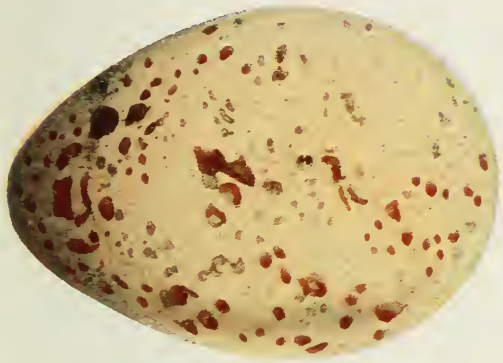

Black Grouse.

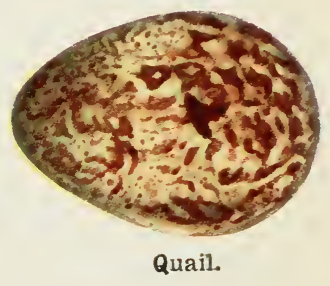

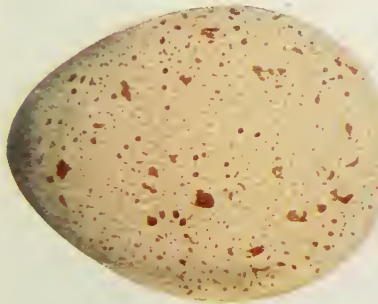

red-legged Partridge.

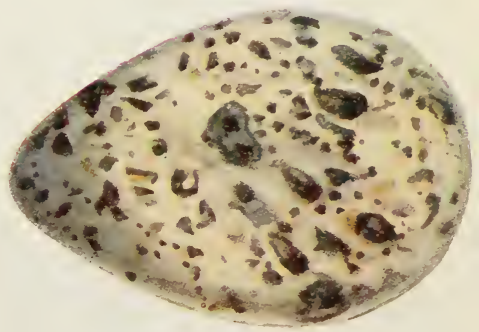

Greenshank. 


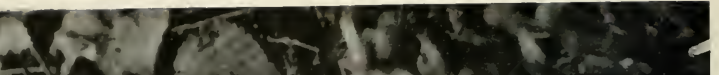
$\operatorname{in}_{\ln }$

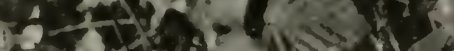

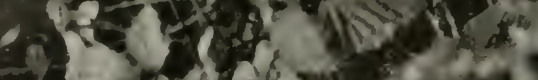

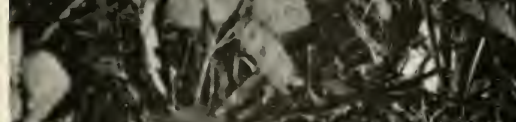

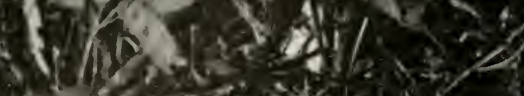

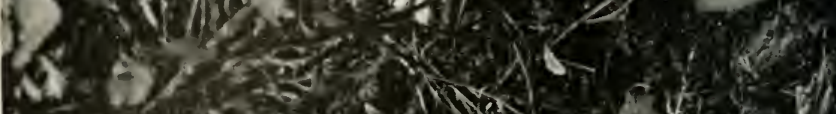
$(a-0)-2 y=2$ $19-2,20$

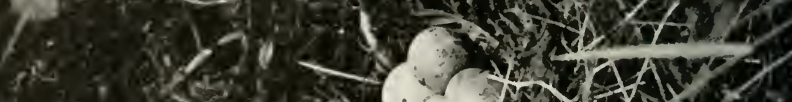

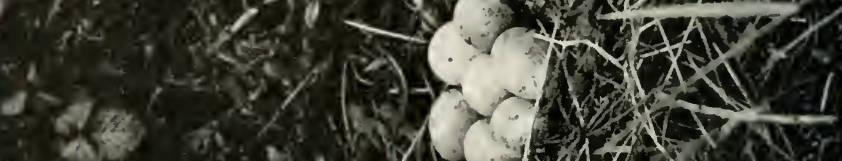

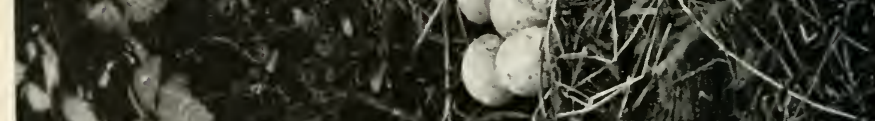
for

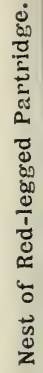


alternation of quick vibrations of its short, rounded wings, and glides with still wings bowed. The tail is spread when the bird rises, plainly showing the chestnut outer feathers. The family parties not only keep together through the winter, but join forces with others, and as coveys roost and feed together, the social habit gives some protection from many enemies. Pairing begins in February, sometimes earlier, and for some weeks there are constant running fights, and much challenging, before mating difficulties are solved. There is little or no bloodshed in these contests, but much healthy exercise. By the end of the month the covey has split into pairs, and the creaky calls, which cannot be expressed by any combination of letters, become infrequent. Though coddled less than the Pheasant, the Partridge gets protection by the removal of its predatory foes, and doubtless its habits are thereby influenced. Yet to a great extent it retains the protective colour which on certain soils and in herbage aids concealment, and has not lost the instinct to lie still and benefit by this gift. In a root-field it is entirely screened, and even on the stubbles it is not unlike a clod of earth when viewed from a distance ; it is most active in the early morning and towards night, lying in quiet little groups during most of the day. Though not so catholic in its tastes as the Pheasant, it is fairly omnivorous, and is a great devourer of insects and other small invertebrates, but grain, grass, fresh shoots, and seeds of all kinds give variety. During the recent over-abundance of the antler moth, Charcas graminis, many Partridges invaded the upper pastures to feed on the swarming caterpillars.

The nest is well concealed, a hollow in thick vegetation in a hedgerow or beneath a bush; it is lined with grass and leaves, and these last are used to cover the ten to twenty olive-brown eggs (Plate I48) when the sitting bird leaves them. The period of paired felicity is long, eggs being seldom laid before the end of April or in May, and summer nests, even in August, are not 
uncommon, and winter clutches, which may be either early or late, are recorded. The "cheepers" (Plate I $\mathbf{5 7}$ ) have buffishbrown down, spotted and striped with black, and brownish bills and legs. They are carefully tended and defended by the old birds, who will boldly attack a threatening foe, even a dog. It has been denied that they will dare to assault man, but once when I blundered upon a family, the irate mother jumped at my legs whilst the little ones scattered and hid. On another occasion when the juveniles, which had just strength of wing to fly for a few feet, whirred off from under our feet, the old bird ran round in circles squealing dolefully. Even when so young the tiny spread tails showed chestnut.

The Partridge is a variable bird, more so than is usually realised, and doubtless the artificial removal of many of its keen-eyed foes has aided the permanence of variation. Dr. Bureau, Mr. J. G. Millais, and Ogilvie-Grant have given full descriptions of the normal colour changes and age variations of the bird, but these are too complicated to be described here. Roughly, it is slate-grey with fine vermiculations of black, and bars and streaks of chestnut and buff, the bars and streaks most pronounced on the wings and flanks. The forehead, cheeks, and throat are chcstnut, and there is a large chocolate horse-shoe-shaped patch on the pale-greyish breast. The head of the female is more streaked than that of the male, and the horse-shoe, if present, is smaller. The bill and legs are blue-grey, and the irides brown; behind the eye is a small red unfeathercd patch. Buffish brown replaces the grey in young birds, and there is little chestnut on the face. Uniform or nearly uniform grey and reddish-brown birds are not un. common, nor are others in which the horse-shoe and other marking are more or less white. The red variety was described as a species by Brisson, and early writers called his $P$. montina the Mountain Partridge, or, according to Latham, the "Cheshire I'artridge." Length, $12{ }^{\circ} 5$ ins. Wing, $6{ }^{\circ} 5$ ins. Tarsus, $I^{\circ} 4$ ins. 


\section{Quail. Coturnix coturnix (Linn.).}

The Quail (Plate 143), our smallest game-bird, occurs throughout Europe, Asia, and north Africa, and is a summer visitor to all parts of the British Isles, even to the Shetlands and Outer Hebrides. The majority arrive in May and depart in October, but occasionally a few remain all winter. It is nowhere normally plentiful, though there are good and bad years; it is a regular visitor in very irregular numbers. The oft-repeated lament that this or that species is decreasing has usually slight foundation, but there is a general opinion that the Quail, in all parts, and especially in Ireland, is less abundant than it was. I venture to doubt it. Destroyers of birds for the table, both here and abroad, have been blamed, but very large numbers are still captured, and there is little evidence of general diminution. The numbers of the Quail are known, historically, to ebb and flow. Even supposing that the bird is decreasing, it is not certain that wholesale massacre by carnivorous man is entirely responsible ; geographical distribution is unstable. We cannot really take credit for the increase of a species like the Turtle-Dove; then why are we to blame because another bird fails to get on? Species declined and vanished long before man was evolved. Any year we may see a temporary recovery of the Quail; I find no evidence that it was ever more than spasmodically plentiful. Indeed, I believe that all statements about its decrease have foundation in the memories of men of advancing years who have recollection of the big Quail years, and forget that these were exceptional. Montagu, in $\mathbf{1 8 0 2}$, made exactly the same remark about former abundance that writers make to-day.

The Quail is a diminutive sandy-buff Partridge, and the two birds have many common habits. As a ground bird it keeps well in cover, its small size an advantage in scant herbage; if flushed by a dog, for a man seldom walks it up, it flies with 
whirr and glide like the larger bird, and drops again almost immediately. Indeed, the only sign of its presence is, as a rule, its liquid trisyllabic call, whit, whit, whit, which gives origin to its vernacular names, "Wet-my-lips," or "Wet-my-feet," and the Cheshire "But-for-But." This is the call or challenge of the male, and there is a low double note common to the sexes. That Quails migrate in hordes is known, and nocturnal travel seems usual, but when the birds are nesting they are less sociable; the autumn "bevy" is often no more than the family, though if many stopped to winter bevies would probably combine. The food differs little from that of the Partridge; Saunders refers to its fondness for chickweed, and if this is so its scarcity cannot be due to food shortage. Small though it is the Quail is a fighter, and we are told that it will duel to the death; no doubt it will in a Chinese cockpit, where it cannot escape, but in a free state a beaten bird seldom waits to be slain. The Quail, in its natural haunts, is difficult to watch. When I kept some in an aviary they were peaceful enough, never interfering with other inmates; they were constantly running about with the low double call, or dusting themselves on the sandy floor. I doubt if the Quail is polygamous under normal circumstances; monogamy is general in England.

The nest is a scratching in herbage, lined with dry grass; the eggs (Plate 154 ), seven to ten in number, are variable, the ground being buff or yellowish, and the deep brown markings either blotches, smears, or fine speckles. They are laid as a rule late in May or in June. The young at first have buff and yellow down and are streaked with black.

The general colour of the old bird is sandy buff, blackish on the back, but broadly streaked on the wings and flanks with yellowish white; the dark brown crown has a central buff stripe, and is further set off by pale superciliary streaks. The male has a double blackish brown collar, from the dark ear-coverts to a brown stripe on the throat. The throat of the female is 
uniform buff, and her breast is more profusely speckled than that of the male. Young males resemble the female. The bill, legs, and irides are brown. Length, 7 ins. Wing, 4.4 ins. Tarsus, $1 \cdot 1$ ins.

\section{Family TETRAONIDÆ. Grouse.}

Ground birds; bill short, stout; wings short, round; tarsi feathered; toes four, hind toe small.

\section{Capercaillie. Tetrao urogallus Linn.}

The handsome Capercaillie (Plate I) has more claim to be called British than the Pheasant and Red-legged Partridge, for though the present stock was introduced so recently as 1837 , the bird is indigenous, and in remote ages made excellent meals for our ancestors, who left its bones amongst other evidences of their feasts in "kitchen-middens" and cave deposits. When it vanished from the forests of England and Wales is unknown, tut it lingered in Scotland and Ireland until Pennant's day, for he saw a bird which had been killed in Inverness, and states that the "Wood Grous," though rare, existed in Tipperary in 1760. Abroad the bird is a native of most European pine forests, and it was from Sweden that the ancestors of the present thriving Scottish birds were obtained; from Perth, where they were turned down, they have colonised the conifer woods in all directions.

The cock is a large, heavily built bird, with strong, curved, whitish bill, grey-black dress, and legs feathered to the toes. Across the breast is a metallic green gorget, and it was this, no doubt, which caught the observant eye of Giraldus when, at the end of the twelfth century, he states that "Wild Peacocks" abound in the Irish woods. The hen is a smaller, much browner bird, rather like a Grey Hen with a more rounded tail. Now 
that the "Cock of the Woods" has increased, it has even extended its habitat to woods of deciduous trees, and apparently the hens regulate the extension of range, wandering to new woods, where, not infrequently; an amorous Black Cock selects one for its harem, and interesting hybrids result. Both Capercaillie and Black Grouse are polygamous. The Capercaillie has the strong, swift, but not long sustained flight of the grouse family; a series of rapid wing movements with intervals when the bird glides with the wings steady, the primaries curved downward. It perches freely, and feeds in the branches on young leaves, buds, shoots, and pine needles, and does not refuse caterpillars or other insects which it finds; fruits and berries of all kinds are taken in their season. Seebohm thought that the hen fed more on the ground, or at any rate less on pine needles, since its flesh has less flavour of turpentine. All grouse fight in the spring, and in addition have some extravagant display performances; that of the victorious cock Capercaillie is a variety entertainment for the benefit of the admiring hens. Perched on a branch or rock, he spreads his ruff and tail and droops his wings, and dancing in excitement produces strange sounds in his "spel" or serenade. Various observers have heard notes which reminded them of the squalls of fighting cats, of the drawing of corks, and the sound of grinding knives. The hens gather to listen to the song, answering with excited croaks. Apparently this performance, which I have never had a chance of witnessing, is triumphal after defeat of rival cocks, and there is approval rather than competition for favours amongst the hens.

The nest is a hollow lined with pine needles and moss, in which six to eight eggs (Plate 153), yellowish in ground and speckled with red-rather like those of the domestic Turkeyare laid late in April or in May. The young have buff down, are mottled and striped, especially on the head, with black, and have a bare red patch behind the eye. 
The male has the upper parts and much of the under parts black, dusted and speckled with grey; the feathers of the neck are elongated and are spread during display; the coverts are reddish brown with white speckles and tips, and both primaries and secondaries, as well as the feathers of the flanks, show a good deal of white on their margins or tips. The tail has a terminal white band in fully mature birds. Above the eye is a long vermilion wattle; the heavy bill is yellowish white, and the irides are brown. The female is reddish brown, mottled on the upper parts with black, buff, and white; the under parts are barred with buff, black, and white. Ogilvie-Grant shows that there is an extra summer or "eclipse" plumage. Young birds closely resemble the hens, and young males do not acquire the white tail band until the second or third year. The size varies greatly. Male: Length, $33-35$ ins. Wing, 14.8 ins. Tarsus, 3 ins. Female: Length, $22-25$ ins. Wing, 12 ins. Tarsus, $2 \cdot 2$ ins.

\section{British Black Grouse. Lyrurus tetrix britannicus Witherby and Lönnberg.}

For long it has been known that the Red Grouse differs from its Continental allies, but in I913 Mr. Witherby and Dr. Lönnberg showed that the British Black Grouse was also an insular race, the distinctions being constant in the female. It differs mainly from the European bird, which ranges from Scandinavia to Switzerland, in more diffused rufous tints-less sharply contrasted-and in the absence of white tips and grey markings on many feathers on the wing-coverts, breast, and other parts. The British Black Grouse (Plate 156) has a wide but rather uneven distribution in Scotland and northern England, but is less frequent in Wales and the south-west, and in the south and east absent or a mere accidental straggler. Various attempts have been made to introduce it in fresh localities, but with 
little success. There is, in some parts, seasonal movement, especially between areas at different altitudes, but little that is more than purely local migration, and yet birds have been shot in unexpected localities; possibly these stragglers have been wanderers from spots where ineffectual attempts have been made to establish the bird. It is unknown in Ireland.

Though common in some northern woodlands, the usual haunt of the Black Grouse is the sparsely wooded fringe of the moor, hilly country where there is a variety of feeding groundmoors, woodlands, and cultivated land. The Black Cock differs from other grouse in his glossy blue-black plumage and lyreshaped tail ; the Grey Hen, his mate, is a less distinctive reddishbrown bird, smaller than the female Capercaillie, and differing from her in having the tail forked and not rounded. The strong, swift flight is typical of all grouse, but in the semi-arboreal habits, and in polygamy, the bird agrees with the last species rather than the next two. The food varies according to locality and season, and, though insects or other animals are eaten, is largely vegetarian; the tender tops of moorland plants, especially ling, heather, crowberry, and bilberry, as well as moorland fruits and berries, are appreciated, and buds, leaves, and fruits of trees are included. Conifers suffer from the Black Grouse, and when the corn is ripe grain is too freely devoured.

The annual display and competitive performances of the males take place in spring, usually in the early morning. The males gather to "lek" or compete in some open space, and fight, dance, and show off, and the females come to look on with more or less evidence of approval. The actual fights look more serious than they are, for little more than a trial of strength results; there is much of the game-cock in the threatening preliminaries, but the blows are mostly with the wing, the feet, though used, being unarmed. Fighting changes to an exhibition of competitive dancing when feminine spectators arrive at the tilting ground; with hoarse cries the excited birds 

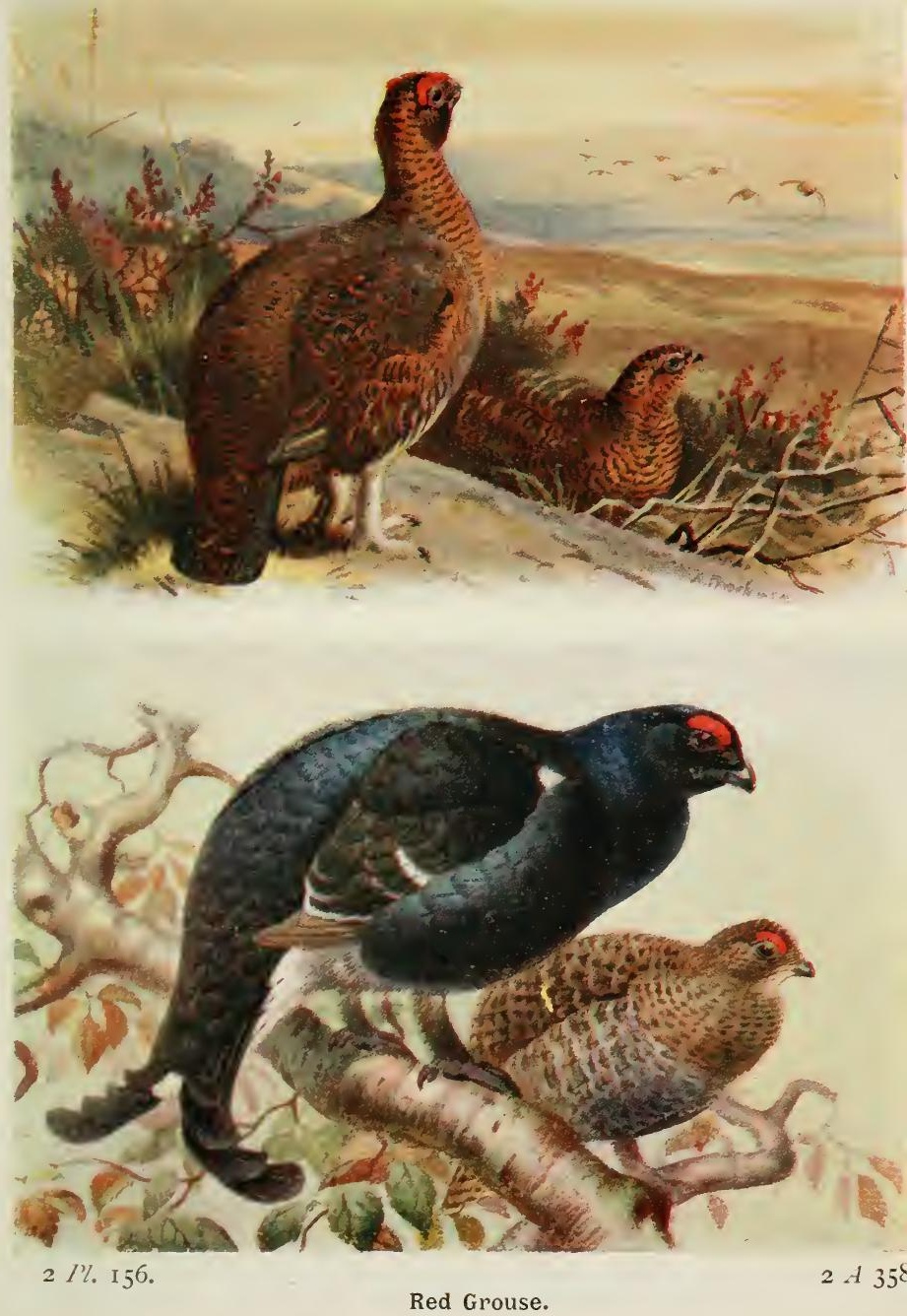

Black Grouse. 


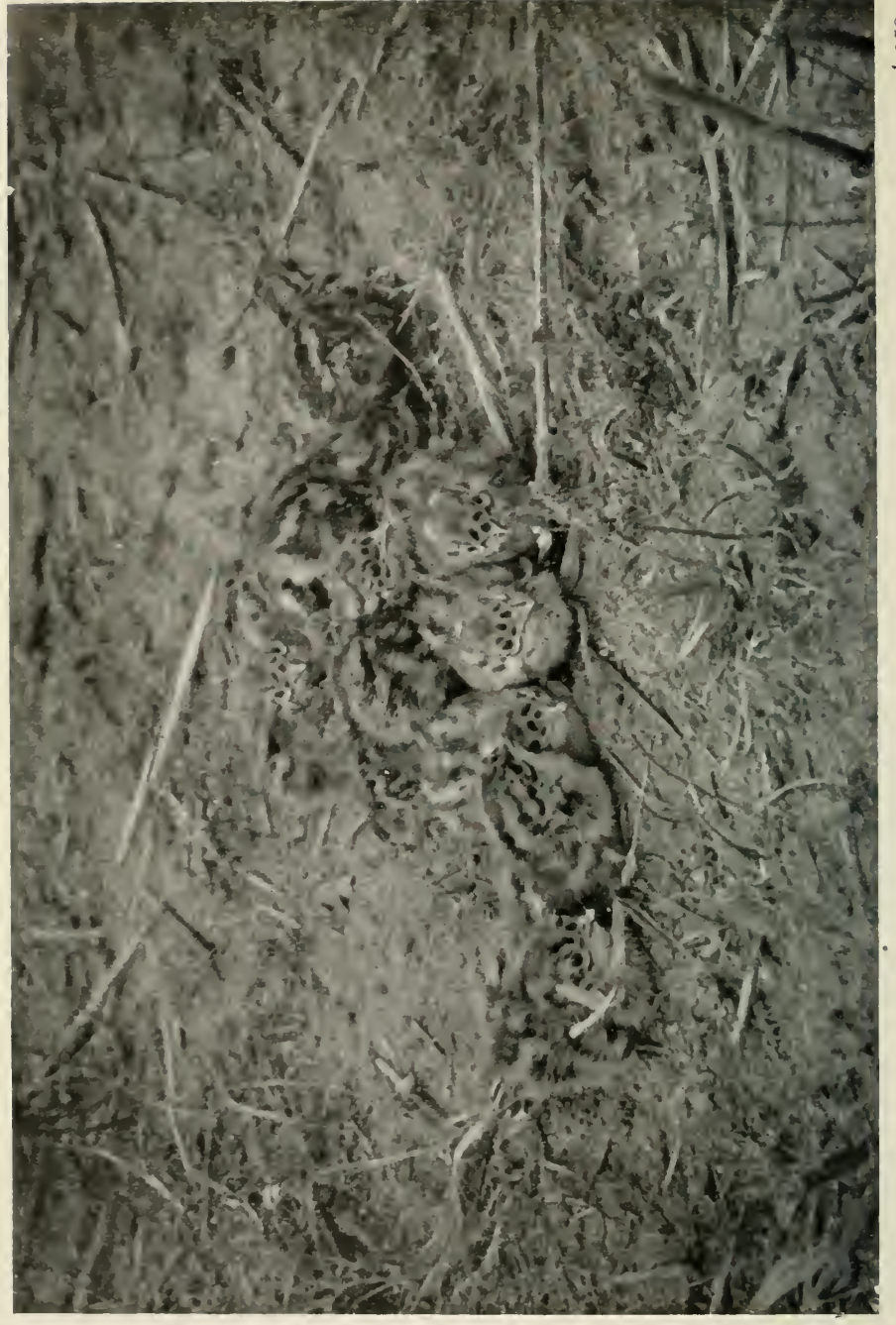

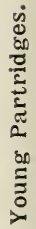
눈 
leap into the air, posture, and dance. More deliberate and sedate exhibition of plumage charms includes many extraordinary attitudes; with drooping wings and elevated widespread tail, the contrast of white wing bar and under tail-coverts with the dark plumage produces effects calculated to charm. The outward and even forward spread of the gracefully curved tail feathers, and the snowy expanse of fluffy feathers beneath, are the more striking features. The exhibition is accompanied by a curious whirring note, which Mr. H. S. Gladstone likens to the sound of a "curling-stone travelling over keen ice." It is not, by any means, proved that regular harems are selected and retained, and the separation or mingling of the sexes after the young are able to look after themselves may vary in different localities; Mr. Abel Chapman points out that there is an autumnal display by the males, but that it has less enthusiasm than that of spring and is received somewhat coldly by the hens.

During summer, when the cock loses his fine tail for a time, and has a browner dress, especially on the head, he takes little interest in the female, and in winter several males and females will feed together without jealousy. Hybrids with other species, such as Pheåsant, Capercaillie, and Red Grouse, are not infrequent, but there is much variation in the plumage of mature birds, as well as rather complicated age changes, and the parentage of some reported hybrids has been challenged.

The nest is usually on the ground in thick herbage, and the six to ten, or even more, eggs (Plate 154) are not unlike small eggs of the last species, rather thinly speckled with reddish brown on a yellowish ground. Nestlings have buff or yellowish down, mottled with black and chestnut, and reddish blackbanded heads.

The normal plumage of the male is glossy blue-black, browner on the wings; the under tail-coverts and a bar on the wing are white, and above the eye is a large vermilion wattle, which 
varies in size according to season, bcing very prominent during the period of display. The bill and toes are blue-black, the irides brown. The female is rufous buff, barred and mottled with black, and the wattle above her eye is smaller. Young birds at first resemble the hen, but young males show a mixture of brown, black, and white in autumn, and early an outward curve of the short tail feathers, though the full tail is not acquired until the third year. Male : Length, $19^{\circ} 75$ ins. Wing, 1o ins. Tarsus, 2.25 ins. Female : Length, 18 ins. Wing, 9 ins. Tarsus, 2 ins.

\section{Red Grouse. Lagopus scoticus (Latham).}

No doubt the Red Grouse (Plate 156 ) is a British insular form, closely allied to the Willow-Grouse, L. lagopus (Linn.), but its plumage differences alone seem sufficient to warrant specific rank. The Willow-Grouse has a white winter diess like that of the Ptarmigan, and in summer its plumage is whiter than that of any Red Grouse. Our bird is generally distributed in Scotland, Ireland, and most of the Welsh counties, but in England is a northern species, breeding so far south as Shropshire, Derbyshire, and Yorkshire.

The Red Grouse is a moorland bird, but is by no means confined to those which are heather clad; indeed, on the Pennines and in other parts there are well-stocked moors where it would be difficult to find heather or ling. On such moors, however, the crowberry, often confused with the heaths, is usually plentiful. The altitude of the moor matters little if other conditions are favourable, but though Grouse are found at sea-level, most of their haunts are above the rooo-foot contour. The appearance of the "Moor-fowl" is familar, though generally as a shot-battered corpse, or as a possible recipient for shot as it comes, a stout, short-winged bird, whirring and gliding over the shoulder of the moor, toward the 
turf batteries. Though richly coloured it is well hidden amongst the irregularities and varied shades of the rough moor; it lies low, rising when disturbed with a startling whirr, and flies just above the heather, turning sideways as it takes advantage of the undulations or steep slopes of the cloughs or corries. Its call, a loud crow, is used as a challenge as it stands, head erect and red wattle raised, on some tussock or mcund, but its alarm, when flushed, is a rapid $k o k, k o k, k o k$, as it flies, and a clear goback, goback, goback, when it alights at a safe distance and runs amongst the tussocks. The young feeds largely on insects, especially caterpillars, though they take a few leaves and shoots of ling and other plants; the old birds subsist mainly on shoots, leaves, and seeds of heather, ling, crowberry, bilberry, and other plants of the "tops," and in autumn on the abundant moorland fruits. Seeds of grasses and rushes are eaten, but raids on cornfields are exceptional. When, in winter, the moor is snow-clad for weeks at a time the Grouse usually descend to lower ground; I have seen pack after pack flying down during a blizzard, and in some parts there is apparently regular local migration from the higher to the lower ground. Mr. Abel Chapman, however, states that on the Borders the Grouse tunnel under the snow to obtain their food and are thus concealed from view. Water, easy to obtain on the hills, is necessary for the bird, but the young are apt to drink too much, with fatal results. Grit, too, is essential to aid digestion, as indeed it is with most birds, and it is common to see Grouse on the unfenced moorland roads picking up grit, or enjoying a sun or dust bath. The Red Grouse is normally hardy, but disease sweeps off great numbers, doubtless because of over-stocking and the interference with natural laws which would weed out the weaklings and strengthen the surviving stock. The care of a moor is only necessary because we wish to improve upon Nature, who will not countenance abundance at the expense of other creatures. 
Although satisfied with one mate the cock Grouse will fight even after he has paired, but as in other species the sexual spars are not serious. In winter the bird is gregarious, but the packs do not "jug" close together like Partridges, and by the end of March they have mostly broken up. The nest is a simple hollow in the ground, often sheltered by ling or other plants, and lined with a few sprigs of heather and dry grass. Seven to ten, or even more, richly coloured red or yellowish eggs, closely mottled and blotched with reddish brown (Plate 154), are laid late in April or in May, the date varying according to the severity of the season. The colour is at first "loose," and smeared eggs are not uncommon. "Cheepers," clothed in mottled and streaked yellowish brown and chestnut down, rapidly get the power of short-distance flight, and when no bigger than thrushes will whirr for a few yards after their parents, but soon learn that there is safety in remaining still (Plate 158).

Authorities differ, not always amiably, about the moults and plumages of the variable Red Grouse, for the subject is somewhat complicated by local variation. The periods of the two moults differ in the male and female. The male has a winter dress, in which he breeds, complete about the end of November and replaced by a summer dress in June; the female is in summer plumage in April, and in winter or autumn dress in August. These times vary greatly according to the health of the birds; disease delays the moults, but apart from this Dr. E. A. Wilson found that almost every bird shows more or less sign of another season's dress.

The feathers on legs and toes are thin and worn in summer, but are thick and long after the autumnal moult. OgilvieGrant groups the more general forms or types of colour variation; in the male he finds red, black, and white spotted forms, and in the female two others, buff barred and buff spotted types, the last being the most frequent. The typical winter and 


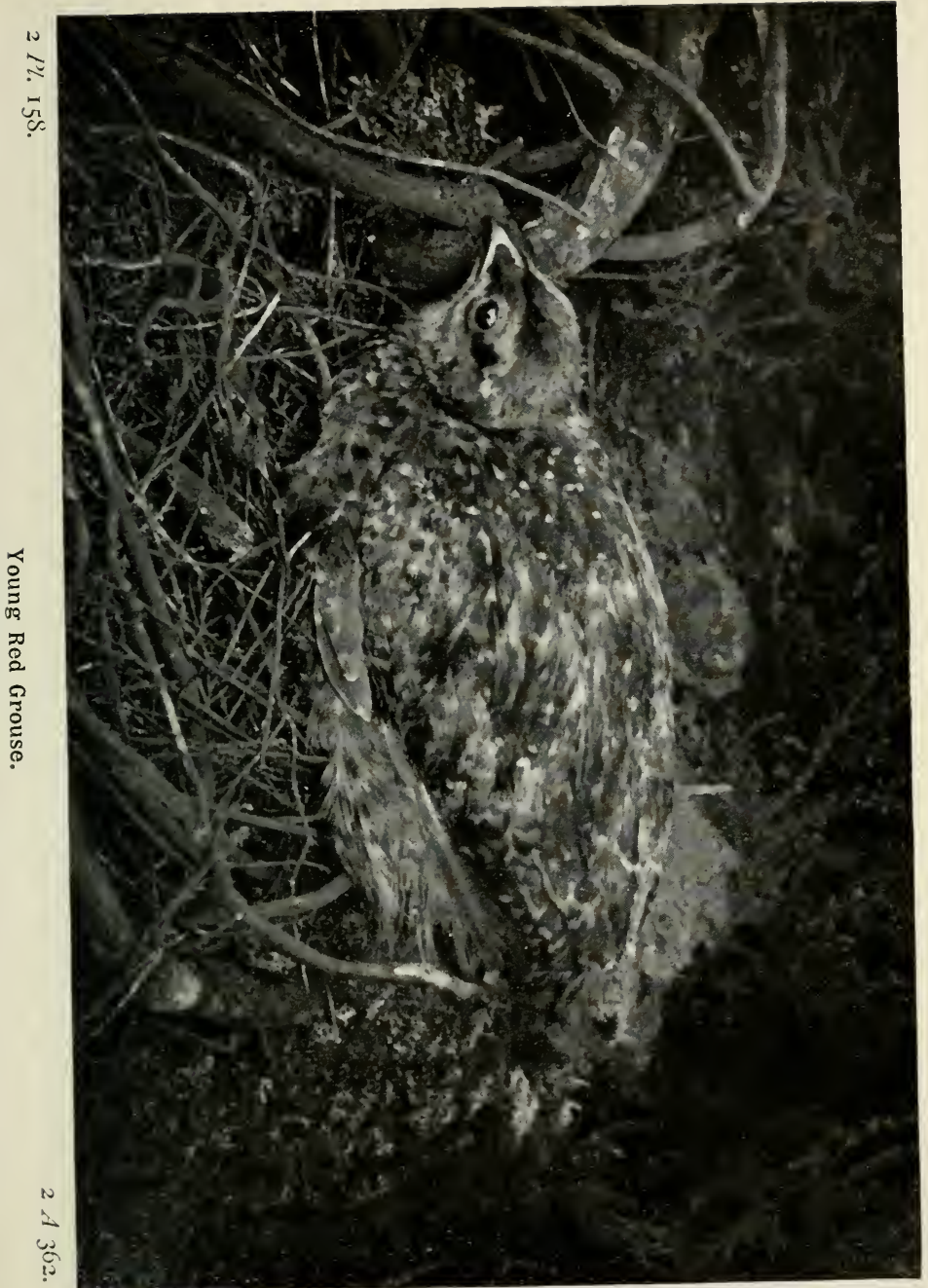




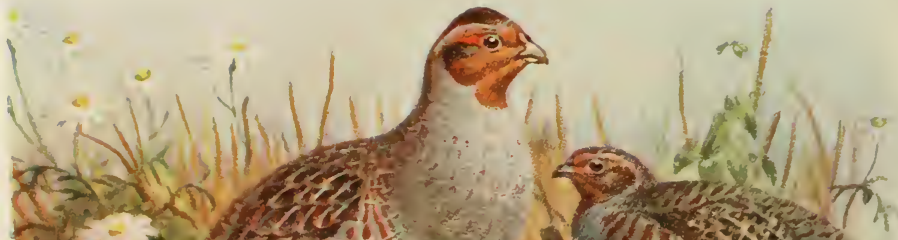

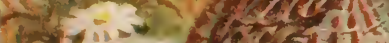

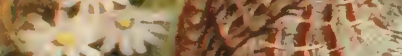

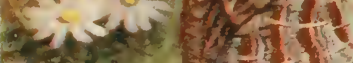
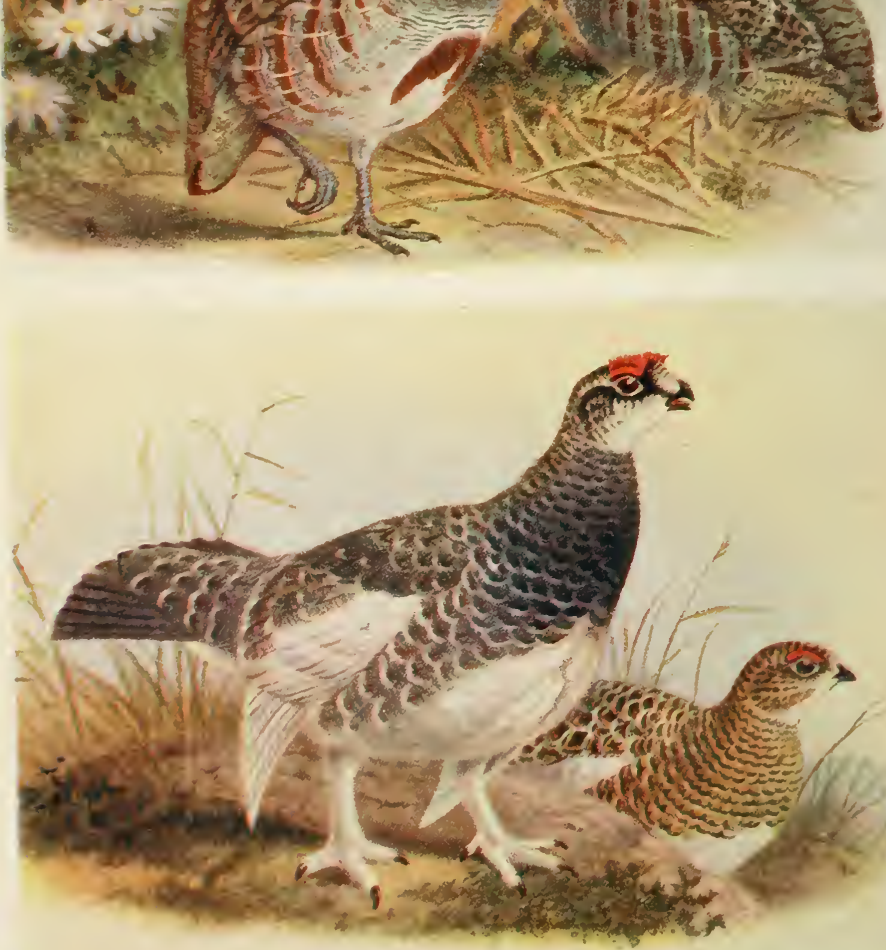

2 I'. I 59.

$2 .+363$.

Partridge.

Ptarmigan (Summer). 
nuptial dress of the male is chestnut-red, barred with wavy black lines; the markings are least conspicuous on the coppery red throat and neck. The bill is blue-black, the irides are brown, and above the eye is a vermilion erectile wattle or comb. In summer the bars are wider and more pronounced, and there is more buff in the general plumage. The female is often a more spotted bird, but when barred shows strong buff and black markings, and often a good deal of white. Length, 15 ins. Wing, 8.25 ins. Tarsus, $x \cdot 8$ ins.

\section{Ptarmigan. Lagopus mutus (Montin).}

The mountain ranges of Europe, from Scandinavia to the Pyrenees, are the home of the Ptarmigan (Plate I59); with us it only occurs in the highest mountains of Scotland and some of the western islands, seldom breeding below the $2000-\mathrm{foot}$ contour.

There is no difficulty in distinguishing the Ptarmigan from other grouse, although its zone overlaps that of the Red Grouse occasionally, for at all ages it is not only a whiter bird, but when mature has white quills in each of its three seasonal phases. It is not a bird of the heathery moor but of the rocky summits, where lichens and mosses replace more luxuriant vegetation, and where, on northern slopes, the snow will linger through the summer. In July, when its blue-grey autumnal dress was nearly complete, I have heard its low croaking, and seen it crouching on the lichen-clad rocks, head and breast low, ready to spring up and fly. When running on snow these grey birds look very like the stones in motion, and in winter dress it is almost invisible, even to the keen eye of the Golden Eagle or the hill fox. It runs and hides rather than take wing, but in flight is wonderfully swift ; it will cross at a great height from peak to peak. Its food is on the whole similar to that of the Red Grouse, though naturally of a more alpine nature; 
it eats mosses and lichens as well as berry-bearing, low. growing plants and dwarf willows. In autumn, sometimes early, the birds pack, and in winter usually descend to a lower zone, but like the Red Grouse it will at times seek food by burrowing in the snow. The packs break up in spring, but the nest, an unlined or scantily lined hollow, is not scratched until May. The seven to ten eggs (Plate I54) are not unlike pale eggs of the Red Grouse, and are often laid in June. Young in down are rather darker than those of the last species, especially on the head. They fly at a very early age, and are carefully guarded and boldly defended by their parents. The hen, and sometimes the cock, will feign lameness to attract attention, and the latter will attack a dog, and it is said a man, if the young are threatened.

The Ptarmigan has three moults. In nuptial dress, worn from about April to July, the male is barred on the upper parts with brown, grey, and buff; the under parts below the breast are mostly white. Black, white-tipped outer tail feathers, and white, black-shafted quills are constant in all phases. The more tawny female has black barring. From August until about October the upper parts are grey, vermiculated with black, and the female is rather browner. In winter the dress of both sexes is white, except for the black on the tail and quill shafts; the lores and a streak through the eye are black in the male and very old females. In the imported Willow Grouse, which is sold as Ptarmigan in winter, there is no black on the lores. Above the eye of both sexes there is a scarlet comb, more pronounced, however, in the male bird; the bill is black, and the irides brown. Until the first autumn moult the primaries of young birds are brownish. Length, 14.5 ins. Wing, $7 \cdot 6$ ins. Tarsus, $1 \cdot 5$ ins. 


\section{REPUTED BRITISH BIRDS.}

As explained in the previous volume, many birds have been added to the British list on slender evidence; some of these are catalogued by the B.O.U. Committee, but I cannot entirely agree with all their conclusions. A number of geese, ducks, cranes, and gallinules have long been kept in parks and on ornamental waters, and examples frequently stray and are shot as "rare birds"; a few of those recorded may have actually wandered to Britain unaided, but it is so difficult to prove the origin of any individual that it is better to be cautious. The following species may be listed as probable wanderers from captivity: Bar-headed Goose, Anser indicus (Lath.); Chinese Goose, Cygnopsis cygnoides (Linn.); Spur-winged Goose, Plectropterus gambensis (Linn.); Muscovy Duck, Cairina moschata (Linn.) ; Summer Duck, sEx sponsa (Linn.) ; Egyptian Goose, Alopochen agyptiacus (Linn.); Baer's Pochard, Nyroca baeri (Radde), Herts, 190r; Little Brown Crane, Grus canadensis (Linn.), Cork, 1905; Demoiselle Crane, Anthropoides virgo (Linn.) ; Crowned Crane, Balearica pavonina (Linn.); Greenbacked Gallinule, Porphyrio porphyrio (Linn.), three, Norfolk; Purple Gallinule, $P$. caruleus (Vand.); Allen's Gallinule, $P$. alleni Thompson, Norfolk, 1902. To these I may add the Falcated Teal, Eunetta falcata (Georgi), said to have been killed in Cheshire, and the Baikal Teal, Querquedula formosum (Georgi), which was shot on the Dee by Mr. L. N. Brooke.

The Eastern Grey Lag-Goose, Anser rubrirostris Hodg., reported from Limerick, 190I, is doubtfully distinct, and the 
Bimaculated Duck, Querquedula bimaculata ( $\mathrm{K}$. and B.), is a hybrid. Two American swans have been included, but in both cases identification and origin may be erroneous. The Whistling Swan, Cygnus columbianus Ord, was included by Macgillivray on the strength of an example bought in an Edinburgh poulterer's, and the Trumpeter-Swan, C. buccinator Rich., was added because Newton considered that a young bird, shot in Suffolk, was referable to this species.

The Ring-necked Duck, Nyroca collaris (Don.), was described by Donovan from a supposed Lincolnshire specimen obtained in Leadenhall Market. The B.O.U. Committee include it, considering that at the beginning of the nineteenth century it must have been a genuine wild bird, but I agree with the editors of the "Hand List" that the evidence is insufficient. The Lesser Scaup, N. affinis (Eyton), another "market" record, is rejected by both, and as a mistake was made about one example of Barrow's Goldeneye, Glaucion islanicum (Gmel.), reported Shetland occurrences are also doubted, although the bird nests in Iceland.

The Little Green Heron, Butorides virescens (Linn.), killed in Cornwall in October, I889, (not April, I890, as stated in the B.O.U. list), is a possible straggler, but the evidence is not sufficient to warrant inclusion. The inclusion of Wilson's Snipe, Gallinago delicata Ord, is founded on an example shot in Buckingham, but the identification is doubtful, as are those of the Rock-Ptarmigan, Lagopus rupestris (Gmelin), said to have been shot on two occasions in Scotland. The supposed occurrence of the Swift Tern, Sterna bergii Licht., was worse than an error, and though Scopoli's Sooty Tern, S. ancethetus Scop., was genuine, it is not certain that the specimen was really obtained in the Thames.

Ussher doubted the two examples of the Noddy Tern, Anous stolidus (Linn.), which were recorded for Ireland, and Oldham and I were not satisfied with the evidence in favour of the 
Cheshire bird, though all three were accepted by Saunders. The B.O.U. Committee include the Cape Pigeon, Daption capense (Linn.), with reserve; I investigated one reported occurrence, not included by them, and found that the bird had been imported. Saunders believes that the Laughing Gull, Larus atricilla Linn., was included in error, and there seems every reason to believe that the supposed occurrence of the American Pied-billed Grebe, Podilymbus podiceps (Linn.), at Weymouth, was due to accidental exchange of skins, and not to any attempt at fraud. The Irish record of the Martinique Gallinule, Porphyrio martinicus (Linn.), was due to an error, and there is no detail about another specimen, supposed to be British.

The eight or more records of the now extinct Passenger Pigeon, Ectopistes migratorius (Linn.), cannot be lightly cast aside, but as the bird was certainly at one time imported alive, it is now impossible to say how all reached Britain, but the last, shot in Yorkshire in 1876 , was an escaped bird. There is little doubt about the Andalusian Hemipode, Turnix sylvatica (Desf.), Barbary Partridge, Caccabis petrosa (Gmel.), and BobWhite, Colinus virginianus (Linn.); they had been released as game-birds. I saw two Californian Quails, Lophortyx californicus Shaw, quite tame birds, which had been captured in a Cheshire wood, and examined in the flesh a Patagonian Crested Tinamou, Calodromas elegans (D'Orb. and Geoff.), shot in the same county, neither of which could possibly reach England unaided. 


\section{INDEX}

AEGIALITIS alexandrina, 191, Plates 57, 78, 81 ; asiatica, 194 ; iubia, 193; hiaticula, 187, Plates 57, 78,79 ; semipalmatus, 192 ; vocifera, 193

IEx sponsa, 365

Alca impennis, 266 ; torda, 263, Plates

I 14, I I 7, I 18

Alle alle, 273. Plate 120

Allen's Gallinule, 365

Alopochen agyptiacus, 365

American Bittern, 97. Plate 32

American Golden Plover, 185

American Pectoral Sandpiper, 137. Plate 56

American Pied-billed Grebe, 367

American Stint, 135

American Wigeon, 4I

Anas platyrhynchos, 26, Plates II,

13, I5 ; strepera, 29, Plates 13, 16,

17

Andalusian Hemipode, 367

Anous stolidus, 366

Anser albifrons, 5, Plate 4; anser,

I, Platis 2, 3; arvensis, 4;

brachyrhynchins, 7, Plate 4; erythropus, 6 ; falalis, 4, Plate

2 ; indicus, 365 ; rubrirostris, 365

Anthropoides virgo, 365

Arctic Skua, 256. Plates 113, I14, I 6

Arctic Tern, 237. Plates 105, IoS Ariea cinerea, 85 , P'lates 30, 31, 44 ; turpurea, 87, Plates 31, 33
Ardeola ibis, 89; ralloides, 90, Plate 32

Arenaria interpres, 204. Plales 82, 88

Avocet, I80. Platcs 74, 75

B.AER'S Pochard, 365

Baikal Teal, 365

Baillon's Crake, 323. Plate I 40

Baird's Sandpiper, I $3 S$

Bald Coot. See Coot

Balearica pavonina, 365

Barbary Partridge, 367

Bar-duck. See Sheld-Duck

Bar-headed Goose, 365

Barnacle-Goose, II. Plate 7

Barrow's Goldeneye, 58, 3066

Bar-tailed Godwit, 169. Plate 7 I

Bartramia longicauda, 153

Bartram's Sandpiper, 153

Bean-Goose, 4. Plate 2

Bewick's Swan, I7. Plate 9

Bimaculated Duck, 366

Bittern, 93. Piates 34, 36, 37, 44

Black-browed Albatross, 295

Black Cock. See Black Grouse

Black Curlew. See Glossy Ibis

Black-duck: Sce Scoter

Black Grouse, 357. P'lates I 54, I 56

Black Guillemot, 270. Plates 94, II9

Black-headed Gull, 222. Plates So, 98, IOI

Black-necked Grebe, 314. Plate 137 
Black Shearwater. See Sooty Shearwater

Black Stork, 99. Plate $3^{S}$

Black-tailed Godwit, I7I. Plates 69, 71

Black Tern, 248. Plates II I, I I3

Black-throated Diver, 297. Plates 127, 129, 136

Black-winged Pratincole, I I 4

Black-winged Stilt, 179. Plate 74

Blue Fulmar. See Fulmar.

Blue Rock. See Rock-Dove

Blue-winged Teal, 34

Bob-White, 367

Bonaparte's Gull, 222

Bonaparte's Sandpiper, I 39

Bonxie. See Great Skua

Botaurus lentiginosus, 97. Plate 32 ; stellaris, 93. Plates 34,36 , 37,44

Bottle-nose. See Puffin

Brahminy Duck. See Ruddy Sheld. Duck

Branta bemicla, Iо, Plate 7; $b$. glaucogaster, IO; canadensis, I3, Plate 5; lencopsis, II, Plate 7; nigricans, Io ; ruficollis, I4

Brent Goose, I0. Plate 7

Bridled Guillemot, 269

British Black Grouse, 357. Plates I 54, 156

British Lesser Black-backed Gull, 215. Plates 91, 94, 99

Broad-billed Sandpiper, 129

Brinnich's Guillemot, 270

Buff-backed Heron, 89

Buff-breasted Sandpiper, I47

Buffel-headed Duck, 6 I

Buffon's Skua, 258. Piate II5

Bulwer:- bulweri, 295

Bulwer's Petrel, 295

Burgomaster Gull. See Glaucous Gull

Burrow-duck. See Sheld-Duck

But-for-But. See Quail

Butorides virescens, 366

Series $I I$.
CACCABIS petrosa, 367 ; rufa, $34^{8}$, Plates 149, 154, 155

Cairina moschata, 365

Calidris arenaria, 148. Plate 6r

Calloo. See Long-tailed Duck

Calodromas elegans, 367

Californian Quail, 367

Canada Goose, 13. Plate 5

Canutus canutus, 130. Plate 53

Cape Pigeon, 367

Capercaillie, 355. Plates I, 153

Cape Verde Dusky Shearwater, 290

Capped Petrel, 294

Carolina Crake, 323

Carr-Swallow. See Black Tern

Caspian Plover, 194

Caspian Tern, 244

Catharacta skua, 253. Plates I1 2, II6

Charadrius apricarius, 182, Plates $76,77,80 ;$ dominicus, 185 ; $d$. fulvus, 185

Chen hyperboreus, 8. Plate ro

Cheshire Partridge. See Partridge

Chinese Goose, 365

Chettusia gregaria, 197

Chlamydotis undulata macqueeni, 108

Ciconia ciconia, 98, Plate 38 ; nigra, 99, Plate 38

Clangula hyemalis, 62 . Plate 24

Cobbler's-awl. See A vocet

Cock-of-the-Woods. See Capercaillie Colinus virginianus, 367

Collared Petrel, 294

Collared Pratincole, I13. Plate 46

Columba livia, 339, Plate 149; cenas, 334, Plate 147; palumbus, 336, Plates 147, 151

Colymbus adamsi, 303 ; arcticus, 297 , Plates 127, 129, 136; immer, 300 , Plate 130; stellatus, 304, Plates I 28, I3 1, I36

Common Gull, 206. Plates 80,89 , 90 Common Heron, 85 . Plates 30, 31, 44

Common Sandpiper, 160. Plates 54 , $6 \mathrm{I}, 65,67$ 
Common Scoter, 71. Plate 27

Common Sheld-Duck, 20. Plates S, 12

Common Snipe, 123. Plates 50, 5 I, 52,54

Common Tern, 233. Plates 94, 103 , I04, 106

Coot, 331. Plates 145, I46, 148

Coot-footed Sandpiper. See Grey Phalarope

Corncrake, 325. Plates I4I, I42, I43, 148

Corpse-eater. See Great Black-backed Gull

Coulterneb. See Puffin

Coturnix coturnix, 353. Plates 143 , I 54

Crane, 103. Plate 4I: See also Heron

Creani-coloured Courser, II I. Plate 46

Crested Tinamou, 367

Crex crex, 325. Plates 141, I42, I43, 148

Cricket Teal. See Garganey

Crowned Crane, 365

Curlew, 173. Plates 57, 70, 72, 73

Curlew-Sandpiper, I45. Plate 59

Curre. See Pochard

Cursorius gallicus, II I. Plate 46

Cushat. See Ring-Dove

Cygnopsis cygnoides, 365

Cygnus bervicki, I7, Plate 9; buccinator, 366 ; columbianus, 366 ; cygnus, I5, Plates 6, 9; olor, 19 , Piates 6, 10

DABCHICK, 316 . Plates 134, 137 Dafila acuta, 44. Plates 13,17 Daption capense, 367

Demoiselle Crane, 365

Diomedea melanophry's, 296

Dipper. Sec Dabchick

Diver. See Great Crested Grebe

Dotterel, 194. Plates 57, 82

Double Snipe. See Great Snipe

Dovekie. See Black Guillemot
Dowitcher. See Red-breasted Snipe Dowker. See Dabchick Ducker. See Dabchick Dunbird. See Pochard Dunlin, I41. Plates 44, 58, 59 Dusky Redshank, 156 . Plate 64 Dusky Shearwater, 290

EARED Grebe. See Black-necked Grebe

Eastern Golden Plover, 185

Eastern Grey-Lag Groose, 365

Eastern Turtle-Dove, 342

Ectodistes migratorius, 367

Egretta alba, 88; garzelta, 89

Egyptian Goose, 365

Eider Duck, 66. Plates 14, 25, 26

Ereunetes pusillus, I 53

Erolia acuminata, I3\$; alpina, 141, Plates 44, 59; bairdi, 138; ferruginea, 145, Plate 59; fuscicollis, 139 ; maculata, 137, Plate 56 ; maritima, 139. Plate 56 ; minuta, I33, Plate 55; minutilla, 135; schinzi, I42; temmincki, 136, Plate 55

Eskimo Curlew, I 78

Eudromias morinellus, 194. Plates 57, 82

Eunetta falcata, 365

FALCA TED Teal, 365

Ferruginous Duck, 48. Plate 15

Flamingo, 84

Fork-tailed Petrel, 281. Plate 123 Fratercula arctica, 275. Plates 108, I 20, I 22, 125

French Partridge. See Red-legged Partridge

Frigate Petrel, $2 \mathrm{~S}_{3}$

Fulica atra, 331. Plates 145, 146, 148

Full Snipe. See Snipe

Fulmar, 291. Plate 126

Fulmarus glacialis, 291. Plate $\mathbf{1 2 6}$ 
3ADWALL, 29. Plates 13, 16, I7 Jairfowl. See Great Auk

Gallinago delicata, 366 ; gallinago, 123. Plates 50, 51, 52, 54; media, 126, Plate 51

Gallinula chloropus, 328. Plates 144, 145,148

Garganey, 31. Plates I8, 21, 22

Gaunt. Sce Great Crested Grebe

Glareola nordmanni, I I4; pratincola, I 13 , Plate 46

Glancion albeola, 61 ; clangula, 58,

Plate 23; islandicum, 366

Glaucous Gull, 2 I8. Plate 96

Glossy Ibis, Iоr. Plate 39

Goldeneye, 58. Plate 23. See also Tufted Duck

Golden Plover, I82. Plates 76, 77, so

Goosander, 76. Plate 29

Grass-Quail. See Corncrake

Great Auk, 266

Great Black-backed Gull. 213. Flates $87,93,97$

Great Black-headed Gull, 22 I

Great Bustard, 105. Plate 42

Great Crested Grebe, 307. Plates 132, I33, I 53

Great Northern Diver, 300. Plate 130

Great Plover, I09. Plates 45, 54

Great Shearwater, 289. Plale 126

Great Skua, 253. Plates II2, I I6

Great Snipe, 126. Plate 51

Great White Heron, 88

Greater Yellowshank, I 57

Green-backed Gallinule, 365

Greenland Dove. See Black Guillemot

Green Plover, 197. Flates $57,83,85$

Green Sandpiper, 164. Plate 68

Greenshank, I 59. Plates 66 , I 54

Green-winged Teal, $3^{8}$

Grey Hen. See Black Grouse

Grey Lag-Goose, I. Piates 2, 3

Grey Partridge. See Partridge

Grey Phalarope, I14. Plate 48
Grey Plover, 186. Plate 77

Grey-rumped Sandpiper, I68

Grundling. See Ringed Clover

Guillemot, 267. Plates I 17, I I9,

I 2 I

Gull-billed Tern, 244. Plate Io7

HEMATOPUS ostralegus, 201.

Plales 8o, 84, 85, 86

Half Snipe. See Jack Snipe

Harcourt's Petrel, $2 \$ 2$

Harlequin Duck, 6I

Heather-bleater. See Snipe

Hell-diver. See Slavonian Grebe

Heniconetta stelleri, $6_{5}$

Heron, 85. Plates 30, 3I, 44

Herring-Gull, 209. Plates 87, 91, 92, 95

Himantopus himantopus, 179. Flate 74

Histrionicus histrionicus, $6 \mathbf{r}$

Hooded Merganser, 8I

Hooper Swan, 15. Plates 6, 9

Horned Grebe. See Slavonian Grebe Houbara Bustard. See Macqueen's Bustard

Hydrochelidon leucopareia, 252 ; leucoptera, 25 I, Plate I I I ; nigra, 248, Plates II I, II 3

ICELAND Gull, 220. Plate 96 Ivory Gull, 229. Plate 103 Ixobrychus minutus, so. Plate 35

JACK Curlew. See Whimbrel Jack Snipe, I27. Plate 53

KENTISH Plover, I9I. Plates 57, $78,8 \mathrm{I}$

Kermadec Petrel, 295

Killdeer Plover, I93

King-Eider, 69. P'ate 26

Kittie-needie. See Sandpiper

Kittiwake, 230. Plates 89, 102, 108

Knot, I30. Plate 53 
LAGOPUS mutus, 363 , Plates 154, 159 ; rupestris, 366 ; scoticus, 360 , Plates $154,156,158$

Landrail, 325. Plates I41, 143, I48 Lapwing, 197. Plates $57,83,85$

Larus atricilla, 367 ; argentatus, 209, Plates 87, 91 ; cachinnans, 212; canus, 206, Plates 8o, 89 ; fuscus, 215 ; f. affinis, 216, Plates 91, 94 ; giaucus, 218 , Plate 96 ; ichthyaïtus, 221 ; leucopterus, 220, Plate 96 : marinus, 213, Plates 87, 93 ; melanocephalus, 221 ; minutus, 226, Plate 100 ; philadelphia, 222 ; ridibundus, 222, Plates 80, 98

Laughing Goose. See White-fronted Goose

Laughing Gull, 367

Leach's Petrel, 2SI. Plate 123

Levantine Shearwater, $2 S_{4}$

Lesser Black-backed Gull, 2 I 5. Plates 91, 94, 99

Lesser Scaup, 366

Lesser Snow-Goose, 8

Lesser Tern, 241. Plates 100, I08, I09

Lesser White-fronted Goose, 6

Limicola falcinellus, 129

Limnocryptes gallinula, 127. Flate 53

Limosa lapponica, 169, P'ate $7 \mathbf{1}$; limosa, I7 1, Plates 69, 7 I

Little Auk, 273. Plate 120

Little Bittern, 90. Plate 35

Little Brown Crane, 365

Little Bustard, 107. Plate 39

Little Crake, 325. Plate I4O

Little Dusky Shearwater, 290

Little Egret, 89

Litlle Grebe, 316. Plat:s 134, 137

Little Green Heron, 366

Little Gull, 226. Plate 100

Little Ringed Plover, 193

Little Stint, 133. Plate 55

Little Tern, 241. Plates 100, 108, 109
Long-tailed Duck, 62. Plate 24 Long-tailed Skua, 258. Plale II 5 Loon. See Great Crested Grebe, Great Northern Diver Lophodytes cucullatus, 81 Lophorty $x$ californicus, 367 Lyrurus tetrix britannicus, 357. Plates 154, 156

MACHETES pugnax, 150. Plates 60,62

Mackerel-cock. See Manx Shearwater

Macqueen's Bustard, Io8

Macrorhamphus griseus, 168. Plate 66

Madeiran Petrel, 282

Magpie-Diver. See Goldeneye, Tufted Duck

Mallard, 26. Plates I I, I3, 15

Manx Shearwater, 284. Plaie I 24

Mareca americana, 4I ; penelope, 38, Plate 19

Marsh Sandpiper, $15 \mathrm{~S}$

Martinique Gallinule, 367

May-bird. See Whimbrel

Mediterranean Black-headed Gull, 221

\section{Mediterranean Great Shearwater, 290}

Megalornis canadensis, 365 ; grus, I03, Plate 4 I

Merganser, 79. Plates 21, 29

Mergellus albellus, 82 . Plate 28

Mergus merganser, 76 ; Plate 29; serrator, 79, Plates 21,29

Moorfowl. See Red Grouse

Moorhen, 328. Plates 144, 145, 148 Morillon. See Goldeneye

Mother Cary's Chicken. See StormPetrel

Mountain Partridge. See Partridge Murre. See Guillemot

Muscovy Duck, 365 
Mussel-Duck. See Sheld-Duck Mute Swan, 19. Plates 6, 10

NETTA mina, 47. Plate 20 Night-Hawk. See Stone-Curlew Night-Heron, 92. Piate 35 Noddy Tern, 366

Norfolk Plover, Iog. Plates 45, 54 North Atlantic Great Shearwater, 290

Numenius arquata, 173, Plates 57, 73; borealis, 178; pheopus, 176, Plate 73; temuirostris, 178

Nycticorax nycticorax, 92. Plate 35

Nyroca affinis, 366 ; baeri, 365 ; collaris, 366 ; ferina, 49, Plates 14, 20; fuligula, 54, Plates 21, 24; marila, 52, Plate 23; nyroca, 48 , Plate I 5

OCEANITES oceanicus, $2 S_{3}$

Oceanodroma castro, 282 ; leucorrhoa, 281, Piate 123

Edemia fusca, 73, Plate 27; nigra, 71, Plate 27; perspicillata, 75, Plate 28

Edicnemus adicnemus, 109. Plates 45,54

Otis tarda, 105, Plate 42; tetrax, 107, Plate 39

Ox-bird. See Dunlin

Oyster-catcher, 201. Plates So, 84, 85,86

PACIFIC Brent Goose, Io

Pacific Eider, 66

Pagophila ebumea, 229. Plate 103

Pale-breasted Brent, Io

Pallas's Sand-Grouse, 343. Plates 150, I 53

Partridge, 350. Plates 148, I57, I 59 Passenger Pigeon, 367

Pectoral Sandpiper, 137. Plate 56
Peewit. See Lapwing

Peewit Gull. See Black-headed Gull Pelagodroma marina, 283

Perdix perdix, 350. Plates 148, 157 I 59

Phalaropus fulicarius, 114 , Plate 48 ; lobatus, II 7 , Plates 44, 48, 49

Phasianus colchicus, 345, Plate $\mathrm{I}_{52}$; torquatus, 345, Plates 148, 152

Pheasant, 345, Plates 148, I52

Phanicopterus antiquorum, 84

Pigmy Curlew. See Curlew-Sandpiper

Pink-footed Goose, 7. Plate 4

Pintail, 44. Plates 13, 17. See also Long-tailed Duck

Plata'ea lencorodia, 99. Plates 36, 40

Plectropterus gambensis, 365

Plegadis falcinellus, IoI. Plate 39

Pochard, 49. Plates I 4, 20

Podiceps auritus, 312, Plate I35; cristatus, 307, Plates 132, I33, I53; fluviatilis, 316, Plates 134, I37; griseigena, 3 10, Plate I35; nigricollis, 314, Plate 137

Podilymbus podiceps, 367

Polish Swan, 20

Pomarine, or Pomatorhine Skua, 26I. Plate II 5

Pope. See Puffin

Porphyrio alleni, 365 ; caruleus, 365 ; martinicus, 367 ; porphyrio, 365

Porzana carolina, 323; parva, 325 , Plate 140; porzana, 321, Plates 138, 148; pusilla intermedia, 323 , Plate 140

Ptarmigan, 363. Plates 154, I59 Pterodroma brevipes, 294; hasitata, 294 ; neglecta, 295

Puffin, 275. Plates 10\$, I20, 122 , 125

Puffinus assimilis boydi, 291; $a$. godmani, 291 ; gravis, 289, Plate 126; griseus, 288, Plate I24; kuhli, 290; k. borealis, 290; obscuizs, 
290 ; 0. baroli, 291 ; puffinus, 284, Plate 124 ; $p$. yelkouan, $2 S_{4}$ Purple Gallinule, 365

Purple Heron, 87. Plates 31, 33 Purple Sandpiper, I39. Plate 56 Purre. See Dunlin

\section{QUAIL, 353. Plates I43, I54}

Querquedula bimaculata, 366 ; crecca, 35, Plates 13, I8; c. carolinensis, $3 \mathrm{~S}$; discors, 34; formosum, 365 ; querquedula, 31, Plates 18, 2 I, 22

RAIN-GOOSE. See Red-throated Diver

Rallus aquaticus, 319. Plates 13S, I53

Rattlewing. See Goldeneye

kazorbill, 263. Plates I I4, I 17, IIS Recurvirostra avocetta, 180 . Plates 74,75

Red-breasted Goose, 14

Red-breasted Merganser, 79. Plates 2I, 29

Red-breasted Snipe, 168. Plate 66 Red-crested Pochard, 47. Platc 20 Red Grouse, 360. Plates I54, I56, I 58

Red-headed Poker. See Pochard Red-headed Smew. See Smew Red-legged Partridge, 348 . Plates I 49, I 54, I 55

Red-necked Grebe, 310. Plate 135 Red-necked Phalarope, II7. Piates $44,48,49$

Redshank, I54. Plates 54, 6.3, 64 Red-throated Diver, 304. Plates 128, I 31, I 36

Reeve. See Ruff

K'hodostethia rosea, 228

Richardson's Skua, 256. Plate's $\mathbf{I}_{\mathbf{3}}$, I 14, I 16

Ring-Dotterel, I $87 . \quad$ Plates 57, 78, 79 Ring-Dove, 336 . Plates 147, 151 Kinged I'lover, $\mathbf{I} 87$. Plates 57,78 , 79
Ring-eyed Scoot. See Bridled Guillemot

Ring-necked Duck, 366

Rissa tridactyla, 230. Plates 89, 102, Ios

Rock-Dove, 339. Plate 149. See also Stock-Duve

Rock-Pigeon. Sie Rock-Dove

Rock-Ptarmigan, 366

Roseate Tern, 239. Plates 105, IOS

Ross's Gull, 228

Rotche. See Little Auk

Ruddy Sheld-Duck, 24. Plate 12

Ruff, I50. Plates 60, 62

SABINE'S Gull, 228. Plate 98 Sabine's Snipe, 126

St. Cuthbert's Duck. See Eider

Sanderling, 148. Plate $6 \mathrm{I}$

Sand-Grouse, 343. Plates I50, I 53

Sand-lark. See Dunlin

Sand-Pigeon. See Stock-Dove

Sandpiper, 160. Plates 54, 61, 65, 67

Sand-runner. See Dunlin

Sanäwich Tern, 245. Plates 94, 107, I IO

Saw-bill. Sce Goosander, Merganser Scaup, 52. Plate 23

Schlegel's Petrel, 295

Scolopax rusticola, I20. Plates 45, 54 Scopoli's Sooty Tern, 366

Scoter, 7 I. Plate 27

Scout. See Guillemot

Sea-Crow. See Black-headed Gull

Sea-Parrot. See Puffin

Sea-Pheasant. See Long-tailed Duck Sea-Pie. See Oyster-catcher

Sea-Pigeon. See Black Guillemot

Sea-Swallow. See Common and Arctic Tern

Semipalmated Ringed Plover, 192 Semipalmated Sandpiper, 153

Seven Whistler. See Whimbrel

Sheep's Guide. See Golden Plover

Sheldrake. See Sheld-Duck

Sheld-Duck, 20 . Plates 8, I 2 
Shell-duck. See Sheld-Duck

Shoeing Horn. See Avocet

Shovelard. See Spoonbill

Shoveler, 42. Plates 19, 21. See also Spoonbill

Siberian Pectoral Sandpiper, ${ }_{3} 3$

Silver Plover. See Grey Plover

Slavonian Grebe, $3 \mathbf{1 2}$. Piate I35

Slender-billed Curlew, I78

Smew, 82. Plate 28

Snipe, 123. Plates 50, 51, 52, 54

Snow-bird. See Ivory Gull

Snow-Goose, $8 . \quad$ Plate 10

Sociable Plover, 197

Solitary Sandpiper, 167

Solitary Snipe. See Great Snipe

Somateria mollissima, 66, Platcs I4, 26 ; m. 7.-nigra, 66; spectabilis, 69, Plate 26

Sooty Shearwater, 288. Plate 124

Sooty Tern, 248

Sora, 323

Spatula clypeata, 42. Plates 19, 21 Spoonbill, 99. Plates 36, 40. See also Shoveler

Spotted Crake, 32I. Plates $13 S, 1_{4} \delta$ Spotted Redshank, I $56 . \quad$ Plate 64

Spotted Sandpiper, 163

Spur-winged Goose, 365

Squacco Heron, 90. Plate 32

Squatarola squatarola, 186. Plate 77 Steller's Eider, 65

Stercorarius longicauduss, 258, Plate I I5; parasiticus, 256, Plates I I4, I16; pomarinus, 26I, Plate II 5

Sterna ancthetus, 366 ; anglica, 244, Plate 107 ; bergii, 366 ; caspia, 244 ; dougalli, 239, Plates 105, I08; fuliginosa, 248; hirundo, 233, Plates 94, I03; minuta, 24I, Plates 100, IOS; paradisea, 237, Plates 105, 108; sandvicensis, 245, Plates 94, 107

Stilt, I79. Plate 74

Stint, 133. Plate 55

Stock-Dove, 334. Plate 147
Stone-Curlew, 109. Plates 43, 45, 47,54

Stone-Curlew. See Bar-tailed Godwit Stonehatch. See Ringed Plover

Storm-Petrel, 279. Plates 123, 153

Streptopelia orientalis, 342 ; turtur,

340 , Plate 150

Summer Duck, 365

Summer Snipe. See Sandpiper

Summer Teal. See Garganey

Summer Yellowlegs. See Yellowshank

Surf-Scoter, 75. Plate 28

Swift Tern, 366

Syrrhaptes paradoxus, 343. Plates I 50,153

TADORVA casarca, 24, Plate 12 ; tadoma, 20, Plates 8 , I 2

Tarrock. See Kittiwake

Teal, 35. Plates $\mathbf{1}_{3}$, I8

Temminck's Stint, 136. Plate 55

Terekia cinerea, $\mathbf{1} 30$

Terek Sandpiper, I30

Tern. See Sandwich Tern

Tetrao urogallus, 355. Plates I, I53 Teuke. See Redshank

Thalassidroma pelagica, 279. Plaies

I 23, I 53

Thick-knee, rog. Plates 45, 54

Tippet-Grebe. See Great Crested Grebe

Titterel. See Whimbrel

Tommy Noddy. See Puffin

Tringa brevipes, 168 ; favipes, 158 ; glareola, 165, Plate 68; hypoleuca, 160, Plates 54, 61 ; incana, 168; macularia, 163; macnlata, 156 ; Plate 64; melanoleuca, I57; nebularia, 159, Plates 66, 154 ; ochropus, 164, Flate 68; solitaria, I67; slagnatilis, I58; totanus, 154, Plates 54, 64

Trumpeter Swan, 366

Tryngites subruficollis, I47

Tufted Duck, 54. Plates 21, 24 
Tullet. See Ringed Plover

Tumix sylvatica, 367

Turnstone, 204. Plates 82,88

Turtle-Dove, 340. Plate 150

Twist-tailed Skua, 261. Plate 115

Tystie. See Black Guillemot

WATERHEN, 328. Plates 144 , 145,148

Water-Rail, 319. Plates 138, 139, 153

Wet-my-lips, Wet-my-feet. See Quail

Whaup. See Curlew

Whimbrel, 176 . Plate 73

Whiskered Tern, 252

Whistler. See Golden Plover, Goldeneye, IVigeon

Whistling Swan, 366

IVhistling Swan. See Whooper

White-billed Northern Diver, 303

White-eyed Pochard, 48. Plate 15

White-fronted Goose, 5. Plate 4

White Nun. Ser Snew

White-sided Duck. See Tufted Duck

White Spoonbill, 99

White Stork, 98. Plate 38

White-winged Black Tern, 25 I. Plate

\section{I I}

Whole Snipe. See Snipe

Whooper Swan, 15. Plates 6, 9
Wigeon, 38. Plate 19

Wild Duck, 26. Plates I1, I3, I5

IVillie Wicket. See Sandpiper

Willock. See Guillemot

Wilson's Petrel, 283

Wilson's Snipe, 366

Winter Yellowlegs. See Greater Yellowshank

Woodcock, 120. Plates 45, 54

Woodcock-Snipe. Sce Great Snipe

Wood-Grouse. See Capercaillie

Wood-pigeon, 336. Plates 147, I 5 I

IVood Sandpiper, 165. Plate 68

Wood Tattler. See Solitary Sandpiper

URIA grylle, 270, Flates 94, 19 ; lomvia, 270 ; troille, 267, F'lates i I 7 , I I 9 , I 2 I

IANELLUS vanellus, 197. Pla'́cs $57,8_{3}, \delta_{5}$

Velvet Scoter, 73. Piate 27

$X E$ IIA sabinii, 228. Flate 98

YELLOW-LEGGED Herring-Gull, 212

Yellowshank, i 58

Yelper. See Arocet, Redshank 


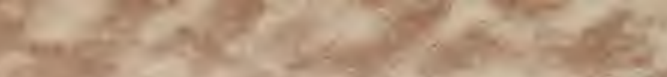

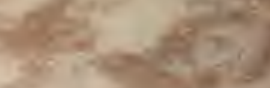

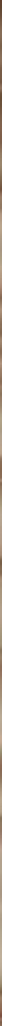

nes.

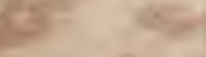




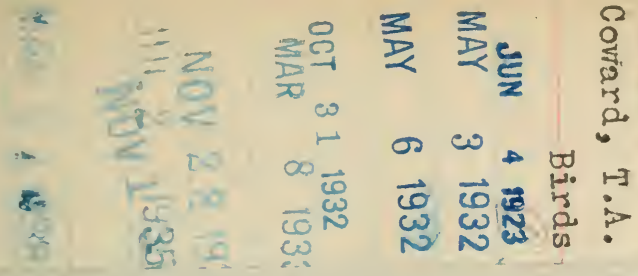


